Prepared for the U.S. Department of Energy

under Contract DE-AC05-76RL01830

\title{
Small-Scale Spray Releases: Initial Aerosol Test Results
}
LA Mahoney
J Blanchard
PA Gauglitz
C Song
ML Kimura
RC Daniel
GN Brown
BE Wells
DE Kurath
D Tran
WC Buchmiller
CA Burns
DM Smith

November 2012

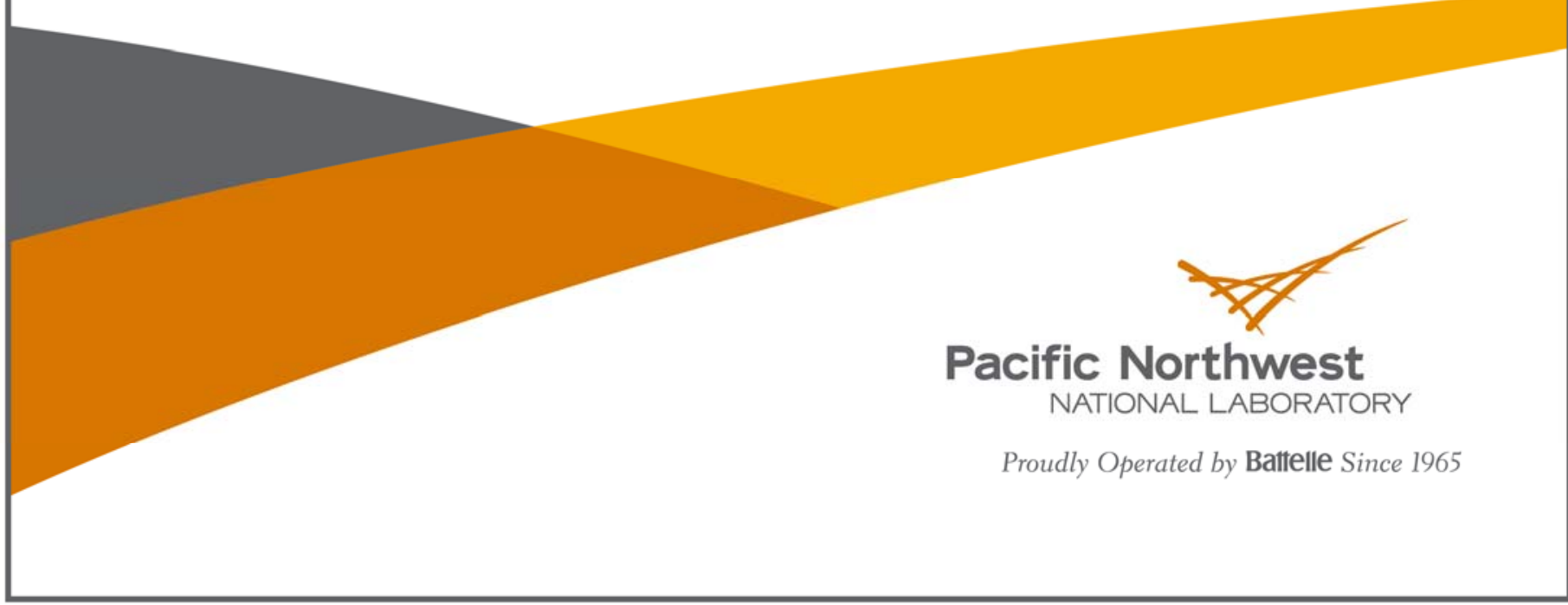




\title{
Small-Scale Spray Releases: Initial Aerosol Test Results
}

\author{
LA Mahoney \\ J Blanchard \\ PA Gauglitz \\ C Song \\ ML Kimura \\ RC Daniel \\ GN Brown \\ BE Wells \\ DE Kurath \\ D Tran \\ WC Buchmiller \\ CA Burns
}

DM Smith

November 2012

Test Specification: None

Work Authorization: WA42AM01

Test Plan: TP-WTPSP-031, Rev. 0.2

Test Exceptions: None

Prepared for

the U.S. Department of Energy

under Contract DE-AC05-76RL01830

Pacific Northwest National Laboratory

Richland, Washington 99352 



\section{Completeness of Testing}

This report describes the results of work and testing specified by Test Plan TP-WTPSP-031, Rev. 0.2. The work followed the quality assurance requirements outlined in the test plan. The descriptions provided in this report are an accurate account of both the conduct of the work and the data collected. Test plan results are reported. Also reported are any unusual or anomalous occurrences that are different from expected results. The test results and this report have been reviewed and verified.

Approved:

Dean E. Kurath, Manager

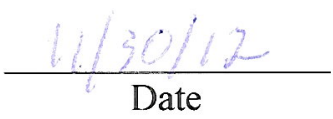

WTP R\&T Support Project 



\section{Testing Summary}

One of the events postulated in the hazard analysis at the Waste Treatment and Immobilization Plant (WTP) and other U.S. Department of Energy (DOE) nuclear facilities is a breach in process piping that produces aerosols with droplet sizes in the respirable range. The current approach for predicting the size and concentration of aerosols produced in a spray leak involves extrapolating from correlations reported in the literature. These correlations are based on results obtained from small engineered spray nozzles using pure liquids with Newtonian fluid behavior. The narrow ranges of physical properties on which the correlations are based do not cover the wide range of slurries and viscous materials that will be processed in the WTP and across processing facilities in the DOE complex.

Two key technical areas were identified where testing results were needed to improve the technical basis by reducing the uncertainty due to extrapolating existing literature results. The first technical need was to quantify the role of slurry particles in small breaches where the slurry particles may plug and result in substantially reduced, or even negligible, respirable fraction formed by high-pressure sprays. The second technical need was to determine the aerosol droplet size distribution and volume from prototypic breaches and fluids, specifically including sprays from larger breaches with slurries where data from the literature are scarce.

To address these technical areas, small- and large-scale test stands were constructed and operated with simulants to determine aerosol release fractions and net generation rates from a range of breach sizes and geometries. The properties of the simulants represented the range of properties expected in the WTP process streams and included water, sodium salt solutions, slurries containing boehmite or gibbsite, and a hazardous chemical simulant. The effect of antifoam agents was assessed with most of the simulants. Orifices included round holes and rectangular slots. For the combination of both test stands, the round holes ranged in size from 0.2 to $4.46 \mathrm{~mm}$. The slots ranged from (width $\times$ length) $0.3 \times 5$ to $2.74 \times 76.2 \mathrm{~mm}$. Most slots were oriented longitudinally along the pipe, but some were oriented circumferentially. In addition, a limited number of multi-hole test pieces were tested in an attempt to assess the impact of a more complex breach. Much of the testing was conducted at pressures of 200 and $380 \mathrm{psi}$, but some tests were conducted at $100 \mathrm{psi}$. Testing the largest postulated breaches was deemed impractical because of the much larger flow rates and equipment that would be required.

This report presents the experimental results and analyses for the aerosol measurements obtained in the small-scale test stand. It includes a description of the simulants used and their properties, equipment and operations, data analysis methodologies, and test results. The results of tests investigating the role of slurry particles in plugging small breaches are reported in Mahoney et al. (2012). The results of the aerosol measurements in the large-scale test stand are reported in Schonewill et al. (2012) along with an analysis of the combined results from both test scales.

\section{S.1 Objectives}

Table S.1 provides a summary of each small-scale aerosol test objective, whether the objective was met, and a discussion of the test results. Other objectives identified in Test Plan TP-WTPSP-031 Rev 0.2 apply to the large-scale aerosol testing and the orifice plugging results discussed in Schonewill et al. (2012) and Mahoney et al. (2012), respectively. 
Table S.1. Summary of Small-Scale Aerosol Test Objectives and Results

\begin{tabular}{|c|c|c|}
\hline Test Objective & $\begin{array}{c}\text { Objectiv } \\
\text { Met? }\end{array}$ & Discussion \\
\hline $\begin{array}{l}\text { Determine the size distribution of } \\
\text { aerosol droplets and the total droplet } \\
\text { volume concentration as a fraction of } \\
\text { the total spray volume for a range of } \\
\text { smaller breach sizes for circular and } \\
\text { rectangular breaches, liquid and slurry } \\
\text { simulants, and WTP process conditions. }\end{array}$ & Yes & $\begin{array}{l}\text { Malvern Insitec-S instruments were used to measure the size } \\
\text { distribution and volume concentration of the aerosol for a } \\
\text { range of smaller breach sizes, liquid and slurry simulants, and } \\
\text { WTP process conditions. The circular orifices had target } \\
\text { diameters of } 0.3 \text { to } 2 \mathrm{~mm} \text {. The rectangular slots had target } \\
\text { dimensions of } 0.3-1 \times 5 \text { to } 0.5 \times 5-20 \mathrm{~mm} \text { (width } \times \text { length). } \\
\text { Most slots were oriented longitudinally along the pipe, but } \\
\text { some were oriented circumferentially. A limited number of } \\
\text { multi-hole tests were completed to assess the impact of a } \\
\text { more complex breach. Total spray volume was calculated } \\
\text { using mass measurements and time data recorded by test } \\
\text { operators. Simulants are discussed in Chapter } 3 \text { of this report } \\
\text { and the parametric study based on the aerosol measurements } \\
\text { is reported in Chapter } 7 \text {. }\end{array}$ \\
\hline $\begin{array}{l}\text { Determine the size distribution of } \\
\text { aerosol droplets and the total droplet } \\
\text { volume concentration as a fraction of } \\
\text { the total spray volume for a chemical } \\
\text { slurry simulant representative of a } \\
\text { washed and leached process stream to } \\
\text { compare with the results from } \\
\text { non-hazardous simulants (compare for } \\
\text { one circular and one rectangular } \\
\text { breach, unless testing results indicate } \\
\text { additional breach sizes need to be } \\
\text { tested). }\end{array}$ & Yes & $\begin{array}{l}\text { Malvern Insitec-S instruments were used to measure the size } \\
\text { distribution and volume concentration of the aerosol using a } \\
\text { chemical slurry simulant. Total spray volume was calculated } \\
\text { using mass measurements and time data recorded by test } \\
\text { operators. The chemical simulant is discussed in Chapter } 3 \text { of } \\
\text { this report and the results of the aerosol measurements are } \\
\text { reported in Chapter } 7 \text {. }\end{array}$ \\
\hline
\end{tabular}

\section{S.2 Results and Performance Against Success Criteria}

The success criteria for achieving the small-scale aerosol test objectives are discussed in Table S.2.

Table S.2. Success Criteria for Small-Scale Aerosol Tests

\begin{tabular}{|c|c|c|}
\hline Success Criteria & $\begin{array}{l}\text { Objective } \\
\text { Met? }\end{array}$ & Discussion \\
\hline \multicolumn{3}{|l|}{ Objectives 2,3 } \\
\hline $\begin{array}{l}\text { Measure the droplet size distribution, } \\
\text { total volume concentration of droplets, } \\
\text { and total volume sprayed for each of } \\
\text { the breaches and simulants tested. }\end{array}$ & Yes & $\begin{array}{l}\text { Malvern Insitec-S instruments were used to measure the size } \\
\text { distribution and volume concentration of the aerosol for each } \\
\text { simulant. The total spray volume was calculated using mass } \\
\text { measurements and time data recorded by test operators. }\end{array}$ \\
\hline $\begin{array}{l}\text { Measure the pressure and flow in the } \\
\text { piping. }\end{array}$ & Yes & $\begin{array}{l}\text { The pressure and flow in the piping were measured and } \\
\text { recorded in a test instruction datasheet and with a data logger. }\end{array}$ \\
\hline $\begin{array}{l}\text { Characterize the viscosity or rheology, } \\
\text { particle size distribution, bulk density, } \\
\text { and surface tension of each simulant } \\
\text { tested. }\end{array}$ & Yes & $\begin{array}{l}\text { The simulants tested were characterized prior to testing and, in } \\
\text { many cases, after testing. See Chapter } 3 \text { and the run summary } \\
\text { in Appendix A. }\end{array}$ \\
\hline $\begin{array}{l}\text { Calculate the test chamber volume } \\
\text { from internal dimensions. }\end{array}$ & Yes & $\begin{array}{l}\text { The test chamber was measured using a standard tape measure } \\
\text { and the volume was calculated; see Chapter } 4 \text { for details. }\end{array}$ \\
\hline
\end{tabular}




\section{S.3 Quality Requirements}

The Pacific Northwest National Laboratory (PNNL) Quality Assurance (QA) Program is based on requirements defined in DOE Order 414.1D, Quality Assurance, and Title 10 of the Code of Federal Regulations (CFR) Part 830, Energy/Nuclear Safety Management and Subpart A, Quality Assurance Requirements (a.k.a., the "Quality Rule"). PNNL has chosen to implement the following consensus standards in a graded approach:

- ASME NQA-1-2000, Quality Assurance Requirements for Nuclear Facility Applications, Part 1, Requirements for Quality Assurance Programs for Nuclear Facilities

- ASME NQA-1-2000, Part II, Subpart 2.7, Quality Assurance Requirements for Computer Software for Nuclear Facility Applications

- ASME NQA-1-2000, Part IV, Subpart 4.2, Graded Approach Application of Quality Assurance Requirements for Research and Development.

The procedures necessary to implement the requirements are documented in PNNL's "How Do I...?" (HDI) system. ${ }^{1}$

The Waste Treatment Plant Support Project (WTPSP) implements an NQA-1-2000 Quality Assurance Program, graded on the approach presented in NQA-1-2000, Part IV, Subpart 4.2. The WTPSP Quality Assurance Manual (QA-WTPSP-0002) describes the technology life cycle stages under the WTPSP Quality Assurance Plan (QA-WTPSP-0001). The technology life cycle includes the progression of technology development, commercialization, and retirement in process phases of basic and applied research and development $(\mathrm{R} \& \mathrm{D})$, engineering and production, and operation until process completion. The life cycle is characterized by flexible and informal QA activities in basic research, which becomes more structured and formalized through the applied R\&D stages.

The work described in this report has been completed under the QA technology level of Developmental Work. WTPSP addresses internal verification and validation activities by conducting an independent technical review of the final data report in accordance with the WTPSP procedure QA-WTPSP-601, Document Preparation and Change. This independent review verifies that the reported results are traceable, that inferences and conclusions are soundly based, and that the reported work satisfies the test plan objectives.

\section{S.4 Simulant Use}

Several simulants were developed and characterized for use in the small-scale aerosol tests. The simulants were selected to represent a range of relevant physical and rheological properties expected in the WTP (Table S.3 and Table S.4). The properties important to aerosol generation include particle size distribution (PSD), viscosity, Bingham plastic rheological parameters (yield stress and plastic viscosity), bulk density, weight percent (wt \%) of undissolved solids (UDS), and surface tension. Actual simulant properties are reported in Chapter 3.

\footnotetext{
${ }^{1}$ Standards-based system for managing the delivery of PNNL policies, requirements, and procedures.
} 
Table S.3. Target Simulants and the WTP Process Stream Categories

\begin{tabular}{|c|c|c|c|}
\hline Simulant Class & Material & Target Property Range & $\begin{array}{c}\text { WTP Process } \\
\text { Stream Categories }\end{array}$ \\
\hline Baseline & Water & $\begin{array}{l}\text { Viscosity of } 1 \mathrm{mPa} \cdot \mathrm{s}(1 \mathrm{cP}) \\
\text { density } 1000 \mathrm{~kg} / \mathrm{m}^{3} \\
\text { surface tension } 73 \mathrm{mN} / \mathrm{m}\end{array}$ & $\begin{array}{l}\text { Ultrafilter Permeate/ } \\
\text { Treated Low Activity } \\
\text { Waste (LAW) }\end{array}$ \\
\hline $\begin{array}{l}\text { Range of } \\
\text { Newtonian } \\
\text { Viscosity }\end{array}$ & $\begin{array}{l}\text { Solutions of water and } \\
\text { non-hazardous salts } \\
\text { (sodium nitrate and } \\
\text { sodium thiosulfate) }\end{array}$ & $\begin{array}{l}\text { Viscosities of } \sim 1.5, \sim 2.5 \mathrm{mPa} \cdot \mathrm{s} \\
(1.5,2.5 \mathrm{cP})\end{array}$ & $\begin{array}{l}\text { Cs Ion Exchange Eluate } \\
\text { Recycle Streams }\end{array}$ \\
\hline $\begin{array}{l}\text { Range of Slurries } \\
\text { (non-hazardous) }\end{array}$ & $\begin{array}{l}\text { Gibbsite and boehmite } \\
\text { particulates in water }\end{array}$ & $\begin{array}{l}\text { The PSDs of the slurries were } \\
\text { selected to match Hanford waste } \\
\text { PSDs (average waste feed and } \\
\text { representatively small PSDs, } \\
\text { because smaller PSDs are least } \\
\text { likely to plug breaches). } \\
8 \text { and } 20 \mathrm{wt} \% \text { solids }\end{array}$ & $\begin{array}{l}\text { Newtonian Slurries } \\
\text { Non-Newtonian Slurries }\end{array}$ \\
\hline $\begin{array}{l}\text { Washed and } \\
\text { Leached Chemical } \\
\text { Slurry Simulant }\end{array}$ & $\begin{array}{l}\text { A washed and leached } \\
\text { version of the simulant } \\
\text { used in Pretreatment } \\
\text { Engineering Platform } \\
\text { (PEP) testing (Kurath } \\
\text { et al. 2009) }\end{array}$ & $\begin{array}{l}\text { Solids loading was adjusted to } \\
\text { meet target Bingham yield } \\
\text { stresses of } 6 \text { and } 30 \mathrm{~Pa}\end{array}$ & Non-Newtonian Slurries \\
\hline
\end{tabular}

Table S.4. Simulant Nomenclature

\begin{tabular}{|c|c|c|c|}
\hline Simulant Description & Alias & Component & Comments \\
\hline $\begin{array}{l}\text { Small treated } \\
\text { Hanford waste PSD }\end{array}$ & STR & Boehmite & $\begin{array}{l}\text { Primary simulant. No antifoam agent (AFA) unless } \\
\text { otherwise stated. }\end{array}$ \\
\hline $\begin{array}{l}\text { Small as-received (SAR) } \\
\text { Hanford waste PSD }\end{array}$ & SAR & Gibbsite & No AFA unless otherwise stated. \\
\hline $\begin{array}{l}\text { Typical as-received } \\
\text { (TAR) Hanford waste } \\
\text { PSD }\end{array}$ & TAR & Gibbsite & No AFA unless otherwise stated. \\
\hline $\begin{array}{l}\text { Aqueous } \mathrm{NaNO}_{3} \text { salt } \\
\text { solution }\end{array}$ & $\mathrm{NaNO}_{3}$ & $\mathrm{NaNO}_{3}$ & $32 \mathrm{wt} \% \mathrm{NaNO}_{3}$ for target viscosity of $\sim 1.5 \mathrm{mPa} \cdot \mathrm{s}$. \\
\hline $\begin{array}{l}\text { Aqueous } \mathrm{Na}_{2} \mathrm{~S}_{2} \mathrm{O}_{3} \text { salt } \\
\text { solution }\end{array}$ & $\mathrm{Na}_{2} \mathrm{~S}_{2} \mathrm{O}_{3}$ & $\mathrm{Na}_{2} \mathrm{~S}_{2} \mathrm{O}_{3}$ & $27 \mathrm{wt} \% \mathrm{Na}_{2} \mathrm{~S}_{2} \mathrm{O}_{3}$ for target viscosity of $\sim 2.5 \mathrm{mPa} \cdot \mathrm{s}$. \\
\hline \multirow{3}{*}{$\begin{array}{l}\text { Washed and leached } \\
\text { iron-rich (FER) chemical } \\
\text { slurry simulant } \\
\text { (non-Newtonian) }\end{array}$} & FER6-B & $\begin{array}{l}\text { Boehmite } \\
\text { Fe-Rich }\end{array}$ & $\begin{array}{l}\text { Target rheology of } 6 \text { Pa Bingham yield stress, } \\
6 \mathrm{mPa} \cdot \mathrm{s} \text { Bingham consistency. No AFA added. }\end{array}$ \\
\hline & FER6+AFA & $\begin{array}{l}\text { Gibbsite } \\
\text { Fe-Rich }\end{array}$ & $\begin{array}{l}\text { Target rheology of } 6 \text { Pa Bingham yield stress, } \\
6 \mathrm{mPa} \cdot \mathrm{s} \text { Bingham consistency. AFA was added. }\end{array}$ \\
\hline & $\begin{array}{c}\text { FER30 } \\
\text { FER30+AFA }\end{array}$ & $\begin{array}{l}\text { Gibbsite } \\
\text { Fe-Rich }\end{array}$ & $\begin{array}{l}\text { Target rheology of } 30 \mathrm{~Pa} \text { Bingham yield stress, } \\
30 \mathrm{mPa} \cdot \mathrm{s} \text { Bingham consistency. AFA was added } \\
\text { after testing of FER } 30 \text { to produce FER30+AFA. }\end{array}$ \\
\hline
\end{tabular}




\section{S.5 Summary of Results}

The small-scale spray release test system consisted of a relatively small enclosure installed in a walk-in fume hood. This system was used for investigating aerosol formation from smaller breach sizes using hazardous and non-hazardous simulant slurries and aqueous solutions. A positive displacement pump recirculated simulant from a 40-gallon agitated feed vessel through the nominal 1 -in. diameter spray loop pipe at the target flow rate of $10 \mathrm{gpm}$. This provided a line velocity of $5.4 \mathrm{ft} / \mathrm{s}$, which was chosen to provide approximately the same wall shear stress (within about 10 percent) that would exist in 3 -in. schedule 40 pipe with a flow velocity of $6.5 \mathrm{ft} / \mathrm{s}$, a typical condition in the WTP system. A wide variety of orifice sizes and geometries could be inserted into the test section. The wall thickness was equivalent to that of a 3 -in. schedule 40 stainless steel pipe, thus providing a leak-path length equal to much of the piping used in the WTP. The distance of the orifice from the splash wall was varied from 1 to $42 \mathrm{in}$. by inserting pipe extensions. Many of the tests were conducted at a target test pressure of 380 psi but additional pressures of 100 and 200 psi were also investigated.

Aerosol measurements were obtained in real time, primarily using a single Malvern Insitec-S instrument. A second aerosol instrument (Process Metrix Particle Counter) also was used in a few tests, but the results from this instrument were used primarily to check the Insitec-S results. The aerosol instruments could be placed at most locations in the aerosol enclosure but were most commonly placed in the center of the upper third of the chamber. A limited number of in-spray measurements were also obtained. A mixing fan placed near the bottom center of the chamber minimized inhomogeneities in the aerosol concentrations. Additional instruments provided real-time measurements of flow rate, simulant density, flow loop pressure and temperature that were recorded with a data logger. Approximately 177 separate spray release tests were conducted including replicates.

The tests were conducted using one of three valve sequences to achieve the target flow rate and pressure. Aerosol data were generally collected for 2 min after the start of the spray. Still images of the sprays were collected as well. The system temperature was maintained between 65 and $85^{\circ} \mathrm{F}$ (maximum of $95^{\circ} \mathrm{F}$ for chemical simulant) to minimize any effects that might be caused by condensation or evaporation. Samples were collected from the feed vessel before and after each test. Selected samples were analyzed to determine the PSD, rheological parameters, bulk density, weight percent of UDS, and surface tension.

The experimental method focused on measuring the rate of increase in the aerosol concentration in the closed chamber of known volume. Because the chamber is a closed system with no purge flow, the aerosol concentration is initially zero and builds up to a steady-state concentration at which point the net generation of aerosol (the generation by spray minus the capture by the splash wall) is equal to the aerosol losses. Based on a material balance, the initial rate of concentration increase (before losses are significant) gives the aerosol net generation rate from a spray. A key component of this approach is to have a concentration measurement for the chamber that is representative of the entire chamber.

There were several advantages to using a closed chamber. First, it allows for isolation of the spray, providing a safe testing platform for spraying simulants with chemical hazards. Second, creating sprays inside a chamber also allows the spray to impact the walls of the chamber and generate aerosol droplets by splatter. This additional mechanism of droplet formation is typical of an actual spray, and adds to the total aerosol formation within the chamber. Third, the approach used to measure the concentration increase in a closed chamber also allows the role of changing the orifice-to-wall distance to be 
determined. Because of the size and configuration of WTP piping, sprays could impact system components (e.g., walls, pipes, valves, etc.) at distances ranging from inches to hundreds of feet. Fourth, the methodology also allows testing to be performed in different sized chambers; a larger chamber could accommodate larger sprays but the overall experimental and data analysis approach would be the same. Because the same experimental method was used in both the small- and large-scale tests, results can be compared to one another and extrapolated to longer distances.

A two-part approach was used to analyze data collected during small-scale spray release testing. The first part used data from the process instruments to determine the average pressure during each test. The average pressure, the orifice dimensions, and the simulant properties were used in calculating WTP model predictions for the test conditions. The leak flow rate was calculated using a manually recorded mass change in the feed vessel.

The second part used data from the Malvern Insitec-S aerosol instrument. The aerosol data were converted to a volume basis (parts per million by volume [ppmv]) and corrected for laser transmission drift. Both differential and cumulative concentration data were analyzed. The data were aligned in time with the process data and then fit with an exponential model to determine the aerosol net generation rate. The net generation rate was divided by the spray leak flow rate to obtain estimates of the release fraction for the experiments.

A series of tests were conducted to identify the best equipment configuration and operating test conditions. These tests accomplished the following:

- Established that a spray duration of 2 minutes was adequate for most test conditions.

- Demonstrated that the Malvern Insitec-S aerosol instrument location used in testing gave a reasonable representation of the chamber concentration by comparing its results to those obtained at other locations.

- Demonstrated that the chamber mixing fan employed during testing promoted mixing and did not lead to additional inhomogeneities in the chamber aerosol concentrations.

- Optimum aerosol instrument configurations were determined; these included air purge flow rate of the Insitec-S and the data sampling and recording rate.

- Established that four types of initial pressure transients (generated by different valving sequences) gave release fractions that were indistinguishable between aerosol particle sizes of 5 and $200 \mu \mathrm{m}$.

Once the equipment configuration and operating test conditions were established, comparisons between small-scale test data (net generation rate) and WTP model predictions (total generation rate) were made for several different parameters. This effort yielded the following conclusions:

- Orifice coefficients, $\mathrm{C}_{\mathrm{D}}$, were determined from differential mass measurements and found to be $0.59 \pm 0.05$ (average \pm standard deviation) when the orifice area was $>2 \mathrm{~mm}^{2}$. This value is consistent with the value of 0.62 used in the WTP model for orifices. However, the discharge coefficient for orifices of $<2 \mathrm{~mm}^{2}$ area was $0.76 \pm 0.06$, which is $\sim 20$ percent more than the value used in the WTP model (i.e., 0.62).

- As pressure increased, the cumulative release fraction increased for water sprays. This increase with pressure was approximately the same as the rate of increase in the WTP model and is consistent with 
the large-scale testing results. For the non-Newtonian simulants, the effect of pressure was variable with the release fraction sometimes increasing and sometimes decreasing with increasing pressure.

- As orifice area increased for round holes, the cumulative release fraction was essentially constant for $<10-\mu \mathrm{m}$ drops from round holes, whereas the WTP model predicts a decrease in release fraction. For these round holes, the cumulative release fractions for $<30-\mu \mathrm{m}$ and $<100-\mu \mathrm{m}$ drops showed an area dependence that is similar to that obtained from the WTP model. For all the round holes, the cumulative net generation rate increases with orifice area because of the increase in total spray flow with increasing area.

- As orifice area increased for slots, the cumulative release fraction decreased and the cumulative net generation rate increased slightly for drops between $<10$ and $<100 \mu \mathrm{m}$. These trends generally match the WTP model.

- Overall, the cumulative release fraction correlates reasonably well with the orifice area for slots and round holes, in agreement with the WTP model. The dependence on orifice area varies between smaller and larger areas. For the tests conducted, the smaller orifice areas were round holes and the larger areas were slots. Only a few slots and round holes had similar areas. Accordingly, there are too few data to determine whether the difference in dependence at small and larger areas is due to orifice area or geometry.

- As viscosity and density increased for a salt solution, the cumulative release fraction was unchanged. This is comparable to the WTP model prediction including both the density and viscosity change. For one pair of salt solutions having identical densities but different viscosities, the cumulative release fraction again was unchanged.

- Low solids concentrations (such as $8 \mathrm{wt} \%$ ) appeared to depress the release fractions below those of water over most or all of the droplet size range, for the baseline slot and round orifices (with dimensions of $1 \mathrm{~mm}$ diameter and $0.5 \times 5 \mathrm{~mm}$, respectively). Further increasing the solids content (to $20 \mathrm{wt} \%$ ) increased the release fraction. The changes produced by solids differed from those in the WTP model, which accounts for the presence of solids by using the physical properties of the fluid. The addition of solids can produce cumulative release fractions that exceed the WTP model in the droplet size range of $\leq 10 \mu \mathrm{m}$.

- Adding AFA to either $8 \mathrm{wt} \%$ small treated (STR) or water, which approximately halved the equilibrium surface tension, did not cause an increase in the release fraction as would have been predicted from the functionality of surface tension in the WTP model. To the extent that an effect could be distinguished, the presence of an AFA caused a slight decrease in the release fraction.

- As the distance between the spray and the splash wall decreased, the cumulative release fraction remained essentially constant between 42 and 18 in., increased slightly between 18 and 3 in., and increased significantly when the distance was reduced to $1 \mathrm{in}$. The WTP model does not consider the effect of obstructions such as walls, and would predict constant release fractions with splash distance.

- In-spray measurements represent an upper bound on the release fraction for a particular spray, in the absence of splatter if the spray hits a wall or object. However, the measurements are difficult to interpret as they are strong functions of the Malvern position within the spray and the Malvern analysis settings. 
A number of factors affected the overall uncertainty in the measured aerosol net generation rates and release fractions. Two types of small-scale tests were conducted that are pertinent to uncertainty estimates:

- The results of replicate tests for a number of test conditions (including five different simulants) were used to evaluate the test-to-test uncertainty. As a first approximation, the 95-percent confidence interval in the cumulative release fraction for any given small-scale test should be a minimum of \pm 40 percent of the stated value at any particular aerosol droplet diameter.

- Two tests compared the Malvern aerosol results with those of a co-located secondary aerosol instrument, the Process Metrix Particle Counter (PPC). For the baseline round hole (1 mm), the PPC concentration was 200 to 300 percent of the Malvern concentration for droplets $\geq 10 \mu \mathrm{m}$, up to the apparent PPC measurement limit of about $30 \mu \mathrm{m}$. The Malvern and PPC concentrations were more similar for the baseline slot $(0.5 \times 5 \mathrm{~mm})$, particularly for cumulative concentrations in the range of $<20$ to $<30 \mu \mathrm{m}$. The comparison is ambiguous because of evidence that the PPC vacuum draw tube affected the Malvern measurements and because the PPC suction rates had not been tested to determine what rate produced the best measurements. For context, the large-scale tests (Sections 8.1.4 and 8.1.5 of Schonewill et al. 2012), in which the PPC suction flow rate was adjusted for best results based on testing, gave a closer comparison between PPC and Malvern results.

\section{S.6 Discrepancies and Follow-on Tests}

The following discrepancies associated with the small-scale tests are noted:

After completion of the prescribed small-scale test objectives, it was observed that the pressure at the orifice varied significantly depending on the valve operation sequence that initiated the spray. Initially, two modes of valve operations were employed: 1) the pre-spray pressure was pre-set to a higher value and, upon spray initiation, it was reduced to the target pressure, and 2) the pre-spray pressure was substantially low ( $\sim 40 \mathrm{psi}$ ) and, upon spray initiation, it was increased to the target pressure. The delay in achieving the target pressure often amounted to several seconds. Subsequent to most of the testing, an alternative valve sequence was developed that allowed the target pressure to be achieved immediately and maintained throughout the tests. Additional testing using water was performed to compare the results obtained using the various valve sequences and determine the impact on the aerosol results. The subsequent analysis of the aerosol release fractions indicated that the release fractions for the various valve sequences were not substantially different. While the improved valve sequence might reduce the experimental uncertainty, the improvement was insufficient to warrant retesting. However, the improved

valve sequence is recommended for future testing because the target pressure is immediately achieved and constant throughout the aerosol tests.

Tests using the chemical simulant with non-Newtonian rheological properties indicated that release fractions are higher than expected, and may exceed projections obtained from the Bechtel National, Inc. (BNI) WTP model. The WTP rheological boundaries for the non-Newtonian slurries range from a yield stress of $6 \mathrm{~Pa}$ and a consistency of $6 \mathrm{mPa} \cdot \mathrm{s}$ to a yield stress of $30 \mathrm{~Pa}$ and a consistency of $30 \mathrm{mPa} \cdot \mathrm{s}$. The rheology of the simulant was generally in the middle of this range. Two attempts were made, one attempt with boehmite added and one with gibbsite. The trial batches using boehmite had acceptable rheological properties, but when boehmite was added to the test vessel, the rheology exhibited extensive hysteresis in the rheometer. Testing with this simulant recipe was not completed because the rheological properties are 
not typical of Hanford tank waste slurries. The source of this aberrant behavior is not known. A second batch, made using gibbsite, exhibited better rheology but did not approach the rheological boundaries.

The suggested follow-on tests are discussed below and are the same as those discussed in Schonewill et al (2012). Initial testing to obtain aerosol release fraction and net generation rates has recently been completed in small- and large-scale test stands, as discussed in this report and in the large-scale aerosol report (Schonewill et al. 2012). These tests were conducted with simulants representing the expected WTP process stream properties over a range of orifice sizes, geometries, and line pressures.

The initial effort was directed at developing data to provide a technical basis for the WTP model predictions with the assumption that the model would be shown to be conservative. As discussed in Schonewill et al. (2012), extrapolation of the results to full-scale indicates that this may not be the case. Since there is considerable uncertainty in the extrapolations, a number of follow-on tests and related investigations are proposed below.

Testing with the spray at different distances from the splash wall demonstrated that longer distance sprays yield a higher release fraction (unless the spray is very close to the splash wall [i.e., 1 in.]). In-spray data has provided an upper bound for selected breaches; although there is uncertainty in the in-spray data, some of the in-spray data exceeds the WTP model. Conducting spray release tests in a larger chamber would help reduce the uncertainty in the upper-bound spray releases. Data obtained with longer sprays also would reduce the uncertainty associated with extrapolation to longer sprays, which is the largest source of uncertainty associated with the extrapolations. Additional emphasis on in-jet measurements is warranted to provide a more direct measurement of the release fractions.

Testing with the chemical simulant in the small-scale chamber showed that these high-solids non-Newtonian slurries, out of all the simulants tested, were the most likely to produce release fractions that exceeded the values obtained from the WTP model. The completed tests with the chemical simulant in the small-scale system did not span the full range of the WTP rheological boundaries because of simulant fabrication and testing difficulties. Additional testing with a chemical simulant that meets or slightly exceeds the rheological boundaries, in terms of solids content and yield stress, should be considered.

While testing with the chemical simulant in the small-scale chamber showed that thicker slurries gave higher release fractions, large-scale testing demonstrated that the aerosol net generation from the largest slots are the most likely to exceed results from the WTP model. Accordingly, there is a need to test slurries exhibiting a non-Newtonian rheology in large-slot sprays to compare this worst-case spray with the WTP model. In the large-scale system, clay slurries with rheological parameters spanning the WTP waste rheological boundaries should be considered. Testing of the clay slurries in the small-scale system will be needed to confirm similarity between the chemical simulant and the clay slurry. Testing with the chemical simulant in the large-scale test stand is precluded by the cost and hazards associated with the simulant. The large-scale system does not have the permits needed to handle hazardous materials.

The WTP is considering increasing the UDS limit from 20 to $27 \mathrm{wt} \%$. While the solids concentration during testing with the chemical simulant exceeded $27 \mathrm{wt} \%$ UDS, testing with gibbsite and boehmite slurries in water was conducted at an upper limit of $20 \mathrm{wt} \%$ UDS. Accordingly, some testing with a solids loading of $27 \mathrm{wt} \%$ for these slurries would provide a more complete set of data that would span the full range of expected waste properties. 
The current testing used particles that have particle densities ranging from about 2.4 to $3.6 \mathrm{~g} / \mathrm{mL}$. Actual Hanford waste has particles that exceed this range (e.g., $\mathrm{PuO}_{2}$ ). Aerosol testing with a slurry simulant that contains a fraction of higher density particles is needed to provide test results for simulants that span the full range of expected waste properties.

While conducting additional tests, alternative lenses for the Malvern aerosol instrument capable of measuring a wider range of PSDs should be considered. The lenses used for the current work have an effective PSD range of 0.5 to $200 \mu \mathrm{m}$. This range was selected because it was focused around the PSD range of greatest interest to WTP $(10$ to $80 \mu \mathrm{m})$. This limited range does not capture the largest droplets and leads to an overestimate of the release fraction for in-spray measurements. With an increased interest in obtaining in-spray measurements, it is desirable to obtain different lenses with a PSD range of 2.5 to $2500 \mu \mathrm{m}$. This will allow the PSD measurements to more directly and accurately represent the release fractions.

While several efforts were made to validate and check the aerosol measurements obtained from the Malvern Insitec-S, there is still some residual uncertainty, especially in the concentration values. The Insitec-S typically is used primarily for particle sizing in process applications. For spray release testing, it was used to determine the aerosol concentration in addition to the PSD. Because use of the Insitec-S for aerosol concentration measurement is not the typical application, some caution with respect to the accuracy of the concentration result is advisable. Another uncertainty was introduced by the apparent presence of a bi-modal distribution with one of the peaks occurring below a particle size of $10 \mu \mathrm{m}$. The peak at the smaller particle sizes is not consistent with expected spray release aerosol generation, and appears to be dependent on the instrument settings and experimental conditions. Efforts undertaken to check the Insitec-S included weekly performance checks of the instruments with a reticle (i.e., a physical standard), comparison of the Insitec-S and the PPC measurements, and an evaluation of the of solid-in-liquid dispersions on a similar Malvern instrument. While these efforts indicate that the Insitec-S results are reasonable, additional activities should be considered to increase confidence in the aerosol measurements.

Method validation tests in which a well characterized spray is introduced to the chamber should also be considered. These tests would apply the same measurement and analysis methods to sprays with known aerosol generation rate and size distribution to determine how well the estimates of aerosol generation rate match the expected values.

Considering the primary sources of uncertainty, the overall estimated uncertainty in the release fractions and net generation rates for the large-scale test stand is on the order of a factor of 2 to 3 . The primary sources of uncertainty are test-to-test variation, non-uniform concentrations in the chamber, and the aerosol measurements. Additional testing in an expanded large-scale chamber is suggested in order to better define these uncertainties and provide better extrapolations to full-scale conditions. These results should allow a better assessment of the available margin in the WTP Documented Safety Analysis. 


\section{Acknowledgments}

The authors would like to thank Jesse Lang, Greg Boeringa, Susan Sande, Mac Zumhoff, GK Shutthanandan, Janani Shutthanandan, Gourihar Kulkarni, Rebecca Erikson, and Laura Turo for their painstaking and indefatigable performance of the aerosol tests. Thanks are owed to John Geeting for his thorough independent technical review. Many thanks are also owed to Phil Schonewill for his analysis of the orifice images. We also thank Kirsten Meier for her QA support. We are also indebted to Mike Parker and Cary Counts for their editorial review of this report. Additionally, we greatly appreciate the data and calculation review efforts by Rich Pires, Rick Shimskey, Amanda Casella, and Ellen Baer.

We also sincerely appreciate the support, advice, and guidance from Mike Epstein (Fauske and Associates), Ameer Hassan (WTP Technical Lead), Susan Omberg-Carro (WTP), Andy Larson (WTP), Chris Harrington (DOE-WTP), Joel Fox (DOE-WTP), Ralph Crowe (Sludge Treatment Project K-Basin) and Bruce Zimmerman (Hanford Tank Farms).

Funding for this effort was provided by the DOE Hanford Waste Treatment and Immobilization Plant Project. 



\section{Acronyms and Abbreviations}

AFA

ASME

BNI

CFR

CSTR

DSA

DOE

FER

HDI

LAW

LRB

ORP

OTP

PEP

PNNL

PPC

ppmv

PSD

QA

R\&D

$\mathrm{R} \& \mathrm{~T}$

RF

SAR

SCFH

SMD

STR

TAR

TI

UDS

WTP

WTPSP antifoam agent

American Society of Mechanical Engineers

Bechtel National, Inc.

Code of Federal Regulations

continuously stirred tank reactor

Documented Safety Analysis

U.S. Department of Energy

Fe-rich (iron-rich)

"How Do I," the standards-based management system for PNNL

low-activity waste

Laboratory Record Book

DOE Office of River Protection

orifice test piece

Pretreatment Engineering Platform

Pacific Northwest National Laboratory

Process Metrix Particle Counter

parts per million by volume

particle size distribution

Quality Assurance

research and development

Research and Technology

release fraction

small as-received

standard cubic foot per hour

Sauter mean diameter

small treated

typical as-received

test instruction

undissolved solid

Hanford Tank Waste Treatment and Immobilization Plant

Waste Treatment Plant Support Project 



\section{Contents}

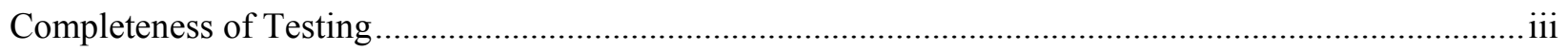

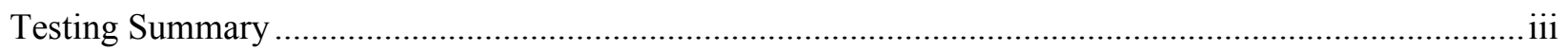

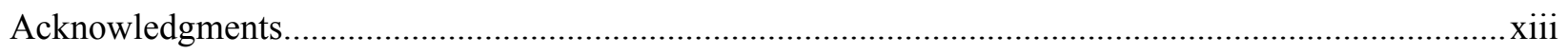

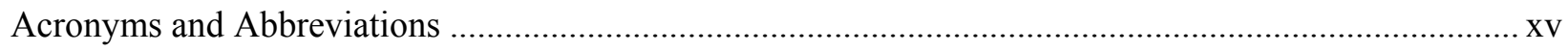

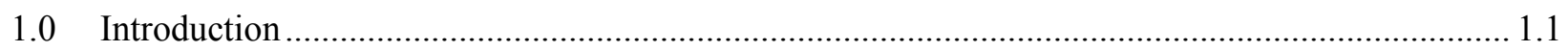

1.1 WTP Model for Estimating Aerosol Release Fraction and Generation .............................. 1.2

1.2 Technical Approach for Calculating Aerosol Release Fraction ........................................... 1.4

1.3 Literature on Aerosol Formation Related to the WTP Model .............................................. 1.6

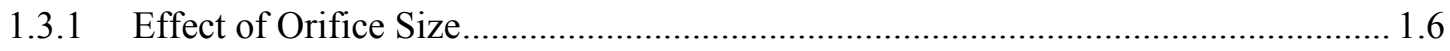

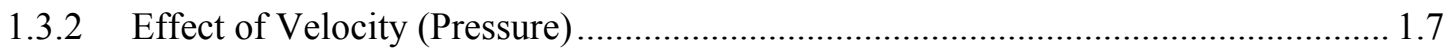

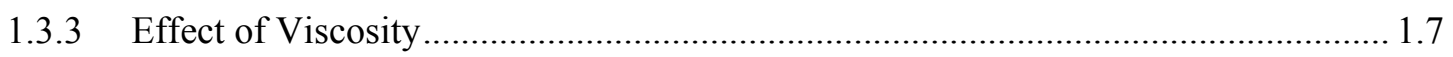

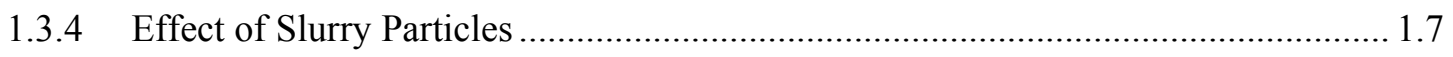

1.3.5 Effect of Surface Tension and Antifoam Agents ................................................. 1.8

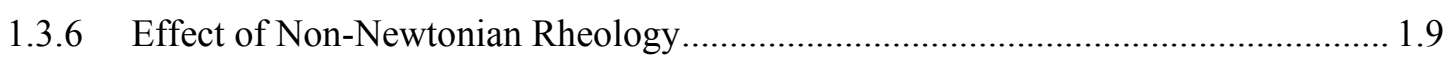

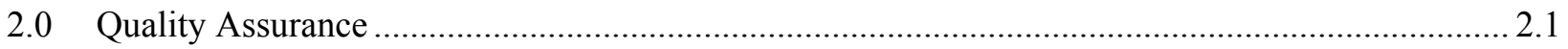

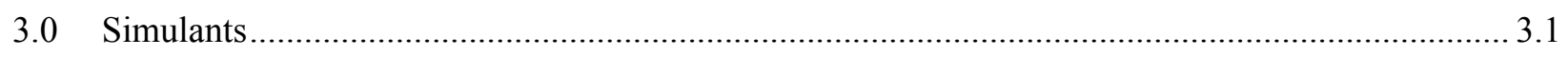

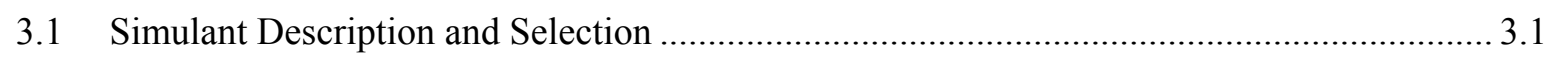

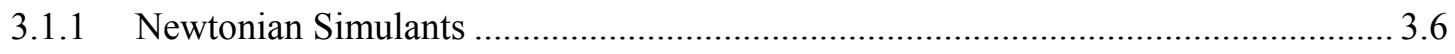

3.1.2 Typical As-Received Hanford Waste Simulant .................................................... 3.7

3.1.3 Small As-Received Hanford Waste Simulant ....................................................... 3.9

3.1.4 Small Treated Hanford Waste Simulant........................................................... 3.10

3.1.5 Iron-Rich Chemical Slurry Simulant............................................................... 3.12

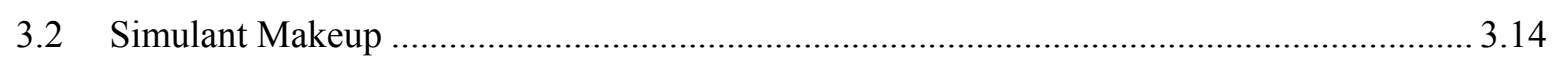

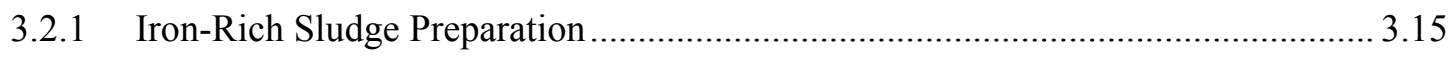

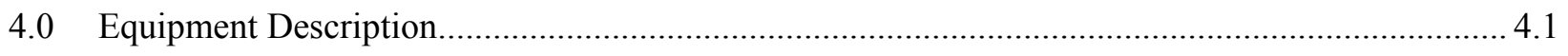

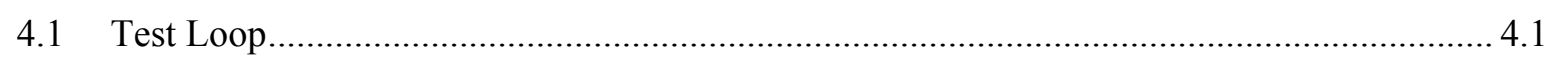

4.2 Test System Data Collection and Instruments.............................................................. 4.6

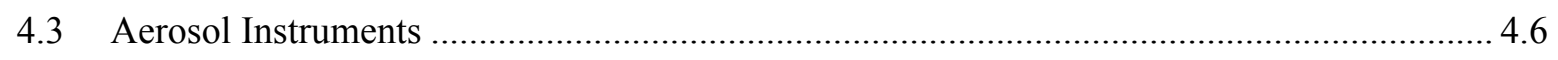

4.3.1 Malvern Insitec-S Particle Size Analyzer........................................................ 4.7

4.3.2 Process Metrix Particle Counter ............................................................................ 4.9

4.4 Orifice Imaging Hardware and Software .................................................................. 4.12

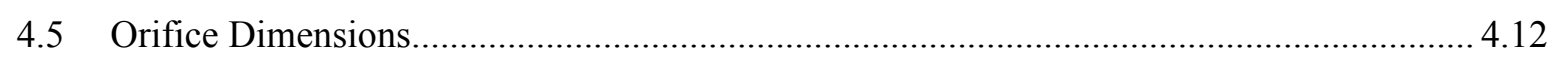

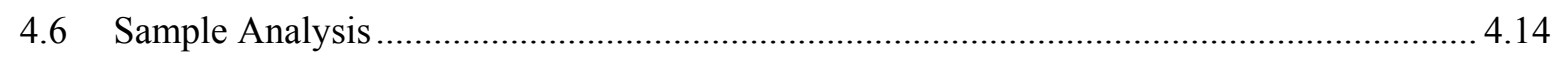

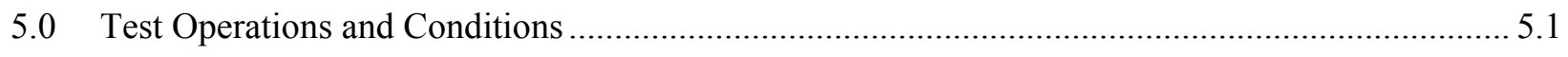

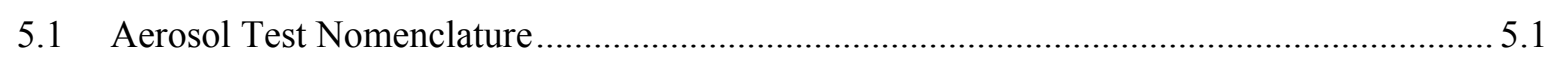

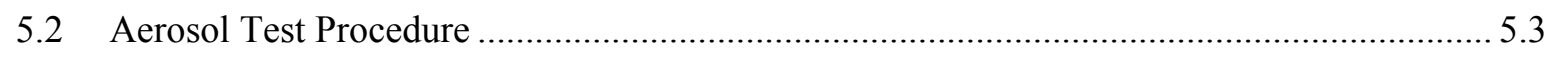




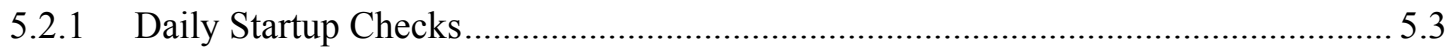

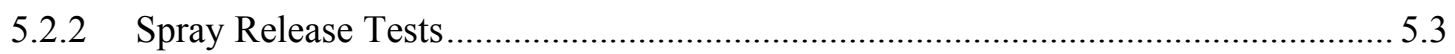

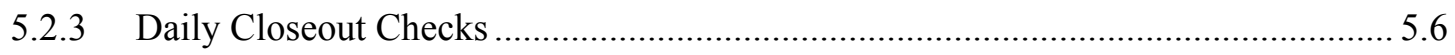

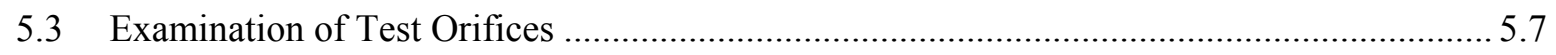

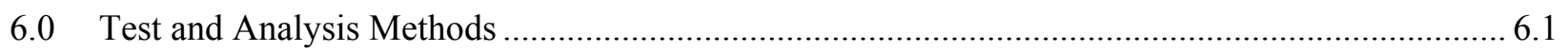

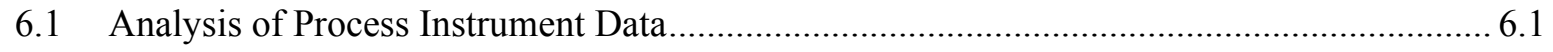

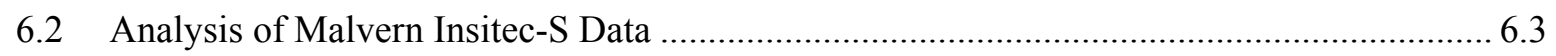

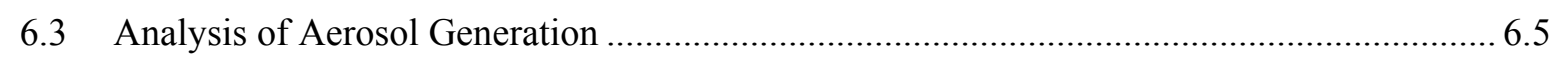

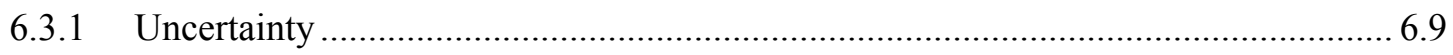

6.4 Analysis of Process Particle Counter Data ....................................................................... 6.10

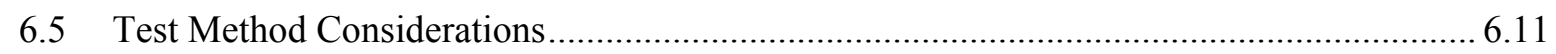

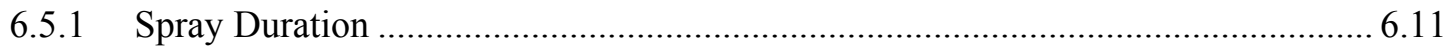

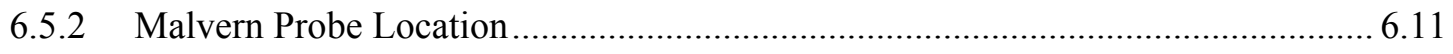

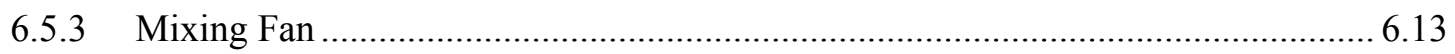

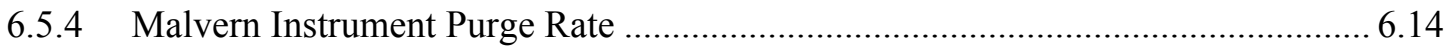

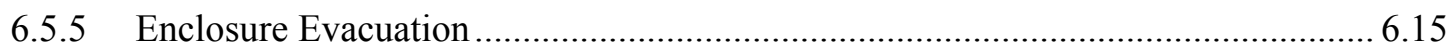

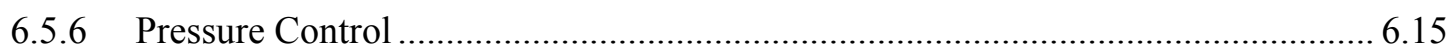

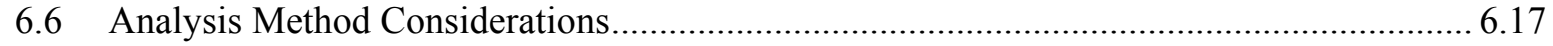

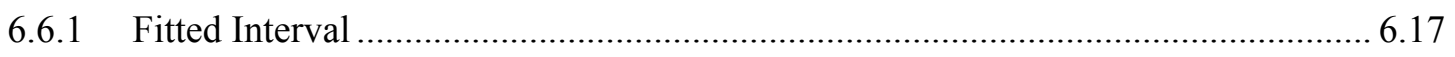

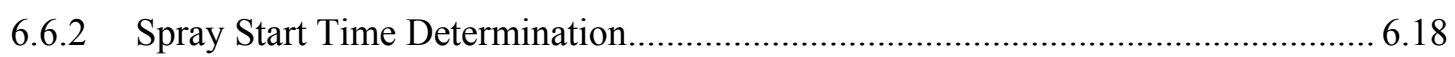

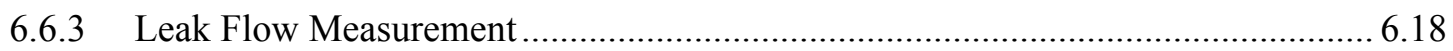

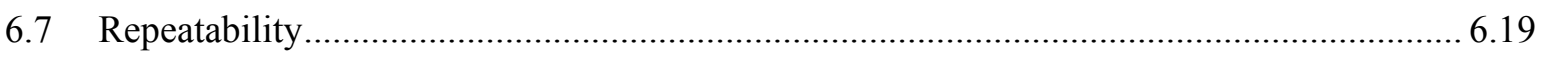

6.8 Comparison Between the Malvern Instrument and the PPC .......................................... 6.23

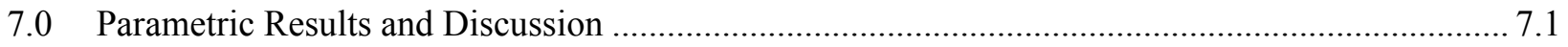

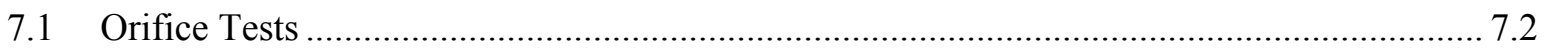

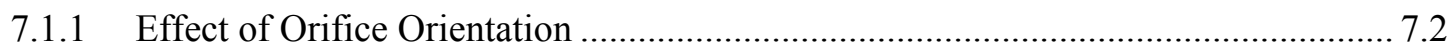

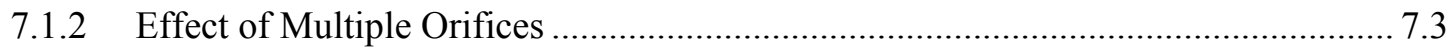

7.1.3 Effect of Orifice Area on Net Generation Rate and Release Fraction....................... 7.7

7.1.4 Effect of Aspect Ratio ................................................................................... 7.10

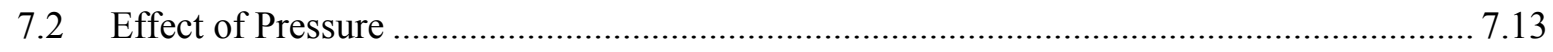

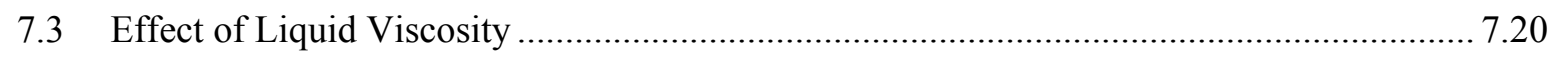

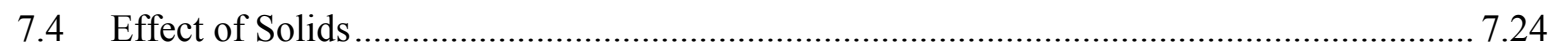

7.5 Effect of Antifoaming Agents ……......................................................................... 7.30

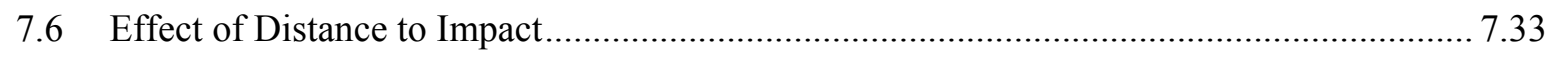

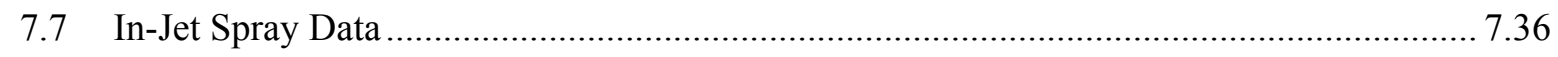

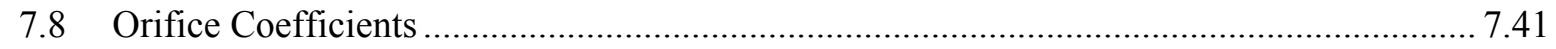

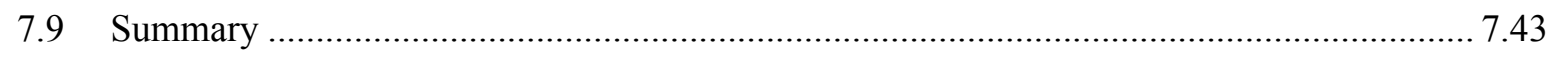

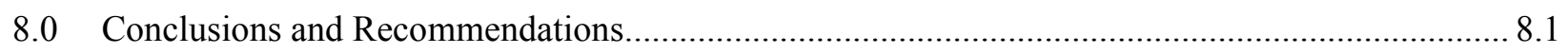

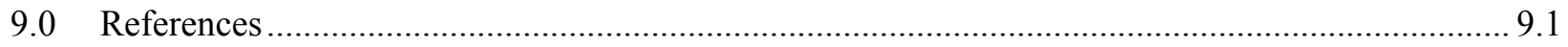


Appendix A - Run Log and Test Conditions................................................................................. A.1

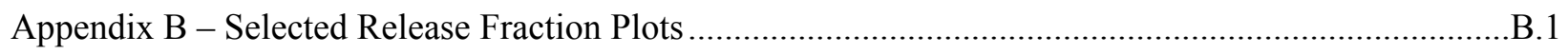

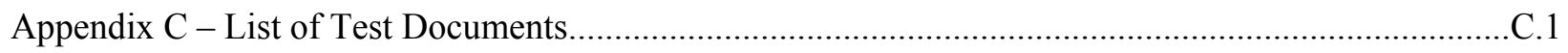

Appendix D - Cross-References for Parametric Plots in Section 7 ..................................................... D. 1

Appendix E - Concentration Plots for Impact Distance Tests............................................................. 1

\section{Figures}

1.1. Schematic of Aerosol Concentration Increasing with Time, Where the Aerosol Net Generation Rate is Calculated from the Initial Slope .......................................................... 1.5

3.1. Cumulative PSDs for Sludge Tanks and Waste Groups and for $5^{\text {th }}$ Percentile, Sludge Composite, and $95^{\text {th }}$ Percentile PSDs by UDS Volume ................................................................ 3.4

3.2. Flowing-Sonicated PSDs for Post-Caustic Leached and Washed Waste........................................ 3.5

3.3. Target Sludge Composite Combined and Measured TAR Simulant PSDs................................... 3.9

3.4. Target $5^{\text {th }}$ Percentile PSD and SAR Simulant PSD at Two Concentrations................................. 3.10

3.5. PSD of Target Group 1/2 Mixture and STR Simulant PSD at Two Concentrations .................... 3.12

3.6. FER Simulant PSD and Target PSD for SAR and TAR Simulants ......................................... 3.14

3.7. Iron-Rich Solids at Vendor After Concentration in Basket Centrifuge ....................................... 3.16

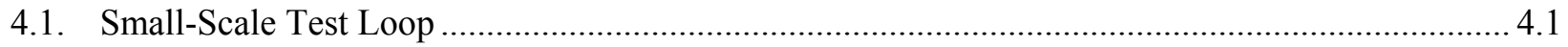

4.2. OTP in Test Header Spraying Water Horizontally Along the Length of Aerosol Test

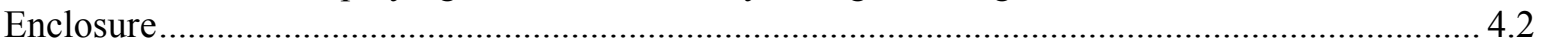

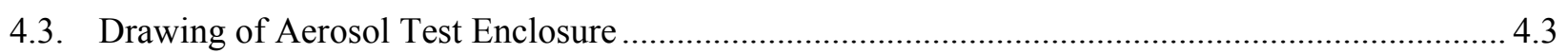

4.4. Front View and Dimensions of the Small-Scale Enclosure …................................................... 4.3

4.5. Detailed Schematic of Small-Scale Testing System ................................................................. 4.5

4.6. Basic Instrument Setup and Operation Principle of the Malvern Insitec-S Particle Size

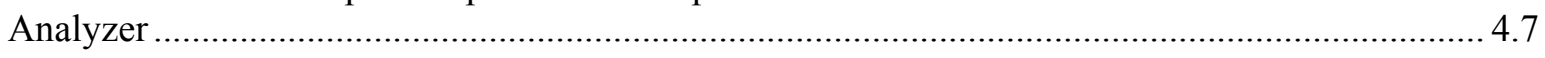

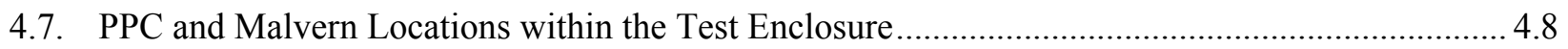

4.8. Schematic Showing the Basic Components and Principle of Operation for the PPC .................. 4.10

4.9. Orifice Images Were Measured Where the Orifice Intersected With the Outer Diameter of

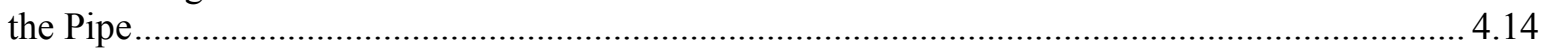

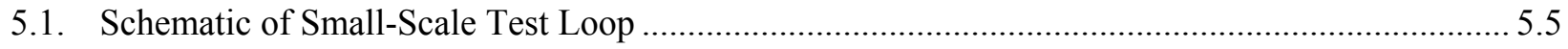

5.2. Illustration of the Pressure Change for the First Compared to the Second Valve Sequence ........... 5.6

6.1. Effect of Malvern Probe Location for a 380-psig Water Spray from a 0.5-mm Hole, with the Mixing Fan On. ............................................................................................................. 6.12

6.2. Effect of Malvern Probe Location for a 380-psig Water Spray from a 0.5-mm Hole, with the Mixing Fan Off.

6.3. Effect of Mixing Fan Speed for a 380-psig Water Spray from a 0.5-mm Hole, with the Malvern Probe in Position 2. 
6.4. Effect of Malvern Purge Air Flow Rate for a 380-psig Water Spray from a 0.5-mm Hole, with the Malvern Probe in Position 2 and a Fan Speed of 6 V ..

6.5. Effect of Pressure Transients for a 380-psig Water Spray from a 0.5 x 5-mm Slot, with the Mixing Fan On

6.6. Repeatability for 380-psig Water Sprays from a 1-mm Hole

6.7. Repeatability for 380-psig Water Sprays from a $0.5 \times 5-\mathrm{mm}$ Axial Slot.................................... 6.20

6.8. Repeatability for 380-psig Sprays of Sodium Thiosulfate Solution from a 1-mm Hole............... 6.21

6.9. Repeatability for 380-psig Sprays of $8 \mathrm{wt} \%$ STR from a $0.5 \times 5-\mathrm{mm}$ Axial Slot.

6.10. Repeatability for 380-psig Sprays of AFA-Containing Iron-Rich (FER) Slurry with a Target 6-Pa Yield Stress from a $0.5 \times 5$-mm Axial Slot.

6.11. Repeatability for 380-psig Sprays of AFA-Containing an FER Slurry with a Target 30-Pa Yield Stress from a $0.5 \times 5-\mathrm{mm}$ Axial Slot

6.12. Comparison of Steady-State Concentrations Measured by the Malvern and PPC Instruments for 380-psi Water Sprays from a 1-mm Round Hole

6.13. Comparison of Steady-State Concentrations Measured by the Malvern and PPC Instruments for 380-psi Water Sprays from a $0.5 \times 5$-mm Axial Slot

7.1. Effect of Slot Orientation for Slots and Round Holes, Using Water at 380 psi........................... 7.3

7.2. Comparison of Release Fractions for Single and Multihole Orifices, Using 0.5-mm Round Holes with Water at 380 psi.

7.3. Comparison of Release Fractions for Single and Multihole Orifices, Using 1-mm Round Holes with Water at 380 psi.

7.4. Net Generation Rate Versus Orifice Area for Single Round Holes and Slots, Using Water at $380 \mathrm{psi}$

7.5. Release Fraction Versus Orifice Area for Single Round Holes and Slots, Using Water at 380 psi

7.6. Release Fraction Versus Slot Length for Slots of $0.5 \mathrm{~mm}$ Width, Using Water at $380 \mathrm{psi}$.......... 7.11

7.7. Release Fraction Versus Slot Width for Slots of 5-mm Length, Using Water at 380 psi ............. 7.12

7.8. Effect of Pressure on Release Fractions for a Water Spray from a Target 1-mm Hole ................. 7.13

7.9. Effect of Pressure on Release Fractions for a Water Spray from a Target $0.5 \times 5-\mathrm{mm}$ Slot ......... 7.14

7.10. Effect of Pressure on Release Fractions for a Spray of FER6-B from a Target 1-mm Hole. ........ 7.15

7.11. Effect of Pressure on Release Fractions for a Spray of FER6-B from a Target $0.5 \times 5$-mm Slot.

7.12. Effect of Pressure on Release Fractions for a Spray of FER6+AFA from a Target 1-mm Hole.

7.13. Effect of Pressure on Release Fractions for a Spray of FER6+AFA from a Target $0.5 \times 5$-mm Slot.

7.14. Effect of Pressure on Release Fractions for a Spray of FER30 from a Target 1-mm Hole.

7.15. Effect of Pressure on Release Fractions for a Spray of FER30 from a Target $0.5 \times 5-\mathrm{mm}$ Slot.

7.16. Effect of Pressure on Release Fractions for a Spray of FER30+AFA from a Target 1-mm Hole.

7.17. Effect of Pressure on Release Fractions for a Spray of FER30+AFA from a Target $0.5 \times 5$-mm Slot. 
7.18. Release Fraction Distribution of Sprays of Water and Salt Solutions at 380 psig from a Target 1-mm Round Hole.

7.19. Effect of Liquid Viscosity on Release Fractions for Sprays of Water and Salt Solutions at 380 psig from a Target 1-mm Round Hole.

7.20. Effect of Liquid Viscosity on Aerosol Net Generation Rates for Sprays of Water and Salt Solutions at 380 psig from a Target 1-mm Round Hole.

7.21. Effect of STR Boehmite Solids on Release Fractions for AFA-Free Sprays at 380 psig from a Target 1-mm Round Hole.

7.22. Effect of STR Boehmite Solids on Release Fractions for AFA-Free Sprays at 380 psig from a Target $0.5 \times 5$-mm Slot.

7.23. Effect of SAR and TAR Gibbsite Solids on Release Fractions for AFA-Free Sprays at 380 psig from a Target 1-mm Round Hole.

7.24. Effect of SAR and TAR Gibbsite Solids on Release Fractions for AFA-Free Sprays at 380 psig from a Target $0.5 \times 5-\mathrm{mm}$ Slot

7.25. Effect of FER Solids on Release Fractions for AFA-Free Sprays at 380 psig from a Target 1-mm Round Hole

7.26. Effect of FER Solids on Release Fractions for AFA-Free Sprays at 380 psig from a Target $0.5 \times 5$-mm Slot.

7.27. Effect of AFA on Release Fractions for Water Sprays at 380 psig from a Target 1-mm Round Hole

7.28. Effect of AFA on Release Fractions for Water Sprays at 380 psig from a Target $0.5 \times 5-\mathrm{mm}$ Slot

7.29. Effect of AFA on Release Fractions for Sprays of $8 \mathrm{wt} \%$ STR at 380 psig from a Target 1-mm Round Hole

7.30. Effect of AFA on Release Fractions for Sprays of $8 \mathrm{wt} \%$ STR at 380 psig from a Target $1-\mathrm{mm} 0.5 \times 5-\mathrm{mm}$ Slot

7.31. Effect of Splash Distance on Release Fractions for Sprays of Water at 380 psig from a Target 1-mm Round Hole.

7.32. Normalized In-Jet Droplet Size Distribution as a Function of Elapsed Time for a Water Spray from a $0.5-\mathrm{mm}$ Orifice at $380 \mathrm{psi}$.

7.33. Comparison of In-Jet Droplet Size Distributions for a Water Spray from a 0.5-mm Orifice at 380 psi, Using Information from Multiple Sources.

7.34. Comparison of In-Jet Droplet Size Distributions for an FER6+AFA Spray from a 1-mm Orifice at $380 \mathrm{psi}$, Using Information from Multiple Sources

7.35. Comparison of Droplet Size Distributions for a Water Spray from a 1-mm Orifice at 200 psi, Using Information from Multiple Sources

7.36. Comparison of Droplet Size Distributions for Sprays of Water and FER6+AFA from a $0.5-\mathrm{mm}$ Orifice at $380 \mathrm{psi}$ Using Information from Multiple Sources.

7.37. Orifice Coefficients Calculated for Sprays of Various Simulants 


\section{Tables}

S.1. Summary of Small-Scale Aerosol Test Objectives and Results.................................................... iv

S.2. Success Criteria for Small-Scale Aerosol Tests .............................................................................. iv

S.3. Target Simulants and the WTP Process Stream Categories ........................................................... vi

S.4. Simulant Nomenclature ............................................................................................................ vi

3.1. WTP Process Stream Categories and Representative Fluid Properties......................................... 3.1

3.2. Target Simulants and the WTP Process Stream Categories ........................................................ 3.2

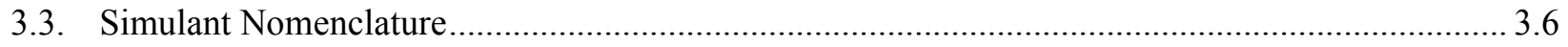

3.4. Components Used to Prepare the Iron-Rich Slurry .................................................................... 3.6

3.5. Small Scale Newtonian Simulant Properties for Aerosol Tests ...................................................... 3.7

3.6. SAR and TAR Simulant Properties for Aerosol Tests ............................................................. 3.8

3.7. Small Treated Simulant Properties for Aerosol Tests ................................................................. 3.11

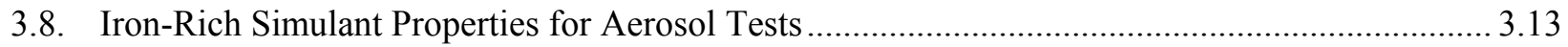

3.9. Components Used to Prepare the Iron-Rich Sludge .................................................................. 3.15

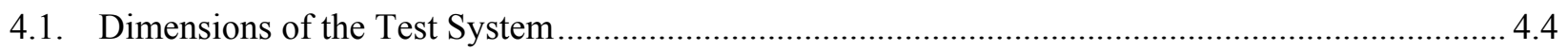

4.2. Instruments Used in Small-Scale Aerosol Tests .............................................................................. 4.6

4.3. Insitec-S Instrument Configuration and Software Parameters Used in Typical

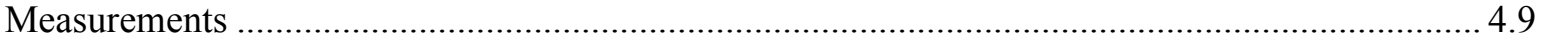

4.4. Exit Dimensions for the Orifices for Which Release Fractions Were Determined....................... 4.13

5.1. Target Ranges of Aerosol Test Parameters .............................................................................. 5.1

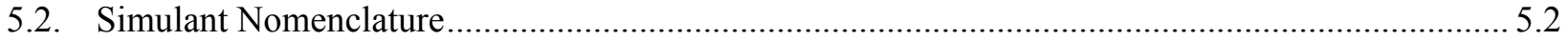




\subsection{Introduction}

One of the events postulated in the hazard analysis for Waste Treatment and Immobilization Plant (WTP) is a breach in process piping that produces a spray with aerosols with droplet sizes in the respirable range. The postulated breach is expected to be rough and irregular, and could result from a number of causes (e.g., jumper connection misalignment, pipe erosion/corrosion, mechanical impact, seal/gasket failures).

In Hanford practice, the generation rate and size distribution of aerosol droplets produced in a spray leak have generally been predicted by using correlations published in the literature. These correlations are based on results obtained from small engineered spray nozzles using solids-free liquids. However, the fluids processed at WTP include slurries and high-viscosity liquids with properties very different than the properties of the liquids used to develop the correlations currently used to evaluate spray leaks. The range of geometries postulated for random breaches differs from the geometry of the engineered spray nozzles used to develop the correlation in terms of both aspect ratio and area. Therefore, the correlations used to model spray leaks from process piping may not accurately represent spray leak conditions at the WTP (or elsewhere on the Hanford Site).

The amount of aerosol produced is a function of the dimensions of the opening, which affects both the total amount of flow and the fraction that becomes respirable aerosol. In some predictive correlations for aerosol generation, the respirable fraction is not sensitive to breach dimensions (Epstein and Plys 2006). In other correlations, the respirable fraction increases significantly as the dimensions of the breach decrease (Hey and Leach 1994). The maximum breach size postulated for WTP spray modeling depends on the pipe size, and for pipe diameters up to 3 in., the maximum opening has a length equal to the pipe diameter and a width equal to one-half of the pipe wall thickness (Larson and Allen 2010). Some models in use on the Hanford site set a minimum breach dimension based on the gas Weber number $\left(\mathrm{We}_{\mathrm{g}}\right)^{2}$ or on plugging considerations. Arguments have been made, for example, that openings with $\mathrm{We}_{\mathrm{g}}<60$ do not support significant jet breakup and, therefore, do not result in significant aerosol production (Zimmerman 2003) or that openings with minimum dimension $<0.6 \mathrm{~mm}$ would be plugged by slurries that contained relatively large particles, as do K-Basin slurries (Crowe 2011). In practice, the plugging assumption may determine a minimum breach size, which can limit the estimated amount of aerosol produced if the correlation used to model aerosol predicts greatly increased respirable droplet production as the breach size decreases.

These considerations indicate two key technical areas where testing is needed to improve the WTP methodology (Larson and Allen 2010) and reduce uncertainty introduced by extrapolating from results found in the literature. The first technical need is to quantify the role of slurry particles in small breaches where slurry particles may plug the hole and prevent high-pressure sprays. The second technical need is to determine aerosol droplet size distribution and total droplet volume from prototypic breaches and fluids, including sprays from larger breaches and sprays of slurries for which literature data are largely absent. These needs were addressed by conducting small- and large-scale testing using simulants to mimic the relevant physical properties projected for actual WTP process streams.

\footnotetext{
${ }^{2}$ The gas Weber number $\left(\mathrm{We}_{\mathrm{g}}\right.$ ) is $\rho_{g} V^{2} D / \sigma$, where $\rho_{g}$ is the gas density, $V$ is the liquid velocity at the orifice, $D$ is the diameter of the orifice, and $\sigma$ is the fluid surface tension.
} 
The purpose of the study described in this report is to provide experimental data and analysis for a portion of the second key technical area - determining aerosol droplet size distribution and total droplet volume from prototypic breaches and fluids - by performing small-scale tests with a range of orifice sizes and orientations representative of the WTP typical conditions. The results from an effort to address the first technical area, breach plugging, can be found in Mahoney et al. (2012).

Simulants were chosen to represent the range of process stream properties projected for the WTP. Experimental data and analysis for large-scale tests are provided in Schonewill et al. (2012). Chapter 1 of this report provides an introduction and a discussion of related tests found in the literature, and also gives details on the WTP model for estimating the aerosol release fraction and generation that was used to compare with the experimental results. Chapter 2 details the basis of the Pacific Northwest National Laboratory (PNNL) Quality Assurance (QA) Program as applied to the River Protection Project WTP quality requirements. Chapter 3 describes liquid and slurry simulants used in testing. Chapter 4 provides a description of the equipment and instruments. Chapter 5 summarizes the test operations and conditions. Chapter 6 provides the analysis methodology. Chapter 7 discusses the results. Chapter 8 contains the conclusions of the study. References are compiled in Chapter 9. The appendices provide a cross-reference table (Appendix A), release fraction (RF) plots for the tests completed (Appendix B), a list of the technical documents governing the work (Appendix C), a cross-reference for Section 7 parametric plots (Appendix D), and aerosol concentration plots for impact-distance tests (Appendix E).

\subsection{WTP Model for Estimating Aerosol Release Fraction and Generation}

Larson and Allen (2010) summarize the methodology used by the WTP for estimating the aerosol release fraction and generation rate of spray releases, and McAllister (2010) provides additional details on the equations and method. The method uses the theoretically-based correlation by Dombrowski and Johns (1963) for estimating the Sauter mean diameter (SMD) and then estimates the aerosol droplet size distributions using the Rosin and Rammler (1933) distribution. An overall objective of the current study is to collect data to determine the range of applicability of the method. The Dombrowski and Johns (1963) equations used in the WTP methodology for estimating the SMD are

$$
\begin{gathered}
d_{l}=0.9614\left(\frac{\mathrm{K}^{2} \sigma^{2}}{\rho_{l} \rho_{a} V^{4}}\right)^{1 / 6}\left[1+2.6 \mu\left(\frac{\mathrm{K} \rho_{a}^{4} V^{7}}{72 \rho_{l}^{2} \sigma^{5}}\right)^{1 / 3}\right]^{1 / 5} \\
d_{d}=1.882 d_{l}\left[1+\frac{3 \mu}{\left(\rho_{l} d_{l} \sigma\right)^{1 / 2}}\right]^{1 / 6} \\
S M D=0.63 d_{d}
\end{gathered}
$$

where $\quad d_{l}=$ the theoretical ligament diameter $(\mathrm{m})$

$d_{d}=$ the theoretical droplet diameter $(\mathrm{m})$

$\mu=$ the liquid viscosity $\left(\mathrm{Pa}^{*} \mathrm{~s}\right)^{3}$

$\rho_{l}=$ the liquid density $\left(\mathrm{kg} / \mathrm{m}^{3}\right)$

$\rho_{a}=$ the air density $\left(\mathrm{kg} / \mathrm{m}^{3}\right)$

\footnotetext{
${ }^{3}$ McAllister (2010) has a typographical error and shows incorrect units for viscosity (uses kinematic viscosity units), but uses the correct viscosity and units in the example calculation.
} 


$$
\begin{aligned}
\sigma & =\text { the surface tension of the liquid }(\mathrm{N} / \mathrm{m}) \\
\mathrm{V} & =\text { the fluid velocity at the breach }(\mathrm{m} / \mathrm{s}) \\
\mathrm{K} & =\text { the spray nozzle parameter }\left(\mathrm{m}^{2}\right) .
\end{aligned}
$$

The K parameter is determined with the (McAllister 2010) relationship

$$
\mathrm{K}=\frac{0.5 \mathrm{~A}}{\sin (\theta / 2)}
$$

where $\mathrm{A}$ is the area of the breach for all shapes and $\theta$ is the full spray angle, assumed to be the maximum value of $150^{\circ}$ for a fan spray. Using the assumed maximum value of the spray angle, $\sin (\theta / 2)$ is practically unity (0.97) and $K$ is approximately $A / 2$.

Other applications of the Dombrowski and Johns (1963) model for spray release evaluations have used models for the $\mathrm{K}$ parameter that distinguish between breaches with different shapes, rather than just using the area for all breaches (Crowe 2010; Williams 2000).

The SMD for a particular spray can be determined using Equations (1.1) to (1.4). To determine the fraction of a spray contained in droplets below any particular size for a spray release accident analysis, a relationship is needed for the droplet size distribution. For the WTP methodology, Larson and Allen (2010) use the Rosin and Rammler (1933) distribution and further assume that the release fraction of a spray is equal to the droplet size distribution. The following equations give the release fraction for sprays used in the WTP methodology:

$$
\begin{gathered}
R F=1-\exp \left[-\left(\frac{S M D}{X} \frac{D}{S M D}\right)^{q}\right] \\
\frac{S M D}{X}=[\Gamma(1-1 / q)]^{-1}
\end{gathered}
$$

where $\quad D=$ droplet size

$$
\begin{aligned}
q & =\text { a fitting constant that provides a measure of the spread in the droplet size } \\
& \text { distribution } \\
R F & =\text { fraction of the total spray volume contained in drops of diameter less than D } \\
S M D & =\text { Sauter mean diameter } \\
X & =\text { a characteristic diameter } \\
\Gamma & =\text { gamma function. }
\end{aligned}
$$

Larson and Allen (2010) evaluated the value of $q$ and chose $q=2.4$, and also noted that this gives a constant value of the ratio $\mathrm{SMD} / \mathrm{X}=0.65415$.

To determine the aerosol generation rate from a spray, the flow rate of the spray is needed in addition to the release fraction given by Equation (1.5). The generation rate $\mathrm{G}$ is given by

$$
\mathrm{G}=\mathrm{Q} * \mathrm{RF}
$$

where $Q$ is the volumetric flow of the spray $\left(\mathrm{m}^{3} / \mathrm{s}\right)$ and $\mathrm{G}$ is the generation rate $\left(\mathrm{m}^{3} / \mathrm{s}\right)$ of droplets less than diameter D. 
For the experiments presented in this report, both a net $\mathrm{G}$ and $\mathrm{Q}$ were measured for individual sprays and the results are presented either as the net generation rate or as the release fraction. Note that the net generation rate is the total spray generation rate (which is the rate predicted by the WTP model) minus losses caused by the impact at the splash wall.

For use in Equation (1.1), the velocity of the liquid leaving the orifice can be determined from the pressure difference with an orifice flow equation (e.g., see Denn 1980), and McAllister (2010) uses the following orifice flow equation with a typical value of 0.62 for the orifice coefficient:

$$
\mathrm{V}=0.62\left(\frac{2 \Delta P}{\rho_{l}}\right)^{1 / 2}
$$

Here $\Delta P$ is the difference between the pressure in the pipe and the discharge pressure (i.e., atmospheric pressure).

In the WTP model, the volumetric flow for calculating the total release with Equation (1.7) is simply the spray velocity times the area of the orifice.

$$
\mathrm{Q}=\mathrm{V} * \mathrm{~A}
$$

The equations presented above represent the WTP model. Predictions from this model are compared with the experimental results shown in Chapter 7. The model predictions presented in Chapter 7 will show the quantitative dependence on the various parameters in the Dombrowski and Johns (1963) correlation.

\subsection{Technical Approach for Calculating Aerosol Release Fraction}

Three experimental methods were considered to measure the aerosol net generation rate and release fraction: 1) direct in-spray measurements, 2) steady-state aerosol concentration measurements in a chamber with different volumetric purge rates, and 3) transient aerosol concentration measurements in a chamber with no purge flow. The benefits and drawbacks of each method are discussed and the selected method is described in this section. Further details regarding the aerosol measurement methodology can be found in Chapter 6.

The first experimental method measures the aerosol directly in the spray, providing an explicit measurement of the aerosol droplet size distribution at a specific position. The release fraction for any given size of droplet is equal to the volume fraction of it in the spray, as given by the droplet size distribution. However, Epstein and Plys (2006) showed that in-spray measurements at a reasonable distance $(0.5$ to $1 \mathrm{~m})$ become difficult for larger orifices because the liquid core of the jet remained intact. In particular, they had to measure the droplet size distribution a short distance from the center of the spray for the largest slot they tested $(1.2 \times 10 \mathrm{~mm})$ to avoid the liquid core. In addition, the measured in-spray droplet size distribution does not account for the spray moving at different velocities and having a spatial variation of droplet concentrations within the spray and, hence, within the region where the aerosol instrument measures the droplet size distribution. This effect introduces uncertainty in equating the spray release fraction with the measured droplet size distribution. The literature gives methods for determining the spatial variation in droplet concentration (Boyaval and Dumouchel 2001) and for determining the velocity distribution across a spray (e.g., see Levy et al. 1997), but these studies also indicate that 
determining spatial variation in the concentration and velocity is quite challenging. Finally, in-spray measurements do not account for droplet formation by splatter should a high-pressure spray impact on surfaces. Primarily because of the expected difficulty in obtaining in-spray measurement for larger orifices and not including the effect of splatter, the in-spray method was not chosen as the primary measurement method.

The second experimental method considered for determining the aerosol net generation rate was to generate a steady spray and measure the steady-state concentration within a chamber by varying the flow rates of clean air introduced into the chamber to dilute the aerosol. The net generation rate then could be calculated from the measured aerosol concentration with different purge rates. However, during shakedown testing, it was determined that the steady-state aerosol concentrations were only slightly greater than the minimum detection limit of the aerosol instrument and that dilution of the aerosol by this method would likely give concentrations that could not be measured. In addition, for some of the larger sprays, the volume of liquid sprayed into the chamber could become quite large and the accumulation of liquid in the chamber would become an experimental challenge for longer-duration steady-state tests. This experimental approach still is reasonable, but for these reasons, it was not selected as the primary measurement method.

The third experimental method, and the one selected, consists of measuring the rate of increase in aerosol concentration in a closed chamber of known volume. Using a simple material balance, the rate of concentration increase gives the aerosol net generation rate from a spray. Figure 1.1 shows a conceptual example of concentration increase with time, for different cumulative droplet volumes, where the initial rate of increase can be estimated from the initial increase in concentration. Eventually, the concentrations no longer increase linearly with time and approach steady-state values. This behavior results from aerosol losses in the chamber. An analysis including this behavior and the method used to determine the initial slope are discussed in Chapter 6.

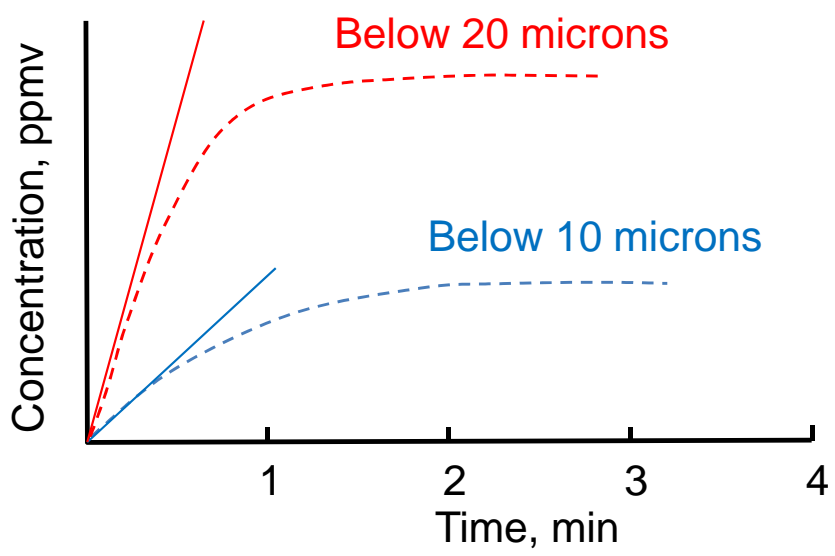

Figure 1.1. Schematic of Aerosol Concentration Increasing with Time, Where the Aerosol Net Generation Rate is Calculated from the Initial Slope (solid lines)

A key component of the approach based on the increase in concentration is to have a concentration measurement in the chamber that is representative of the entire chamber. An advantage of using a chamber is that it allows for isolation of the spray, providing a safe testing platform for spraying 
simulants that are chemically hazardous. This methodology also allows testing to be performed in different-sized chambers where a larger chamber could accommodate larger sprays but the overall experimental and data analysis approach would be the same. Creating sprays inside a chamber also allows the spray to impact the walls of the chamber and generate aerosol droplets by splatter. This additional mechanism of droplet formation is typical of an actual spray, and adds to the total aerosol formation within the chamber. The approach of measuring the concentration increase in a closed chamber also allows the role of changing orifice-to-wall distances to be determined. Because of the size and configuration of WTP piping, sprays could impact internal systems (e.g., walls, pipes, valves) at distances ranging from inches to hundreds of feet. In addition, because the same experimental method was used in both the small- and large-scale tests, results can be compared and extrapolated to longer distances with more confidence than previously. For the reasons discussed above and because of the overall method flexibility, the primary method used to determine aerosol net generation rate is to measure the rate based on the initial rate of concentration increase in a closed chamber.

\subsection{Literature on Aerosol Formation Related to the WTP Model}

The formation of aerosols for sprays from a range of nozzles and fluids has been widely studied and good summaries are available in textbooks (Lefebvre 1989; Nasr et al. 2002; Ashgriz 2011) and review articles (Eggers and Villermaux 2008). For spray release estimates, the U.S. Department of Energy (DOE) publication Airborne Release Fractions/Rates and Respirable Fractions for Nonreactor Nuclear Facilities (DOE 1994) provides a compilation of information and guidance for release fractions, but these estimates were based on a limited amount of experimental data. There are a number of correlations in the literature; however, these correlations sometimes give quite different results for the effect of breach size and shape, fluid properties, and spray velocity.

A number of recent studies have evaluated the existing correlations of aerosol formation from high-pressure sprays and also have developed improved release fraction estimates. As discussed previously in Section 1.1, Larson and Allen (2010) discussed differences in the available correlations and specifically compared the selected approach, based on the correlation in Dombrowski and Johns (1963), with the predicted droplet size from the modified Merrington and Richardson correlation given by Lefebvre (1989). Crowe (2010) and Williams (2000) both compared the Dombrowski and Johns (1963) correlation to other correlations, and Lefebvre (1989) provided a useful summary of a number of additional correlations for plane orifice atomizers.

Epstein and Plys (2006) gave a broad summary of available correlations and, in particular, discussed the different predictions for the effect of orifice size. Epstein and Plys (2006) also reported new experimental results for high-pressure water sprays. This work is essentially the only study that provides drop size distributions for orifices and pressures that specifically address the data needs for evaluating sprays that result from accidental breaches. The specific findings from Epstein and Plys (2006) are discussed below in sections on the effect of orifice size and pressure. Other sections give brief summaries of the literature on the additional parameters evaluated in this report.

\subsubsection{Effect of Orifice Size}

The most notable difference in the existing correlations is for the effect of orifice size. Epstein and Plys (2006) measured droplet size distributions from circular holes with diameters ranging from 0.3 to 
$2.38 \mathrm{~mm}$ and from two rectangular slots with dimensions of $0.3 \times 10 \mathrm{~mm}$ and $1.2 \times 10 \mathrm{~mm}$. For all but the largest slot, the measured drop size distribution did not depend on the size or shape of the orifice. Measurements from the largest slot were different, but this slot generated a long liquid core that interfered with size distribution measurement. This finding agreed with the original correlation from Merrington and Richardson (1947) that also showed no effect of orifice size on the SMD and, hence, no effect on the release fraction (see Equation (1.5)), for the spray. If the release fraction is a constant with increasing orifice diameter or area, Equations (1.7) and (1.9) show that the total aerosol generated increases with orifice size simply because of the increase in flow rate through the orifice.

As shown with the experimental results in Chapter 7, the WTP method predicts a decrease in the release fraction with increasing orifice area, but the total aerosol generated (see Equation (1.7)) will still increase with increasing orifice area because of the increase in flow rate. In contrast, the modified Merrington and Richardson correlation given by Lefebvre (1989) yields an SMD that increases and, hence, a release fraction through Equation (1.5) that decreases more with increasing orifice diameter. For the modified Merrington and Richardson correlation, the decrease in release fraction is sufficiently large so the total generation is predicted to decrease with increasing orifice diameter and flow.

The differences in the existing correlations are sufficient to make it uncertain whether larger or smaller orifices will have the largest total aerosol generation rate. Accordingly, one of the primary objectives of the current experimental measurements is to obtain data for a sufficient range of orifice sizes to reduce the uncertainty about the effect of orifice size.

\subsubsection{Effect of Velocity (Pressure)}

Increasing the spray pressure increases the liquid velocity exiting the orifice (see Equation (1.8)), and this affects aerosol formation in two ways. First, the increased jet velocity reduces the droplet size and, hence, increases the release fraction. The recent work of Epstein and Plys (2006) showed SMD to be proportional to (initial jet velocity $)^{-0.558}$, which is similar to the Dombrowski and Johns result given by Equation (1.1), assuming the last group of terms in Equation (1.1) is small compared to one in which SMD is proportional to (initial jet velocity) $)^{-2 / 3}$. The second effect of spray pressure is to increase the total flow of the spray and, hence, the total aerosol generation rate as given by Equation (1.7).

\subsubsection{Effect of Viscosity}

A number of studies, including the original data and correlation of Merrington and Richardson (1947) and the Dombrowski and Johns (1963) correlation, evaluated the effect of viscosity on droplet formation. These correlations, and others in the literature (see summaries by Lefebvre [1989] and Epstein and Plys [2006]), generally showed that increasing the viscosity increases the droplet size and, hence, decreases the release fraction; however, the dependence is generally small.

\subsubsection{Effect of Slurry Particles}

There have been a few previous studies that have evaluated the role of slurry particles on aerosol droplet formation. While there are many specific observations, there are some overall general findings. One group of studies evaluated the role of slurry particle size and generally determined that, if the slurry particles are smaller than the droplets, the slurry particles do not tend to affect the droplet distribution 
(Mulhem et al. 2006, 2003, 2001; Fritsching et al. 2009). When the slurry particles become progressively larger and specifically larger than droplets that would be generated in the absence of the slurry particles, droplet formation is naturally influenced. Droplets smaller than the slurry particles can still be formed, but these droplets will not contain slurry particles, and the larger droplets will contain the slurry particles. Breitling et al. (2001) presented both computational fluid dynamics and experimental results for shear-thinning lime slurries sprayed from hollow cone pressure swirl nozzles. The results showed little difference between the slurry and water, but there was no information on the size of the lime particles. Hecht et al. (2007) found that increasing solids loading resulted in a small decrease in the droplet size. Son and Kihm (1998) studied the effect of coal slurry particles on spray formation. The coal slurries were non-Newtonian and had progressively higher apparent viscosities for progressively smaller coal particles. The aerosol results showed that larger aerosol droplets were generated as the coal particle size became smaller, and Son and Kihm (1998) suggested that the primary reason was the increase in apparent viscosity for the smaller particle slurries. Dombrowski and Munday (1968) found that a small volume fraction of wetting particles did not change the breakup of a fan jet but that a high particle concentration in the slurry changed the behavior markedly and resulted in larger droplets. Finally, Hecht and Bayly (2009) discussed how aerosol formation from concentrated non-Newtonian slurries is affected by a range of phenomena associated with the particles, their interaction, and the complicated rheology.

Overall, the literature on aerosol formation with slurries suggests that slurry particles can affect droplet formation in ways that can both increase and decrease the size of the droplets.

\subsubsection{Effect of Surface Tension and Antifoam Agents}

The effect of reduced surface tension resulting from the use of antifoam agents (i.e., blends of surface-active agents) was addressed by testing in the small-scale test system. The breakup of fast-moving droplets into smaller droplets depends on the magnitude of the aerodynamic forces acting on the droplet. A number of previous studies (e.g., Hinze 1955; Pilch and Endman 1987; Eggers and Villermaux 2008) showed that the droplet breakup mechanism depends on the gas Weber number, We $e_{\mathrm{g}}$ which is the ratio of the disruptive aerodynamic force to the stabilizing surface tension force

$$
W e_{g}=\frac{\rho_{g} V^{2} D}{\sigma}
$$

where

$$
\begin{aligned}
\rho_{g} & =\text { the gas density } \\
V & =\text { the droplet velocity } \\
D & =\text { the droplet diameter (often assumed orifice diameter) } \\
\sigma & =\text { the surface tension of the fluid. }
\end{aligned}
$$

In general, increasing the Weber number causes breakup into smaller droplets (Pilch and Endman 1987).

For pure fluids, reducing the surface tension increases the Weber number, and this is expected to decrease the size of droplets formed by breakup. When surface active agents such as antifoam agents are present and cause a reduction in the surface tension, it is important to consider the time scale for the interface formation. When the formation of an interface is rapid compared to the time it takes surface active species to diffuse to and adsorb at the interface, the surface tension is different than the equilibrium value, and this time-dependent surface tension often is called the dynamic surface tension (Berg 2010). The dynamic surface tension approaches that of the pure fluid as the time scale for interface formation 
becomes progressively shorter. Recently, Gauglitz et al. (2011) reviewed the literature on droplet breakup and estimated that the time scale for droplet breakup would be about $0.001 \mathrm{~s}$ and that the dynamic surface tension at this time scale would be expected to be essentially equal to that of water for aqueous systems. Accordingly, the conclusion of this review was that small quantities of surface active species would not affect aerosol formation.

Dombrowski and Munday (1968) discussed the role of surfactants on droplet formation from fan sprays, and they similarly commented that the timescale for the breakup of the liquid sheet was less than $0.001 \mathrm{~s}$ and that the majority of the fan had a surface tension equal to that of water. The surfactant solutions studies by Dombrowski and Munday (1968) used hard water that generated a fine precipitate, so the tests showing the effect of adding surfactant actually demonstrated the combined effect of potential surface tension reduction and the presence of fine particulates. For the two surfactant concentrations reported, the lowest concentration ( 0.05 percent) gave larger drop sizes when compared to water, and the higher concentration ( 0.25 percent) did not appear to change the drop size. Bühler et al. (2001) studied the effect of two surfactants on droplet formation from hollow-cone and de Laval nozzles. These tests used different surfactant concentrations and generated sprays at pressures varying from $2 \times 10^{5}$ to $4 \times 10^{6} \mathrm{~Pa}$ (30 to $600 \mathrm{psig}$ ). They used a bubble tensiometer to determine the dynamic surface tension of the solutions from time scales below 0.01 to $0.4 \mathrm{~s}$. They commented that the droplet formation in this study was on the order of $0.01 \mathrm{~s}$, and at this time scale, all the solutions had a surface tension very near that of pure water. The aerosol size distributions were determined with a Malvern light-scattering instrument, and the results showed that adding surfactants caused a small or negligible increase of the droplet mean diameter. The conclusion from Bühler et al.'s (2001) work was that the addition of surfactants caused little change in droplet size distribution, compared to that for water, because the surface tension was equal to that of water at the time scale for droplet formation.

Based on these results, it is expected that the addition of an antifoaming agent, which will reduce equilibrium surface tension, will have a negligible effect on droplet formation.

\subsubsection{Effect of Non-Newtonian Rheology}

As noted by Nasr et al. (2002), there are very few systematic data showing how non-Newtonian fluid properties affect aerosol formation, and whether aerosol is different than for Newtonian fluids. Concentrated slurries will typically show non-Newtonian fluid properties, and often can be described as Bingham plastics (if they have a yield stress) or shear-thinning fluids (Poloski et al. 2004). Breitling et al. (2001) presented results from both computational fluid dynamic modeling and experiments for shear-thinning lime slurries sprayed from hollow cone pressure swirl nozzles. The results showed little difference between the slurry and water. Mansour and Chigier (1995) evaluated air-blast atomization of shear-thinning visco-elastic and visco-inelastic polymer solutions. The shear-thinning visco-inelastic solutions, which can be considered similar to non-Newtonian slurries, generally showed behavior similar to Newtonian fluids with comparable viscosity. For these fluids, the SMD could be correlated with the high shear rate limit of the viscosity and the SMD increased with increasing viscosity. Overall, these results suggest that high-pressure sprays of non-Newtonian slurries, with generally small particles, should behave similarly to Newtonian fluids with viscosities that match the high shear-rate viscosities of the slurries. 



\subsection{Quality Assurance}

The PNNL Quality Assurance (QA) Program is based on requirements defined in DOE Order 414.1D, Quality Assurance, and Title 10 of the Code of Federal Regulations (CFR) Part 830, Energy/Nuclear Safety Management and Subpart A, Quality Assurance Requirements (a.k.a., the "Quality Rule"). PNNL has chosen to implement the following consensus standards in a graded approach:

- ASME NQA-1-2000, Quality Assurance Requirements for Nuclear Facility Applications, Part 1, Requirements for Quality Assurance Programs for Nuclear Facilities

- ASME NQA-1-2000, Part II, Subpart 2.7, Quality Assurance Requirements for Computer Software for Nuclear Facility Applications

- ASME NQA-1-2000, Part IV, Subpart 4.2, Graded Approach Application of Quality Assurance Requirements for Research and Development.

The procedures necessary to implement the requirements are documented in PNNL's "How Do I...?" (HDI) system. ${ }^{4}$

The Waste Treatment Plant Support Project (WTPSP) implements an NQA-1-2000 Quality Assurance Program, graded on the approach presented in NQA-1-2000, Part IV, Subpart 4.2. The WTPSP Quality Assurance Manual (QA-WTPSP-0002) describes the technology life cycle stages under the WTPSP Quality Assurance Plan (QA-WTPSP-0001). The technology life cycle includes the progression of technology development, commercialization, and retirement in process phases of basic and applied research and development (R\&D), engineering and production, and operation until process completion. The life cycle is characterized by flexible and informal QA activities in basic research, which becomes more structured and formalized through the applied R\&D stages.

The work described in this report has been completed under the QA technology level of Developmental Work. WTPSP addresses internal verification and validation activities by conducting an independent technical review of the final data report in accordance with the WTPSP procedure QA-WTPSP-601, Document Preparation and Change. This independent review verifies that the reported results are traceable, that inferences and conclusions are soundly based, and that the reported work satisfies the test plan objectives.

\footnotetext{
${ }^{4}$ Standards-based system for managing the delivery of PNNL policies, requirements, and procedures.
} 



\subsection{Simulants}

This chapter lists the slurry simulants used in the aerosol tests, states the basis for their selection, and describes the preparation method. Simulant descriptions and selection are discussed in Section 3.1, and the makeup of simulants is described in Section 3.2.

\subsection{Simulant Description and Selection}

Table 3.1 summarizes WTP process streams and typical ranges for important fluid properties. ${ }^{5}$ The ranges of properties and descriptions are generalized representations; actual waste examples may vary. The process stream categories shown in Table 3.1 are those that were chosen to be simulated in the spray leak testing. The non-Newtonian simulants represent slurries that are expected to be in the vessels commonly referred to as the non-Newtonian vessels. These include the ultrafiltration feed vessels (UFP-VSL-00002 A/B) and the high-level waste lag storage and blend vessels (HLP-VSL-0027 A/B and -0028). During some of the process steps the slurries in the ultrafiltration feed vessels are expected to exhibit a Newtonian rheology. Some of the other vessels are expected to contain Newtonian slurries and include (but are not limited to), the high-level waste receipt vessel (HLP-VSL-00022) and the ultrafiltration feed preparation vessels (UFP-VSL-0001 A/B).

Table 3.1. WTP Process Stream Categories and Representative Fluid Properties

\begin{tabular}{|c|c|c|c|}
\hline WTP Process Stream Categories & Solids & Composition & Viscosity Rheology \\
\hline $\begin{array}{l}\text { Ultrafilter permeate, low-activity } \\
\text { waste }\end{array}$ & Negligible & $\begin{array}{l}\text { Caustic solution } \\
5-10-\mathrm{M} \mathrm{Na}\end{array}$ & $\begin{array}{l}\text { Newtonian } \\
2-3 \mathrm{mPa} \cdot \mathrm{s}(\mathrm{cP})\end{array}$ \\
\hline Cs ion exchange eluate & Negligible & $\begin{array}{l}\mathrm{Na}, \mathrm{K}, \mathrm{Cs} \text { ions with } \\
0.5-\mathrm{M} \mathrm{HNO}_{3}\end{array}$ & $\begin{array}{l}\text { Newtonian } \\
0.5 \mathrm{cP} \text { and above }\end{array}$ \\
\hline Recycle streams & $<2 \mathrm{wt} \%$ & $0.2-2-\mathrm{M} \mathrm{Na}$ & $\begin{array}{l}\text { Newtonian } \\
0.5 \mathrm{cP} \text { and above }\end{array}$ \\
\hline Newtonian slurries & About $2-16 \mathrm{wt}^{\mathrm{(a)}}$ & Up to $8-\mathrm{M} \mathrm{Na}$ & $\begin{array}{l}\text { Newtonian }{ }^{(b)} \\
\text { about } 1-3 \mathrm{cP}\end{array}$ \\
\hline Non-Newtonian slurries & Up to $\sim 20 \mathrm{wt} \%$ & $0.2-2-\mathrm{M} \mathrm{Na}$ & $\begin{array}{l}\text { Non-Newtonian } \\
6 \mathrm{cP} / 6 \mathrm{~Pa} \text { to } 30 \mathrm{cP} / 30 \mathrm{~Pa}\end{array}$ \\
\hline
\end{tabular}

(a) The upper limit of about $16 \mathrm{wt} \%$ corresponds to a limit of $200 \mathrm{~g} / \mathrm{L}$ in the waste acceptance criteria (ICD-19 2011). A new upper limit of $144 \mathrm{~g} / \mathrm{L}$ in $7-\mathrm{M} \mathrm{Na}$ feed, corresponding to about $10 \mathrm{wt} \%$ solids, has been recommended (Campbell et al. 2010).

(b) This category also could be a weakly non-Newtonian fluid based on the feed acceptance criteria allowing up to 1 Pa Bingham yield stress slurries to be delivered to the WTP (ICD-19 20116 $)$.

WTP $=$ Hanford Tank Waste Treatment and Immobilization Plant.

\footnotetext{
${ }^{5}$ These categories and ranges of process parameters were provided as guidance for proposal preparation.

${ }^{6}$ ICD 19. 2011. ICD 19 - Interface Control Document for Waste Feed, 24590 WTP ICD MG 01 19, Rev. 5, River Protection Project, Richland, Washington.
} 
Table 3.2 summarizes the four target simulant classes presented in the test plan for the spray leak testing effort. ${ }^{7}$ The simulant classes and materials were chosen to represent the range of wastes shown in Table 3.1. The final column of Table 3.2 shows the correlation between each chosen simulant and representative WTP process stream category. Tap water was used for shakedown testing. Two aqueous salt solutions with different viscosities, obtained by adjusting the salt concentration, were chosen to represent process streams in the WTP that are Newtonian fluids but with higher viscosities than water. The primary process streams in the WTP that are represented by these Newtonian liquid simulants include the ultrafilter permeate, treated low-activity waste (LAW), Cs ion exchange eluate, and recycle streams. There are a number of process streams in the WTP that consist of slurries with a range of solids concentrations. The rheology of the slurries ranges from being essentially Newtonian fluids to non-Newtonian materials. Slurries in the WTP were represented by non-hazardous particles with different particle size distributions (PSDs) in water or dilute salt solutions and by a washed and leached version of the simulant used in the Pretreatment Engineering Platform (PEP) testing. Because the liquid simulants were solids-free, they were used only for the aerosol tests and not the plugging tests (Mahoney et al. 2012).

Table 3.2. Target Simulants and the WTP Process Stream Categories

\begin{tabular}{|c|c|c|c|}
\hline Simulant Class & Material & Target Property Range & $\begin{array}{l}\text { WTP Process } \\
\text { Stream Categories }\end{array}$ \\
\hline Baseline & Water & $\begin{array}{l}\text { Viscosity of } 1 \mathrm{mPa} \cdot \mathrm{s}(1 \mathrm{cP}) \\
\text { density } 1000 \mathrm{~kg} / \mathrm{m}^{3} \\
\text { surface tension } 73 \mathrm{mN} / \mathrm{m}\end{array}$ & $\begin{array}{l}\text { Ultrafilter Permeate/ } \\
\text { Treated Low Activity } \\
\text { Waste (LAW) }\end{array}$ \\
\hline $\begin{array}{l}\text { Range of } \\
\text { Newtonian } \\
\text { Viscosity }\end{array}$ & $\begin{array}{l}\text { Solutions of water and } \\
\text { non-hazardous salts } \\
\text { (sodium nitrate and } \\
\text { sodium thiosulfate) }\end{array}$ & $\begin{array}{l}\text { Viscosities of } \sim 1.5, \sim 2.5 \mathrm{mPa} \cdot \mathrm{s} \\
(1.5,2.5 \mathrm{cP})\end{array}$ & $\begin{array}{l}\text { Cs Ion Exchange Eluate } \\
\text { Recycle Streams }\end{array}$ \\
\hline $\begin{array}{l}\text { Range of Slurries } \\
\text { (non-hazardous) }\end{array}$ & $\begin{array}{l}\text { Gibbsite and boehmite } \\
\text { particulates in water }\end{array}$ & $\begin{array}{l}\text { The PSDs of the slurries were } \\
\text { selected to match Hanford waste } \\
\text { PSDs (average waste feed and } \\
\text { representatively small PSDs, } \\
\text { because smaller PSDs are least } \\
\text { likely to plug breaches). } \\
8 \text { and } 20 \mathrm{wt} \% \text { solids }\end{array}$ & $\begin{array}{l}\text { Newtonian Slurries } \\
\text { Non-Newtonian Slurries }\end{array}$ \\
\hline $\begin{array}{l}\text { Washed and } \\
\text { Leached Chemical } \\
\text { Slurry Simulant }\end{array}$ & $\begin{array}{l}\text { A washed and leached } \\
\text { version of the simulant } \\
\text { used in Pretreatment } \\
\text { Engineering Platform } \\
\text { (PEP) testing (Kurath } \\
\text { et al. 2009) }\end{array}$ & $\begin{array}{l}\text { Solids loading was adjusted to } \\
\text { meet target Bingham yield } \\
\text { stresses of } 6 \text { and } 30 \mathrm{~Pa}\end{array}$ & Non-Newtonian Slurries \\
\hline
\end{tabular}

The PSDs for the simulants used in aerosol tests were selected based on the available PSD data for Hanford wastes. Simulants representing the washed and leached process stream were included because this stream is expected to present a relatively high spray release hazard. ${ }^{7}$ Gauglitz PA. 2011. Test Plan for Spray Leak Quantification to Support WTP Spray Release Methodology,
TP-WTPSP-031 R0.2, Pacific Northwest National Laboratory, Richland, Washington. 
Wells et al. (2011) provided composite combined PSDs for unprocessed sludge and unprocessed saltcake waste. Given the expected dilutions required for the waste retrieval and feed operations, only sludge waste (i.e., waste in which greater than $75 \mathrm{vol} \%$ of the solid phase is insoluble) was considered appropriate for the waste, as-received, by the WTP. These PSDs are termed "composite," because they are the undissolved solid (UDS) volume-weighted composite of available tank waste PSDs, and "combined," because the volume-weighted PSDs are formed from multiple measurements on a given tank by 1) determining the probability associated with each particle size, 2) ordering the particle sizes by increasing size, and 3) determining the cumulative probability of each size.

Different PSDs may be determined based on the flow rate and presence/absence of sonication in the PSD instrument during measurement. Because waste feed and retrieval operations may potentially break up flocs or soft agglomerates, the set of PSDs referred to as "sludge, flowing-sonicated" (Wells et al. 2011) were used because they best represented the size distribution expected in the shear conditions in turbulent pipe flow and spray leaks. In addition, it is known that the PSDs measured with the sample flowing and with sonication used in the instrument often give the smallest PSDs for a given sample. Because a slurry with the smallest particle size is least likely to plug a breach, using the flowing-sonicated PSDs as the targets for simulants should provide conservatism for testing.

Figure 3.1 provides PSDs from Wells et al. (2011) considered most appropriate for spray leak behavior of as-received waste as described above. As shown in the figure, significant variation exists between the PSDs of wastes from different tanks. Within the PSD for any given tank waste, diameters typically vary by approximately a factor of 100. Because aerosol formation was expected to depend on the PSD of the slurry particles, three representative PSDs were selected based on these data. Figure 3.1 shows these three PSDs as 1) the $5^{\text {th }}$ percentile curve, 2) the sludge composite curve, and 3) the $95^{\text {th }}$ percentile curve.

The sludge composite, flowing-sonicated PSD was developed by Wells et al. (2011) based on data from actual waste testing. If a tank waste is considered to be represented with respect to particle size regardless of the number of measurements for a given tank, then PSDs for approximately 6 percent of the Hanford waste UDS volume and 30 percent of the Hanford waste sludge UDS volume are represented by the sludge composite, flowing-sonicated PSD. The $5^{\text {th }}$ and $95^{\text {th }}$ percentile PSDs were obtained by using a volume-weighted combination of the individual PSDs in Figure 3.1, and determining the appropriate particle sizes representing the $5^{\text {th }}$ and $95^{\text {th }}$ percentiles for the full distribution.

Figure 3.2 provides the flowing-sonicated PSDs for post-caustic leached and washed actual waste samples from Wells et al. (2011). Because treatment of the samples removed solids susceptible to leaching and washing, all samples for which there were data, including the saltcake groups, were considered. The individual PSDs for the waste groups differ from each other to a greater extent after treatment than before. The Group 3/4 Mixture shown in Figure 3.2 and $5^{\text {th }}$ percentile PSD shown in Figure 3.1 have relatively equivalent PSDs; however, the Group 1/2 Mixture PSD is noticeably smaller than all of the PSDs in Figure 3.1. Because a slurry with the smallest PSD is least likely to plug a breach, the Group 1/2 Mixture was considered a conservative and appropriate PSD to consider for spray leak behavior from treated waste.

In the following sections, the specific simulant materials blended to match these representative PSDs are described. The simulant nomenclature is summarized in Table 3.3. The particle densities of the dry, solid component materials used to prepare the simulants are shown in Table 3.4. 


\begin{tabular}{|lll|}
\hline- AW-103 & - AY-101 & - AY-102 \\
\hline AZ-101 & - AZ-102 & - C-107 \\
\hline C-104 & - C-106 & - SY-102 \\
- S-107 & - SX-108 & - T-204 \\
- T-110 & - T-203 & - CWR1 sludge (M12 Group 4) \\
1C and 2C sludge (M12 Group 1) & - CWP1 and CWP2 sludge (M12 Group 3) & - 95th percentile by UDS volume \\
\hline$\square-$ Sludge Composite, Flowing Sonicated & $-\square-5$ th percentile by UDS volume & $\square$ \\
\hline
\end{tabular}

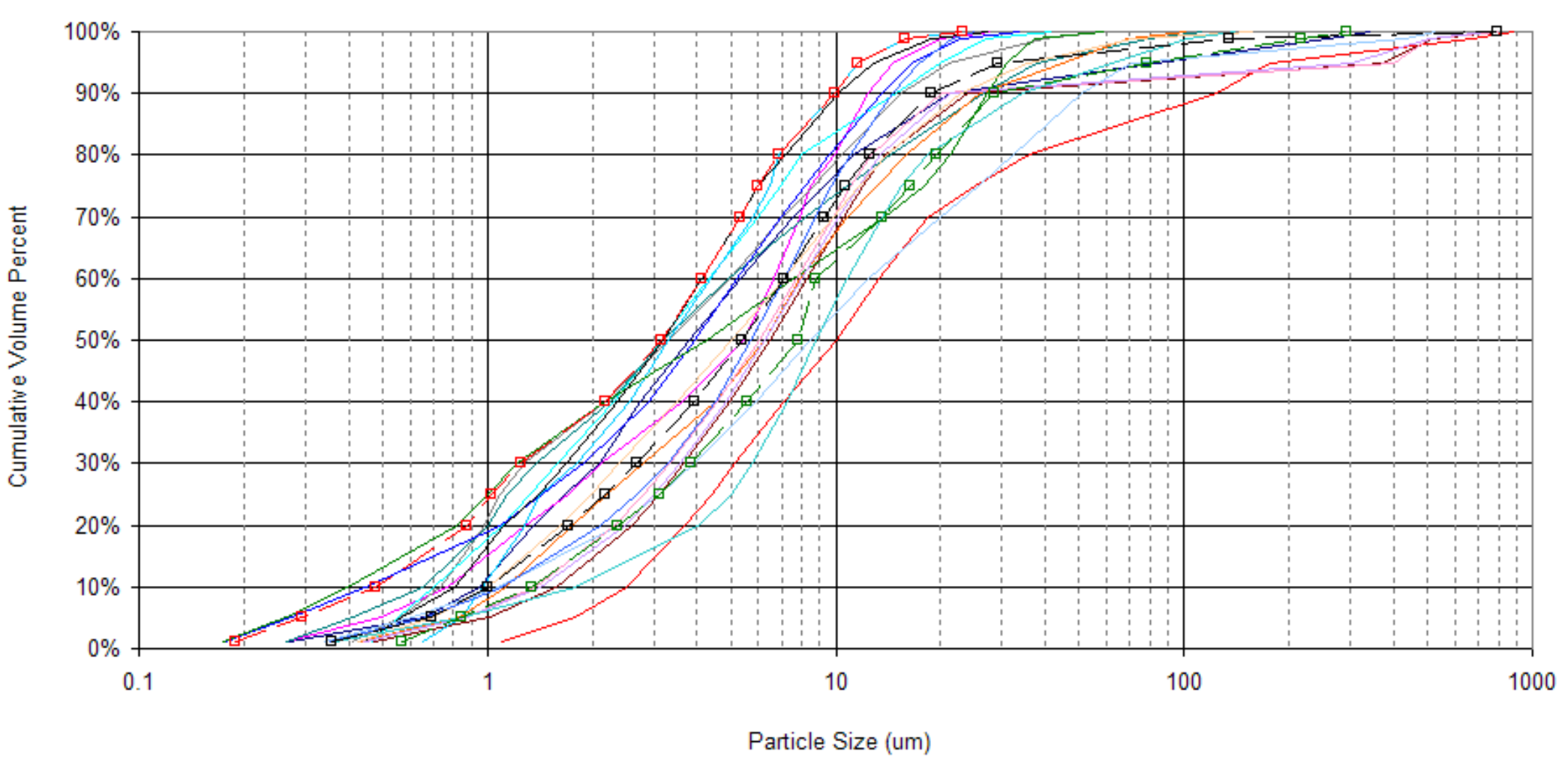

Figure 3.1. Cumulative PSDs (Flowing-Sonicated) for Sludge Tanks and Waste Groups and for $5^{\text {th }}$ Percentile, Sludge Composite (typical), and $95^{\text {th }}$ Percentile PSDs by UDS Volume 


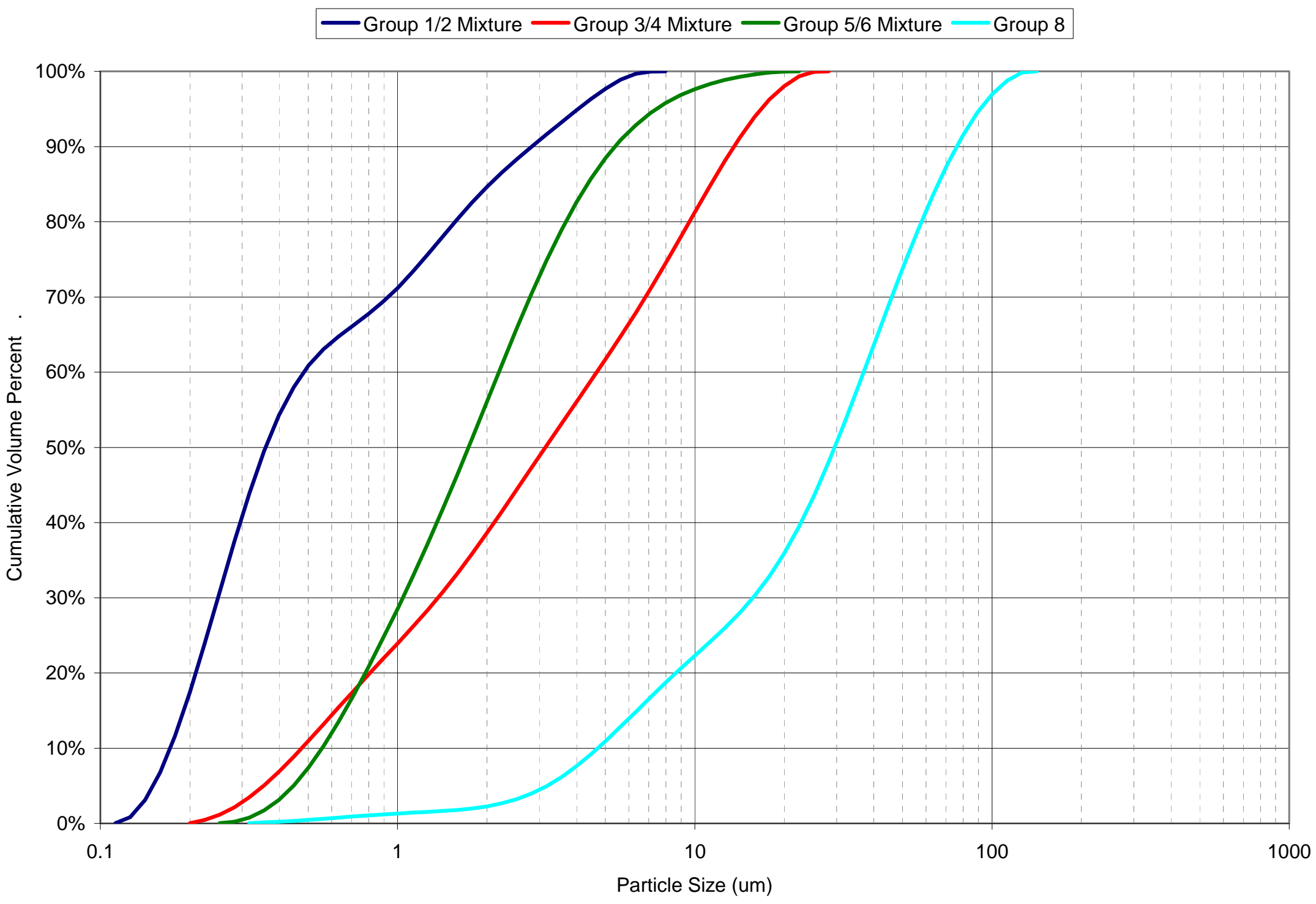

Figure 3.2. Flowing-Sonicated PSDs for Post-Caustic Leached and Washed Waste (exception: Group 8 was measured using Flowing-Unsonicated instrument settings) 
Table 3.3. Simulant Nomenclature

\begin{tabular}{|c|c|c|c|}
\hline Simulant Description & Alias & Component & Comments \\
\hline $\begin{array}{l}\text { Small treated } \\
\text { Hanford waste PSD }\end{array}$ & STR & Boehmite & Primary simulant. No AFA unless otherwise stated. \\
\hline $\begin{array}{l}\text { Small as-received } \\
\text { Hanford waste PSD }\end{array}$ & SAR & Gibbsite & No AFA unless otherwise stated. \\
\hline $\begin{array}{l}\text { Typical as-received } \\
\text { Hanford waste PSD }\end{array}$ & TAR & Gibbsite & No AFA unless otherwise stated. \\
\hline $\begin{array}{l}\text { Aqueous } \mathrm{NaNO}_{3} \text { salt } \\
\text { solution }\end{array}$ & $\mathrm{NaNO}_{3}$ & $\mathrm{NaNO}_{3}$ & $32 \mathrm{wt} \% \mathrm{NaNO}_{3}$ for target viscosity of $\sim 1.5 \mathrm{mPa} \cdot \mathrm{s}$. \\
\hline $\begin{array}{l}\text { Aqueous } \mathrm{Na}_{2} \mathrm{~S}_{2} \mathrm{O}_{3} \text { salt } \\
\text { solution }\end{array}$ & $\mathrm{Na}_{2} \mathrm{~S}_{2} \mathrm{O}_{3}$ & $\mathrm{Na}_{2} \mathrm{~S}_{2} \mathrm{O}_{3}$ & $27 \mathrm{wt} \% \mathrm{Na}_{2} \mathrm{~S}_{2} \mathrm{O}_{3}$ for target viscosity of $\sim 2.5 \mathrm{mPa} \cdot \mathrm{s}$. \\
\hline \multirow{3}{*}{$\begin{array}{l}\text { Washed and leached } \\
\text { iron-rich (FER) chemical } \\
\text { slurry simulant } \\
\text { (non-Newtonian) }\end{array}$} & FER6-B & $\begin{array}{l}\text { Boehmite } \\
\text { Fe-Rich }\end{array}$ & $\begin{array}{l}\text { Target rheology of } 6 \mathrm{~Pa} \text { Bingham yield stress, } 6 \mathrm{mPa} \cdot \mathrm{s} \\
\text { Bingham consistency. No AFA added. }\end{array}$ \\
\hline & FER6+AFA & $\begin{array}{l}\text { Gibbsite } \\
\text { Fe-Rich }\end{array}$ & $\begin{array}{l}\text { Target rheology of } 6 \mathrm{~Pa} \text { Bingham yield stress, } 6 \mathrm{mPa} \cdot \mathrm{s} \\
\text { Bingham consistency. AFA was added. }\end{array}$ \\
\hline & $\begin{array}{l}\text { FER30 } \\
\text { FER30+AFA }\end{array}$ & $\begin{array}{l}\text { Gibbsite } \\
\text { Fe-Rich }\end{array}$ & $\begin{array}{l}\text { Target rheology of } 30 \text { Pa Bingham yield stress, } \\
30 \mathrm{mPa} \cdot \mathrm{s} \text { Bingham consistency. AFA was added after } \\
\text { testing of FER } 30 \text { to produce FER30+AFA. }\end{array}$ \\
\hline \multicolumn{4}{|c|}{$\begin{array}{l}\text { AFA }=\text { Antifoam agent. } \\
\text { PSD }=\text { Particle size distribution. } \\
\text { SAR }=\text { Small as-received. } \\
\text { STR }=\text { Small treated. } \\
\text { TAR }=\text { Typical as-received. }\end{array}$} \\
\hline
\end{tabular}

Table 3.4. Components Used to Prepare the Iron-Rich Slurry

\begin{tabular}{lc}
\hline \multicolumn{1}{c}{ Simulant Component Material } & Particle Density $\left(\mathrm{g} / \mathrm{cm}^{3}\right)$ \\
\hline Almatis C333 gibbsite & $2.42^{(\mathrm{a})}$ \\
Nabaltec APYRAL 40CD gibbsite & $2.42^{(\mathrm{a})}$ \\
NOAH Technologies R6011 gibbsite & $2.42^{(\mathrm{a})}$ \\
Nabaltec APYRAL AOH60 boehmite & $3.01^{(\mathrm{a})}$ \\
NOAH Technologies R6000 boehmite & $3.01^{(\mathrm{a})}$ \\
NOAH Iron Rich Lot \#0236944/1.1 & $3.56 \pm 0.01^{(\mathrm{b})}$ \\
\hline (a) Value provided by vendor. & \\
(b) Value determined by gas pycnometry of deionized water rinsed, dried solids. \\
\hline
\end{tabular}

\subsubsection{Newtonian Simulants}

Table 3.5 provides the composition and properties of the Newtonian simulants (water, water + antifoam agent [AFA], $\mathrm{NaNO}_{3}$, and $\mathrm{Na}_{2} \mathrm{~S}_{2} \mathrm{O}_{3}$ ) used during aerosol testing. The simulants were fabricated from tap water, $\mathrm{AFA}, \mathrm{NaNO}_{3}$, and $\mathrm{Na}_{2} \mathrm{~S}_{2} \mathrm{O}_{3}$ as described in the table. Because of the lack of particles during preparation, the Newtonian simulants were not analyzed for PSD or UDS. The surface tension of the tap water was measured as $72.0 \pm 0.1 \mathrm{mN} / \mathrm{m}$, very close to literature values. The surface tension of the AFA-modified tap water was lower, as expected, at $29.3 \pm 0.1 \mathrm{mN} / \mathrm{m}$. This surface tension value is very similar to previous measurements using an identical batch of AFA (Stewart et al. 2007). 
The two salt solutions were targeted to have nearly identical solution densities, but different viscosities ( 1.5 and $2.5 \mathrm{mPa}$ s). The measured viscosities for the $\mathrm{NaNO}_{3}$ and $\mathrm{Na}_{2} \mathrm{~S}_{2} \mathrm{O}_{3}$ solutions were $1.8 \pm 0.1$ and $2.6 \pm 0.1 \mathrm{mPa}$ s, respectively. The respective surface tensions were measured at $76.2 \pm 0.3$ and $77.6 \pm 0.1 \mathrm{mN} / \mathrm{m}$.

Table 3.5. Small Scale Newtonian Simulant Properties for Aerosol Tests

\begin{tabular}{lcccc}
\hline Properties/Simulant ID & $\mathrm{H}_{2} \mathrm{O}$ & $\mathrm{H}_{2} \mathrm{O}+\mathrm{AFA}$ & $\mathrm{NaNO}_{3}$ & $\mathrm{Na}_{2} \mathrm{~S}_{2} \mathrm{O}_{3}$ \\
\hline $\mathrm{NaNO}_{3}(\mathrm{~kg})$ & --- & --- & 60.89 & --- \\
$\mathrm{Na}_{2} \mathrm{~S}_{2} \mathrm{O}_{3} \cdot 5 \mathrm{H}_{2} \mathrm{O}(\mathrm{kg})$ & --- & --- & -- & 82.11 \\
Dow Corning Q2-3183A antifoam $(\mathrm{g})$ & --- & 62.00 & --- & -- \\
Tap water $(\mathrm{kg})$ & $\mathrm{NM}$ & 151.11 & 127.62 & 106.40 \\
Measured solution density $(\mathrm{kg} / \mathrm{L})$ & $\mathrm{NM}$ & $\mathrm{NM}$ & $1.237 \pm 0.001$ & $1.239 \pm 0.001$ \\
Measured surface tension $(\mathrm{mN} / \mathrm{m})$ & $72.0 \pm 0.1$ & $29.3 \pm 0.1$ & $76.2 \pm 0.3$ & $77.6 \pm 0.1$ \\
Reference surface tension $(\mathrm{mN} / \mathrm{m})$ & 72.1 & $\mathrm{NA}$ & $\mathrm{NA}$ & $77.3(\mathrm{est})$ \\
Viscosity (Newtonian fluid) $(\mathrm{mPa} \cdot \mathrm{s})$ & $\mathrm{NM}$ & $\mathrm{NM}$ & $1.8 \pm 0.1$ & $2.6 \pm 0.1$ \\
Target viscosity (mPa·s) & $\mathrm{NA}$ & $\mathrm{NA}$ & 1.50 & 2.50 \\
Data set ID & $\mathrm{SL} 46$ & $\mathrm{SV} 30$ & $\mathrm{SV} 45$ & $\mathrm{SV} 44$ \\
\hline$---\quad$ Material not used in simulant formulation. & & & \\
NA $=$ Not applicable. & & & & \\
NM = Not measured. & & & & \\
\hline
\end{tabular}

\subsubsection{Typical As-Received Hanford Waste Simulant}

Table 3.6 provides the composition and properties of the typical as-received (TAR) simulant used during aerosol testing. The simulant was fabricated from tap water and hydrated alumina particles (gibbsite, Almatis C333) at the $8 \mathrm{wt} \%$ UDS target. Figure 3.3 shows the target PSD for TAR waste, which was the sludge composite PSD shown in Figure 3.1, together with the measured PSD of the 8 wt $\%$ UDS TAR simulant used in the current study. Figure 3.3 also shows the PSD of the TAR simulant prepared using identical materials for a recent companion study (Mahoney et al. 2012). Simulant PSDs were measured under conditions of flow and sonication, unsonicated, and post-sonicated (i.e., PSD measured without sonication on a sample that had been previously sonicated), with essentially no difference observed between the three methods. Only the unsonicated data are presented in Table 3.6 and Figure 3.3. The simulant particles were larger than the target over the lower 95 percent of the volume, but appeared to contain less of the large $(>100 \mu \mathrm{m})$ particles found in the largest 5 percent of the target volume. It should be noted that the largest particle sizes likely resulted from agglomeration of particles, because the largest primary particle sizes are $<100 \mu \mathrm{m} .^{8}$

The TAR simulant was measured to be Newtonian, as noted in Table 3.6. The Bingham consistency of the slurry was $1.2 \pm 0.1 \mathrm{mPa} \cdot \mathrm{s}$ and the Bingham yield stress was $0.1 \pm 0.1 \mathrm{~Pa}$. The surface tension of the centrifuged, filtered $(0.45 \mu \mathrm{m}$ nylon) supernate was $72.1 \pm 0.1 \mathrm{mN} / \mathrm{m}$, which is essentially identical to the tap water results provided in Table 3.5. The wt $\%$ UDS was measured to be $7.77 \mathrm{wt} \%$, which is close

\footnotetext{
${ }^{8}$ Gauglitz PA. 2011. Test Plan for Spray Leak Quantification to Support WTP Spray Release Methodology, TP-WTPSP-031 R0.2, Pacific Northwest National Laboratory, Richland, Washington.
} 
to the $8 \mathrm{wt} \%$ target. The measured slurry density $(1.046 \mathrm{~kg} / \mathrm{L})$ was nearly identical to the value estimated from the simulant recipe and the component densities. The $20 \mathrm{wt} \%$ UDS TAR simulant was prepared and used only during the orifice plugging tests (Mahoney et al. 2012).

Table 3.6. SAR and TAR Simulant Properties for Aerosol Tests

\begin{tabular}{|c|c|c|c|}
\hline Component/Property & TAR $8 \mathrm{wt} \%$ UDS & SAR $8 \mathrm{wt} \%$ UDS & SAR $20 \mathrm{wt} \%$ UDS \\
\hline Almatis C333 gibbsite $(\mathrm{kg})$ & 12.69 & --- & --- \\
\hline Nabaltec APYRAL 40CD gibbsite $(\mathrm{kg})$ & --- & 8.25 & 22.26 \\
\hline NOAH Technologies R6011 gibbsite (kg) & --- & 4.44 & 12.00 \\
\hline Tap water (kg) & 145.88 & 145.88 & 136.99 \\
\hline Targeted Wt\% UDS (g/g) ${ }^{(\mathrm{a})}$ & $8.00 \%$ & $8.00 \%$ & $20.00 \%$ \\
\hline Measured Wt $\%$ UDS $(g / g)^{(b)}$ & $7.77 \%$ & $8.45 \%$ & $20.58 \%$ \\
\hline Calculated slurry density $(\mathrm{kg} / \mathrm{L})$ & 1.047 & 1.047 & 1.131 \\
\hline Measured slurry density $(\mathrm{kg} / \mathrm{L})$ & $1.046 \pm 0.002$ & $1.044 \pm 0.001$ & $1.128 \pm 0.001$ \\
\hline Surface tension $(\mathrm{mN} / \mathrm{m})$ & $72.1 \pm 0.1$ & $72.3 \pm 0.1$ & $72.7 \pm 0.1$ \\
\hline Bingham yield stress $(\mathrm{Pa})$ & $0.1 \pm 0.1$ & $0.1 \pm 0.1$ & $0.9 \pm 0.1$ \\
\hline Bingham consistency $(\mathrm{mPa} \cdot \mathrm{s})$ & $1.2 \pm 0.1$ & $1.5 \pm 0.1$ & $2.9 \pm 0.1$ \\
\hline $\operatorname{PSD} \mathrm{d}_{01}(\mu \mathrm{m})$ & 0.61 & 0.56 & 0.53 \\
\hline $\operatorname{PSD} d_{05}(\mu \mathrm{m})$ & 1.03 & 0.92 & 0.95 \\
\hline $\operatorname{PSD} d_{10}(\mu \mathrm{m})$ & 1.52 & 1.29 & 1.41 \\
\hline $\operatorname{PSD} \mathrm{d}_{20}(\mu \mathrm{m})$ & 2.65 & 1.88 & 2.09 \\
\hline $\operatorname{PSD} d_{25}(\mu \mathrm{m})$ & 3.33 & 2.14 & 2.39 \\
\hline $\operatorname{PSD} d_{30}(\mu \mathrm{m})$ & 4.10 & 2.41 & 2.69 \\
\hline $\operatorname{PSD~d}_{40}(\mu \mathrm{m})$ & 5.96 & 2.98 & 3.31 \\
\hline $\operatorname{PSD} \mathrm{d}_{50}(\mu \mathrm{m})$ & 8.29 & 3.65 & 4.02 \\
\hline $\operatorname{PSD}_{60}(\mu \mathrm{m})$ & 11.2 & 4.50 & 4.89 \\
\hline $\operatorname{PSD} d_{70}(\mu \mathrm{m})$ & 14.9 & 5.74 & 6.12 \\
\hline $\operatorname{PSD} d_{75}(\mu \mathrm{m})$ & 17.2 & 6.69 & 7.00 \\
\hline $\operatorname{PSD} d_{80}(\mu \mathrm{m})$ & 20.1 & 8.13 & 8.23 \\
\hline $\operatorname{PSD} d_{90}(\mu \mathrm{m})$ & 29.5 & 15.4 & 13.8 \\
\hline $\operatorname{PSD}_{95}(\mu \mathrm{m})$ & 39.8 & 25.0 & 21.2 \\
\hline $\operatorname{PSD}_{99}(\mu \mathrm{m})$ & 75.7 & 107 & 43.7 \\
\hline $\operatorname{PSD} d_{100}(\mu \mathrm{m})$ & 356 & 448 & 502 \\
\hline Data Set ID & SV42 & SV38 & SV40 \\
\hline
\end{tabular}

(a) Calculated from mass.

(b) Measured by moisture analyzer.

--- $\quad=$ Material not used in simulant formulation.

PSD $=$ Particle size distribution.

SAR $=$ Small as-received.

TAR $=$ Typical as-received.

USD $=$ Undissolved solid.

The nomenclature $d_{n}$ indicates that a fraction of total particle volume $=(n / 100)$ is present in drops whose diameter is less than $d_{n}$. 


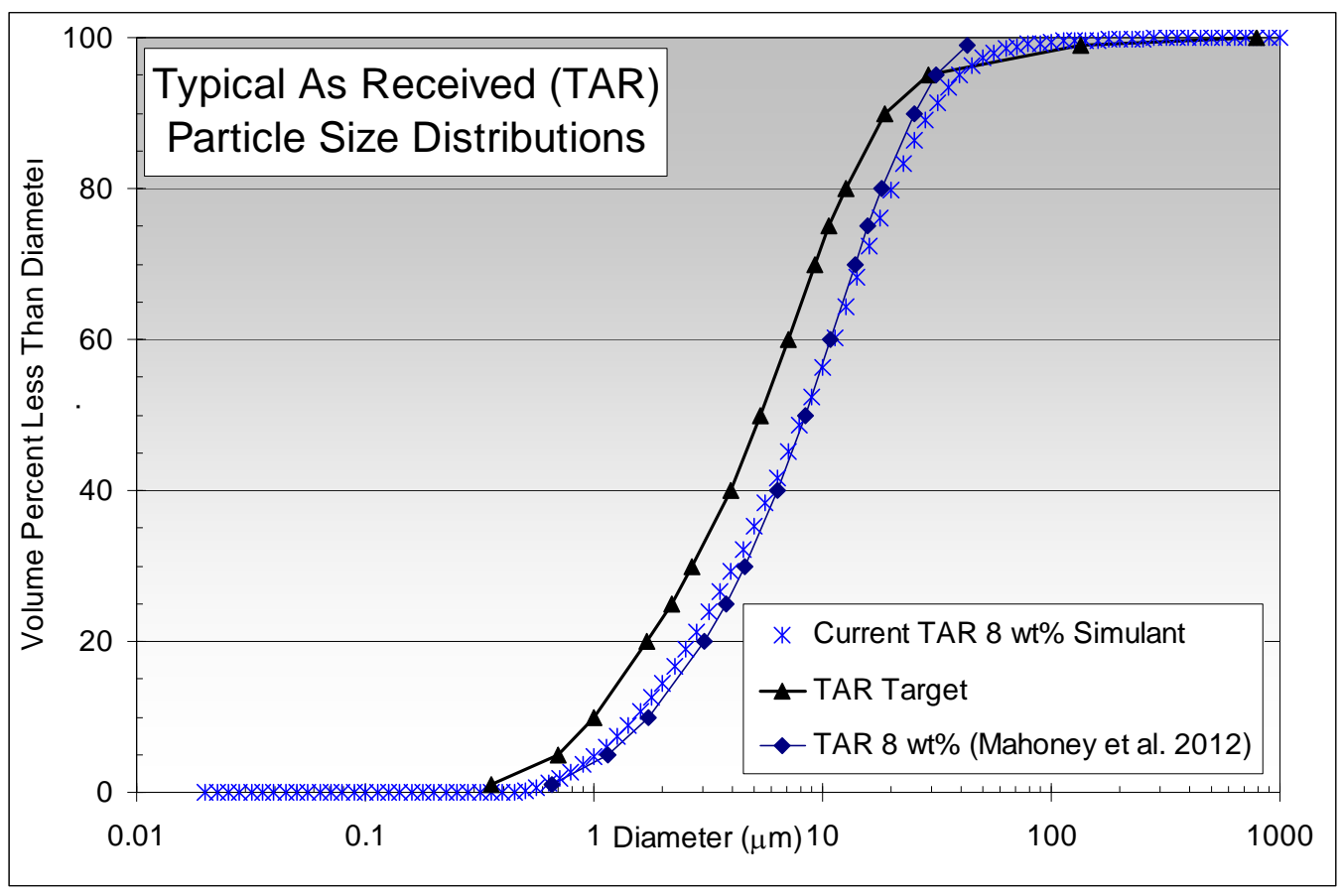

Figure 3.3. Target Sludge Composite Combined and Measured TAR Simulant PSDs

\subsubsection{Small As-Received Hanford Waste Simulant}

Table 3.6 provides the composition and properties of the 8 and $20 \mathrm{wt} \%$ UDS small as-received (SAR) simulants used during aerosol testing. The simulants were fabricated from tap water and hydrated alumina particles (gibbsite, NOAH Technologies R6011 [35 percent] and Nabaltec APYRAL 40CD [65 percent]). Figure 3.4 shows the target PSD for SAR waste, which was the $5^{\text {th }}$ percentile PSD shown in Figure 3.1, together with the measured PSD of the 8 and $20 \mathrm{wt} \%$ UDS SAR simulant used in the current study. Figure 3.4 also shows the PSD of the SAR simulant prepared using identical materials for a recent companion study investigating orifice plugging (Mahoney et al. 2012). Simulant PSDs were measured under conditions of flow and sonication, unsonicated, and post-sonicated, with only minor differences observed between the three methods. Sonication appeared to increase particle agglomeration between 5 and $100 \mu \mathrm{m}$. Only the unsonicated data are presented in Table 3.6 and Figure 3.4. It should be noted that the largest particle sizes likely resulted from particle agglomeration because the largest primary particle sizes are $<100 \mu \mathrm{m}$.

The $8 \mathrm{wt} \%$ UDS SAR simulant was measured to be Newtonian as is shown in Table 3.6. The Bingham consistency of the slurry was $1.5 \pm 0.1 \mathrm{mPa} \cdot \mathrm{s}$, and the Bingham yield stress was $0.1 \pm 0.1 \mathrm{~Pa}$ (very close to the detection limit of the instrument). At $20 \mathrm{wt} \% \mathrm{UDS}$, the Bingham consistency was $2.9 \pm 0.1 \mathrm{mPa} \cdot \mathrm{s}$, and the Bingham yield stress was $0.9 \pm 0.1 \mathrm{~Pa}$. The surface tension of the centrifuged, filtered ( $0.45 \mu \mathrm{m}$ nylon) supernate for the 8 and $20 \mathrm{wt} \%$ UDS SAR simulants was measured to be $72.3 \pm 0.1$ and $72.7 \pm 0.1 \mathrm{mN} / \mathrm{m}$, respectively, slightly higher than the tap water results shown in Table 3.5. 


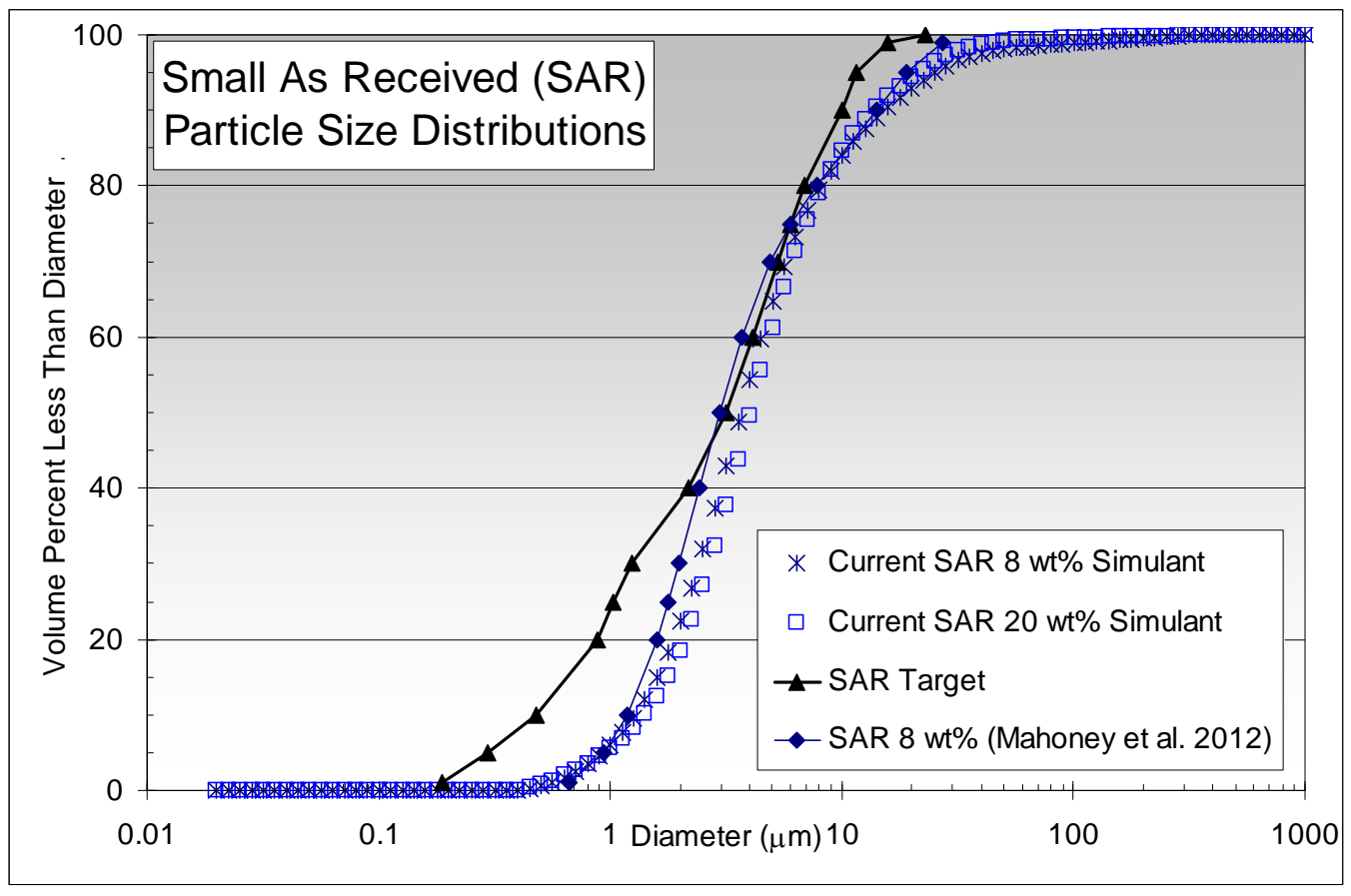

Figure 3.4. Target $5^{\text {th }}$ Percentile PSD and SAR Simulant PSD at Two Concentrations

\subsubsection{Small Treated Hanford Waste Simulant}

Table 3.7 provides the composition and properties of the small treated (STR) simulant used during aerosol testing. The simulant was fabricated from tap water and boehmite particles (Nabaltec APYRAL AOH60 [80 percent] and NOAH Technologies R6000 [20 percent]). Figure 3.5 shows the target PSD for the STR simulant, which was the Group 1/2 PSD shown in Figure 3.1, together with the measured PSD (unsonicated) of the 8 and $20 \mathrm{wt} \%$ UDS STR simulant used in the current study. Figure 3.5 also shows the PSD of the STR simulant prepared using identical materials for a recent companion study (Mahoney et al. 2012), where the PSD is reasonably close to the STR target. The simulant PSDs were measured under conditions of flow and sonication, unsonicated, and post-sonicated. For clarity, only the unsonicated PSDs are shown in Figure 3.5. The AFA-modified STR simulant appears to exhibit increased particle agglomeration as is shown in Figure 3.5. The STR simulants contain larger particles than the target over almost the complete volume. It should be noted that the largest particle sizes likely resulted from particle agglomeration, because the largest primary particle sizes are small. As noted in the test plan, the maximum particle size of the Nabaltec APYRAL AOH60 is $7.8 \mu \mathrm{m} .{ }^{9}$ While a maximum particle size is not available for the NOAH R6000 material, the median diameter is $0.21 \mu \mathrm{m}$, and the material is generally supposed to be less than $1 \mu \mathrm{m}$. There is no apparent reason why the STR simulants prepared for this study should contain larger and more variable particle sizes than the earlier testing (Mahoney et al. 2012).

\footnotetext{
${ }^{9}$ Gauglitz PA. 2011. Test Plan for Spray Leak Quantification to Support WTP Spray Release Methodology, TP-WTPSP-031 R0.2, Pacific Northwest National Laboratory, Richland, Washington.
} 
Table 3.7. Small Treated (STR) Simulant Properties for Aerosol Tests

\begin{tabular}{|c|c|c|c|}
\hline Component/Property & STR $8 \mathrm{wt} \%$ UDS & STR $20 \mathrm{wt} \%$ UDS & $\begin{array}{l}\text { STR } 8 w t \% \\
\text { UDS+AFA }\end{array}$ \\
\hline Nabaltec APYRAL AOH60 boehmite (kg) & 10.22 & 27.91 & 10.22 \\
\hline NOAH Technologies R6000 boehmite (kg) & 2.55 & 6.98 & 2.55 \\
\hline Dow Corning Q2-3183A antifoam (g) & --- & --- & 63.86 \\
\hline Tap water $(\mathrm{kg})$ & 146.88 & 139.55 & 146.88 \\
\hline Targeted Wt\% UDS $(\mathrm{g} / \mathrm{g})^{(\mathrm{a})}$ & $8.00 \%$ & $20.0 \%$ & $8.00 \%$ \\
\hline Measured Wt\% UDS $(\mathrm{g} / \mathrm{g})^{(\mathrm{b})}$ & $7.81 \%$ & $19.8 \%$ & NM \\
\hline Calculated slurry density $(\mathrm{kg} / \mathrm{L})$ & 1.054 & 1.152 & 1.054 \\
\hline Measured slurry density $(\mathrm{kg} / \mathrm{L})$ & $1.048 \pm 0.001$ & $1.126 \pm 0.004$ & $1.048 \pm 0.001$ \\
\hline Surface tension $(\mathrm{mN} / \mathrm{m})$ & $71.2 \pm 0.1$ & $71.0 \pm 0.1$ & $40.7 \pm 0.1$ \\
\hline Bingham yield stress $(\mathrm{Pa})$ & $1.4 \pm 0.1$ & $0.1 \pm 0.1$ & $1.5 \pm 0.1$ \\
\hline Bingham consistency $(\mathrm{mPa} \cdot \mathrm{s})$ & $2.9 \pm 0.1$ & $1.6 \pm 0.1$ & $2.8 \pm 0.1$ \\
\hline $\operatorname{PSD} \mathrm{d}_{01}(\mu \mathrm{m})$ & 0.41 & 0.40 & 0.35 \\
\hline $\operatorname{PSD} \mathrm{d}_{05}(\mu \mathrm{m})$ & 0.56 & 0.53 & 0.46 \\
\hline $\operatorname{PSD} \mathrm{d}_{10}(\mu \mathrm{m})$ & 0.70 & 0.64 & 0.56 \\
\hline $\operatorname{PSD} d_{20}(\mu \mathrm{m})$ & 0.96 & 0.84 & 0.75 \\
\hline $\operatorname{PSD~d}_{25}(\mu \mathrm{m})$ & 1.09 & 0.94 & 0.85 \\
\hline $\operatorname{PSD~d}_{30}(\mu \mathrm{m})$ & 1.23 & 1.04 & 0.96 \\
\hline $\operatorname{PSD~d}_{40}(\mu \mathrm{m})$ & 1.54 & 1.27 & 1.24 \\
\hline $\operatorname{PSD}_{50}(\mu \mathrm{m})$ & 1.92 & 1.56 & 1.69 \\
\hline $\operatorname{PSD~d}_{60}(\mu \mathrm{m})$ & 2.41 & 1.94 & 4.11 \\
\hline $\operatorname{PSD}_{70}(\mu \mathrm{m})$ & 3.09 & 2.52 & 50.9 \\
\hline $\operatorname{PSD} \mathrm{d}_{75}(\mu \mathrm{m})$ & 3.57 & 2.97 & 64.7 \\
\hline $\operatorname{PSD~d}_{80}(\mu \mathrm{m})$ & 4.23 & 3.67 & 79.0 \\
\hline $\operatorname{PSD~d}_{90}(\mu \mathrm{m})$ & 7.53 & 9.39 & 119 \\
\hline $\operatorname{PSD}_{95}(\mu \mathrm{m})$ & 22.8 & 44.0 & 159 \\
\hline $\operatorname{PSD}_{99}(\mu \mathrm{m})$ & 57.9 & 130 & 314 \\
\hline $\operatorname{PSD}_{100}(\mu \mathrm{m})$ & 112 & 399 & 632 \\
\hline Data Set ID & SV34 & SV36 & SV32 \\
\hline
\end{tabular}

(a) Calculated from mass.

(b) Measured by moisture analyzer.

$---\quad=$ Material not used in simulant formulation.

$\mathrm{NM}=$ Not measured.

PSD $=$ Particle size distribution.

UDS $=$ Undissolved solid.

The nomenclature $d_{n}$ indicates that a fraction of total particle volume $=(n / 100)$ is present in drops whose diameter is less than $d_{n}$.

The surface tensions of the centrifuged, filtered ( $0.45 \mu \mathrm{m}$ nylon) supernate for the 8 and $20 \mathrm{wt} \% \mathrm{UDS}$ STR simulants were $71.2 \pm 0.1$ and $71.0 \pm 0.1 \mathrm{mN} / \mathrm{m}$, respectively, which is slightly lower than the tap water results provided in Table 3.5. The surface tension of the centrifuged and filtered $(0.45 \mu \mathrm{m}$ nylon) AFA-modified supernate for the $8 \mathrm{wt} \%$ UDS STR was $40.7 \pm 0.1 \mathrm{mN} / \mathrm{m}$, which is somewhat higher than 
the AFA-modified tap water results provided in Table 3.5. It is possible that filtering removed some of the AFA along with the solids.

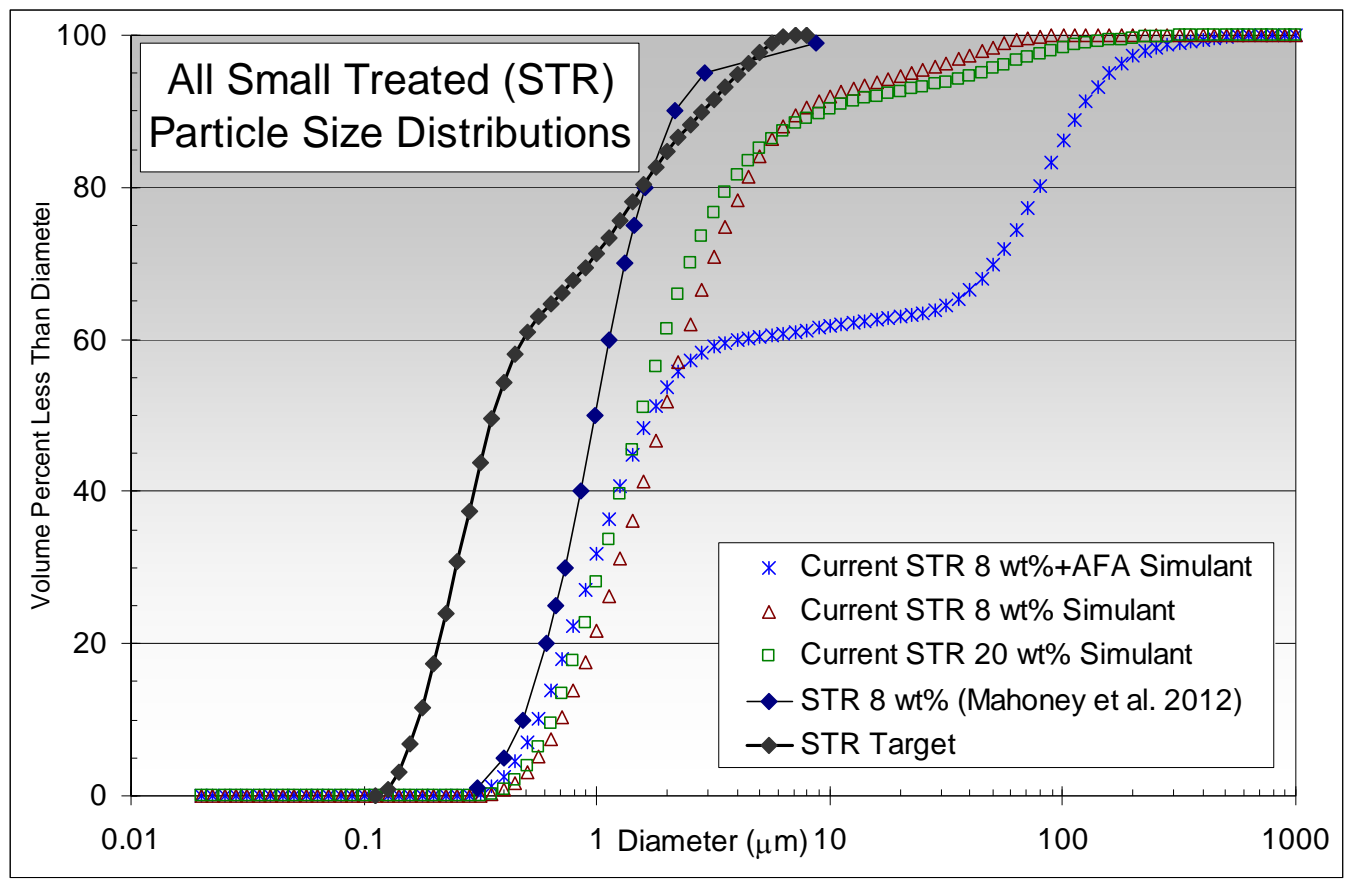

Figure 3.5. PSD of Target Group 1/2 Mixture and STR Simulant PSD at Two Concentrations

The $8 \mathrm{wt} \%$ UDS STR simulant exhibited a Bingham consistency of $2.9 \pm 0.1 \mathrm{mPa} \cdot \mathrm{s}$ and a Bingham yield stress of $1.4 \pm 0.1 \mathrm{~Pa}$. The AFA-modified $8 \mathrm{wt} \%$ UDS STR displayed similar properties at $2.8 \pm 0.1 \mathrm{mPa} \cdot \mathrm{s}$ and $1.5 \pm 0.1 \mathrm{~Pa}$, respectively. At $20 \mathrm{wt} \% \mathrm{UDS}$, the STR simulant appeared to be essentially a Newtonian fluid with a Bingham consistency of $1.6 \pm 0.1 \mathrm{mPa} \cdot \mathrm{s}$ and a Bingham yield stress of $0.1 \pm 0.1 \mathrm{~Pa}$. This is contrary to expected behavior (i.e., increasing solid concentrations leading to more non-Newtonian rheological behavior), but results were confirmed by analyzing replicate aliquots of the simulant feed. Previous rheological testing of STR simulant samples showed similar inconsistent behavior for the 8 and $20 \mathrm{wt} \%$ UDS simulants (Section 3.1.4, Mahoney et al. 2012). The weakly non-Newtonian behavior of the $8 \mathrm{wt} \%$ UDS STR used during the aerosol testing is not understood.

\subsubsection{Iron-Rich Chemical Slurry Simulant}

A chemical slurry simulant representing the washed and leached process stream in the WTP is one of the simulant categories given in Table 3.2, because WTP process streams with washed and leached waste give some of the largest hazards from spray releases. ${ }^{10}$ Figure 3.2 shows PSDs for different washed and leached actual waste samples. As shown in Figure 3.2, the majority of particles in actual washed and leached waste samples fell within the 0.2 and $20 \mu \mathrm{m}$ size range for the three smaller PSDs. As summarized in Chapter 4 of Wells et al. (2011), the washed and leached wastes typically exhibit a non-Newtonian rheology if the UDS concentration is sufficiently high.

\footnotetext{
${ }^{10}$ Based on guidance provided by the WTP Project.
} 
Table 3.8 provides the composition and properties of the iron-rich (FER) simulants used during aerosol testing. The simulants were fabricated from bottled deionized water, an iron-rich hydroxide slurry (NOAH Technologies), and either Nabaltec APYRAL 40CD gibbsite or AOH60 boehmite. Figure 3.6 shows the target PSD for SAR and TAR wastes, together with the measured PSD of the $15 \mathrm{wt} \%$ UDS FER6-B, FER30, FER6+AFA, and FER30+AFA simulants. The simulant PSDs were measured under conditions of flow and sonication, unsonicated, and post-sonicated, with only minor differences $>10 \mu \mathrm{m}$ observed between the three methods. Only the unsonicated data are presented in Table 3.8 and Figure 3.6. The largest particle sizes likely result from particle agglomeration.

Table 3.8. Iron-Rich (FER) Simulant Properties for Aerosol Tests

\begin{tabular}{|c|c|c|c|c|}
\hline Component/Property & FER6-B & FER30 & FER6+AFA & FER30+AFA \\
\hline Nabaltec APYRAL 40CD gibbsite $(\mathrm{kg})$ & --- & 46.920 & Field Dilute & 46.920 \\
\hline Nabaltec APYRAL AOH60 boehmite $(\mathrm{kg})$ & 15.152 & --- & --- & --- \\
\hline NOAH Iron-Rich Lot \#0236944/1.1 (kg) & $67.90^{(\mathrm{a})}$ & $149.654^{(\mathrm{b})}$ & Field Dilute & $149.654^{(\mathrm{b})}$ \\
\hline Dow Corning Q2-3183A antifoam (ppm) & --- & --- & $400 \mathrm{ppm}$ & 400 ppm \\
\hline Bottled deionized water $(\mathrm{kg})$ & 85.988 & 10.052 & Field Dilute & 10.052 \\
\hline Targeted $\mathrm{Wt} \%$ undissolved solid (UDS) $(\mathrm{g} / \mathrm{g})^{(\mathrm{c})}$ & $15.00 \%$ & $38.00 \%$ & $32.00 \%$ & $38.00 \%$ \\
\hline Measured Wt\% UDS (g/g) ${ }^{(\mathrm{d})}$ & $15.59 \%$ & $35.56 \%$ & $30.86 \%$ & $35.69 \%$ \\
\hline Calculated slurry density $(\mathrm{kg} / \mathrm{L})$ & 1.164 & 1.365 & NA & 1.365 \\
\hline Measured slurry density $(\mathrm{kg} / \mathrm{L})$ & $1.138 \pm 0.006$ & $1.360 \pm 0.008$ & $1.322 \pm 0.002$ & $1.395 \pm 0.002$ \\
\hline Surface tension $(\mathrm{mN} / \mathrm{m})$ & $69.3 \pm 0.1$ & $59 \pm 2^{(\mathrm{e})}$ & $37.8 \pm 0.2$ & $37.7 \pm 0.5$ \\
\hline Bingham yield stress $(\mathrm{Pa})-\mathrm{Up} \operatorname{Ramp}^{(\mathrm{f})}$ & $7.3 \pm 0.5$ & & & \\
\hline Down Ramp ${ }^{(g)}$ & $4.9 \pm 0.1$ & $11.5 \pm 0.3$ & $9.9 \pm 0.2$ & $15.4 \pm 0.5$ \\
\hline Bingham consistency $(\mathrm{mPa} \cdot \mathrm{s})-\mathrm{Up}$ Ramp & $9.8 \pm 0.7$ & & & \\
\hline Down Ramp & $52 \pm 3$ & $12.4 \pm 0.1$ & $13.5 \pm 0.1$ & $15.9 \pm 0.5$ \\
\hline Particle size distribution (PSD) $\mathrm{d}_{01}(\mu \mathrm{m})$ & 0.34 & 0.44 & 0.38 & 0.40 \\
\hline $\operatorname{PSD} \mathrm{d}_{05}(\mu \mathrm{m})$ & 0.53 & 0.67 & 0.74 & 0.73 \\
\hline $\operatorname{PSD} \mathrm{d}_{10}(\mu \mathrm{m})$ & 0.79 & 0.89 & 1.15 & 1.05 \\
\hline $\operatorname{PSD}_{20}(\mu \mathrm{m})$ & 1.68 & 1.31 & 1.76 & 1.60 \\
\hline $\operatorname{PSD~d}_{25}(\mu \mathrm{m})$ & 2.25 & 1.53 & 2.03 & 1.85 \\
\hline $\operatorname{PSD}_{30}(\mu \mathrm{m})$ & 2.78 & 1.78 & 2.30 & 2.12 \\
\hline $\operatorname{PSD~d}_{40}(\mu \mathrm{m})$ & 3.81 & 2.39 & 2.87 & 2.72 \\
\hline $\operatorname{PSD~d}_{50}(\mu \mathrm{m})$ & 4.89 & 3.46 & 3.51 & 3.51 \\
\hline $\operatorname{PSD} d_{60}(\mu \mathrm{m})$ & 6.17 & 8.78 & 4.31 & 4.82 \\
\hline $\operatorname{PSD}_{70}(\mu \mathrm{m})$ & 7.82 & 16.8 & 5.44 & 8.53 \\
\hline $\operatorname{PSD~d}_{75}(\mu \mathrm{m})$ & 8.90 & 20.4 & 6.27 & 13.3 \\
\hline $\operatorname{PSD}_{80}(\mu \mathrm{m})$ & 10.3 & 24.4 & 7.49 & 19.7 \\
\hline $\operatorname{PSD} d_{90}(\mu \mathrm{m})$ & 15.3 & 36.4 & 15.7 & 49.8 \\
\hline $\operatorname{PSD}_{95}(\mu \mathrm{m})$ & 22.6 & 49.6 & 50.1 & 94.9 \\
\hline $\operatorname{PSD}_{99}(\mu \mathrm{m})$ & 65.8 & 116 & 140 & 218 \\
\hline $\operatorname{PSD~d}_{100}(\mu \mathrm{m})$ & 79.6 & 224 & 632 & 632 \\
\hline Data Set ID & SV59 & SV51 & SV63 & SV55 \\
\hline
\end{tabular}

(a) Mass of vendor-supplied slurry at $15 \mathrm{wt} \%$ UDS.

(b) Mass of vendor-supplied slurry at $21 \mathrm{wt} \%$ UDS.

(c) Calculated from mass.

(d) Measured by moisture analyzer.

(e) Increased steadily during four sequential measurements.

(f) Increasing rotation rate during rheological measurements.

(g) Decreasing rotation rate during rheological measurements.

--- = material not used in simulant formulation.

The nomenclature $d_{n}$ indicates that a fraction of total particle volume $=(n / 100)$ is present in drops whose diameter is less than $\mathrm{d}_{\mathrm{n}}$. 


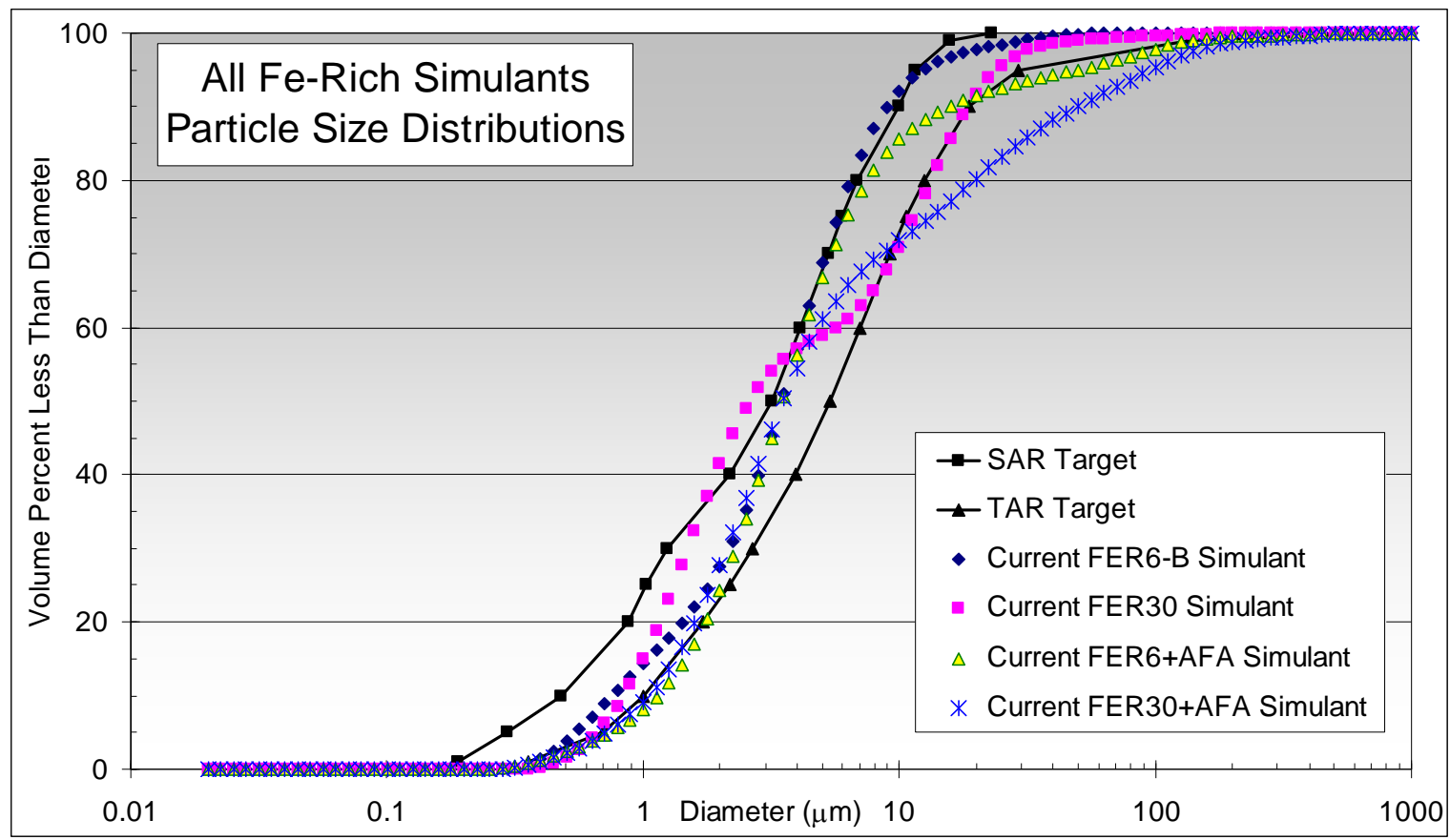

Figure 3.6. FER Simulant PSD and Target PSD for SAR and TAR Simulants

The various FER simulants were measured to be non-Newtonian, as shown in Table 3.8. The Bingham consistency of the slurry ranged from 9.8 to $15.9 \mathrm{mPa}$ s, and the Bingham yield stress ranged from 4.9 to $15.4 \mathrm{~Pa}$. The FER-6B (boehmite) simulant exhibited significant rheological hysteresis as the Bingham consistency was approximately $10 \mathrm{mPa} \cdot \mathrm{s}$ (up ramp) and in excess of $50 \mathrm{mPa} \cdot \mathrm{s}$ (down ramp).

\subsection{Simulant Makeup}

All simulants used in the aerosol tests were created using similar procedures. ${ }^{11}$ The required components were weighed out on calibrated scales, added to tap water, and mixed. Most simulants were prepared by the simple addition of powdered alumina (gibbsite or boehmite) to tap water. Preparation of the FER simulant was similar, except that the iron-rich sludge component was supplied from the vendor as a slurry and distilled water was used instead of tap water. After all components were added, the completed simulants were blended for a minimum of $30 \mathrm{~min}$ in a nominal 80-gal stainless steel vessel, sampled, then allowed to sit until needed for testing. In certain cases (e.g., FER30), the simulant was continually blended until it was used. When containers were removed from storage, they were mechanically mixed before transferring the simulant to the feed vessel in the spray test apparatus.

\footnotetext{
${ }^{11}$ The simulant makeup procedure for this purpose was governed by the following test instructions: TI-WTPSP-040, "Simulant Blending to Support Small-Scale Spray Testing." TI-WTPSP-050, "Simulant Blending to Support Small-Scale Spray Testing." TI-WTPSP-062, "Chemical Simulant Blending to Support Small-Scale Spray Testing." TI-WTPSP-076, "Dilution of Chemical Simulant to Support Small-Scale Spray Testing."
} 


\subsubsection{Iron-Rich Sludge Preparation}

The chemical slurry simulant representing non-Newtonian washed and leached waste is based on the method used to make simulants for testing in the PEP (Kurath et al. 2009). The PEP simulant involved making a precipitated iron-rich sludge (Scheele et al. 2009) and adding gibbsite, boehmite, $\mathrm{CrOOH}$, and various sodium salts. The leaching and washing steps in the PEP pretreatment process removed the gibbsite, some of the boehmite, most of the $\mathrm{CrOOH}$, and the majority of the sodium salts from the solids phase (Kurath et al. 2009). For the present study, a simplified FER simulant preparation approach was used. The appropriate amount of gibbsite or boehmite was added to a commercially-supplied iron-rich sludge, diluted with distilled water, and AFA was added at $400 \mathrm{ppm}$ as needed.

The iron-rich sludge fraction of the simulant was manufactured by NOAH Technologies Corporation using the first part of the recipe detailed in Appendix A of Scheele et al. (2009) up through the hydroxide neutralization step. The trace quantities of $\mathrm{Ce}, \mathrm{La}$, and $\mathrm{Nd}$ used in the PEP simulant were omitted to reduce cost and schedule delays. The removal of these trace metals was expected to produce negligible change in the fluid-flow behavior of the simulant. The chemical constituents used to prepare the sludge are shown in Table 3.9. In contrast to the PEP simulant, the current slurry was prepared at $\sim 15 \mathrm{wt} \%$ UDS. Excess liquid was removed by centrifugation and the solids were rinsed three times with deionized water. The resulting paste (Figure 3.7) was down-blended with deionized water. The dry particle density of the iron-rich solids was determined to be $3.56 \pm 0.01 \mathrm{~g} \mathrm{~cm}^{-3}$ by gas pycnometry after the material had been rinsed with deionized water and centrifuged several times to remove traces of dissolved salts.

Table 3.9. Components Used to Prepare the Iron-Rich Sludge

\begin{tabular}{lcccc}
\hline \multicolumn{1}{c}{ Compounds } & Formula & Mass $(\mathrm{kg})$ & Metal & Fe-Ratio \\
\hline Potassium permanganate & $\mathrm{KMnO}_{4}$ & 9.326 & $\mathrm{Mn}$ & 0.2143 \\
Manganous nitrate & $\mathrm{Mn}\left(\mathrm{NO}_{3}\right)_{2}, 50 \mathrm{wt} \%$ solution & 31.695 & $\mathrm{Ca}$ & 0.0292 \\
Calcium nitrate & $\mathrm{Ca}\left(\mathrm{NO}_{3}\right)_{2} \cdot 4 \mathrm{H}_{2} \mathrm{O}$ & 6.507 & $\mathrm{Fe}$ & 1.0000 \\
Ferric nitrate & $\mathrm{Fe}\left(\mathrm{NO}_{3}\right)_{3} \cdot 9 \mathrm{H}_{2} \mathrm{O}$ & 273.658 & $\mathrm{Mg}$ & 0.0092 \\
Magnesium nitrate & $\mathrm{Mg}\left(\mathrm{NO}_{3}\right)_{2} \cdot 6 \mathrm{H}_{2} \mathrm{O}$ & 3.659 & $\mathrm{Ni}$ & 0.0327 \\
Nickel nitrate & $\mathrm{Ni}\left(\mathrm{NO}_{3}\right)_{2} \cdot 6 \mathrm{H}_{2} \mathrm{O}$ & 6.135 & $\mathrm{Sr}$ & 0.0081 \\
Strontium nitrate & $\mathrm{Sr}_{\left(\mathrm{NO}_{3}\right)_{2}}$ & 0.740 & $\mathrm{Zr}$ & 0.0262 \\
Zirconyl nitrate & $\mathrm{ZrO}\left(\mathrm{NO}_{3}\right)_{2} \cdot \mathrm{xH}_{2} \mathrm{O} \times 6$ & 3.692 & & \\
Sodium hydroxide & $\mathrm{NaOH}, 50 \mathrm{wt} \%$ solution & 186.100 & & \\
\hline
\end{tabular}




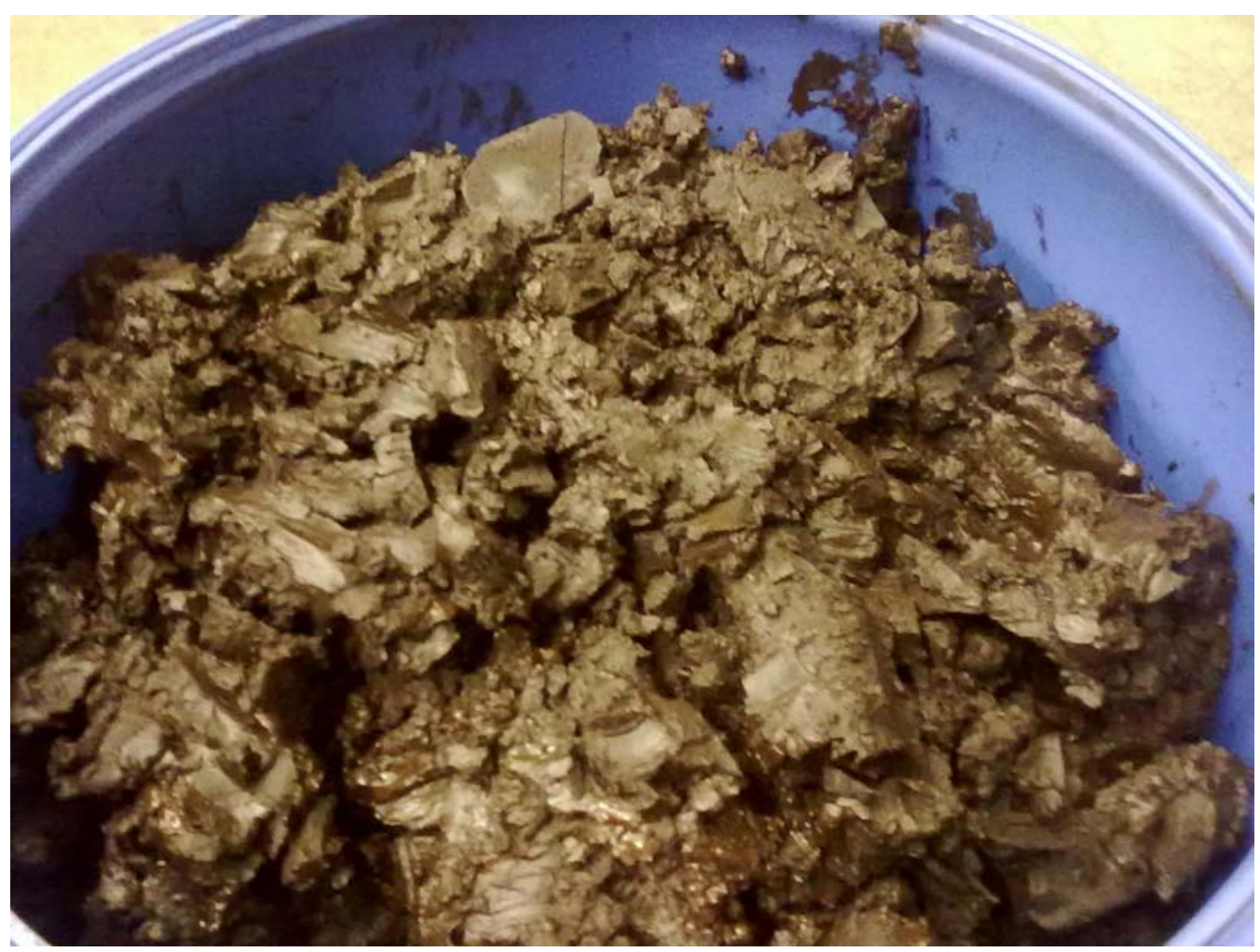

Figure 3.7. Iron-Rich Solids at Vendor After Concentration in Basket Centrifuge 


\subsection{Equipment Description}

Aerosol tests were conducted in the aerosol test enclosure, using a test loop that allowed slurries and liquids to recirculate at constant flow rates and pressures for testing a range of orifice sizes and geometries. Each individual test was defined by a single orifice, pressure, and selected slurry simulant or liquid solution. A data logger was used to record temperature, pressure, and flow rate signals. Data collected by aerosol measurement instruments were logged on a separate laptop computer (through an interface box). These data were post-analyzed using the instrument software to obtain averaged data, which was exported by the instrument software to a text file. Visual observations pertaining to the aerosol instrumentation data collection were recorded in the test instruction (TI) associated with the individual test. Visual observations of sprays were recorded in a project-specific laboratory record book (LRB). Simulant samples were taken and characterized for various properties; see Chapter 3 for further details.

The small-scale test loop is described in Section 4.1. Test equipment, instruments used to collect data related to aerosol generation, and instruments used to measure orifice sizes are described in Section 4.2, Section 4.3, and Section 4.4, respectively. Orifice dimensions are discussed in Section 4.5, and sample analysis is described in Section 4.6.

\subsection{Test Loop}

The small-scale test loop was located in the walk-in hood in Laboratory 107 of the Applied Process Engineering Laboratory (APEL), and is shown in Figure 4.1.

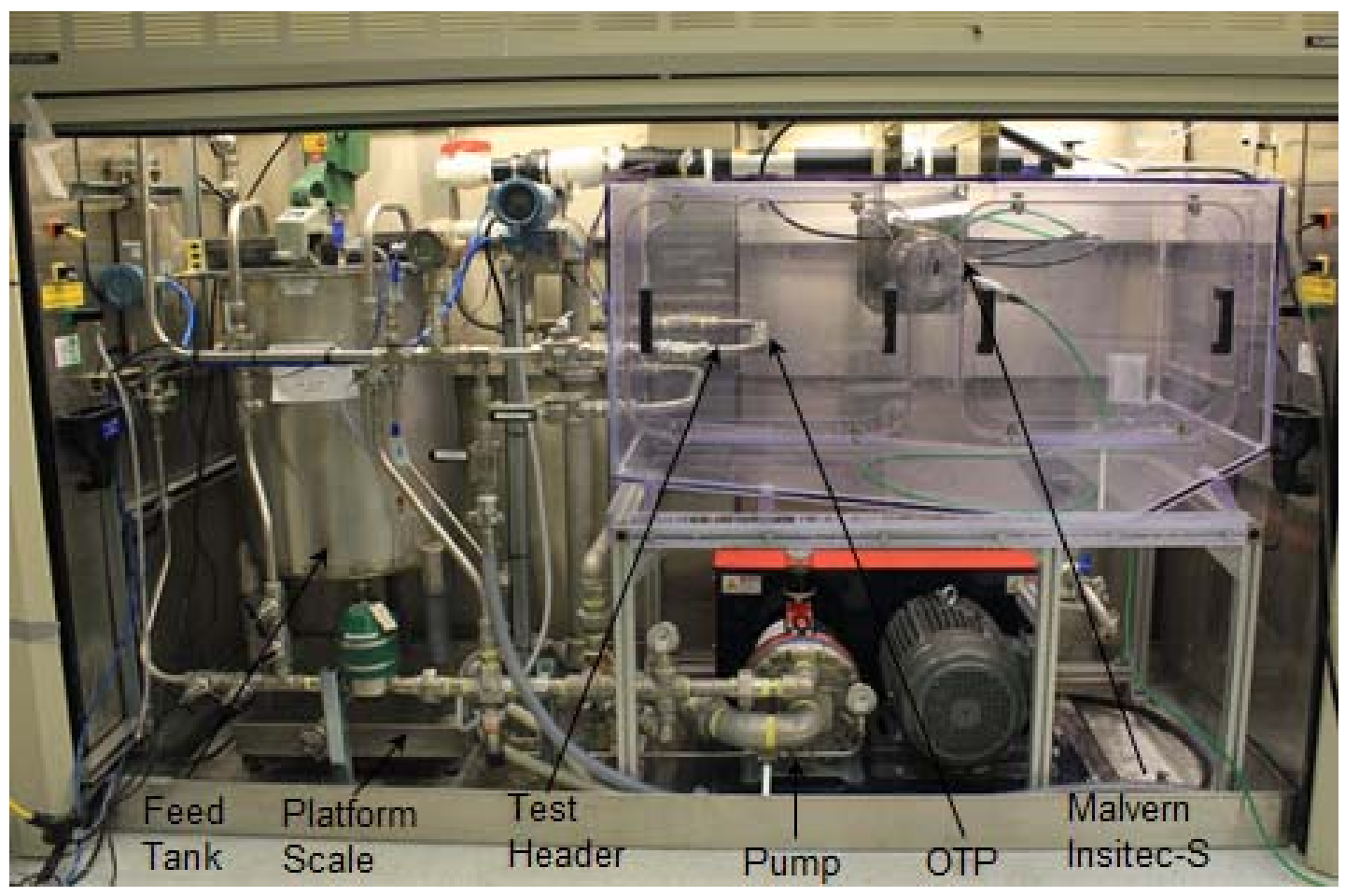

Figure 4.1. Small-Scale Test Loop 
Each simulant and liquid solution used in the test was prepared in a secondary tank and transferred into the system feed tank using a portable diaphragm pump. Simulant was circulated from the feed tank through the pump, into the horizontal test header, and then back to the feed tank. Flow rate was measured upstream of the test header with a Micro Motion Coriolis flow meter. The target flow rate of $10 \mathrm{gpm}$, and pressures of up to 380 psi were achieved using a Hydra-Cell D/G-35-X diaphragm feed pump controlled by a Honeywell variable frequency drive (VFD). The feed tank was mixed at all times, using a Lightnin Model X5P25 0.25-HP clamp mount mixer for most of the tests. The FER simulant required a Lightnin Model X5P100 1-HP clamp mount mixer with two impellers, the second of which was attached approximately 9 in. above the bottom blade on the 33-in. shaft.

Swappable orifice test pieces (OTP) were positioned in an interchangeable portion of the test header within the aerosol test enclosure. The wall thickness of each OTP was equivalent to that in a 3-in. schedule-40, stainless steel pipe, thus providing a leak-path length equal to the large-scale breaches and much of the piping used in the WTP. The inner surface of each OTP was flush with the inner wall of the 300-Series, stainless-steel tubing. As shown in Figure 4.2, the jet from the orifice was aimed horizontally along the length of the enclosure.

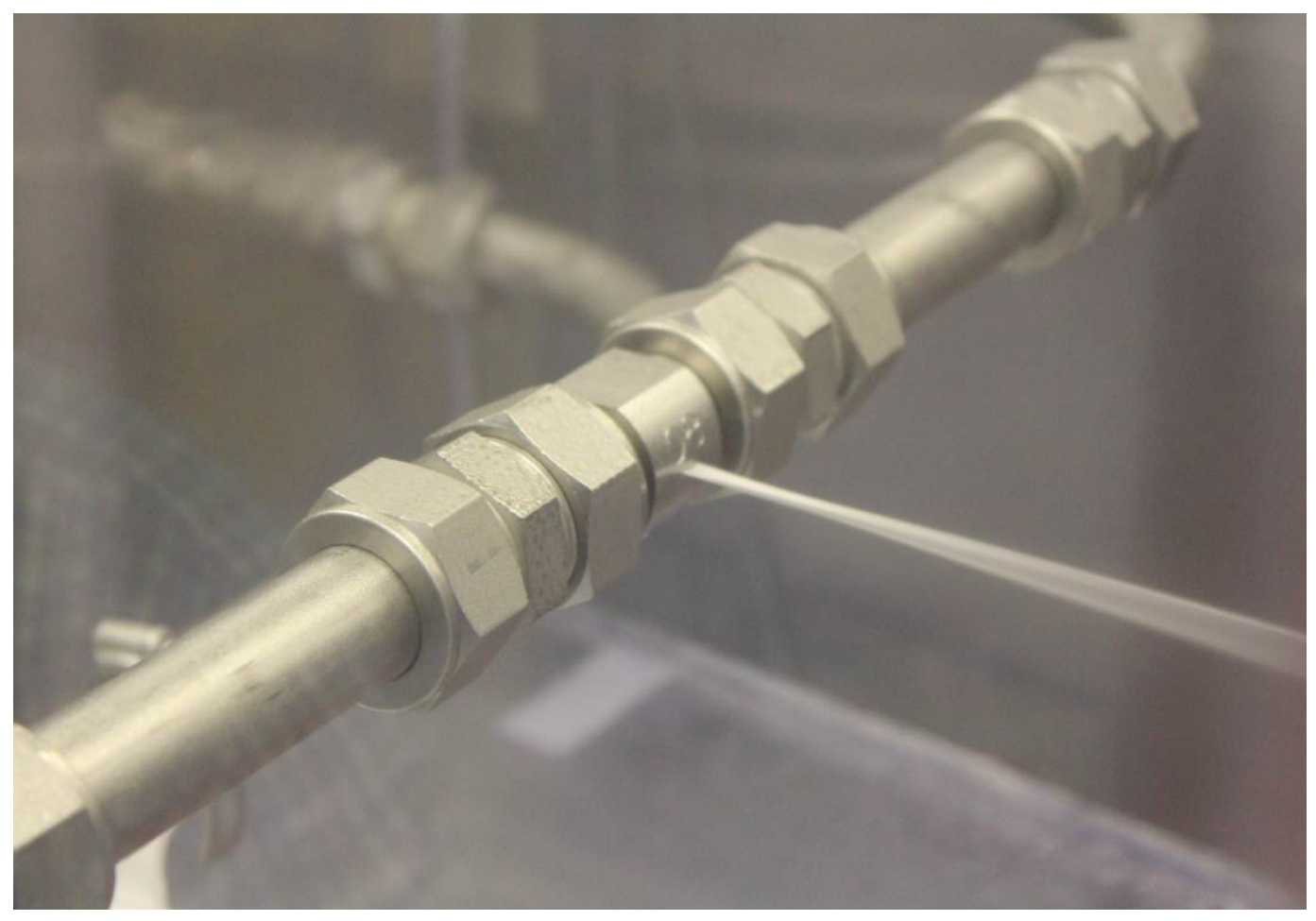

Figure 4.2. OTP in Test Header Spraying Water Horizontally Along the Length of Aerosol Test Enclosure

Figure 4.3 presents a drawing of the aerosol test enclosure and shows windows in appropriate locations for viewing sprays. The test header was located at the left end of the enclosure; the sloped bottom directed the collected spray to the drain near the right end. The overall dimensions of the aerosol test enclosure were approximately 30 -in. wide $\times 30$-in. high $\times 57$-in. long. More exact dimensions and equipment locations are given in Figure 4.4 and Table 4.1. The test header elevation was halfway 
between the floor and the greatest height of the enclosure. The internal volume of the aerosol test enclosure was $24.8 \mathrm{ft}^{3}$.

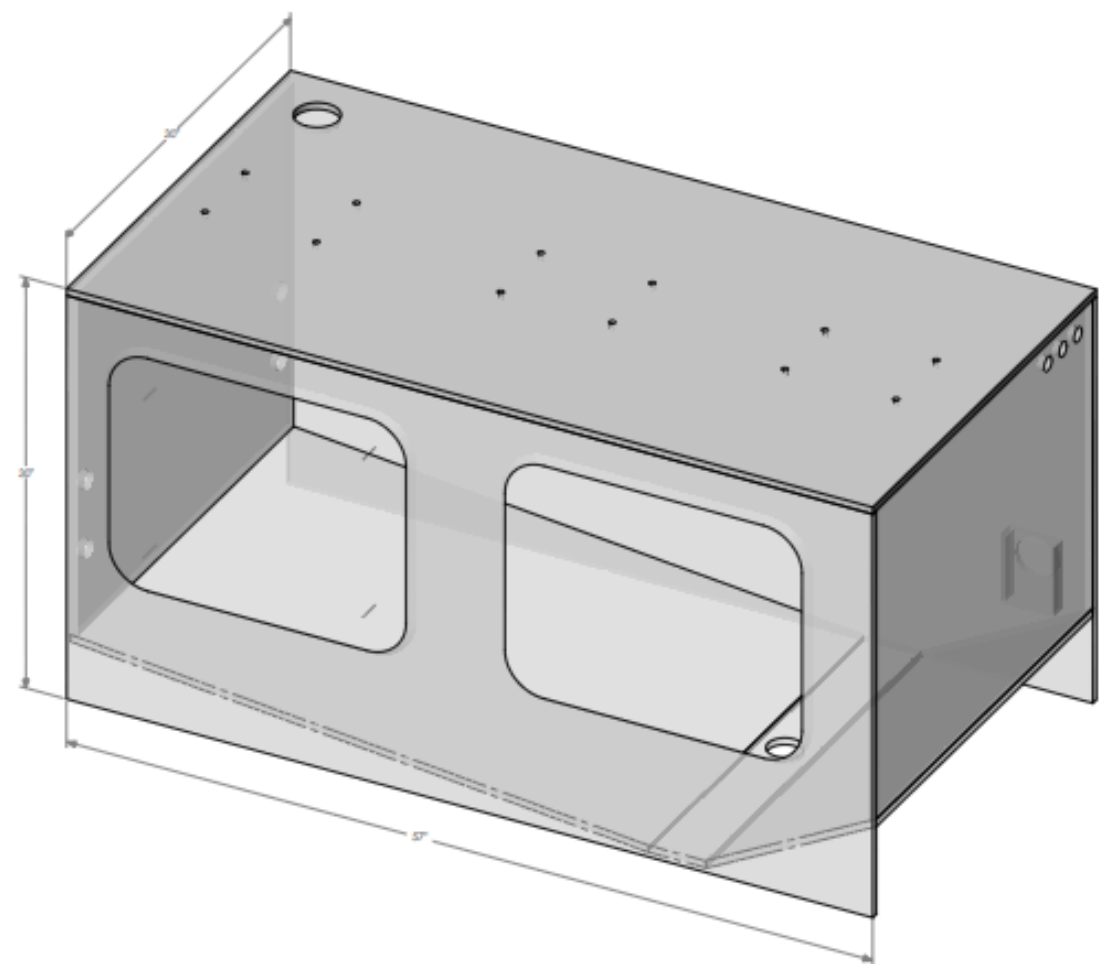

Figure 4.3. Drawing of Aerosol Test Enclosure

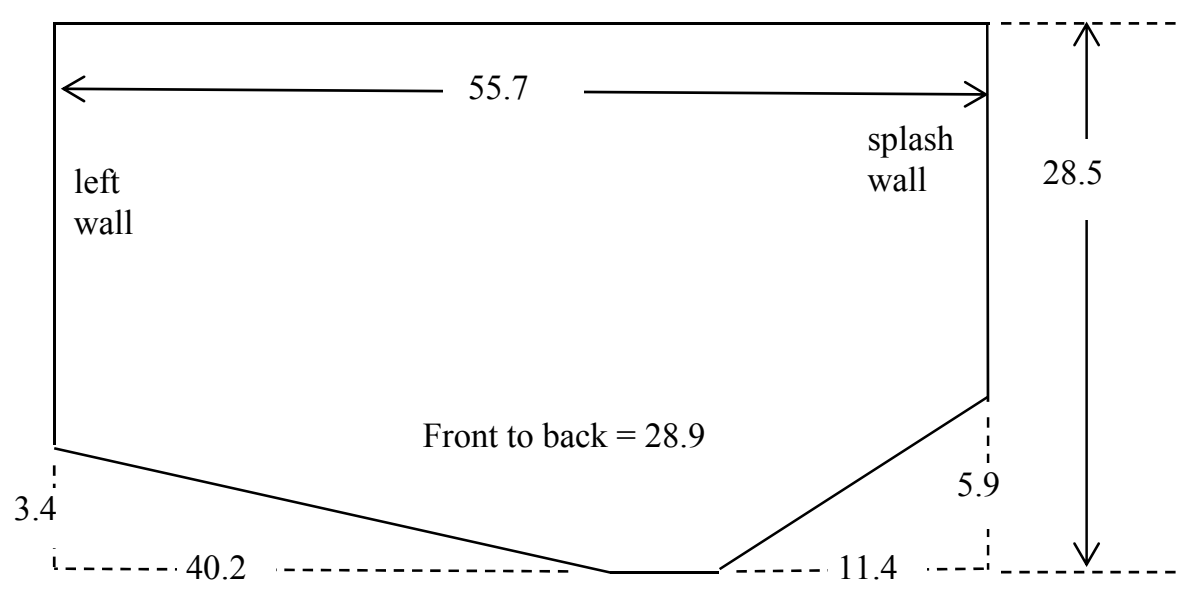

Figure 4.4. Front View and Dimensions (in.) of the Small-Scale Enclosure 
Table 4.1. Dimensions of the Test System

\begin{tabular}{|c|c|c|c|}
\hline & \multicolumn{3}{|c|}{ Distance (in.) From } \\
\hline & Ceiling & Left (Upstream) Wall & Front Wall \\
\hline $\begin{array}{l}\text { Centerline of orifice in its } \\
\text { standard position }\end{array}$ & 14.4 & $\begin{array}{c}13.7 \\
\text { (42 in from splash wall) }\end{array}$ & 14.4 \\
\hline $\begin{array}{l}\text { Top left front corner of } \\
\text { Malvern when in Position } 2 \\
\text { (default in-chamber) }\end{array}$ & 2.6 & 23.6 & 10.7 \\
\hline $\begin{array}{l}\text { Top left front corner of } \\
\text { Malvern when in Position } 4 \\
\text { (in-spray) }\end{array}$ & 9.6 & 23.6 & 10.7 \\
\hline $\begin{array}{l}\text { Top left front corner of } \\
\text { Malvern when in Position } 1\end{array}$ & 9.6 & 2.7 & 10.8 \\
\hline $\begin{array}{l}\text { Top left front corner of } \\
\text { Malvern when in Position } 6\end{array}$ & 14.8 & 23.5 & 10.8 \\
\hline $\begin{array}{l}\text { Top of front edge of blower } \\
\text { when Malvern is in Position } 1 \text {, } \\
2, \text { or } 4\end{array}$ & 20.9 & 10.2 & $14 \pm 1$ \\
\hline $\begin{array}{l}\text { Top of front edge of blower } \\
\text { when Malvern is in Position } 6\end{array}$ & 4.6 & 16.1 & $14 \pm 1$ \\
\hline $\begin{array}{l}\text { Malvern framework is } 9.6 \text { in. } \\
\text { is centered both vertically and } \\
\text { Fan has a } 3 \text {-in. outer diameter }\end{array}$ & $\begin{array}{l}\text { tom, } 9 \\
\text { sht wit } \\
\text { aust an }\end{array}$ & $\begin{array}{l}\text { to right, } 7.0 \text { in. front } \\
\text { amework. } \\
\text { l. long. }\end{array}$ & Laser beam \\
\hline
\end{tabular}

As shown in Figure 4.5, the small-scale test system included a bypass header and a pump purge line, both equipped with isolation valves. For all but the largest orifice slot sizes, the bypass header allowed the simulant to be recirculated while the system was adjusted to the target flow rate and pressure. The largest orifices required pressure and flow to be set while spraying. The purge line, located below the pump suction line (and connected to the pump housing), provided an additional recirculation flow path back to the feed tank, and could be used to either bypass the test loop altogether or to allow the majority of fluid to recirculate after the target test flow rate and pressure had been set. In many of the aerosol tests, the flow rate and pressure were set, and the purge line isolation valve then was opened while other pre-spray tasks were completed (e.g., the aerosol instrument background check). The resulting unrestricted flow and lower line pressure ( $\sim 50$ psi versus a target test pressure of 380 psi) became critical during simulant testing to minimize overheating of the simulant. Upon initiating a spray, the bypass header and pump purge valves were closed. Manually controlled flow control valves were used to maintain the designated target pressure in the test header. A mixing fan installed under the bypass header was employed to improve mixing and provide a more homogeneous aerosol concentration in the aerosol test enclosure. The fan setting that provided adequate aerosol mixing within the enclosure was determined to be $6 \mathrm{~V}$. 


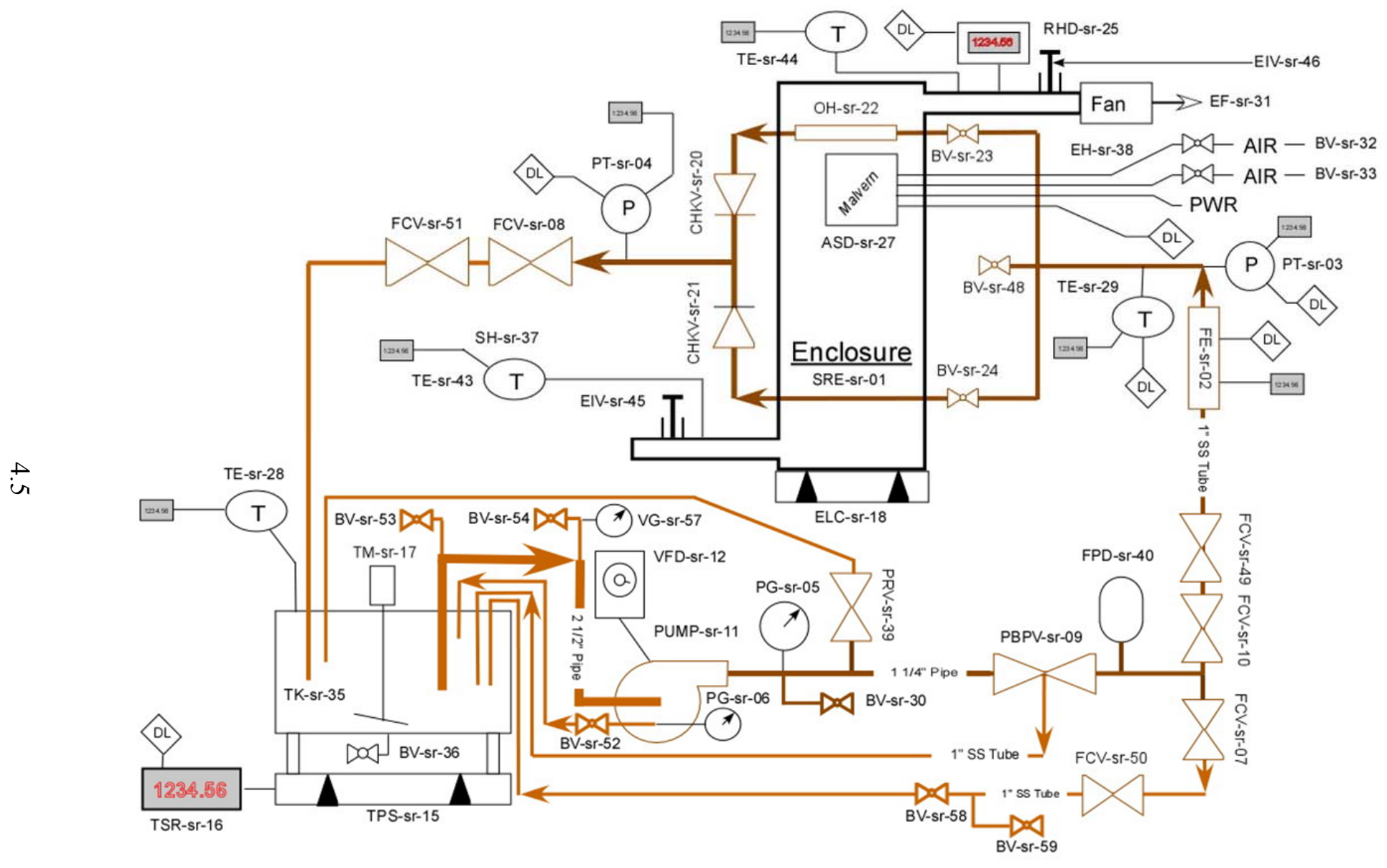

Legend:
Flow meter
Temp Sensor
Local Indicator
Ball Valve
Check Valve
Isolation Valve
Load Cell
Pump

Figure 4.5. Detailed Schematic of Small-Scale Testing System 
The test header was constructed using Swagelok tubing with a nominal outer diameter of $1.0 \mathrm{in}$. and a nominal wall thickness of $0.065 \mathrm{in}$. The fluid velocity at the target flow rate of $10 \mathrm{gpm}$ was $5.4 \mathrm{ft} / \mathrm{s}$. The velocity was calculated using the nominal outer diameter of 1-in. tubing with a wall thickness of $0.065 \mathrm{in}$. A flow rate of approximately $10 \mathrm{gpm}$ through the test header was calculated to provide the same wall shear stress (within about 10 percent) as would exist in 3-in. schedule-40 pipes with a flow velocity of $6.5 \mathrm{ft} / \mathrm{s}$. This flow velocity and pipe size are typical of the smaller lines in the WTP equipment, and were used in the test header for the large-scale tests; therefore, the approximate matching of wall shear stress provided consistent conditions for the orifice entry point between the two test stands. The simulants for which the matched-shear-stress criterion was approximately met were Newtonian simulants and non-Newtonian simulants with Bingham yield stresses of $\leq 6 \mathrm{~Pa}$ and Bingham consistencies of $\leq 6 \mathrm{mPa} \cdot \mathrm{s}$.

For the majority of the aerosol tests, a feed volume of 40 gal or less was adequate and recycling simulant from the aerosol test enclosure back into the feed tank was not necessary. However, in some cases it was necessary to transfer simulant, while spraying, back into the feed vessel using a diaphragm transfer pump.

\subsection{Test System Data Collection and Instruments}

A calibrated Omega Data Logger, connected to a PC, was used to collect temperature data and raw voltages that could be converted, using the instrument calibration data, into the appropriate units for the measured data. Time, temperature, and voltage data were saved in Excel spreadsheets. Inventory changes in the loop were accounted for by manually recording the mass in the feed tank before and after each test using a scale that was calibrated to a local display.

Table 4.2 lists instruments used to collect data to support data analysis for the small-scale aerosol tests.

Table 4.2. Instruments Used in Small-Scale Aerosol Tests

\begin{tabular}{|c|c|c|}
\hline Instrument Name & Measurement & $\begin{array}{c}\text { Calibrated } \\
\text { Range }\end{array}$ \\
\hline Micro Motion Coriolis mass flow sensor & Flow rate in test header ${ }^{(a, b)}$ & $1-35 \mathrm{gpm}$ \\
\hline Honeywell pressure transmitter & Pressure in test header upstream of the OTP ${ }^{(a, b)}$ & $0-500$ psig \\
\hline Honeywell pressure transmitter & Pressure in test header downstream of the OTP $\mathrm{OP}^{(\mathrm{a}, \mathrm{b})}$ & $0-500$ psig \\
\hline Thermocouple (Type T) & Temperature upstream of test header ${ }^{(a, b)}$ & $32-120^{\circ} \mathrm{F}$ \\
\hline Thermocouple (Type T) & Feed tank temperature ${ }^{(\mathrm{b})}$ & $32-120^{\circ} \mathrm{F}$ \\
\hline Feed tank platform scale & Mass in the feed tank $k^{(b)}$ & $0-600 \mathrm{lb}$ \\
\hline \multicolumn{3}{|c|}{$\begin{array}{l}\text { (a) Connected to data logger OMB DAQ 2416-4AO, Serial No. 29991; Software: } \\
\text { Calibrated by the Pacific Northwest National Laboratory standards laboratory. } \\
\text { (b) Calibrated to local display. }\end{array}$} \\
\hline
\end{tabular}

\subsection{Aerosol Instruments}

The size distribution and concentration of aerosol droplets in the small-scale spray leak test chamber were measured using a Malvern Insitec-S particle size analyzer (Insitec-S) and a Process Metrix Particle 
Counter (PPC). Both instruments are based on the same laser diffraction technique but use different measurement approaches, which differentiate these two instruments primarily in the detection ranges of particle sizes and concentrations. The principles of measurement and operation for both instruments are described in the following sections.

\subsubsection{Malvern Insitec-S Particle Size Analyzer}

The Insitec-S is an open frame aerosol size analyzer that uses laser diffraction to determine aerosol size and concentration. The basic instrument setup and operation principle are illustrated in Figure 4.6. The laser module, housed in the transmitter module, produces a collimated beam that is $10 \mathrm{~mm}$ in diameter and has a wavelength of $670 \mathrm{~nm}$. The receiver module houses the lens and detector assemblies. The lens has a focal length of $100 \mathrm{~mm}$ and focuses the scattered light onto the detector held within the receiver module. Two glass windows, which are located at the interfaces with the transmitter module and the receiver module, respectively, separate the laser, lens and detectors from the humid wet chamber environment. The measurement volume is the volume between the glass windows swept out by the laser beam as it passes from the laser source to the detector assembly. The distance between the laser source and detector assembly is set by a $150-\mathrm{mm}$ spacer bar. To minimize direct contamination from water and slurry, two spray shrouds were installed on top of the glass windows. The shrouds are approximately $1.5 \mathrm{in}$. in diameter and $1.7 \mathrm{in}$. in height, where the diameter refers to the diameter on the outside of the conical shrouds. The measurement volume can be calculated from the spacer bar length (subtracting the shroud height on both sides) and beam diameter, resulting in a volume of $5.5 \mathrm{~cm}^{3}$. A purge gas system is used to separate the droplets in the small-scale testing chamber from the windows, thus keeping the windows clean. The purge gas was generated by an air compressor and was particle free. A purge gas flow of 1.2 standard cubic foot per hour $(\mathrm{SCFH})$ was used for each glass window.

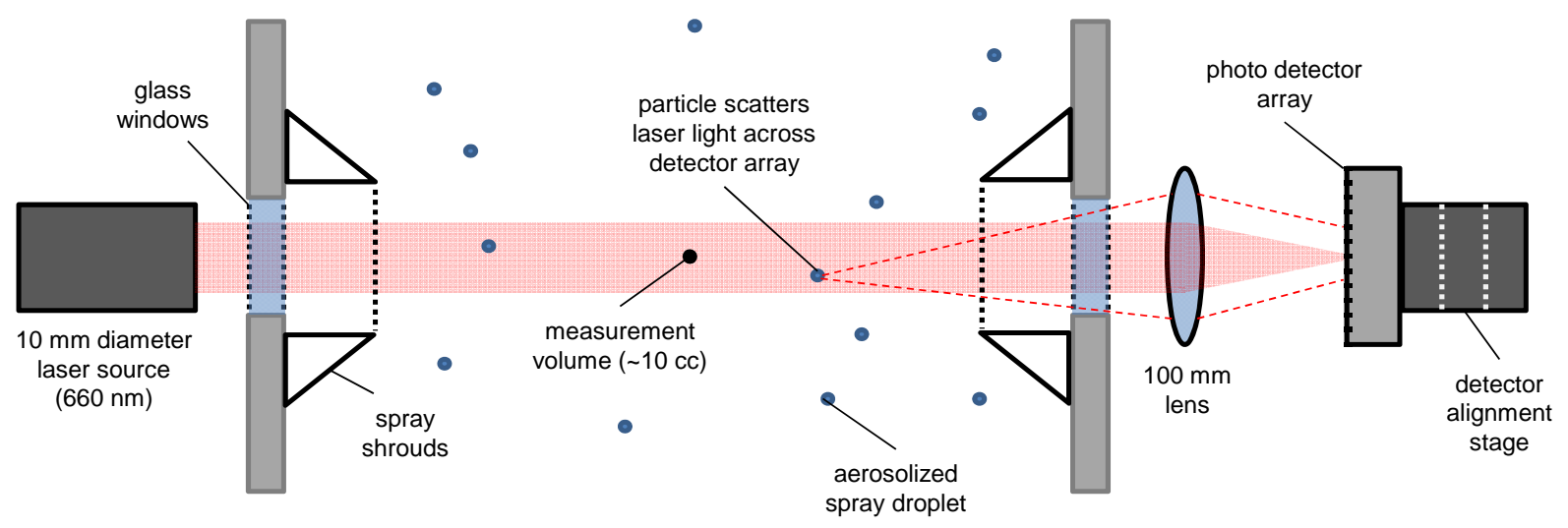

Figure 4.6. Basic Instrument Setup and Operation Principle of the Malvern Insitec-S Particle Size Analyzer

The detector assembly consists of the receiver electronics and the optical detector array. The optical detector array is made up of 32 individual detectors, each of which collects the light scattered by a particular range of angles. Light from the laser beam is scattered by the particles within the measurement volume. This scattered light is focused by the lens and picked up by the detector array. Unscattered light is focused by the lens so that it passes through the pinhole at the center of the detector array and is subsequently measured by the beam power detector to give the light transmission. The angle at which a 
particle diffracts light is inversely proportional to the size of the particle. By measuring the angle of diffraction, the size of the particle is determined. In cases where the particle loading is high, the measurement process is complicated by scattered light being re-scattered by other droplets before it reaches the detector. A 'multiple scattering' algorithm can be applied to correct for these cases. The decrease of the light transmission relative to that measured when no aerosol is present (termed the background light transmission), along with the size distribution estimated from the diffraction pattern, can be used to determine the volume concentration of droplets.

The nominal size range measured by the Insitec-S is dictated by the focal length of the lens. For small-scale testing, the 100 -mm lens yields a nominal measuring range of 0.5 to $200 \mu \mathrm{m}$. In general, the Insitec-S can measure aerosols in the range of 0.01 to 1000 parts per million by volume (ppmv), which is determined primarily by the length of the spacer bars and the geometry of the spray. For small-scale testing, the Insitec-S can detect particle concentrations above a lower threshold of $\sim 0.1 \mathrm{ppmv}$.

During small-scale testing, the Insitec-S was usually located at the middle of the small-scale testing chamber, vertically positioned above the core of the spray (Position 2 in Figure 4.7). However, the location was not fixed, as the specific instrument test locations were varied to determine the concentration behavior in the small-scale testing chamber.

In tests with large slot orifices that generated heavy spray, a horizontal $8 \mathrm{in}$. by $8 \mathrm{in}$. plexiglass plate was mounted beneath the Insitec-S, but not covering it, to serve as a splash guard. There was approximately $47 / 8$ in. of open space between the orifice and the nearest edge of the plate, and there was about 2 1/2 in. of the plate length extending under the instrument. This plate prevented spray and condensation from collecting on the instrument lenses.

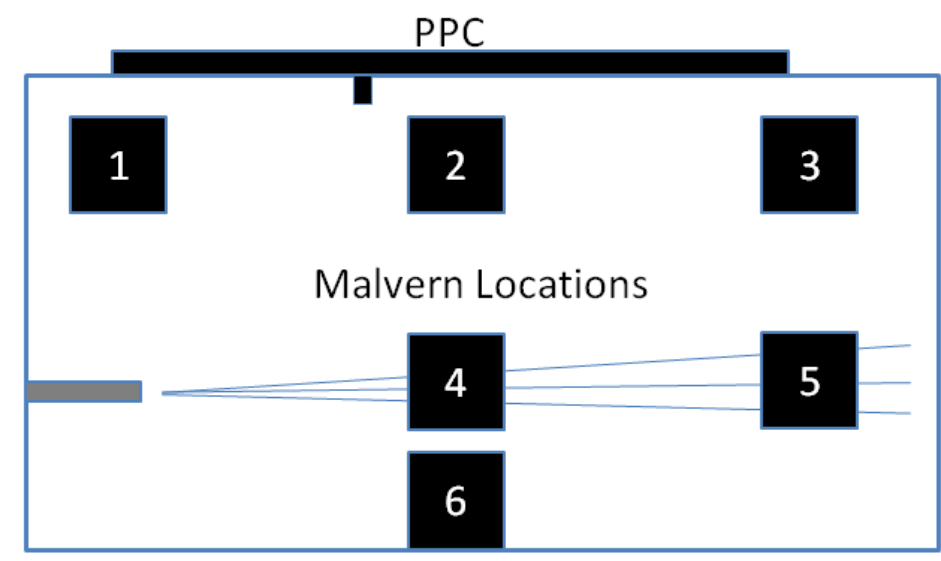

Figure 4.7. PPC (top) and Malvern (numbered) Locations within the Test Enclosure

The Insitec-S was interfaced to a single control computer through a local communications interface box (Part\# MPS2092). Malvern's RTSizer software (Version 7.40, Copyright 2010) was used to collect, analyze, and report the aerosol data sampled by the Insitec-S. The primary program outputs were aerosol size and concentration; other measurement parameters, including raw data such as the raw light scattering signal, laser transmission, and background, and other calculated parameters such as the SMD, were reported also. The typical instrument configuration and software settings used for analysis are listed in Table 4.3Table 4.3. A complete description of parameters is given in the RTSizer user manual (Malvern 
Instruments Ltd. 2010). The first three parameters, the lens, gain, and update period, must be set prior to data collection because they cannot be changed using post-analysis properties. The lens parameter must be set to match the focal length of the lens installed in the instrument. The gain is a photodiode multiplier that determines the instrument response to scattered light. The highest gain setting of $2 \times$ was employed because aerosol concentrations were expected to be low ( $\leq 10 \mathrm{ppmv}$ based on initial estimates). The update period (or accumulation period) determines the time period over which results are integrated. Longer update periods tend to smooth variations in aerosol concentration with time, yielding smoother data, but may also time-average over periods during which aerosol concentration transience is of interest (e.g., the initial increase in concentration from which release fraction estimates are made). Shorter updated periods can be selected to capture fast transients; however, they tend to yield an increase in noise-to-signal ratio. For small-scale testing, the update period was set to $1 \mathrm{~s}$.

Table 4.3. Insitec-S Instrument Configuration and Software Parameters Used in Typical Measurements

\begin{tabular}{ll}
\hline \multicolumn{1}{c}{ Parameter } & \\
\hline Lens & $100 \mathrm{~mm}$ \\
Gain & $2 \times$ \\
Update period & $1 \mathrm{~s}$ \\
Particulate Refractive Index & Varies depending on test slurry \\
Media Refractive Index & Air: $1.00+0.00 \mathrm{i}$ \\
Particle Density & 1.00 gm/cc (typically not set to true density, as this parameter is only used in \\
& specific surface area calculations) \\
Scattering Threshold & 2 \\
Minimum Size & $0.10 \mu \mathrm{m}$ \\
Maximum Size & $1500 \mu \mathrm{m}$ \\
First Scattering Start & 1 (default value) \\
Multiple Scatter & On \\
Spray Properties & Checked: Uniform spray concentration in measurement volume \\
\hline
\end{tabular}

Users can change parameters (e.g., the particulate and media refractive index and scattering threshold) for post-analysis processing undertaken to evaluate the effect of instrument results. Refractive index and spray properties are two such parameters. The refractive index is a complex number that specifies how light refracts through a material (real component) and how the material attenuates or absorbs light (imaginary component). Because all aerosols are tested in air, the media refractive index always is set to that of air $(1.00+0 \mathrm{i})$. The particulate refractive index depends on the material being tested and is discussed in greater detail in the large-scale spray release report (Schonewill et al. 2012). The spray properties parameter allows for definition of the shape, size, and concentration profile of the spray as it passes through the measurement volume.

\subsubsection{Process Metrix Particle Counter}

A PPC was used in some small-scale tests to provide a secondary measurement of aerosol concentration and size distribution. 
As shown in Figure 4.8, the PPC consists of two relatively small-diameter (i.e., 33.7 and $152 \mu \mathrm{m}$ ) laser beams that pass through an aerosol-filled measuring zone. The lasers operate in sequence over a specified duty cycle (e.g., $2 \mathrm{~s}$ ) so only one laser is active during a given period and light scattering may be attributed entirely to scattering as droplets enter the active laser beam. The measurement volume defined by the collection optics, slit, and laser beams is typically $10^{-4}$ to $10^{-6} \mathrm{~cm}^{3}$ and is roughly ellipsoidal in shape. Scattered light is only collected and focused on the photodetector for droplets that enter the measuring volume. Both small and large laser beams strike the collection optics off-center, with undeflected laser angles of 8 and 3 degrees, respectively. A photomask blocks low angle diffraction, so the solid angle over which scattered light is collected is an off-center circular segment. Two sapphire windows are installed in front of the laser sources and the photodetector, respectively.

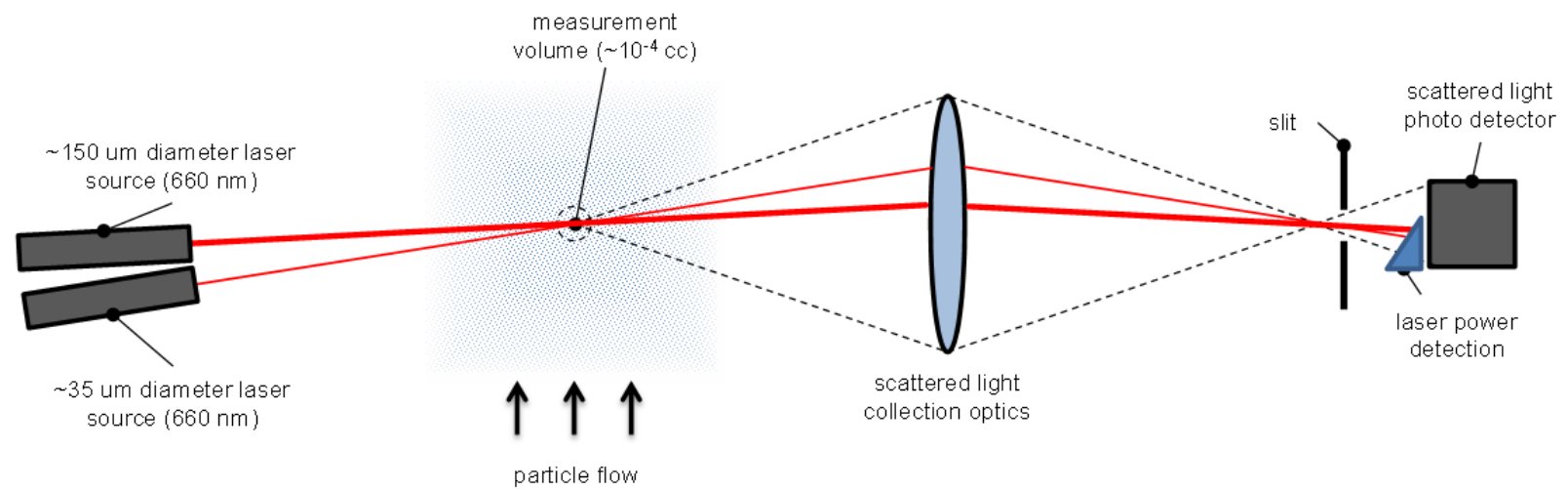

Figure 4.8. Schematic Showing the Basic Components and Principle of Operation for the PPC. The PPC is a two-laser aerosol size and concentration analyzer that operates on the principle of laser diffraction. Interaction of the laser with single droplets yields a diffraction pattern. The diffraction pattern is collected over a fixed range of scattering angles and focused onto a single photodetector. The power of scattered light, along with the frequency of scattering events, is accumulated over a fixed data collection period and translated into aerosol concentration and size distribution.

The collected light is focused onto a photomultiplier tube that converts laser power into an equivalent voltage signal. The measurement volume is sufficiently small, so for concentrations below 4,000 and 400,000 droplets $/ \mathrm{cm}^{3}$ (corresponding to the 152 and $33.7 \mu \mathrm{m}$ beams, respectively), it may be assumed that only one particle is in the measurement volume at a given time. Thus, each scattering event resolved by the photodetector can be attributed to a single particle passing through the measurement volume. The laser intensity is not uniform across the cross-section of the beam; rather the beam profile is Gaussian and gradually decreases from its peak intensity at the center of the beam to zero at large radial distances from the beam center. Because of this variation in beam intensity, the size cannot be inferred directly from a single scattering event. However, if enough scattering events are collected (typically 1000 to 10,000 particle interactions), then it may be assumed that all particle scattering configurations have been sampled, and the size and concentration of the accumulated scattering ensemble may be calculated. The accumulation period necessary to collect a statistically significant number of scattering events is concentration dependent, with higher particle concentrations requiring lower accumulation times relative to lower particle concentrations. As such, the accumulation period should nominally be selected to provide the required level of statistical significance. The PPC allows the user to set accumulation from as low as $5 \mathrm{~s}$ up to several hours. It should be noted that accumulation will time-average any transient 
conditions that occur during the accumulation period, which will smooth any variations in the data, but may also damp transients of interest such as the initial rise in concentration from which release fraction is determined. For the purposes of small-scale testing, the minimum available accumulation period of $5 \mathrm{~s}$ was selected to minimize the time averaging that occurs in the initial rise in concentration.

The large laser beam (152 $\mu \mathrm{m}$ diameter) can measure droplets ranging from 3.54 to $71.11 \mu \mathrm{m}$, while the small laser beam ( $33.7 \mu \mathrm{m}$ diameter) can detect droplets ranging from 0.53 to $2.59 \mu \mathrm{m}$. This yields an overall dynamic size range of 0.53 to $71.11 \mu \mathrm{m}$ for PPC measurements. The size range may be impacted should insufficient sample counts be reached. At higher concentrations (e.g., 4,000 droplets $/ \mathrm{cm}^{3}$ for the larger beam), the probability that more than one particle may simultaneously exist in the measurement volume increases. When this condition exists, the instrument software cannot correctly interpret simultaneous scattering of multiple droplets. The upper limit of the volume concentration is 10 ppmv. $^{12}$ Because the PPC can detect and accumulate single scattering events, there is no theoretical limit (at least with respect to the principle of operation) on the lower concentration limit of the instrument. However, practical limits exist with respect to the reasonable accumulation periods. Specifically, at low concentrations, the number of laser interactions that occur during the set accumulation period may not be sufficient to yield acceptable size and count statistics. In addition, although lower concentrations may be achieved by increasing the accumulation period, the accumulation period may not be set longer than the expected rise time for concentration to reach equilibrium without losing the ability to resolve aerosol net generation rates. In particle terms, this introduces a lower concentration limit of approximately 0.01 ppmv. These constraints generally limit the concentration range measurable by the PPC from approximately 0.01 to $10 \mathrm{ppmv}$.

For small-scale testing, the PPC was co-located with the Insitec-S. It was not installed directly in the chamber, but rather was placed on the top-outside of the chamber. It was connected to a nominal 0.75 -in. conductive draw tube inserted approximately $1 \mathrm{ft}$ down from the top of the chamber (placing the sample location for the PPC at approximately the same level as that for the Insitec-S instrument). A vacuum pump was used to create suction to draw sample from the aerosol chamber into the PPC. A PPC vacuum gas flow rate of 0.5 standard cubic feet per minute ( $\mathrm{scfm}$ ) was set for small-scale tests. Particle-free purge gas, generated from an air compressor, flowed across the sapphire windows to prevent contamination of the windows from droplets in the small-scale chamber. A purge gas flow of $1.0 \mathrm{SCFH}$ was used per window.

PPC control and data acquisition is controlled through a computer using the Process Particle Counter Version 2.30.001 software provided by Process Metrix. The main software parameters that can be adjusted to control experiments are 1) the accumulation period, 2) the frequency that results are reported, and 3) the laser duty cycle. (Note that the parameters cannot be changed during post-measurement analysis.) As discussed above, the accumulation period was set to $5 \mathrm{~s}$ for small-scale measurements. A result report interval of $2 \mathrm{~s}$ was selected for small-scale measurements, which is the highest frequency at which results may be reported by the software. The laser duty cycle selected also was $2 \mathrm{~s}$, with 80 percent $(1.6 \mathrm{~s})$ of the cycle employing the $152-\mu \mathrm{m}$ laser beam and 20 percent $(0.4 \mathrm{~s})$ using the $33.7-\mu \mathrm{m}$ laser beam. The PPC was factory-configured for standard opaque droplets, and uses a hard-coded refractive index of $1.5+0.5 \mathrm{i}$ for particulate systems and $1.0+0 \mathrm{i}$ for the media refractive index. A more detailed description of parameters is given in the PPC user manual (Process Metrix 2007).

${ }^{12}$ PPC Technical Specification. Process Metrix. 2007. 


\subsection{Orifice Imaging Hardware and Software}

The sizes of the orifices used in the aerosol tests were measured using an imaging system composed of a digital camera, lens, lens spacer, and a micro-ruler. The camera used was an Edmund Optics EO-1918C, with image size of $1600 \times 1200$ pixels (horizontal $\times$ vertical). An InfiniGage CW lens and lens spacers, also from Edmund Optics, were attached to the camera, and images were captured with StreamPix software, version 5.3.0. An MR-1 Micro-Ruler, supplied by Geller MicroAnalytical Laboratory Inc. and calibrated per QA requirements, also was used.

\subsection{Orifice Dimensions}

The dimensions of the orifices used in the aerosol tests are given in Table 4.4. These dimensions were measured where the orifice intersects the outer diameter of the pipe (i.e., the exit point for the spray traveling through the orifice passage) as shown in Figure 4.9. Attempts to determine the dimensions of the orifice where it intersects the inner diameter of the pipe, while viewing from the outer diameter, were unsuccessful. This was largely because the small orifices acted as pinhole lenses, producing a falsely magnified image of the inner-diameter orifice size. Alternative methods to obtain inner-end dimensions produced unreliable results, and destructive means of examination were not pursued because the OTPs were needed throughout testing. The inner-end dimensions that were measurable were consistently smaller than those at the outer end. The depth of each orifice (length of the passage) was within 10 percent of the thickness of 3 -in. schedule-40 pipes (i.e., 0.216 in.). 
Table 4.4. Exit Dimensions for the Orifices for Which Release Fractions Were Determined

\begin{tabular}{|c|c|c|c|c|c|}
\hline $\begin{array}{c}\text { Orifice } \\
\text { Designation }\end{array}$ & $\begin{array}{l}\text { Target Orifice } \\
\text { Dimensions } \\
(\mathrm{mm})\end{array}$ & $\begin{array}{l}\text { Exit Diameter or } \\
\text { Length } \times \text { Width } \\
(\mathrm{mm})\end{array}$ & $\begin{array}{l}\text { Cross-Sectional } \\
\text { Area at Exit } \\
\left(\mathrm{mm}^{2}\right)\end{array}$ & Type & $\begin{array}{c}\text { Slot or } \\
\text { Multi-hole } \\
\text { Orientation }\end{array}$ \\
\hline OTP-31 & 0.3 & 0.306 & 0.074 & Round & $\mathrm{N} / \mathrm{A}$ \\
\hline OTP-13 & 0.5 & 0.531 & 0.22 & Round & $\mathrm{N} / \mathrm{A}$ \\
\hline OTP-03 & 0.5 & 0.534 & 0.22 & Round & N/A \\
\hline ОТР-05 & 1.0 & 0.975 & 0.75 & Round & N/A \\
\hline OTP-41 & 0.5 & $\begin{array}{c}\text { Range: } \\
0.456-0.479\end{array}$ & $\begin{array}{l}\text { Total: } \\
0.87\end{array}$ & $\begin{array}{l}\text { Multiple } \\
\text { (5) Round }\end{array}$ & Axial \\
\hline ОТР-33 & $0.3 \times 5.0$ & $0.355 \times 4.984$ & 1.8 & Slot & Axial \\
\hline OTP-16 & $0.5 \times 5.0$ & $0.534 \times 4.886$ & 2.6 & Slot & Axial \\
\hline OTP-19 & $0.5 \times 5.0$ & $0.541 \times 4.999$ & 2.7 & Slot & Circumferential \\
\hline OTP-06 & 2.0 & 2.015 & 3.2 & Round & N/A \\
\hline OTP-17 & $0.7 \times 5.0$ & $0.700 \times 5.022$ & 3.5 & Slot & Axial \\
\hline OTP-42 & 1.0 & $\begin{array}{c}\text { Range: } \\
0.984-1.014\end{array}$ & $\begin{array}{c}\text { Total: } \\
3.9\end{array}$ & $\begin{array}{l}\text { Multiple } \\
\text { (5) Round }\end{array}$ & Axial \\
\hline OTP-37 & $0.5 \times 10$ & $0.499 \times 9.902$ & 4.9 & Slot & Axial \\
\hline OTP-18 & $1.0 \times 5.0$ & $1.017 \times 4.928$ & 5.0 & Slot & Axial \\
\hline OTP-39 & $0.5 \times 15$ & $0.533 \times 14.868$ & 7.9 & Slot & Axial \\
\hline OTP-40 & $0.5 \times 20$ & $0.543 \times 19.935$ & 11 & Slot & Axial \\
\hline
\end{tabular}

In all tests, the OTP was axially mounted in the test header. Dead-end tests were conducted by plugging the test header at the end of the OTP. The breach shape (circular holes and slots) and orientation (axial or circumferential) of the slot through which the fluid was discharged was varied so the effect of shape and orientation on spray release behavior could be evaluated. 


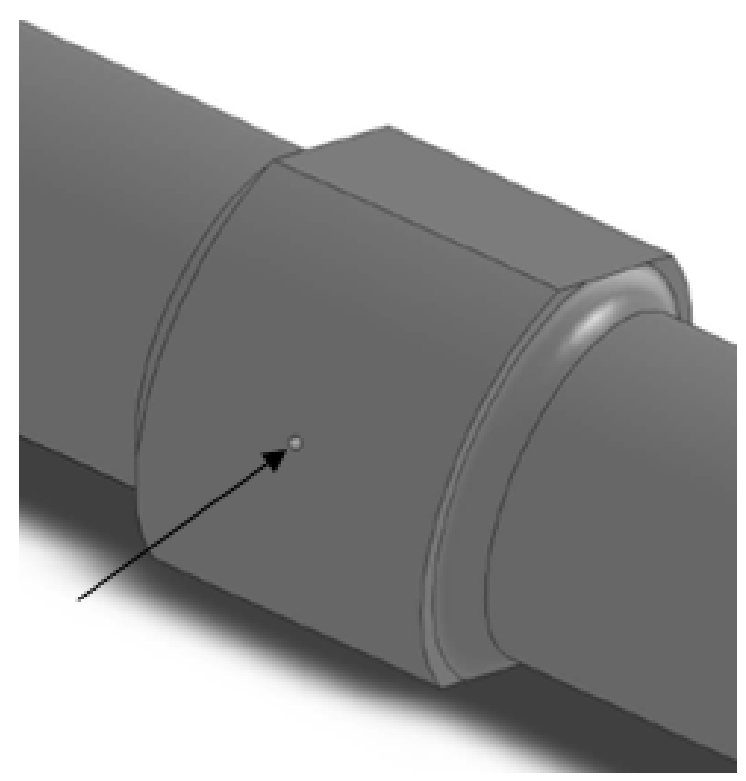

Figure 4.9. Orifice Images Were Measured Where the Orifice Intersected With the Outer Diameter of the Pipe

\subsection{Sample Analysis}

Samples were characterized for physical properties including PSD, surface tension, bulk density, yield stress, rheology, and UDS concentration. Sample analyses, with the exception of surface tension measurements, were performed according to test procedure RPL-COLLOID-02, Measurement of Physical and Rheological Properties of Solutions, Slurries, and Sludges. ${ }^{13}$ Surface tension measurements were conducted per operating procedure OP-WTPSP-035, Measurement of Static Surface Tension of Liquids, Dispersions, and Slurries. ${ }^{14}$

PSD measurements were made using a Mastersizer 2000 Particle Size Analyzer (Malvern Instruments, Inc.) with a Hydro $\mathrm{S}$ wet-dispersion accessory. The PSD measurement range was nominally 0.02 to $2000 \mu \mathrm{m}$. The Mastersizer 2000 Particle Size Analyzer uses laser diffraction technology. The Hydro S wet-dispersion accessory consisted of a 150-mL sonic dispersion unit coupled with a sample flow cell, allowing the flow, stirring rate, and sonication to be controlled and altered during measurements. The PSD measurements were performed on simulant samples containing solids dispersed in a liquid, with and without sonication. Additional PSD measurement details may be found in Appendix E, Section E.1.2.4, of Kurath et al (2009).

Rheological characterizations were performed using a Haake RS600 rheometer operated with RheoWin Pro software Version 2.97 (Thermo Fisher Corporation). The RS600 rheometer was equipped with a low-inertia torque motor and coaxial cylinder measurement geometry. The drive shaft of the motor was centered by an air bearing, which ensures virtually frictionless transmission of the applied torque to

\footnotetext{
${ }^{13}$ Daniel RC. 2011. Measurement of Physical and Rheological Properties of Solutions, Slurries, and Sludges. RPL-COLLOID-02, Rev. 2 (unpublished), Pacific Northwest National Laboratory, Richland, Washington.

${ }^{14}$ Tran DN. 2011. Measurement of Static Surface Tension of Liquids, Dispersions, and Slurries. OP-WTPSP-035, Rev. 0.0 (unpublished), Pacific Northwest National Laboratory, Richland, Washington.
} 
the sample. Unless specified otherwise, all rheological analyses were conducted at $25^{\circ} \mathrm{C}$. Each rheogram (flow curve) was obtained by following the method used to perform rheology measurements for PEP samples, by shearing the sample at a controlled rate from zero to $1000 \mathrm{~s}^{-1}$ for $5 \mathrm{~min}$, holding constant at $1000 \mathrm{~s}^{-1}$ for $1 \mathrm{~min}$, and then shearing at a controlled rate from $1000 \mathrm{~s}^{-1}$ to zero for $5 \mathrm{~min}$. Prior to measuring a flow curve, each sample was gently shaken by hand and sheared at a constant rate of $250 \mathrm{~s}^{-1}$ for $3 \mathrm{~min}$. The purpose of pre-measurement mixing was to ensure that the material being analyzed was homogenized and provided a representative sample. Additional flow-curve measurement details may be found in Appendix E, Section E.1.2.3, of Kurath et al. (2009).

Surface tension measurements were performed using a commercial force-balance K-12 MK6 Tensiometer (Kruss USA). The tensiometer consisted of a K-12 MK6 Tensiometer processor unit, a force measuring unit (the balance), a Wilhelmy platinum plate, and a quartz sample vessel. The static surface tension of each sample was measured using the plate method (a.k.a., the Wilhelmy method), which is based on a force measurement. A platinum plate with exactly known geometry was vertically hung above the sample liquid. The lower edge of the plate was then brought into contact with the sample liquid surface. The sample liquid wet the plate and pulled it into the liquid. The pull from the sample liquid due to wetting is known as the Wilhelmy force. The Wilhelmy force was measured by moving up the plate to the level of the sample liquid surface. The resulting force was determined from the weight measured by the balance. Surface tension measurements for all samples were carried out at room temperature. 



\subsection{Test Operations and Conditions}

The objective of the aerosol tests was to measure aerosol droplet size distributions and concentration produced from prototypic breaches and fluids with physically prototypic WTP slurries and liquid solutions. Data were collected using a range of pressures and orifice sizes and geometries representative of the postulated WTP conditions. Orifice size ranges and pressures used in the small-scale aerosol tests are shown in Table 5.1. The simulants tested are described in Chapter 3.

Table 5.1. Target Ranges of Aerosol Test Parameters

\begin{tabular}{|c|c|c|}
\hline Parameter & Parameter Range & Comments \\
\hline Pressure (psig) & $100,200,380$ & $\begin{array}{l}200 \text { and } 380 \text { psig are the highest pressures } \\
\text { postulated during important accident scenarios at } \\
\text { the WTP. }{ }^{15} \text { The acceptable range was } \pm 10 \% \text { of } \\
\text { the target set point. }\end{array}$ \\
\hline Circular breach diameter $(\mathrm{mm})$ & $0.3-2.0$ & $\begin{array}{l}\text { A breach size of } 0.3 \mathrm{~mm} \text { was the smallest orifice } \\
\text { size that never plugged during the plugging tests } \\
\text { (Mahoney et al 2012). }\end{array}$ \\
\hline $\begin{array}{l}\text { Rectangular breach size range } \\
(\mathrm{mm})(\text { length range } \times \text { width range) }\end{array}$ & $\begin{array}{l}5 \times 0.3-1 \\
5-20 \times 0.5\end{array}$ & $\begin{array}{l}\text { Rectangular breaches independently varied by } \\
\text { width and length, and } \pm 20 \% \text { of the target were } \\
\text { acceptable. Measuring instruments were chosen } \\
\text { based on breach sizes. The depth of the breach } \\
\text { was equivalent to the nominal wall thickness of } \\
0.065 \text { in., and was measured with calibrated } \\
\text { calipers. }\end{array}$ \\
\hline
\end{tabular}

The success criteria for aerosol tests are listed below:

- Measure the droplet size distribution, total volume concentration of droplets, and total volume sprayed for each of the breaches and simulants tested

- Measure the pressure and flow in the piping

- Characterize the PSD, viscosity or rheology, bulk density, and surface tension of each simulant tested

- Calculate the test chamber volume from internal dimensions.

Section 5.1 details the tests performed to meet the test objectives, and Section 5.2 outlines the testing procedure.

\subsection{Aerosol Test Nomenclature}

Testing was conducted on various geometric, operational, and simulant parameters. Geometric parameter changes included shape, size and orientation of the orifice opening, and distance from the orifice to the back wall (or splash wall). The operational and simulant parameters that were varied

\footnotetext{
${ }^{15}$ Gauglitz PA. Test Plan for Spray Leak Quantification to Support WTP Spray Release Methodology.
} TP-WTPSP-031, Pacific Northwest National Laboratory, Richland, Washington. 
included pressure, fluid viscosity, AFA, slurry particle size and concentration, and slurry rheology. A run list of the aerosol tests that were completed is provided in Appendix A and simulant nomenclature is provided in Table 5.2.

Table 5.2. Simulant Nomenclature

\begin{tabular}{lll}
\hline \multicolumn{1}{c}{ Simulant Description } & Alias & \multicolumn{1}{c}{ Comments } \\
\hline Small treated Hanford waste PSD & $\mathrm{STR}$ & Primary simulant. No AFA unless otherwise stated. \\
$\begin{array}{l}\text { Small as-received Hanford waste PSD } \\
\text { Typical as-received Hanford waste }\end{array}$ & $\mathrm{SAR}$ & No AFA unless otherwise stated. \\
$\begin{array}{l}\text { PSD } \\
\text { Aqueous salt solution }\end{array}$ & No AFA unless otherwise stated. \\
& $\mathrm{NaNO}_{3}$ & $\sim 1.5 \mathrm{cP} \mathrm{NaNO}$ and $\sim 2.5 \mathrm{Na}_{2} \mathrm{~S}_{2} \mathrm{O}_{3}$ cP solutions were tested \\
& $\mathrm{Na}_{2} \mathrm{~S}_{2} \mathrm{O}_{3}$ & \\
Washed and leached chemical slurry & $\mathrm{FER}$ & Contains AFA unless otherwise stated. \\
simulant (non-Newtonian) & & \\
\hline AFA $=$ Antifoam agent. & & \\
FER $=$ Iron-rich. & & \\
PSD $=$ Particle size distribution. & & \\
SAR $=$ Small as-received. & & \\
STR $=$ Small treated. & & \\
TAR $=$ Typical as-received. &
\end{tabular}

Tests were named using the Test identification (ID) formula

\section{SS-A-WWN-XXX-OYY-RZ-SG-EX\#}

where

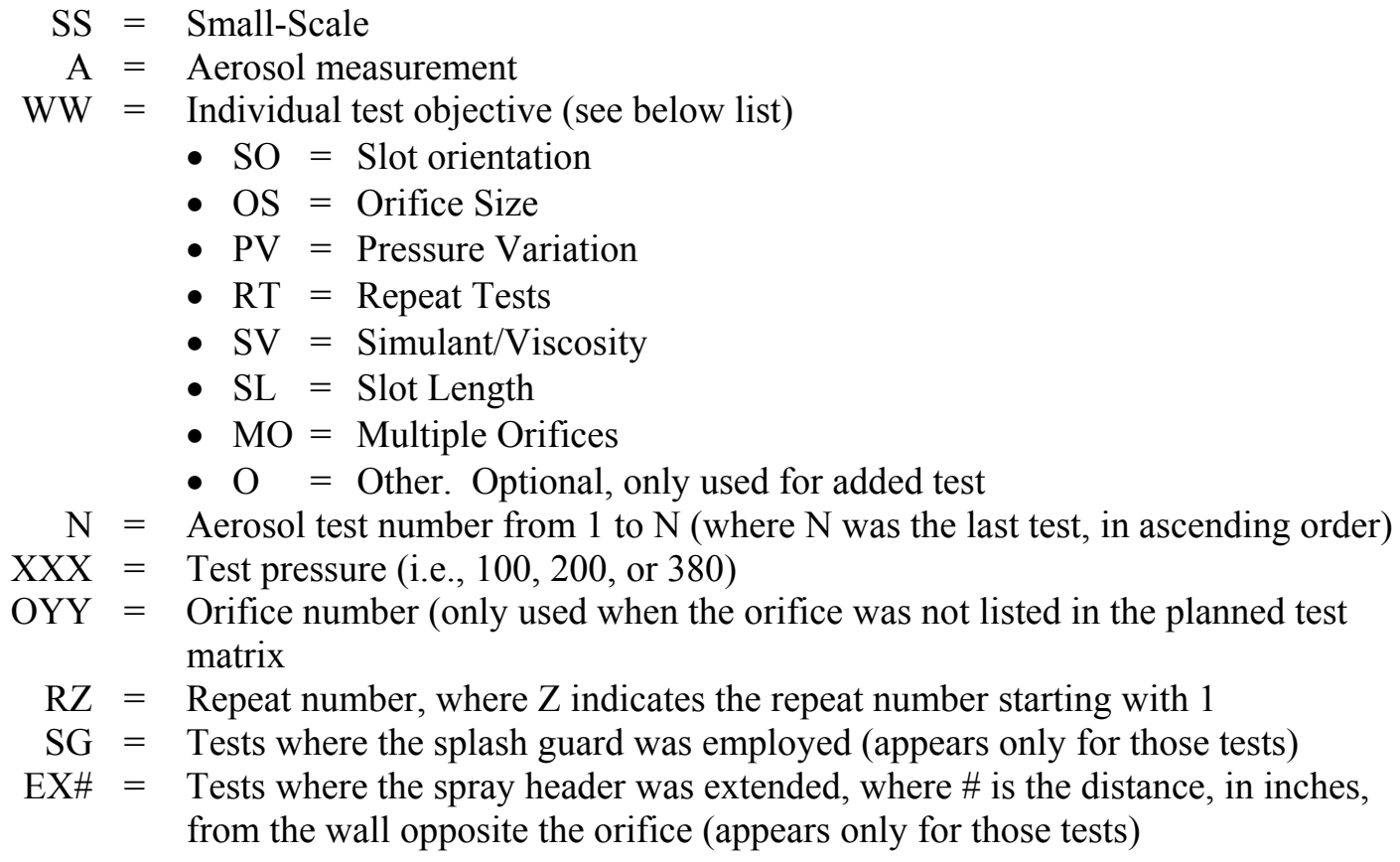

Unless otherwise noted, slot orifices were oriented axially (along the direction of flow). 


\subsection{Aerosol Test Procedure}

The aerosol test procedure was developed to support aerosol observations and to ensure that those observations were made under well-characterized conditions while maintaining staff safety and equipment operability. Each test was conducted in accordance with an approved TI. The general test approach is described below:

- Daily startup checks

- Spray release tests

- Daily closeout checks.

The check/test procedures are summarized in the following sections.

\subsubsection{Daily Startup Checks}

The primary startup condition that was checked on a daily basis was the mass of the simulant in the feed tank. The feed tank platform scale was checked at the start of each day (with the exception of water testing) to determine evaporative losses. If the weight had decreased since the previous weighing, water was assumed to have evaporated, and City of Richland water was added to make up the difference (except when using the FER simulant, in which case distilled water was added).

\subsubsection{Spray Release Tests}

\subsubsection{Pre-Test System Preparation}

Each TI defined the required test conditions and simulant to be used. If a feed tank was to be filled with different simulant than was used in the previous test, the first step was to confirm that the feed tank and flow system had been cleaned. Each new simulant, other than water, was prepared in a separate tank (known as the transfer tank), and then brought into Laboratory 107. Prior to transferring simulant into the feed tank, the agitator in the transfer tank was turned on to the maximum speed that did not entrain air or create a vortex. After at least $30 \mathrm{~s}$ of agitation and recirculation, a portable diaphragm pump was used to transfer the batch of simulant to the system feed tank. In some cases the simulant, as received in the transfer tank, did not contain the full amount of liquid because several gallons had been reserved as rinse liquid. In these cases, the reserved liquid was used to rinse settled solids from the transfer tank as simulant was transferred to the feed tank. As the transfer proceeded, the agitator speed in the transfer tank was decreased, and the agitator speed in the feed tank was increased, always taking care to avoid air entrainment and vortices. When the feed tank was filled, the weight of the simulant was measured. The hood vacuum supply was used to prime the test system pump and lines by drawing simulant from the feed tank into the pump inlet. The simulant then was circulated through the system lines until visual observation confirmed that air was purged from the system (i.e., no bubbles were present in the simulant).

Next, the data logger was set up for testing, the test header (with the required OTP in place) was securely installed, and a pre-test checklist of system configuration checks was completed. With the exception of water, the checklist required agitating and recirculating the simulant for at least 5 min, while the simulant density (measured by the Coriolis meter in the flow loop) was recorded every $30 \mathrm{~s}$. The 
density check time was reduced when using FER simulant to minimize excessive heating of the simulant. The simulant temperature in the test header was recorded at the beginning and end of the 5-min period and adjusted to be within the testing operational tolerance of $65^{\circ} \mathrm{F}$ to $85^{\circ} \mathrm{F}\left(95^{\circ} \mathrm{F}\right.$ maximum for chemical simulant), if necessary. If the measured densities were within a specified tolerance of the target density, chosen to indicate that the solids concentration was within 10 percent of the target value, the test proceeded and five pretest samples were taken from the top of the feed tank. While both pre-test and post-test samples were taken in all tests, not all were selected for analysis. Appendix A gives a complete listing of the tests and analyses performed.

\subsubsection{Aerosol Test}

If more than $2 \mathrm{hr}$ had elapsed between tests, a 2-min pre-spray to wet the aerosol test enclosure was performed, followed by a 2- to 3-min evacuation of the enclosure to remove residual aerosol. The pre-spray was intended to give a consistent wall wetness to obtain consistent splash behavior. In addition, the spray and the evaporation from the wetted walls tended to humidify the enclosure and minimize evaporation of droplets.

The target test flow and pressure were set during the pre-spray or, if no pre-spray was required, right before beginning the aerosol spray. Following the pre-spray, the system was recirculated while the mixing blower was turned on, the tank mass recorded, and an aerosol instrument background check performed. After a 1-min period, during which background aerosol data were collected and the target pressure and flow settings were set (if necessary), the test engineer verified spray test readiness with the aerosol engineer and data taker, and then initiated the spray test, which, in all but one test, was 2 min in duration. The spray test was completed when the aerosol engineer indicated that sufficient aerosol data had been collected (usually, 2 min sufficed), and the test engineer announced the end of the test. Post-test samples were collected after the end of the spray test. After samples were collected, many of the spray tests were replicated to collect repeat data.

\subsubsection{Aerosol Instrument Operation}

The aerosol engineer collected data using the Insitec-S and PPC instruments. Before each test, the aerosol engineer performed a background measurement for the Insitec-S instrument while the lights inside the fume hood were turned off and a valid background measurement (indicated by RTSizer software) was obtained. No background measurement was required for the PPC. The aerosol engineer verified that the purge flow, suction flow, instrument configuration, and software settings were set correctly. During the spray test, the aerosol engineer continuously monitored the aerosol data, especially the cumulative volume concentration $\left(\mathrm{C}_{\mathrm{v}}\right)$ and the transmission, to evaluate whether reasonable data were being collected. After the test, the aerosol engineer exported the data and performed a quick evaluation of the data by plotting size-dependent $\mathrm{C}_{\mathrm{v}}$ to ensure the initial concentration increased smoothly and was followed by a stable steady-state period. In some cases, the concentration data would exhibit erratic increases or condensation on the lenses would result in faulty data. In these cases, the aerosol engineer would determine if repeat testing was needed. Performance checks for Insitec-S and PPC were carried out bimonthly using a calibrated reticle. 


\subsubsection{Valve Configurations}

The system was operated using three different valve sequences. The first valve sequence, used in early tests in which the orifice diameter was small, consisted of pre-setting the pressure to a value higher than the test target to achieve the desired test condition once the flow was directed through the test header. The pump purge valve remained closed. A test was initiated by opening the test header valve and immediately closing the header bypass valve. Figure 5.1 shows a schematic of the system and identifies the relevant valves and lines.

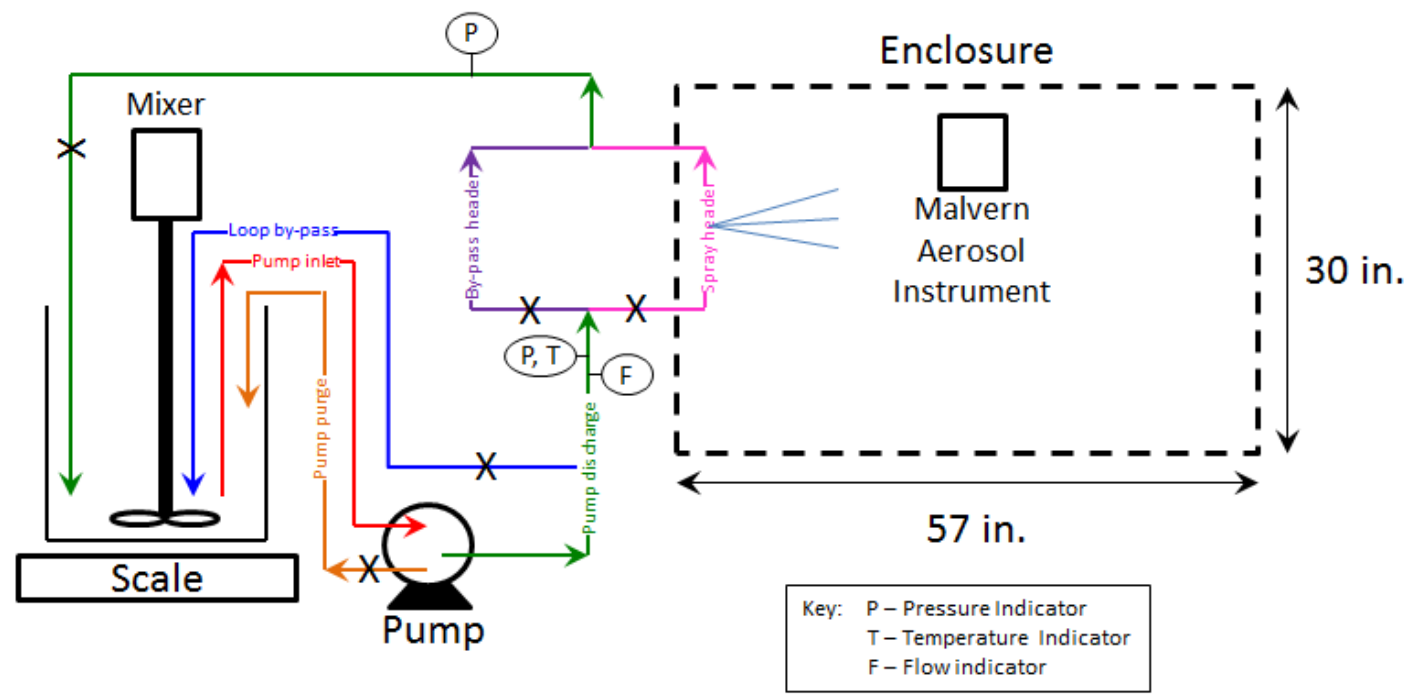

Figure 5.1. Schematic of Small-Scale Test Loop

The second valve sequence was necessary when using large orifices where the pressure could not be preset because it would exceed the system pressure limit of 500 psi. Instead, the pressure and flow rate were set to target values during the pre-spray, while the test header was spraying. Next, the pump purge valve was quickly opened, the header bypass valve was opened, and the spray header valve was closed. This sequence had the advantage of minimizing simulant heating, and was subsequently adopted for operational consistency. The effect of valve sequences on transitional pressures as the system moved toward the target pressure is illustrated in Figure 5.2. 

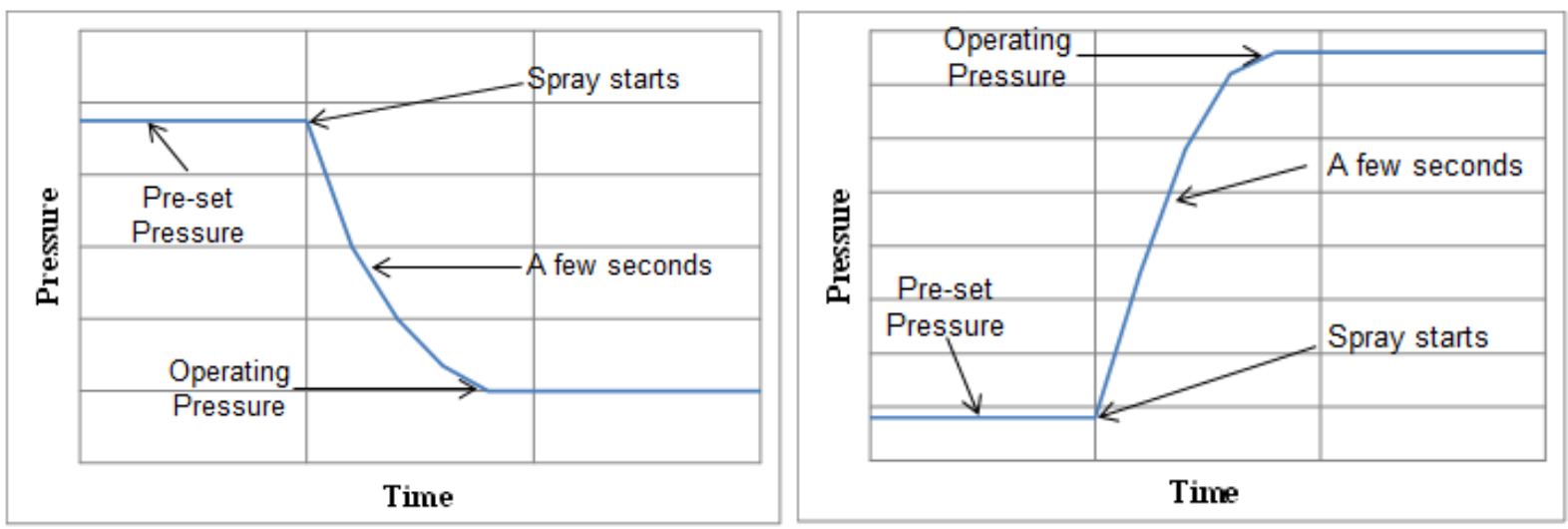

Figure 5.2. Illustration of the Pressure Change for the First (left) Compared to the Second (right) Valve Sequence

The few seconds that were required for valves to be aligned and the pressures to reach the target values were a concern because the aerosol net generation rate was determined from the initial concentration rise, during which the spray was being generated by a different pressure than the target pressure. The second valve sequence was of particular concern as the pre-set pressure was approximately $40 \mathrm{psi}$ and increased to a maximum target of $380 \mathrm{psi}$, which often took several seconds. Therefore, during follow-on testing, a third valve sequence was introduced in which the target pressure was preset to generally within 5 to 10 psi to the actual operating pressure of the system. This approach allowed for comparison of the pressure effects and is discussed in Chapter 6.

\subsubsection{Post-Test Activities}

Subsequent to completion of all replicate tests, a short spray was initiated (so images could be taken for documentation purposes), post-test samples were collected, the aerosol test enclosure was evacuated, and the data logger data were saved. The mixing blower and pump also were turned off. The test piece was either cleaned in place (when additional testing required the same test piece) or removed and cleaned as necessary. Pertinent test information was recorded in the LRB. Simulant collected in the aerosol test enclosure was reused (i.e., pumped back into the feed tank) or removed for disposal.

If a different type of simulant was planned for the next test, a cleaning and flushing process was followed. While the tank was being drained, the simulant was mixed with the agitator until the simulant level reached the agitator blades, at which point the agitator was turned off. A diaphragm pump was attached, and City of Richland water was used to rinse and flush the system.

\subsubsection{Daily Closeout Checks}

At the completion of testing each day, closeout checks were completed to ensure the system was left in the correct configuration, and the appropriate data, including final tank feed mass, were taken. 


\subsection{Examination of Test Orifices}

Prior to use with a non-water simulant, each OTP was cleaned and examined. The general process was as follows:

1. Confirming pre-test that the orifice to be tested was clean and clear

2. Confirming post-test that the test-piece orifice was clean and unplugged (verified by sticking a gauge pin through the orifice, running water through the orifice, and then visually inspecting the orifice with a microscope)

3. Placing a sticker in the LRB indicating that the OTP had been cleaned and inspected. 



\subsection{Test and Analysis Methods}

The spray release tests were conducted to estimate the net amount of aerosol generated as a function of orifice geometry, system pressure, and fluid. Ultimately, the quantities of interest are the cumulative release fraction and net generation rate of the aerosol, which can be compared directly to the predictions of the WTP model that currently is in use. The release fraction is the volumetric net generation rate of aerosol $(G)$ divided by the volumetric flow rate $\left(Q_{\text {spray }}\right)$ of the spray leak. The net generation rate of aerosol was determined by measuring the volume and size distribution of the aerosol (using a Malvern instrument) and performing a non-linear least squares fit to the data. The spray leak flow rate was calculated based on process instrument data recorded in the test instruction during testing.

In this chapter, the techniques used to calculate both of these quantities, as well as other auxiliary quantities such as the orifice coefficient, are described. First, the analysis of process instrument data is discussed, including the approach used to estimate the spray leak flow rate. Next, the analysis of Malvern Insitec-S data is discussed, with a focus on how the net generation rate was calculated for the small-scale experiments. Next, the treatment of concentration data from the PPC (the secondary aerosol instrument) is briefly presented. Finally, elements of the test procedure and data analysis that had the potential to make the results less meaningful are discussed.

The analysis methods used here are similar (and identical in most respects) to the methods used for the large-scale aerosol data (Chapters 3, 7, and 8 of Schonewill et al. 2012); however, there are enough differences that the methods are described in full.

\subsection{Analysis of Process Instrument Data}

Data from the process instruments installed on the flow loop and within the chamber were captured by a data logger that recorded measurements at a sampling rate of $1 \mathrm{~Hz}$ (see Section 4.2 for more detail). The following instruments were used to meet the data objectives listed below:

1. Recording the pressure upstream of the orifice for use in WTP model aerosol predictions and estimation of the orifice coefficient

2. Recording the temperature in the test section to support estimates of water viscosity and density used in WTP model aerosol predictions

3. Recording the feed-tank, load-cell (scale) measurements of feed tank weight to calculate the mass of fluid lost from the system during a spray. This information was used to estimate the volumetric flow rate of the spray.

4. Recording the start and end times of the spray for use in a variety of calculations.

To achieve objective 1, the upstream header pressures recorded by the data logger during a test were averaged during the time period of interest. The time period chosen depended on the application of the average pressure. To calculate the WTP model droplet size distribution, the pressure was averaged over the same time period used for fitting the model used to determine measured aerosol net generation rates. For calculations of the measured orifice coefficient and the WTP model total leak flow rate, the pressure was averaged over the entire time of the spray (i.e., the length of time over which the total flow through the orifice [the leak flow] was measured). For these purposes, the spray-period average pressure was used 
to be consistent with the basis of the measured total leak flow rate, which was found from spray-start and spray-end feed tank weight measurements.

In all cases, averaging was carried out by squaring the average of the square root of the time series of pressures. This functionality was chosen because the flow rate through the orifice depends on the square root of pressure (see Equation (6.2) below). The dependence of the spray size distribution on pressure is more complex - see Equations (1.1) through (1.6). The square root dependence is approximate in this case. As discussed in Section 6.5.6, the initial pressure variation during a small-scale test can have a significant effect on the average pressure during the time period selected for curve fitting.

Objective 2 was met using two temperatures manually recorded as identified in the TI before and after the spray. These measurements were averaged and used to interpolate water viscosity and density from a lookup table of standard properties. Viscosity and density of simulants other than water were taken from laboratory measurements and were not adjusted to match the test temperature because there are no data for viscosity temperature dependence. The density-temperature dependence for non-water simulants was considered negligible, based on the changes seen in the water density. This approach differs from that used in large-scale testing, where the temperature variation of water was used for other simulants.

Objective 3 was met by calculating the leak flow rate using the mass of fluid present in the tanks before and after an experiment. This approach was simpler for the small-scale tests than for the large-scale tests because the large-scale tests had to account for two simulant feed tanks and also pump leakage. In the small-scale tests, there was only one feed tank and no leakage. The initial and final masses were manually recorded in triplicate before and after the spray. The spray start and stop times (based on the data logger clock) were used to specify a spray time $\Delta t_{\text {spray }}$, and the volumetric flow rate was estimated using the following relationship

$$
Q_{\text {spray }}=\left(\frac{\Delta M}{\rho(\langle T\rangle)}\right) / \Delta t_{\text {spray }}
$$

where $\Delta M$ is the difference between start and end weight, $\rho$ is the density of the fluid used, and $\langle T\rangle$ is the average temperature.

To meet objective 4, the start and stop times of the spray were recorded in the TI during each test. Two separate unsynchronized clocks were used, one for the data logger and one for the Malvern instrument. A set of start and stop times was recorded for each clock.

Using the following expression, which was derived by rearranging Equations (1.8) and (1.9) to solve for the orifice coefficient instead of assuming a value of 0.62 , the spray leak flow rate was used to estimate the orifice coefficient, $C_{D}$, for each test

$$
C_{D}=\frac{Q_{\text {spray }} / A}{\sqrt{2\langle P\rangle / \rho(\langle T\rangle)}}
$$

where $A$ is the cross-sectional area of the orifice, $\langle P\rangle$ is the average pressure during the spray, and $Q_{\text {spray }}$ is the flow rate given by Equation (6.1). 


\subsection{Analysis of Malvern Insitec-S Data}

The data from the single Malvern Insitec-S instrument installed in the small-scale chamber was collected by a single computer at $1 \mathrm{~Hz}$ via commercial software (see Section 4.3.1 for more detail). The data of interest were the volume concentration of aerosol, $C_{v}$, measured in ppmv, and the percent volume of aerosol as a function of predefined droplet size bins $(\phi)$, which is a differential or discrete measurement. Arrays of date/time stamps and the Malvern laser transmission also were required to perform the calculations. These calculations were very similar to those performed in the large-scale tests (Section 7.2 of Schonewill et al. 2012), but were considerably simplified because there was no need to average the readings from three Malvern instruments.

In the first step of analysis, the laser transmission reading is examined to determine if any adjustments are required to get a more accurate measurement of $C_{v}$. As described in Section 4.3.1, the Malvern Insitec-S measures aerosol based on refraction of laser light. Transmission is a measure of the received laser power, which is reduced by the presence of aerosol in its path between the source and the detector. Transmission is written as

$$
\tau=\frac{S(t)}{S_{0}}
$$

where $S(t)$ is the undeflected laser power measured at time $t$ and $S_{o}$ is the background undeflected laser power. The background is a fixed value that the operator sets by selecting the $S(t)$ reading at some time before $t=0$, when the spray starts. Ideally, the transmission should be 100 percent before the spray enters the chamber.

To check the need for correction, the laser power measured immediately before the start of the spray is compared to the fixed background laser power. If laser power drift has caused the initial undeflected laser power to change since the time when the background laser power was fixed, an adjustment is needed. In cases where the undeflected laser power drifts to less than the background value, the uncorrected transmission would be too small and the value of $C_{v}$ would be too large. There also are cases in which the initial undeflected laser power data are greater than the background values. This would overestimate transmission and underestimate $C_{v}$. If the drift discrepancy is great enough, an apparent transmission greater than 100 percent would be calculated using Equation (6.3). The Malvern software would take that as an error and report a PSD but not a concentration $C_{v}$. When this happens, the true concentration cannot be recovered by drift adjustment.

A more detailed discussion of the derivation of the adjustment factor is given in the large-scale report (Equations (7.7) through (7.11) of Schonewill et al. 2012). In summary, the correction for $C_{v}$ can be written as

$$
\frac{C_{v, a d j}}{C_{v, 0}}=\frac{\ln (\tau(t))}{\ln \left(\tau_{0}\right)} \approx \frac{(1-\tau(t))}{\left(1-\tau_{0}\right)} \approx \frac{1-S(t) / S(0)}{1-S(t) / S_{0}}
$$

where $C_{v, a d j}$ is the adjusted $C_{v}, C_{v, o}$ is the original measured $C_{v}$, and $S(0)$ is the initial undeflected laser power at the start of aerosol generation $(t=0)$. The corrected background $S(0)$ was chosen to be the average over the $5 \mathrm{~s}$ before the spray began. Note that, if the transmission is 90 percent or greater, the final term on the right of Equation (6.4) can be used; this is the approximate linearized form of the equation derived with a Taylor series expansion. It was used for all the tests in which the Malvern probe 
was located outside the jet. The non-linearized logarithmic form of the equation was used for calculations of in-jet concentrations.

The second step in the analysis of Malvern data is to transform the raw data into a form that can be fitted to obtain the volumetric net generation rate. The aerosol data must be put on a volume basis

$$
\Phi_{i}=C_{v} \phi_{i}
$$

where $\phi_{i}$ is the fraction of volume between size bin $k$ and $k-1$ as reported by the Malvern, $\Phi_{i}$ is the differential ppmv in the bin, and $i$ is the size bin of interest ranging from 1 to $N$. The Malvern Insitec-S instrument has 60 size bins scaled logarithmically from 0.1 to $2000 \mu \mathrm{m}$, although in small-scale use, the effective range of the Malvern instrument was 0.5 to $200 \mu \mathrm{m}$. Equation (6.5) can be cumulated to give the cumulative ppmv below a certain droplet size

$$
\Phi_{c, k}=\sum_{i=1}^{k} \Phi_{i}
$$

where the subscript $c, k$ indicates the cumulative ppmv below the droplet diameter associated with size bin $k$. The cumulative ppmv also can be normalized to calculate a PSD (volume fraction) of the aerosol. Mathematically this is expressed as

$$
\phi_{c, k}=\frac{\Phi_{c, k}}{C_{v}}
$$

Both the differential (Equation (6.5)) and cumulative concentrations (Equation (6.6)) were used in the analysis of far-field (i.e., not in-jet) aerosol concentration data described in this chapter. The in-jet data were analyzed in terms of its cumulative PSD (Equation (6.7)), because the assumption of uniform concentration in the chamber could not be applied to in-jet data, making it inappropriate to use concentration data to calculate aerosol net generation. However, these in-jet PSDs were of interest because they are a close approximation to the size distribution that would be present if the only aerosol generation mechanism present was jet breakup, not splash impact, and if there were no losses.

In the data collected during the tests covered in this report, the volume contribution of the smaller drops was very small and the droplets that were $<0.5 \mu \mathrm{m}$ in size were below the effective range of the instrument. This resulted in sparse and noisy data at small droplet sizes. To compensate for this, the differential concentrations were cumulated up to $1.01 \mu \mathrm{m}$. At this droplet size, the differential and cumulative concentrations (as used in modeling) were identical.

The average cumulative or differential concentrations were obtained as functions of time. During the time the spray was active, data were observed to increase rapidly to a steady-state concentration. The term "steady-state" should not be interpreted to mean the concentration was consistently at a precise single value, but rather that the data fluctuated around some mean concentration. In some tests, the fluctuations were sizable and in others they were not. The fluctuations usually became more significant as the orifice size increased (and consequently, the volumetric flow of the spray). Given the chaotic nature of turbulent jet flow and the data acquisition rate of the Malvern instrument, noise in the data was expected. 
For plotting purposes, a canonical set of diameter bins was chosen to represent the entire data set, namely $5.25,10.17,19.67,32.28,52.97$, and $102.5 \mu \mathrm{m}$. These diameters were chosen because they covered the region of the most interest in safety analysis (i.e., 10- to $80-\mu \mathrm{m}$ droplets). Calculations, however, were performed on the range of valid data between 1.01 and $198.4 \mu \mathrm{m}$. As discussed earlier, only a tiny fraction of small drops (on a volume basis) were measured. Therefore, analysis of cumulative concentrations for droplets less than $1.01 \mu \mathrm{m}$ was not attempted. At the large end of the range, the Malvern Insitec-S instruments in small-scale tests were not configured to accurately measure droplets larger than approximately $200 \mu \mathrm{m}$; this represented the upper bound of the small-scale analysis. (The instrument is able to interpret a maximum range of 0.1 to $450 \mu \mathrm{m}$ with the $100-\mathrm{mm}$ lens used in the small-scale test, but the volume fraction of droplets outside the nominal measuring range may not be accurately determined.)

\subsection{Analysis of Aerosol Generation}

The first step in analysis was to determine the volumetric net generation rate of aerosol, which was done by fitting a model to the Malvern concentration/time data. The functionality of the model was selected after examination of the data and the theoretical background. The measured concentrations of most sizes of droplets tended to follow a curve strongly resembling an exponential approach to a steady-state value, suggesting an eventual balance between constant generation rate and losses with a roughly first-order dependence on aerosol concentration. In some ranges of droplet sizes, generally less than $15 \mu \mathrm{m}$, the increase was approximately linear, implying negligible losses. As discussed in Section 3 of the large-scale aerosol testing report (Schonewill et al. 2012), the observed quasi-exponential form of the concentration transients can be confirmed from theoretical arguments, which are briefly summarized below.

To determine the form of the rate equation that is fitted to the concentration transient data, the test enclosure (exclusive of the immediate vicinity of the jet) is treated as a continuously stirred tank reactor (CSTR). In the CSTR approximation, the control volume in which aerosol measurement is made is assumed to be homogeneous. Homogeneity results from instantaneous and complete mixing of the contents of the control volume. For the small-scale test enclosure, control volume homogeneity is expected to result from turbulent air mixing provided by the high-velocity jet and by the mixing fan.

The form and functionality of loss equations (and even the loss mechanisms considered) depend on the control volume assumed. If the entire box volume is considered, there is no convective transport of aerosol out of the control volume and only loss to the walls must be considered. As discussed in Section 6.5.2, measurements made in three different locations (positions 1, 2, and 6) gave very similar results, indicating that it is acceptable to assume uniform concentration and behavior throughout the small-scale enclosure. A control volume including the entire enclosure was used, therefore. The volume of the enclosure was $0.7025 \mathrm{~m}^{3}$ and was not changed during testing.

Aerosol was generated by primary and secondary jet breakup and by "splatter" droplets formed when the jet, or droplets formed by jet breakup, hit the splash wall at the downstream end of the enclosure. The in-flight and impact breakup events have not been distinguished in the current tests. To avoid the complexity of droplet-generation mechanics, the model only considers the far-field concentration of aerosol. When considered far from the spray, net aerosol generation may be treated as a constant influx 
of spray droplets of given size to the control volume; the size of these droplets did not further decrease through additional breakup processes.

This size distribution can change with time as aerosols are preferentially retained or removed from the system. If no mechanism for droplet loss exists, the aerosol concentration will increase linearly with time, and the size distribution will not change. For systems that include losses, the aerosol concentration will increase until some equilibrium aerosol concentration is reached. Loss in the region outside the spray is assumed to occur through several means:

- Aerosol is deposited by convective transport on the surfaces of the test enclosure. The loss rates are proportional to the surface area, the droplet convective velocity, some form of a capture coefficient, and the droplet concentration.

- Aerosol settles out of the control volume at a rate proportional to the floor area, the droplet settling velocity, and the droplet concentration.

- Aerosol is entrained into the jet at a rate proportional to the entrainment velocity and the droplet concentration, then captured at the splash wall to an extent dependent on the local jet characteristics and on droplet size and properties.

- Aerosols coalesce or aggregate into larger aerosol structures. Coalescence is generally a two-particle interaction, so the rate of formation of larger droplets by coalescence is proportional to the product of the concentrations of two smaller droplet sizes. Coalescence yields a net decrease in the number of aerosol particles and a transfer of aerosol volume to larger size classifications. This means that the total loss/generation of aerosol volume resulting from coalescence is always zero. In typical small-scale tests, the far-field total aerosol concentrations are less than $5 \mathrm{ppmv}$, and aerosol concentrations for specific size classifications are typically less than $0.5 \mathrm{ppmv}$ per classification. At these concentrations, the frequency of second-order reactions is expected to be low relative to first-order reactions. This, combined with the fact that the overall impact of coalescence on the total volume concentration is zero, means that particle loss to aerosol coalescence can likely be neglected in far-field considerations of aerosol dynamics.

- Evaporative loss was also a possible mechanism but was not considered significant because each test began with a wetted enclosure and the relative humidity was expected to be high. Evaporation produces a loss of total concentration, but the effect on concentration in a given size range at a given time is more complex: the concentration in a bin would increase because of evaporation from the next-larger size range but would also decrease because of evaporation that takes droplets down into the next-smaller size range.

The overall aerosol balance is derived by considering the sum of generation and loss terms. Because the evaporative mechanism and the second-order mechanism of coalescence are not considered, and quantifying the amount lost via each first-order mechanism is not necessary for the data analysis, the loss terms may be lumped into a single term for simplicity:

$$
\frac{d \Phi_{i}}{d t}=\frac{g_{a, i}}{V_{e}}-\lambda_{i} \Phi_{i}
$$

where $\lambda_{i}$ is the loss rate coefficient (units of $1 / \mathrm{s}$ ) including all the loss mechanisms that are first-order in aerosol concentration for droplets of size $i, V_{e}$ is the enclosure volume, and $g_{a, i}$ is the net aerosol generation rate (volume/sec) of droplets of size $i$. The net aerosol generation rate equals rate of 
production, by the jet, minus rate of capture of simulant at the splash wall. Simulant capture at the splash wall is included in the net generation rate $g_{a, i}$, not the loss rate coefficient $\lambda_{i}$, because capture depends primarily on jet and droplet properties and so has zero-order dependence on the aerosol concentration.

The solution to this differential equation is

$$
\Phi_{i}=\frac{g_{a, i}}{V_{e} \lambda_{i}}\left(1-e^{-\lambda_{i} t}\right)
$$

An initial aerosol concentration of zero has been assumed. From Equation (6.9), it can be seen that the equilibrium concentration is $\Phi_{i}^{e q}=g_{a, i} / V_{e} \lambda_{i}$.

Equation (6.9) can be used to analyze the dynamics of aerosol concentration at all times, including the initial period when the concentration is increasing as well as the approach to equilibrium. It is useful for sprays in which the aerosol concentration increases rapidly and the initial data have near-constant slope but are too few for good fitting. In such cases the leveling-off period, with non-constant slope, must be included to provide enough points for a good determination.

Equation (6.9) expresses the aerosol material balance in terms of the concentration in each differential size bin of the size distribution. The cumulative aerosol concentration up to size $k$ is given by Equation (6.6). Substituting Equation (6.9) into this yields

$$
\Phi_{c, k}=\Phi_{c . k}^{e q}\left(1-\frac{1}{\Phi_{c, k}^{e q}} \sum_{i=1}^{k} \Phi_{i}^{e q} e^{-\lambda_{i} t}\right)
$$

The range of rate constants in the exponentials in the sum typically can be approximated well by a single rate constant. If a single rate constant is assigned, Equation (6.10) is reduced to

$$
\Phi_{c, k}=\frac{G_{a, k}}{V_{e} \Lambda_{k}}\left(1-e^{-\Lambda_{k} t}\right)
$$

where Equation (6.11) has adopted the notation of Equation (6.9). Here $\Lambda_{k}$ is the cumulative loss rate constant (units 1/s) for droplets up to size $k$ and $G_{a, k}$ is the net aerosol generation rate (volume/s) of droplets up to size $k$.

The parameters $G_{a, k}$ and $\Lambda_{k}$ were found by fitting Equation (6.11) to cumulative concentrations $\Phi_{c, k}$. Similarly, the parameters $g_{a, i}$ and $\lambda_{i}$ were found by fitting Equation (6.9) to differential concentrations $\phi_{i}$. The differential-fit net generation rates were then cumulated to obtain the cumulative net generation rates $G_{a, k}$ based on differential fits.

$$
\dot{G}_{a, k}=\sum_{i=1}^{k} g_{a, i}
$$

This cumulation process puts the net generation rates obtained by differential fits on the same cumulative basis as the net generation rates from cumulative fits so that they could be compared. 
The data fitting was carried out using a non-linear least squares algorithm ${ }^{16}$ for the first $20 \mathrm{~s}$ of the spray, subject to some constraints. (For comparison, the fitting time period was typically $60 \mathrm{~s}$ in large-scale testing.) The choice was made to constrain the values of the adjustable parameters for net generation rate and loss rate constant $\left(G_{a, k}\right.$ and $\Lambda_{k}$, or $g_{a, i}$ and $\lambda_{i}$ ) so that only meaningful values would be produced. The upper-limit and lower-limit constraints on the fitted net generation rate were based on the final concentration at the end of $20 \mathrm{~s}$. If the fitted net generation rate meant the 20 -s concentration was reached in $0.5 \mathrm{~s}$, the fitting procedure was terminated for producing an unreasonably high initial slope. A fitted slope this high was meaningless because it meant a concentration increase that was too rapid to be captured with a 1-Hz Malvern data collection rate. If the fitted net generation rate meant that 1 percent of the 20 -s concentration was reached in $60 \mathrm{~s}$, the fitting procedure was terminated for producing an unreasonably low initial slope. The upper-limit and lower-limit constraints set on the loss rate constant were (arbitrarily) 100/sec and 1E-05/sec.

The bi-square weight method was used to make the fit more robust to outliers and/or spurious noise. In the bi-square weight method, the weight given each data point in the algorithm varies depending on proximity to the current best-fit curve. Data that is outside of what would be expected from random variation in the data is given a weight of zero.

The net generation rate calculated by the algorithm was assigned 95-percent confidence intervals, which included the uncertainty of predicting the curve based on the data and the random variation expected in a new observation. Goodness-of-fit was assessed in three ways: 1) comparison to lower-limit and upper-limit fitting constraints, 2) a convergence criterion, and 3) the adjusted coefficient of determination $\left(\overline{\mathrm{R}}^{2}\right)$. Data for which the fit returned an upper-limit or lower-limit constraint value were rejected, as were data that did not converge. Fits that did not appear to describe the data well were detected by using the adjusted coefficient of determination to screen the results, with fits of $\overline{\mathrm{R}}^{2}<0.5$ rejected. The choice of 0.5 is arbitrary and does not prove that fits with $\overline{\mathrm{R}}^{2}<0.5$ were significantly poorer compared to those greater than 0.5 . However, it does indicate that less than half the variability in the data is described by the model fit.

Estimates of net generation rate were obtained primarily from the cumulative fit method, which tended to produce good fits over a wider range of droplet sizes than did the differential fit. Based on the physical arguments made earlier, the net generation and loss terms in the model of Equation (6.9) should, in general, be a function of the droplet size. When the differential data is fit, the concentration is defined for narrow droplet size ranges. Thus, variations in net generation and loss behavior with size are isolated by treating the data separately in each size. However, the differential data has some statistical drawbacks: the data are smaller in absolute magnitude than the cumulative concentration data and much noisier, particularly for the smallest droplet sizes. The noisier data are more difficult to fit, and the results have a greater uncertainty. In addition, a bad fit for one differential concentration bin raises the question of how to cumulate it with other bins that have good fits. In this report, the bad differential fits are excluded from plots as individual points but are included in cumulation. This approach makes the cumulated differential-fit net generation rates $G_{a, k}$ doubtful in some cases.

The cumulative-fit data are more attractive numerically but treat the droplet net generation rates and losses in aggregate, which is physically less plausible. The larger the droplet size bin, the wider the range of sizes that are described by a single loss coefficient and net generation rate in the cumulative fit. See

\footnotetext{
${ }^{16}$ The algorithm was the fit function in MATLAB ${ }^{\circledR}$ version R2011b (The MathWorks, Inc.).
} 
Appendix B for a collection of plots that show how cumulative and differential fits compared for the small-scale runs included in this report. In most cases the two types of fits produce closely comparable results.

Once an estimate of the cumulative net generation rate was obtained using the model fit to the data, the cumulative release fraction could be calculated as

$$
R F_{c, k}=G_{a . k} / Q_{\text {spray }}
$$

An estimate of the uncertainty in the release fraction can be determined using the confidence intervals from the model fit to the data

$$
\begin{aligned}
& R F_{c, k}^{+}=G_{a, k}^{+} / Q_{\text {spray }}-R F_{c, k} \\
& R F_{c, k}^{-}=R F_{c, k}-G_{a, k}^{-} / Q_{\text {spray }}
\end{aligned}
$$

where $G_{a, k}^{+}$and $G_{a, k}^{-}$are the upper and lower ends of the 95-percent confidence intervals on the net generation rate, respectively. When shown, the uncertainty is usually displayed as error bars in plots of release fraction (as calculated by Equation (6.14)) or net generation rate (using $G_{a, k}^{+}$and $G_{a, k}^{-}$directly). Other potential sources of uncertainty - the uncertainty in the leak flow measurements used in calculating the RF, to name one- - are not included.

A screening process was applied to focus on the test results that were considered to be the highest quality for aerosol generation analysis. Some runs were excluded based on a review of the pressure, laser, and leak flow rate data. For any given test condition, runs that were preferred for analysis were the runs in which

- the effects of laser drift were negligible during the first $20 \mathrm{~s}$,

- flow loop pressure reached the target value quickly and remained constant at that value, and

- leak flow rates were high enough to indicate that partial plugging was not occurring.

For some test conditions, none of the tests that were conducted met the criteria listed above. These runs will be noted when their results are discussed. For other test conditions, more than one run met the criteria equally well. In these cases, the first run (chronologically) was used, an arbitrary criterion that was set to avoid selection bias.

The final step in aerosol release analysis was to compare the measurement-based release fraction to the release fraction predicted by the WTP model for the same experimental conditions. The WTP model is described in detail in Section 1.1 in Equations (1.1) through (1.9). The plots provided in Appendix B show the excellent agreement between release fractions derived from the differential and cumulative methods; this is typical of data from the majority of the tests.

\subsubsection{Uncertainty}

Error bars representing uncertainty estimates are shown in most of the plots in this report. In the tests used to define the experimental method, as discussed in Section 6.5, each curve usually represents the 
mean of three replicate runs. (The exception is Figure 6.4.) In these plots, the error bars represent two times the standard error of the mean, an approximation to the 95-percent confidence interval around the mean. The standard error of the mean is equal to $\sigma / \sqrt{N}$, where $\sigma$ is the sample standard deviation calculated with the STDEV function in Excel and $N$ is the number of samples.

In the plots of parametric effects in Section 7 and in Figure 6.4, the data that are plotted are from selected single runs. The error bars represent an approximate $95 \%$ confidence interval that combines the 95-percent confidence interval from the model fit to the run data (Equation 6.14) with an estimate of $95^{\text {th }}$ percentile experimental variability. This estimate, which is 40 percent of the value, is based on a median value for two times the relative standard deviation of the release fractions in the sets of replicate runs discussed in Section 6.7. The value of two times the relative standard deviation was chosen because it is nearly equal to the 95-percent confidence interval for the data set. The error estimates for the model fit and experimental variability are combined by taking the square root of the sum of the squares of the two estimates. This results in greater uncertainties for individual data points whose fits had wider uncertainty.

This approach to finding the overall data uncertainty is approximate statistically because the 95-percent confidence intervals on the fit are not exactly analogous to experimental standard deviations and because the standard deviations of the sets include a contribution from fit uncertainty, meaning that the fit uncertainty is over-counted by adding it on. The error bars, therefore, do not represent rigorous uncertainties, but should give a reasonable idea of the uncertainty of the data.

\subsection{Analysis of Process Particle Counter Data}

In two tests, the PPC was co-located with the Malvern Insitec-S instrument in position 2, and PPC data were collected using commercial software. Some analysis was performed using the PPC data, primarily to determine whether data from the Malvern instrument in position 2 and the PPC were in agreement, which gave added confidence in the accuracy of the measurements. The fits to the concentration transients were not carried out for PPC data because the 5-s accumulation time for the PPC made it hard to interpret concentration transients in the same way as for the Malvern instrument.

The PPC data needed to be transformed to a concentration distribution that was on the same basis as the Malvern instruments. The standard PSD output from the PPC is expressed in terms of $d N_{i} / d\left(\ln d_{p, i}\right)$, which gives the differential number concentration of particles $N$ in size bin $i$ (e.g., number of particles per cubic centimeters) normalized to the differential change in the log of the particle diameter over bin $i$. Define the following expression

$$
\alpha_{i}=\frac{d N_{i}}{d \ln d_{p, i}}
$$

so $\alpha_{i}$ is the data obtained by the PPC instrument.

A detailed derivation of the transformation in particle size distribution is given in the large-scale report (Equations (7.18) through (7.23) in Section 7.3 of Schonewill et al. 2012). The final expression for converting the PPC PSD output into a non-normalized volume fraction is 


$$
x_{i}=\frac{\pi}{6} \alpha_{i}\left(d_{u, i} d_{l, i}\right)^{3 / 2} \ln \left(\frac{d_{u, i}}{d_{l, i}}\right) .
$$

where $d_{u, i}$ and $d_{l, i}$ are the upper and lower size limits of bin $i$. The volume fraction given by Equation (6.16) is divided by the total at $i=N$ to give the differential volume fraction normalized to sum to unity, as is standard. Multiplying that result by $C_{v}$ gives the differential volume concentration, and summing the differential volume fraction to a size bin $k$ yields the cumulative volume concentration.

Even after converting the PPC data to the same basis as the Malvern instrument data, two issues make a direct comparison difficult. First, there is a difference in the measurable particle range between the two instruments. The PPC instrument is configured to measure only between a range of 0.5 and $67 \mu \mathrm{m}$, requiring that, to perform a comparison, PSDs from the Malvern instrument must be adjusted for particle size bins outside of this range. Second, the default refractive index used by the PPC to analyze the scattering data is fixed to that of an opaque particle $(\mathrm{RI}=1.5+0.5 \mathrm{i})$. The refractive index will not represent the material used for a large portion of the testing, with the majority of the tests conducted using water. Because this refractive index is a fixed parameter in the PPC instrument (i.e., it cannot be changed), the easiest way to generate a comparison is to post-analyze Malvern data with the same RI and compare the concentrations measured by the Malvern instrument and the PPC.

\subsection{Test Method Considerations}

Certain elements of the test procedure could potentially reduce the meaningfulness of aerosol net generation results. These test conditions were investigated and included the duration of the spray (Section 6.5.1), the location of the Malvern probes (Section 6.5.2), the location and speed of the mixing fan (Section 6.5.3), the purge rate for the Malvern instrument (Section 6.5.4), the extent to which the enclosure was evacuated before each spray (Section 6.5.5), and the type of pressure transient during the initial concentration rise of the test (Section 6.5.6). The performance of the test system was assessed with several tests, including a comparison of Malvern measurements with measurements made by a PPC instrument that used a different principle of measurement than the Malvern instrument. The repeatability of Malvern measurements was tested also.

\subsubsection{Spray Duration}

Based on early tests with small orifices (i.e., those that would be expected to take the longest time to rise to a given concentration), the spray duration was set to a minimum of $2 \mathrm{~min}$. The choice of spray duration will be discussed further in Section 6.6.1, in connection with the number of data points required to obtain a good data fit.

\subsubsection{Malvern Probe Location}

As discussed in Section 6.6, uniformity of concentration throughout the enclosure was assumed to convert the initial rise rate of concentration to a volumetric aerosol net generation rate. This assumption was tested by putting the Malvern probe (described in Section 4.3.1) in three different "far-field" locations, denoted as position 1, position 2, and position 6, as shown in Figure 4.7. None of these were located in the jet proper. 
Position 2 was above the orifice (the axis of the jet) and roughly halfway along its length, i.e., halfway between the orifice and the downstream "splash" wall. Position 1 was above the orifice, at about the same elevation as position 2. Position 6 was below the orifice and as far along the jet as position 2 . See Figure 4.1 for an illustration that shows the Malvern instrument in position 2.

Figure 6.1 shows the aerosol release fractions that were determined from Malvern measurements taken in the three locations, using a 380-psi water spray from a $0.5-\mathrm{mm}$ hole (target size). The run identifiers are given in the figure legend. In these tests the enclosure mixing fan was operated at a speed corresponding to a $6-\mathrm{V}$ setting. When the Malvern probe was located in positions 1 and 2, the fan was placed beneath the jet. When the probe was located in position 6 , the fan was placed above the jet to avoid blowing directly into the probe.

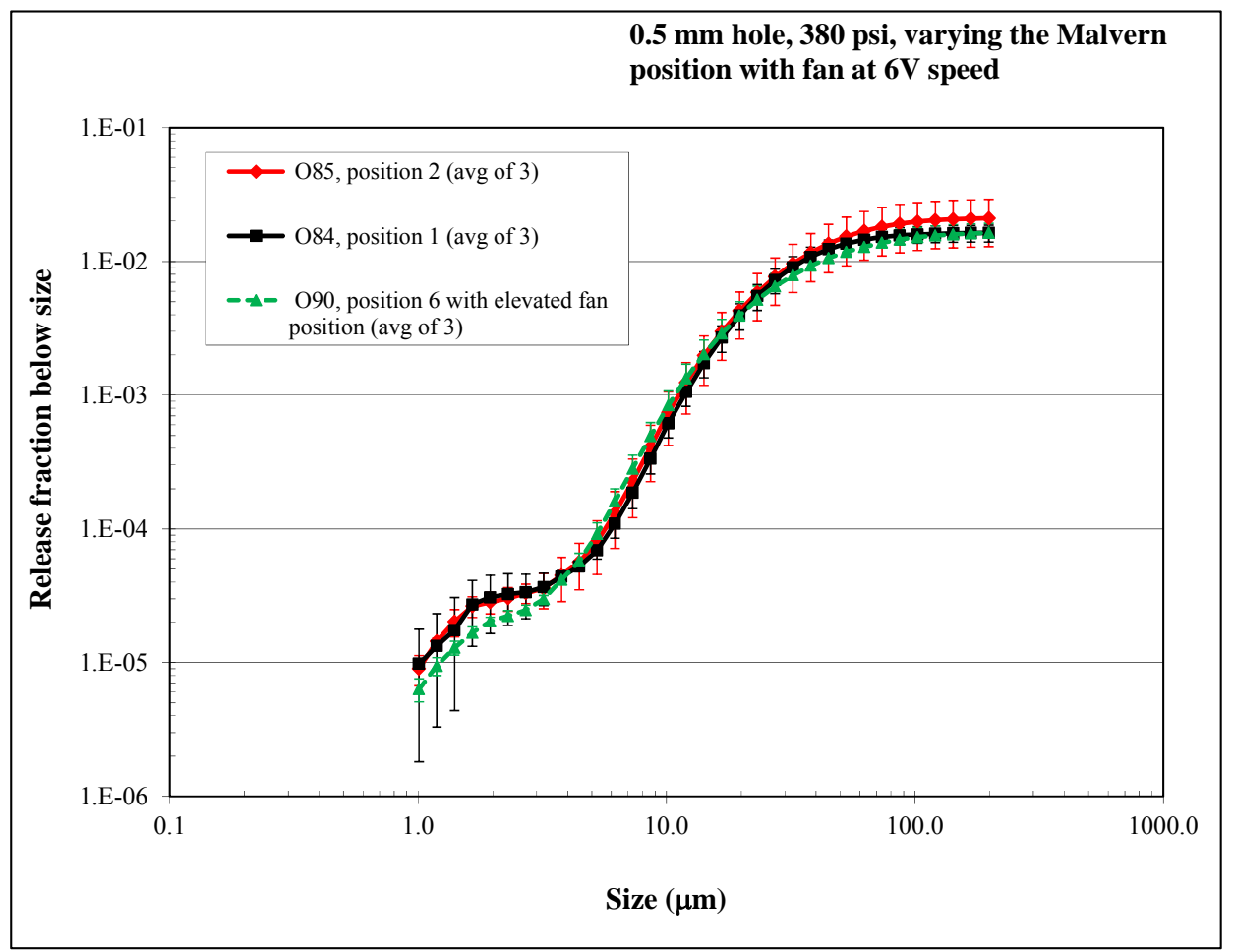

Figure 6.1. Effect of Malvern Probe Location for a 380-psig Water Spray from a 0.5-mm Hole, with the Mixing Fan On. The average of three tests (O85A-C; O84A-C, O90A-C) is plotted for each condition; error bars show two times the standard error of the mean.

The average release fraction over three tests is plotted for each test condition (Malvern instrument and fan location). The error bars show two times the standard error of the mean, roughly equivalent to a 95-percent confidence interval for the mean. ${ }^{17}$ The results show that the three probe locations gave indistinguishable release-fraction results between about $4-\mu \mathrm{m}$ and $20-\mu \mathrm{m}$ droplet size. It also can be seen that for droplet sizes where the probe location made a difference, position 2 gave the highest (conservative) value of release fraction.

\footnotetext{
${ }^{17}$ The standard error of the mean is equal to the standard deviation of the data set (in this case, three values) divided by the square root of the number of values (in this case, square root of 3 ).
} 
Figure 6.2 compares release fractions for probes at positions 2 and 6 , for tests where the fan was not operating. The two probe locations give distinguishable results because the two curves are outside each others' 95-percent confidence intervals. Position 2 gave the higher value of release fraction for all sizes.

Consistent with these results, the default position of the Malvern probe in other tests was position 2.

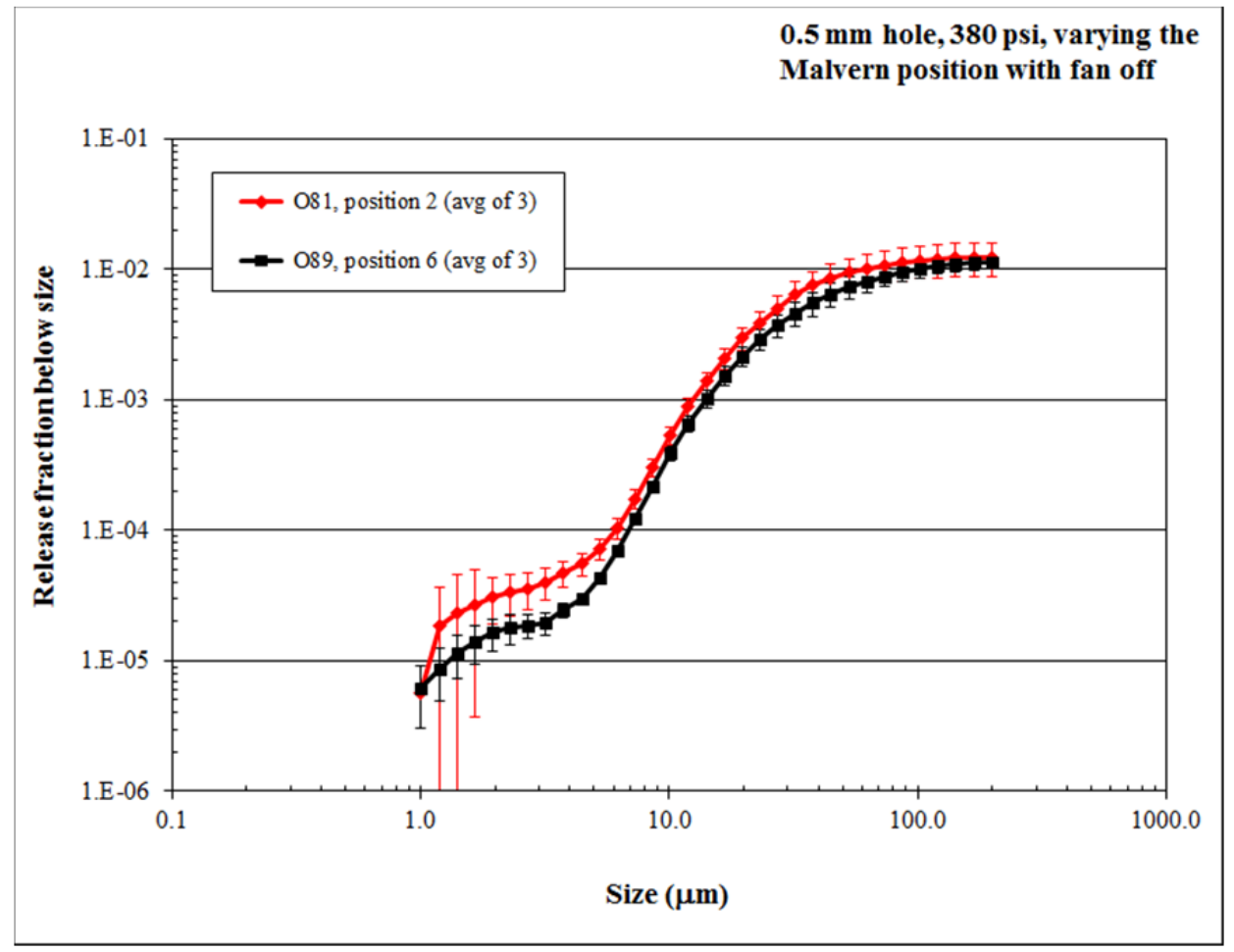

Figure 6.2. Effect of Malvern Probe Location for a 380-psig Water Spray from a 0.5-mm Hole, with the Mixing Fan Off. The average of three tests (O81A-C; O89A-C) is plotted for each condition; error bars show two times the standard error of the mean.

\subsubsection{Mixing Fan}

Because it was important for the concentration in the enclosure to be reasonably uniform, at least outside the small region occupied by the jet itself, a mixing fan was installed in the enclosure and tested at different fan speeds (identified by the voltage that was set at the fan control). ${ }^{18}$ Figure 6.3 shows the effect on release fraction of different fan speeds, using a 380-psig water spray from a $0.5-\mu \mathrm{m}$ hole (target size) and having the Malvern probe in position 2. The two lowest fan speeds (i.e., fan off and fan at $3 \mathrm{~V}$ ) gave distinguishably lower release fractions at sizes above about $20 \mu \mathrm{m}$. The two highest fan speeds gave very similar release fraction results, but the $11-\mathrm{V}$ fan speed produced a somewhat less smooth curve of release fraction versus size. The relative standard deviation of the three $11-\mathrm{V}$ runs ranged from 12 to 30 percent over the size range of 10 to $200 \mu \mathrm{m}$, while the relative standard deviation of the three 6-V runs ranged from 33 to 37 percent. Both of these sets of results were acceptable.

The default fan speed in other tests was selected to be $6 \mathrm{~V}$.

\footnotetext{
${ }^{18}$ The volumetric flow rate of the fan was not measured.
} 


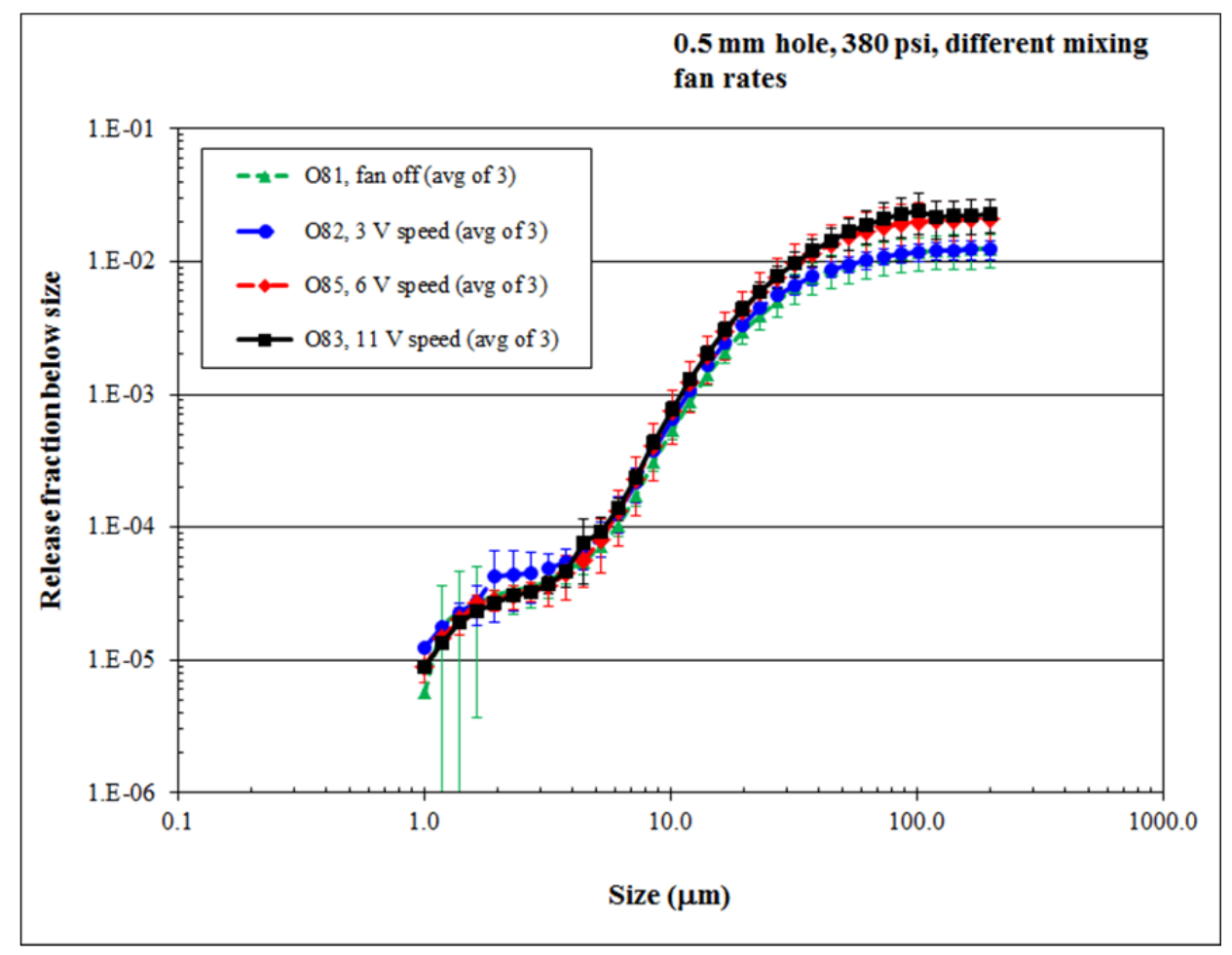

Figure 6.3. Effect of Mixing Fan Speed for a 380-psig Water Spray from a 0.5-mm Hole, with the Malvern Probe in Position 2. The average of three tests (O81A-C; O82A-C; O85A-C; O83A-C) is plotted for each condition; error bars show two times the standard error of the mean.

\subsubsection{Malvern Instrument Purge Rate}

The Malvern instrument uses an adjustable low-flow air purge to keep its windows clear of condensation and splatter. A range of instrument purge rates were tested to determine their effect on release-fraction results, which are shown in Figure 6.4. In this figure, each curve contains the release fractions from a single test, and the error bars are the 95-percent confidence interval of the fit that gave the aerosol net generation rate.

Above a droplet size of $\sim 3 \mu \mathrm{m}$, the release fractions are indistinguishable for purge rates of 1.2 SCFH/window and 2.4 SCFH/window. Below a droplet size of $\sim 5 \mu \mathrm{m}$, the $4 \mathrm{SCFH} /$ window case shows high release fractions compared to other cases. This curve is not plotted below $4 \mu \mathrm{m}$ because the fits to data were bad (low $\mathrm{R}^{2}$ values), indicating noisy data. Above a droplet size of $\sim 10 \mu \mathrm{m}$, the run with $0.6 \mathrm{SCFH} /$ window showed higher values of release fraction than for the $1.2 \mathrm{SCFH} /$ window case, but not so much higher as to be significantly outside the uncertainty range. In addition, the lower release fraction for smaller droplets at a purge of $0.6 \mathrm{SCFH} /$ window made it less desirable than the $1.2 \mathrm{SCFH} /$ window purge rate.

Because the goal was to select the instrument purge rate that was high enough to keep the windows clean but not so high as to adversely affect the aerosol results, the default Malvern purge rate in other tests was selected to be $1.2 \mathrm{SCFH} /$ window. 


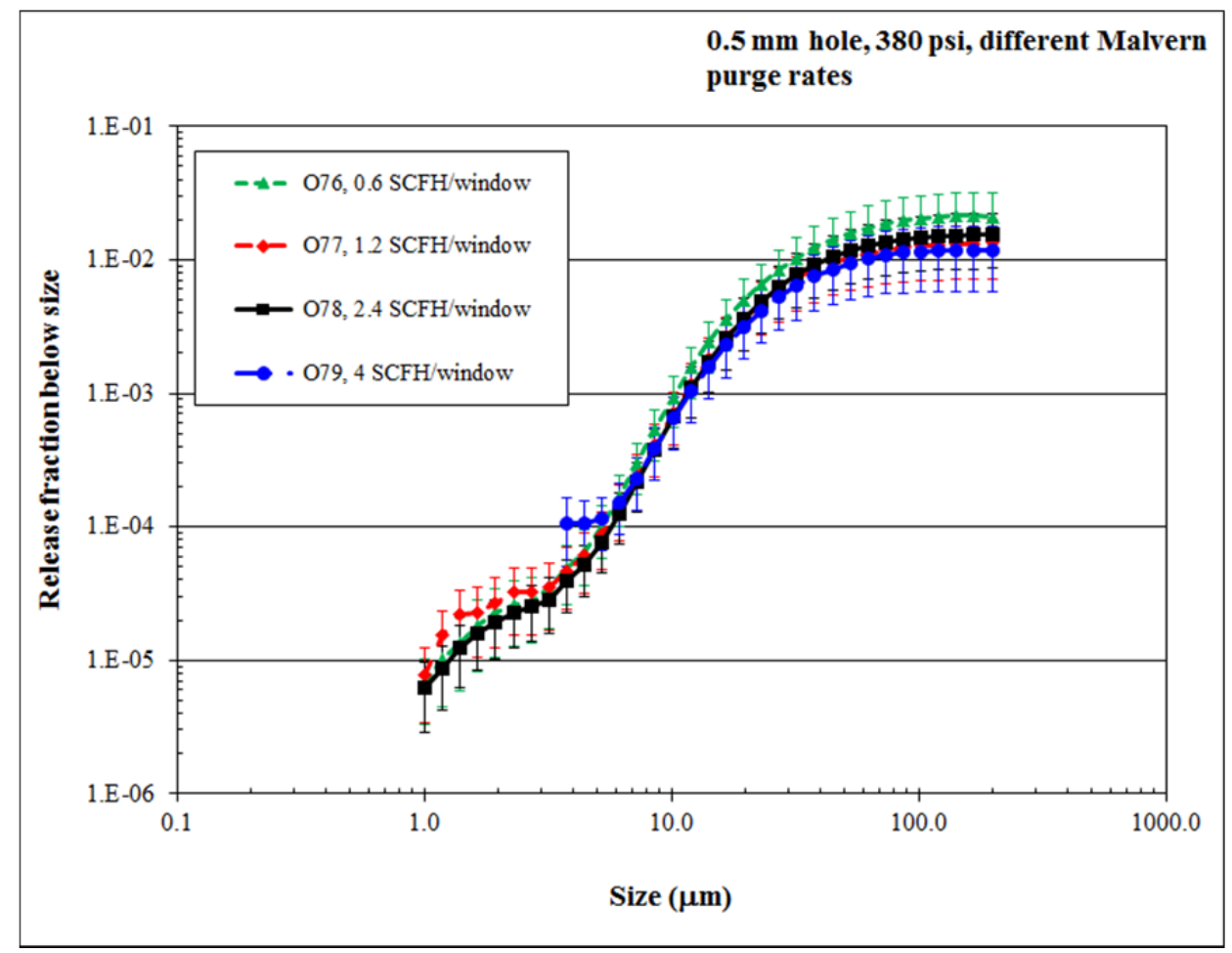

Figure 6.4. Effect of Malvern Purge Air Flow Rate for a 380-psig Water Spray from a 0.5-mm Hole, with the Malvern Probe in Position 2 and a Fan Speed of 6 V. A single test (O76A, O77A, O78A, O79B) is plotted for each condition; error bars show an approximate 95-percent confidence interval including model fit and experimental variability.

\subsubsection{Enclosure Evacuation}

The test procedure often included a pre-spray step, during which no aerosol measurements were made, as a way of pre-wetting the walls to obtain a consistently wetted initial test condition. There also were a number of tests in which multiple sprays were carried out and aerosol measurements were made on the sprays. To remove residual aerosol, the enclosure was evacuated before the first test spray of the day and after every spray. The effect of enclosure evacuation was not evaluated for this report. However, it was observed that the enclosure aerosol concentration was below Malvern detection limits prior to every test.

\subsubsection{Pressure Control}

As discussed in Section 5.2.2.3, for many of the tests, the valving sequences that were used caused the pressure in the test header to change significantly in the first few seconds of spray. In many cases, the pressure change was an increase from about 40 psig to the target pressure $(380,200$, or $100 \mathrm{psig})$; in a smaller number of cases, there was a decrease in pressure from about 450 psig to the 380 psig target. Because this pressure increase occurred during the concentration increase transient that was used to determine aerosol net generation rates (Section 6.6.1), a set of tests was carried out to determine the effect of pressure change during the concentration transient. 
Four types of pressure transient were tested using water sprays from a (target) $0.5 \mathrm{x} 5$-mm slot. The first was a constant-pressure "transient" in which the pressure never varied by more than 5 to $10 \mathrm{psig}$, or $<3$ percent of the target pressure of $380 \mathrm{psig}$. The second transient was a 3-s pressure decrease from 480 to $380 \mathrm{psig}$, which is similar to the left-hand plot in Figure 5.2. The third transient was a 4-s pressure increase from $100 \mathrm{psig}$ to $380 \mathrm{psig}$, which is similar to the right-hand plot in Figure 5.2. The fourth transient was a "downspike" pressure decrease in which the pressure decreased from 480 to 240 psig in $1 \mathrm{~s}$, then increased to 380 psig over $3 \mathrm{~s}$. These transients reflected the different patterns seen in the tests used to provide net generation rate estimates.

Figure 6.5 shows the release fractions for the four types of pressure transients. The average release fractions over three tests are plotted for each test condition (Malvern and fan location). The error bars show two times the standard error of the mean, which is roughly equivalent to a 95-percent confidence interval for the mean. Points for which there are no error bars indicate that only one of the three runs in the set had an acceptable fit, so no standard deviation could be calculated.

Although the initial pressure transient affects both the total concentration and the droplet size distribution produced by the jet, as will be shown in Section 7.7, the release fractions calculated from the in-chamber concentration transients are not sensitive to the pressure transient. Figure 6.5 shows that the four types of pressure transients gave release fractions that were indistinguishable (within test repeatability) between 5 and $200 \mu \mathrm{m}$. Therefore, these types of pressure transients were not considered to have a significant effect on estimates of net generation rate and release fraction.

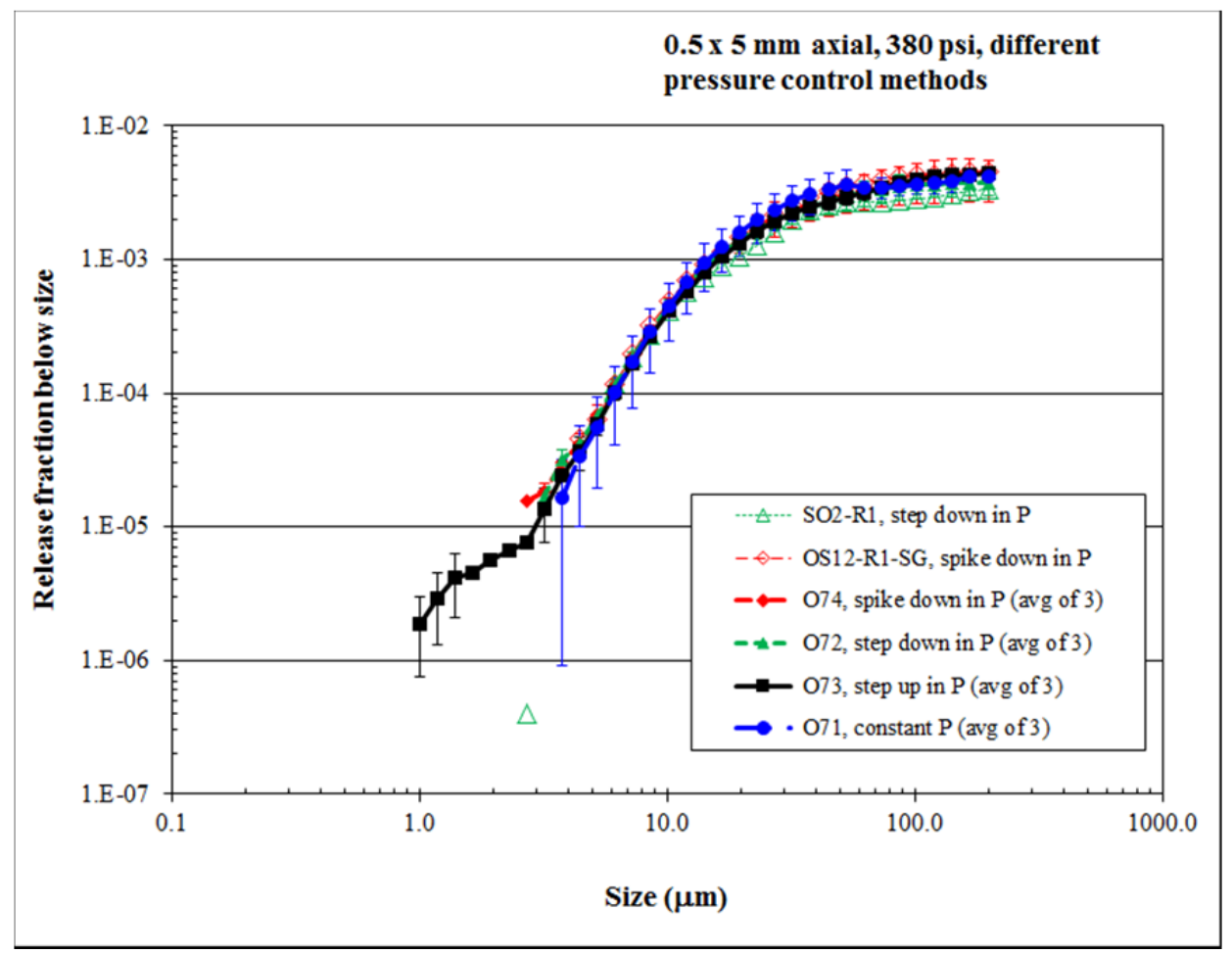

Figure 6.5. Effect of Pressure Transients for a 380-psig Water Spray from a 0.5 x 5-mm Slot, with the Mixing Fan On. The average of three tests (O74A-C; O72A-C; O73A-C; O71A-C) is plotted for each condition; error bars show two times the standard error of the mean. 


\subsection{Analysis Method Considerations}

To recapitulate, a model (derived and explained in Section 6.3) was numerically fitted to the initial concentration increase data for each droplet size to find the initial slope, from which the aerosol net generation rate was obtained. The fit-based net generation rates for all droplet sizes were then converted to release fractions by dividing by the measured total leak flow rate through the test orifice. Release fractions were compared to those predicted by the WTP spray model (McAllister 2010) for a fluid with the properties of the tested simulant.

One important consideration in devising the data analysis method was selecting a time period that would include the initial concentration increase period but not include too many points at steady-state concentration, whose residuals might outweigh those of the increase period and distort the results (Section 6.6.1). Another consideration was accounting for the delay between the manually-recorded spray start time and the actual time when leak flow began so that the true start time could be used (Section 6.6.2). The accuracy of the leak flow measurement (Section 6.6.3) was checked also. Section 6.7 discusses the repeatability of results between Malvern runs at the same conditions, and Section 6.8 presents a comparison between the concentrations measured by the Malvern instrument and the PPC when co-located.

\subsubsection{Fitted Interval}

In the small-scale tests, aerosol concentration typically increased rapidly, and the equilibrium concentration was reached well before $120 \mathrm{~s}$, at which point the spray was shut off. Smaller droplets generally had longer rise times (smaller loss rate constants) than large droplets. The concentrations of the smaller droplets often showed a quasi-linear increase with time, and did not necessarily reach an equilibrium value by the end of the spray.

However, for the sizes of most interest in safety analysis $(10$ to $100 \mu \mathrm{m})$, fitting the model to the entire spray period would have meant that at least half the data points included in the fit were at equilibrium. These data points would have contributed much less information about aerosol generation than the initial transient did, and would have added to the sum of prediction errors and, thereby, reduced the sensitivity of the fit to the prediction errors in the transient. Additionally, for large orifices, it was not uncommon for sprays to wet the lens and cause high, inaccurate concentrations after 25 to $35 \mathrm{~s}$.

Therefore, only the first $20 \mathrm{~s}$ of spray concentration data were used in performing cumulative and differential fits. The reasonableness of this time limit was checked by reviewing the time constants of the initial concentration transients, calculated by taking the inverse of the loss rate constants obtained using cumulative fits. Overall the small-scale runs used in this report, the median time constants for the various droplet sizes ranged from 3 to $10 \mathrm{~s}$, with the shortest time constants being associated with the largest

droplets $(200 \mu \mathrm{m})$. The $90^{\text {th }}$-percentile time constants over all runs also were calculated. These were the time constants, for each droplet size, that were greater than those found in 90-percent of the runs. The $90^{\text {th }}$-percentile time constants, over all runs, ranged from 19 to $60 \mathrm{~s}$ for droplets that were $\leq 9 \mu \mathrm{m}$. In this range, the droplets between 5 and $9 \mu \mathrm{m}$ had the longest time constants. For droplets of sizes $>9 \mu \mathrm{m}$, the time constants decreased monotonically from $26 \mathrm{~s}$ at $10 \mu \mathrm{m}$ to $6 \mathrm{~s}$ at $200 \mu \mathrm{m}$. To put this in context, a 26 -s time constant in Equation (6.11) means that $54 \%$ of the overall concentration change occurs in the first $20 \mathrm{~s}$ of the spray. 
It was concluded that in 90 percent of the runs, a 20 -s fitting time allowed at least $\sim 50$ percent of the concentration transient for droplets in the 10 to $200 \mu \mathrm{m}$ size range to be observed and used in determining the net generation rate. Having 20 data points within the first 50 percent of the concentration change was expected to provide a good fit. By the same token, the minimum 120-s duration of the spray was more than adequate to support determination of the net generation rate.

\subsubsection{Spray Start Time Determination}

Because the initial concentration transient often lasted less than $20 \mathrm{~s}$, the results of model fits were sensitive to an exact determination of the spray start time. In the test procedure, the start time was determined at a signal from the test leader, at which point the time was manually recorded and valving changes commenced. There was room for 1- or 2-s error in either direction, as well as some possibility of typographical errors.

To give a consistent start time from one test to another and to do so in a potentially conservative way, it was assumed that spray from the header started at $1 \mathrm{~s}$ before the first measurement of aerosol concentration on the Malvern instrument. This is the shortest aerosol transport time consistent with a 1-s spacing of data points (i.e., a 1-Hz data collection rate). Being the shortest transport time, it tends to lead to overestimates of the initial aerosol increase rate and of the aerosol net generation rate, which is a conservative approach.

A separate spray start time determination was made for the header pressure versus time data. These measured pressures were used in calculating average pressures for use in determining the WTP-model predicted spray size distribution and the orifice coefficient. Because of the size of the initial pressure transient (see Sections 5.2.2.3 and 6.5.6), the effective average pressure could vary considerably depending on exactly when the spray start time was with respect to the pressure transient.

The clock used for the pressure data was not the same one used for the Malvern instrument, and the two clocks were not always synchronized. As a result the Malvern spray start time could not be used as a guide to the pressure data spray start time. Instead, the header pressure and header flow data were examined to find the first high rate-of-change that occurred near the start time recorded in the test instruction. This point in time, when head conditions changed, was taken to be the spray start time for the purpose of interpreting pressure data.

\subsubsection{Leak Flow Measurement}

The leak flow (total flow from the orifice) was measured by recording the weight in the feed tank at two times, before the test header was opened to start the spray and after the header was shut off to end the spray. The weight measurement was complicated by the thrust produced by flow into and out of the feed tank during operations. This thrust affected the weight reading of the feed tank scale, thus, affecting the accuracy of weight measurement unless the thrust conditions were the same at spray start and spray end when weights were measured.

In early runs, the average measured water flow through a target $0.5-\mathrm{mm}$ round orifice at a target pressure of 380 psig was $0.18 \mathrm{gpm}$, whereas in later runs, the same pressure and orifice produced an average measured water flow of $0.23 \mathrm{gpm}$. This was an apparent increase of nearly 30 percent. The 
difference between the means of the two sets of measurements was greater than two standard deviations, indicating a significant difference between the two flow data sets. Increases in measured flow rates, from early to later runs, were also seen for a $1-\mathrm{mm}$ round orifice and a $0.5 \times 5-\mathrm{mm}$ slot. However, for these larger flow rates, the relative change in measured flow was $10 \%$ or less.

An examination of the orifices showed no sign that orifice size had been increased by wear. It was therefore concluded that the test procedure used in the early runs (identified as SO1 through O70 in Appendix A) had been more successful at providing matched thrust conditions at the start and end of the spray than was the procedure used in later tests (O71 through O90). The change in procedure addressed the addition of a needle valve to the system to allow finer pressure control. The change in measured flow from earlier to later runs was in a non-conservative direction, in that the flow increased and would lead to lower release when divided into the measured net generation rate.

To counter this potential bias, the later runs were assigned leak flow rates that were equal to the average values measured for the early runs at the same simulant (water), orifice size, and pressure. The assigned leak flow rates were used to calculate release fractions; therefore, for the later runs no orifice coefficients are reported. (The coefficients are discussed in Section 7.8).

\subsection{Repeatability}

The repeatability of the test results was tested by comparing Malvern-based release fractions that were found for different runs conducted at the same test conditions, where two or three good data sets were available for a single test condition. Figure 6.6 and Figure 6.7 show the results for water spraying through two different orifices, a 1-mm round hole and an axially-oriented $0.5 \times 5$-mm slot (target dimensions). Each plotted curve comes from a single test. Both of these water tests indicate that the repeated runs gave very similar results. Tests conducted with an aqueous sodium thiosulfate $\left(\mathrm{Na}_{2} \mathrm{~S}_{2} \mathrm{O}_{3}\right)$ salt solution of 2.5-cP Newtonian viscosity (Figure 6.8) showed equally tight repeatability.

As shown in Figure 6.9, the repeatability for STR slurry (with $8 \mathrm{wt} \%$ fine-particle boehmite solids) was not so close. In this set of tests, the highest and lowest values differed by factors of two to three. The break in the curve for test SV35B of this set indicates some difficulty in fitting the data for that test, which may be relevant to the cause of variation between tests.

The results of the non-Newtonian simulant tests, conducted with washed and leached FER chemical slurry containing AFA and having a target yield stress of $6 \mathrm{~Pa}$, are shown in Figure 6.10 and Figure 6.11. These tests, in which two different strengths of the slurry were sprayed, show similar behavior. For droplet sizes less than about $10 \mu \mathrm{m}$, the tests were strictly repeatable. More difference was seen between individual runs for larger droplet sizes.

Over the size range from 10 to $100 \mu \mathrm{m}$, the relative standard deviations range from 8 to 26 percent for the triplicate data sets in Figure 6.6, Figure 6.8, Figure 6.10, and Figure 6.11. The relative standard deviation tends to increase with droplet size in this size range. The relative standard deviations in Figure 6.9 , the $8 \mathrm{wt} \% \mathrm{STR}$, are 41 to 48 percent, decreasing with droplet size. The median relative standard deviation of all the data between 10 and $100 \mu \mathrm{m}$ in the triplicate data sets is 21 percent. 


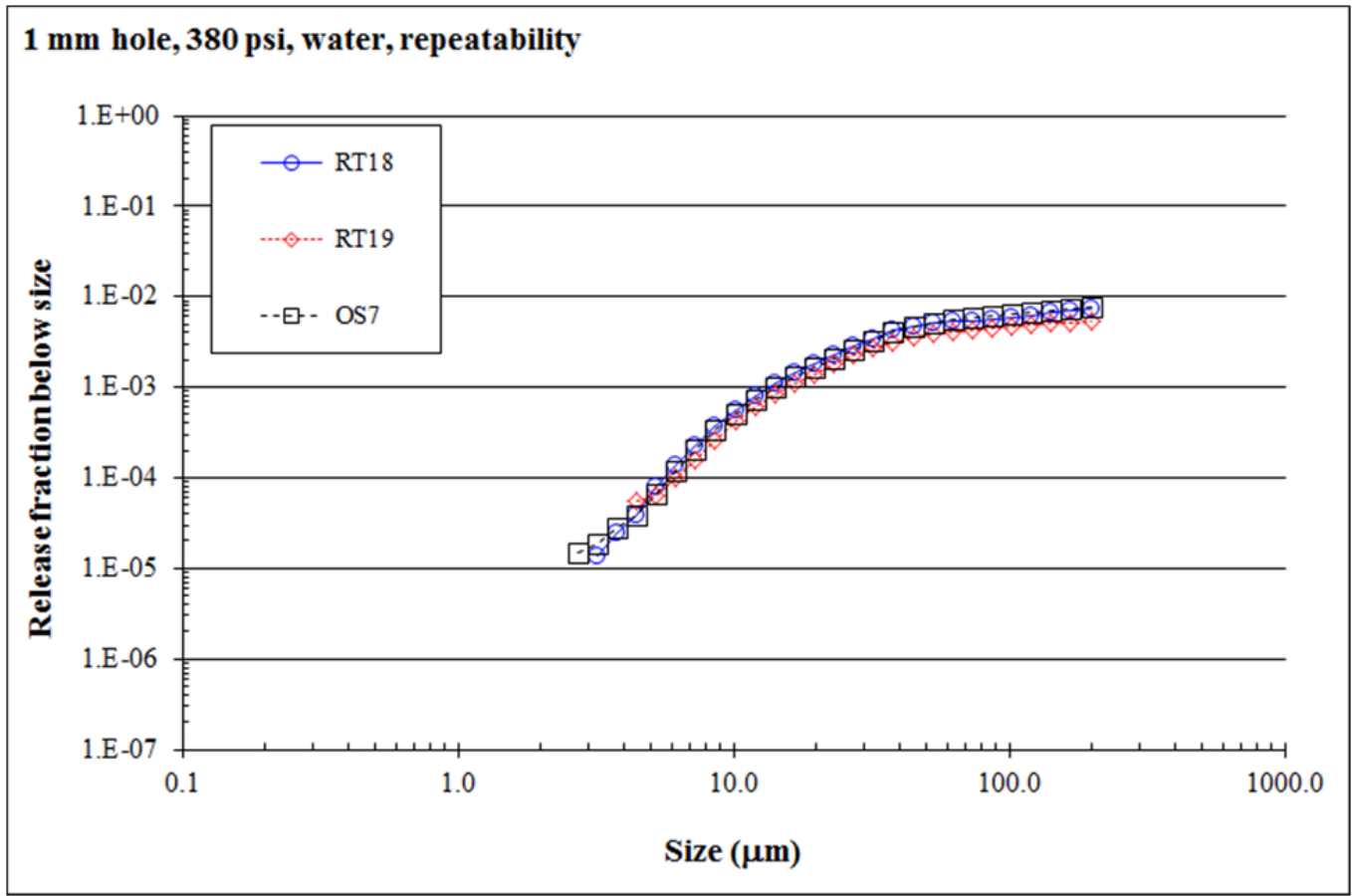

Figure 6.6. Repeatability for 380-psig Water Sprays from a 1-mm Hole. Each curve is a single test.

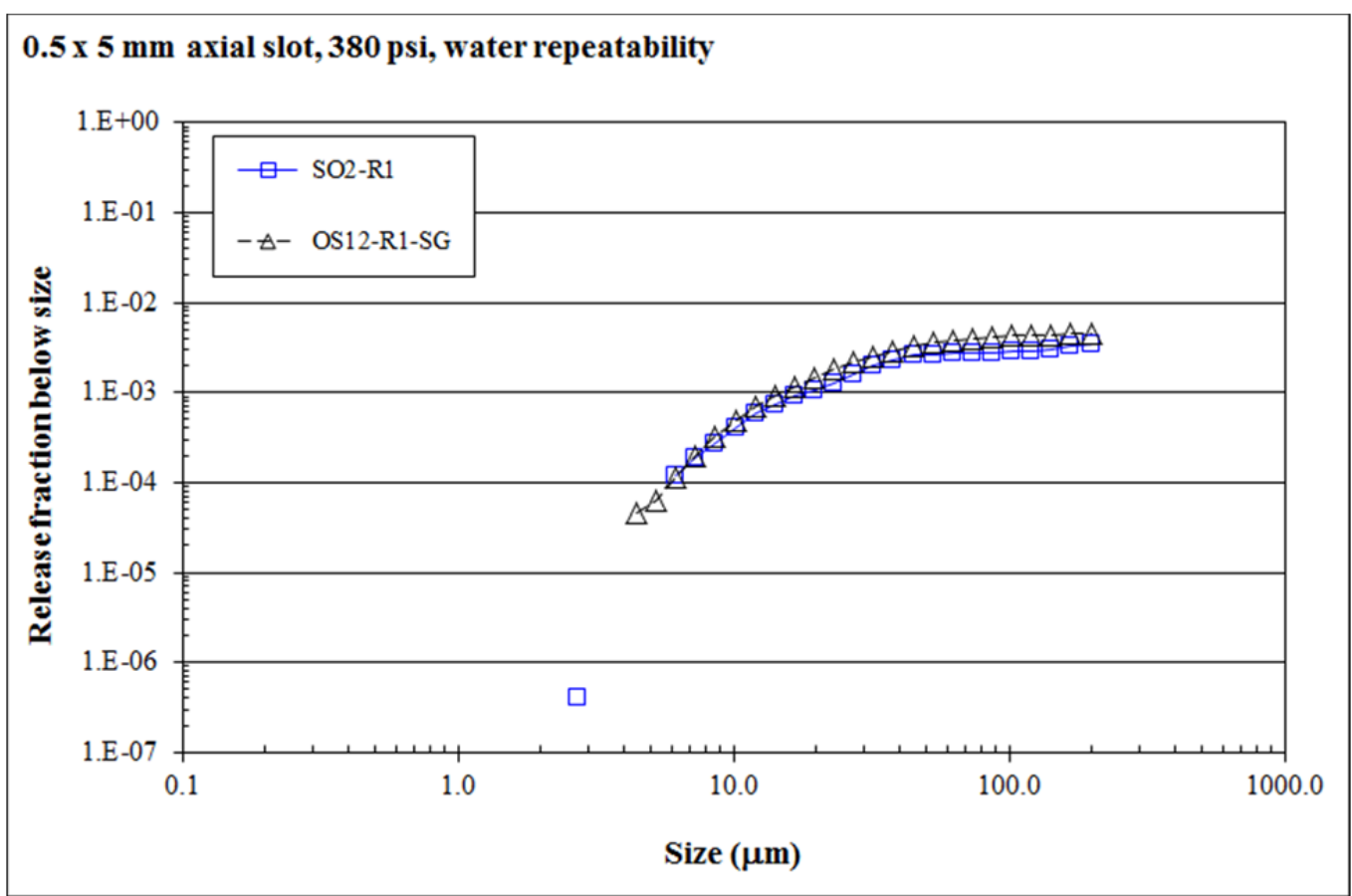

Figure 6.7. Repeatability for 380-psig Water Sprays from a $0.5 \times 5-\mathrm{mm}$ Axial Slot. Each curve is a single test. 


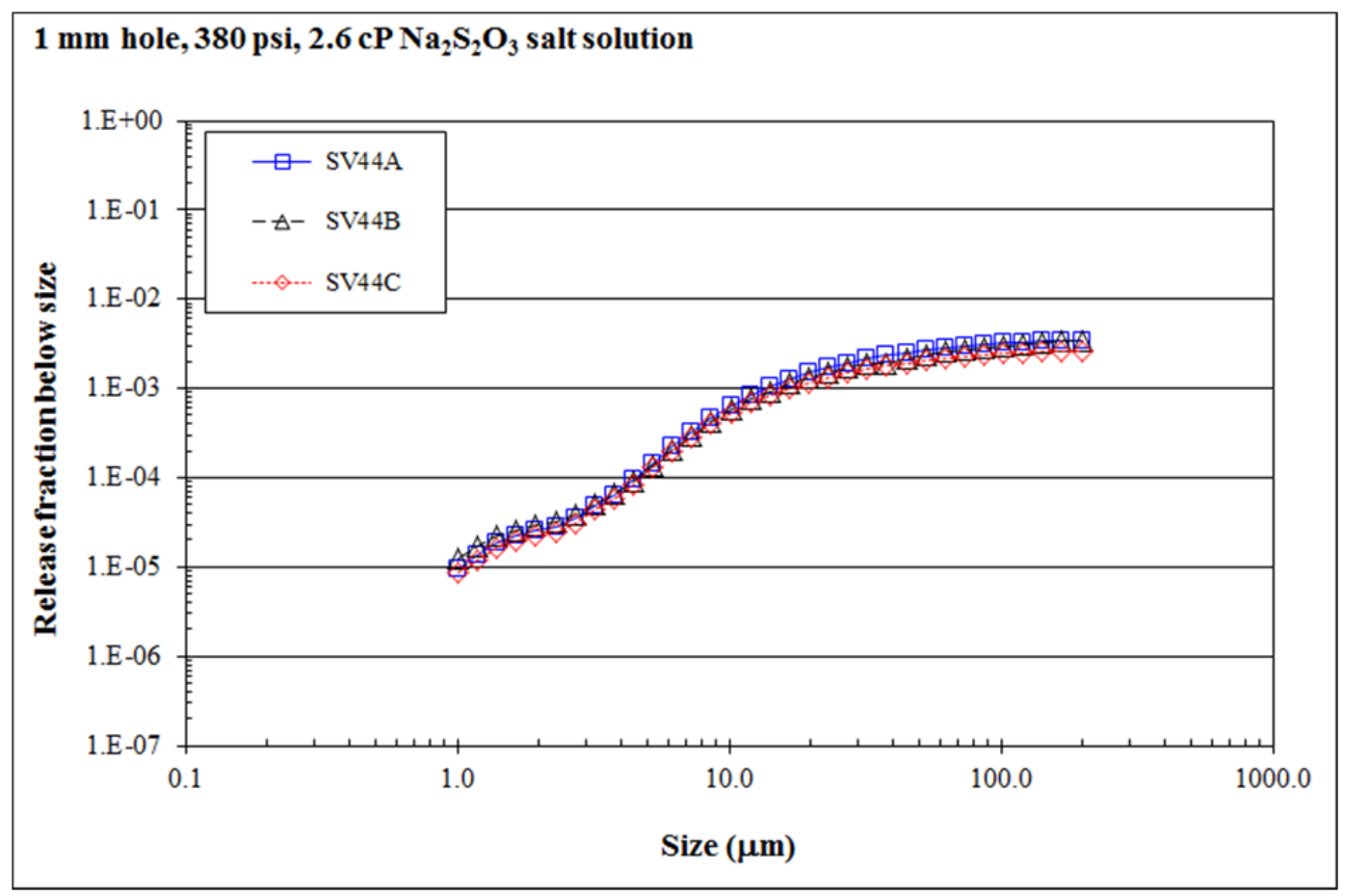

Figure 6.8. Repeatability for 380-psig Sprays of Sodium Thiosulfate Solution from a 1-mm Hole. Each curve is a single test.

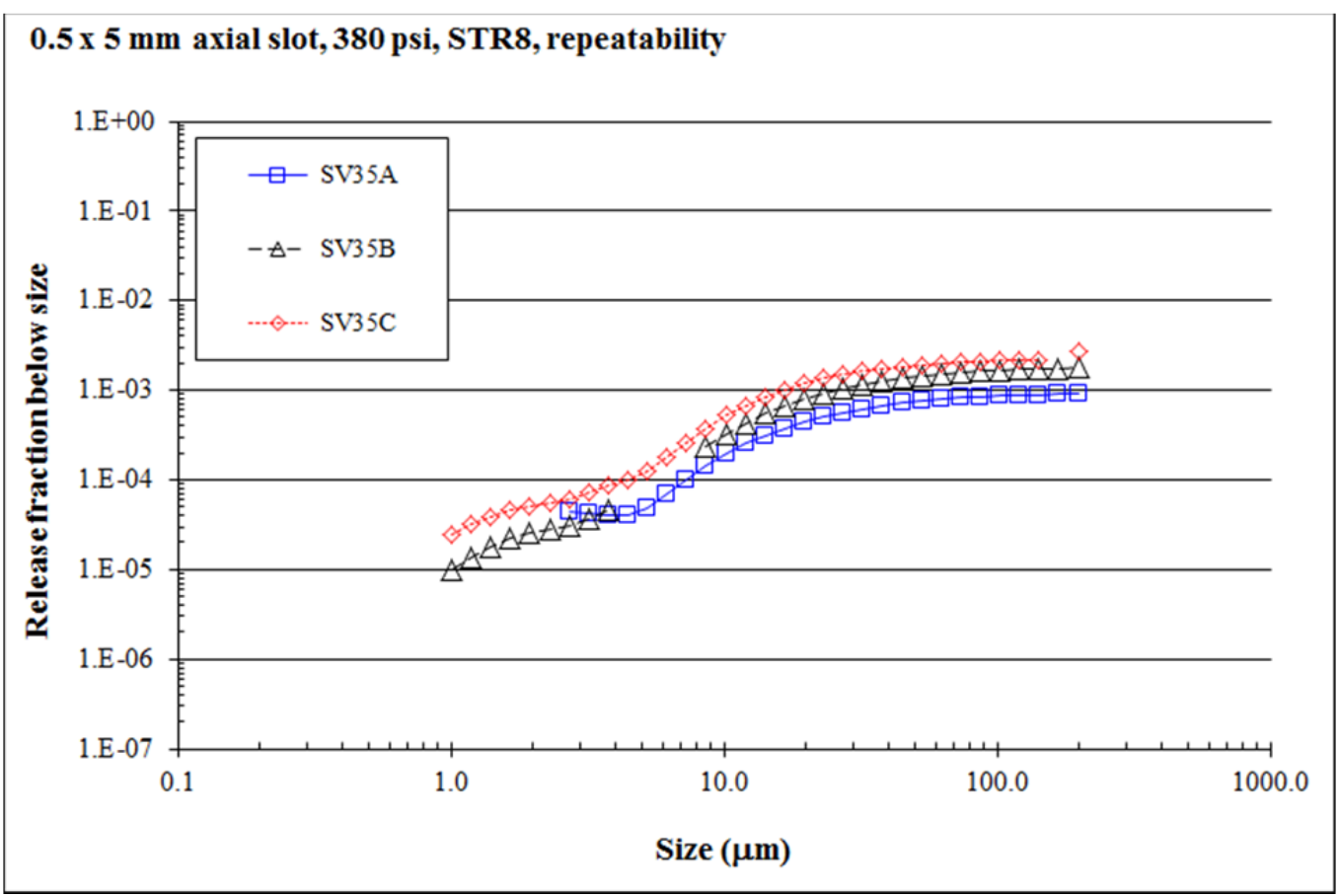

Figure 6.9. Repeatability for 380-psig Sprays of $8 \mathrm{wt} \%$ STR from a $0.5 \times 5-\mathrm{mm}$ Axial Slot. Each curve is a single test. 


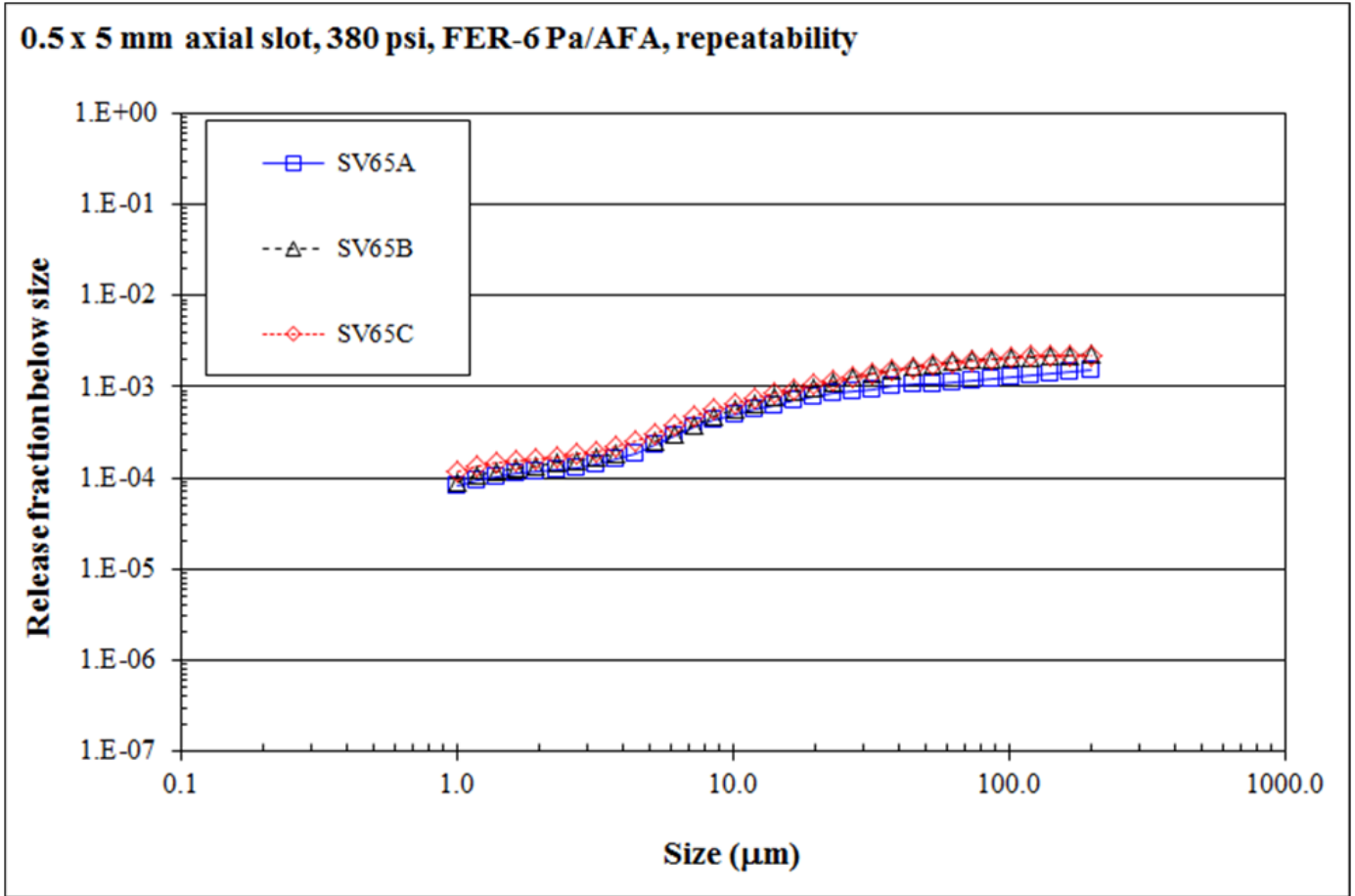

Figure 6.10. Repeatability for 380-psig Sprays of AFA-Containing Iron-Rich (FER) Slurry with a Target 6-Pa Yield Stress from a $0.5 \times 5-\mathrm{mm}$ Axial Slot. Each curve is a single test.

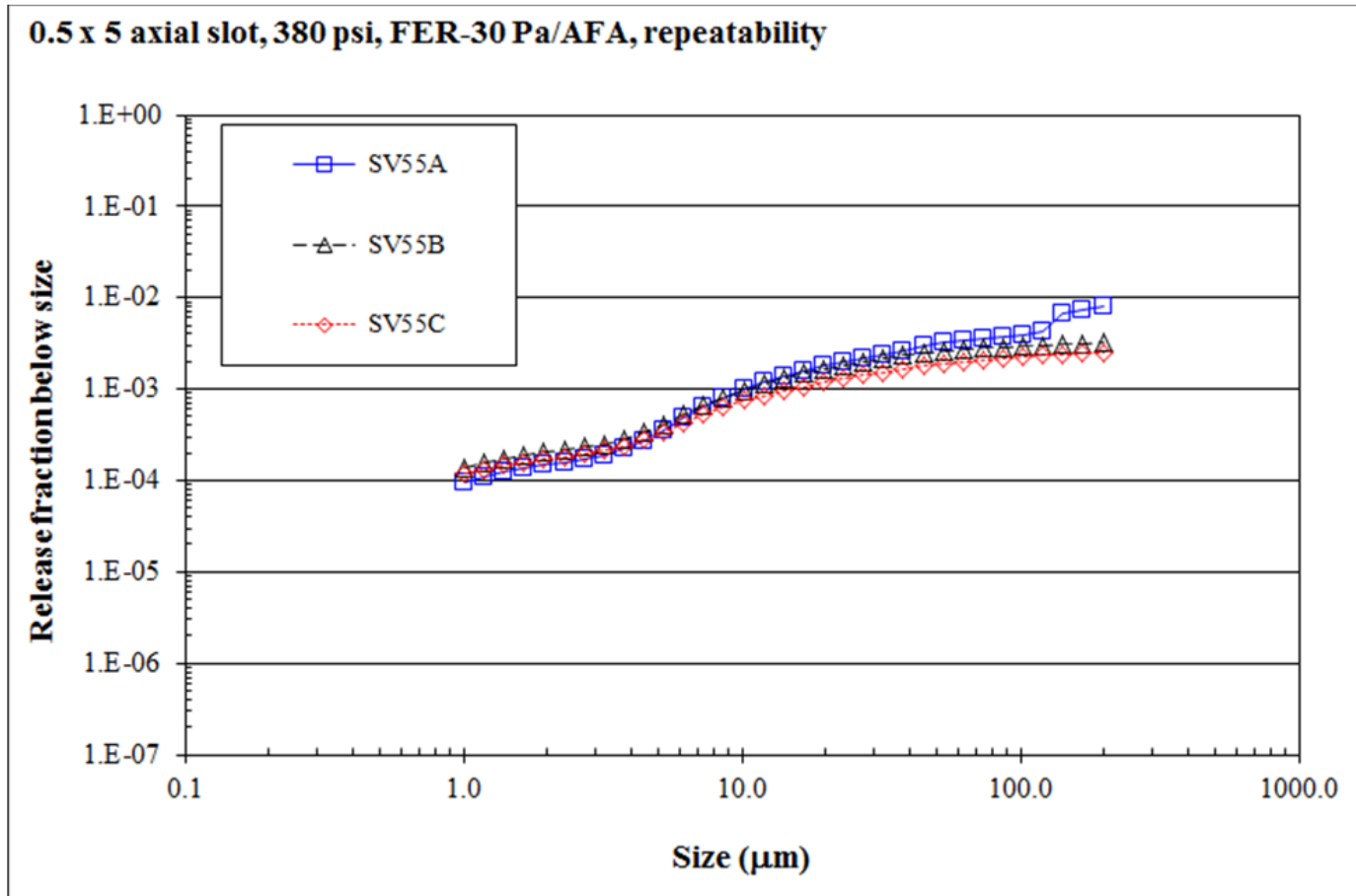

Figure 6.11. Repeatability for 380-psig Sprays of AFA-Containing an FER Slurry with a Target 30-Pa Yield Stress from a $0.5 \times 5-\mathrm{mm}$ Axial Slot. Each curve is a single test. 


\subsection{Comparison Between the Malvern Instrument and the PPC}

The remaining test of the measurement approach was the comparison of data from the Malvern instrument with data from another instrument, the PPC, whose measurements were made based on a different physical principle. The relatively long accumulation time of the PPC instrument $(5 \mathrm{~s})$ made it pointless to try to calculate the release fraction from the concentration transient. Therefore, the steady-state cumulative concentrations measured by the Malvern and PPC instruments, when co-located during the same run, were compared for water sprays from the default round hole (target diameter $1 \mathrm{~mm}$, run $\mathrm{O} 24$ ) and the default slot (target dimensions $0.5 \times 5 \mathrm{~mm}$, run O23). In addition, the comparison included concentrations measured by the Malvern instrument at the same conditions but without the PPC co-located (runs RT18 and SO2-R1).

The concentrations used to represent steady-state were 20 -s averages centered on a point $60 \mathrm{~s}$ into the spray. The Malvern data from the water sprays was processed into PSDs assuming the same solid-phase refractive index that was hard-wired into the PPC (see Section 6.4). The comparisons are shown in Figure 6.12 and Figure 6.13. Size bins are omitted above $200 \mu \mathrm{m}$ for the Malvern instrument and above $32 \mu \mathrm{m}$ for the PPC. The PPC showed little or no volume concentration above $32 \mu \mathrm{m}$, possibly because of the low number concentration of larger droplets, and according to the Malvern manual, the nominal size range with the $100-\mathrm{mm}$ lens used in the small-scale study is 0.5 to $200 \mu \mathrm{m}$.

Water, $0.975 \mathrm{~mm}$ axial hole, $380 \mathrm{psig}$; Malvern in position 2

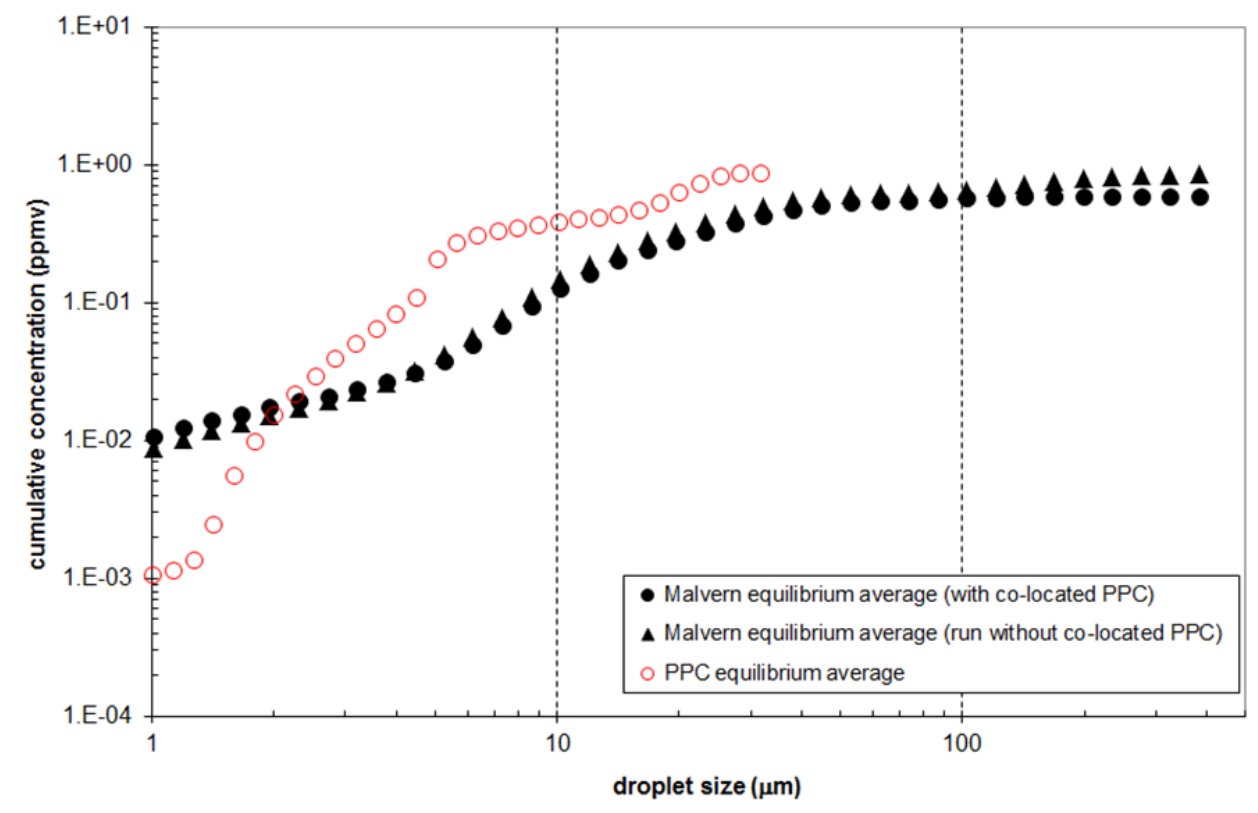

Figure 6.12. Comparison of Steady-State Concentrations Measured by the Malvern and PPC Instruments for 380-psi Water Sprays from a 1-mm Round Hole

It is clear from the figures that the presence of the co-located PPC changed the concentration measured by the Malvern, starting at about $10 \mu \mathrm{m}$ and producing nearly complete removal of droplets larger than about $100 \mu \mathrm{m}$. For the round 1-mm hole (Figure 6.12), the PPC concentration was two to 
three times the Malvern concentration for droplets at and above $10 \mu \mathrm{m}$, up to the apparent PPC measurement limit of about $30 \mu \mathrm{m}$. Both instruments indicate bimodal distributions, but the locations of the peaks are different. For the $0.5 \times 5-\mathrm{mm}$ slot (Figure 6.13), the Malvern and PPC concentrations are more similar, particularly between 20 and $30 \mu \mathrm{m}$.

Water, $0.534 \times 4.886 \mathrm{~mm}$ axial slot, 380 psig; Malvern and PPC in position 2

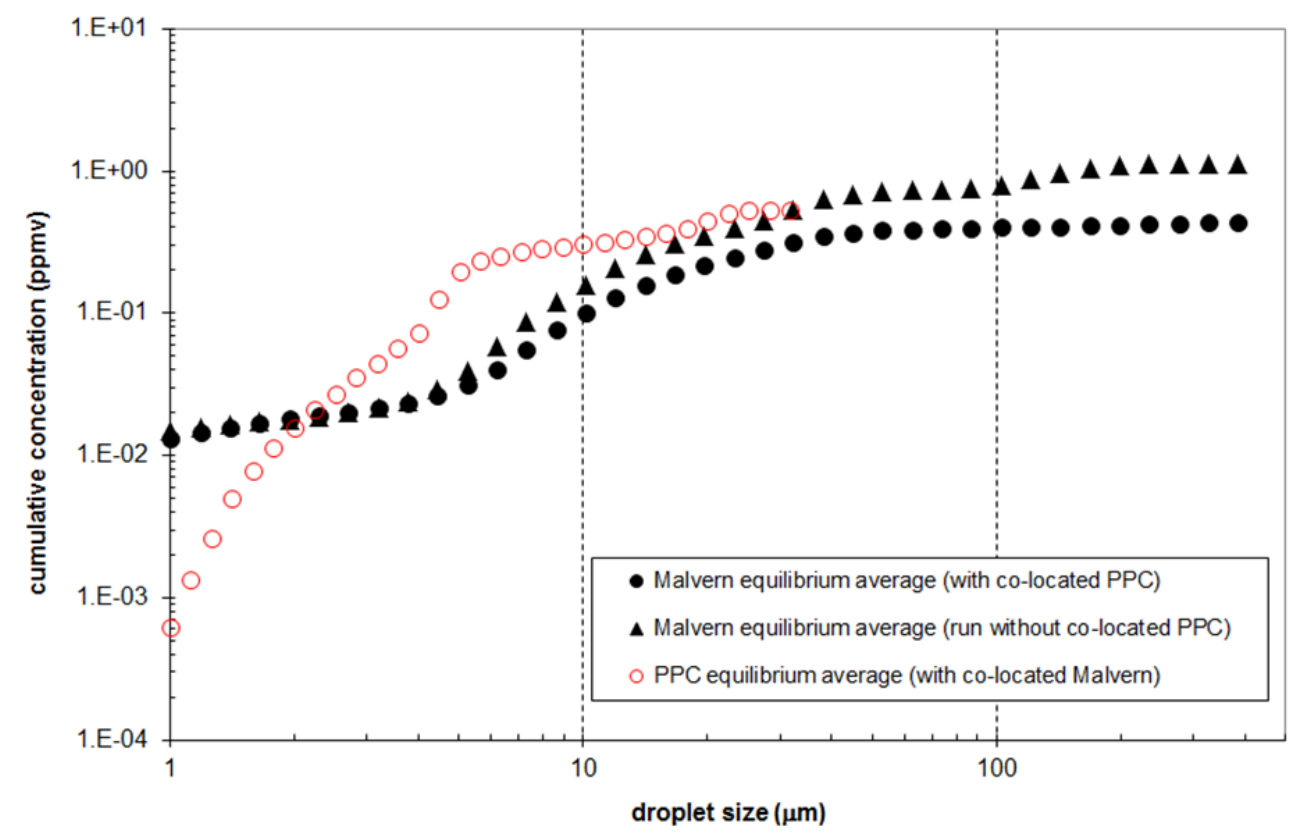

Figure 6.13. Comparison of Steady-State Concentrations Measured by the Malvern and PPC Instruments for 380-psi Water Sprays from a $0.5 \times 5-\mathrm{mm}$ Axial Slot

The reasons for the differences between the concentrations measured by the Malvern instrument (without the co-located PPC) and the PPC are not completely clear. The Malvern concentration (hence the release fractions derived from it) was consistently lower, raising the possibility of non-conservatism in the Malvern measurements. However, the large-scale tests provide substantial countervailing evidence:

- In the large-scale tests (Section 8.1.5 of Schonewill et al. 2012), the Malvern instruments characteristically measured higher concentrations than did the PPC. In these tests, the PPC suction rate (1.5 SCFM) had been tested for two test orifice sizes, $2 \mathrm{~mm}$ and $4.46 \mathrm{~mm}$, (Section 8.1 .4 of Schonewill et al. 2012) and found to give higher concentrations at all droplet sizes than did lower or higher suction rates. The authors commented that this "optimization" might not hold for all orifice sizes. A PPC suction rate of 0.5 SCFM was used in the small-scale tests, but no tests were performed at small scale to determine whether that suction rate gave the best performance for the smaller orifices and different measurement configuration at small scale.

- A Malvern Mastersizer 2000, which has a different configuration than the Malvern Insitec-S but uses the same ensemble laser diffraction method, was tested with a suspension of glass beads of known size distribution. At bead concentrations between 0.03 and $0.2 \mathrm{ppmv}$, the measured concentration was 36 percent higher than the mass-balance concentration. This indicates that Malvern concentration measurements are reasonably accurate and, if anything, conservative. 
- In the majority of large-scale tests, the concentrations measured by the Malvern instrument were larger than those measured by the PPC, except that the concentration of droplets in the 10- to $30-\mu \mathrm{m}$ range was higher in the PPC measurements. The PPC and Malvern readings agreed to within a factor of 0.5 to 2 times of each other for droplet diameters between 10 and $30 \mu \mathrm{m}$. For droplet diameters $<10 \mu \mathrm{m}$, there was increased divergence between aerosol concentration readings for the Malvern instrument and PPC, with the Malvern reading being high relative to that of the PPC.

- In its summary, the large-scale report noted the need for caution in comparing Malvern and PPC measurements because of the difference in sampling methods and sampling volumes and the difficulty in determining whether the PPC samples were drawn iso-kinetically and whether sample was being deposited in the PPC draw tube. The report concluded that “... evaluation of Insitec-S performance using PPC data is inconclusive beyond stating that order-of-magnitude agreement between the instruments was achieved."

In addition, there are no data with which to evaluate the extent to which the presence of the co-located Malvern instrument affected the measurements made by the PPC in the small-scale tests.

It is concluded that the Malvern instrument was probably the more reliable of the two instruments under small-scale conditions, and that there was no loss of conservatism from its use. 



\subsection{Parametric Results and Discussion}

In this chapter, we discuss the results obtained from parametric analyses whose basis was defined in Sections 6.1 through 6.4 and whose testing and data analysis methods were examined in Sections 6.5 and 6.6. The focus is on examining the effects of various parameters on the release fraction and/or net generation rate. Of particular interest are comparisons of the WTP model predictions with the small-scale test results as a function of parametric changes.

Although the aerosol concentration data were analyzed by both cumulative and differential fits to obtain net aerosol generation rates, as was described in Section 6.3, only results from the cumulative fits are shown. Because the release fractions estimated by the two types of fits are typically indistinguishable within the 95-percent confidence intervals of the fits, the cumulative method was chosen because it usually had a wider range of droplet size bins whose concentration fits satisfied the $\overline{\mathrm{R}}^{2}$ criterion. For a complete set of plots of release fractions, calculated by both the differential and cumulative method for each test, refer to Appendix B.

Note that certain plotting conventions are generally followed in the subsequent discussions of parametric effects. Cumulative release fractions and net generation rates, determined using the cumulative method, are presented for three undersize bins, 10.17, 32.28, and $102.50 \mu \mathrm{m}$. Henceforth, these are referred to as $<10,<32$, and $<102 \mu \mathrm{m}$ for simplicity. Measured data are shown with large symbols joined by thin lines; the corresponding WTP model predictions are shown with small symbols joined by heavy lines. The WTP model and the data are both on the same basis with respect to evaporation, in that the model (as used here) does not include evaporative effects and the data are not expected to have been significantly affected by evaporation. Because the WTP model predictions are based on average pressure during the fit period, not on the run target pressures, the lines may appear irregular (in cases where the average pressure departed noticeably from the target pressure). In cases where the fits were bad (per the criteria in Section 6.3), no measured-data symbols appear for the affected droplet sizes.

The release fractions and net generation rates that are plotted are from single runs selected from sets of runs at the same condition, if other runs existed. The selection process is described in Section 6.3. The error bars on the plots represent an approximation to the 95-percent confidence level, and include an estimate of experimental variability and of the uncertainty of the model fit that produced the release fractions.

The error bars are not exact uncertainties but should give a reasonable idea of the uncertainty of the data. More detail can be found in Section 6.3.1.

The parametric results discussed in this chapter are included in five sections, each organized around a single concept or variable that was studied. In Section 7.1, parametric studies of orifice size and orifice orientation are presented. These tests were all conducted with water as the working fluid. In Section 7.2, the effect of pressure is discussed. In Section 7.3, the effect of viscosity is presented by comparing water and salt solution test results that were acquired using baseline orifice sizes (1-mm round hole). In Section 7.4 and Section 7.5, the effects of solids loading and AFA, respectively, are investigated, again using tests with baseline orifice sizes (1- $\mathrm{mm}$ round hole and $0.5 \times 5 \mathrm{~mm}$ slot) to compare water and slurry data. In Section 7.6, the effect of proximity to the splash wall (e.g., distance between spray jet and the 
splash wall) is presented using data collected when orifices were moved to different distances relative to the back wall of the aerosol chamber. The section also discusses in-spray aerosol measurements as representatives of the spray size distribution when splash does not occur (effectively an infinite distance to the splash wall). The droplet size distributions in in-jet sprays are described in Section 7.7. Section 7.8 presents the orifice coefficients measured as a byproduct of aerosol testing. Finally, a summary of this work and the conclusions are presented in Section 7.9.

\subsection{Orifice Tests}

The small-scale aerosol testing of orifice effects was primarily conducted using process water. In this section, the effect of various orifice parameters on release fractions and/or net generation rates are shown and discussed.

The geometry of a leak is not explicitly accounted for in the WTP model because the cross-sectional area of the orifice (via the $K$ parameter in Equation (1.4)) is the only orifice-related parameter that affects the release fraction. To test this assumption, several different variations on orifice geometry were carried out:

- Orifices of similar cross-sectional area but different orientations in the spool piece

- Groups of closely-spaced small orifices

- Orifices of varying aspect ratio.

\subsubsection{Effect of Orifice Orientation}

The orifices whose orientation was varied were of two different types. The first was a slot with target dimensions of $0.5 \times 5 \mathrm{~mm}\left(2.5-\mathrm{mm}^{2}\right.$ area $)$. The axial slot was oriented with its length parallel to the header axis and the circumferential slot was rotated 90 degrees and oriented as an arc around part of the circumference of the header. In these orientations, flow through the header was maintained. In a third orientation, known as "dead-end," the axial slot was mounted at the end of the header after capping the header to close it off. Strictly speaking, the "dead-end" variant is a change not in the orientation of the hole, but in its relation to the header. A round hole whose target diameter was $0.5 \mathrm{~mm}\left(0.20-\mathrm{mm}^{2}\right.$ area $)$ also was tested in both the default orientation and a dead-end orientation.

The results from tests using water at $380 \mathrm{psi}$ for these variously oriented orifices are shown in Figure 7.1. The WTP model predictions for $<10-\mu \mathrm{m}$ droplets are included (dashed line) as a way of showing the expected effect of the different average pressures during the tests. Note that good fits were not obtained for all three droplet sizes in all runs; therefore, the symbols for those sizes are missing (e.g., the 102-mm droplets for the dead-end round hole). The measured release fractions for $<10 \mu \mathrm{m}$ droplets are consistently less than the WTP model, an order of magnitude less for the round holes.

The cumulative release fractions are indistinguishable from each other, except that the circumferential slot may have a lower release fraction. Based on this comparison, it can be concluded that the orientation of the orifice does not have an appreciable effect on the release fraction or, if it does, that the default axial orientation is conservative. In addition, the flow rate was not affected significantly by the orifice orientation (see Section 7.8). The lack of orientation effect having been demonstrated, all other tests were conducted with axial orifices. 


\section{RF: variously-oriented $0.5 \mathrm{~mm}$ round holes and $0.5 \times 5 \mathrm{~mm}$ slots, water@380 psig; small-scale}

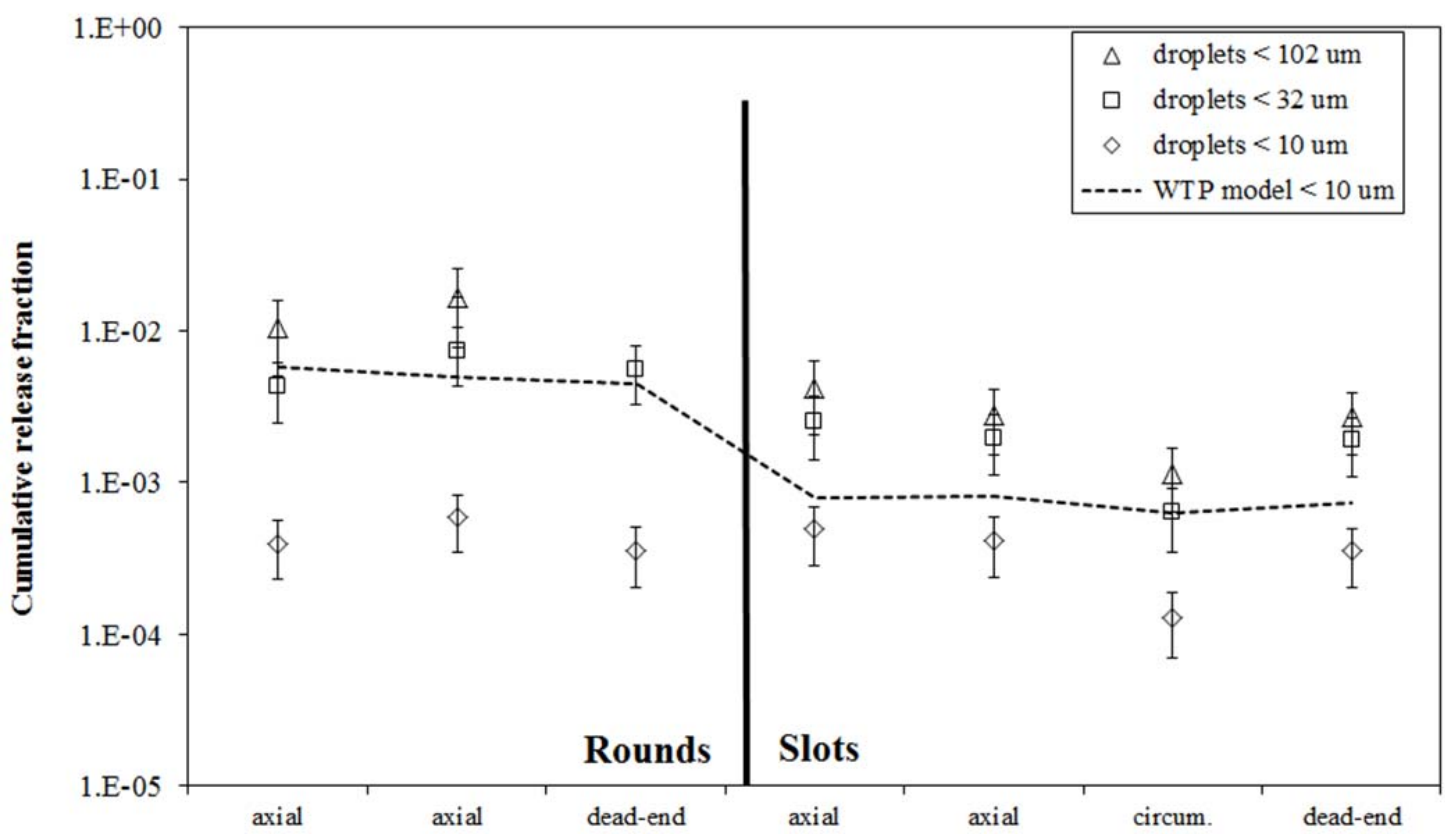

Figure 7.1. Effect of Slot Orientation for Slots and Round Holes, Using Water at 380 psi. The WTP model prediction is shown by the black dashed line. One test is plotted for each condition, except that there are two axial tests; error bars show an approximate 95-percent confidence interval including model fit and experimental variability. For the round holes, the term "axial" means that there was fluid flow through the header (the default condition) instead of a dead end configuration. Appendix D identifies the tests in the plot.

\subsubsection{Effect of Multiple Orifices}

A second exploration of the effect of orientation was performed by testing an array of five round holes lined up with the header axis, with each orifice separated by a distance equal to the hole diameter, with target values of either $0.5 \mathrm{~mm}$ or $1 \mathrm{~mm}$. These tests were conducted in an attempt to determine the impact on the release fractions of a breach with an irregular shape. Actual breaches caused by erosion, corrosion, or equipment failure would not have an engineered shape such as the orifices used in the tests, but would have irregular edges and varying widths. Testing with more realistic breaches was not conducted because of the challenges associated with fabricating such breaches and then characterizing the dimensions.

Figure 7.2 shows the relationship between release fractions for a single $0.5-\mathrm{mm}$ hole and an array of five $0.5-\mathrm{mm}$ holes. By the WTP model, the release fraction would be expected to be the same for the two cases if it is based on the area of an individual hole. (WTP predictions, which use the area of the single hole, show a variation in release fraction because 1) the average pressures were different for the cases, and 2) the average area per hole in the five-hole orifice with target diameter of $0.5 \mathrm{~mm}$ is about 77 percent of that in the single-hole $0.5-\mathrm{mm}$ orifice.) Instead, the five $0.5-\mathrm{mm}$ holes produce a substantially smaller release fraction. Hypothetically, the decrease may have resulted from particle capture by adjacent streams; another possibility is that the closely spaced streams joined into a single jet downstream of the 
orifice and so produced less spray. A further cross check was made by comparing the five 0.5 -mm holes $\left(0.87 \mathrm{~mm}^{2}\right)$ with a $1-\mathrm{mm}$ hole $\left(0.75 \mathrm{~mm}^{2}\right)$. The $1-\mathrm{mm}$ hole has a significantly higher release fraction than the five $0.5-\mathrm{mm}$ holes, although the total areas were about equal. The release fraction of the five-hole spray is not well explained either by a single hole of matched diameter or by a single hole of the same total area.

One confusing factor is the difference in average pressures between the cases being considered, ranging from about $320 \mathrm{psig}$ (for the five-hole orifice array and one of the runs with a single $0.5-\mathrm{mm}$ hole) to about $380 \mathrm{psig}$ (the $1-\mathrm{mm}$ holes and the other run with a single 0.5 -mm hole). However, the predicted effect of pressure can be seen in the WTP lines for the two runs for the single $0.5-\mathrm{mm}$ hole, and is much less than the difference between the release fractions of the 1-mm hole and the five $0.5-\mathrm{mm}$ holes. If the five-hole orifice had been run at $380 \mathrm{psig}$, presumably its release fraction would have been higher, and closer to the release fraction observed from the 1-mm hole.

The same type of plot is presented in Figure 7.3 for the array of five 1-mm holes. For these larger (and more widely spaced) holes, the release fraction is only slightly smaller, but possibly not significantly smaller, for five holes than for one hole. The array of 1-mm orifices had a cross-sectional area that was similar to that of the $2-\mathrm{mm}$ orifice $\left(3.94 \mathrm{~mm}^{2}\right.$ for the five $1-\mathrm{mm}$ holes versus $3.19 \mathrm{~mm}^{2}$ for the 2-mm hole). Comparison shows that, in this case, the release fraction of the five-hole spray may possibly be explained as a function of total orifice area, as was found in the large-scale tests (Section 8.2.2, Schonewill et al. 2012) for orifices of the same size. Here again, pressure is a confusing factor: about 360 to $380 \mathrm{psig}$ for the three runs with a single 1-mm hole, 290 psig for the five 1-mm holes, and about 360 for the 2-mm hole. If the five-hole array had been run at 380 psig, presumably its release fraction would have been larger, and closer to that of the 2-mm hole.

Because of this ambiguity, and because more parametric studies on the effect of orientation and/or spacing between orifices were not performed, caution should be exercised when extrapolating this observation to more disparate orifice types. For example, an array of 1-mm orifices separated by much larger distances might have a different behavior. Specifically, the jets emanating from the orifices would have more time to spread out and aerosolize before interacting with each other. At some point, orifices separated by large enough distances would have to be treated as entirely separate spray leak events. The transition between these two extremes, where geometry and orientation of the orifices influence the release fraction of aerosol, was not explored. In any case, the measured release fractions for droplets of a given size are consistently less than the WTP model for both multiple-hole orifices. 

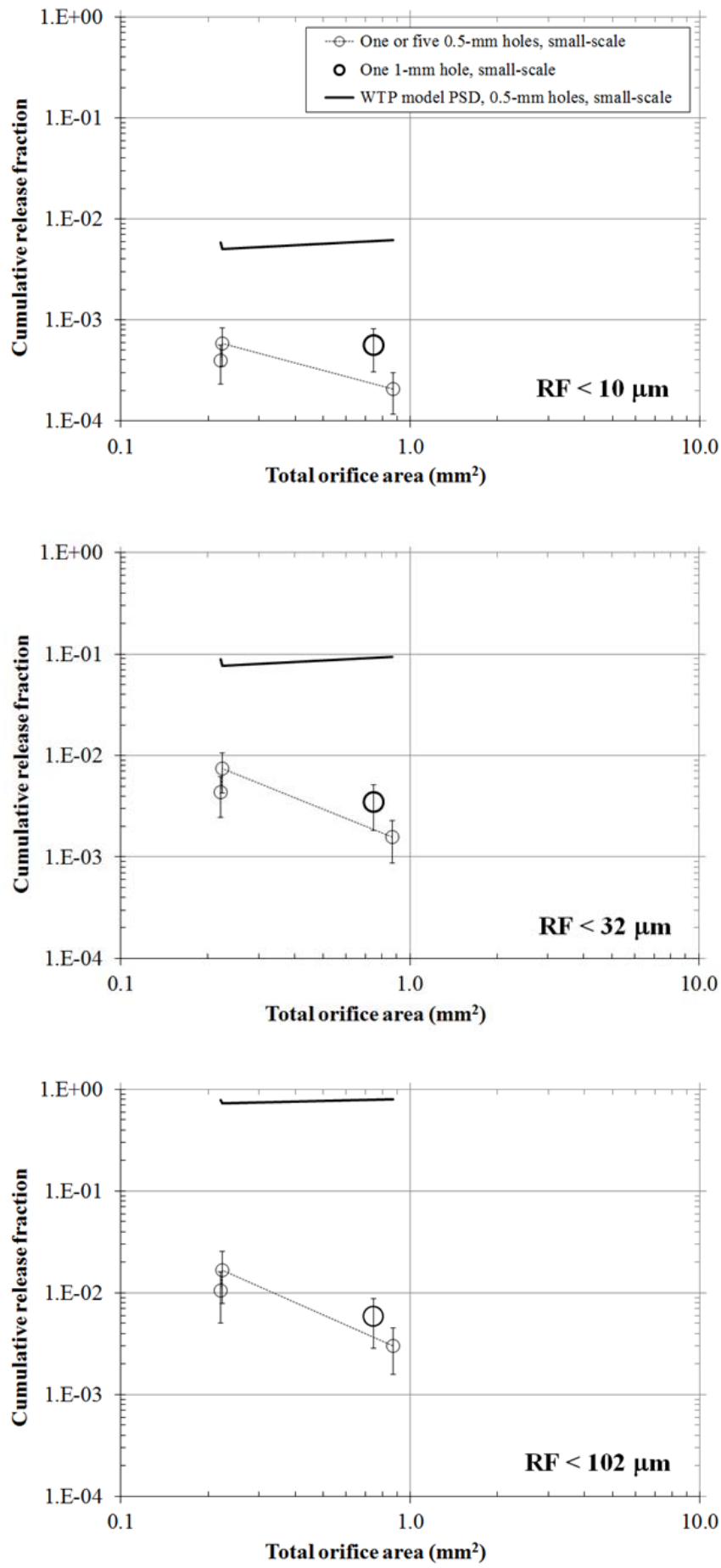

Figure 7.2. Comparison of Release Fractions for Single and Multihole Orifices, Using 0.5-mm Round Holes with Water at 380 psi. WTP model predictions, which use the area of a single hole, are shown by the thick black lines. Error bars show an approximate 95-percent confidence interval including model fit and experimental variability. Appendix D identifies the tests in the plot. 

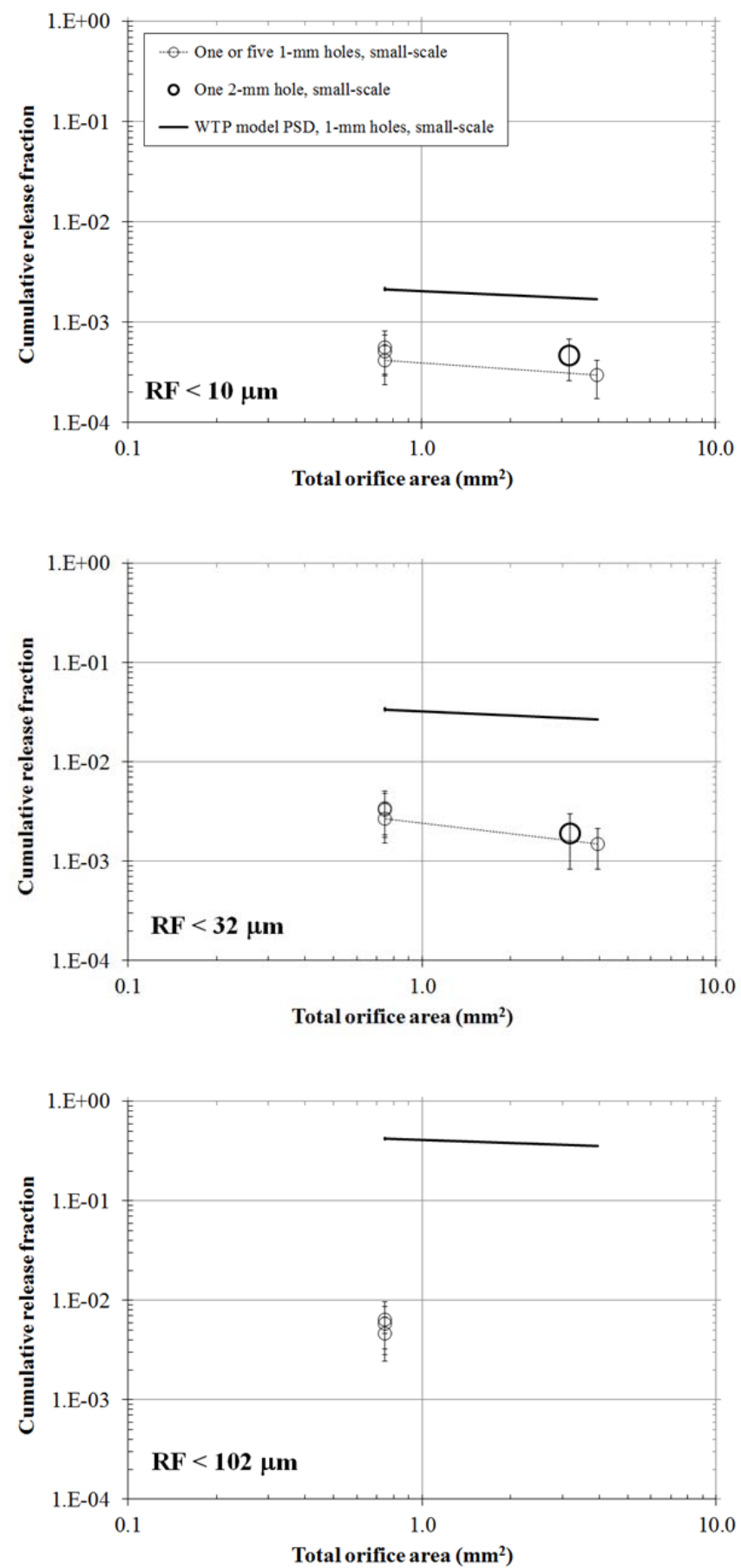

Figure 7.3. Comparison of Release Fractions for Single and Multihole Orifices, Using 1-mm Round Holes with Water at 380 psi. WTP model predictions, which use the area of a single hole, are shown by the thick black lines. Error bars show an approximate 95-percent confidence interval including model fit and experimental variability. Appendix D identifies the tests in the plot. 


\subsubsection{Effect of Orifice Area on Net Generation Rate and Release Fraction}

As mentioned in the previous section, the WTP model predicts that the release fraction decreases with increasing cross-sectional area. According to Equations (1.1) through (1.4), the SMD is approximately dependent on $\operatorname{area}^{1 / 3}$. As the SMD increases, the release fraction at lower sizes will decrease according to the expression in Equations (1.5) and (1.6). The results presented in Section 7.1.2, based on a handful of tests, suggested that the release fraction might be related to orifice size strictly through the cross-sectional area. The effect of orifice area on the aerosol net generation rate also is important. The dependence of net generation rate on area is via 1) the release fraction, as just discussed, and 2) the flow rate of the spray, which is directly proportional to cross-sectional area (see Equation (1.7)). The proportional relationship with flow rate is stronger than the model-predicted weak decrease of the release fraction with area; therefore, the generation rate should increase with increasing area.

As shown in Figure 7.4, this was observed for all the round orifices tested in the small-scale system. The orifices represented in the figure have target dimensions of $0.3 \mathrm{~mm}, 0.5 \mathrm{~mm}, 1 \mathrm{~mm}$, and $2 \mathrm{~mm}$. The generation rate predicted by the WTP model is shown for comparison. The experimental net generation rates have an appreciably greater dependence on area for all three droplet size bins, particularly for the $10-\mu \mathrm{m}$ size bin.

The relationship between net generation rate and orifice area is not as well defined for the rectangular slots. The average data are from tests conducted at $380 \mathrm{psi}$ using slots of the following target dimensions (listed from smallest to largest area orifices): $0.3 \times 5 \mathrm{~mm}, 0.5 \times 5 \mathrm{~mm}, 0.5 \times 10 \mathrm{~mm}, 1 \times 5 \mathrm{~mm}$, $0.5 \times 15 \mathrm{~mm}$, and $0.5 \times 20 \mathrm{~mm}$. The dependence on area for the net generation rate is closer to that of the WTP model than was the case for round holes, but there is not a clear monotonic trend. It should be noted that the narrowest slot, $0.3 \times 5 \mathrm{~mm}$, was missing some initial data because of laser drift, so may be suspect; this may explain why it does not show the same trend as the data from larger slots.

Figure 7.5 shows the relationship between release fraction and orifice area. Consistent with the behavior of the net generation rate, the $10-\mu \mathrm{m}$ release fraction increases slightly or holds level for the round holes, then decreases (though not monotonically) for the slots. It is not clear whether this is the result of dependence on area or on hole shape, or both. The cumulative release fraction for droplets that are $<30 \mu \mathrm{m}$ from the round holes has a slope more similar to that of the WTP model, though the decrease of the measured release fraction with increasing area is not so strong as the decrease for the WTP model. There are not many data points for the release fraction of the $<100-\mu \mathrm{m}$ droplets from round holes, but those few seem to match the model dependence. The measured cumulative release fractions for droplets of a given size are consistently less than the WTP model at all the tested areas, although the measured values for $<10$ - $\mu \mathrm{m}$ droplets approach the WTP model at about $3 \mathrm{~mm}^{2}$ area. Orifices with area of $0.2 \mathrm{~mm}^{2}$ or less produce RFs and net generation rates that are less than $10 \%$ of the WTP model predictions. 

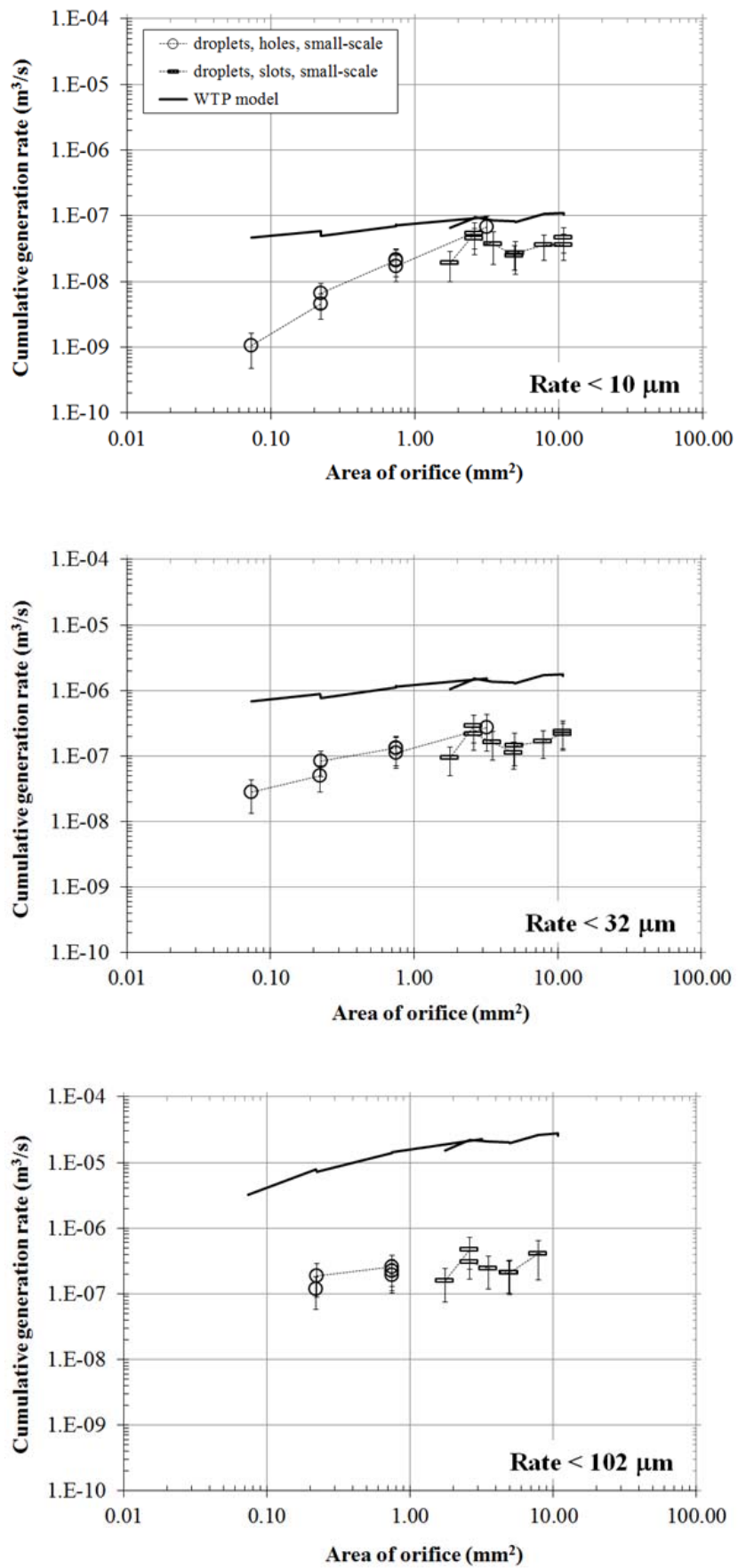

Figure 7.4. Net Generation Rate Versus Orifice Area for Single Round Holes and Slots, Using Water at 380 psi. WTP model predictions are shown by the thick black lines. Error bars show an approximate 95-percent confidence interval including model fit and experimental variability. The smallest slot test was missing some initial data because of laser drift and may be suspect. The release fraction from smallest round hole test may be 30\% low because of flow measurement inaccuracy. Appendix D identifies the tests in the plot. 

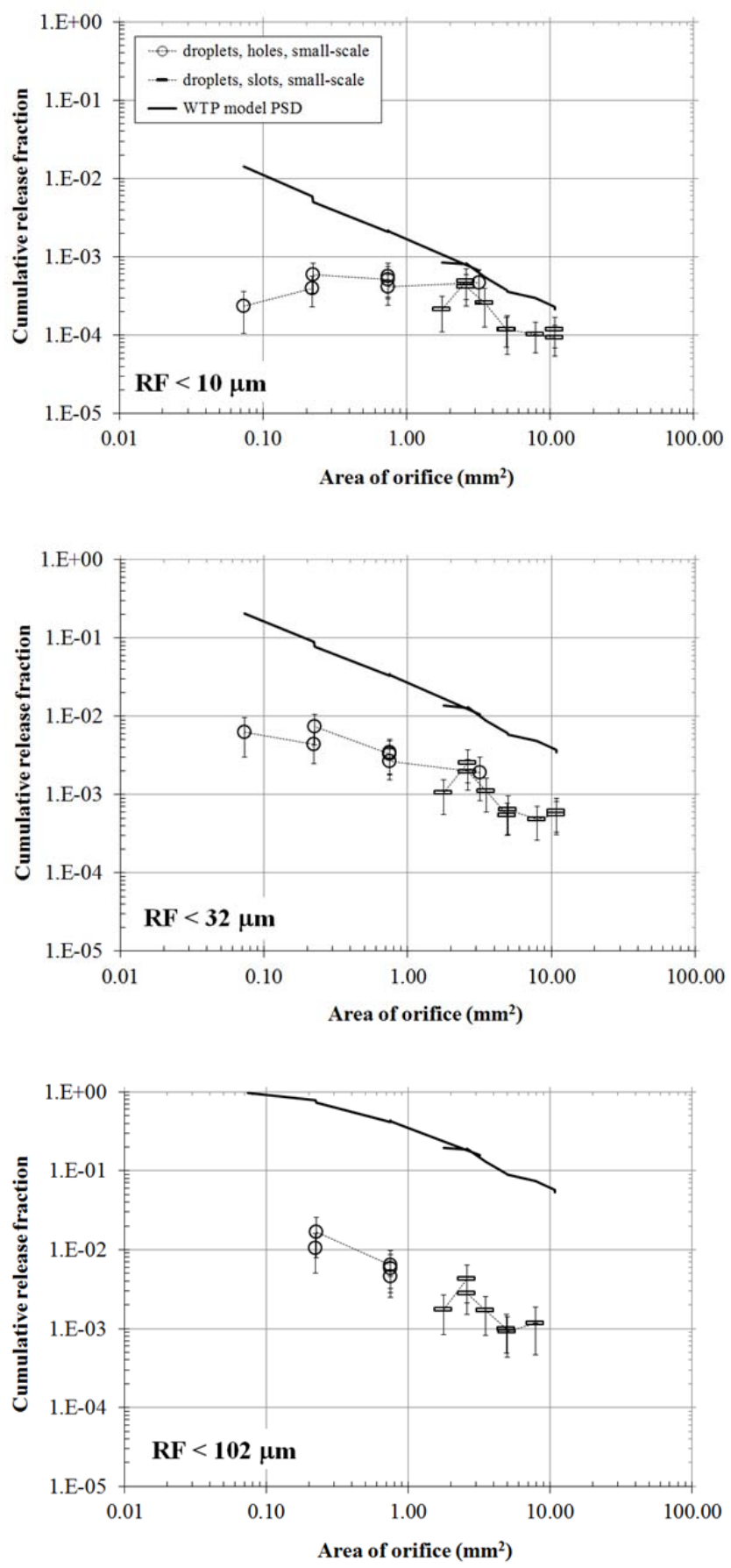

Figure 7.5. Release Fraction Versus Orifice Area for Single Round Holes and Slots, Using Water at 380 psi. WTP model predictions are shown by the thick black lines. Error bars show an approximate 95-percent confidence interval including model fit and experimental variability. The smallest slot test was missing some initial data because of laser drift and may be suspect. The release fraction from smallest round hole test may be 30\% low because of flow measurement inaccuracy. Appendix D identifies the tests in the plot. 


\subsubsection{Effect of Aspect Ratio}

The set of slots studied in this report were selected to provide a subset that had orifices of the same width but increasing lengths (i.e., $0.5 \times 5 \mathrm{~mm}, 0.5 \times 10 \mathrm{~mm}, 0.5 \times 15,0.5 \times 20 \mathrm{~mm}$ ). Data from this subset can be examined to observe the effect of changing length on the cumulative release fraction. In Figure 7.6, the variation of release fraction at 380 psi is shown as a function of length (plotted as area). The figure has plotted the release fraction instead of the generation rate against the area, and the WTP model predicts a decrease in release fraction with increasing length. The data has an overall trend that is close to WTP model predictions. However, the decrease in release fraction from the smallest to the second-smallest slot is more pronounced for the measured release fractions than for the data, and the slopes of release fractions for the three largest orifice sizes are less pronounced. The figure suggests that there is an aspect ratio above which the atomization efficiency is constant with increasing slot length.

The set of slots studied in this report also contained a subset that had orifices of the same length but increasing widths $(0.35 \times 5 \mathrm{~mm}, 0.5 \times 5 \mathrm{~mm}, 0.7 \times 5 \mathrm{~mm}, 1 \times 5 \mathrm{~mm})$. Figure 7.7 presents data from that subset at $380 \mathrm{psi}$. The results imply that changes in the width of an orifice lead to deviations from the model predictions that are larger than if the length is changed. The release fraction from the narrowest slot is lower than the remaining three slots; the larger slots show a trend of release fraction decreases with area that is slightly greater than that predicted by the WTP model. It should be noted that the narrowest slot, $0.35 \times 5 \mathrm{~mm}$, was missing some initial data because of laser drift so the results may be suspect; this may explain why it does not show the same trend as the data from larger slots.

Changing the area by changing the slot length appeared to produce changes in release fractions that matched the WTP model, within the uncertainty. Changing the area by changing the slot width may have had a greater effect on the release fraction than predicted by the WTP model, although the presence of a suspect run makes the trend harder to interpret. The measured release fractions were less than the WTP model for the same droplet size range in all cases. 

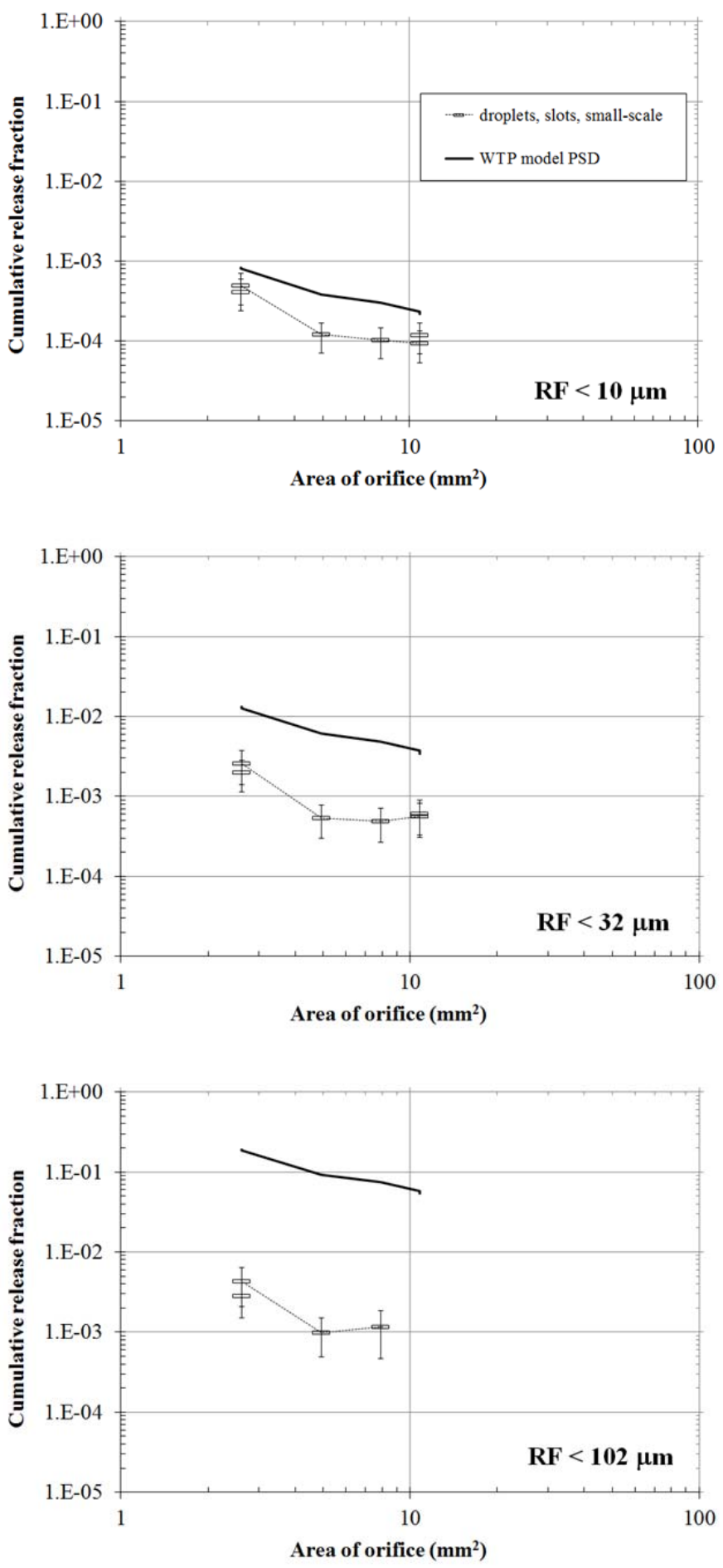

Figure 7.6. Release Fraction Versus Slot Length for Slots of $0.5 \mathrm{~mm}$ Width, Using Water at 380 psi. WTP model predictions are shown by the thick black lines. Error bars show an approximate 95-percent confidence interval including model fit and experimental variability. Appendix D identifies the tests in the plot. 

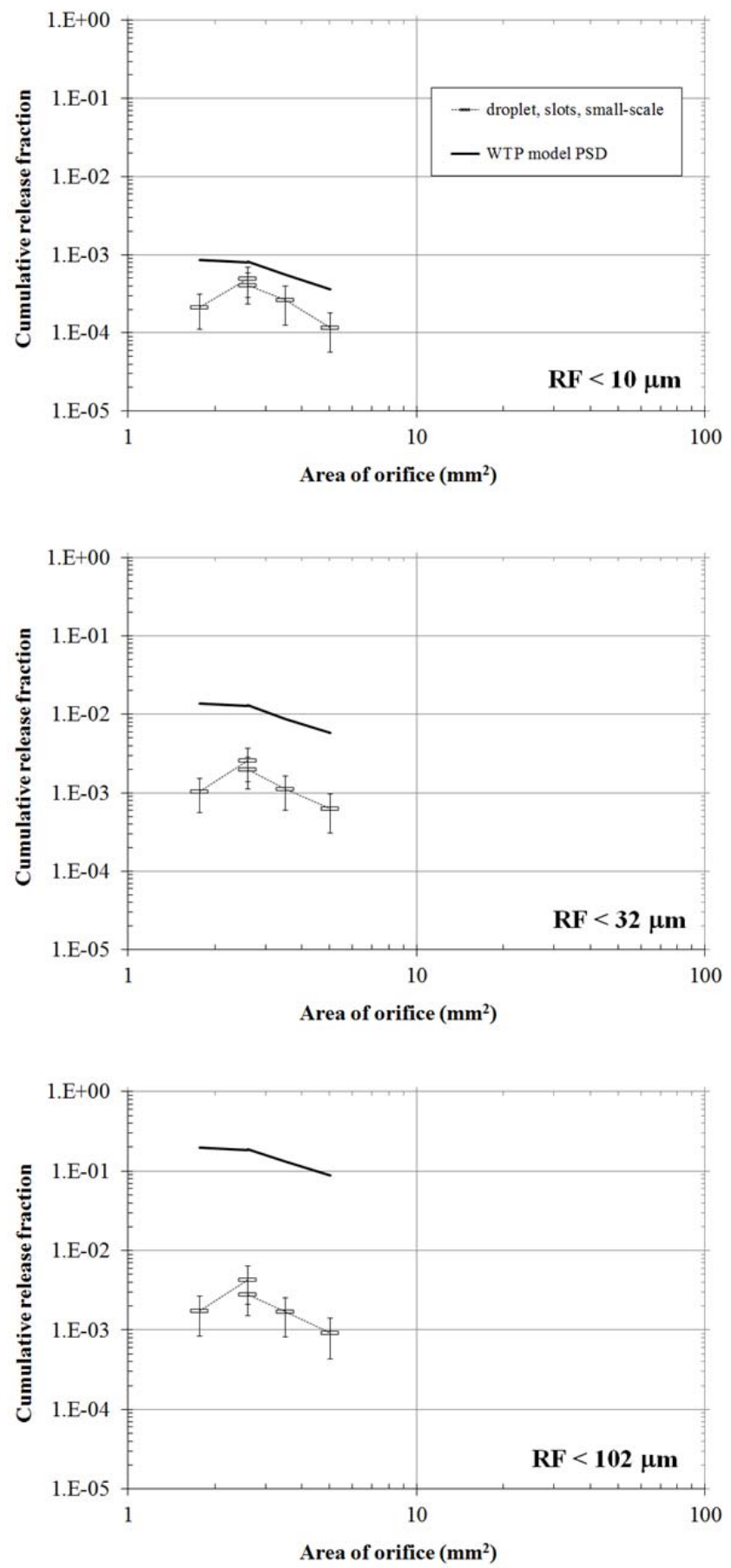

Figure 7.7. Release Fraction Versus Slot Width for Slots of 5-mm Length, Using Water at 380 psi. WTP model predictions are shown by the thick black lines. Error bars show an approximate 95-percent confidence interval including model fit and experimental variability. The narrowest slot was missing some initial data because of laser drift so the data may be suspect. Appendix D identifies the tests in the plot. 


\subsection{Effect of Pressure}

The small-scale aerosol testing of orifice effects was conducted for a limited set of pressures, using process water and an FER simulant slurry. In the WTP model, the pressure affects the aerosol generation rate through the square-root dependence of leak flow rate on pressure and through the effect of jet velocity (dependent on the square-root of pressure) upon the spray SMD. As discussed in Section 1.2.2, SMD is proportional to $\mathrm{U}^{-2 / 3}$ when the leading term in Equation (1.1) is much greater than the other terms. The dependence of the SMD on pressure is thus SMD $\sim \Delta \mathrm{P}^{-1 / 3}$, and based on Equation (1.5), this is predicted to result in larger release fractions as pressure increases.

In the small-scale tests, three target pressures were employed: 100,200 , and $380 \mathrm{psig}$. The effect of pressure on water sprays can be observed by comparing the release fractions measured at these three pressures for a constant orifice size. Two examples are shown in Figure 7.8 (a round hole) and Figure 7.9 (a rectangular slot). Although the number of tests is small and well-fit data were not available for all droplet sizes, the increase in the release fraction with increasing pressure appears to be approximately that of the WTP model, for water. It should be noted that the 100-psig and 200-psig runs for the slot were missing some initial data because of laser drift so the data may be suspect, which makes the slot pressure trend difficult to interpret. Nevertheless, it can be seen that the measured release fractions were less than the WTP model for the same droplet size range in all the water sprays.

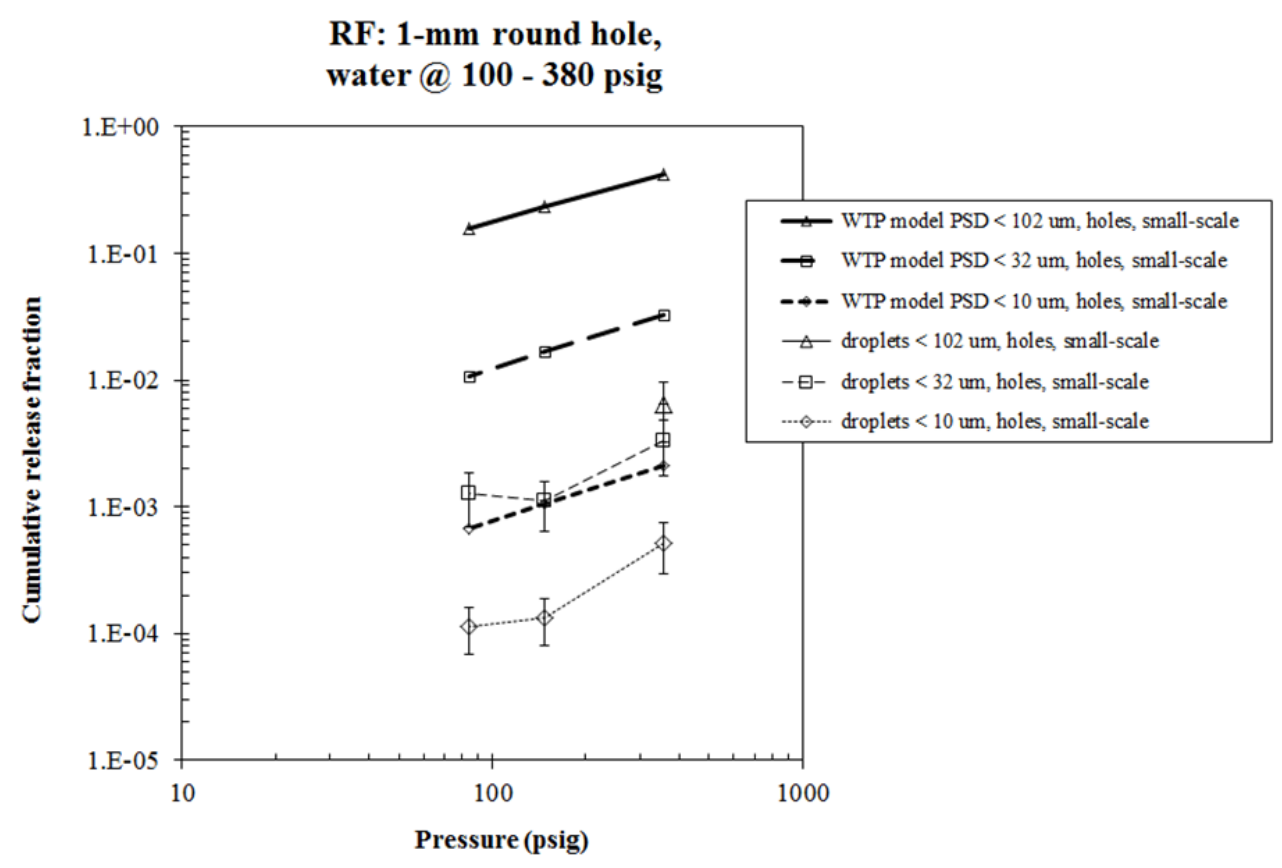

Figure 7.8. Effect of Pressure on Release Fractions for a Water Spray from a Target 1-mm Hole. WTP model predictions are shown by the thick black lines. Error bars show an approximate 95-percent confidence interval including model fit and experimental variability. Appendix D identifies the tests in the plot. 


\section{RF: axially-oriented $0.5 \times 5 \mathrm{~mm}$ slots, water@100 - 380 psig}

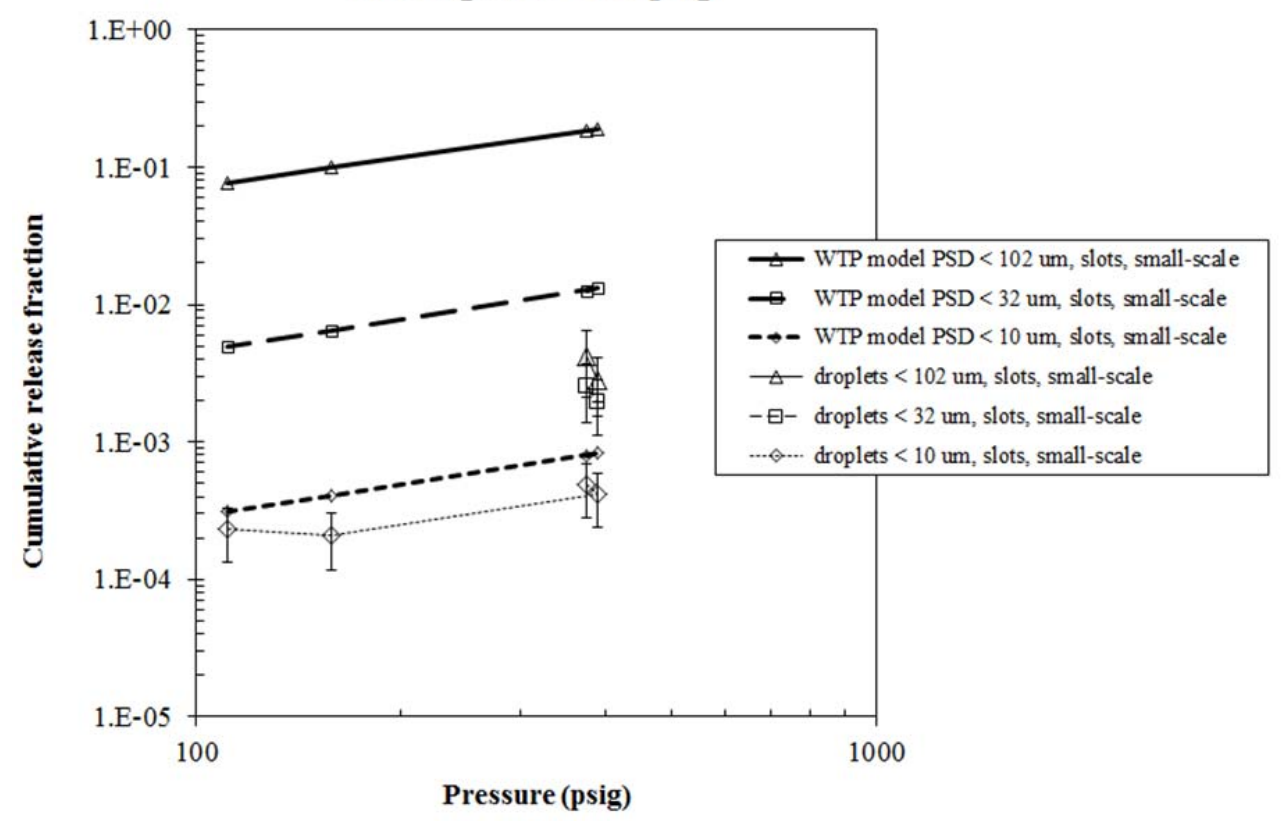

Figure 7.9. Effect of Pressure on Release Fractions for a Water Spray from a Target $0.5 \times 5-\mathrm{mm}$ Slot. WTP model predictions are shown by the thick black lines. Error bars show an approximate 95-percent confidence interval including model fit and experimental variability. The 100-psig and 200-psig runs were missing some initial data because of laser drift so the data may be suspect. Appendix D identifies the tests in the plot.

Several tests with four different variants of non-Newtonian FER simulant slurry also were conducted, although the only two pressures considered were 200 and 380 psig:

- "FER6-B." Boehmite-containing FER slurry with a target yield stress of 6 Pa (the actual rheological properties, per Table 3.8, were $7.3 \mathrm{~Pa}$ and $9.8 \mathrm{mPa} \cdot \mathrm{s}$, for the up-ramp of rheometry), shown in Figure 7.10 and Figure 7.11

- "FER6+AFA." Gibbsite-containing FER slurry plus AFA with a target yield stress of 6 Pa (actually 9.9 $\mathrm{Pa}$ and $13.5 \mathrm{mPa} \cdot \mathrm{s}$, for the rheometric down-ramp), shown in Figure 7.12 and Figure 7.13

- "FER30." Gibbsite-containing FER slurry with a target yield stress of $30 \mathrm{~Pa}$ (actually $11.5 \mathrm{~Pa}$ and $12.4 \mathrm{mPa} \cdot \mathrm{s}$, for the rheometric down-ramp), shown in Figure 7.14 and Figure 7.15

- "FER30+AFA." Gibbsite-containing FER slurry plus AFA with a target yield stress of $30 \mathrm{~Pa}$ (actually 15.4 $\mathrm{Pa}$ and $15.9 \mathrm{mPa} \cdot \mathrm{s}$, for the rheometric down-ramp), shown in Figure 7.16 and Figure 7.17. 


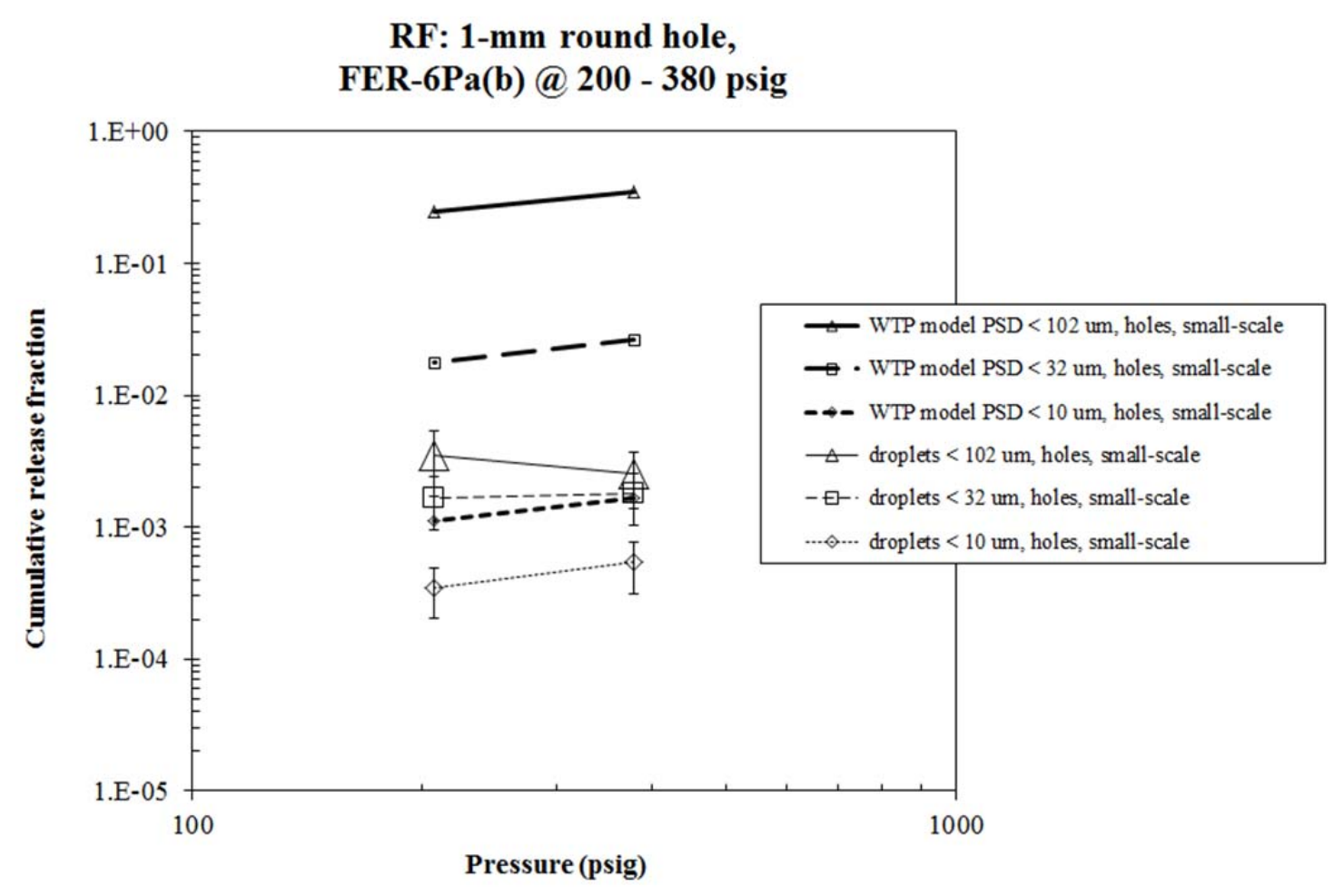

Figure 7.10. Effect of Pressure on Release Fractions for a Spray of FER6-B from a Target 1-mm Hole. WTP model predictions are shown by the thick black lines. Error bars show an approximate 95-percent confidence interval including model fit and experimental variability. Appendix D identifies the tests in the plot.

The pressure trends do not appear to follow those predicted by the WTP model. ${ }^{19}$ The model shows an increase in release fraction with increasing pressure because of the effect of higher jet velocity, whereas the data show several cases of release fraction decreasing with increasing pressure. The trends are not perfectly clear, in that lines often could be drawn that would match the WTP model pressure dependence while remaining within the error bars. However, the repeated presence of decreasing best-fit release fractions, with increasing pressure, suggests the downward trend is real.

\footnotetext{
${ }^{19}$ In Figure 7.11 through Figure 7.17, the WTP model predictions for FER simulants are calculated using the measured Bingham consistency as the viscosity.
} 


\section{RF: axially-oriented $0.5 \times 5 \mathrm{~mm}$ slots, FER-6Pa(b)@200-380 psig}

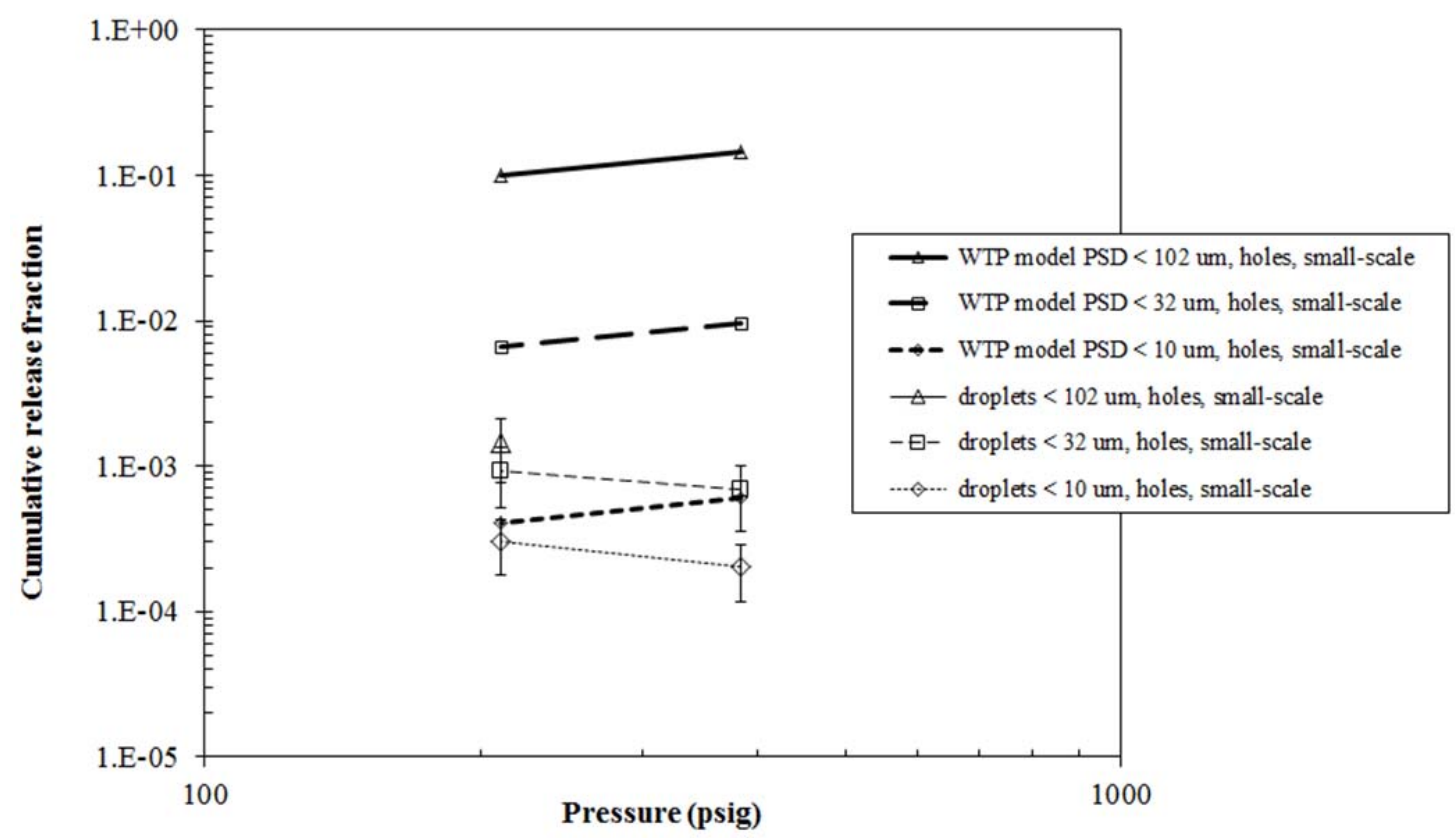

Figure 7.11. Effect of Pressure on Release Fractions for a Spray of FER6-B from a Target $0.5 \times 5$-mm Slot. WTP model predictions are shown by the thick black lines. Error bars show an approximate 95-percent confidence interval including model fit and experimental variability. Appendix D identifies the tests in the plot.

Generally speaking, the release fractions follow similar pressure trends for all four FER simulants. The trends for round holes match those of the WTP model slightly more closely than the trends for slots, but the difference is not great. To the extent that good fits for the release fractions were obtained for larger droplet sizes $(<30 \mu \mathrm{m}$ and $<100 \mu \mathrm{m})$, they are likelier to have release fractions that decrease with increasing pressure than are the $<10-\mu \mathrm{m}$ droplets. Because the release fraction does not increase with increasing pressure as much as for the WTP model, or show the opposite trend, a (speculative) extrapolation of the pressure trend indicates that the measured release fractions could exceed the WTP model at pressures somewhere below 200 psig. Figure 7.13, Figure 7.15, and Figure 7.17 (i.e., the slot orifice) all show cases where the measured release fraction for $<10-\mu \mathrm{m}$ droplets equals or exceeds the WTP model at 200 or 380 psig. Other droplet size ranges and other conditions produced release fractions less than the WTP model.

It should be noted that the FER3 0 run with the round hole and 380 psig pressure resulted in irregular pressure during the spray, and the FER30+AFA run with the slot and 200 psig pressure showed low flow and is thought to have had a partially-plugged orifice. These runs may be suspect, but there are enough non-suspect runs to suggest that the FER simulant pressure trends do not match the WTP model. 


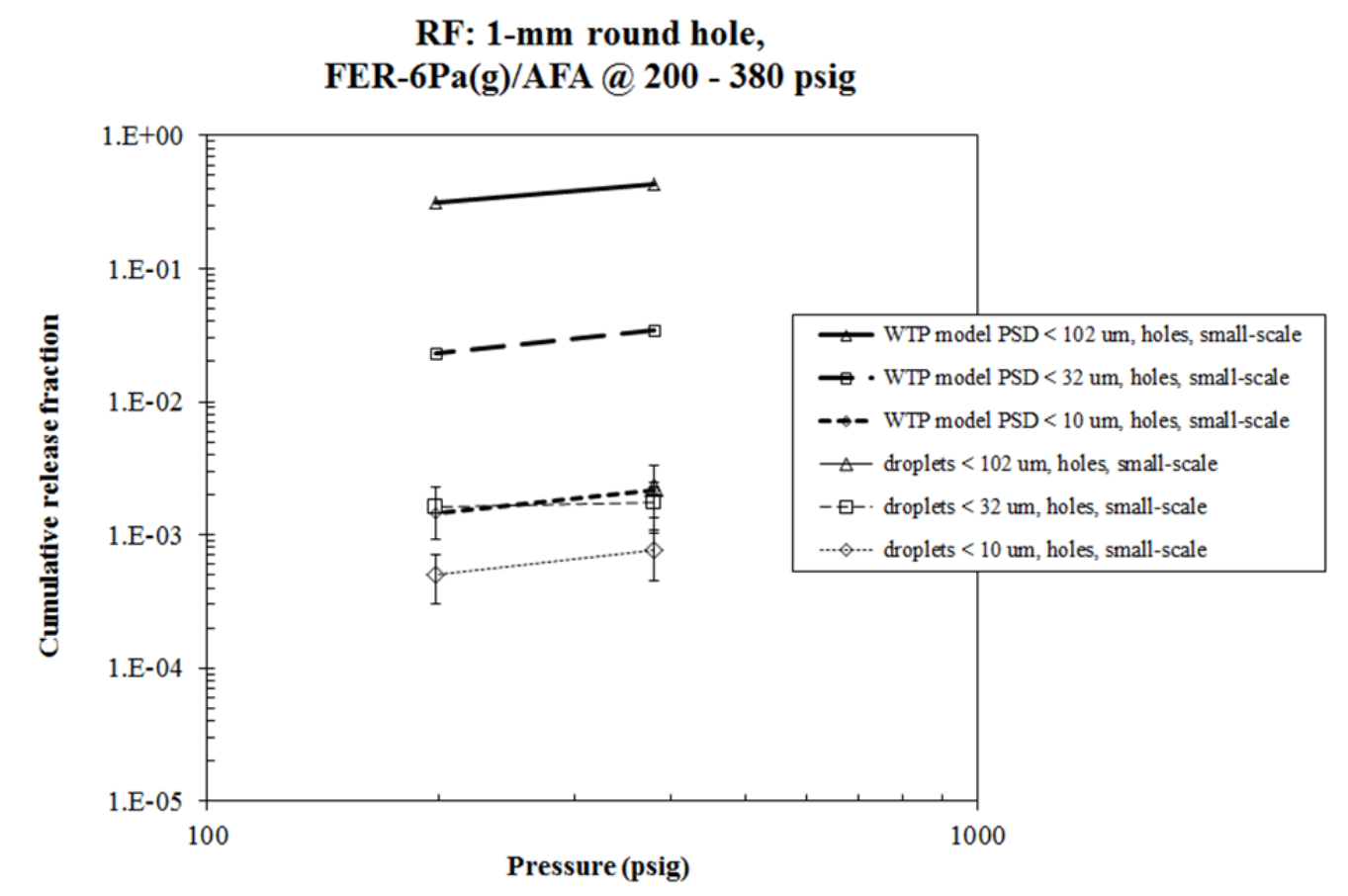

Figure 7.12. Effect of Pressure on Release Fractions for a Spray of FER6+AFA from a Target 1-mm Hole. WTP model predictions are shown by the thick black lines. Error bars show an approximate 95-percent confidence interval including model fit and experimental variability. Appendix D identifies the tests in the plot.

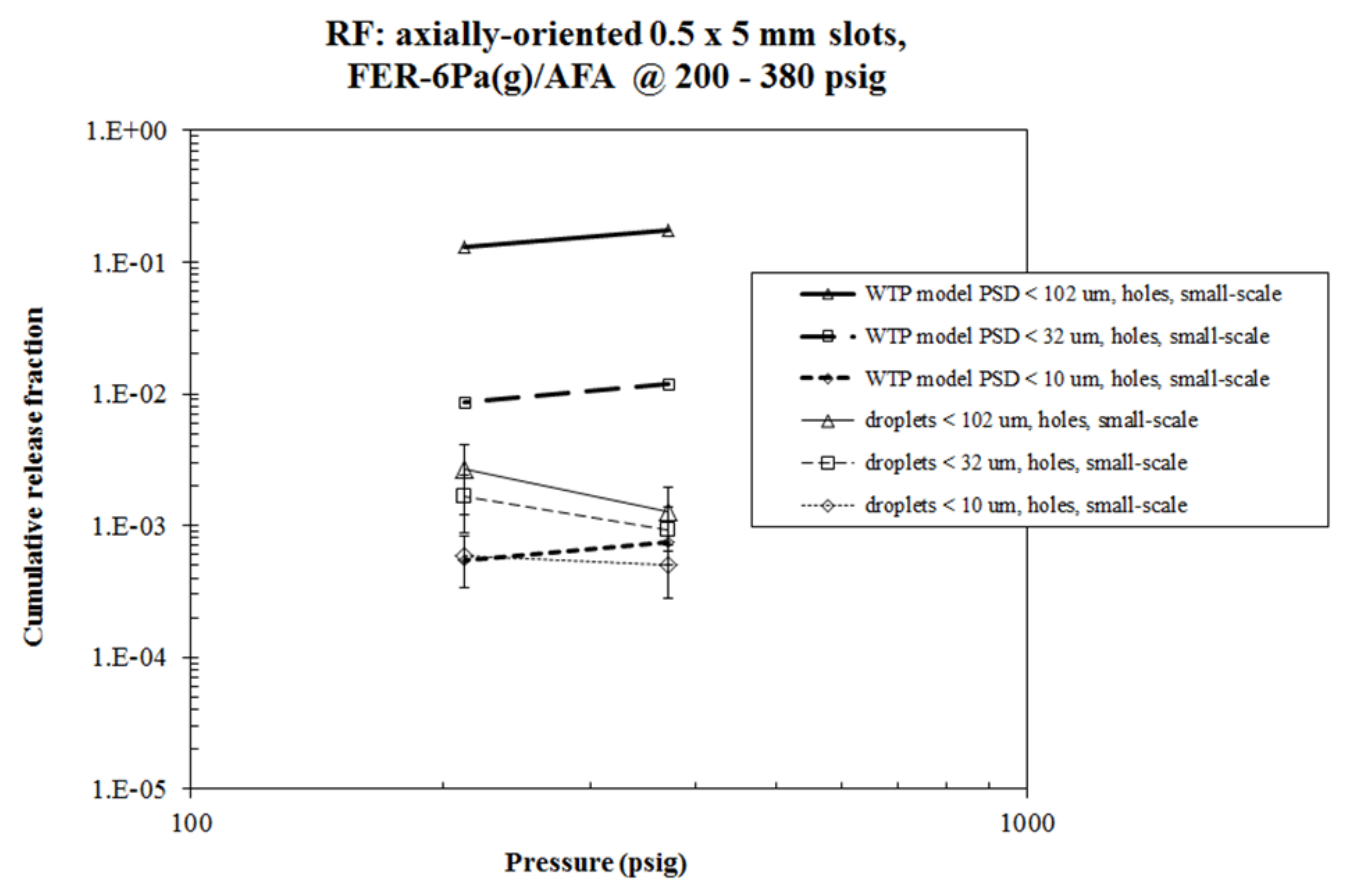

Figure 7.13. Effect of Pressure on Release Fractions for a Spray of FER6+AFA from a Target $0.5 \times 5$-mm Slot. WTP model predictions are shown by the thick black lines. Error bars show an approximate 95-percent confidence interval including model fit and experimental variability. Appendix D identifies the tests in the plot. 
RF: 1-mm round hole, FER-30Pa(g)@200-380psig

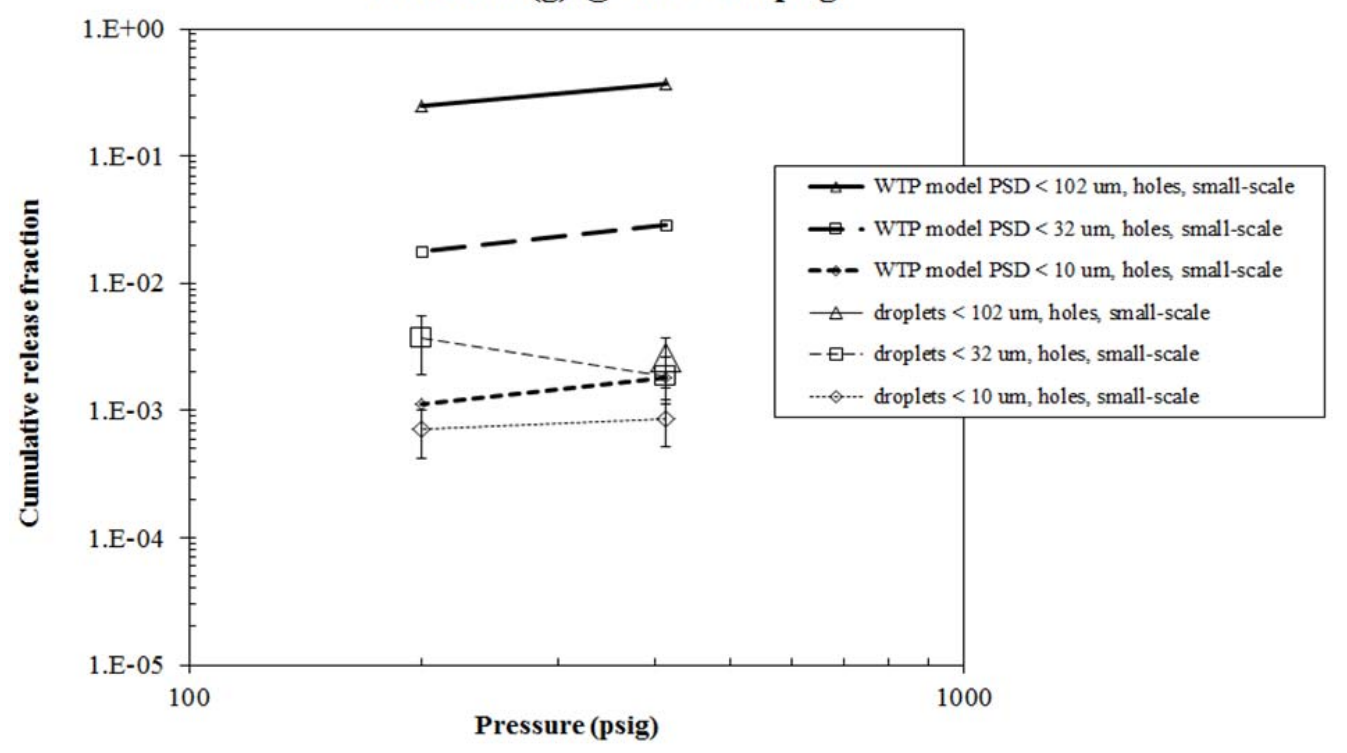

Figure 7.14. Effect of Pressure on Release Fractions for a Spray of FER30 from a Target 1-mm Hole. WTP model predictions are shown by the thick black lines. Error bars show an approximate 95-percent confidence interval including model fit and experimental variability. The run at 380 psig had pressure control difficulties so the data are suspect. Appendix D identifies the tests in the plot.

\section{RF: axially-oriented $0.5 \times 5 \mathrm{~mm}$ slot, FER-30Pa(g)@200-380psig}

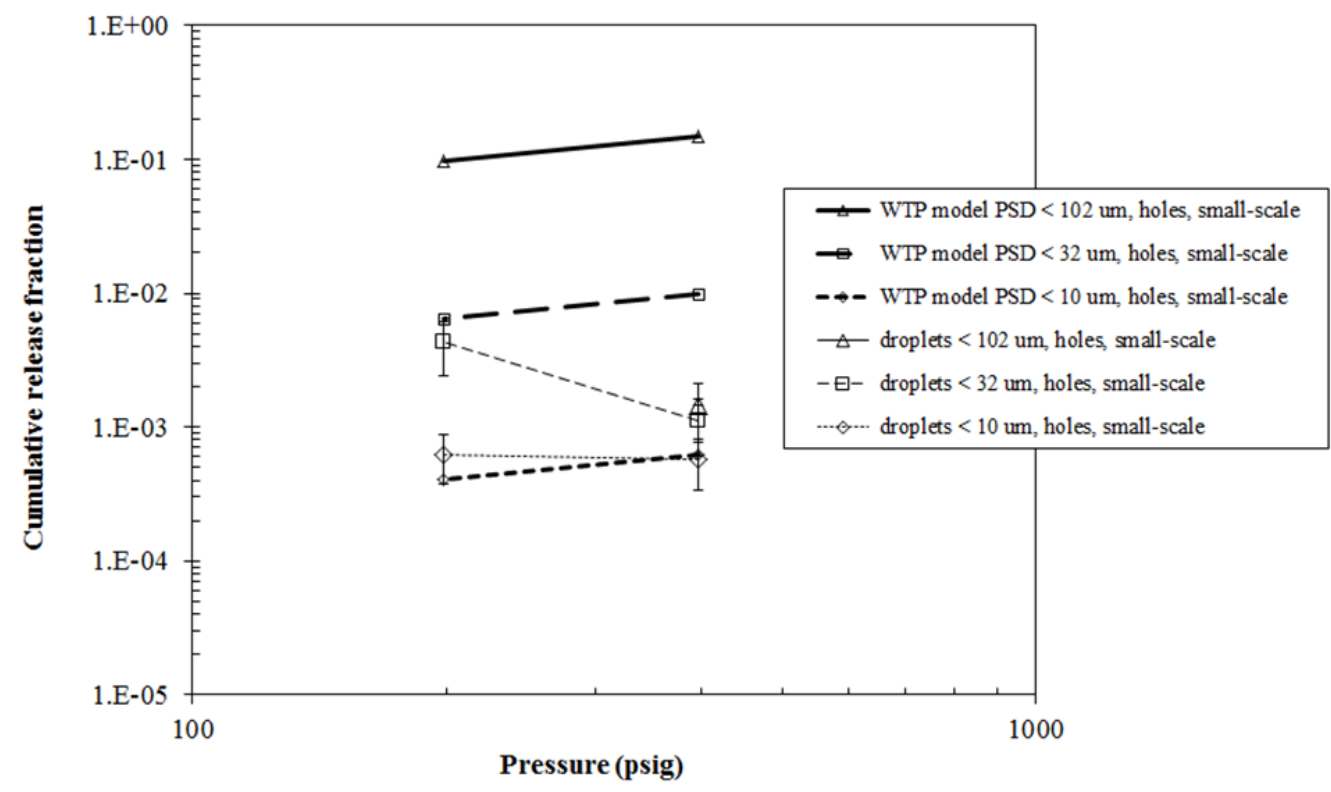

Figure 7.15. Effect of Pressure on Release Fractions for a Spray of FER30 from a Target

$0.5 \times 5$-mm Slot. WTP model predictions are shown by the thick black lines. Error bars show an approximate 95 -percent confidence interval including model fit and experimental variability. Appendix D identifies the tests in the plot. 
RF: 1-mm round hole, FER-30Pa(g)/AFA@200-380psig

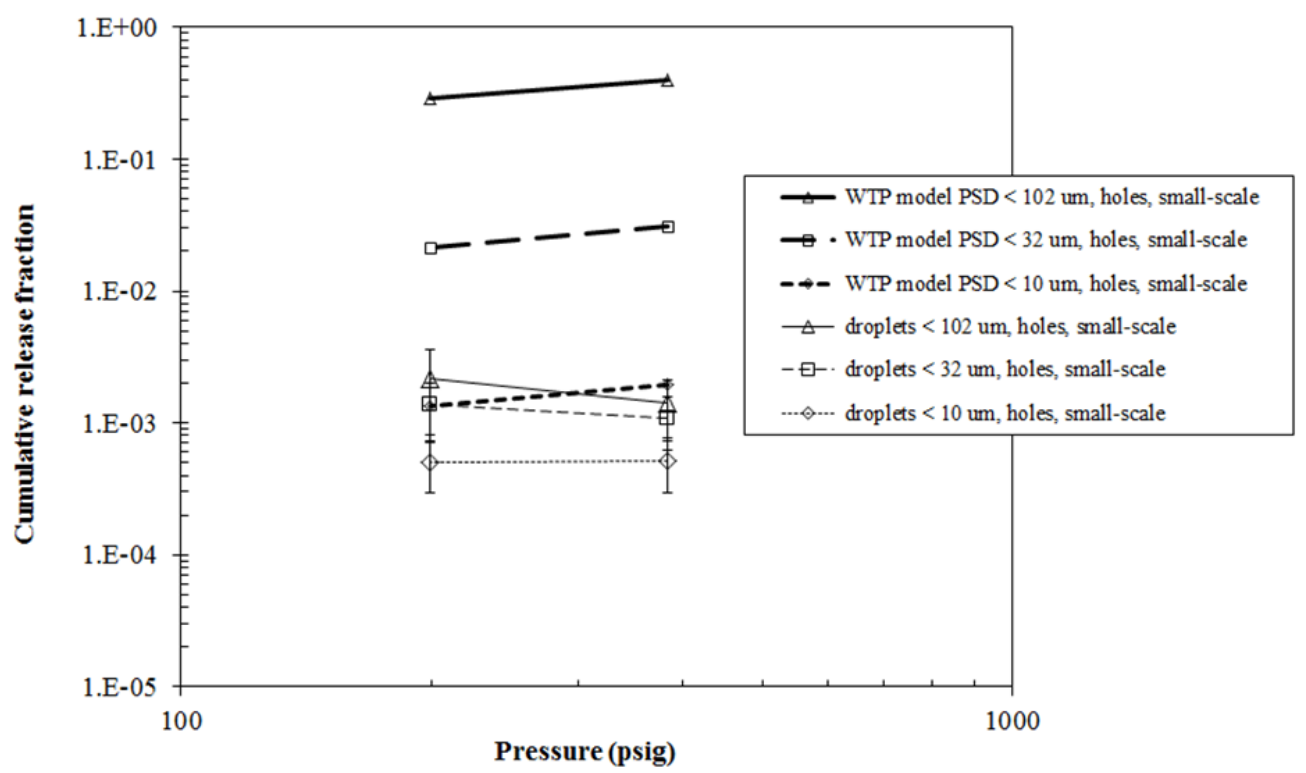

Figure 7.16. Effect of Pressure on Release Fractions for a Spray of FER30+AFA from a Target 1-mm Hole. WTP model predictions are shown by the thick black lines. Error bars show an approximate 95-percent confidence interval including model fit and experimental variability. Appendix D identifies the tests in the plot.

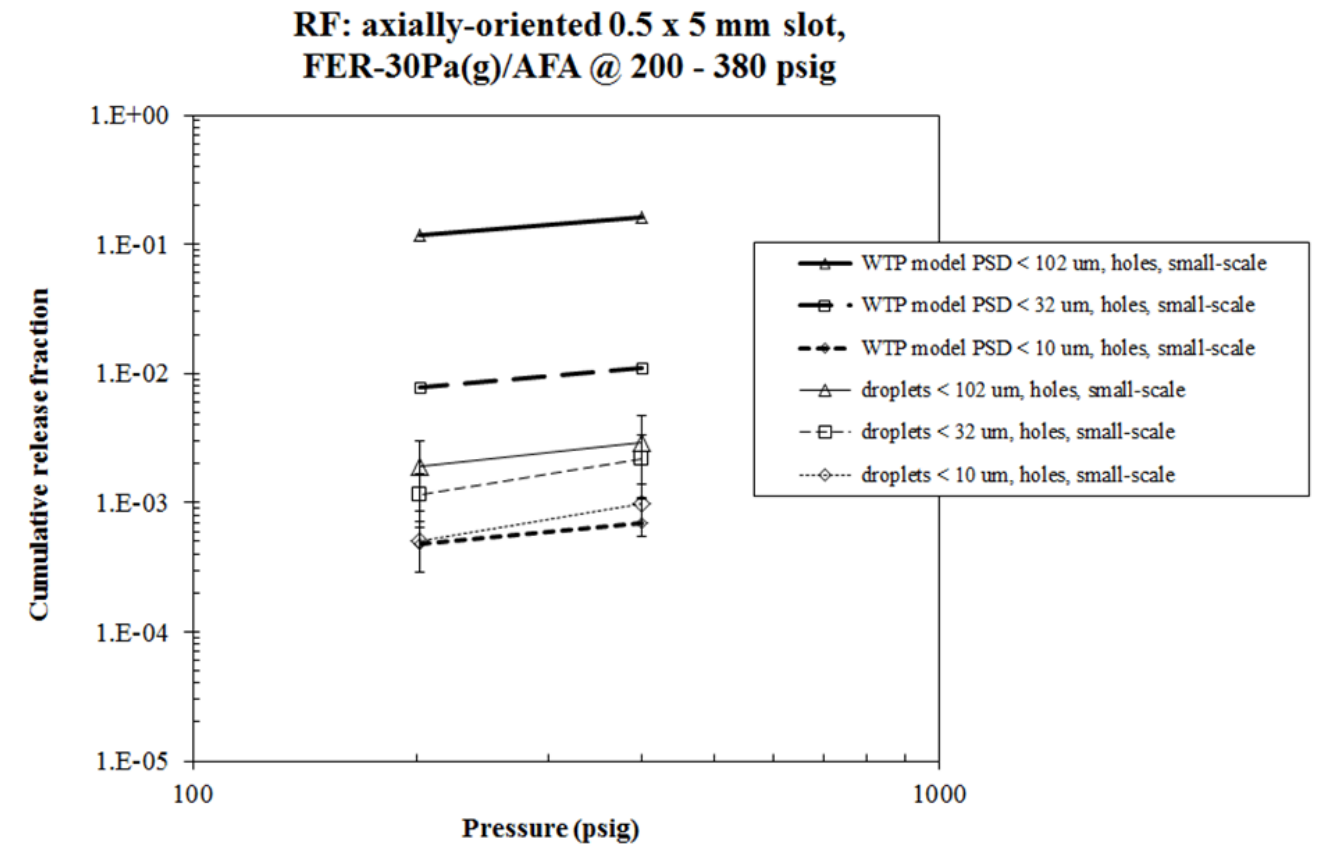

Figure 7.17. Effect of Pressure on Release Fractions for a Spray of FER30+AFA from a Target $0.5 \times 5$-mm Slot. WTP model predictions are shown by the thick black lines. Error bars show an approximate 95-percent confidence interval including model fit and experimental variability. The run at 200 psig may have had a partly-blocked orifice so the data are suspect. Appendix D identifies the tests in the plot. 


\subsection{Effect of Liquid Viscosity}

The WTP model includes a small effect of liquid (or slurry) viscosity on the release fraction. Based on Equations (1.1), (1.2), and (1.3), the SMD has a weak positive dependence on viscosity. This will result in a small decrease in release fraction with increasing viscosity if all other parameters remain the same. However, increasing the viscosity without changing other physical parameters of the fluid (i.e., density, surface tension, presence of solid particles) is challenging. Two liquid simulants were used in small-scale testing: a sodium thiosulfate $\left(\mathrm{Na}_{2} \mathrm{~S}_{2} \mathrm{O}_{3}\right)$ solution with a viscosity of $2.6 \mathrm{mPa} \cdot \mathrm{s}$, and a sodium nitrate $\left(\mathrm{NaNO}_{3}\right)$ solution with a viscosity of $1.8 \mathrm{mPa} \cdot \mathrm{s}$ (Table 3.5). These salt solutions had densities of about $1.24 \mathrm{~kg} / \mathrm{L}$ and surface tensions of 76 to $78 \mathrm{mN} / \mathrm{m}$; by comparison, the properties of the process water were $\sim 1 \mathrm{mPa} \cdot \mathrm{s}$ viscosity, $\sim 1 \mathrm{~kg} / \mathrm{L}$ density, and $72 \mathrm{mN} / \mathrm{m}$ surface tension.

The difference in density between water and the salt solutions reduces the certainty of any conclusions that may be drawn from a comparison of solutions to water, because the density affects both the WTP prediction (see Equations (1.1), (1.2), and (1.8)) and the experimental data (needed to calculate the spray leak volumetric flow rate). However, the properties of the two salt solutions are similar enough to allow the effects of viscosity to be distinguished.

The liquid viscosity tests were conducted at 380 psig using a target $1-\mathrm{mm}$ round hole. Figure 7.18 shows the release fraction size distribution of sprays of salt solutions and water. The two salt solutions behave indistinguishably, but give distinguishably lower cumulative release fractions for droplets $>30 \mu \mathrm{m}$, and higher release fractions for droplets $<5 \mu \mathrm{m}$. A complete comparison cannot be made for small sizes, because there were no good fits for water below $3 \mu \mathrm{m}$.

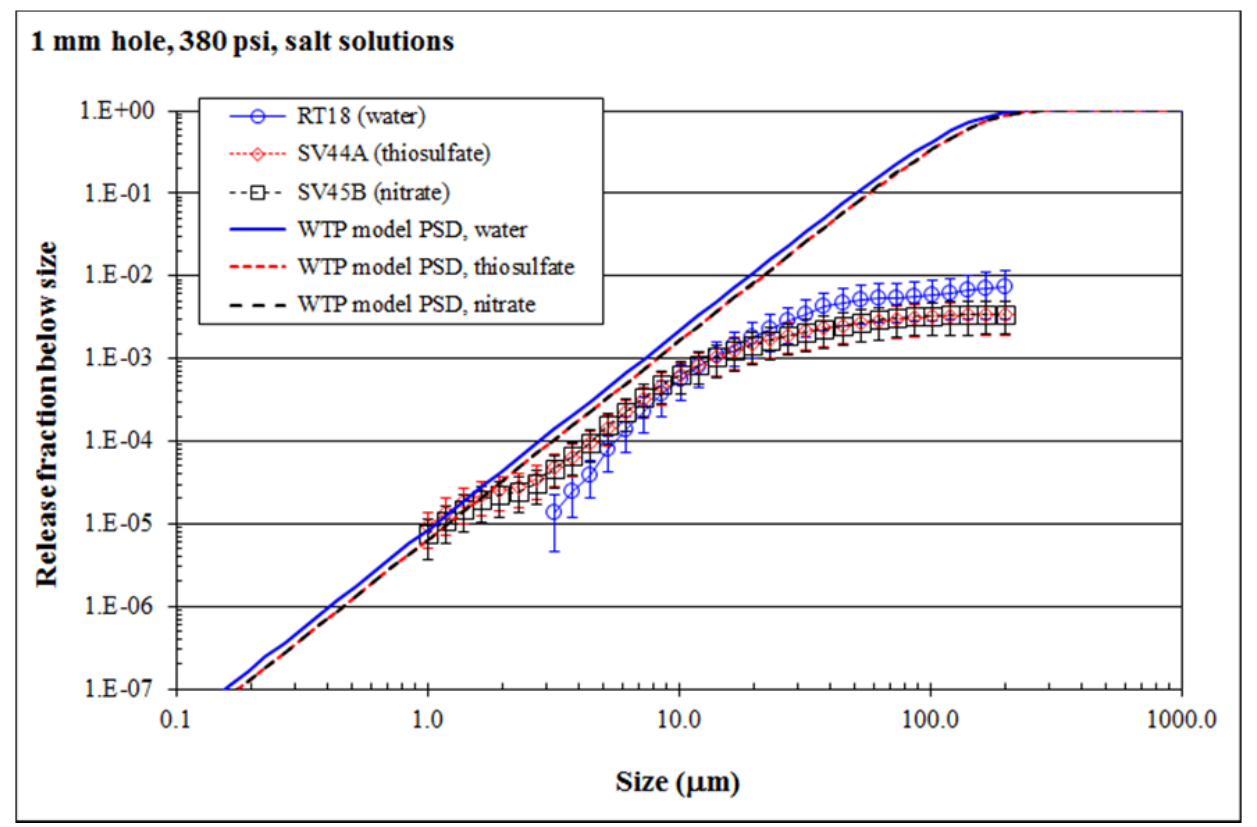

Figure 7.18. Release Fraction Distribution of Sprays of Water and Salt Solutions at 380 psig from a Target 1-mm Round Hole. WTP model predictions are shown by the thick lines (long-dashed black for sodium nitrate $\left[\mathrm{NaNO}_{3}\right]$, short-dashed red for sodium thiosulfate $\left[\mathrm{Na}_{2} \mathrm{~S}_{2} \mathrm{O}_{3}\right]$, solid blue for water). Each point is from a single run and error bars show an approximate 95-percent confidence interval that includes model fit and experimental variability. 
An example of a parametric comparison between the release fractions of water and salt solutions is shown in Figure 7.19. A slight decrease in release fraction with viscosity is seen for the $<32$ - and $<100-\mu \mathrm{m}$ droplets, but the trend for the $<10-\mu \mathrm{m}$ droplets is less well defined. The trends approximately match the WTP model predictions, but are more difficult to interpret because of the density difference between the salt solutions and water. On the other hand, the WTP model takes the density difference into account as well, and the difference between the model lines on the figure is smaller in magnitude than the difference between the test data.

The confounding effect of density can be reduced by comparing generation rates instead of release fractions. This comparison is made in Figure 7.20 for the same pressure and orifice. The WTP model predicts a slight decrease in cumulative generation rate between the two fluid viscosities. The experimental data for net generation rate show a greater decrease for the larger droplets than for the WTP model, and less decrease (possibly no effect) for the $<10$-mm droplets. However, the error bars envelop many or all of the trends, so the difference between data trends and WTP model trends may not be significant. The measured release fraction is consistently less than the WTP model for the same droplet size range and condition. 

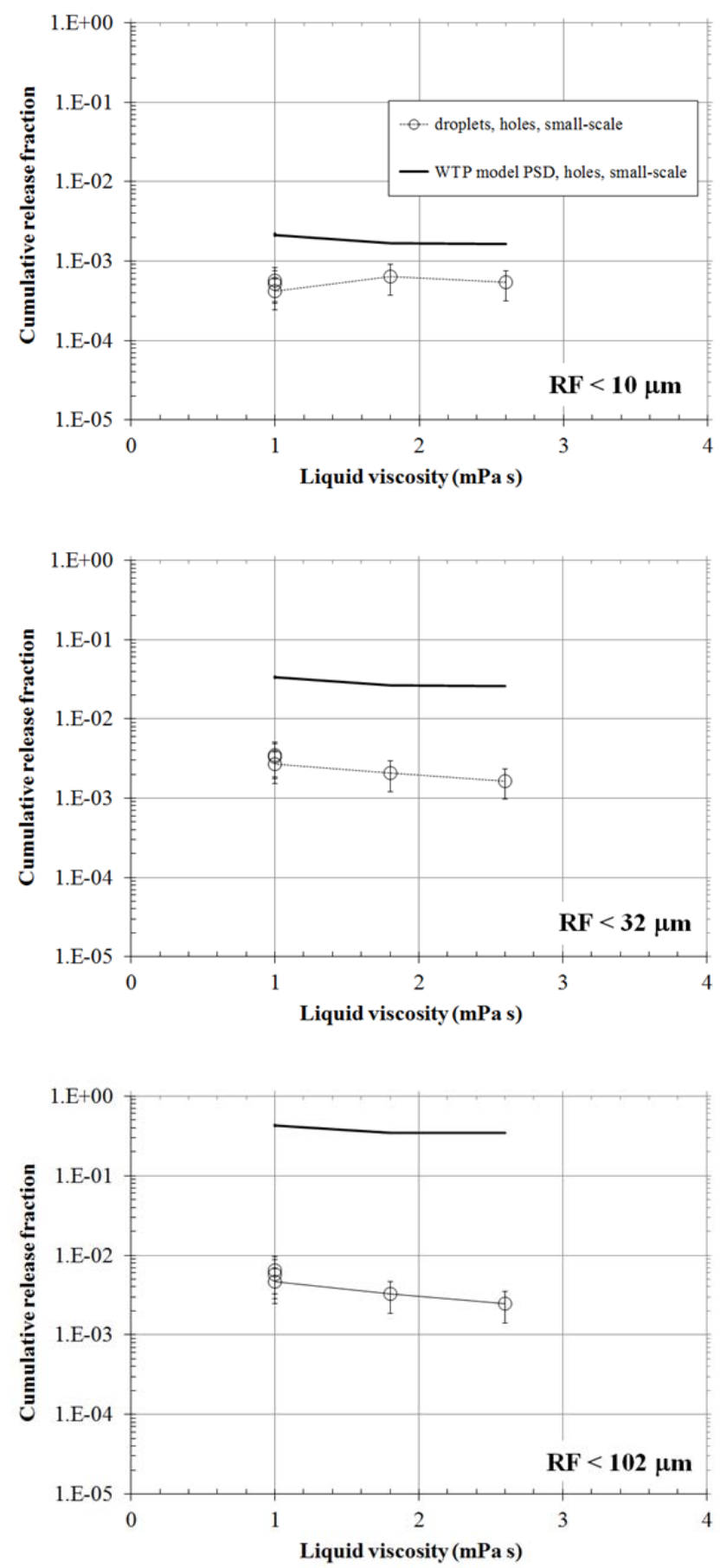

Figure 7.19. Effect of Liquid Viscosity on Release Fractions for Sprays of Water and Salt Solutions at 380 psig from a Target 1-mm Round Hole. WTP model predictions are shown by the thick black lines. Error bars show an approximate 95-percent confidence interval including model fit and experimental variability. Appendix D identifies the tests in the plot. 

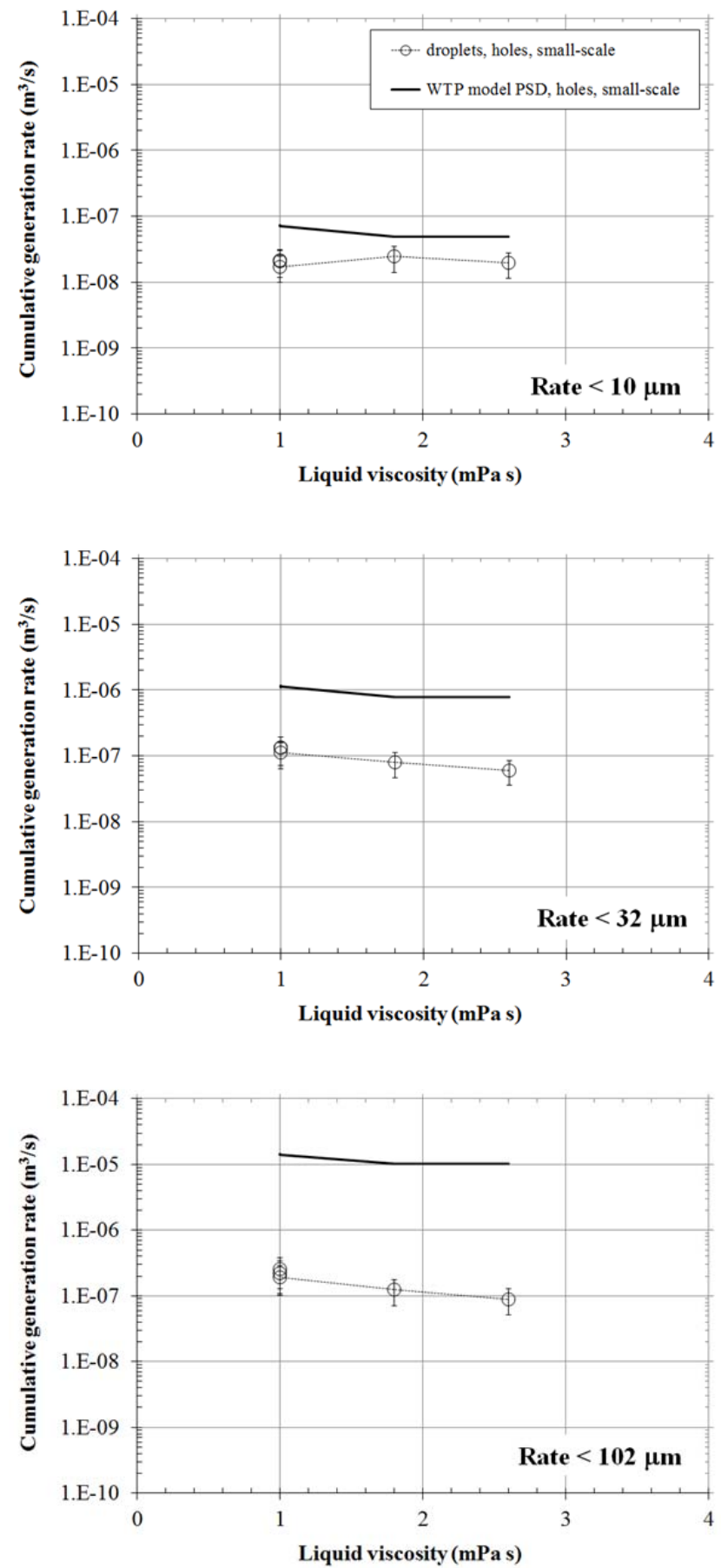

Figure 7.20. Effect of Liquid Viscosity on Aerosol Net Generation Rates for Sprays of Water and Salt Solutions at 380 psig from a Target 1-mm Round Hole. WTP model predictions are shown by the thick black lines. Error bars show an approximate 95-percent confidence interval including model fit and experimental variability. Appendix D identifies the tests in the plot. 


\subsection{Effect of Solids}

The effect of solids loading in slurry is addressed in the WTP model by using the properties (density, viscosity, surface tension) of the slurry. The effects of the presence of solids on breakup and atomization of the jet are not incorporated into the model because it was based on tests of liquid sprays. Some of these impacts are discussed in Section 1.2.4.

The following slurry simulants were used in small-scale testing:

- Slightly non-Newtonian STR simulant at $8 \mathrm{wt} \%$ boehmite solids, and Newtonian STR simulant at $20 \mathrm{wt} \%$ boehmite solids (Section 3.1.4)

- Newtonian SAR simulants at 8 and $20 \mathrm{wt} \%$ gibbsite solids (Section 3.1.3)

- Newtonian TAR simulant at $8 \mathrm{wt} \%$ gibbsite solids (Section 3.1.2).

Because slurry particles introduce some opacity to the system, they are fundamentally different than water, which is optically transparent. The measuring instruments depend on the scattering of laser light, so acquisition of high-quality data depends on proper specification of the refractive index of the material being measured. This is complicated by the possibility of aerosol generated that only contains solid, only contains liquid, or contains some mixture of both (i.e., a composite droplet). The approach used in this work was to use a composite refractive index based on mixing rules. Section 7.4.4 and Section 8.4 of the large-scale report (Schonewill et al. 2012) discuss the mixing rules, the resulting refractive index estimates, and the way in which data were checked for robustness to the choice of refractive index. The variation of the measured concentration and PSD with refractive index was found to be small, especially at droplet sizes of $10 \mu \mathrm{m}$ and larger, so the choice of refractive index was considered to be of minor concern. Although the refractive index did not have a significant impact, for all other analyses the composite slurry refractive index was used to analyze data. Because the aerosol was visually confirmed to be opaque, the finite absorbance of laser light (expressed as the imaginary component of the refractive index) had to be accounted for.

Two different orifices, a target $1-\mathrm{mm}$ round hole and a target $0.5 \times 5-\mathrm{mm}$ slot, were used as the baseline orifices for slurry tests. The test target pressure was 380 psig. Figure 7.21 and Figure 7.22 show the effect of STR boehmite solids on the cumulative release fractions for spray from, respectively, the baseline round hole and the baseline slot. ${ }^{20}$ The release fractions are lower for the $8 \mathrm{wt} \%$ slurry than the $20 \mathrm{wt} \%$ slurry. For both orifices, the release fractions of at least one of the slurries are higher than those of water, but only for droplet sizes $<5 \mu \mathrm{m}$. At droplet sizes $>10 \mu \mathrm{m}$, the release fraction for $20 \mathrm{wt} \% \mathrm{STR}$ is a little lower than that of water, whereas the release fraction of $8 \mathrm{wt} \%$ STR is distinguishably lower than water. The difference between the two slurry concentrations is more pronounced for the slot than for the round hole. As can be seen by comparing to the WTP model curves, the apparent differences between the slurries and water are greater than would be predicted from the fluid properties. However, the uncertainties in measurement make it unclear whether the observed differences are significant. Note that for the baseline slot, the measured release fractions are equal to the WTP model release fractions, within uncertainty between $<3 \mu \mathrm{m}$ and $<10 \mu \mathrm{m}$.

\footnotetext{
${ }^{20}$ In Figure 7.21 through Figure 7.26, the WTP model predictions for slurries are calculated using the measured viscosity, except that for the FER simulant the measured Bingham consistency is used for the viscosity.
} 


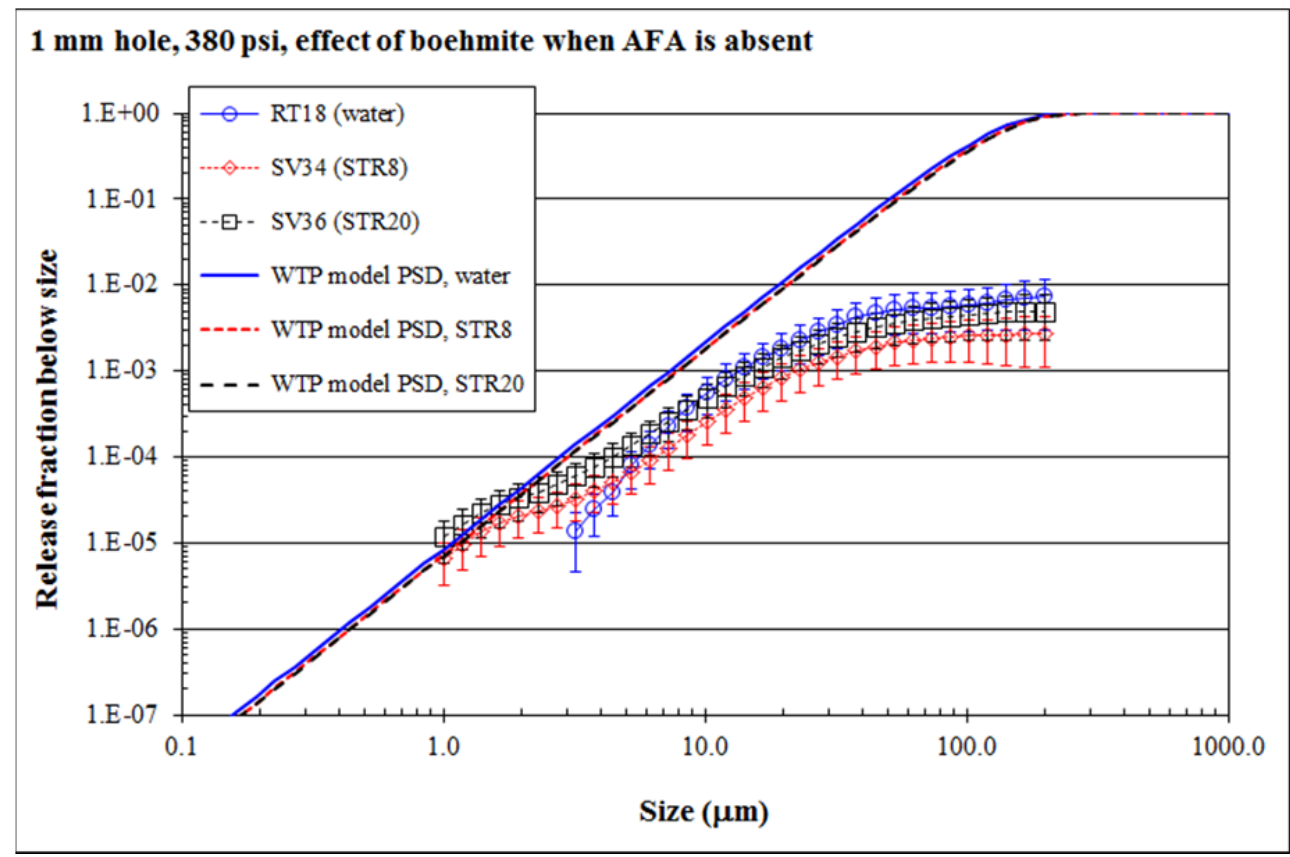

Figure 7.21. Effect of STR Boehmite Solids on Release Fractions for AFA-Free Sprays at 380 psig from a Target 1-mm Round Hole. WTP model predictions are shown by the thick lines (long-dashed black for STR at $20 \mathrm{wt} \%$, short-dashed red for STR at $8 \mathrm{wt} \%$, solid blue for water). Each point is from a single run and error bars show an approximate 95-percent confidence interval that includes model fit and experimental variability. 


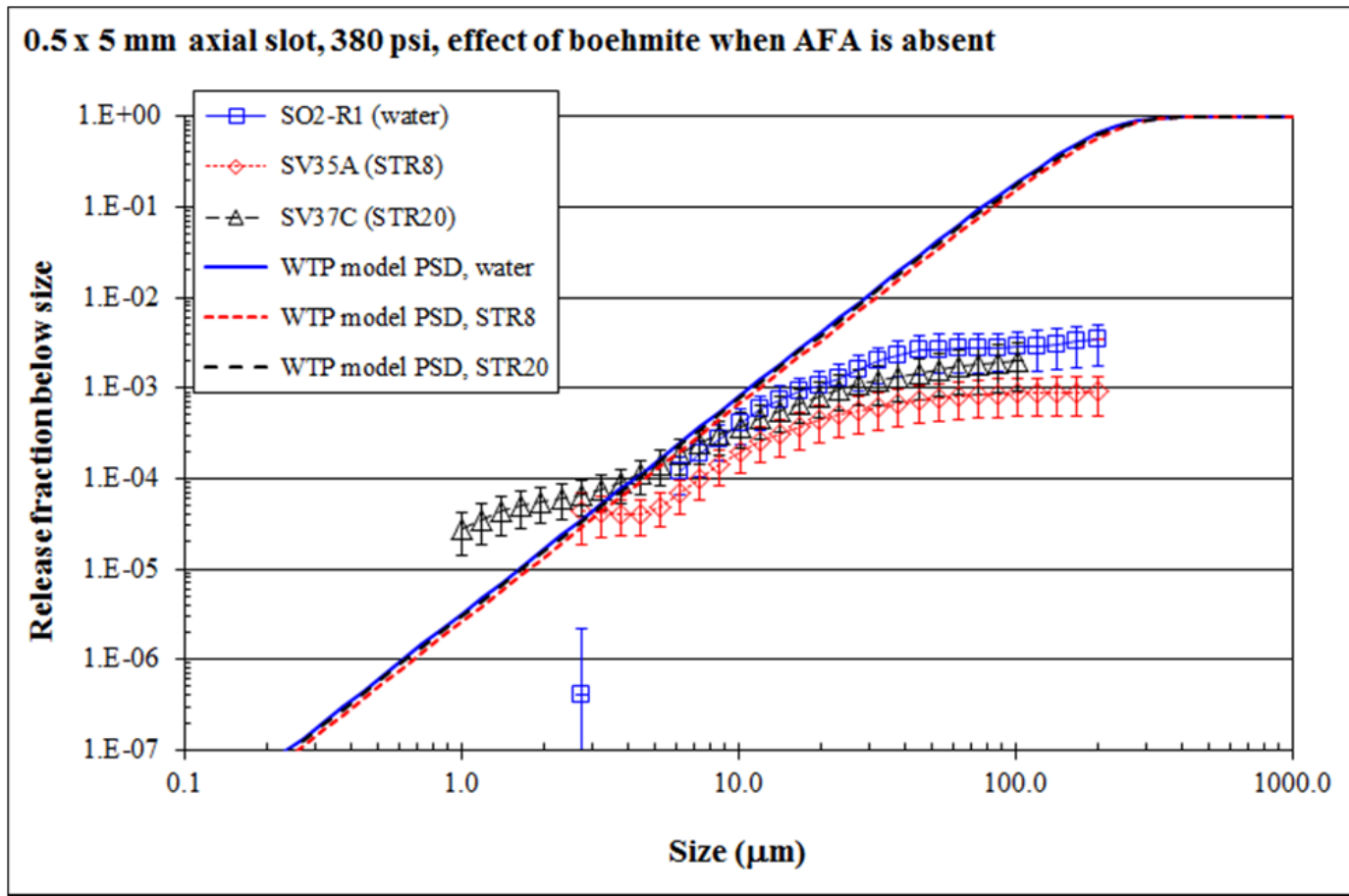

Figure 7.22. Effect of STR Boehmite Solids on Release Fractions for AFA-Free Sprays at 380 psig from a Target $0.5 \times 5$-mm Slot. WTP model predictions are shown by the thick lines (long-dashed black for STR at $20 \mathrm{wt} \%$, short-dashed red for STR at $8 \mathrm{wt} \%$, solid blue for water). Each point is from a single run and error bars show an approximate 95-percent confidence interval that includes model fit and experimental variability.

Figure 7.23 and Figure 7.24 show the effect of SAR and TAR gibbsite solids on the cumulative release fraction for sprays from, respectively, the baseline round hole (1-mm) and the baseline slot $(0.5 \times 5 \mathrm{~mm})$. Much the same pattern is seen as for the boehmite solids. For droplets $<10 \mu \mathrm{m}$, the measured release fractions are close to or greater than the WTP model predictions. In this size range, the $8 \mathrm{wt} \%$ TAR release fractions exceed the $20 \mathrm{wt} \%$ SAR release fractions, which exceed the $8 \mathrm{wt} \% \mathrm{SAR}$ release fractions. Because the only difference between SAR and TAR is the larger particle size in the solids of the latter, it is possible that larger particle size can lead to higher release fractions for smaller droplets. However, the $8 \mathrm{wt} \%$ SAR release fractions are more distinguishable from the other slurries than the $8 \mathrm{wt} \%$ TAR and $20 \mathrm{wt} \%$ SAR are from each other. It should be noted that the pressure was irregular and out of range in the $8 \mathrm{wt} \% \mathrm{SAR}$ run for the round hole so data from that run may be suspect. 


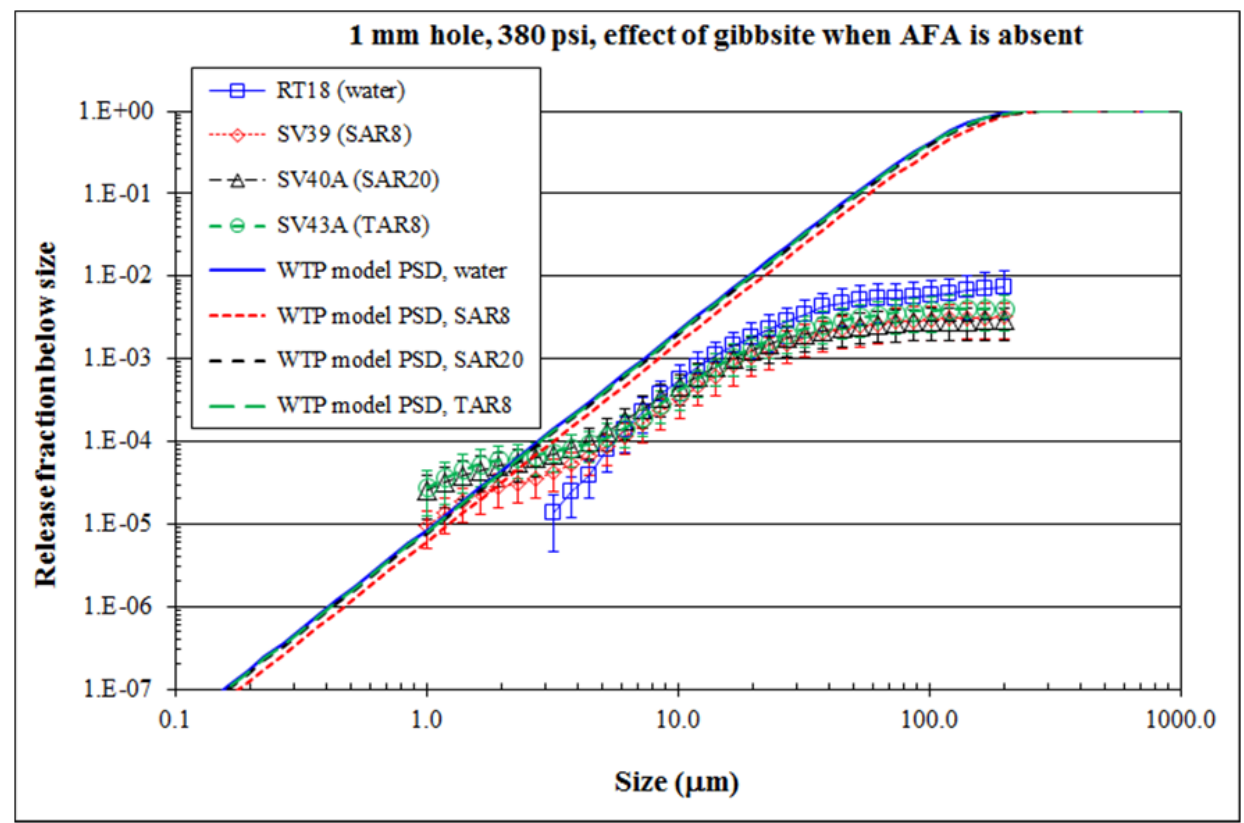

Figure 7.23. Effect of SAR and TAR Gibbsite Solids on Release Fractions for AFA-Free Sprays at 380 psig from a Target 1-mm Round Hole. WTP model predictions are shown by the thick lines (long-dashed green for TAR at $8 \mathrm{wt} \%$, long-dashed black for SAR at $20 \mathrm{wt} \%$, short-dashed red for SAR at $8 \mathrm{wt} \%$, solid blue for water). Each point is from a single run and error bars show an approximate 95-percent confidence interval that includes model fit and experimental variability. Run SV39 is suspect because of pressure control difficulties. 


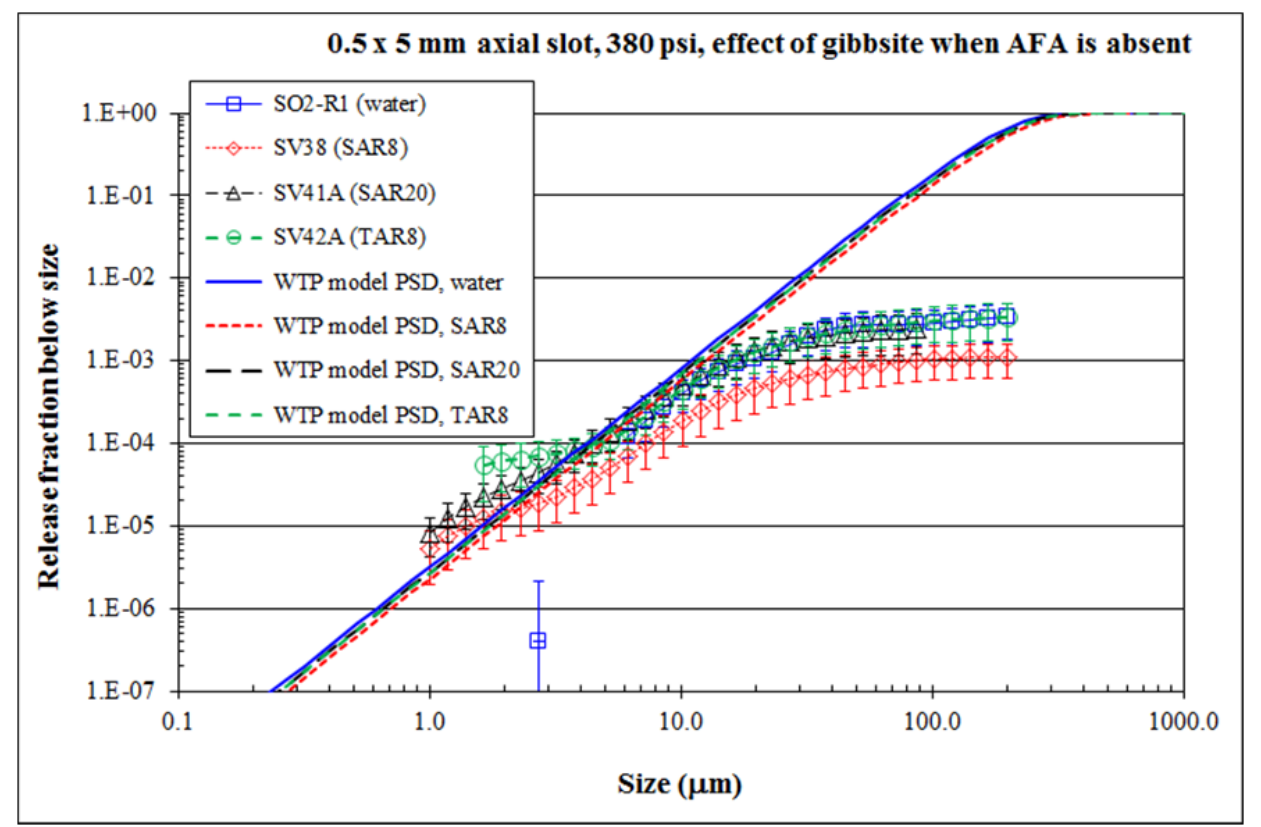

Figure 7.24. Effect of SAR and TAR Gibbsite Solids on Release Fractions for AFA-Free Sprays at 380 psig from a Target $0.5 \times 5-\mathrm{mm}$ Slot. WTP model predictions are shown by the thick lines (long-dashed green for TAR at $8 \mathrm{wt} \%$, long-dashed black for SAR at $20 \mathrm{wt} \%$, short-dashed red for SAR at $8 \mathrm{wt} \%$, solid blue for water). Each point is from a single run, and error bars show an approximate 95-percent confidence interval that includes model fit and experimental variability.

The last type of solids tested was the non-Newtonian FER type. Figure 7.25 and Figure 7.26 show the effect of FER solids on the cumulative release fraction for spray from, respectively, the baseline round hole $(1-\mathrm{mm})$ and the baseline slot $(0.5 \times 5 \mathrm{~mm})$. (It should be noted that the pressure was irregular and out of range in the FER30 run for the round hole, so that run may be suspect.) For droplets $<10 \mu \mathrm{m}$ the measured release fractions of the higher-solids simulant (iron-rich made with gibbsite at a target yield stress of $30 \mathrm{~Pa}$ ) are distinguishably greater than those of water and are near to or greater than the WTP model predictions.

Three general statements can be made about the slurries included in small-scale spray testing:

1. The addition of solids can produce release fractions that are higher than the WTP model in the droplet size range of $\leq 10 \mu \mathrm{m}$.

2. The baseline slot produces release fractions that are higher, with respect to model predictions, than the baseline round hole.

3. The release fraction increases as solids content increases, within the range included in the tests. However, low solids concentrations (such as $8 \mathrm{wt} \%$ ) may depress the release fractions below those of water over most or all of the droplet size range. 


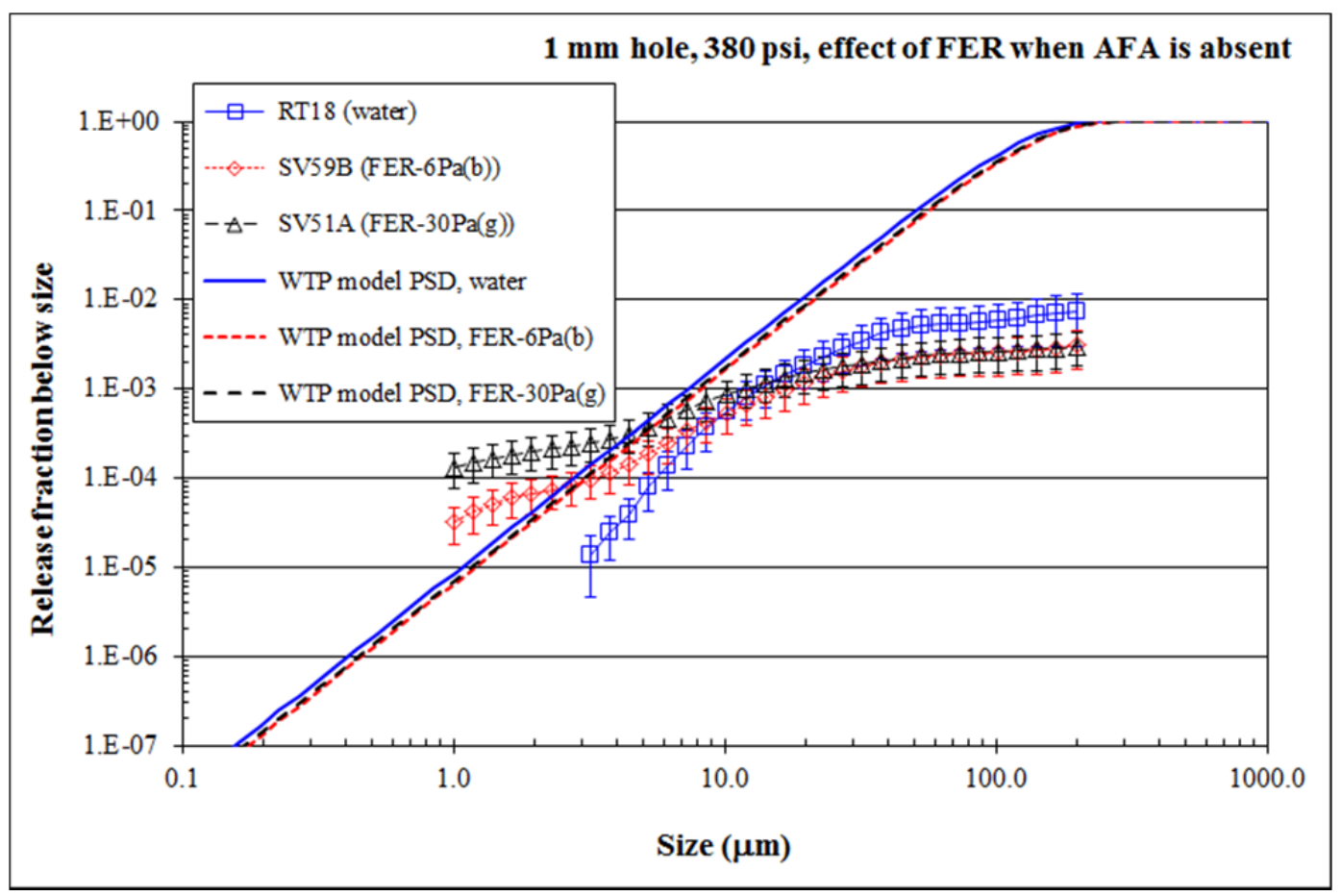

Figure 7.25. Effect of FER Solids on Release Fractions for AFA-Free Sprays at 380 psig from a Target 1-mm Round Hole. WTP model predictions are shown by the thick lines (long-dashed black for gibbsite FER at target yield stress of $30 \mathrm{~Pa}$, short-dashed red for boehmite FER at target yield stress of $30 \mathrm{~Pa}$, solid blue for water). Each point is from a single run and error bars show an approximate 95-percent confidence interval that includes model fit and experimental variability. Run SV51A is suspect because of pressure control difficulties. 


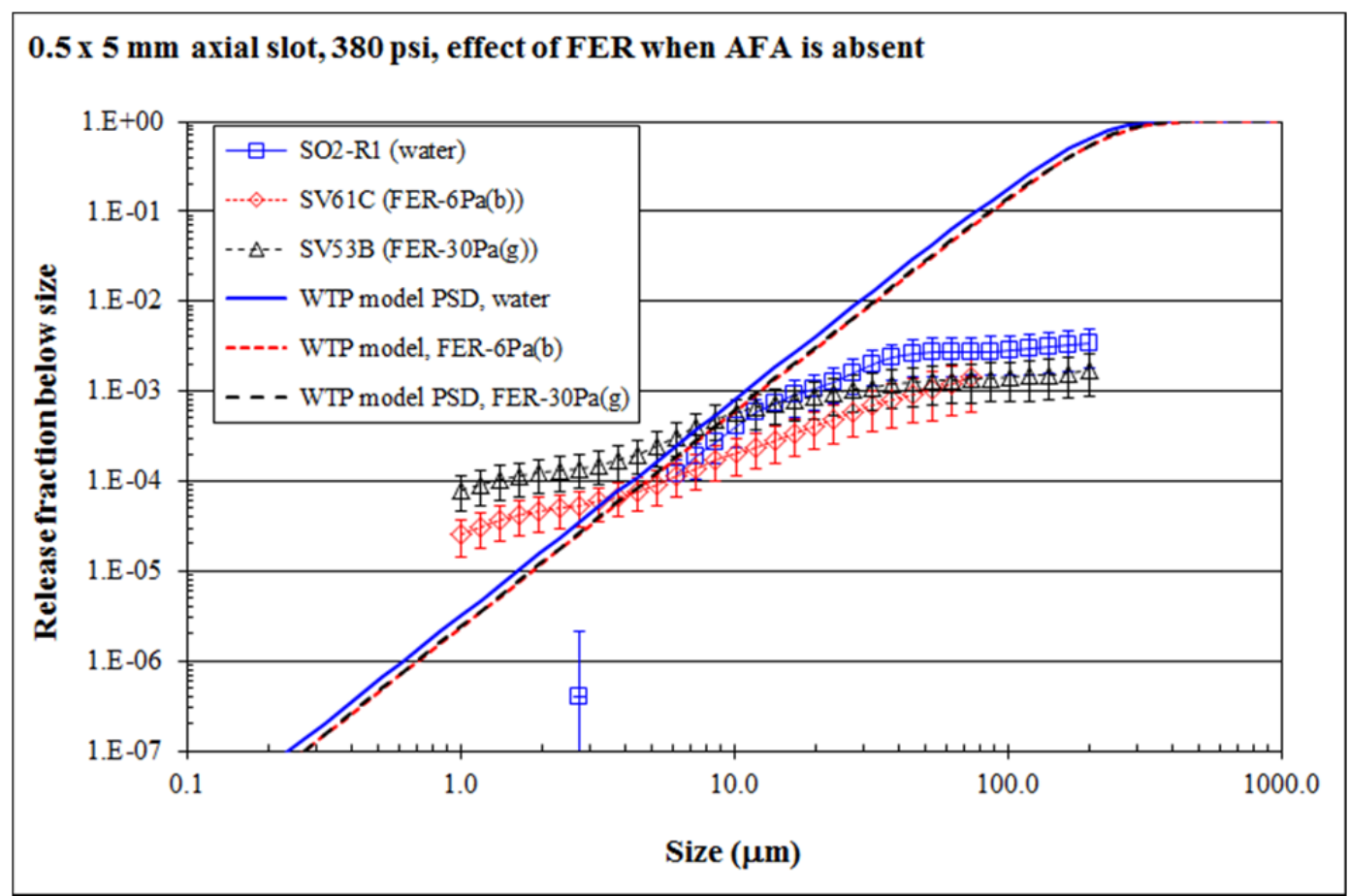

Figure 7.26. Effect of FER Solids on Release Fractions for AFA-Free Sprays at 380 psig from a Target $0.5 \times 5$-mm Slot. WTP model predictions are shown by the thick lines (long-dashed black for gibbsite FER at target yield stress of $30 \mathrm{~Pa}$, short-dashed red for boehmite FER at target yield stress of $30 \mathrm{~Pa}$, solid blue for water). Each point is from a single run, and error bars show an approximate 95-percent confidence interval that includes model fit and experimental variability.

\subsection{Effect of Antifoaming Agents}

The WTP model accounts for the effect of AFA on sprays by using a lowered surface tension in the calculations. As can be seen in Equations (1.1), (1.2), (1.3), and (1.5), the SMD is approximately proportional to the $1 / 3$ power of surface tension. A decrease in the surface tension therefore decreases the predicted SMD and therefore increases the release fraction of small droplets. To check the effect of AFA on the aerosol generation from liquids and slurries, the small-scale tests used water with and without AFA and $8 \mathrm{wt} \%$ STR with and without AFA.

Figure 7.27 and Figure 7.28 show the effect of AFA on the cumulative release fraction for water sprays from, respectively, the baseline round hole (1-mm) and the baseline slot $(0.5 \times 5 \mathrm{~mm})$, and Figure 7.29 and Figure 7.30 do the same for sprays of $8 \mathrm{wt} \% \mathrm{STR} .{ }^{21}$ Water/AFA sprays appeared to produce lower release fractions than water sprays, while AFA made little or no apparent difference in $8 \mathrm{wt} \%$ STR sprays. However, in all cases the difference between the release fraction distributions with and without AFA was comparable to the uncertainty, so the effect of AFA was not significant. This result is consistent with the expectation that aerosol generation depends on the dynamic surface tension of the AFA/water mixture (essentially that of water) rather than the equilibrium surface tension (see

${ }^{21}$ In Figure 7.29 and Figure 7.30, the WTP model predictions for slurries are calculated using the measured Newtonian slurry viscosity. 
Section 1.3.5). It should be noted that the slot spray of $8 \mathrm{wt} \%$ STR with AFA was missing some initial data because of laser drift and may be suspect.

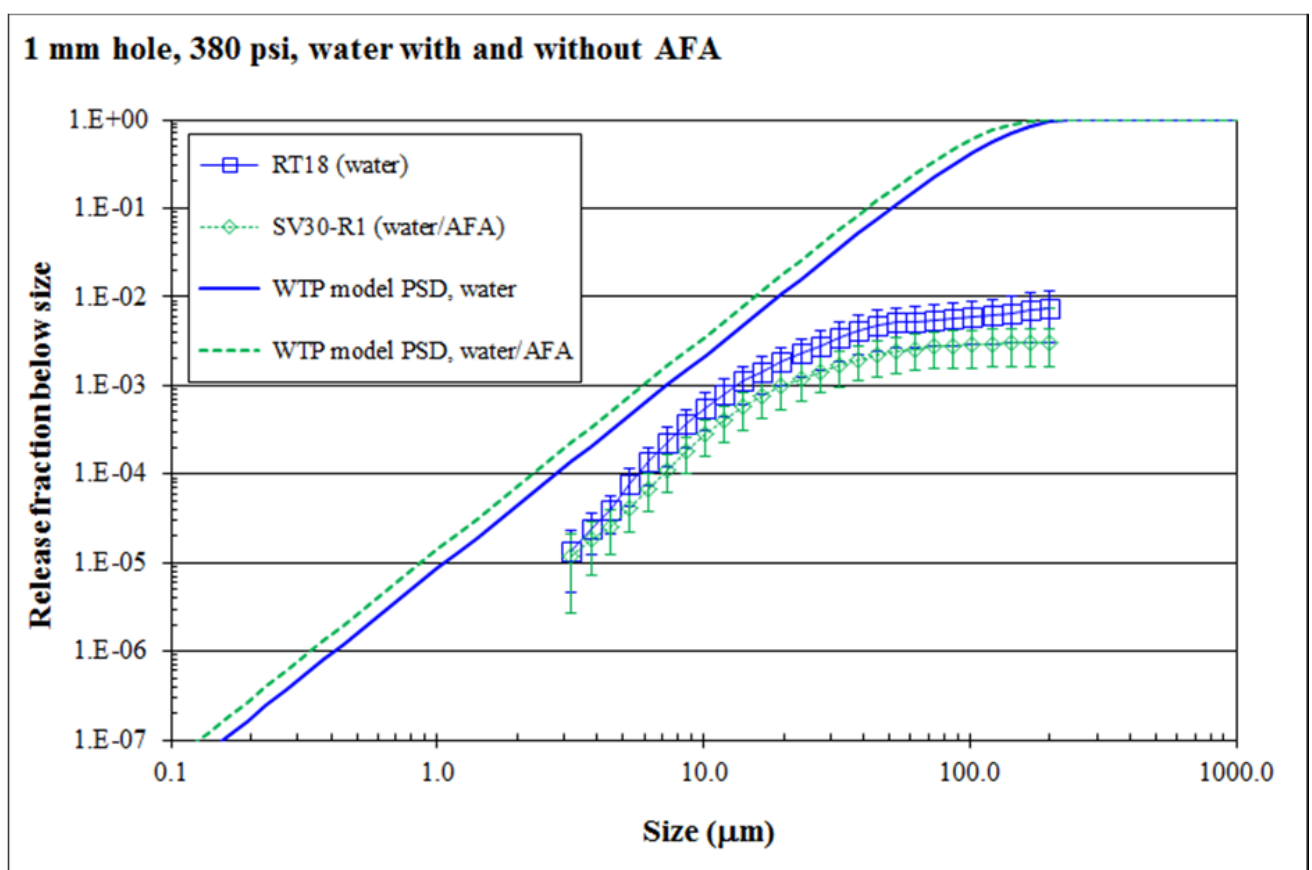

Figure 7.27. Effect of AFA on Release Fractions for Water Sprays at 380 psig from a Target 1-mm Round Hole. WTP model predictions are shown by the thick lines (short-dashed green for water with AFA, solid blue for water). Each point is from a single run, and error bars show an approximate 95-percent confidence interval that includes model fit and experimental variability. 


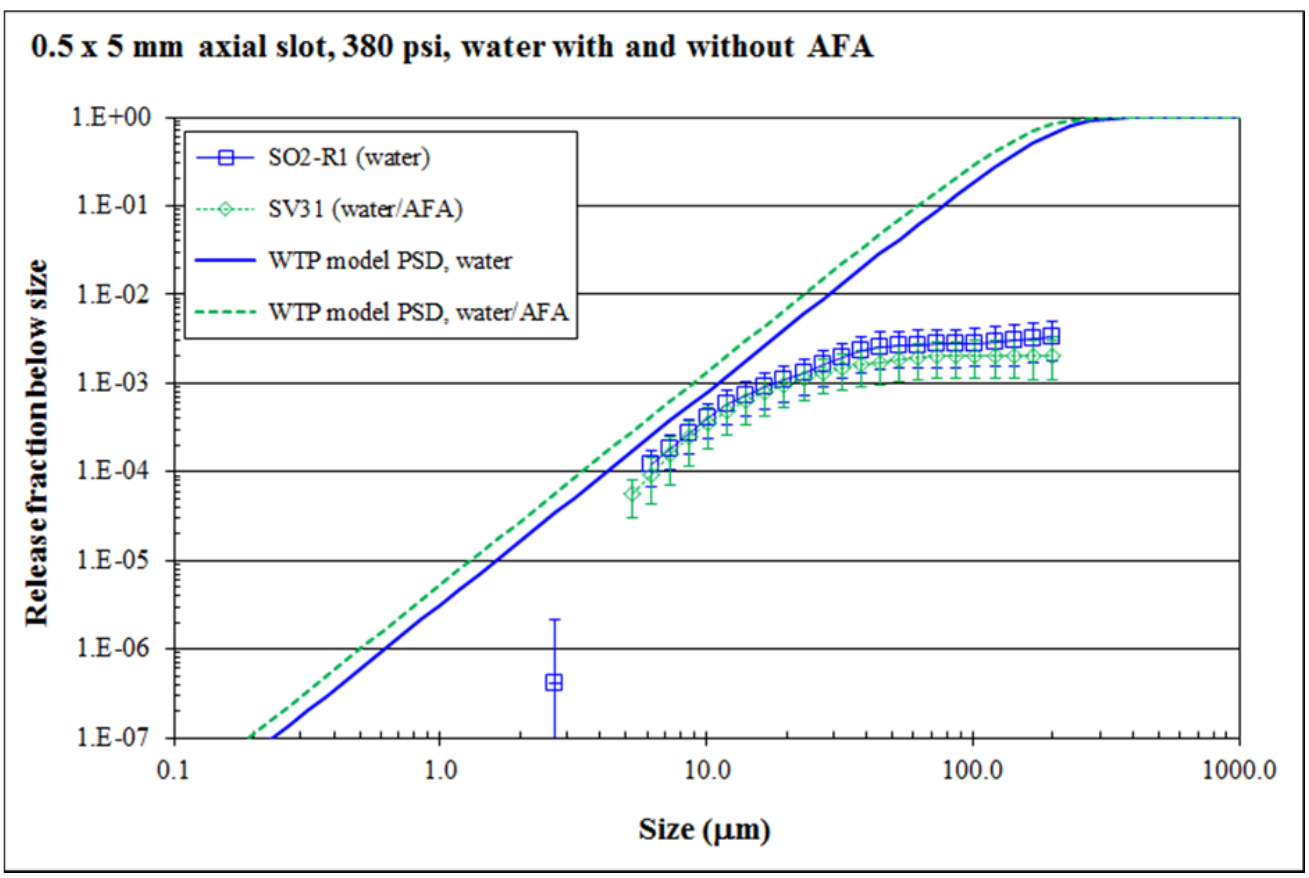

Figure 7.28. Effect of AFA on Release Fractions for Water Sprays at $380 \mathrm{psig}$ from a Target $0.5 \times 5$-mm Slot. WTP model predictions are shown by the thick lines (short-dashed green for water with AFA, solid blue for water). Each point is from a single run, and error bars show an approximate 95-percent confidence interval that includes model fit and experimental variability.

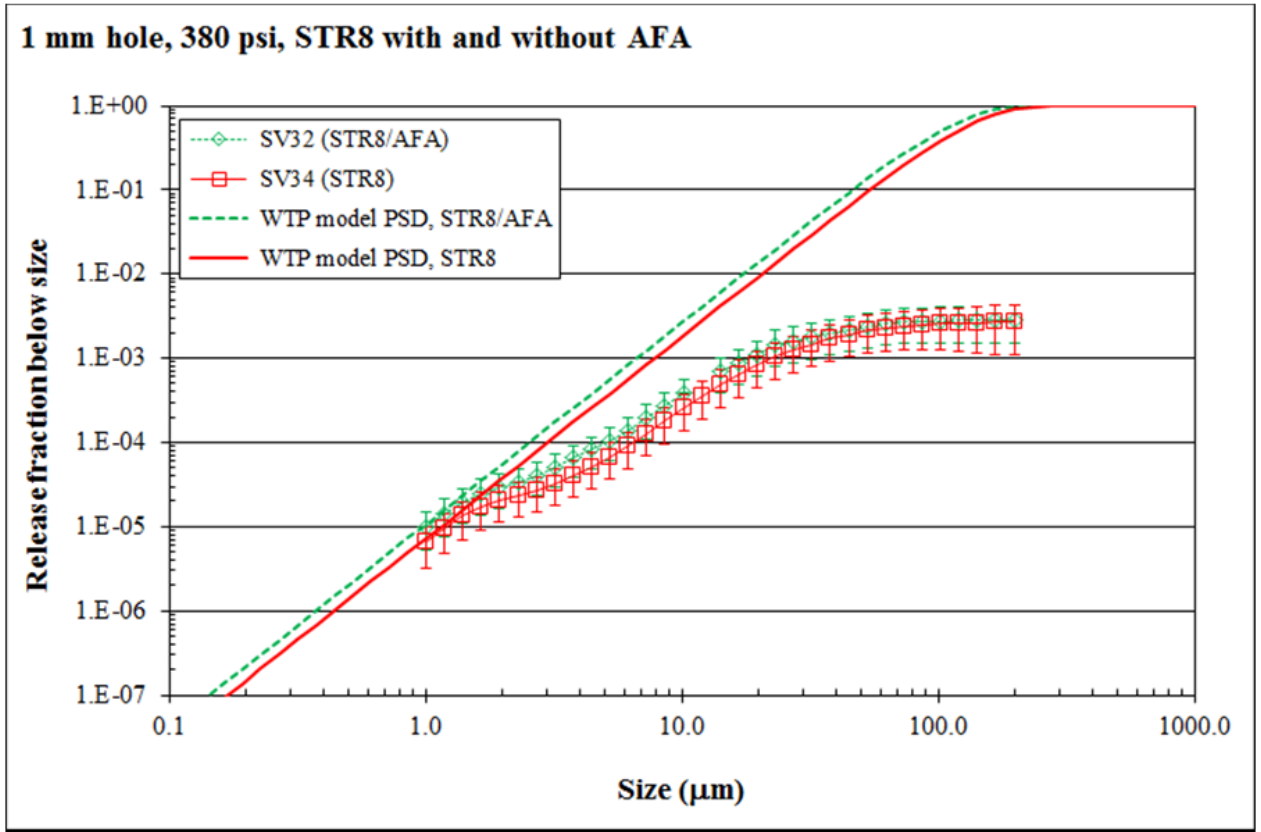

Figure 7.29. Effect of AFA on Release Fractions for Sprays of $8 \mathrm{wt} \%$ STR at $380 \mathrm{psig}$ from a Target 1-mm Round Hole. WTP model predictions are shown by the thick lines (short-dashed green for $8 \mathrm{wt} \%$ STR with AFA, solid red for $8 \mathrm{wt} \% \mathrm{STR}$ ). Each point is from a single run, and error bars show an approximate 95-percent confidence interval that includes model fit and experimental variability. 


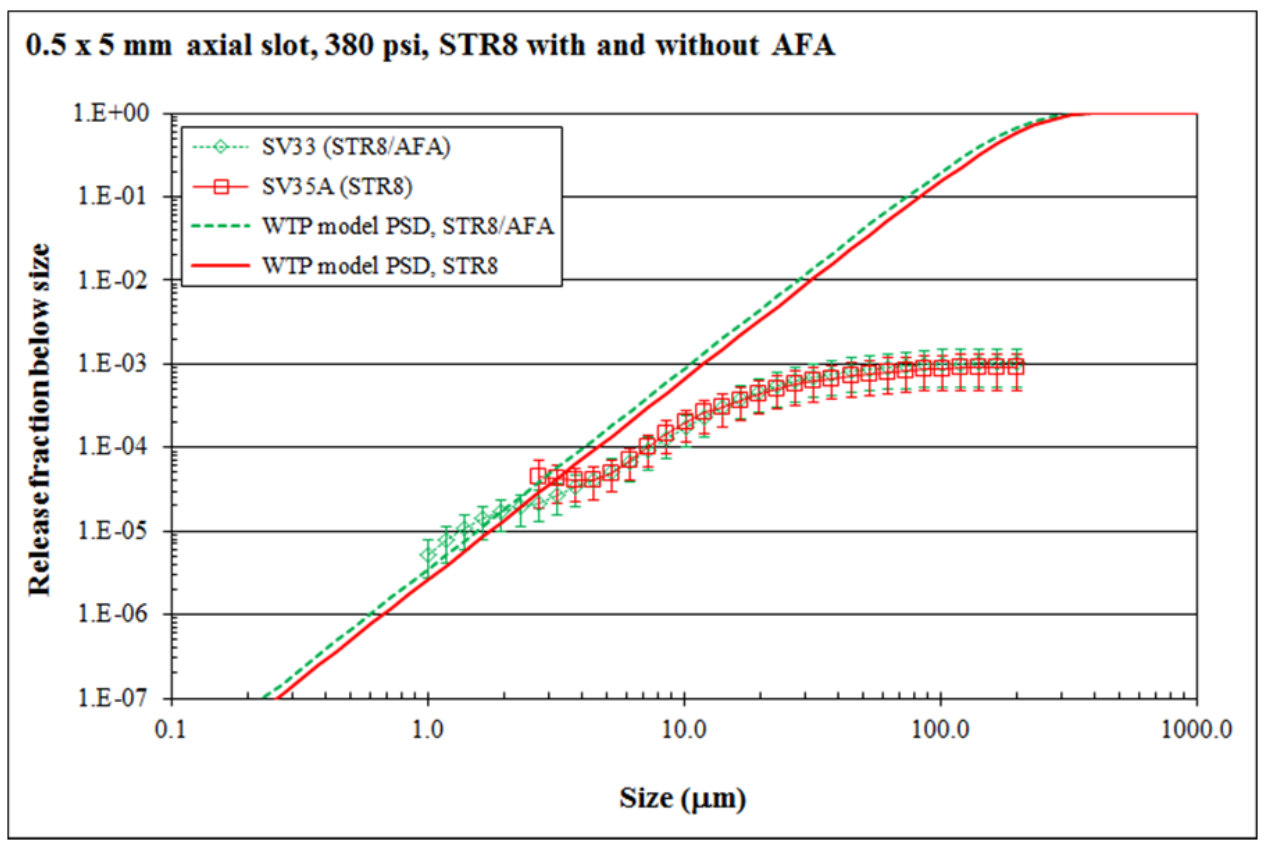

Figure 7.30. Effect of AFA on Release Fractions for Sprays of $8 \mathrm{wt} \%$ STR at $380 \mathrm{psig}$ from a Target 1 -mm $0.5 \times 5-\mathrm{mm}$ Slot. WTP model predictions are shown by the thick lines (short-dashed green for $8 \mathrm{wt} \%$ STR with AFA, solid red for $8 \mathrm{wt} \% \mathrm{STR}$ ). Each point is from a single run, and error bars show an approximate 95-percent confidence interval that includes model fit and experimental variability. Run SV34 is suspect because laser drift caused the loss of some initial data.

\subsection{Effect of Distance to Impact}

The WTP model, being based solely on jet breakup tests and mechanisms, does not include an algorithm to estimate the effect of impact breakup at walls. Tests were conducted with water at $380 \mathrm{psig}$ at different distances from the orifice (a target 1-mm round hole) to the splash wall. To change the distance, the orifice test piece was mounted on an extension bar that extended from the standard test header along the jet axis (i.e., the orifice was moved, not the splash wall). The Malvern instrument remained at position 2, so it was further from the orifice for short splash distances (long standoffs) than for long splash distances.

Figure 7.31 shows the variation of the $<10-\mu \mathrm{m},<32-\mu \mathrm{m}$, and $<102-\mu \mathrm{m}$ cumulative release fractions with distance between the 1-mm orifice and the splash wall. The distances plotted are 1, 3, 6, 18, and 42 in. (the standard distance for testing). The release fractions do not change appreciably as the distance increases from 6 to 42 in.; there is a suggestion of increasing release fractions for the larger drops, but the increase is small compared to the uncertainty. (For comparison, the large-scale tests showed approximately an order of magnitude increase in release fractions for a large range of droplet sizes as the distance increased from 43 to $227 \mathrm{in}$.) As the distance is decreased from 6 to 1 in., there is a definite and steep increase in the release fractions, particularly for the $<10-\mu \mathrm{m}$ droplets (a factor of $\sim 3$, in their case). One possible cause for the higher release fractions is that the jet is not completely broken up at 1 in. distance from the orifice, and the splash process is accordingly different. 
Another mechanism present is the re-entrainment of aerosol into the jet. The longer the jet, the more aerosol would be re-entrained and therefore lost to the region represented by in-chamber aerosol measurements. Because re-entrainment losses have a first-order dependence on aerosol concentration, they would increase the loss coefficient $\left(\Lambda_{k}\right.$ in Eqn 6.11). Re-entrainment would not be expected to affect the net generation rate, $G_{a, k}$, because the net generation rate represents processes that have zero-order dependence on aerosol concentration. Hence the release fraction should also be unaffected by re-entrainment. The steady-state concentration, which depends on both net generation and losses, would be decreased by re-entrainment.

For more information see the plots in Appendix E, which show concentration versus time for several droplet size ranges for the five impact distances that were tested. 

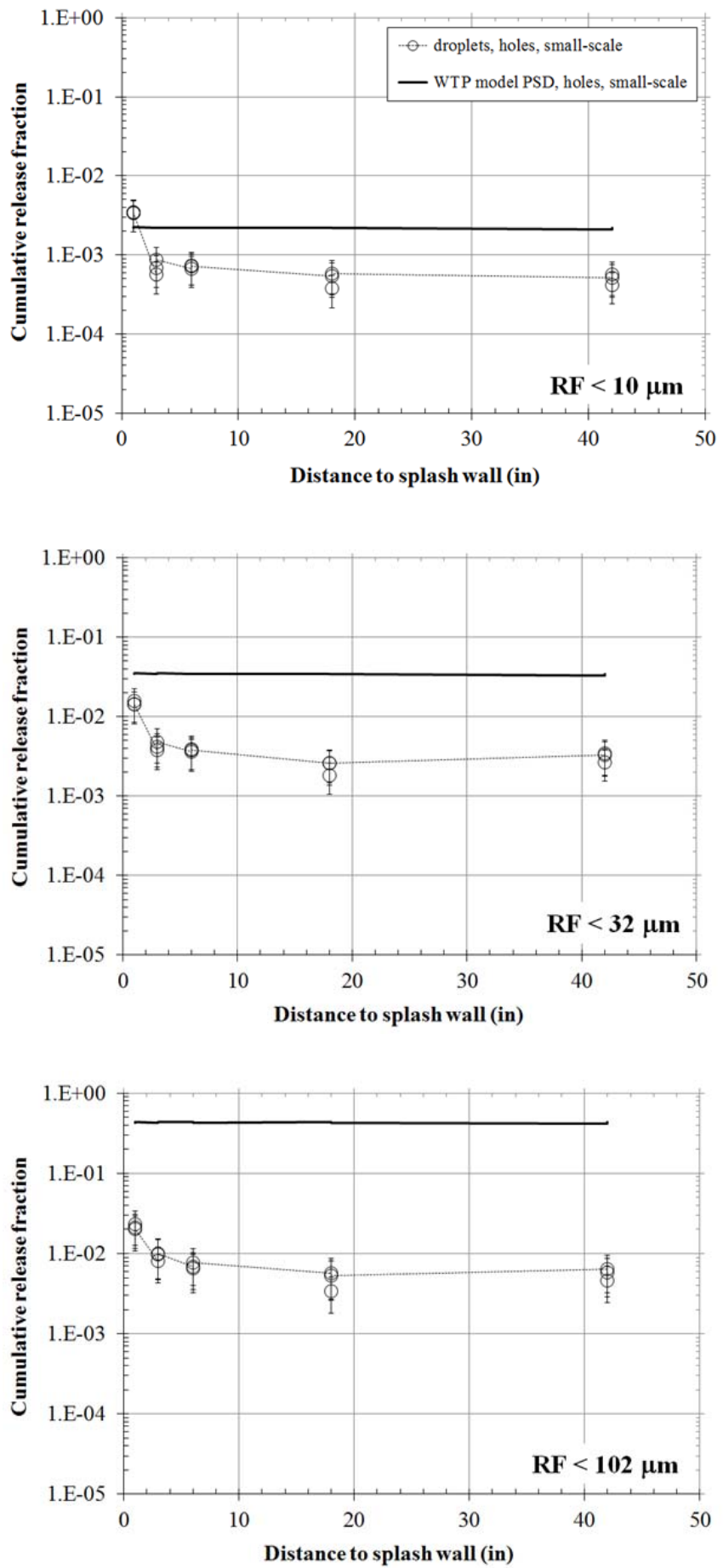

Figure 7.31. Effect of Splash Distance on Release Fractions for Sprays of Water at 380 psig from a Target 1-mm Round Hole. WTP model predictions are shown by the thick black lines. Error bars show an approximate 95-percent confidence interval including model fit and experimental variability. Appendix D identifies the tests in the plot. 


\subsection{In-Jet Spray Data}

Because of losses to the walls in the confined geometry of the small-scale tests, the release fractions underestimate the concentration of aerosol that would be generated in an open system. The underestimation can be seen in the figures in Appendix B, which show that the release fraction of $<100-\mu \mathrm{m}$ droplets, a size range that makes up most of the spray, is always less than 4 percent, often considerably less. A jet with no impacts and no losses would break up in mid-air with 100 percent of its mass being released as droplets. Its size distribution would probably differ from that of the jets observed under the confined testing conditions, because loss mechanisms are size dependent.

The changes caused by splash impacts and by losses can be assessed to some extent by measuring the aerosol concentration in the jet itself. Theoretically, this measurement gives an estimate of the release fraction when there are no losses and no aerosol generated from splatter, and can be considered an upper bound on the RF. In practice, this type of measurement is constrained by the size of the spray jet as it spreads out in the chamber. If the jet does not lie entirely within the instrument measurement volume, the measurement cannot be considered an upper bound. Furthermore, the concentration of aerosol is large, which complicates accurate measurement of the aerosol and risks flooding the system or swamping the lenses with condensate.

In-spray measurements were performed using water and an FER simulant containing gibbsite and AFA and having a target yield stress of $6 \mathrm{~Pa}$ (FER6+AFA). The water tests were at $380 \mathrm{psig}$ and used a target $0.5-\mathrm{mm}$ round hole, while the FER tests were carried out at both 380 and 200 psig and used target $1-\mathrm{mm}$ and $0.5-\mathrm{mm}$ round holes (four FER tests total). The tests were conducted in the same manner as other tests, but a different analysis method was used because the concentration in the jet is not representative of the concentration in the chamber; therefore, concentrations cannot be used to calculate release fractions. The quantity of interest for in-jet tests is the normalized aerosol distribution (volume fraction) as a function of droplet size. The normalized distribution is the cumulative concentration of aerosol divided by the sum of the concentration across all droplet sizes, as described by Equation (6.7). ${ }^{22}$

The normalized particle distribution for the $0.5-\mathrm{mm}$ water spray at $380 \mathrm{psig}$ is shown in Figure 7.32. ${ }^{23}$ Each distribution shown is a single point in time. At this in-spray measurement location (position 4, located above position 6 at the jet axis), there is no evidence of any significant transient behavior after about $10 \mathrm{~s}$. The sharp corner in the size distribution curves at the point where they reach 100 percent (at about $400 \mu \mathrm{m}$ ) indicates that larger droplets were not measured by the Malvern instrument, which means the volume fractions shown may overestimate the true volume fractions.

\footnotetext{
${ }^{22}$ In the discussion of in-jet droplet size distributions, it is assumed that the entrained-aerosol contribution in the jet was small compared to local generation. The total concentration in the jet (once the jet had reached final pressure) was about 200 times the total concentration in the chamber for tests at the same conditions (water at 380 psi through a $0.5-\mathrm{mm}$ orifice, test $\mathrm{O} 25$ versus tests $\mathrm{O} 85 \mathrm{~A}-\mathrm{C}$ ). There was less difference for the cumulative concentrations at small sizes. For $<10-\mu \mathrm{m}$ drops, the in-jet concentration was about 5 times the in-chamber concentration, still a low value.

${ }^{23}$ In test $\mathrm{O} 25$, the test shown in Figure 7.32, the pressure rose from $\sim 220$ psig to the target 380 psig over 5 seconds time. At the lower initial pressure, the spray would be expected to form larger droplets; hence the variation with time in droplet size distribution that appears in Figure 7.32. The size distribution is essentially constant after 5 seconds and can be considered representative. The pressure showed similar initial transient behavior in a number of tests, both in-chamber and in-spray, but (as noted in Section 6.5.6) the release fractions calculated by fitting the initial concentration transient were not sensitive to the initial pressure transient.
} 
The data sets for the FER simulant also did not show significant continuing change by $20 \mathrm{~s}$, so the distribution at 20-s elapsed time was selected for all comparisons. The data of Figure 7.32 also shows that there are only a very small fraction of droplets that are $<10 \mu \mathrm{m}$ in diameter in the jet of the water spray.

The normalized droplet size distribution at $20 \mathrm{~s}$ in the jet of a 0.5 -mm water spray at $380 \mathrm{psig}$ is shown in Figure 7.33. The in-jet cumulative size distribution (shown as blue circles) can be considered a cumulative release fraction, on the assumption that it describes all the droplets produced by jet breakup in a no-loss, no-wall-impact situation. The figure also shows the PSD predicted by the WTP model, the release fractions based on measurements made at Malvern position 2 (outside the jet) during another test at the same conditions, and measurements made by Epstein and Plys (2006) ${ }^{24}$ in a water jet from a 0.6-mm round orifice at 400 psig. The in-jet PSD data from the current tests match the Epstein and Plys data closely in the size range of interest, 10 to $100 \mu \mathrm{m}$, providing some evidence of repeatability. The slopes of the in-jet PSD data resemble the slope of the WTP model, and also resemble the slope of the release fraction size distribution curve in the size range between 8 and $20 \mu \mathrm{m}$.

Water@ 380 psig \& axially-oriented round $0.534 \mathrm{~mm}$ orifice: small-scale test O25 with Malvern in Position 4 (in the jet).

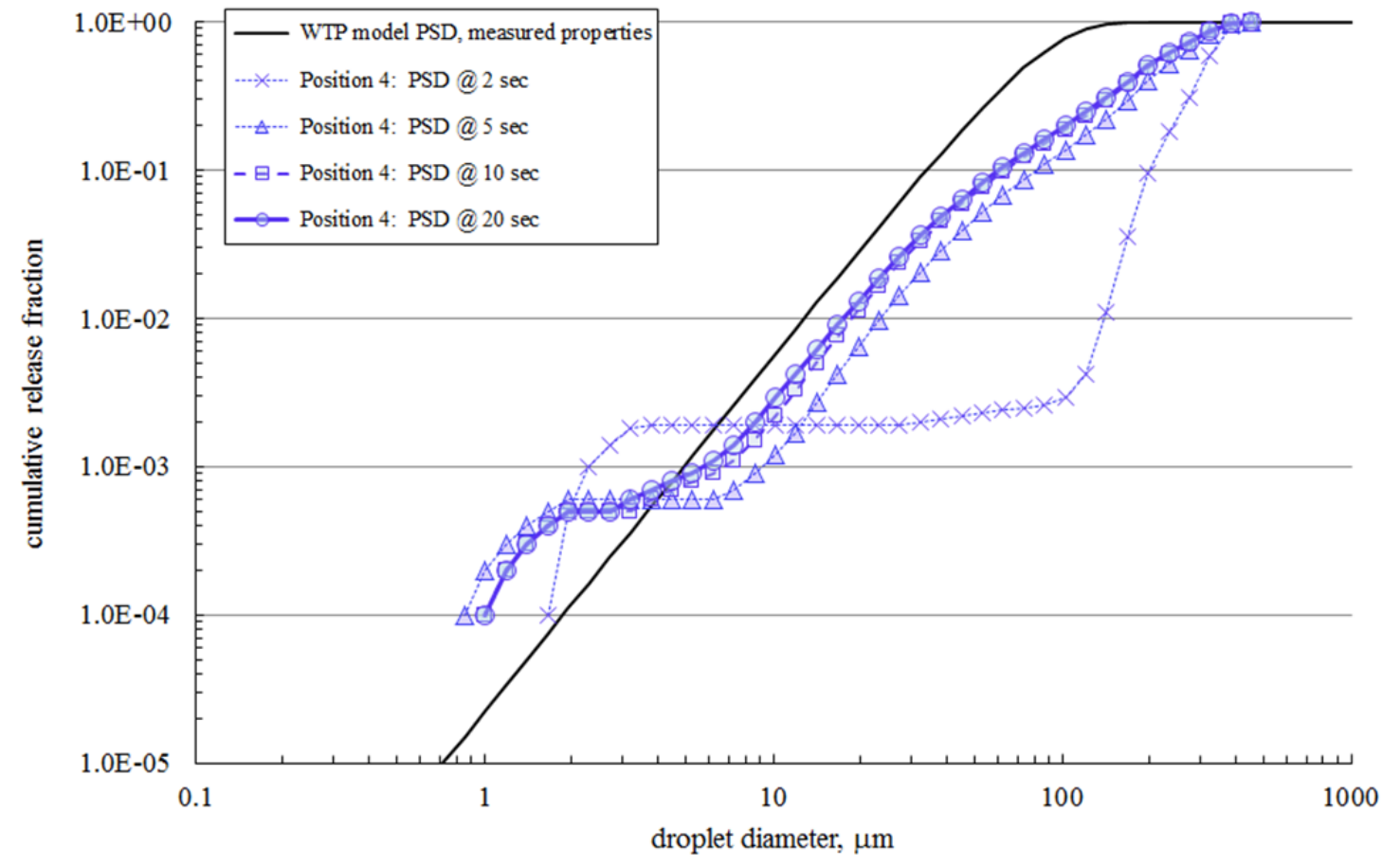

Figure 7.32. Normalized In-Jet Droplet Size Distribution as a Function of Elapsed Time for a Water Spray from a $0.5-\mathrm{mm}$ Orifice at $380 \mathrm{psi}$. Each distribution was measured at a single point in time, as identified in the legend.

\footnotetext{
${ }^{24}$ Data from Epstein and Plys (2006) that are included in Figure 7.33 were not generated and qualified within the PNNL NQA-1 QA program (Chapter 2).
} 

Water @ 380 psig \& axially-oriented round 0.534 mm orifice: small-scale test SO1 (Malvern in Position 2)
and small-scale test 025 with Malvern in Position 4 (in the jet).

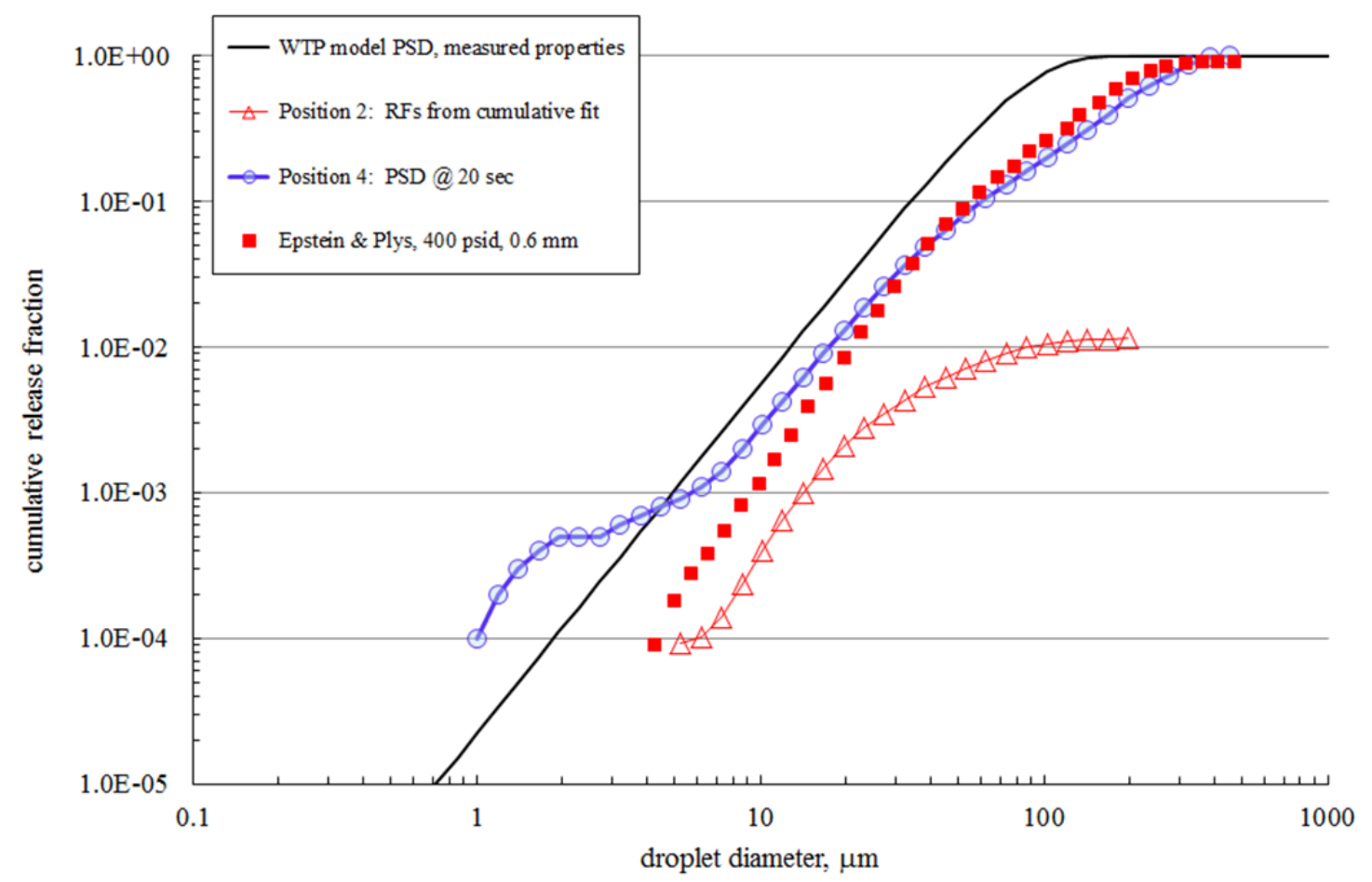

Figure 7.33. Comparison of In-Jet Droplet Size Distributions for a Water Spray from a 0.5-mm Orifice at $380 \mathrm{psi}$, Using Information from Multiple Sources

Figure 7.34 and Figure 7.35 show the data for the FER6+AFA sprays from the 1-mm orifice at both pressures tested (200 and $380 \mathrm{psig}){ }^{25}$ The figures include WTP model predictions and release fractions based on measurements made at Malvern position 2 (outside the jet) during another test at the same conditions. At the higher pressure, the FER6+AFA spray size distribution has a slope similar to that of the WTP model for sizes above $\sim 30 \mu \mathrm{m}$ and approaches the WTP model at droplet sizes of 7 to $8 \mu \mathrm{m}$. At the lower pressure, the FER spray is bimodal with a small peak below $1 \mu \mathrm{m}$. It crosses the WTP model line at $12 \mu \mathrm{m}$, indicating that the model would not be conservative for a free jet of FER6+AFA for which no settling or wall losses were assumed.

\footnotetext{
${ }^{25}$ In Figure 7.34 and Figure 7.36, the WTP model predictions for FER simulant are calculated using the measured Bingham consistency for the viscosity.
} 
FER-6Pa(g)/AFA slurry @ 380 psig \& axially-oriented round $0.975 \mathrm{~mm}$ orifice: small-scale test SV63B (Malvern in Position 2) and small-scale test O67A with Malvern in Position 4 (in the jet).

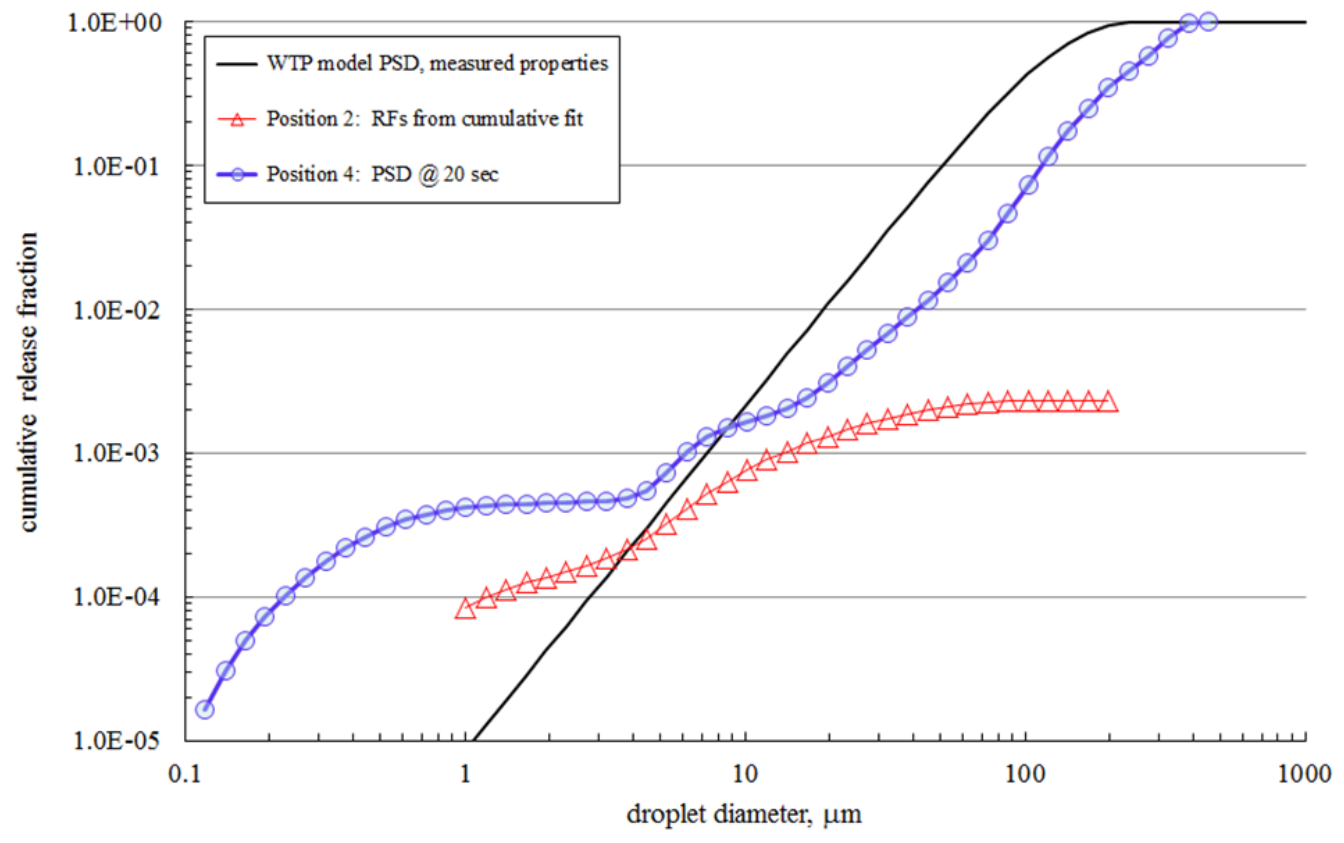

Figure 7.34. Comparison of In-Jet Droplet Size Distributions for an FER6+AFA Spray from a 1-mm Orifice at 380 psi, Using Information from Multiple Sources

FER-6 Pa(g)/AFA slurry @ 200 psig \& axially-oriented round 0.975 mm orifice: small-scale test SV64B (Malvern in Position 2) and small-scale test O68A with Malvern in Position 4 (in the jet).

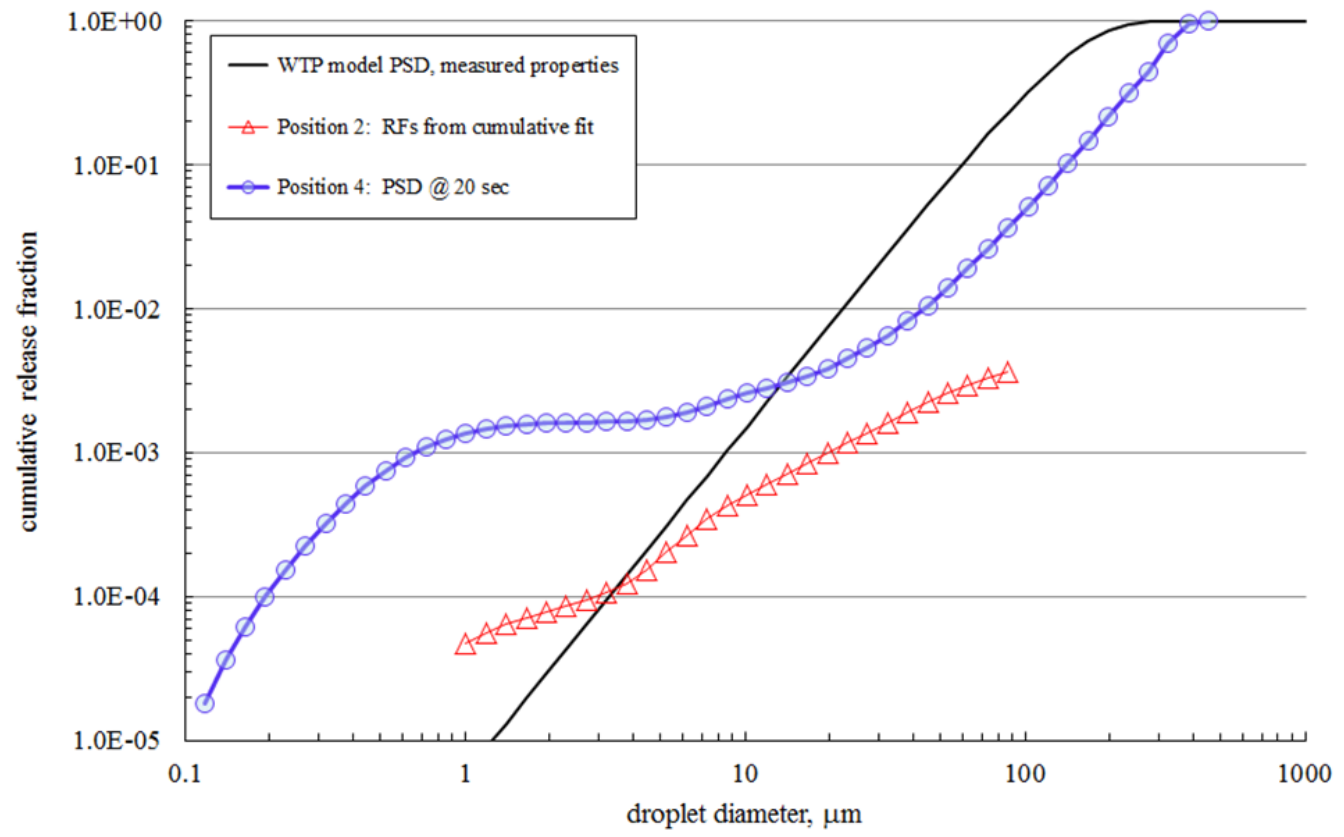

Figure 7.35. Comparison of Droplet Size Distributions for a Water Spray from a 1-mm Orifice at 200 psi, Using Information from Multiple Sources 
Figure 7.36 compares the size distributions for water and FER6+AFA sprays from the 0.5 -mm orifice at 380 psig. The figure also includes WTP model predictions, which are not very different for the two simulants under these conditions. The size distribution for water is consistently higher than or equal to that of FER6+AFA under these conditions. The difference between the two measured spray size distributions appears greater than that predicted by the WTP model for the two sets of properties, although the uncertainties of the measured size distributions are not known and might account for some of the difference between the distributions.

FER-6 Pa(g)/AFA slurry @ 380 psig \& axially-oriented round 0.534 mm orifice: small-scale test O69B with Malvern in Position 4 (in the jet).

Water@380 psig \& axially-oriented round $0.534 \mathrm{~mm}$ orifice: small-scale test $\mathrm{O} 25$ with Malvern in Position 4 (in the jet)

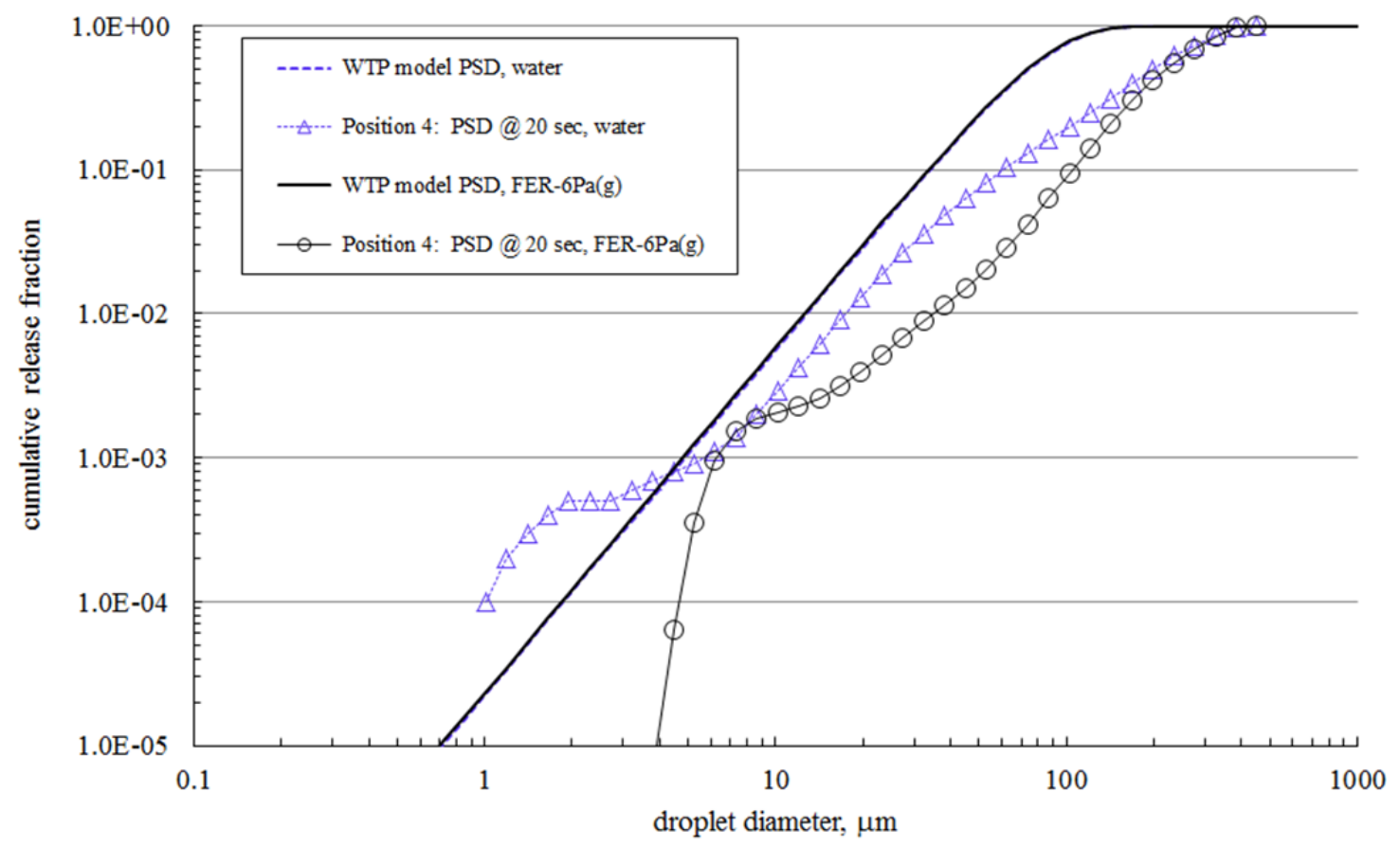

Figure 7.36. Comparison of Droplet Size Distributions for Sprays of Water and FER6+AFA from a 0.5 -mm Orifice at $380 \mathrm{psi}$ Using Information from Multiple Sources. WTP model predictions are shown by the lines (solid black for FER6+AFA, short-dashed blue for water).

For the large-scale tests, Section 8.6 (Schonewill et al. 2012), it was demonstrated that the distance of the Malvern probe from the spray origin affected the droplet size distribution. Data from large-scale testing of the 2-mm orifices have a droplet size distribution that has a smaller fraction of droplets at any given diameter than the $1-\mathrm{mm}$ data when the measurement is performed at $59 \mathrm{in}$. from the orifice. At $23.5 \mathrm{in}$. from the orifice, the opposite is true. The $2-\mathrm{mm}$ data have a droplet size distribution with a larger fraction of droplets than the 1-mm data. This dependence on the axial location of the Malvern probe was not explored during small-scale, in-jet testing.

In addition, the same section of the large-scale report pointed out that the Malvern instrument settings used to post-analyze and export the in-jet data affected the results, generally at volume fractions of $10^{-3}$ or 
less. The effect of these settings is such that it may explain the apparent bimodal distribution of droplet sizes, in particular the small peak in the range of $<1 \mu \mathrm{m}$. In the large-scale tests, when Malvern post-processing of in-jet laser scattering assumed that the spray was centrally located and confined to a narrow region (i.e., a region approximately $6 \mathrm{~cm}$ in diameter), there was no peak in the $<1 \mu \mathrm{m}$ range. However, if a wider spray was assumed, the result was a bimodal droplet distribution with separated peaks that seemed unphysical for water droplet formation. For comparison, in the small-scale tests, the post-processing of in-jet data assumed that the spray was centrally located and confined to a region $7 \mathrm{~cm}$ in diameter, where the lenses were spaced $15 \mathrm{~cm}$ apart. Typically, when the Malvern instruments were mounted in the chamber outside of the spray (positions 2, 6, and 1, for small-scale tests), the aerosol was assumed to be spread uniformly across the measurement zone.

\subsection{Orifice Coefficients}

The orifice coefficients shown in Figure 7.37 are shown as a function of the cross-sectional area of the orifice (units of $\mathrm{mm}^{2}$ ) for 65 parametric tests including the full range of simulants, pressures, and orifice sizes. There is little visible effect of simulant, even though the non-Newtonian simulant tests are included in the set. There did appear to be an effect of orifice size, which produces two distinguishable populations of orifice coefficients above and below an orifice area of $2 \mathrm{~mm}^{2}$. For larger orifices, all except one of the runs were made with slot orifices.

The orifice coefficients were calculated using the area of the outer end of the orifice as a basis. Since the inner area was generally smaller (Section 4.5), orifice coefficients calculated on the basis of the inner end would be higher than given here.

Most of the orifice coefficients showed good reproducibility. The average and standard deviation of the set of 35 large-orifice coefficients were $0.59 \pm 0.05$, a range that includes the value of 0.62 used in WTP modeling. For orifices with area $<2 \mathrm{~mm}^{2}$, the average and standard deviation of the set of 30 small-orifice coefficients were $0.76 \pm 0.06$, which is significantly larger than 0.62 . Most of these small orifices were round holes.

The orifice coefficients for different orifice orientations were compared to each other to find out whether orientation affected flow rate. The $0.5-\mathrm{mm}$ round holes with default and dead-end orientations had almost identical discharge coefficients ( 0.69 to 0.71 for tests SO1, OS8-R1, and SO4-R1). The $0.5 \times 5 \mathrm{~mm}$ slots with axial, circumferential, and dead-end orientations had discharge coefficients ranging from 0.57 to 0.63 (tests SO2-R1, SO3, and SO5-R1), closely repeatable behavior. It was concluded that the orientation of these orifices did not affect flow rate. 


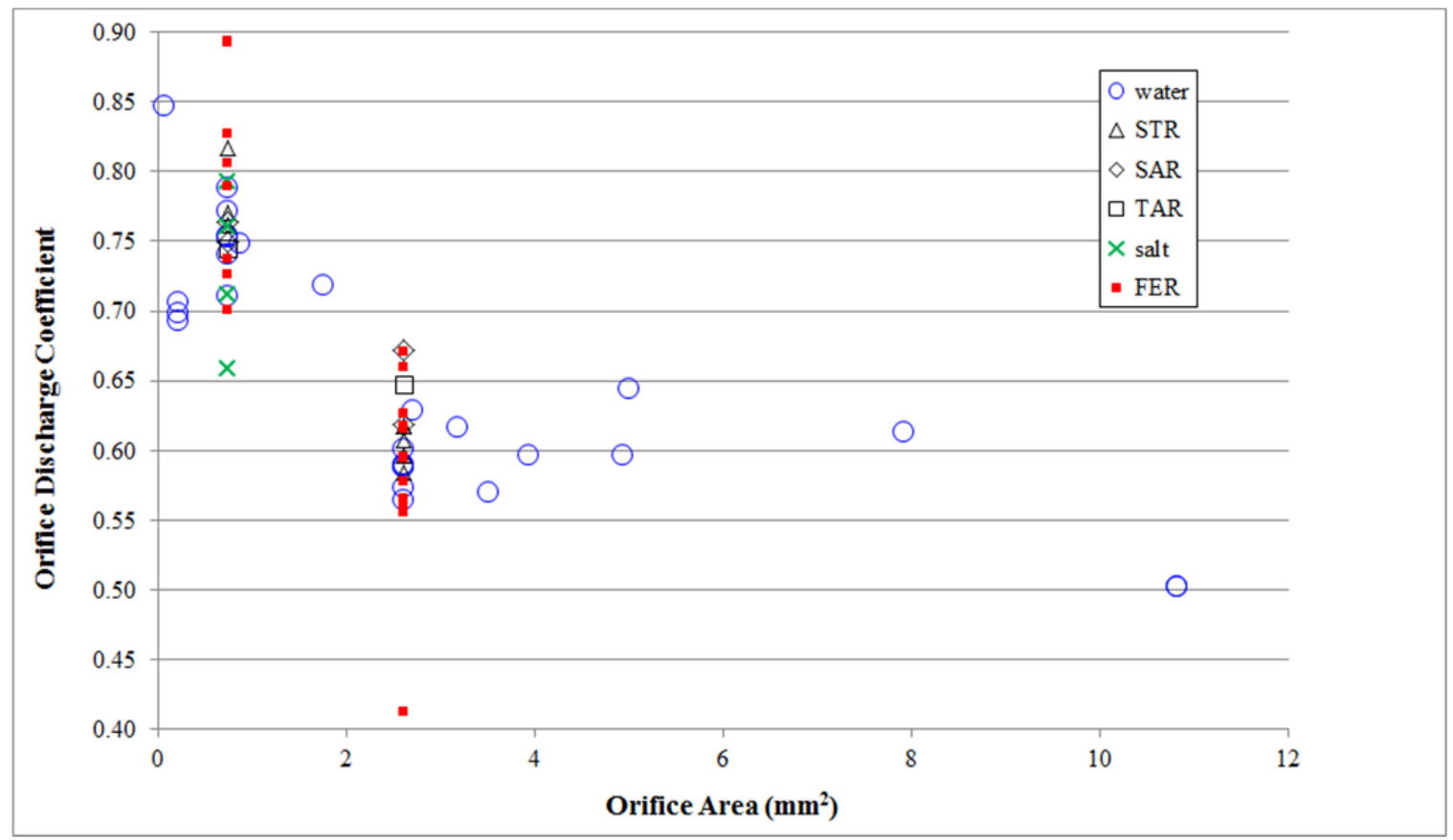

Figure 7.37. Orifice Coefficients Calculated for Sprays of Various Simulants. The WTP model uses a coefficient of 0.62 for leak rate calculations.

The results that were not within $10 \%$ of the averages stated above were

- SV52C (30-Pa FER@200 psi, 1 mm hole, 0.89 coefficient),

- SV59B (6-Pa FER@ 380 psi, 1 mm hole, 0.89 coefficient),

- OS9 (water@ 380 psi,0.3 mm hole, 0.85 coefficient),

- SV56A (30-Pa FER/AFA@ 380 psi, 0.5 x 5 mm slot, 0.41 coefficient),

- SL48-R1A (water@ 380 psi, 0.5 x 20 mm hole, 0.50 coefficient), and

- SL48-R1B (water@ 380 psi, 0.5 x 20 mm hole, 0.50 coefficient).

Of these, the values for SL48-R1A and SL48-R1B are probably accurate because they show good repeatability. There may have been partial plugging in test SV56A, which would account for the low coefficient. SV52C and SV59B (with high coefficients) showed no suspect behavior. The Reynolds numbers for the Phase 1 FER tests, including SV52C and SV59B, were 2000 - 4000, based on measured densities and Bingham consistencies. Discharge coefficients for square-edged orifices can be as high as 0.95 in this Reynolds number range (Perry and Chilton 1973). The high measured discharge coefficients in these tests are therefore considered likely to be accurate.

Run OS9, using the smallest orifice of the set, gave some difficulty in measuring the flow rate because the difference between start and end feed masses, used to calculate the flow rate, was relatively small. The estimated Reynolds number for the test was 16000 , so it would not be expected to show the higher coefficient that is present (at least for square-edged circular orifices) between in the Reynolds number range 100 - 4000. If the actual discharge coefficient was 0.65 , then the measured flow rate was about $30 \%$ high and the calculated RF was therefore about $30 \%$ low. 
A standard reference (Perry and Chilton 1973) states that for small square-edged or sharp-edged circular orifices within a pipe the orifice coefficient would be expected to be between 0.595 and 0.620 at the relatively high velocities (and Reynolds numbers) that are present in the Newtonian orifice flows. However, the orifice test-piece configuration is not an orifice mounted in a pipe, with liquid discharging into liquid, but a hole in the side of a pipe, with liquid discharging into air. The losses within such a hole may be less than for the standard orifice, as the measurements seem to indicate for the holes of less than $2-\mathrm{mm}^{2}$ area.

\subsection{Summary}

The results presented in this section focus on the effect of parameter variations on either the cumulative release fraction or net generation rate as a function of droplet diameter. Comparisons between small-scale test data (net generation) and WTP model predictions (total generation) were made for several different parameters. This yielded the following conclusions:

1. As pressure increased, the cumulative release fraction increased for water sprays. This increase with pressure was approximately the same as the rate of increase in the WTP model and is consistent with the large-scale testing results. For the non-Newtonian simulants, the effect of pressure was variable with the release fraction sometimes increasing and sometimes decreasing with increasing pressure (Section 7.2).

2. As orifice area increased for round holes, the cumulative release fraction was essentially constant for $<10-\mu \mathrm{m}$ drops from round holes, whereas the WTP model predicts a decrease in release fraction. For these round holes, the cumulative release fractions for $<30-\mu \mathrm{m}$ and $<100-\mu \mathrm{m}$ drops showed an area dependence that is similar to that obtained from the WTP model. For all the round holes, the cumulative net generation rate increases with orifice area because of the increase in total spray flow with increasing area (Section 7.1.3).

3. As orifice area increased for slots, the cumulative release fraction decreased and the cumulative net generation rate increased slightly for drops between $<10$ and $<100 \mu \mathrm{m}$. These trends generally match the WTP model (Section 7.1.3).

4. Overall, the cumulative release fraction correlates reasonably well with the orifice area for slots and round holes, in agreement with the WTP model. The dependence on orifice area varies between smaller and larger areas. For the tests conducted, the smaller orifice areas were round holes and the larger areas were slots. Only a few slots and round holes had similar areas. Accordingly, there are too few data to determine whether the difference in dependence at small and larger areas is due to orifice area or geometry.

5. Linear arrays of round holes were tested to simulate the effect of cracks of varying width (Section 7.1.2). The array of five $0.5-\mathrm{mm}$ holes with $0.5-\mathrm{mm}$ spacing between holes $(1 \mathrm{~mm}$ center-to-center) gave a lower release fraction than a single hole of about the same total area. The array of 1-mm holes spaced 1-mm apart ( $2 \mathrm{~mm}$ center-to-center) gave a release fraction closer to that of a single hole with about the same total area.

6. Orifice orientation and orifice aspect ratio have little or no effect on the release fraction (Sections 7.1.1, 7.1.4).

7. As viscosity and density increased for a salt solution, the cumulative release fraction was unchanged. This is comparable to the WTP model prediction, including both the density and viscosity change. 
For one pair of salt solutions having identical densities but different viscosities, the cumulative release fraction again was unchanged (Section 7.3).

8. Low solids concentrations ( $8 \mathrm{wt} \%$ ) appeared to depress the release fractions below those of water over most or all of the droplet size range (Section 7.4). Further increasing the solids content increased the release fraction, within the range included in the tests. This is not consistent with the WTP model, which accounts for the presence of solids only by changes in the physical properties of the fluid. The addition of solids can produce release fractions that exceed the WTP model in the droplet size range of $\leq 10 \mu \mathrm{m}$.

9. An AFA added to $8 \mathrm{wt} \%$ STR and water did not increase the release fraction, as would have been predicted from the functionality of surface tension in the WTP model (Section 7.5). To the extent that an effect could be distinguished, the AFA decreased the release fraction.

10. As the distance between the spray and the splash wall decreased, the cumulative release fraction remained essentially constant between 42 and $18 \mathrm{in}$., increased slightly between 18 and 3 in., and increased significantly when the distance was reduced to $1 \mathrm{in}$. The WTP model does not consider the effect of obstructions such as walls, and would predict constant release fractions with splash distance (Section 7.6).

11. In the absence of splatter if the spray hits a wall or object, in-spray measurements represent an upper bound on the release fraction for a particular spray. However, the measurements are difficult to interpret as they are strong functions of the position of the Malvern detector within the spray and the Malvern analysis settings (Section 7.7).

12. The discharge coefficient for orifices of less than $2-\mathrm{mm}^{2}$ area may exceed the value of 0.62 used in the WTP model by $\sim 20$ percent (Section 7.8). 


\subsection{Conclusions and Recommendations}

Aerosol generation tests were performed at a small scale to quantify release fractions and net generation rates for a range of orifice sizes and shape, fluids, and spray pressures that represent expected WTP process stream properties and potential spray release scenarios. The test results were compared with WTP model predictions of total generation rate. In addition, testing was conducted to evaluate variations in repeat tests, effect of different pressure control methods, and uniformity of aerosol measurements in the test chamber.

Test results related to the effect of orifice size and shape, fluid properties, spray pressures, and length of spray within the chamber can be summarized as described below:

- Orifice coefficients, $\mathrm{C}_{\mathrm{D}}$, were determined from differential mass measurements and found to be $0.59 \pm 0.05$ (average \pm standard deviation) when the orifice area was $>2 \mathrm{~mm}^{2}$. This value is consistent with the value of 0.62 used in the WTP model for orifices. However, the discharge coefficient for orifices of $<2 \mathrm{~mm}^{2}$ area was $0.76 \pm 0.06$, which is $\sim 20$ percent more than the value used in the WTP model (i.e., 0.62).

- As pressure increased, the cumulative release fraction increased for water sprays. This increase with pressure was approximately the same as the rate of increase in the WTP model and is consistent with the large-scale testing results. For the non-Newtonian simulants, the effect of pressure was variable with the release fraction sometimes increasing and sometimes decreasing with increasing pressure.

- As orifice area increased for round holes, the cumulative release fraction was essentially constant for $<10-\mu \mathrm{m}$ drops from round holes, whereas the WTP model predicts a decrease in release fraction. For these round holes, the cumulative release fractions for $<30-\mu \mathrm{m}$ and $<100-\mu \mathrm{m}$ drops showed an area dependence that is similar to that obtained from the WTP model. For all the round holes, the cumulative net generation rate increases with orifice area because of the increase in total spray flow with increasing area.

- As orifice area increased for slots, the cumulative release fraction decreased and the cumulative net generation rate increased slightly for drops between $<10$ and $<100 \mu \mathrm{m}$. These trends generally match the WTP model.

- Overall, the cumulative release fraction correlates reasonably well with the orifice area for slots and round holes, in agreement with the WTP model. The dependence on orifice area varies between smaller and larger areas. For the tests conducted, the smaller orifice areas were round holes and the larger areas were slots. Only a few slots and round holes had similar areas. Accordingly, there are too few data to determine whether the difference in dependence at small and larger areas is due to orifice area or geometry.

- As viscosity and density increased for a salt solution, the cumulative release fraction was unchanged. This is comparable to the WTP model prediction including both the density and viscosity change. For one pair of salt solutions having identical densities but different viscosities, the cumulative release fraction again was unchanged.

- Low solids concentrations (such as $8 \mathrm{wt} \%$ ) appeared to depress the release fractions below those of water over most or all of the droplet size range, for the baseline slot and round orifices $(0.5 \times 5 \mathrm{~mm}$ and $1 \mathrm{~mm}$, respectively). Further increasing the solids content (to $20 \mathrm{wt} \%$ ) increased the release 
fraction. This is not consistent with the WTP model, which accounts for the presence of solids only by changes in the physical properties of the fluid. The addition of solids can produce release fractions that exceed the WTP model in the droplet size range of $\leq 10 \mu \mathrm{m}$.

- Adding AFA to either $8 \mathrm{wt} \%$ STR or water, which approximately halved the equilibrium surface tension, did not cause an increase in the release fraction as would have been predicted from the functionality of surface tension in the WTP model. To the extent that an effect could be distinguished, the presence of an AFA caused a slight decrease in the release fraction.

- As the distance between the spray and the splash wall decreased, the cumulative release fraction remained essentially constant between 42 and 18 in., increased slightly between 18 and 3 in., and increased significantly when the distance was reduced to 1 in. The WTP model does not consider the effect of obstructions such as walls, and would predict constant release fractions with splash distance.

- In-spray measurements represent an upper bound on the release fraction for a particular spray, in the absence of splatter if the spray hits a wall or object. However, the measurements are difficult to interpret as they are strong functions of the Malvern position within the spray and the Malvern analysis settings.

A number of factors affect the overall uncertainty in the measured aerosol net generation rates and release fractions. Two types of small-scale tests are pertinent to uncertainty estimates:

- The results of replicate tests for a number of test conditions (including five different simulants) were used to evaluate the test-to-test uncertainty. As a first approximation, the 95-percent confidence interval in the cumulative release fraction for any given small-scale test should be a minimum of \pm 40 percent of the stated value at any particular aerosol droplet diameter.

- Two tests compared the Malvern aerosol results with those of a co-located secondary aerosol instrument, the PPC. For the baseline round hole $(1 \mathrm{~mm})$, the PPC concentration was 200 to 300 percent of the Malvern concentration for droplets $\geq 10 \mu \mathrm{m}$, up to the apparent PPC measurement limit of about $30 \mu \mathrm{m}$. The Malvern and PPC concentrations were more similar for the baseline slot $(0.5 \times 5 \mathrm{~mm})$, particularly for cumulative concentrations in the range of $<20$ to $<30 \mu \mathrm{m}$. The comparison is ambiguous because the PPC suction rates had not been tested to determine what rate produced the best measurements. For context, the large-scale tests (Sections 8.1.4 and 8.1.5 of Schonewill et al. 2012), in which the PPC suction flow rate was adjusted for best results based on testing, gave a closer comparison between PPC and Malvern results.

Based on the testing results, the following recommendations address the key technical issues for which additional small-scale tests and evaluations will provide results for important test conditions that have not previously been obtained:

- For non-Newtonian slurries, the variation in the trends of release fraction with increasing pressure (either increasing or decreasing trends) does not have an obvious physical cause. More tests with a range of pressures should be conducted with the non-Newtonian simulants.

- The relatively high orifice discharge coefficients observed for small orifices should be checked experimentally.

- The Malvern-PPC comparison tests gave ambiguous results. Because of this ambiguity and the fact that the initial-transient analysis method in this study has not been used in the literature, method 
validation tests are recommended. These tests would apply the same measurement and analysis methods to sprays with known leak rate and size distribution to determine how well the estimates of aerosol net generation rate match the expected values. 



\subsection{References}

10 CFR 830, Subpart A. 2010. "Nuclear Safety Management." Subpart A, "Quality Assurance Requirements.” Code of Federal Regulations, U.S. Department of Energy, Washington, D.C.

Ashgriz N. 2011. Handbook of Atomization and Sprays: Theory and Applications. Springer, New York, New York.

ASME - American Society of Mechanical Engineers. 2001. Quality Assurance Requirements for Nuclear Facility Applications, Part 1, "Requirements for Quality Assurance Programs for Nuclear Facilities." New York, New York.

ASME - American Society of Mechanical Engineers. 2001. Quality Assurance Requirements for Nuclear Facility Applications, Part II, Subpart 2.7, "Quality Assurance Requirements for Computer Software for Nuclear Facility Applications.” New York, New York.

ASME - American Society of Mechanical Engineers. 2001. Quality Assurance Requirements for Nuclear Facility Applications, Part IV, Subpart 4.2, "Graded Approach Application of Quality Assurance Requirements for Research and Development." New York, New York.

Berg JC. 2010. An Introduction to Interfaces and Colloids: The Bridge to Nanoscience. World Scientific Publishing Co., Hackensack, New Jersey.

Boyaval S and C Dumouchel. 2001. "Deconvolution Technique to Determine Local Spray Drop Size Distributions - Application to High-Pressure Swirl Atomizers." In Proceedings of the $17^{\text {th }}$ Annual Conference on Liquid Atomization and Spray Systems, September 2-6, 2001, Zurich, Switzerland.

Breitling M, S Nonnenmacher, S Schutz, and M Piesche. 2001. "Atomization of Non-Newtonian Liquids by Axial Hollow Cone Pressure Swirl Nozzles." In Proceedings of the $17^{\text {th }}$ Annual Conference on Liquid Atomization and Spray Systems, September 2-6, 2001, Zurich, Switzerland.

Bühler F, U Gärtner and S Clement. 2001. "Influence of the Surface Tension on the Atomization of Water." In Proceedings of the $17^{\text {th }}$ Annual Conference on Liquid Atomization and Spray Systems, September 2-6, 2001, Zurich, Switzerland.

Campbell T, M Parker, A Moon, B Fant, K Clossey, and J Cook. 2010. EFRT Issue M3 PJM Vessel Mixing Assessment, Volume 8-HLP-22. 24590-WTP-RPT-ENG-08-021-08, Rev. 1, River Protection Project, Waste Treatment Plant, Richland, Washington.

Crowe RD. 2010. Sludge Treatment Project (STP) Methodology for Spray Leak Scenarios. PRC-STP-00292, Rev 0, CH2M HILL Plateau Remediation Company, Richland, Washington.

Crowe RD. 2011. Sludge Treatment Project - Engineered Container Retrieval and Transfer System Draft Preliminary Design Accident Analysis. PRC-STP-CN-N-00401, Rev 1, CH2M HILL Plateau Remediation Company, Richland, Washington.

Denn MM. 1980. Process Fluid Mechanics. Prentice-Hall, Inc., Englewood Cliffs, New Jersey. 
DOE Order 414.1D. 2011. “Quality Assurance.” U.S. Department of Energy, Washington, D.C.

DOE - U.S. Department of Energy. 1994. Airborne Release Fractions/Rates and Respirable Fractions for Nonreactor Nuclear Facilities. DOE-HDBK-3010-94, U.S. Department of Energy, Washington, D.C.

Dombrowski N and WR Johns. 1963. "The Aerodynamic Instability and Disintegration of Viscous Liquid Sheets." Chemical Engineering Science 18:203-214.

Dombrowski N and G Munday. 1968. Biochemical and Biological Engineering Science. N Blakebrough editor, Chapter 16 - Spray Drying, 2:209-320. Academic Press, New York.

Eggers J and E Villermaux. 2008. "Physics of Liquid Jets." Reports of Progress in Physics 71(3):036601. doi:10.1088/0034-4885/71/3/036601.

Epstein M and MG Plys. 2006. Measured Drop Size Distributions with Cold Sprays Emanating from Small Leak Openings. FAI/06-55, Fauske \& Associates, LLC., Burr Ridge, Illinois.

Fritsching U, B Mulhem, O Kurt, and G Schulte. 2009. "Influence of Suspended Solid Particles on Suspension Atomization Processes." ICLASS 2009, $11^{\text {th }}$ Triennial International Annual Conference on Liquid Atomization and Spray Systems, July 2009, Vail, Colorado.

Gauglitz PA, LA Mahoney, J Blanchard, and JA Bamberger. 2011. Surface Tension Estimates for Droplet Formation in Slurries with Low Concentrations of Hydrophobic Particles, Polymer Flocculants or Surface-Active Contaminants. PNNL-20466, Rev. 0 (46497-RPT15, Rev. 0), Pacific Northwest National Laboratory, Richland, Washington.

Hecht JP and AE Bayly. 2009. "Atomization for Spray Drying: Unanswered Questions and Industrial Needs." ICLASS 2009, $11^{\text {th }}$ Triennial International Annual Conference on Liquid Atomization and Spray Systems, July 2009, Vail, Colorado.

Hecht JP, JA Stamper, and DK Giles. 2007. "Pneumatic Atomization of Laundry Detergent Slurries as Affected by Solid Particle Size and Concentration." Presented at ILASS Americas, $20^{\text {th }}$ Annual Conference on Liquid Atomization and Spray Systems, May 2007, Chicago, Illinois.

Hey BE and DS Leach. 1994. A Model for Predicting Respirable Releases from Pressurized Leaks. WHC-SD-GN-SWD-20007 Rev. 0, Westinghouse Hanford Company, Richland, Washington.

Hinze JO. 1955. "Fundamentals of the Hydrodynamic Mechanism of Splitting in Dispersion Processes." American Institute of Chemical Engineering Journal 1(3):289-295.

Kurath DE, BD Hanson, MJ Minette, DL Baldwin, BM Rapko, LA Mahoney, PP Schonewill, RC Daniel, PW Eslinger, JL Huckaby, JM Billing, PS Sundar, GB Josephson, JJ Toth, ST Yokuda, EBK Baer, SM Barnes, EC Golovich, SD Rassat, CF Brown, JGH Geeting, GJ Sevigny, AJ Casella, JR Bontha, RL Aaberg, PM Aker, CE Guzman-Leong, ML Kimura, SK Sundaram, RP Pires, BE Wells, and OP Bredt. 2009. Pretreatment Engineering Platform Phase-1 Final Test Report. PNNL-18894, WTP-RPT-197, Pacific Northwest National Laboratory, Richland, Washington. 
Larson AR and BT Allen. 2010. WTP Methodology for Spray Leak Scenarios.

24590-WTP-RPT-ENS-10-001, Rev. 1, River Protection Project, Waste Treatment Plant, Richland, Washington.

Lefebvre AH. 1989. Atomization and Sprays. CRC Press, Taylor and Francis Group, Boca Raton, Florida.

Levy N, S Amara, J-C Champoussin, and N Guerrassi. 1997. "Non-Reactive Diesel Spray Computations Supported by PDA Measurements." SAE Paper 970049.

Mahoney LA, PA Gauglitz, J Blanchard, ML Kimura, and DE Kurath. 2012. Small-scale Spray Releases: Orifice Plugging Test Results. PNNL-21361, WTP-RPT-219 Rev. 0, Pacific Northwest National Laboratory, Richland, Washington.

Malvern Instruments Ltd. 2010. RTSizer and Insitec Analyser User Manual. MAN0467 Issue 1.0, Malvern Instruments Ltd., Malvern, Worcestershire, United Kingdom.

Mansour A and N Chigier. 1995. "Air-Blast Atomization of Non-Newtonian Liquids." Journal of Non-Newtonian Fluid Mechanics 58:161-194.

McAllister J. 2010. Severity Level Calculations for the Pretreatment Facility Based on Updated MAR. Calculation No. 24590-PTF-Z0C-W14T-00036, Rev. B, River Protection Project, Waste Treatment Plant, Richland, Washington.

Merrington AC and EG Richardson. 1947. "The Break-Up of Liquid Jets." Proceedings of the Physical Society 59(331):1-13.

Mulhem B, G Schulte, and U Fritsching. 2006. "Solid-Liquid Separation in Suspension Atomization." Chemical Engineering Science 61:2582-2589.

Mulhem B, U Fritsching, G Schulte, and K Bauckhage. 2001. "Effect of Solid Particle Size on Suspension Atomization." In Proceedings of the $17^{\text {th }}$ Annual Conference on Liquid Atomization and Spray Systems, September 2-6, 2001, Zurich, Switzerland.

Mulhem B, U Fritsching, G Schulte, and K Bauckhage. 2003. "Effect of Solid Particle Characteristics on Suspension Atomization." Atomization and Sprays 13:321-343.

Nasr GG, AJ Yule, and L Bendig. 2002. Industrial Sprays and Atomization: Design, Analysis and Applications. Springer, New York, New York.

Perry RH and CH Chilton. 1973. Chemical Engineers' Handbook. McGraw-Hill, New York.

Pilch M and CA Endman. 1987. "Use of Breakup Time Data and Velocity History Data to Predict the Maximum Size of Stable Fragment for Acceleration-Induced Breakup of a Liquid Drop." International Journal of Multiphase Flow 13(6):741-757. 
Poloski AP, PA Meyer, LK Jagoda, and PR Hrma. 2004. Non-Newtonian Slurry Simulant Development and Selection for Pulse Jet Mixer Testing. PNWD-3495, WTP-RPT-111 Rev. 0, Battelle--Pacific Northwest Division, Richland, Washington.

Process Metrix. 2007. Process Particle Counter Manual. Process Metrix, Pleasanton, California.

Rosin P and E Rammler. 1933. "The Laws Governing the Fineness of Powdered Coal." Journal of the Institute of Fuel 7:29-36.

Scheele RD, GN Brown, and DE Kurath. 2009. Scale-up, Production, and Procurement of PEP Simulants. PNNL-18678, WTP-RPT-204 Rev 0, Pacific Northwest National Laboratory, Richland, Washington.

Schonewill PP, PA Gauglitz, JR Bontha, RD Daniel, JJ Jenks, DE Kurath, JM Billing, HE Adkins, Jr, CW Enderlin, CA Burns, C Fischer, CD Lukins, JL Shutthanandam, and DM Smith. 2012. Large-Scale Spray Releases: Aerosol Test Results. WTP-RPT-217 Rev 0 (to be published), Pacific Northwest National Laboratory, Richland, Washington.

Son SY and KD Kihm. 1998. "Effect of Coal Particle Size on Coal-Water Slurry (CWS) Atomization." Atomization and Sprays 8:503-521.

Stewart CW, CE Guzman-Leong, ST Arm, MG Butcher, EC Golovich, LK Jagoda, WR Park, RW Slaugh, YF Su, CF Wend, LA Mahoney, JM Alzheimer, JA Bailey, SK Cooley, DE Hurley, CD Johnson, LD Reid, HD Smith, BE Wells, and ST Yokuda. 2007. Results of Large-Scale Testing on Effects of Anti-Foam Agent on Gas Retention and Release. PNNL-17170, WTP-RPT-156 Rev 0, Pacific Northwest National Laboratory, Richland, Washington.

Wells BE, DE Kurath, LA Mahoney, Y Onishi, JL Huckaby, SK Cooley, CA Burns, EC Buck, JM Tingey, RC Daniel, and KK Anderson. 2011. Hanford Waste Physical and Rheological Properties: Data and Gaps. PNNL-20646, EMSP-RPT-006, Rev 0, Pacific Northwest National Laboratory, Richland, Washington.

Williams JC. 2000. Analysis of Waste Leak and Toxic Chemical Release Accidents from Waste Feed Delivery (WFD) Dilute System. RPP-5098, Rev. 1, Fluor Hanford, Richland, Washington.

Zimmerman BD. 2003. Waste Transfer Leaks Technical Basis Document. RPP-13750, Rev. 0, CH2M HILL Hanford Group, Inc., Richland, Washington. 
Appendix A

Run Log and Test Conditions 

The following table provides a summary of the aerosol tests performed, the associated testing parameters, and the page of this report on which the cumulative release fraction plot for the test appears. Tests were named using the Test identification (ID) formula SS-A-WWN-XXX-OYY-RZ-SG-EX\#

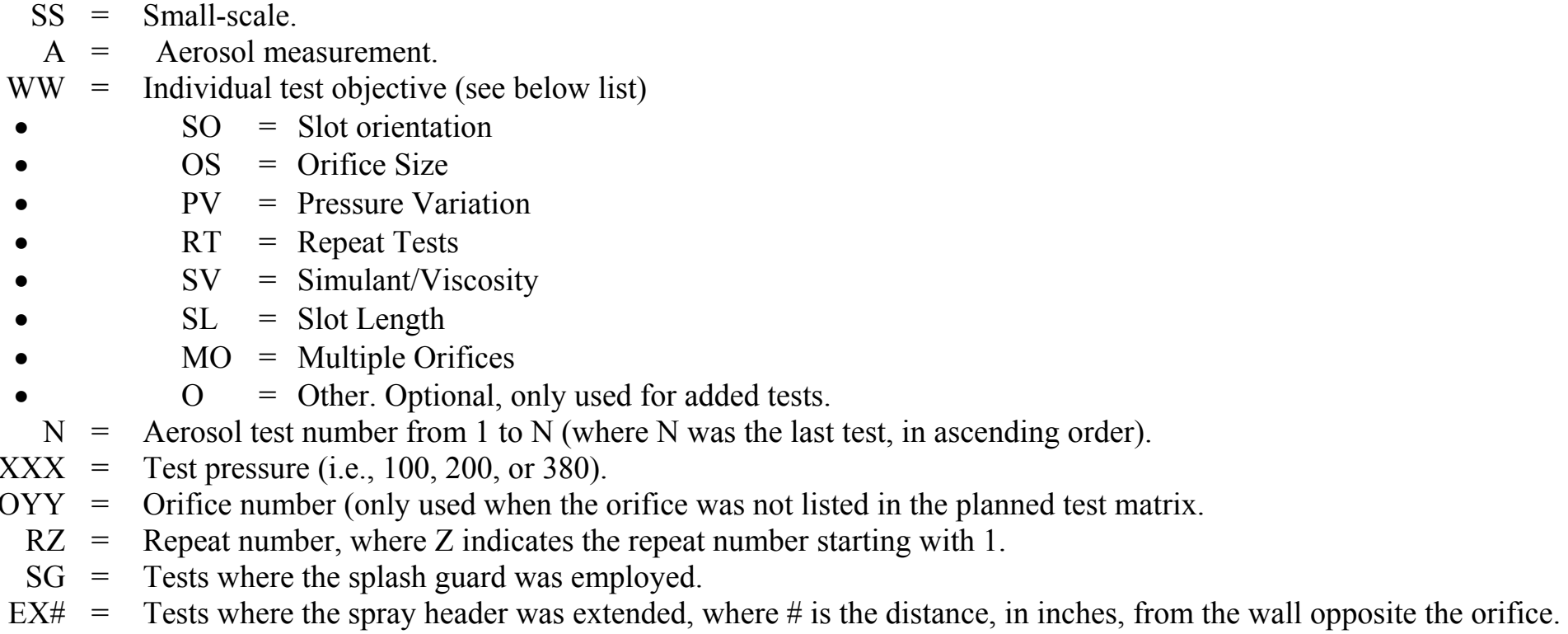

Unless otherwise noted, slot orifices were oriented axially (along the direction of flow)

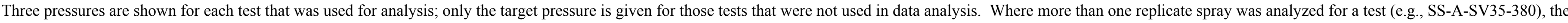
replicate sprays are indicated by letters (A, B, C). A letter is also used to identify which spray was used for tests in which replicate sprays were made, but only one of the replicates was used.

For analyzed tests, the first of the three pressures is the test target pressure $\left(P_{\text {targ }}\right)$. The second pressure is the square of the average of square-root of pressure during the 20-second correlation-fit period $\left(P_{R F}\right)$; this pressure was used to

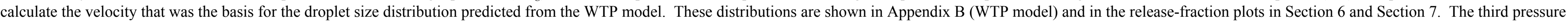

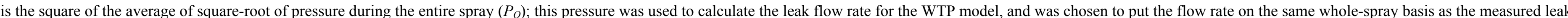
flow rate. The WTP-model generation rates that are shown in some of the plots in Section 7 were found by multiplying the model flow rate (based on spray-period pressure) times the model size distribution (based on fit-period pressure).

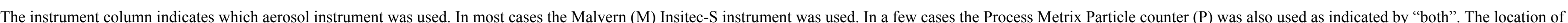
the Malvern aerosol instrument is indicated by a number. The position of the instrument in the spray chamber may be found in Figure 4.6 .

The analyses conducted on the simulants are indicated in several columns and include particle size distribution (PSD), rheology, bulk density, undissolved solids (UDS) and surface tension. The pre/post indicates whether the samples were taken pre-test or post-test.

Three columns are provided that give traceability to the technical work documents. These include the test instruction (TI) the test data package (TDP) and the laboratory record book (LRB)

The last column indicates the location in Appendix B where the results from data from each run are plotted.

\begin{tabular}{|c|c|c|c|c|c|c|c|c|c|c|c|c|c|c|c|c|c|}
\hline Test ID & Simulant ${ }^{\left(a^{2}\right)}$ & $\begin{array}{c}\text { Orifice Size } \\
(\mathrm{mm})\end{array}$ & Orientation & $\begin{array}{c}\mathrm{P}_{\text {targ }} / \mathrm{P}_{\mathrm{RF}} / \mathrm{P}_{\mathrm{Q}} \\
(\mathrm{psig})\end{array}$ & $\begin{array}{c}\text { Spray } \\
\text { Duration } \\
\text { (min) }\end{array}$ & $\begin{array}{c}\text { Instrument } \\
\text { (M, P, Both) }\end{array}$ & $\begin{array}{l}\text { Malvern } \\
\text { Position }\end{array}$ & $\begin{array}{c}\text { PSD } \\
\text { (Pre/Post) }^{(b)}\end{array}$ & $\begin{array}{l}\text { Rheology } \\
\text { (Pre/Post) }\end{array}$ & $\begin{array}{c}\text { Bulk } \\
\text { Density } \\
\text { (Pre/Post) }\end{array}$ & $\begin{array}{c}\text { UDS } \\
\text { (Pre/Post) }\end{array}$ & $\begin{array}{c}\text { Surface } \\
\text { Tension } \\
\text { (Pre/Post) }\end{array}$ & Observations & TI\# & $\begin{array}{l}\text { Testing } \\
\text { TDP\# }\end{array}$ & $\begin{array}{l}\text { LRB } \\
\text { PG \# }\end{array}$ & $\begin{array}{c}\mathrm{RF} \\
\mathrm{plot} \\
\mathrm{pg} \#^{(c)}\end{array}$ \\
\hline SS-A-SO1-380 & $\mathrm{H}_{2} \mathrm{O}$ & 0.531 & Axial & $380 / 383 / 382$ & 2 & $\mathrm{M}$ & 2 & - & - & - & - & Pre & - & 037 & 640 & 94 & B. 2 \\
\hline SS-A-SO2-380 & $\mathrm{H}_{2} \mathrm{O}$ & $0.534 \times 4.886$ & Axial & 380 & 2 & $\mathrm{M}$ & 2 & - & - & - & - & - & Repeated & 037 & 641 & 95 & $\mathrm{n} / \mathrm{a}$ \\
\hline SS-A-SO2-380-R1 & $\mathrm{H}_{2} \mathrm{O}$ & $0.534 \times 4.886$ & Axial & $380 / 389 / 381$ & 2 & M & 2 & - & - & - & - & - & - & 054 & 670 & 123 & B. 3 \\
\hline
\end{tabular}




\begin{tabular}{|c|c|c|c|c|c|c|c|c|c|c|c|c|c|c|c|c|c|}
\hline Test ID & Simulant ${ }^{(\mathrm{a})}$ & $\begin{array}{c}\text { Orifice Size } \\
(\mathrm{mm})\end{array}$ & Orientation & $\begin{array}{l}\mathrm{P}_{\text {targ }} / \mathrm{P}_{\mathrm{RF}} / \mathrm{P}_{\mathrm{Q}} \\
(\mathrm{psig})\end{array}$ & $\begin{array}{c}\text { Spray } \\
\text { Duration } \\
\text { (min) }\end{array}$ & $\begin{array}{l}\text { Instrument } \\
(\mathrm{M}, \mathrm{P}, \mathrm{Both})\end{array}$ & $\begin{array}{l}\text { Malvern } \\
\text { Position }\end{array}$ & $\begin{array}{c}\text { PSD } \\
\text { (Pre/Post) }^{(b)}\end{array}$ & $\begin{array}{l}\text { Rheology } \\
\text { (Pre/Post) }\end{array}$ & $\begin{array}{c}\text { Bulk } \\
\text { Density } \\
\text { (Pre/Post) }\end{array}$ & $\begin{array}{c}\text { UDS } \\
\text { (Pre/Post) }\end{array}$ & $\begin{array}{c}\text { Surface } \\
\text { Tension } \\
\text { (Pre/Post) }\end{array}$ & Observations & TI \# & $\begin{array}{l}\text { Testing } \\
\text { TDP\#\# }\end{array}$ & $\begin{array}{l}\text { LRB } \\
\text { PG \# }\end{array}$ & $\begin{array}{c}\mathrm{RF} \\
\text { plot } \\
\mathrm{pg} \#^{\left({ }^{(c)}\right.}\end{array}$ \\
\hline SS-A-SO3-380 & $\mathrm{H}_{2} \mathrm{O}$ & $0.541 \times 4.999$ & Circumf. & $380 / 288 / 361$ & 2 & M & 2 & - & - & - & - & - & - & 054 & 643 & 101 & B. 3 \\
\hline SS-A-SO4-380 & $\mathrm{H}_{2} \mathrm{O}$ & $0.534 \times 4.886$ & Dead-end & 380 & 2 & M & 2 & - & - & - & - & - & Repeated & 037 & 644 & 97 & $\mathrm{n} / \mathrm{a}$ \\
\hline SS-A-SO4-380-R1 & $\mathrm{H}_{2} \mathrm{O}$ & 0.531 & Dead-end & $380 / 272 / 363$ & 2 & M & 2 & - & - & - & - & - & - & 054 & 658 & 103 & B.4 \\
\hline SS-A-SO5-380 & $\mathrm{H}_{2} \mathrm{O}$ & $0.534 \times 4.886$ & Dead-end & 380 & 2 & M & 2 & - & - & - & - & - & Repeated & 037 & 645 & 96 & $\mathrm{n} / \mathrm{a}$ \\
\hline SS-A-SO5-380-R1 & $\mathrm{H}_{2} \mathrm{O}$ & $0.534 \times 4.886$ & Dead-end & $380 / 332 / 372$ & 2 & M & 2 & - & - & - & - & - & - & 037 & 653 & 100 & B.4 \\
\hline SS-A-OS6-380 & $\mathrm{H}_{2} \mathrm{O}$ & 2.015 & Axial & $380 / 365 / 379$ & 2 & M & 2 & - & - & - & - & - & - & 037 & 646 & 97 & B. 5 \\
\hline SS-A-OS7-380 & $\mathrm{H}_{2} \mathrm{O}$ & 0.975 & Axial & $380 / 356 / 380$ & 2 & M & 2 & - & - & - & - & - & - & 037 & 647 & 97 & B. 5 \\
\hline SS-A-OS8-380 & $\mathrm{H}_{2} \mathrm{O}$ & 0.534 & Axial & 380 & 2 & M & 2 & - & - & - & - & - & Repeated & 037 & 648 & 98 & $\mathrm{n} / \mathrm{a}$ \\
\hline SS-A-OS8-380-R1 & $\mathrm{H}_{2} \mathrm{O}$ & 0.534 & Axial & $380 / 318 / 371$ & 2 & M & 2 & - & - & - & - & - & - & 054 & 656 & 102 & B.6 \\
\hline SS-A-OS9-380 & $\mathrm{H}_{2} \mathrm{O}$ & 0.306 & Axial & $380 / 383 / 381$ & 2 & M & 2 & - & - & - & - & - & Repeated & 037 & 649 & 98 & B.6 \\
\hline SS-A-OS9-380-R1 & $\mathrm{H}_{2} \mathrm{O}$ & 0.306 & Axial & 380 & 2 & M & 2 & - & - & - & - & - & - & 054 & 657 & 102 & $\mathrm{n} / \mathrm{a}$ \\
\hline SS-A-OS10-380 & $\mathrm{H}_{2} \mathrm{O}$ & $1.017 \times 4.928$ & Axial & 380 & 2 & M & 2 & - & - & - & - & - & - & 037 & 642 & 99 & $\mathrm{n} / \mathrm{a}$ \\
\hline SS-A-OS10-380-R1-SG & $\mathrm{H}_{2} \mathrm{O}$ & $1.017 \times 4.928$ & Axial & $380 / 267 / 359$ & 2 & M & 2 & - & - & - & - & - & Splash Guard Used & 054 & 671 & 123 & B.7 \\
\hline SS-A-OS11-380 & $\mathrm{H}_{2} \mathrm{O}$ & $0.700 \times 5.022$ & Axial & $380316 / 371$ & 2 & M & 2 & - & - & - & - & - & - & 037 & 650 & 99 & B.7 \\
\hline SS-A-OS11-380-R1-SG & $\mathrm{H}_{2} \mathrm{O}$ & $0.700 \times 5.022$ & Axial & 380 & 2 & M & 2 & - & - & - & - & - & Splash Guard Used. & 054 & 672 & 124 & $\mathrm{n} / \mathrm{a}$ \\
\hline SS-A-OS12-380 & $\mathrm{H}_{2} \mathrm{O}$ & $0.508 \times 5.004$ & Axial & 380 & 2 & M & 2 & - & - & - & - & - & Repeated & 037 & 651 & 100 & $\mathrm{n} / \mathrm{a}$ \\
\hline SS-A-OS12-380-R1 & $\mathrm{H}_{2} \mathrm{O}$ & $0.508 \times 5.004$ & Axial & 380 & 2 & M & 2 & - & - & - & - & - & Repeated & 054 & 665 & 111 & $\mathrm{n} / \mathrm{a}$ \\
\hline SS-A-OS12-380-R2 & $\mathrm{H}_{2} \mathrm{O}$ & $0.534 \times 4.886$ & Axial & 380 & 2 & M & 2 & - & - & - & - & - & - & 054 & 667 & 122 & $\mathrm{n} / \mathrm{a}$ \\
\hline SS-A-OS12-380-R1-SG & $\mathrm{H}_{2} \mathrm{O}$ & $0.534 \times 4.886$ & Axial & $380 / 375 / 383$ & 2 & M & 2 & - & - & - & - & - & Splash Guard Used & 054 & 673 & 124 & B. 8 \\
\hline SS-A-OS13-380 & $\mathrm{H}_{2} \mathrm{O}$ & $0.355 \times 4.984$ & Axial & $380 / 274 / 362$ & 2 & M & 2 & - & - & - & - & Post & - & 037 & 652 & 101 & B. 8 \\
\hline SS-A-PV14-200 & $\mathrm{H}_{2} \mathrm{O}$ & 0.975 & Axial & 200/148/193 & 2 & M & 2 & - & - & - & - & - & - & 054 & 659 & 109 & B. 9 \\
\hline SS-A-PV15-200 & $\mathrm{H}_{2} \mathrm{O}$ & $0.508 \times 5.004$ & Axial & 200 & 2 & M & 2 & - & - & - & - & - & Repeated & 054 & 660 & 109 & $\mathrm{n} / \mathrm{a}$ \\
\hline SS-A-PV15-200-R1 & $\mathrm{H}_{2} \mathrm{O}$ & $0.534 \times 4.886$ & Axial & 200/158/193 & 2 & M & 2 & - & - & - & - & - & - & 054 & 668 & 122 & B. 9 \\
\hline SS-A-PV16-100 & $\mathrm{H}_{2} \mathrm{O}$ & 0.975 & Axial & $100 / 84 / 101$ & 2 & M & 2 & - & - & - & - & Post & - & 054 & 661 & 110 & B. 10 \\
\hline SS-A-PV17-100 & $\mathrm{H}_{2} \mathrm{O}$ & $0.508 \times 5.004$ & Axial & 100 & 2 & M & 2 & - & - & - & - & - & Repeated & 054 & 662 & 111 & $\mathrm{n} / \mathrm{a}$ \\
\hline SS-A-PV17-100-R1 & $\mathrm{H}_{2} \mathrm{O}$ & $0.534 \times 4.886$ & Axial & 100/111/104 & 2 & M & 2 & - & - & - & - & - & - & 54 & 669 & 123 & B. 10 \\
\hline SS-A-RT18-380 & $\mathrm{H}_{2} \mathrm{O}$ & 0.975 & Axial & $380 / 380 / 378$ & 2 & M & 2 & - & - & - & - & - & - & 054 & 663 & 110 & B.11 \\
\hline SS-A-RT19-380 & $\mathrm{H}_{2} \mathrm{O}$ & 0.975 & Axial & $380 / 366 / 380$ & 2 & M & 2 & - & - & - & - & - & - & 054 & 664 & 109 & B.11 \\
\hline SS-A-O20-380 & $\mathrm{H}_{2} \mathrm{O}$ & 0.306 & Axial & 380 & 10 & M & 2 & - & - & - & - & - & - & 054 & 666 & 120 & $\mathrm{n} / \mathrm{a}$ \\
\hline SS-A-O21-380-EX6 & $\mathrm{H}_{2} \mathrm{O}$ & 0.975 & Axial & 380 & 2 & M & 2 & - & - & - & - & - & $\begin{array}{l}\text { Header extended to } 6 \text { in. from } \\
\text { back wall }\end{array}$ & 054 & 674 & 124 & $\mathrm{n} / \mathrm{a}$ \\
\hline SS-A-O22-380-EX18 & $\mathrm{H}_{2} \mathrm{O}$ & 0.975 & Axial & 380 & 2 & M & 2 & - & - & - & - & - & $\begin{array}{l}\text { Header extended to } 18 \text { in. } \\
\text { from back wall }\end{array}$ & 054 & 675 & 127 & $\mathrm{n} / \mathrm{a}$ \\
\hline SS-A-O23-380 & $\mathrm{H}_{2} \mathrm{O}$ & $0.534 \times 4.886$ & Axial & 380 & 2 & Both & 2 & - & - & - & - & - & Malvern and PPC used & 054 & 676 & 137 & $\mathrm{n} / \mathrm{a}$ \\
\hline SS-A-O24-380 & $\mathrm{H}_{2} \mathrm{O}$ & 0.975 & Axial & 380 & 2 & Both & 2 & - & - & - & - & - & Malvern and PPC used & 054 & 677 & 137 & $\mathrm{n} / \mathrm{a}$ \\
\hline SS-A-O25-380 & $\mathrm{H}_{2} \mathrm{O}$ & 0.534 & Axial & 380 & 2 & M & 4: Center & - & - & - & 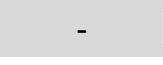 & - & In-jet data & 054 & 678 & 132 & $\mathrm{n} / \mathrm{a}$ \\
\hline SS-A-O26-380 & $\mathrm{H}_{2} \mathrm{O}$ & 0.534 & Axial & 380 & 2 & M & $4:+2 \mathrm{~cm}$ & - & - & - & - & - & In-jet data & 054 & 679 & 131 & $\mathrm{n} / \mathrm{a}$ \\
\hline
\end{tabular}




\begin{tabular}{|c|c|c|c|c|c|c|c|c|c|c|c|c|c|c|c|c|c|}
\hline Test ID & Simulant ${ }^{(a)}$ & $\begin{array}{l}\text { Orifice Size } \\
(\mathrm{mm})\end{array}$ & Orientation & $\mathrm{P}_{\text {targ }} / \mathrm{P}_{\mathrm{PF}} / \mathrm{P}_{\mathrm{Q}}$ & $\begin{array}{c}\text { Spray } \\
\text { Duration } \\
\text { (min) }\end{array}$ & $\begin{array}{l}\text { Instrument } \\
\text { (M, P, Both) }\end{array}$ & $\begin{array}{l}\text { Malvern } \\
\text { Position }\end{array}$ & $\underset{\text { (Pre/Post) }^{(b)}}{\text { PSD }}$ & $\begin{array}{l}\text { Rheology } \\
\text { (Pre/Post) }\end{array}$ & $\begin{array}{c}\text { Bulk } \\
\text { Density } \\
\text { (Pre/Post) }\end{array}$ & $\underset{\text { (Pre/Post) }}{\text { UDS }}$ & $\begin{array}{l}\text { Surface } \\
\text { Tension } \\
\text { (Pre/Post) }\end{array}$ & Observations & TI \# & $\begin{array}{l}\text { Testing } \\
\text { TDP \# }\end{array}$ & $\begin{array}{l}\text { LRB } \\
\text { PG \# }\end{array}$ & $\begin{array}{c}\mathrm{RF} \\
\mathrm{plot} \\
\mathrm{pg} \#^{\left({ }^{(c)}\right.}\end{array}$ \\
\hline SS-A-O27-380 & $\mathrm{H}_{2} \mathrm{O}$ & 0.534 & Axial & 380 & 2 & $\mathrm{M}$ & $4:+4 \mathrm{~cm}$ & - & - & - & - & - & In-jet data & 054 & 680 & 131 & $\mathrm{n} / \mathrm{a}$ \\
\hline SS-A-O28-380 & $\mathrm{H}_{2} \mathrm{O}$ & 0.534 & Axial & 380 & 2 & M & $4:-2 \mathrm{~cm}$ & - & - & - & - & - & In-jet data & 054 & 681 & 132 & $\mathrm{n} / \mathrm{a}$ \\
\hline SS-A-O29-380 & $\mathrm{H}_{2} \mathrm{O}$ & 0.534 & Axial & 380 & 2 & M & 4: $-4 \mathrm{~cm}$ & - & - & - & - & Post & In-jet data & 054 & 682 & 134 & $\mathrm{n} / \mathrm{a}$ \\
\hline SS-A-SV30-380 & $\mathrm{H}_{2} \mathrm{O}$ AFA & 0.975 & Axial & 380 & 2 & M & 2 & - & - & - & - & Pre / Post & - & 054 & 683 & 139 & $\mathrm{n} / \mathrm{a}$ \\
\hline SS-A-SV30-380-R1 & $\mathrm{H}_{2} \mathrm{O}$ AFA & 0.975 & Axial & $380 / 301 / 366$ & 2 & M & 2 & - & - & - & - & - & - & 054 & 686 & 140 & B. 12 \\
\hline SS-A-SV31-380 & $\mathrm{H}_{2} \mathrm{O}$ AFA & $0.534 \times 4.886$ & Axial & $380 / 322 / 378$ & 2 & M & 2 & - & - & - & - & - & - & 054 & 684 & 139 & B. 12 \\
\hline SS-A-SV31-380-R1 & $\mathrm{H}_{2} \mathrm{O}$ AFA & $0.534 \times 4.886$ & Axial & 380 & 2 & M & 2 & - & - & - & - & - & - & 054 & 685 & 140 & $\mathrm{n} / \mathrm{a}$ \\
\hline SS-A-SV32-380 & STR8 AFA & 0.975 & Axial & $380 / 332 / 376$ & 2 & M & 2 & Pre & Pre & Pre & - & Pre & - & 054 & 687 & 142 & B. 13 \\
\hline SS-A-SV33-380 & STR8 AFA & $0.534 \times 4.886$ & Axial & $380 / 287 / 351$ & 2 & M & 2 & Post & Post & Post & - & Post & - & 054 & 688 & 142 & B. 13 \\
\hline SS-A-SV34-380 & STR8 & 0.975 & Axial & $380 / 332 / 376$ & 2 & M & 2 & Pre & Pre & Pre & - & Pre & - & 054 & 689 & 144 & B.14 \\
\hline SS-A-SV35-380 & STR8 & $0.534 \times 4.886$ & Axial & $\begin{array}{l}\text { A: } 3800327 / 380 \\
\text { B: } 380331 / 376 \\
\text { C: } 380329 / 370\end{array}$ & 2 & M & 2 & - & - & - & - & - & Three completed sprays (A-C) & 054 & 690 & 147 & $\begin{array}{l}\text { B.14- } \\
\text { B. } 15\end{array}$ \\
\hline SS-A-SV36-380 & STR20 & 0.975 & Axial & $380 / 318 / 366$ & 2 & M & 2 & Pre & Pre & Pre & - & Pre & - & 054 & 691 & 148 & B.16 \\
\hline SS-A-SV37-380 & STR20 & $0.534 \times 4.886$ & Axial & $\begin{array}{c}380 \\
\text { C: } 380 / 384 / 380\end{array}$ & 2 & M & 2 & - & - & - & - & - & Four completed sprays (A-D) & 054 & 692 & 149 & B. 16 \\
\hline SS-A-SV38-380 & SAR8 & $0.534 \times 4.886$ & Axial & $380 / 264 / 346$ & 2 & M & 2 & Pre & Pre & Pre & - & Pre & - & 054 & 693 & 151 & B. 17 \\
\hline SS-A-SV39-380 & SAR8 & 0.975 & Axial & $380 / 259 / 339$ & 2 & M & 2 & - & - & - & - & - & - & 054 & 694 & 153 & B. 17 \\
\hline SS-A-SV40-380 & SAR20 & 0.975 & Axial & A: $380 / 379 / 381$ & 2 & M & 2 & Pre & Pre & Pre & - & Pre & Two completed sprays (A-B) & 054 & 695 & 155 & B. 18 \\
\hline SS-A-SV41-380 & SAR20 & $0.534 \times 4.886$ & Axial & A: $380 / 364 / 377$ & 2 & M & 2 & - & - & - & - & - & Three completed sprays (A-C) & 054 & 696 & 155 & B. 18 \\
\hline SS-A-SV42-380 & TAR8 & $0.534 \times 4.886$ & Axial & A: $380 / 325 / 368$ & 2 & M & 2 & Pre & Pre & Pre & - & Pre & Two completed sprays (A-B) & 054 & 697 & 157 & B.19 \\
\hline SS-A-SV43-380 & TAR8 & 0.975 & Axial & A: $380 / 366 / 380$ & 2 & M & 2 & - & - & - & - & - & Two completed sprays ( $\mathrm{A}$ and $\mathrm{C}$ ) & 054 & 698 & 158 & B.19 \\
\hline SS-A-SV44-380 & $\mathrm{Na}_{2} \mathrm{~S}_{2} \mathrm{O}_{3}$ & 0.975 & Axial & $\begin{array}{l}\text { A: } 380 / 327 / 372 \\
\text { B: } 380 / 325 / 372 \\
\text { C: } 380 / 325 / 372\end{array}$ & 2 & M & 2 & - & Pre & Pre & - & Pre & Three completed sprays (A-C) & 054 & 699 & 159 & $\begin{array}{l}\text { B. } 20- \\
\text { B.21 }\end{array}$ \\
\hline SS-A-SV45-380 & $\mathrm{NaNO}_{3}$ & 0.975 & Axial & B: $380 / 317 / 369$ & 2 & M & 2 & - & Pre & Pre & - & Pre & Two completed sprays (B-C) & 054 & 700 & 164 & B. 21 \\
\hline SS-A-SL46-380 & $\mathrm{H}_{2} \mathrm{O}$ & $0.499 \times 9.902$ & Axial & B: $380 / 279 / 363$ & 2 & M & 2 & - & - & - & - & Pre & $\begin{array}{l}\text { Began using LRB 61236. Two } \\
\text { completed sprays (A-B) }\end{array}$ & 054 & 701 & 3 & B. 22 \\
\hline SS-A-SL47-380 & $\mathrm{H}_{2} \mathrm{O}$ & $\begin{array}{l}0.533 \times \\
14.868\end{array}$ & Axial & B: $380 / 338 / 372$ & 2 & M & 2 & - & - & - & - & - & Two completed sprays (A-B) & 054 & 702 & 3 & B. 22 \\
\hline SS-A-SL48-380 & $\mathrm{H}_{2} \mathrm{O}$ & $\begin{array}{l}0.543 \times \\
19.935\end{array}$ & Axial & 380 & 2 & M & 2 & - & - & - & - & - & Repeated & 054 & 703 & 4 & $\mathrm{n} / \mathrm{a}$ \\
\hline SS-A-SL48-380-R1 & $\mathrm{H}_{2} \mathrm{O}$ & $\begin{array}{l}0.543 \times \\
19.935\end{array}$ & Axial & $\begin{array}{l}\text { A: } 380 / 334 / 372 \\
\text { B: } 380 / 304 / 368\end{array}$ & 2 & M & 2 & - & - & - & - & - & Four completed sprays (A-C, E) & 054 & 747 & 5 & B. 23 \\
\hline SS-A-MO49-380 & $\mathrm{H}_{2} \mathrm{O}$ & $5 @ 0.470$ & Axial & A: $380 / 321 / 369$ & 2 & M & 2 & - & - & - & - & - & Two completed sprays (A-B) & 054 & 704 & 8 & B. 24 \\
\hline SS-A-MO50-380 & $\mathrm{H}_{2} \mathrm{O}$ & $5 @ 1.002$ & Axial & F: $380 / 290 / 362$ & 2 & M & 2 & - & - & - & - & - & Three completed sprays (D-F) & 054 & 705 & 8 & B.24 \\
\hline SS-A-SV51-380 & FER30Pa(g) & 0.975 & Axial & A: $380 / 412 / 404$ & 2 & M & 2 & Pre / Post & Pre / Post & Pre / Post & Pre / Post & Pre / Post & Two completed sprays (A and C) & 054 & 754 & 17 & B. 25 \\
\hline SS-A-SV52-200 & FER30 $\mathrm{Pa}(\mathrm{g})$ & 0.975 & Axial & C: $200 / 200 / 205$ & 2 & M & 2 & - & - & - & - & - & Three completed sprays (A-C) & 054 & 755 & 21 & B. 25 \\
\hline SS-A-SV53-380 & FER30 $\mathrm{Pa}(\mathrm{g})$ & $0.534 \times 4.886$ & Axial & B: $380 / 398 / 396$ & 2 & M & 2 & - & - & - & - & - & Two completed sprays (A-B) & 054 & 756 & 22 & B.26 \\
\hline
\end{tabular}




\begin{tabular}{|c|c|c|c|c|c|c|c|c|c|c|c|c|c|c|c|c|c|}
\hline Test ID & Simulant ${ }^{(a)}$ & $\begin{array}{l}\text { Orifice Size } \\
\quad(\mathrm{mm})\end{array}$ & Orientation & $\begin{array}{l}\mathrm{P}_{\text {targ }} / \mathrm{P}_{\mathrm{RF}} / \mathrm{P}_{\mathrm{Q}} \\
(\mathrm{psig})\end{array}$ & $\begin{array}{l}\text { Spray } \\
\text { Duration } \\
(\mathrm{min})\end{array}$ & $\begin{array}{l}\text { Instrument } \\
\text { (M, P, Both) }\end{array}$ & $\begin{array}{l}\text { Malvern } \\
\text { Position }\end{array}$ & $\begin{array}{c}\text { PSD } \\
\text { (Pre/Post) }^{(b)}\end{array}$ & $\begin{array}{l}\text { Rheology } \\
\text { (Pre/Post) }\end{array}$ & $\begin{array}{c}\text { Bulk } \\
\text { Density } \\
\text { (Pre/Post) }\end{array}$ & $\begin{array}{c}\text { UDS } \\
\text { (Pre/Post) }\end{array}$ & $\begin{array}{l}\text { Surface } \\
\text { Tension } \\
\text { (Pre/Post) }\end{array}$ & Observations & TI \# & $\begin{array}{l}\text { Testing } \\
\text { TDP \# }\end{array}$ & $\begin{array}{l}\text { LRB } \\
\text { PG \# }\end{array}$ & $\begin{array}{c}\mathrm{RF} \\
\text { plot } \\
\operatorname{pg} \#^{\left(c^{(c)}\right.}\end{array}$ \\
\hline $\begin{array}{l}\text { SS-A-SV54-200 } \\
\end{array}$ & FER30 Pa(g) & $0.534 \times 4.886$ & Axial & A: 200/198/206 & 2 & $\mathrm{M}$ & 2 & - & Pre & - & - & - & Two completed sprays (A-B) & 054 & 757 & 24 & B.26 \\
\hline SS-A-SV55-380 & $\begin{array}{c}\text { FER30 Pa(g) } \\
\text { AFA }\end{array}$ & $0.534 \times 4.886$ & Axial & $\begin{array}{l}\text { A: } 380 / 384 / 386 \\
\text { B: } 380 / 400 / 385 \\
\text { C: } 380 / 399 / 387\end{array}$ & 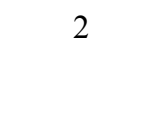 & M & 2 & Pre / Post & Pre / Post & Pre / Post & Pre / Post & Pre / Post & Three completed sprays (A-C) & 054 & 760 & 26 & $\begin{array}{l}\text { B. } 27- \\
\text { B. } 28\end{array}$ \\
\hline SS-A-SV56-200 & $\begin{array}{c}\text { FER30 Pa(g) } \\
\text { AFA }\end{array}$ & $0.534 \times 4.886$ & Axial & A: 200/201/206 & 2 & M & 2 & - & - & - & - & - & Three completed sprays (A, C, F) & 054 & 761 & 27 & B.28 \\
\hline SS-A-SV57-380 & $\begin{array}{l}\text { FER30 Pa(g) } \\
\text { AFA }\end{array}$ & 0.975 & Axial & B: $380 / 384 / 393$ & 2 & M & 2 & - & - & - & - & - & Two completed sprays (A-B) & 054 & 762 & 28 & B.29 \\
\hline SS-A-SV58-200 & $\begin{array}{c}\text { FER30 Pa(g) } \\
\text { AFA }\end{array}$ & 0.975 & Axial & A: 200/199/203 & 2 & M & 2 & - & Post & - & - & - & Two completed sprays (A-B) & 054 & 763 & 29 & B.29 \\
\hline SS-A-SV59-380 & FER6Pa(b) & 0.975 & Axial & B: $380 / 379 / 381$ & 2 & M & 2 & Pre & Pre & Pre & Pre & Pre & Two completed sprays (A-B) & 054 & 748 & 9 & B. 30 \\
\hline SS-A-SV60-200 & FER6Pa(b) & 0.975 & Axial & B: $200 / 207 / 213$ & 2 & M & 2 & Pre & Post & Post & Post & Post & Two completed sprays (A-B) & 054 & 749 & 10 & B. 30 \\
\hline SS-A-SV61-380 & FER6Pa(b) & $0.534 \times 4.886$ & Axial & C: $380 / 384 / 383$ & 2 & M & 2 & - & - & - & - & - & Three completed sprays (A-C) & 054 & 750 & 13 & B. 31 \\
\hline SS-A-SV62-200 & FER6Pa(b) & $0.534 \times 4.886$ & Axial & A: 200/210/205 & 2 & M & 2 & - & - & - & - & - & Two completed sprays (A-B) & 054 & 751 & 14 & B. 31 \\
\hline SS-A-SV63-380 & $\begin{array}{c}\text { FER6Pa }(\mathrm{g}) \\
\text { AFA }\end{array}$ & 0.975 & Axial & B: $380 / 380 / 389$ & 2 & M & 2 & Pre / Post & Pre / Post & Pre / Post & Pre / Post & Pre / Post & Two completed sprays (A-B) & 054 & 765 & 32 & B. 32 \\
\hline SS-A-SV64-200 & $\begin{array}{l}\text { FER6Pa(g) } \\
\text { AFA }\end{array}$ & 0.975 & Axial & B: 200/198/198 & 2 & M & 2 & - & - & - & - & - & Three completed sprays (A-C) & 054 & 766 & 35 & B. 32 \\
\hline SS-A-SV65-380 & $\begin{array}{c}\text { FER6Pa(g) } \\
\text { AFA }\end{array}$ & $0.534 \times 4.886$ & Axial & $\begin{array}{l}\text { A: } 380 / 371 / 392 \\
\text { B: } 380 / 366 / 392 \\
\text { C: } 380 / 377 / 390\end{array}$ & 2 & M & 2 & - & Pre & - & - & - & Three completed sprays (A-C) & 054 & 767 & 36 & $\begin{array}{l}\text { B. } 33- \\
\text { B. } 34\end{array}$ \\
\hline SS-A-SV66-200 & $\begin{array}{c}\text { FER6Pa(g) } \\
\text { AFA }\end{array}$ & $0.534 \times 4.886$ & Axial & A: 200/212/205 & 2 & M & 2 & - & - & - & - & - & Two completed sprays (A-B) & 054 & 768 & 37 & B. 34 \\
\hline SS-A-O67-380 & $\begin{array}{l}\text { FER6Pa(g) } \\
\text { AFA }\end{array}$ & 0.975 & Axial & 380 & 2 & M & 4:Center & - & - & - & - & - & In-jet data & 054 & 769 & 41 & $\mathrm{n} / \mathrm{a}$ \\
\hline SS-A-O68-200 & $\begin{array}{c}\text { FER6Pa(g) } \\
\text { AFA }\end{array}$ & 0.975 & Axial & 200 & 2 & M & 4:Center & - & - & - & - & - & In-jet data & 054 & 770 & 41 & $\mathrm{n} / \mathrm{a}$ \\
\hline SS-A-O69-380 & $\begin{array}{c}\text { FER6Pa(g) } \\
\text { AFA }\end{array}$ & 0.534 & Axial & 380 & 2 & M & 4:Center & - & - & - & - & - & In-jet data & 054 & 771 & 42 & $\mathrm{n} / \mathrm{a}$ \\
\hline SS-A-O70-200 & $\begin{array}{c}\text { FER6Pa(g) } \\
\text { AFA }\end{array}$ & 0.534 & Axial & 200 & 2 & M & 4:Center & - & - & - & - & - & In-jet data & 054 & 772 & 42 & $\mathrm{n} / \mathrm{a}$ \\
\hline SS-A-O71-380 & $\mathrm{H}_{2} \mathrm{O}$ & $0.534 \times 4,886$ & Axial & $\begin{array}{l}\text { A: } 380 / 379 / 378 \\
\text { B: } 380 / 378 / 378 \\
\text { C: } 380 / 379 / 379\end{array}$ & 2 & M & 2 & - & - & - & - & - & $\begin{array}{l}\text { Constant target pressure TI. } \\
\text { Five completed sprays (A-E) }\end{array}$ & 086 & 780 & 58 & $\begin{array}{l}\text { B. } 35- \\
\text { B. } 36\end{array}$ \\
\hline SS-A-O72-380 & $\mathrm{H}_{2} \mathrm{O}$ & $0.534 \times 4.886$ & Axial & $\begin{array}{l}\text { A: } 380 / 386 / 380 \\
\text { B: } 380 / 386 / 380 \\
\text { C: } 380 / 387 / 374\end{array}$ & 2 & M & 2 & - & - & - & - & - & $\begin{array}{l}\text { Started at high pressure and reduced } \\
\text { to target TI. } \\
\text { Four completed sprays (A-D) }\end{array}$ & 087 & 781 & 58 & $\begin{array}{l}\text { B. } 36- \\
\text { B. } 37\end{array}$ \\
\hline SS-A-O73-380 & $\mathrm{H}_{2} \mathrm{O}$ & $0.534 \times 4.886$ & Axial & $\begin{array}{l}\text { A: } 380 / 348 / 375 \\
\text { B: } 380 / 337 / 372 \\
\text { C: } 380 / 345 / 360\end{array}$ & 2 & M & 2 & - & - & - & - & - & $\begin{array}{l}\text { Started at low pressure and } \\
\text { increased to target TI. } \\
\text { Five completed sprays (A-E) }\end{array}$ & 088 & 784 & 60 & $\begin{array}{l}\text { B. } 38- \\
\text { B. } 39\end{array}$ \\
\hline SS-A-O74-380 & $\mathrm{H}_{2} \mathrm{O}$ & $0.534 \times 4.886$ & Axial & $\begin{array}{l}\text { A: } 380 / 372 / 378 \\
\text { B: } 380 / 377 / 379 \\
\text { C: } 380 / 385 / 381\end{array}$ & 2 & M & 2 & - & - & - & - & - & $\begin{array}{l}\text { Start at high pressure with empty } \\
\text { header and reduced to target TI. } \\
\text { Five completed sprays (A-E) }\end{array}$ & 087 & 785 & 67 & $\begin{array}{l}\text { B. } 39- \\
\text { B. } 40\end{array}$ \\
\hline
\end{tabular}




\begin{tabular}{|c|c|c|c|c|c|c|c|c|c|c|c|c|c|c|c|c|c|}
\hline Test ID & Simulant ${ }^{(\mathrm{a})}$ & $\begin{array}{l}\text { Orifice Size } \\
\quad(\mathrm{mm})\end{array}$ & Orientation & $\begin{array}{l}\mathrm{P}_{\operatorname{targ}} / \mathrm{P}_{\mathrm{RF}} / \mathrm{P}_{\mathrm{Q}} \\
(\mathrm{psig})\end{array}$ & $\begin{array}{l}\text { Spray } \\
\text { Duration } \\
(\mathrm{min})\end{array}$ & $\begin{array}{l}\text { Instrument } \\
\text { (M, P, Both) }\end{array}$ & $\begin{array}{l}\text { Malvern } \\
\text { Position }\end{array}$ & $\begin{array}{c}\text { PSD } \\
\text { (Pre/Post) }^{(\mathrm{b})}\end{array}$ & $\begin{array}{l}\text { Rheology } \\
\text { (Pre/Post) }\end{array}$ & $\begin{array}{c}\text { Bulk } \\
\text { Density } \\
\text { (Pre/Post) }\end{array}$ & $\begin{array}{c}\text { UDS } \\
\text { (Pre/Post) }\end{array}$ & $\begin{array}{l}\text { Surface } \\
\text { Tension } \\
\text { (Pre/Post) }\end{array}$ & Observations & TI \# & $\begin{array}{l}\text { Testing } \\
\text { TDP \# }\end{array}$ & $\begin{array}{l}\text { LRB } \\
\text { PG \# }\end{array}$ & $\begin{array}{l}\mathrm{RF} \\
\text { plot } \\
\mathrm{pg} \#^{(\mathrm{c})}\end{array}$ \\
\hline SS-A-075-380-EX1 & $\mathrm{H}_{2} \mathrm{O}$ & 0.975 & Axial & $\begin{array}{l}\text { A: } 380 / 376 / 379 \\
\text { B: } 380 / 380 / 380 \\
\text { C: } 380 / 383 / 383\end{array}$ & 2 & M & 2 & - & - & - & - & - & $\begin{array}{l}\text { This and subsequent tests used } \\
\text { Constant Target Pressure TI-086. } \\
\text { Header extended to } 1 \text { in. from back } \\
\text { wall. Three completed sprays } \\
\text { (A-C) }\end{array}$ & 086 & 786 & 70 & $\begin{array}{l}\text { B. } 41- \\
\text { B.42 }\end{array}$ \\
\hline SS-A-O75-380-EX3 & $\mathrm{H}_{2} \mathrm{O}$ & 0.975 & Axial & $\begin{array}{l}\text { A: } 380 / 378 / 377 \\
\text { B: } 380 / 381 / 380 \\
\text { C: } 380 / 382 / 382\end{array}$ & 2 & M & 2 & - & - & - & - & - & $\begin{array}{l}\text { Header extended to } 3 \text { in. from back } \\
\text { wall. Three completed sprays } \\
\text { (A-C) }\end{array}$ & 086 & 787 & 71 & $\begin{array}{l}\text { B. } 42- \\
\text { B.43 }\end{array}$ \\
\hline SS-A-O75-380-EX6 & $\mathrm{H}_{2} \mathrm{O}$ & 0.975 & Axial & $\begin{array}{l}\text { A: } 380 / 382 / 382 \\
\text { B: } 380 / 380 / 380 \\
\text { C: } 380 / 378 / 378\end{array}$ & 2 & M & 2 & - & - & - & - & - & $\begin{array}{l}\text { Header extended to } 6 \text { in. from back } \\
\text { wall. Three completed sprays } \\
\text { (A-C) }\end{array}$ & 086 & 788 & 71 & $\begin{array}{l}\text { B. } 44- \\
\text { B.45 }\end{array}$ \\
\hline SS-A-075-380-EX18 & $\mathrm{H}_{2} \mathrm{O}$ & 0.975 & Axial & $\begin{array}{l}\text { A: } 380 / 380 / 380 \\
\text { B: } 380 / 378 / 377 \\
\text { C: } 380 / 378 / 378\end{array}$ & 2 & M & 2 & - & - & - & - & - & $\begin{array}{l}\text { Header extended to } 18 \mathrm{in} \text {. from } \\
\text { back wall. Three completed sprays } \\
\text { (A-C) }\end{array}$ & 086 & 789 & 72 & $\begin{array}{l}\text { B. } 45- \\
\text { B. } 46\end{array}$ \\
\hline SS-A-O76-380 & $\mathrm{H}_{2} \mathrm{O}$ & 0.534 & Axial & A: 380/383/382 & 2 & M & 2 & - & - & - & - & - & $\begin{array}{l}\text { Malvern purge } 0.6 \mathrm{SCFH} \text { per } \\
\text { window. Two completed sprays } \\
\text { (A-B) }\end{array}$ & 086 & 790 & 68 & B.47 \\
\hline SS-A-O77-380 & $\mathrm{H}_{2} \mathrm{O}$ & 0.534 & Axial & A: 380/380/380 & 2 & M & 2 & - & - & - & - & - & $\begin{array}{l}\text { Malvern purge } 1.2 \mathrm{SCFH} \text { per } \\
\text { window (standard). Two completed } \\
\text { sprays (A-B) }\end{array}$ & 086 & 791 & 68 & B. 47 \\
\hline SS-A-O78-380 & $\mathrm{H}_{2} \mathrm{O}$ & 0.534 & Axial & A: $380 / 382 / 383$ & 2 & M & 2 & - & - & - & - & - & $\begin{array}{l}\text { Malvern purge } 2.4 \text { SCFH per } \\
\text { window. Two completed sprays } \\
\text { (A-B) }\end{array}$ & 086 & 793 & 68 & B. 48 \\
\hline SS-A-O79-380 & $\mathrm{H}_{2} \mathrm{O}$ & 0.534 & Axial & B: 380/379/380 & 2 & M & 2 & - & - & - & - & - & $\begin{array}{l}\text { Malvern purge } 4 \text { SCFH per } \\
\text { window. Three completed sprays } \\
\text { (A-C) }\end{array}$ & 086 & 792 & 69 & B.48 \\
\hline SS-A-O80-380 & $\mathrm{H}_{2} \mathrm{O}$ & 0.534 & Axial & 380 & 2 & M & 2 & - & - & - & - & - & $\begin{array}{l}\text { Malvern purge 0 SCFH per } \\
\text { window. One completed spray (A) }\end{array}$ & 086 & 794-01 & 69 & $\mathrm{n} / \mathrm{a}$ \\
\hline SS-A-O81-380 & $\mathrm{H}_{2} \mathrm{O}$ & 0.534 & Axial & $\begin{array}{l}\text { A: } 380 / 382 / 383 \\
\text { B: } 380 / 387 / 384 \\
\text { A: } 380 / 387 / 383\end{array}$ & 2 & M & 2 & - & - & - & - & - & $\begin{array}{l}\text { Mixing fan } 0 \text { volts. Three } \\
\text { completed sprays (A-C) }\end{array}$ & 086 & 795 & 69 & $\begin{array}{l}\text { B. } 49- \\
\text { B. } 50\end{array}$ \\
\hline SS-A-O82-380 & $\mathrm{H}_{2} \mathrm{O}$ & 0.534 & Axial & $\begin{array}{l}\text { A: } 380 / 379 / 379 \\
\text { B: } 380 / 378 / 380 \\
\text { A: } 380 / 381 / 381\end{array}$ & 2 & M & 2 & - & - & - & - & - & $\begin{array}{l}\text { Mixing fan } 3 \text { volts. Three } \\
\text { completed sprays (A-C) }\end{array}$ & 086 & 796 & 70 & $\begin{array}{l}\text { B. } 50- \\
\text { B.51 }\end{array}$ \\
\hline SS-A-O83-380 & $\mathrm{H}_{2} \mathrm{O}$ & 0.534 & Axial & $\begin{array}{l}\text { A: } 380 / 381 / 379 \\
\text { B: } 380 / 380 / 380 \\
\text { A: } 380 / 379 / 382\end{array}$ & 2 & M & 2 & - & - & - & - & - & $\begin{array}{l}\text { Mixing fan } 11 \text { volts. Three } \\
\text { completed sprays (A-C) }\end{array}$ & 086 & 797 & 70 & $\begin{array}{l}\text { B. } 52- \\
\text { B.53 }\end{array}$ \\
\hline SS-A-O84-380 & $\mathrm{H}_{2} \mathrm{O}$ & 0.534 & Axial & $\begin{array}{l}\text { A: } 380 / 379 / 378 \\
\text { B: } 380 / 377 / 376 \\
\text { A: } 380 / 381 / 380\end{array}$ & 2 & M & 1 & - & - & - & - & - & $\begin{array}{l}\text { Malvern in position } 1 \text {. Three } \\
\text { completed sprays (A-C) }\end{array}$ & 086 & 798 & 73 & $\begin{array}{l}\text { B. } 53- \\
\text { B.54 }\end{array}$ \\
\hline SS-A-O85-380 & $\mathrm{H}_{2} \mathrm{O}$ & 0.534 & Axial & $\begin{array}{l}\text { A: } 380 / 379 / 378 \\
\text { B: } 380 / 375 / 374 \\
\text { A: } 380 / 380 / 380\end{array}$ & 2 & M & 2 & - & - & - & - & - & Three completed sprays (A-C) & 086 & 799 & 72 & $\begin{array}{l}\text { B. } 55- \\
\text { B.56 }\end{array}$ \\
\hline SS-A-O86-380 & $\mathrm{H}_{2} \mathrm{O}$ & 0.534 & Axial & 380 & 2 & M & 2 & & - & - & - & - & $\begin{array}{l}\text { Pre-spray, evacuate, run } \mathrm{A} \text {, } \\
\text { evacuate, run } \mathrm{B} \text {, evacuate, run } \mathrm{C} \text {, no } \\
\text { evacuate, run } \mathrm{D} \text {, no evacuate, run } \mathrm{E} \text {, } \\
\text { no evacuate, run } \mathrm{F}\end{array}$ & 086 & 800 & 73 & $\mathrm{n} / \mathrm{a}$ \\
\hline
\end{tabular}




\begin{tabular}{|c|c|c|c|c|c|c|c|c|c|c|c|c|c|c|c|c|c|}
\hline Test ID & Simulant ${ }^{(a)}$ & $\begin{array}{l}\text { Orifice Size } \\
\quad(\mathrm{mm})\end{array}$ & Orientation & $\begin{array}{l}\mathrm{P}_{\text {targ }} / \mathrm{P}_{\mathrm{PF}} / \mathrm{P}_{\mathrm{Q}} \\
(\mathrm{psig})\end{array}$ & $\begin{array}{l}\text { Spray } \\
\text { Duration } \\
\text { (min) }\end{array}$ & $\begin{array}{l}\text { Instrument } \\
\text { (M, P, Both) }\end{array}$ & $\begin{array}{l}\text { Malvern } \\
\text { Position }\end{array}$ & $\begin{array}{c}\text { PSD } \\
\text { (Pre/Post) }^{(b)}\end{array}$ & $\begin{array}{l}\text { Rheology } \\
\text { (Pre/Post) }\end{array}$ & $\begin{array}{c}\text { Bulk } \\
\text { Density } \\
\text { (Pre/Post) }\end{array}$ & $\begin{array}{c}\text { UDS } \\
\text { (Pre/Post) }\end{array}$ & $\begin{array}{c}\text { Surface } \\
\text { Tension } \\
\text { (Pre/Post) }\end{array}$ & Observations & TI \# & $\begin{array}{l}\text { Testing } \\
\text { TDP \# }\end{array}$ & $\begin{array}{l}\text { LRB } \\
\text { PG \# }\end{array}$ & $\begin{array}{c}\mathrm{RF} \\
\text { plot } \\
\mathrm{pg} \#^{\left(c^{c}\right.}\end{array}$ \\
\hline SS-A-087-380 & $\mathrm{H}_{2} \mathrm{O}$ & 0.975 & Axial & $\begin{array}{l}\text { A: } 380 / 377 / 379 \\
\text { B: } 380 / 380 / 380 \\
\text { A: } 380 / 379 / 380\end{array}$ & 2 & M & 2 & - & - & - & - & - & $\begin{array}{l}\text { Mixing fan off. Three completed } \\
\text { sprays (A-C) }\end{array}$ & 086 & 801 & 77 & $\begin{array}{l}\text { B.56- } \\
\text { B.57 }\end{array}$ \\
\hline SS-A-088-380 & $\mathrm{H}_{2} \mathrm{O}$ & 0.534 & Axial & 380 & 2 & M & 6 & - & - & - & - & - & Three completed sprays (A-C) & 086 & 802 & 75 & $\mathrm{n} / \mathrm{a}$ \\
\hline SS-A-089-380 & $\mathrm{H}_{2} \mathrm{O}$ & 0.534 & Axial & $\begin{array}{l}\text { A: } 380 / 387 / 387 \\
\text { B: } 380 / 381 / 380 \\
\text { A: } 380 / 378 / 378\end{array}$ & 2 & M & 6 & - & - & - & - & - & $\begin{array}{l}\text { Mixing fan off. Three completed } \\
\text { sprays (A-C) }\end{array}$ & 086 & 803 & 75 & $\begin{array}{l}\text { B. } 58- \\
\text { B.59 }\end{array}$ \\
\hline SS-A-O90-380 & $\mathrm{H}_{2} \mathrm{O}$ & 0.534 & Axial & $\begin{array}{l}\text { A: } 380 / 378 / 378 \\
\text { B: } 380 / 381 / 381 \\
\text { A: } 380 / 380 / 380\end{array}$ & 2 & M & 6 & - & - & - & - & - & $\begin{array}{l}\text { Mixing fan moved vertically above } \\
\text { spray header. Three completed } \\
\text { sprays (A-C) }\end{array}$ & 086 & 804 & 75 & $\begin{array}{l}\text { B. } 59- \\
\text { B.60 }\end{array}$ \\
\hline
\end{tabular}


Appendix B

Selected Release Fraction Plots 



\section{Appendix B}

\section{Selected Release Fraction Plots}

This appendix contains plots of cumulative release fraction versus droplet size for the runs used in technical discussions in Chapters 6 and 7. These runs are a subset of those listed in Appendix A, which describe the conditions for each run.

Each figure shows the WTP model prediction for the runs, based on the known system conditions and simulant properties. Each figure also shows the cumulative release fraction obtained in two ways: 1) by a fit to the cumulative concentration under each size (i.e., the "cumulative fit"), and 2) by cumulating fits to the differential concentrations in all the bins under each size (i.e., the "cumulated differential fit").

As noted in Section 6.3, some of the cumulative and differential fits were considered to be bad fits. A fit could be bad in one of three ways: 1) the output of the fit was equal to the lower-limit or upper-limit fitting constraints, 2) the fitting routine did not achieve convergence, or 3 ) the adjusted coefficient of determination $\left(\overline{\mathrm{R}}^{2}\right)$ of the fit was less than 0.5 . In the first and second cases, the fitting routine did not return any numeric values for the upper and lower ends of the 95-percent confidence interval on the fitted value. In the third case, as was also true for good fits, the 95-percent confidence interval was returned.

The cumulative fits for different size bins are independent of each other, so a bad fit at one size does not affect the fits for cumulative release fractions for larger sizes. The differential fits, however, were added (cumulated) to give cumulative release fractions. The ends of their confidence interval also were cumulated. Thus, a bad fit for one differential concentration bin raises the question of how to cumulate it with other bins for which fits are good. In this report, the bad differential fits are included in cumulations, although the individual points for bad differential fits were excluded from the plots. Bad differential fits used in cumulations make the cumulated differential-fit net generation rates and release fractions doubtful in some cases. For this reason, among others, only cumulative fits appear in the analyses included in Chapters 6 and 7.

The plot of release fraction versus droplet size for run SO1 (i.e., the first plot) is an example of such a case. The cumulative fit is shown by the blue upward-pointing triangles together with its 95-percent confidence interval. The cumulated differential fit also is shown on the plot by the green downward-pointing triangles. The fit on the first (i.e., the smallest) bin of the differential release fractions was a bad fit, with output equal to the upper-limit fitting constraint, which is an unrealistically high value as discussed in Section 6.3. The effect of this high value is carried through in the cumulated differential release fractions at larger sizes, causing them to be overestimated even though the differential fits to the larger size bins were good. For run SO1, once the contributions from good differential fits outweigh the contribution from the bad fit at the smallest size, the cumulative fit and the cumulated differential fit give nearly equal values.

The bad fit at the smallest size also affects the error bars for the cumulated differential fits. Because there was no numeric confidence limit for that size, there are no error bars. The non-numeric value of confidence interval was accumulated with the good values for larger sizes, causing all the error bars in the cumulated differential curve to be zeroed out. 
A review of the plots in this appendix shows that, except in cases where a bad fit of type 1 or 2 causes inaccuracy in the cumulated differential fit, the two approaches to fitting (cumulative and cumulated differential) give very similar results in the size range from $<10 \mu \mathrm{m}$ to $<100 \mu \mathrm{m}$ except where there is a bad differential fit. The bad fit of type 1 or 2 can be recognized in a plot by the zero-length error bars.

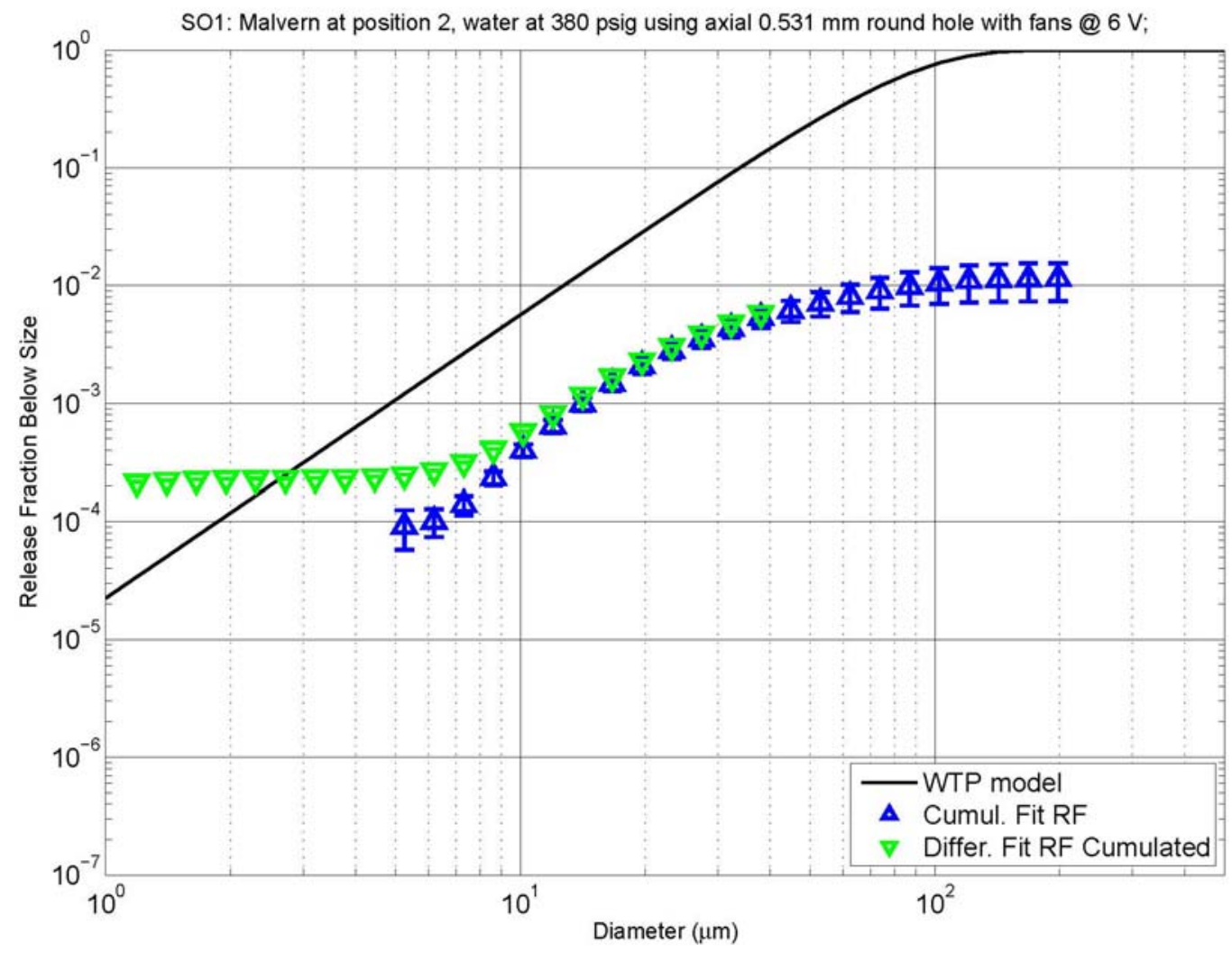



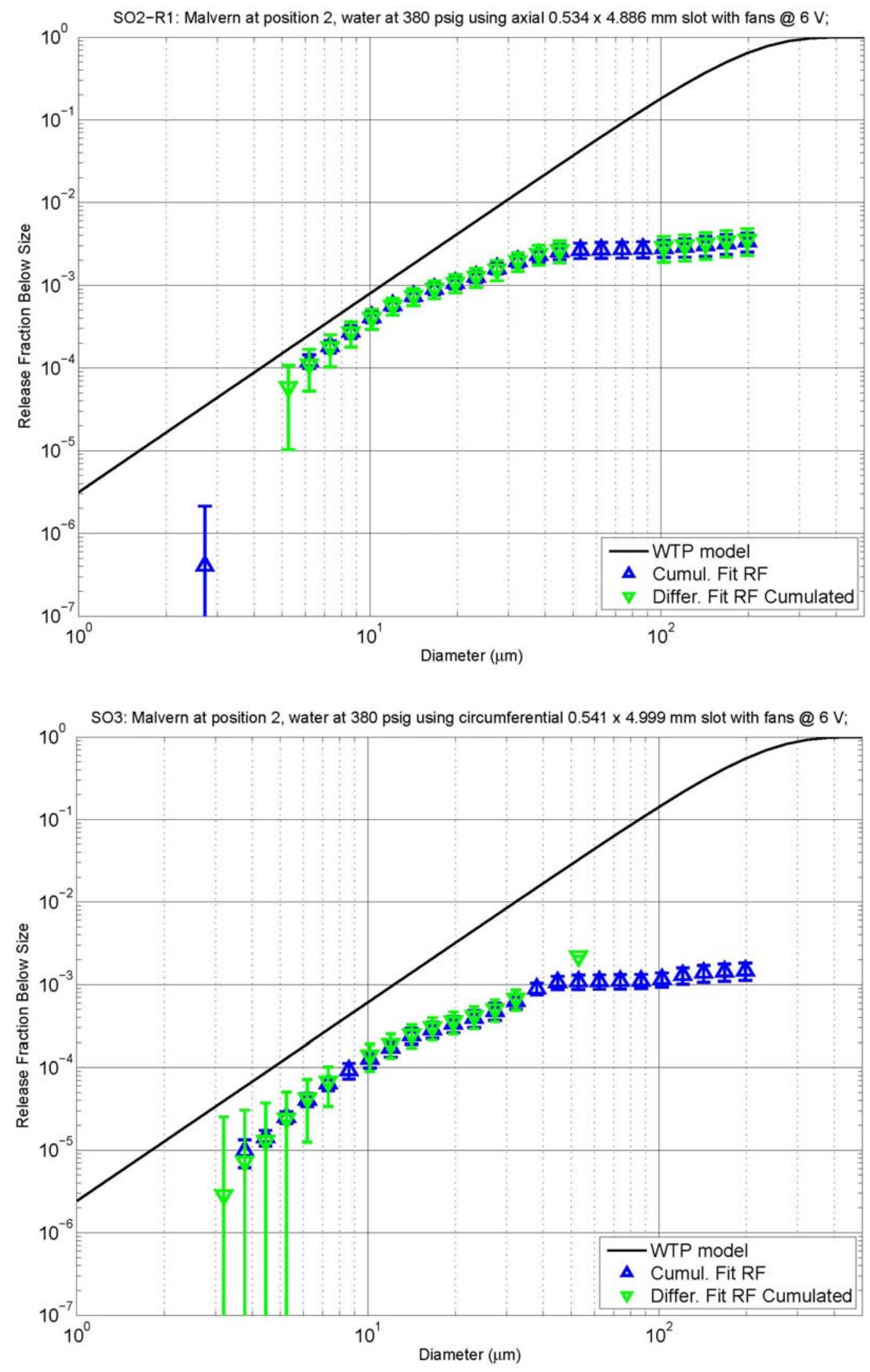

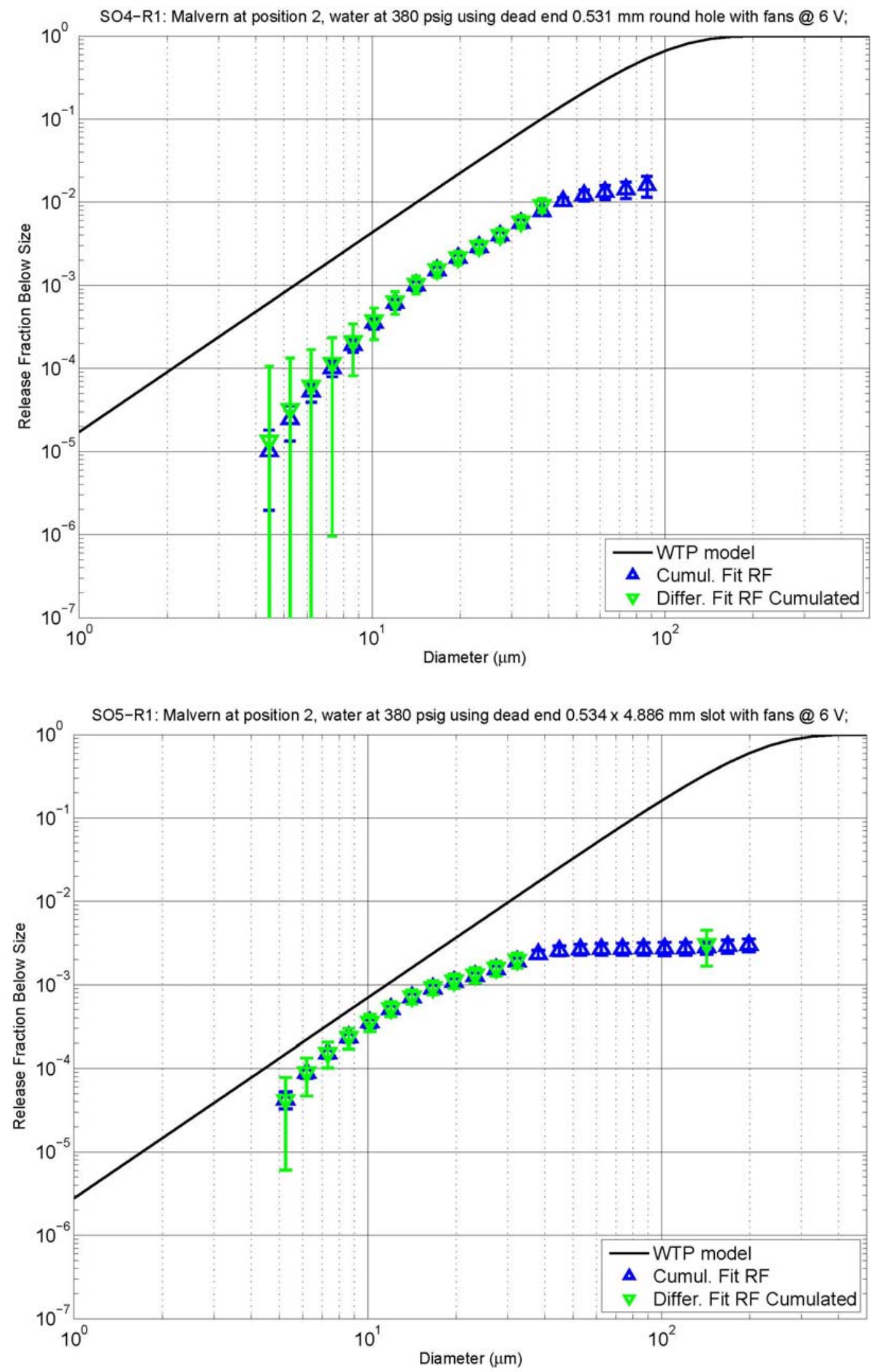

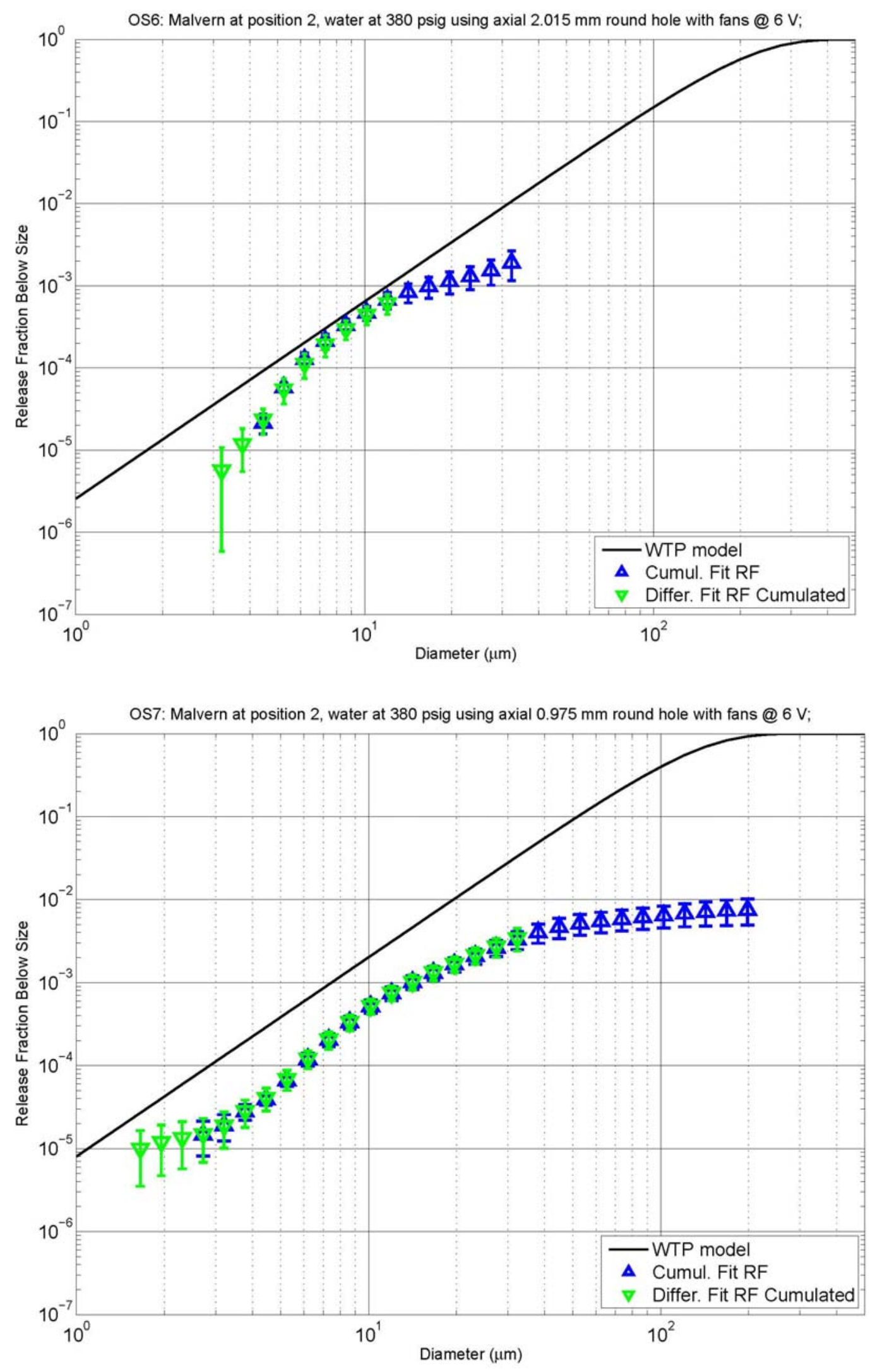

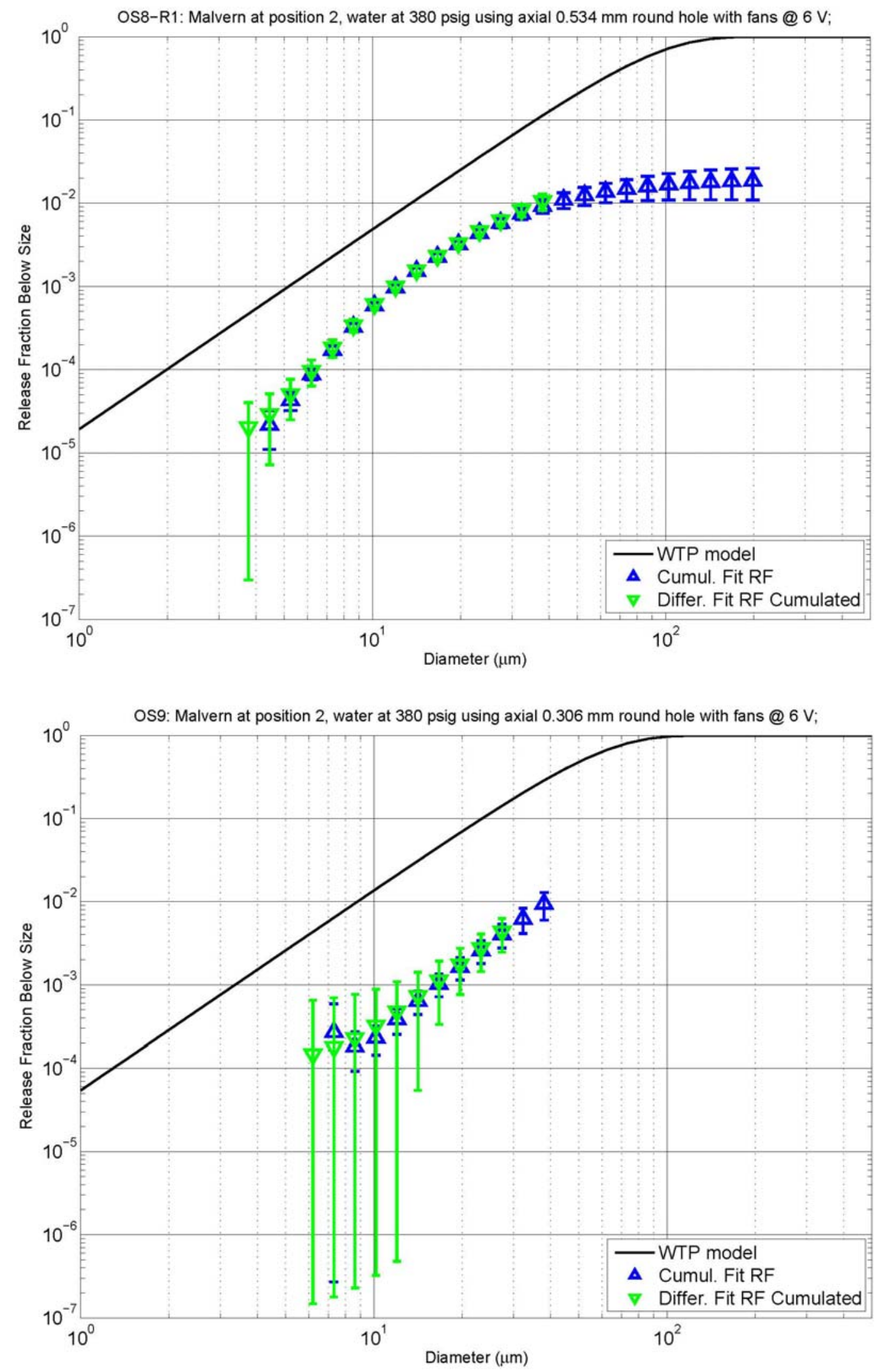

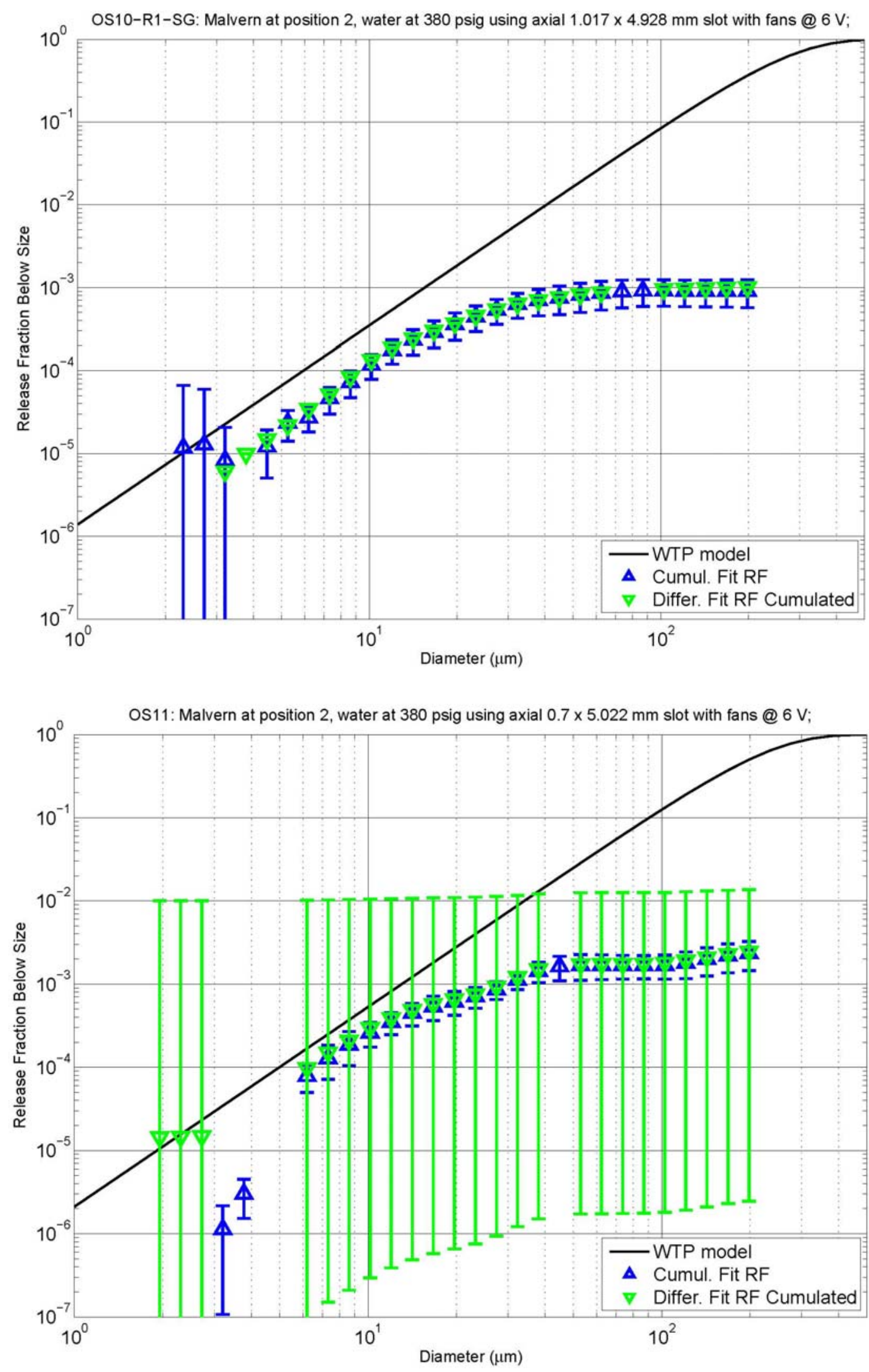

B. 7 

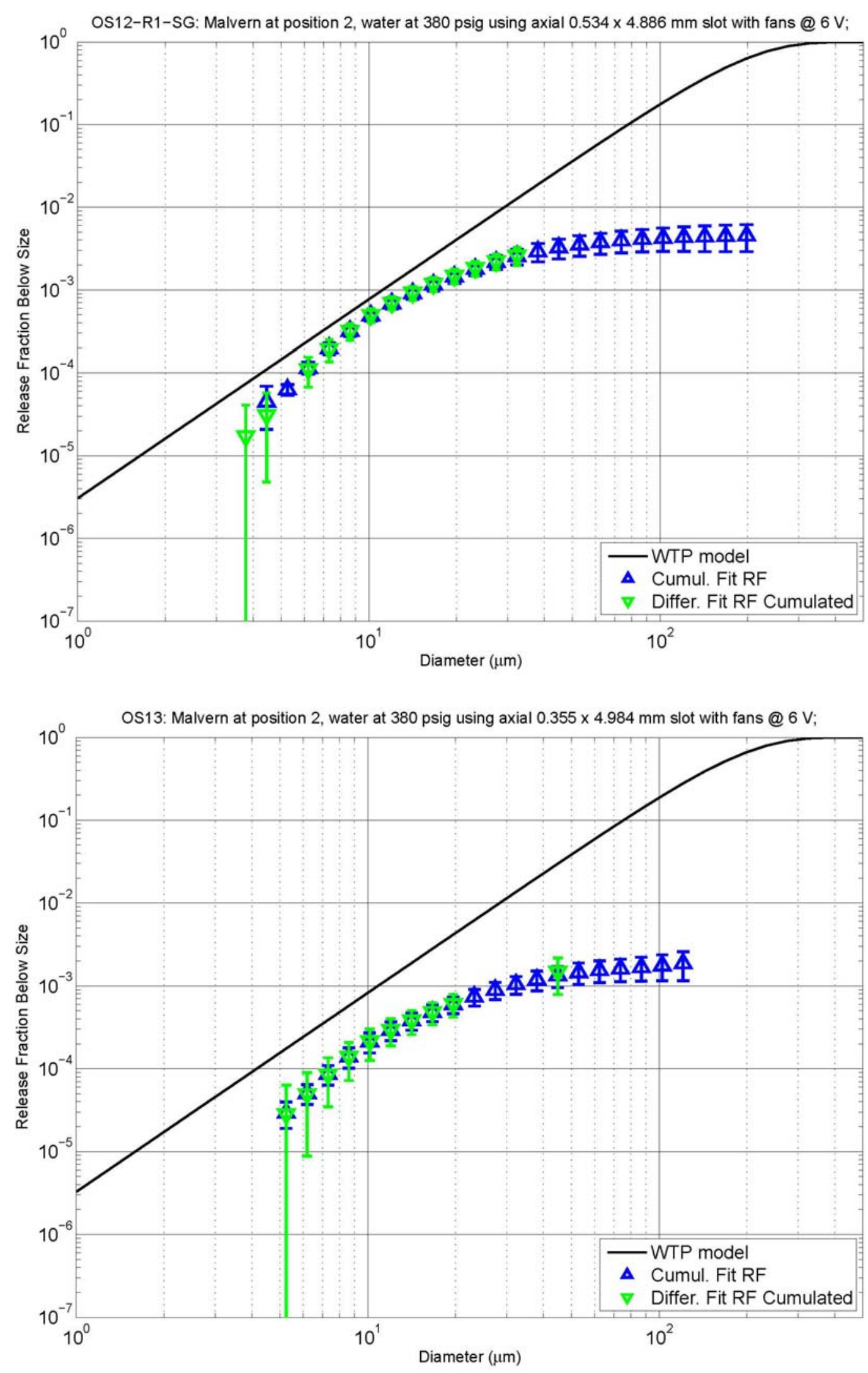

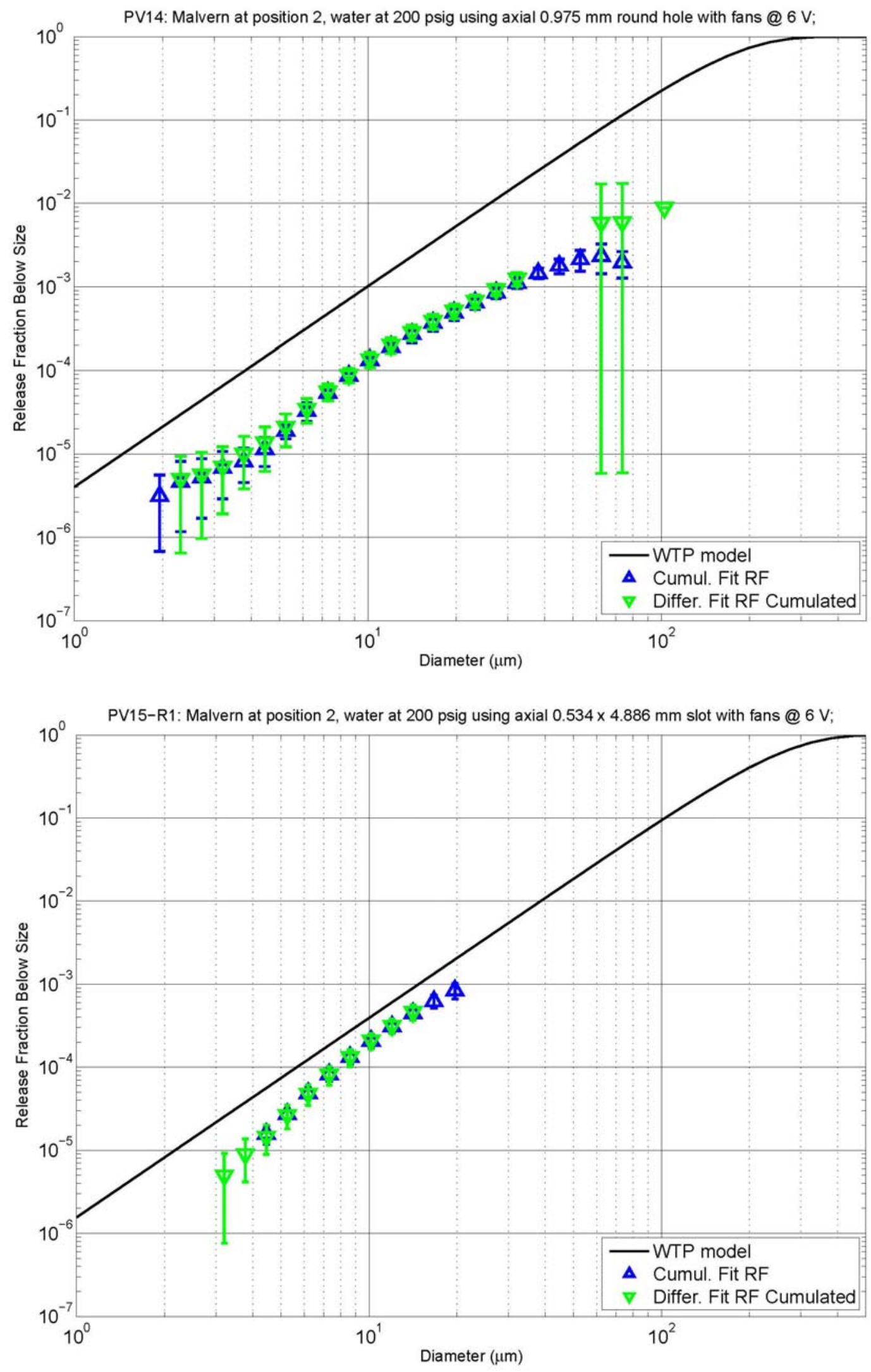

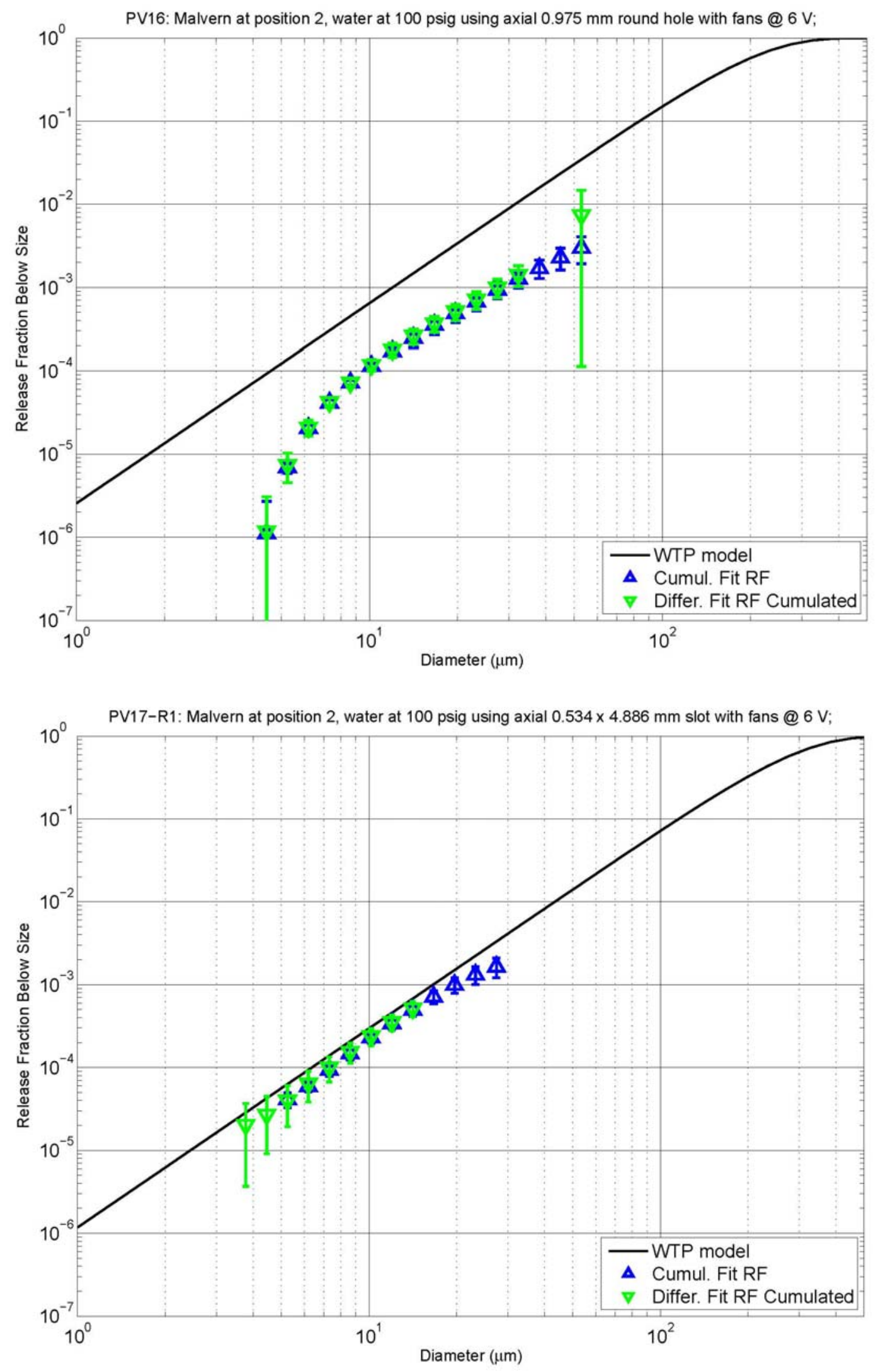

B. 10 

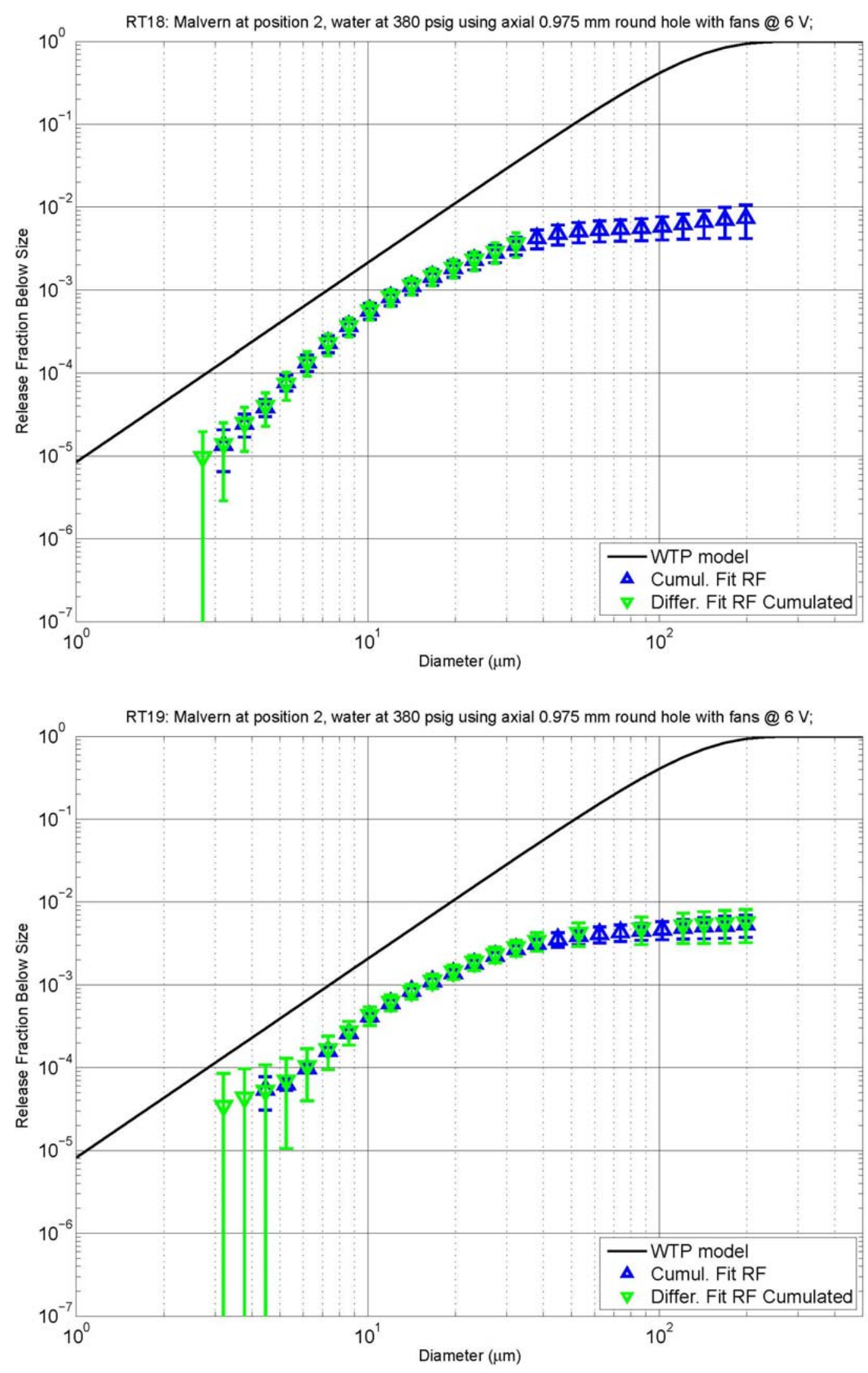

B. 11 

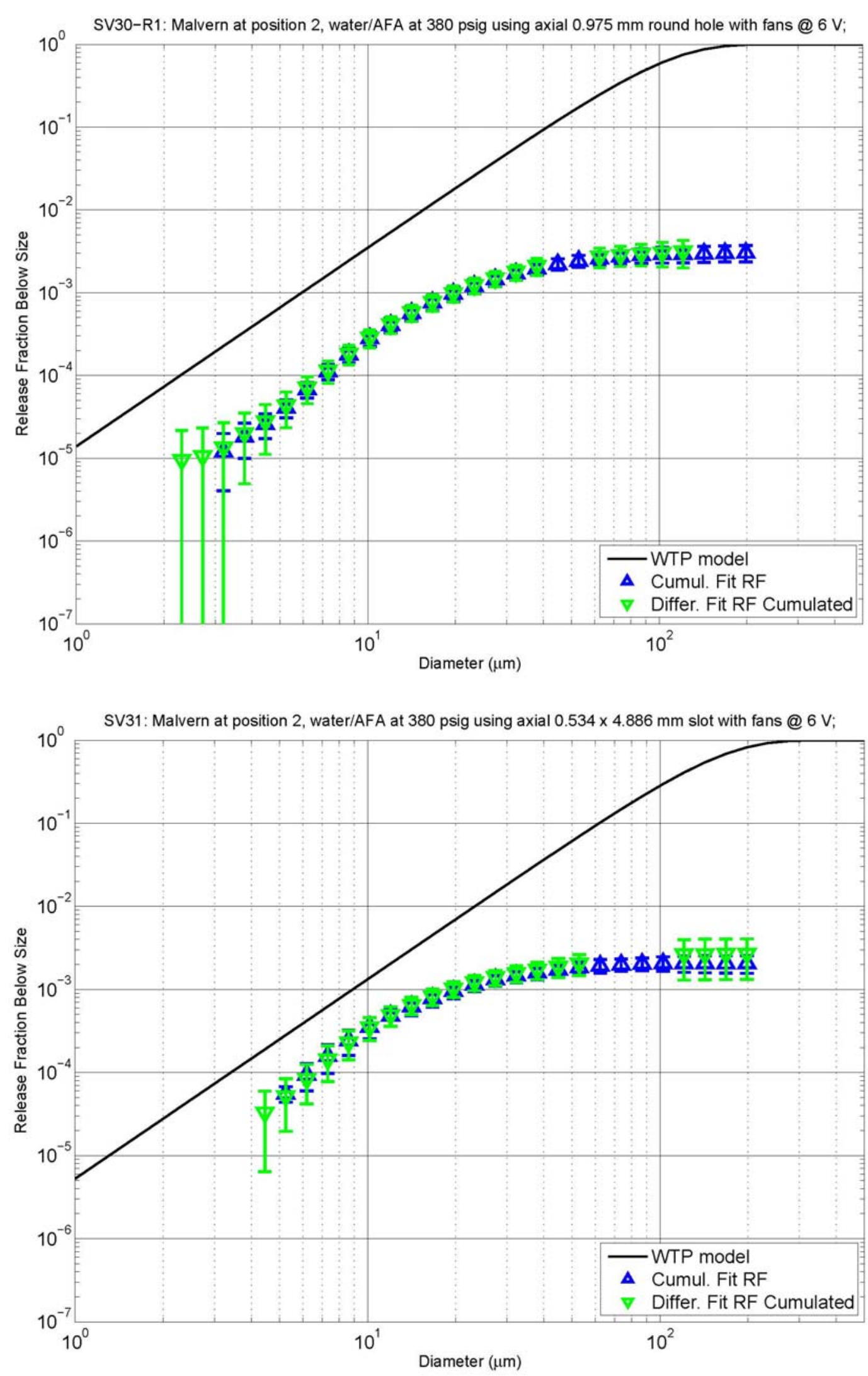

B. 12 

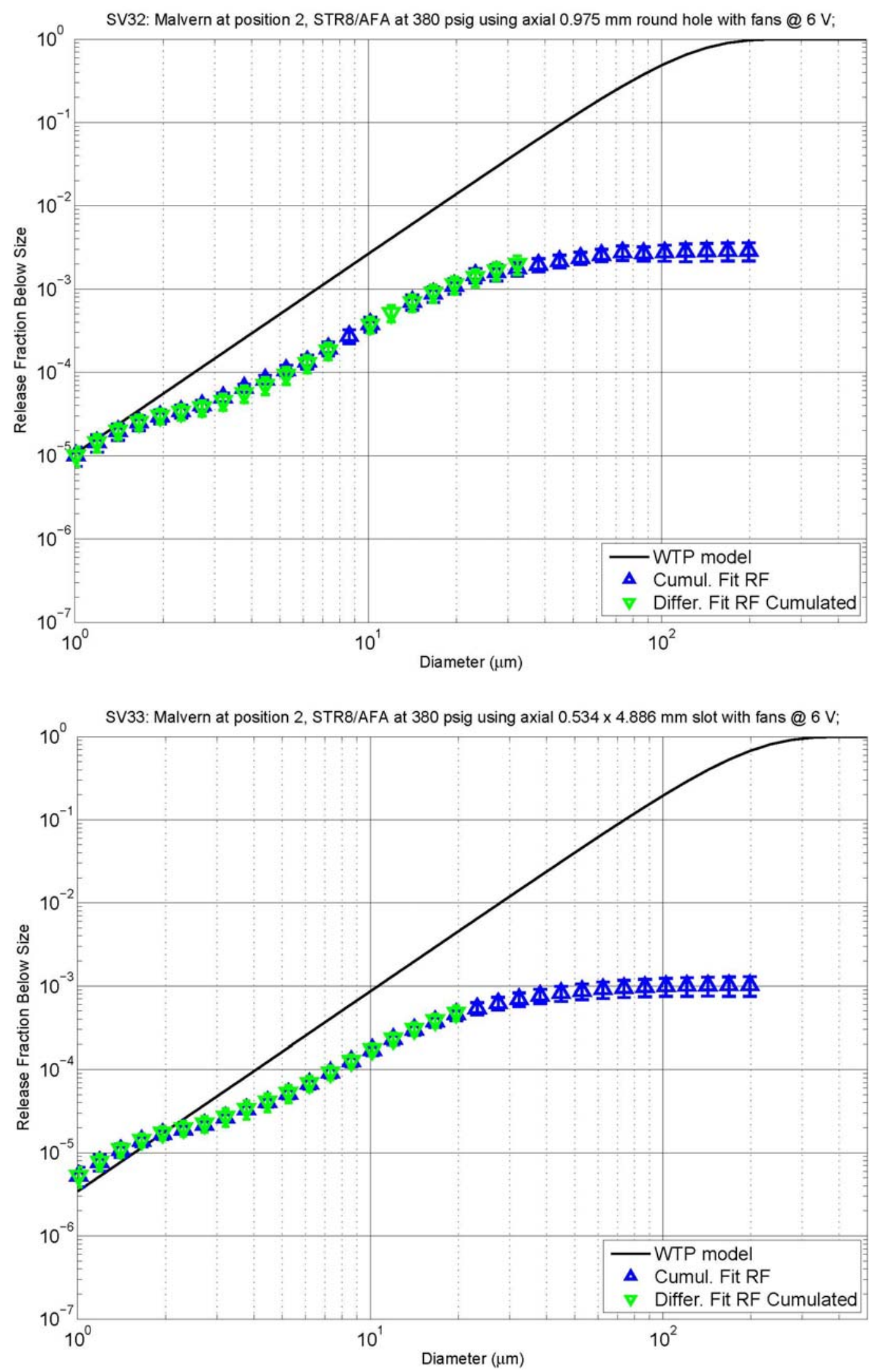

B. 13 

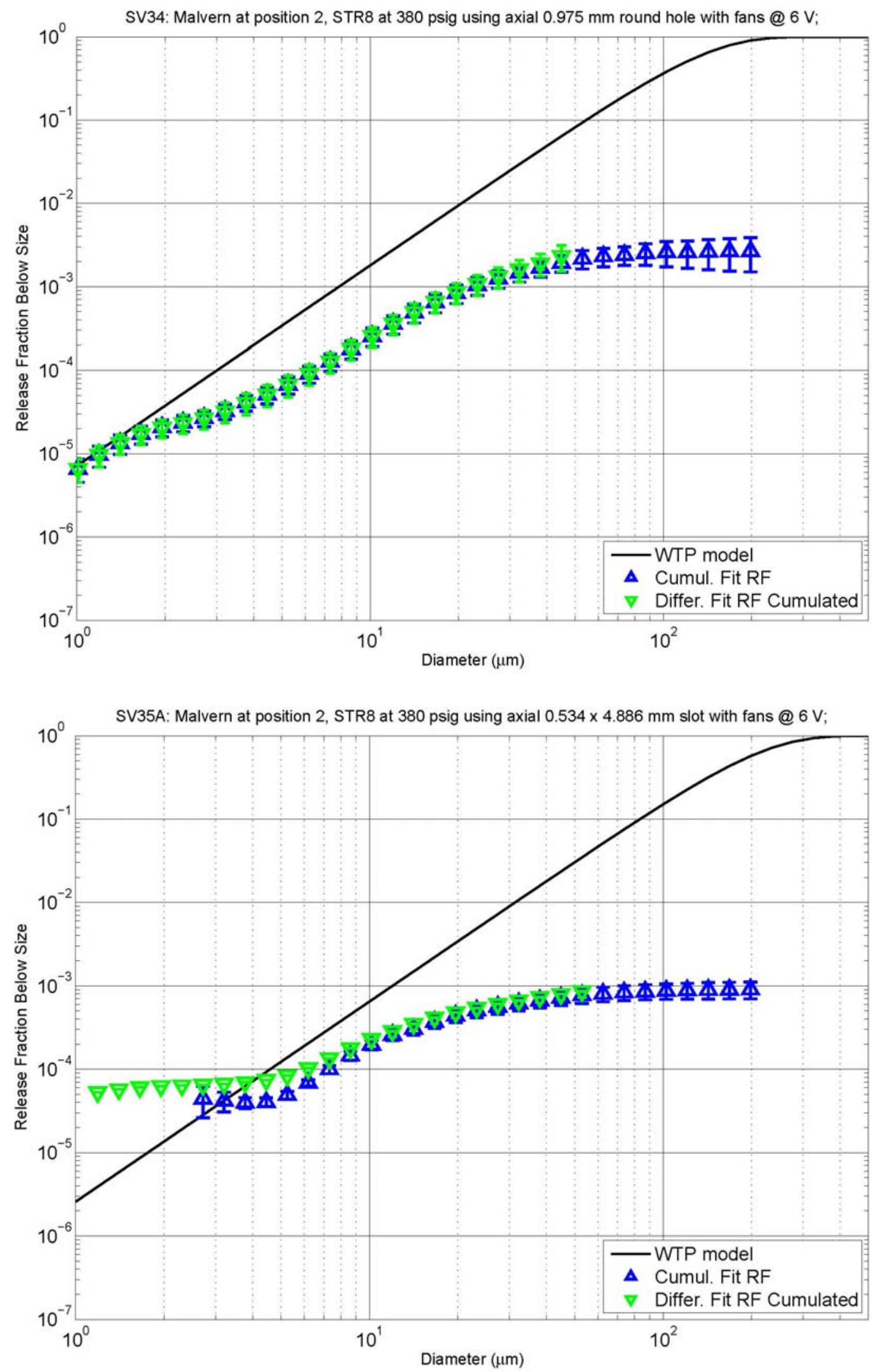

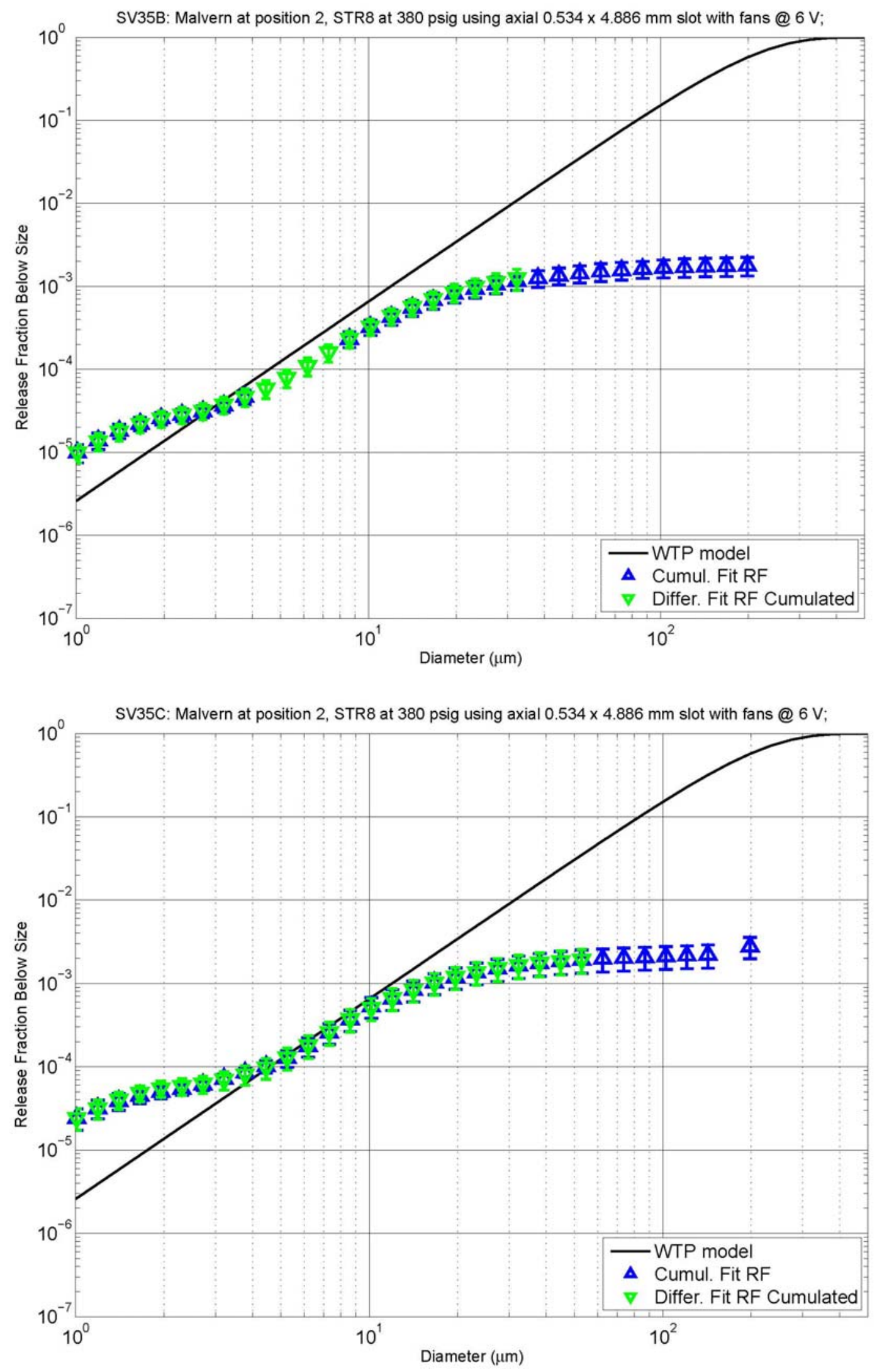

B. 15 

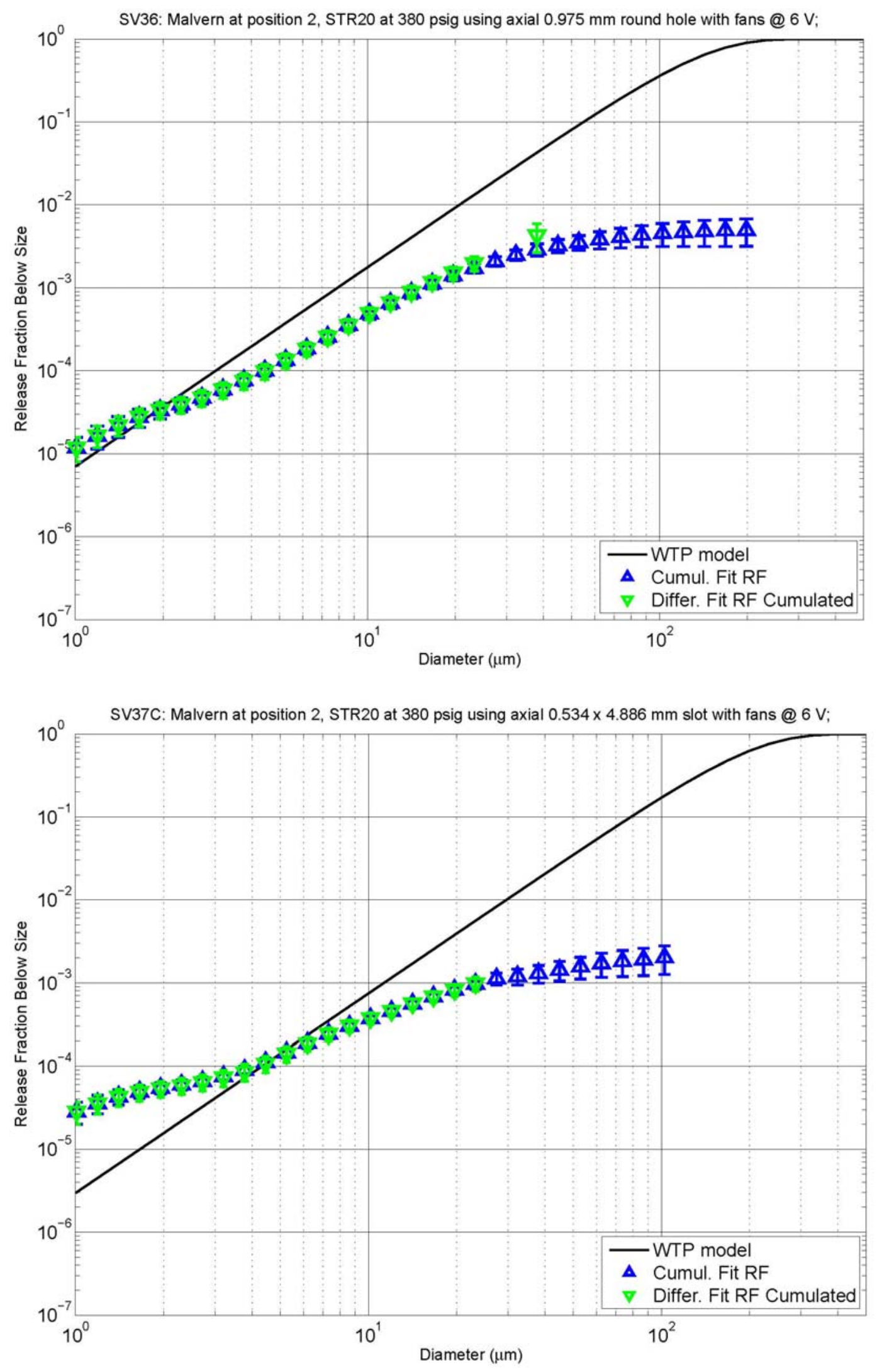

B. 16 

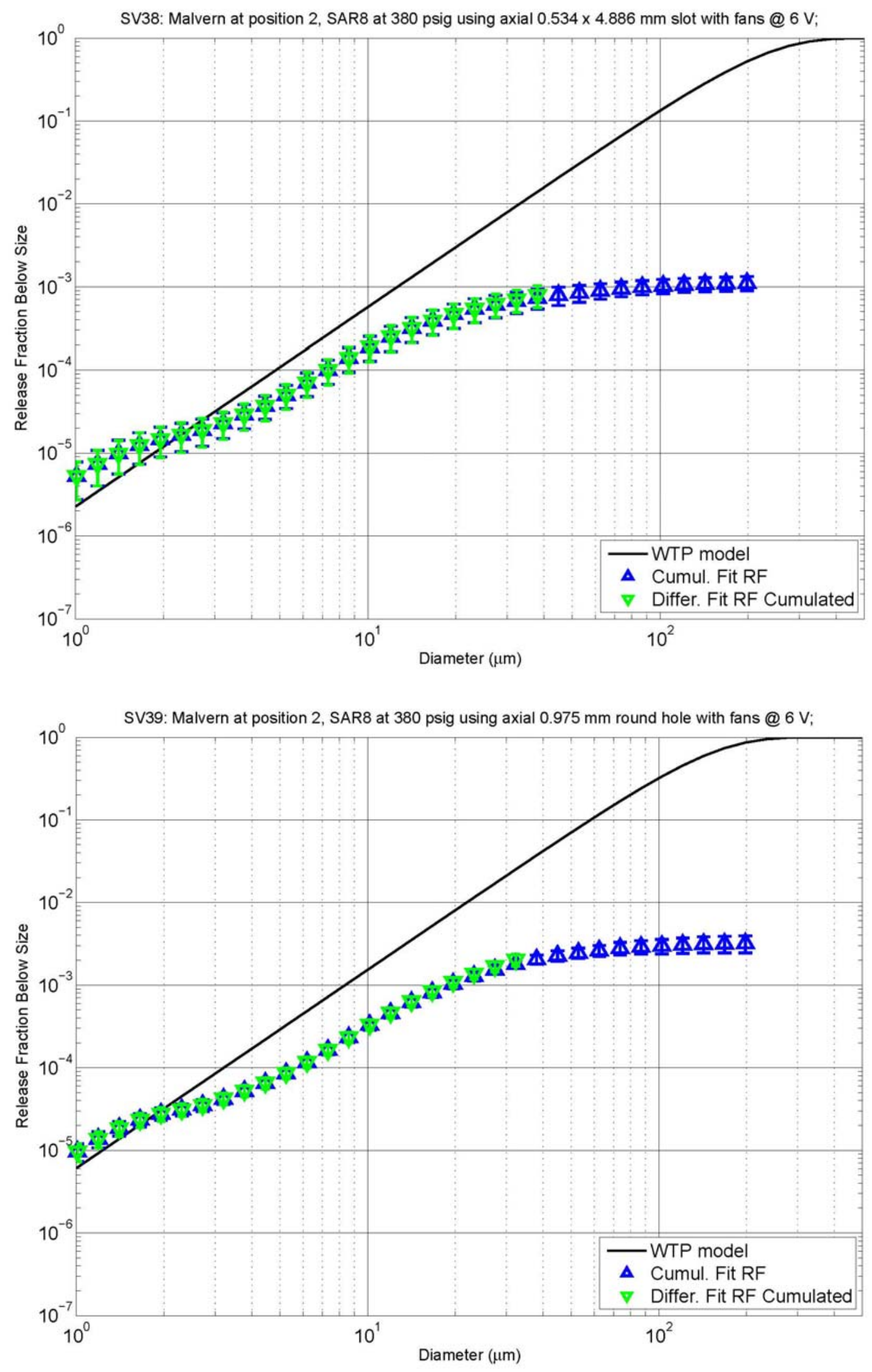

B. 17 

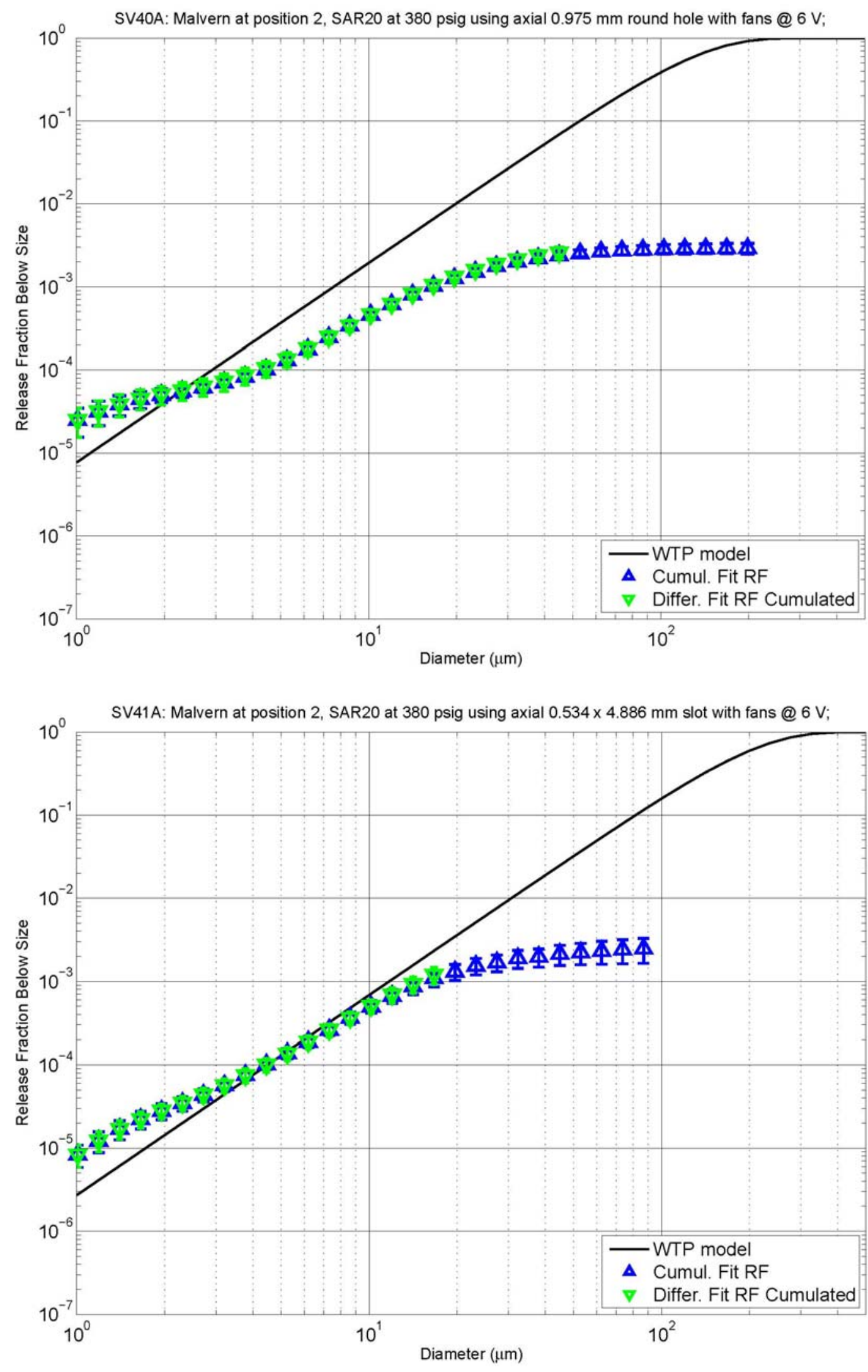

B. 18 

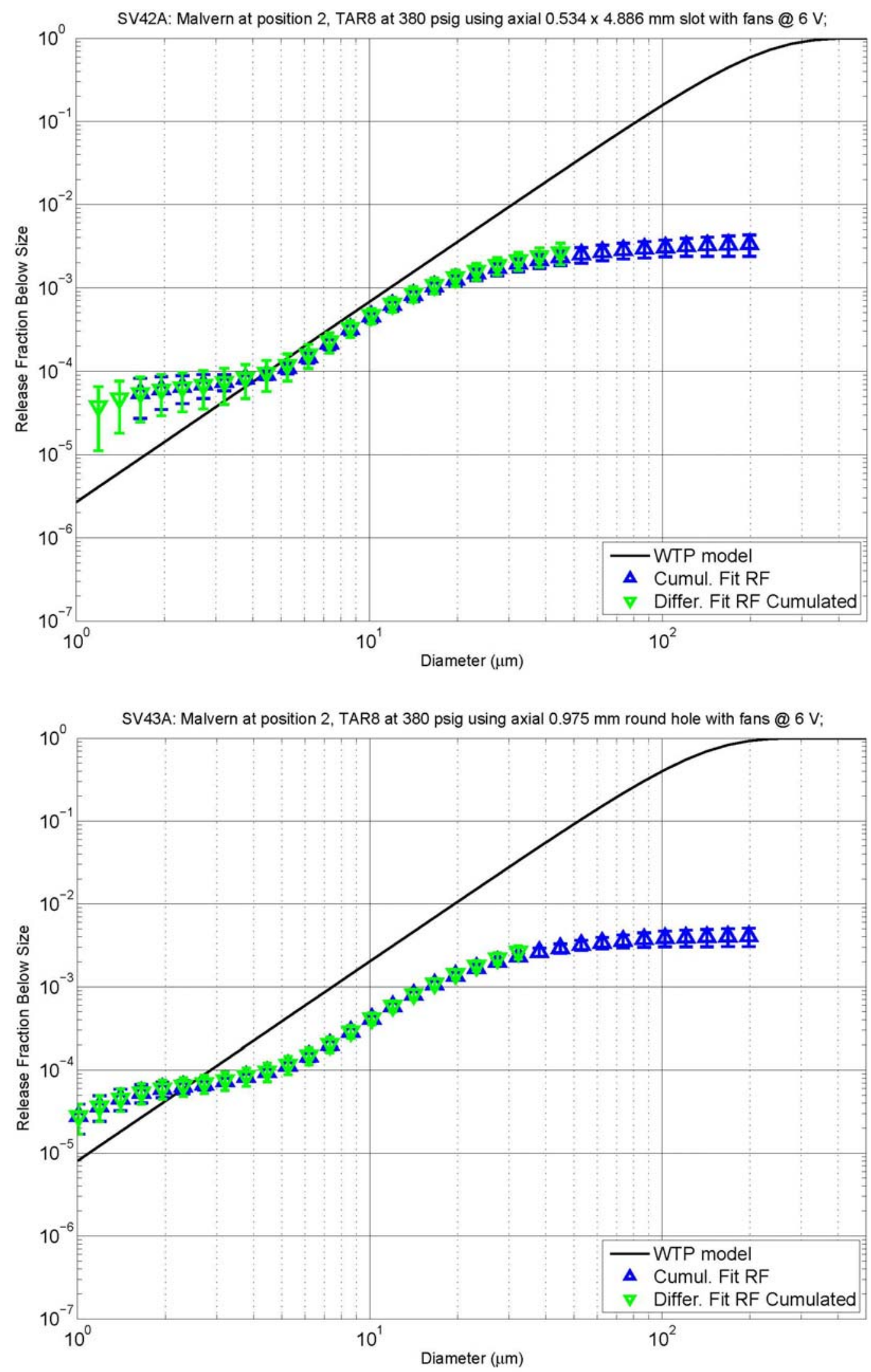

B. 19 
SV44A: Malvern at position 2, Na2S2O3 sol'n at 380 psig using axial 0.975 mm round hole with fans @ 6 V;

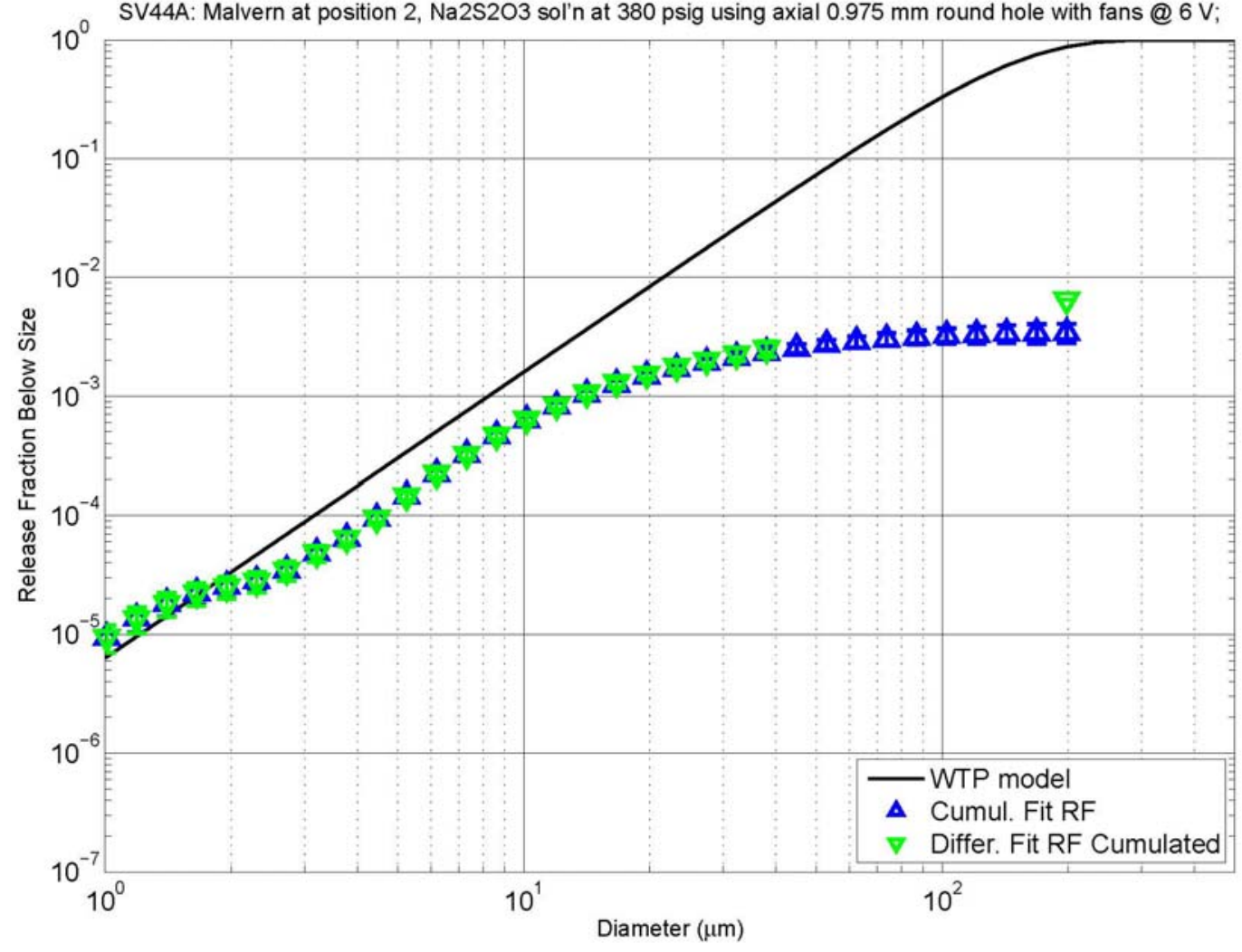

SV44B: Malvern at position 2, Na2S2O3 sol'n at 380 psig using axial 0.975 mm round hole with fans @ 6 V;

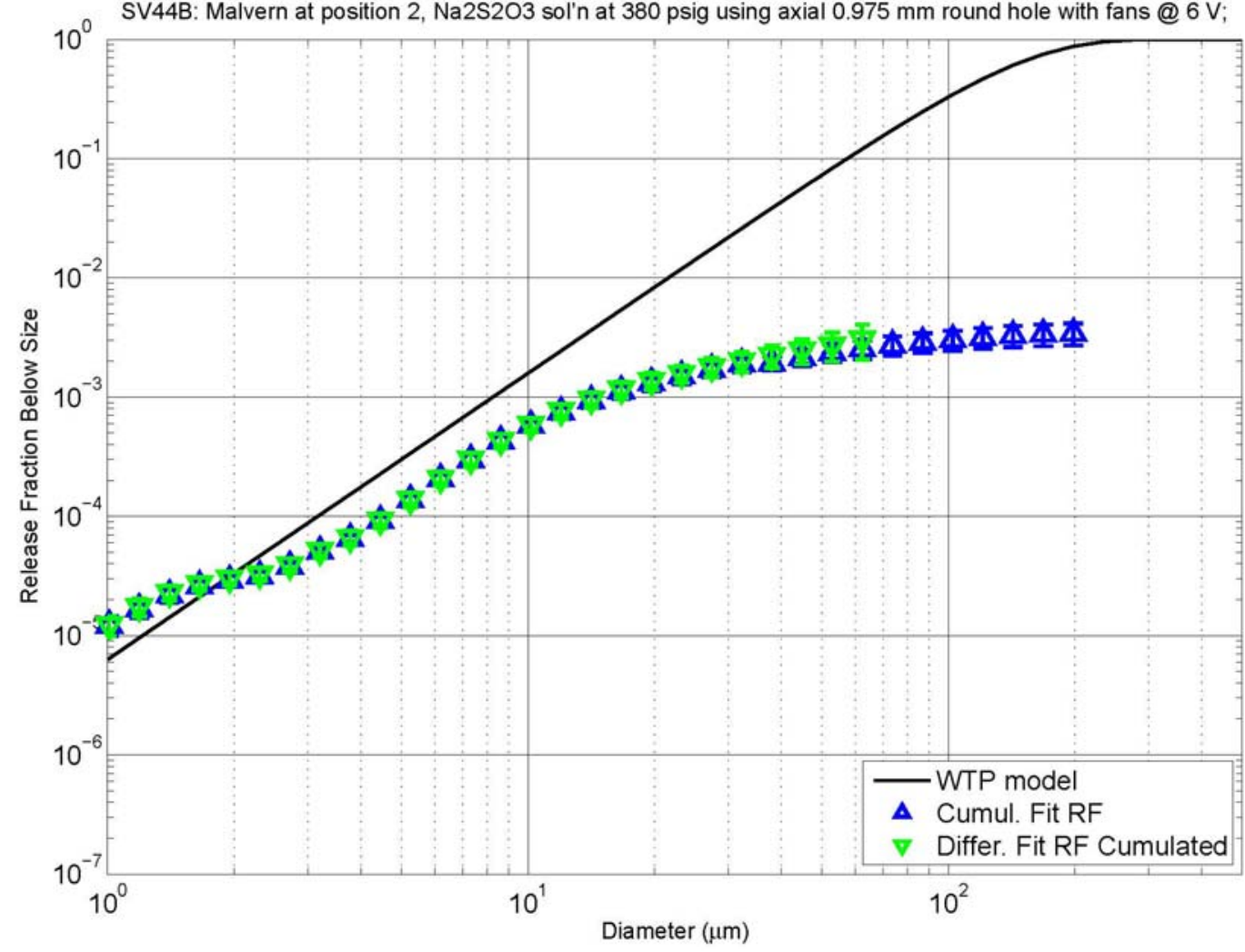


SV44C: Malvern at position 2, Na2S2O3 sol'n at 380 psig using axial $0.975 \mathrm{~mm}$ round hole with fans @ 6 V;

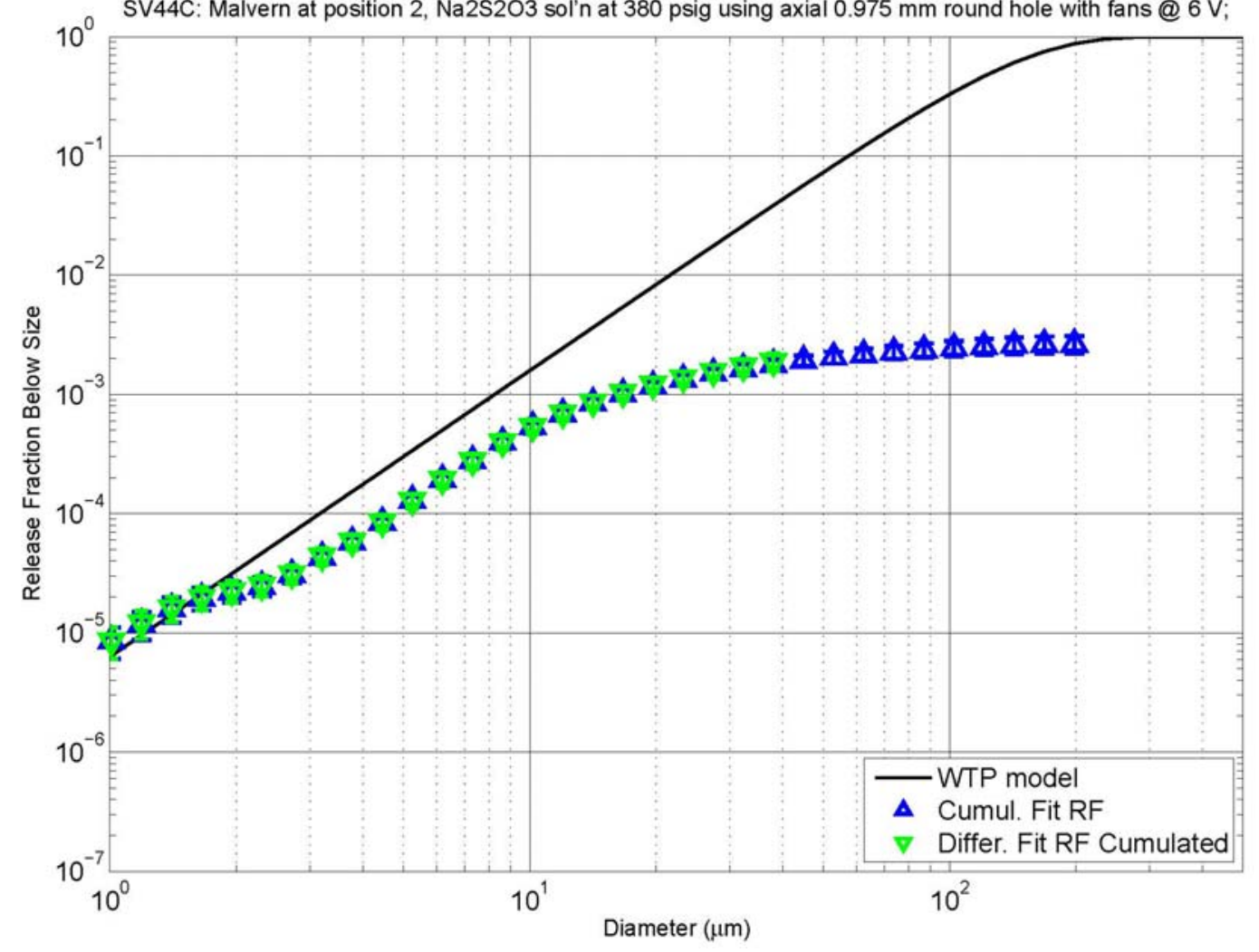

SV45B: Malvern at position 2, NaNO3 sol'n at 380 psig using axial 0.975 mm round hole with fans @ 6 V;

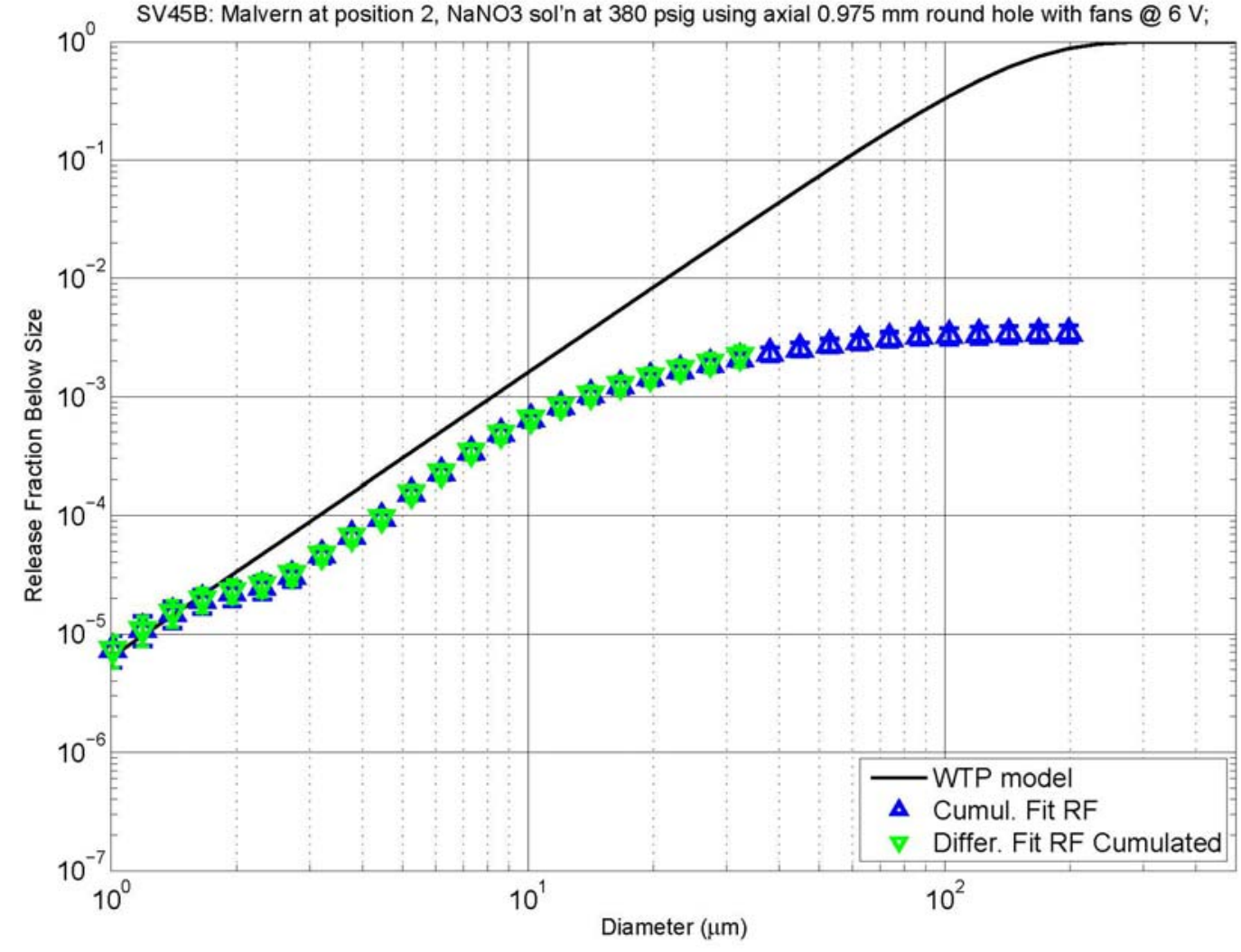



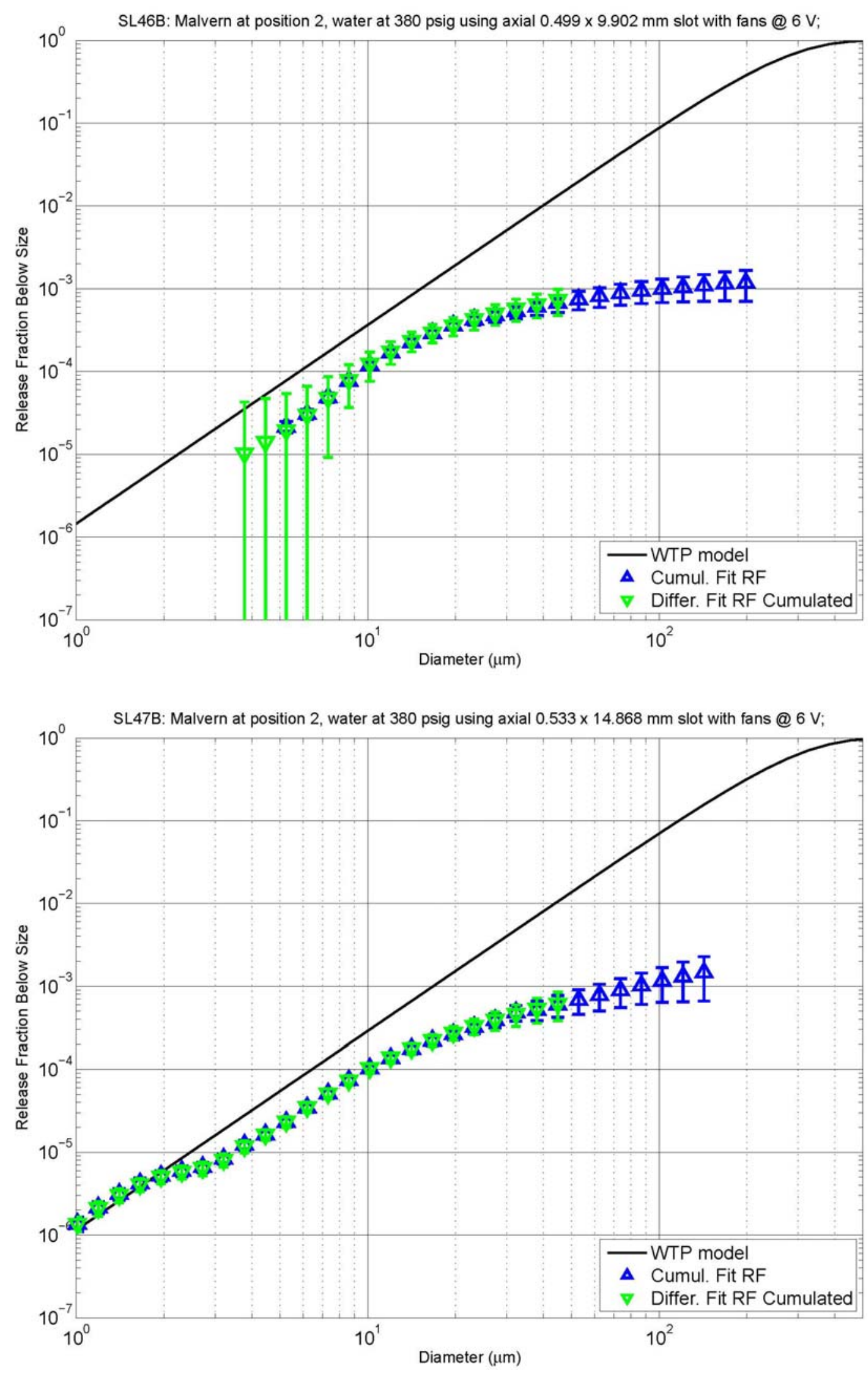

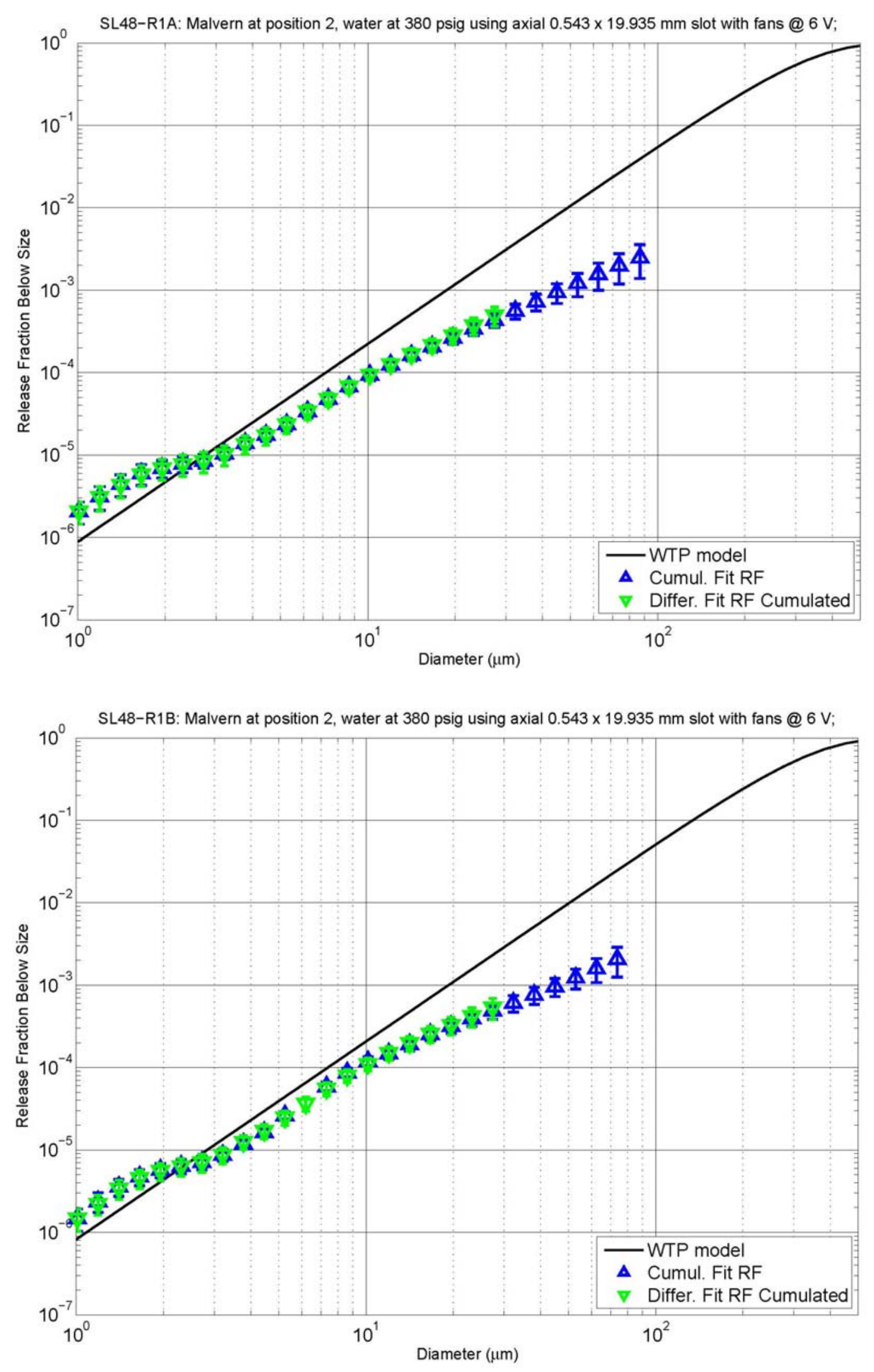

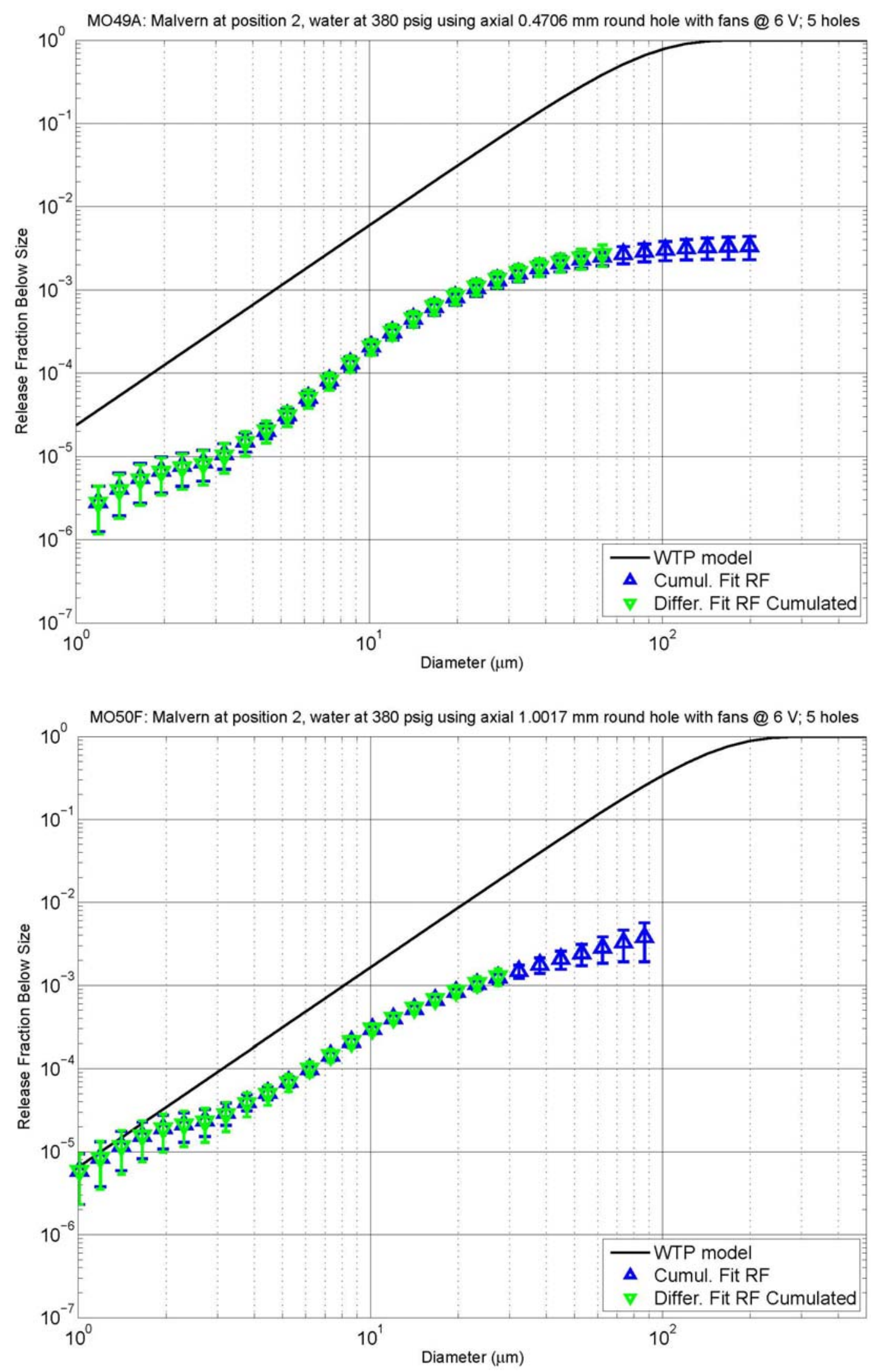

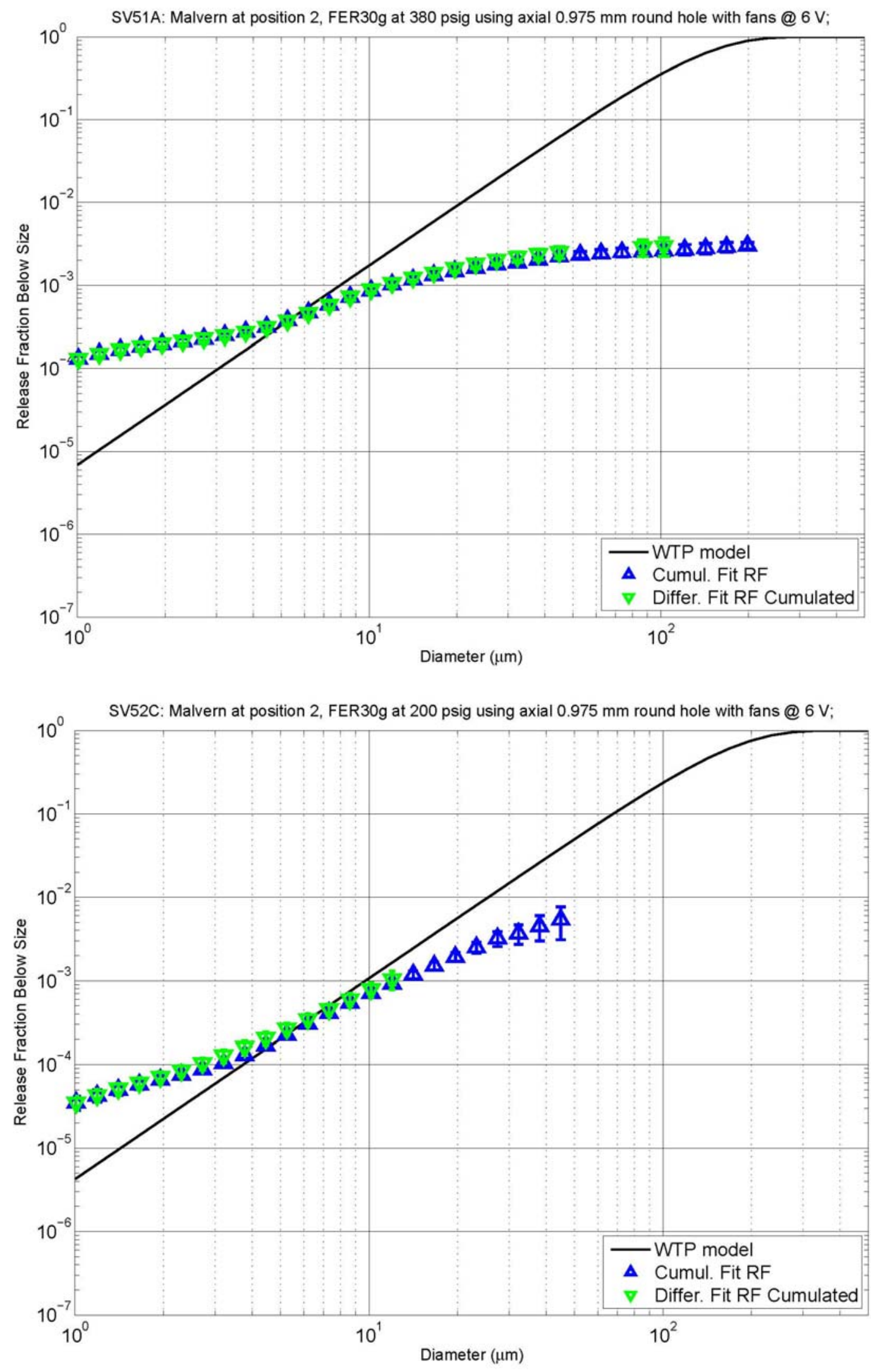

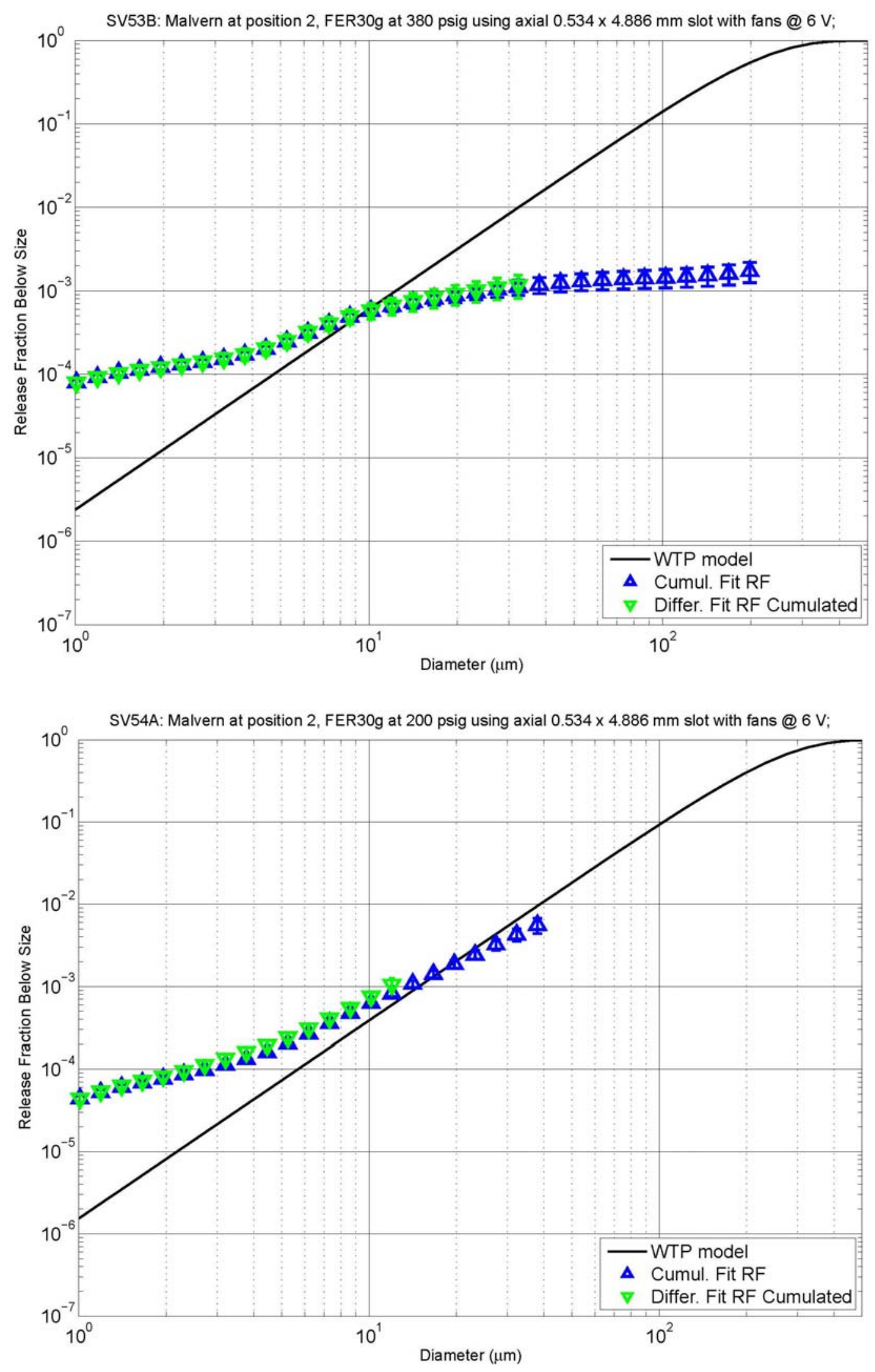
SV55A: Malvern at position 2, FER30g/AFA at 380 psig using axial 0.534 x 4.886 mm slot with fans @ 6 V;
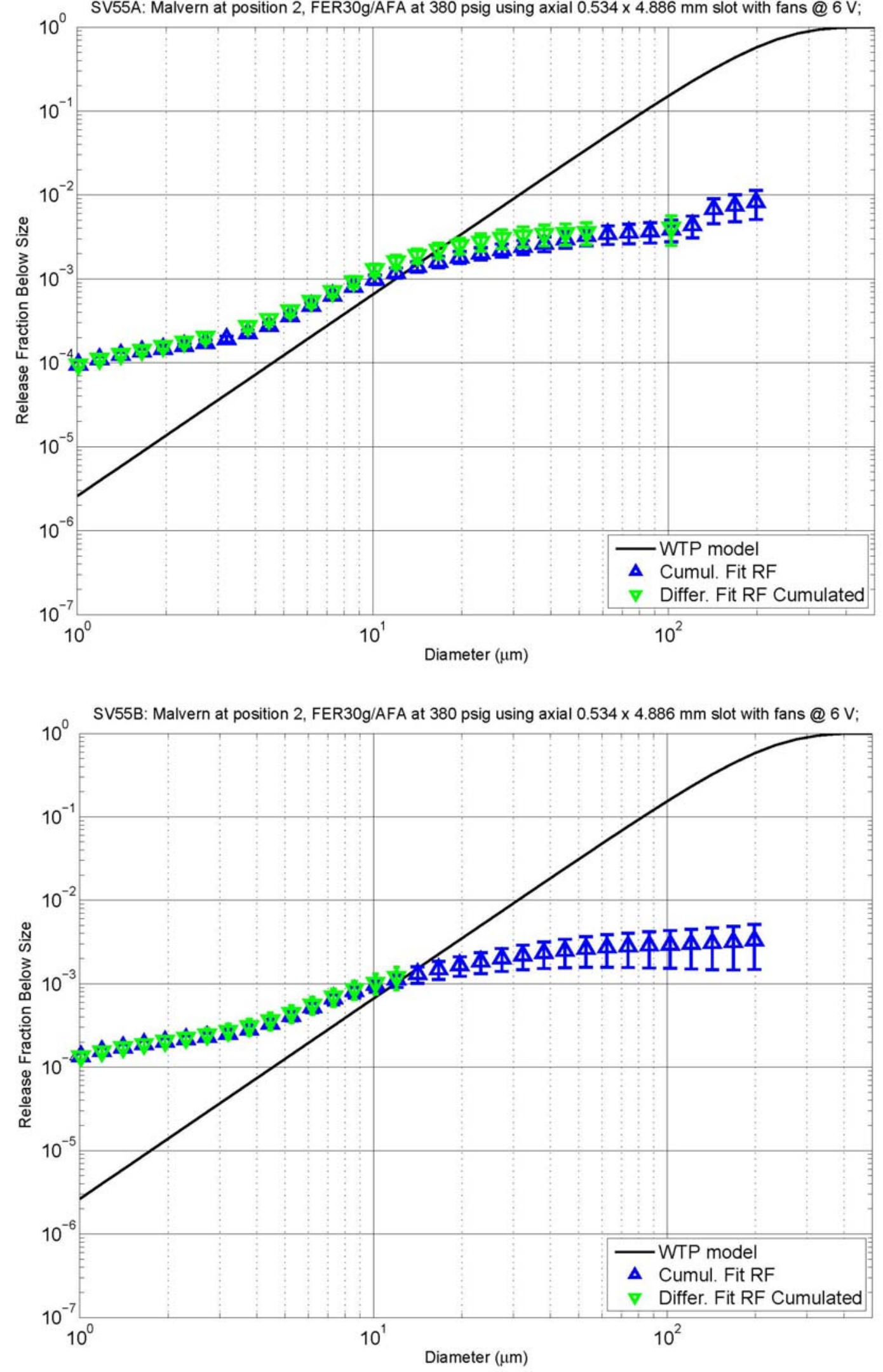

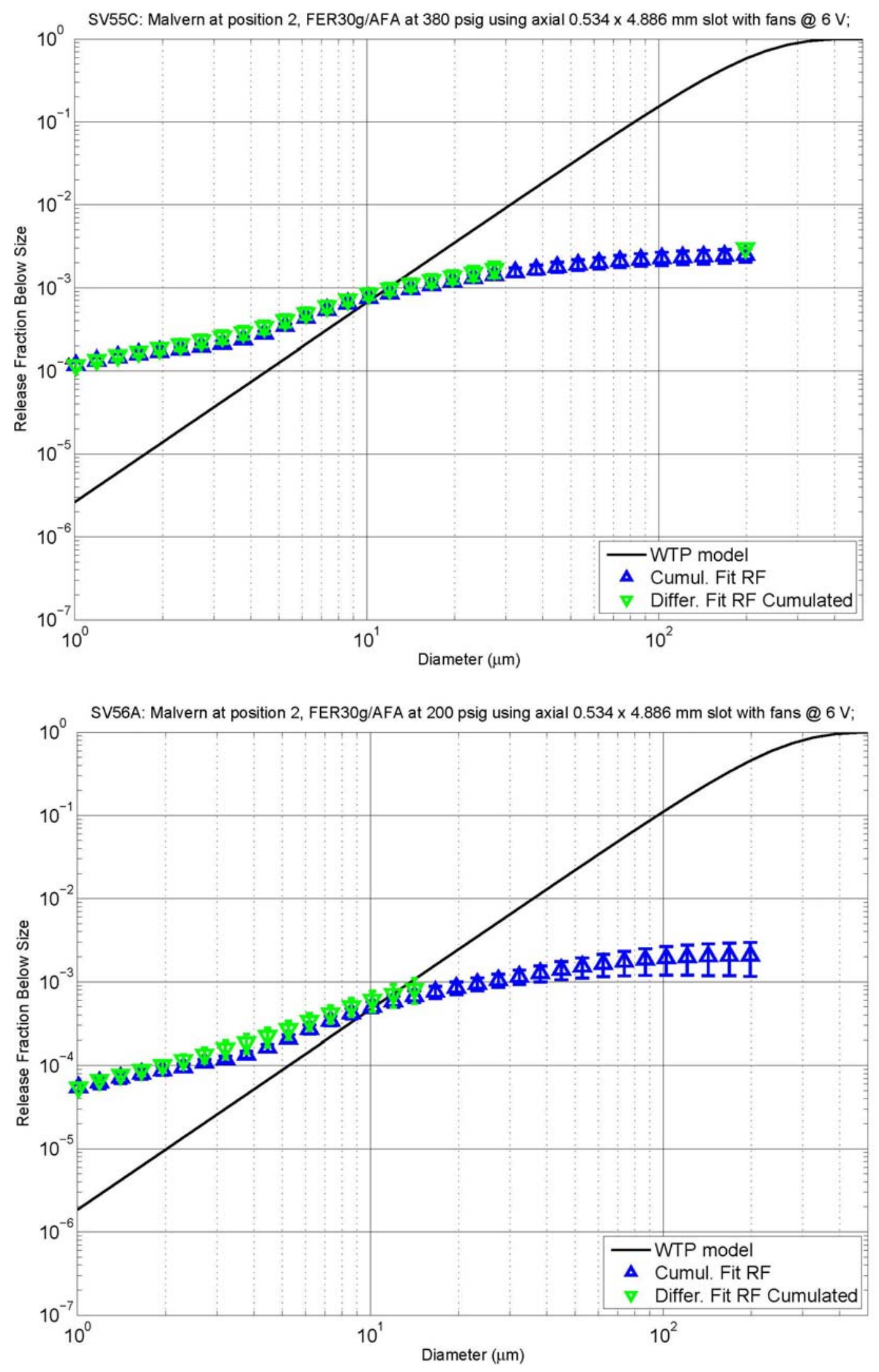

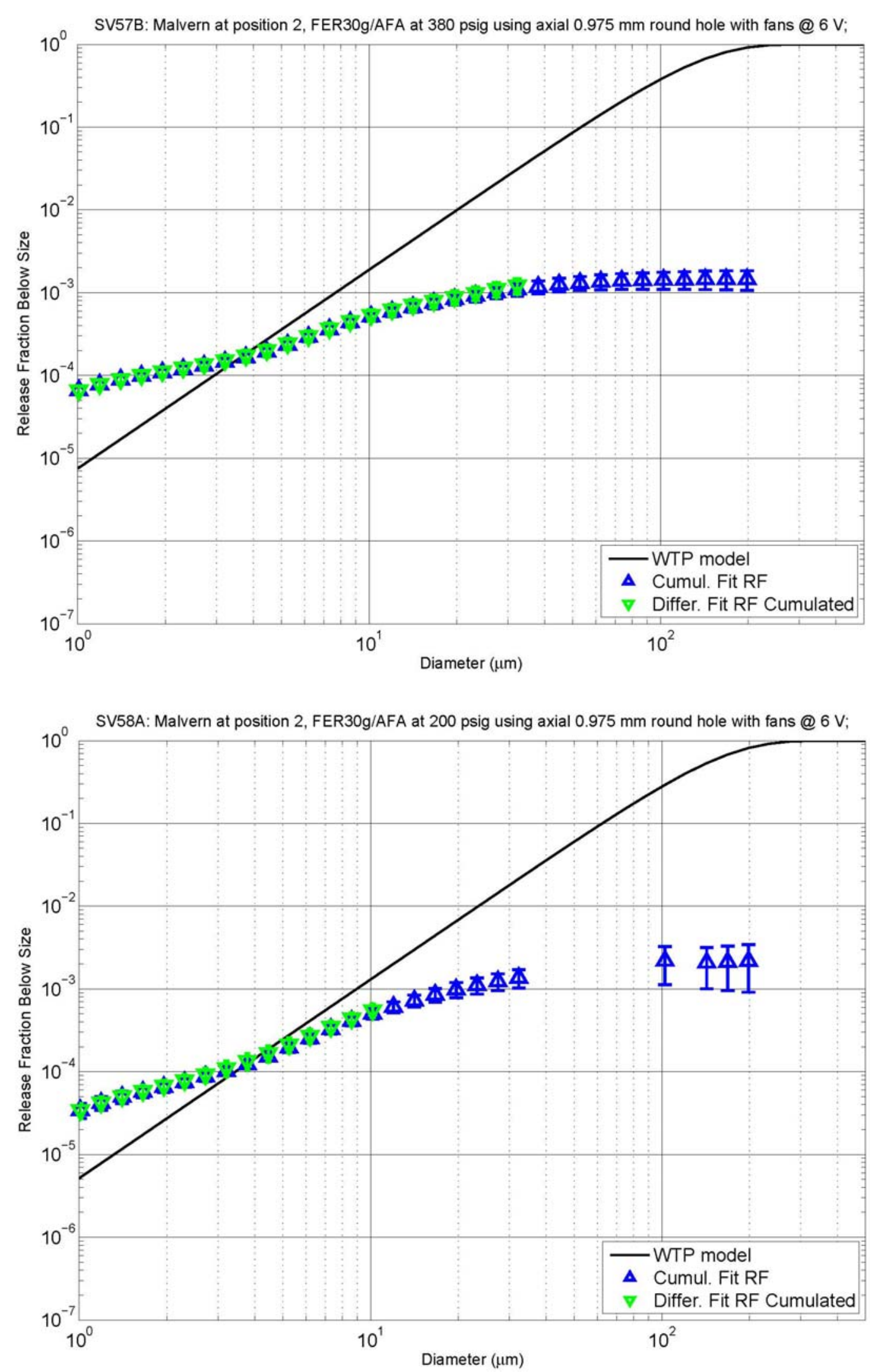

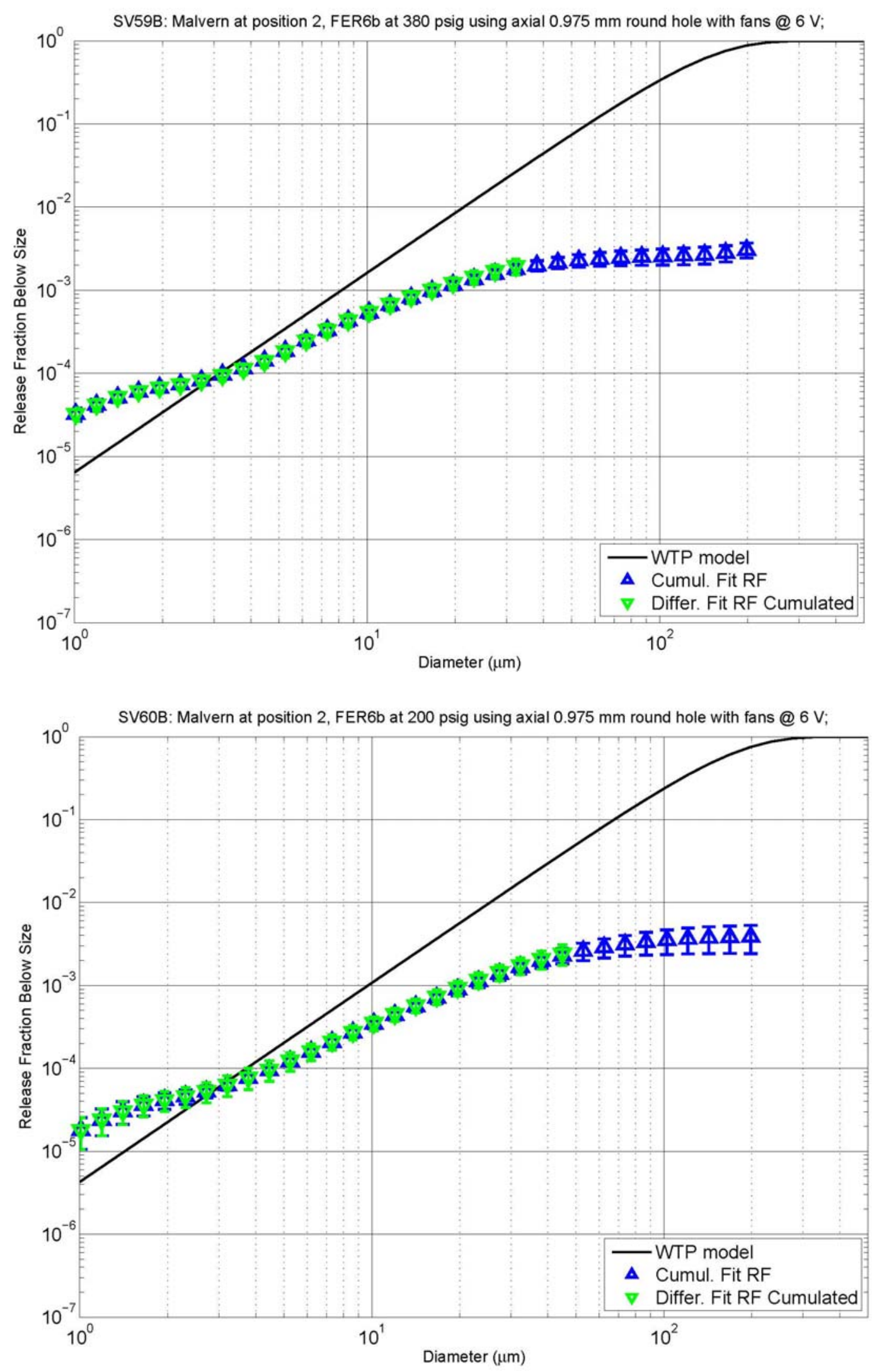

B. 30 

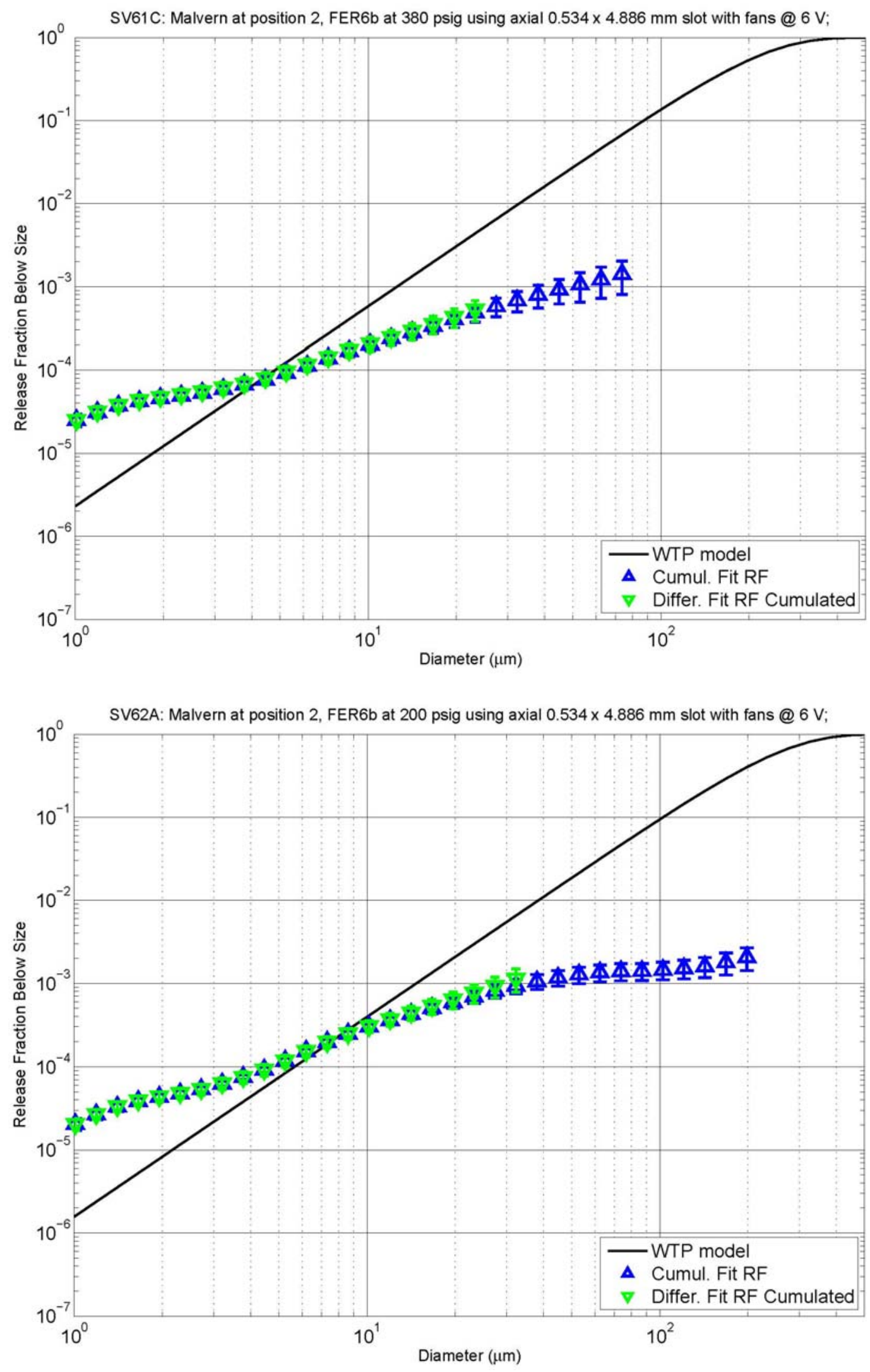

B. 31 

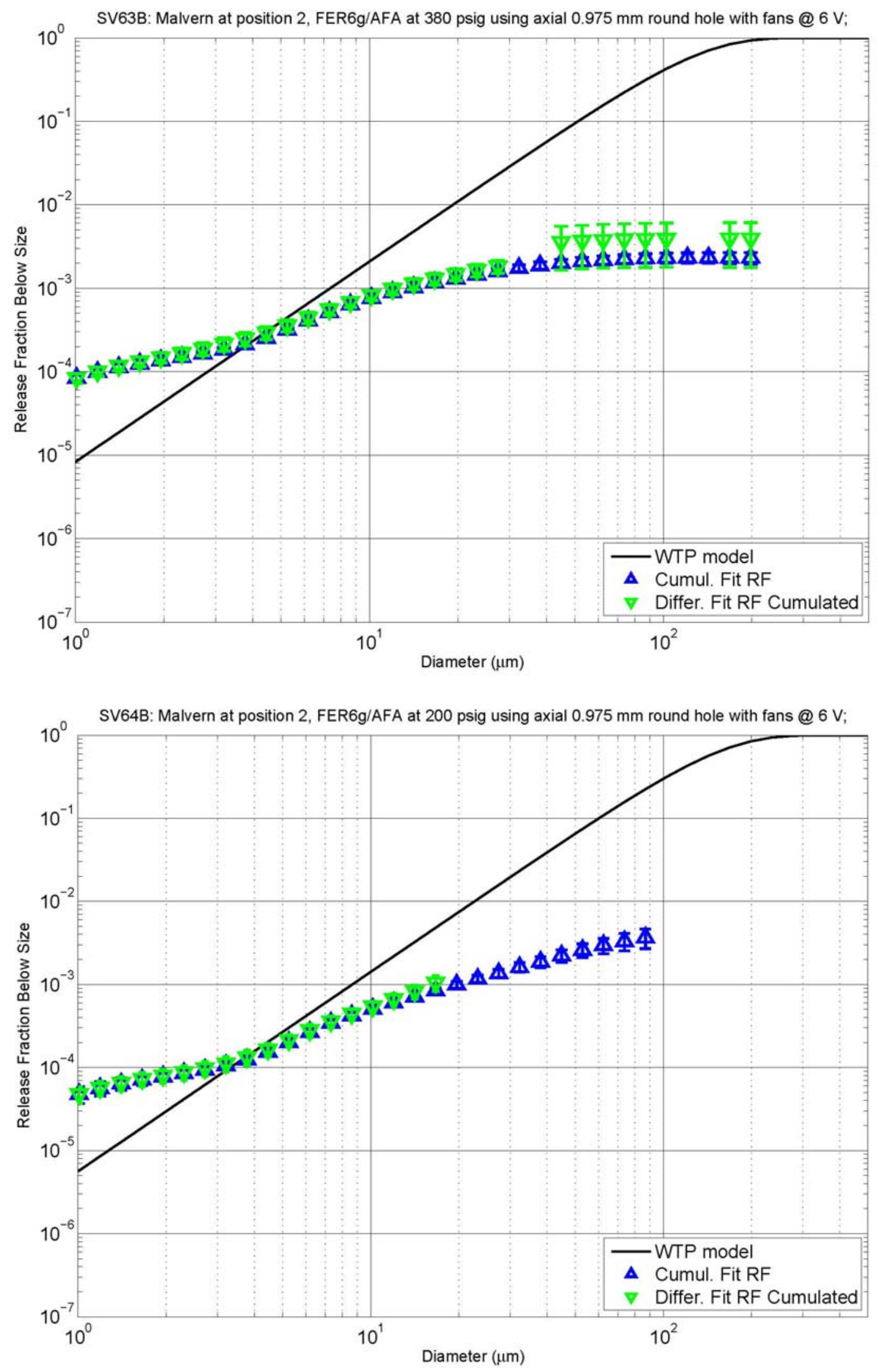

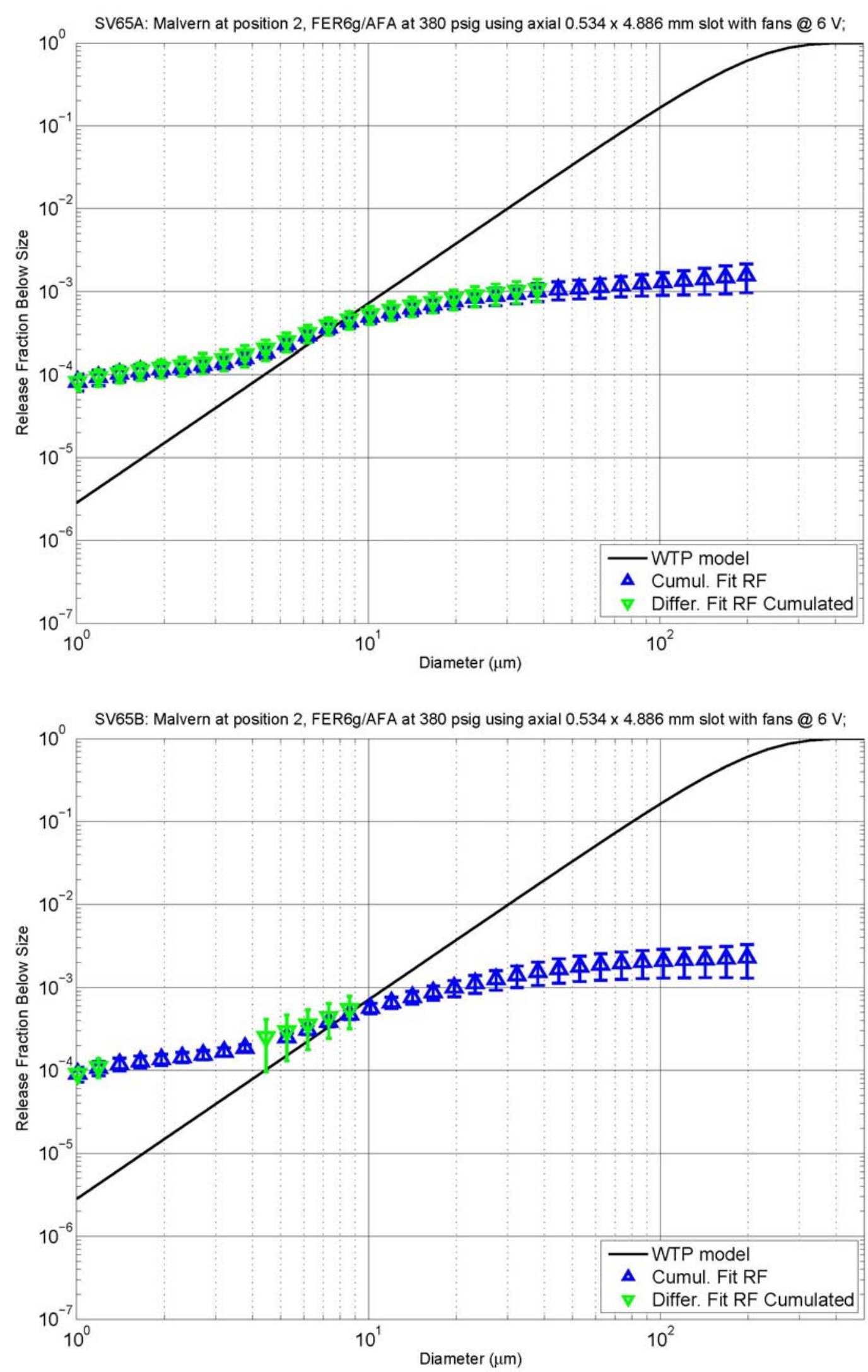

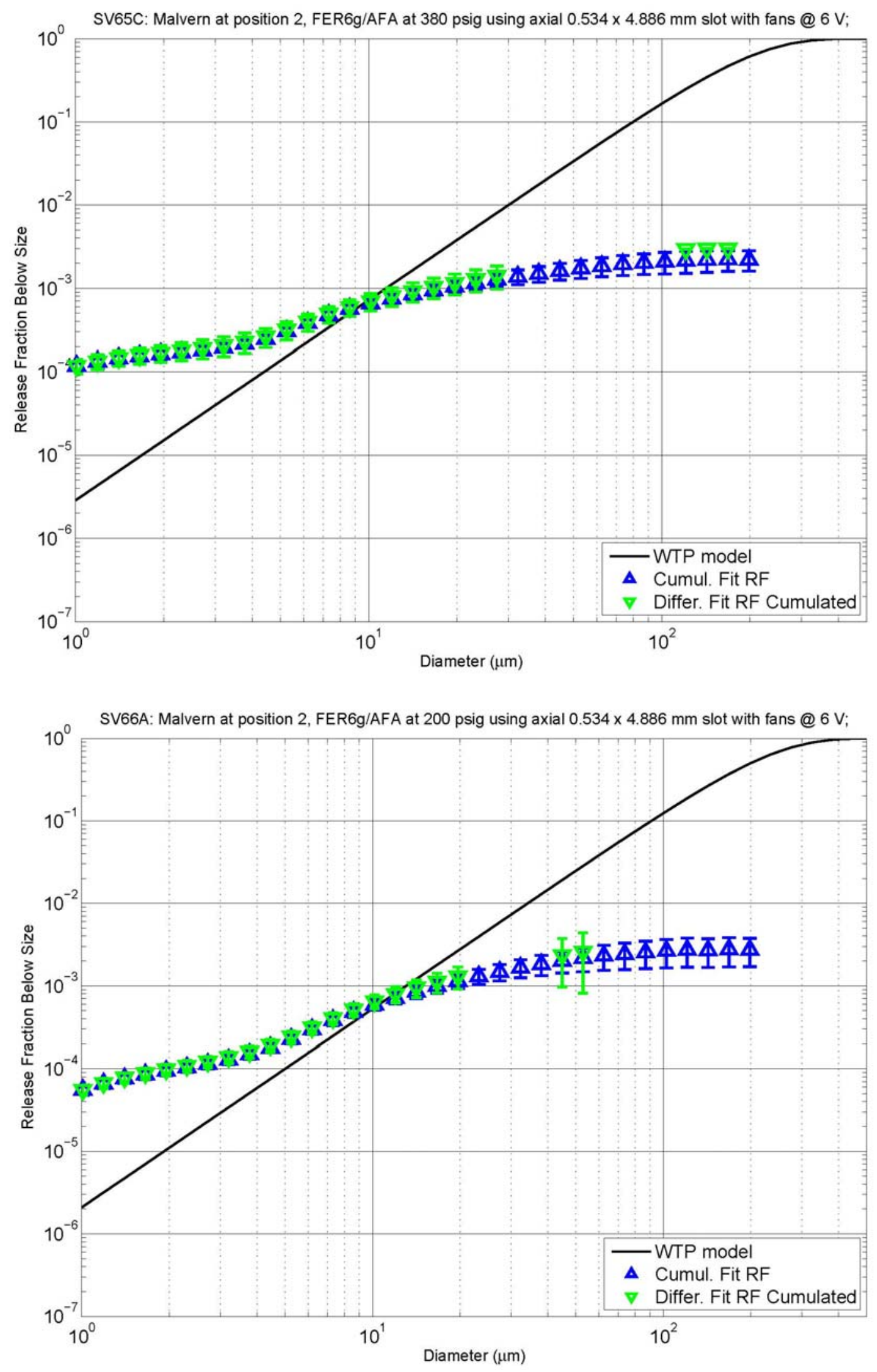

B. 34 

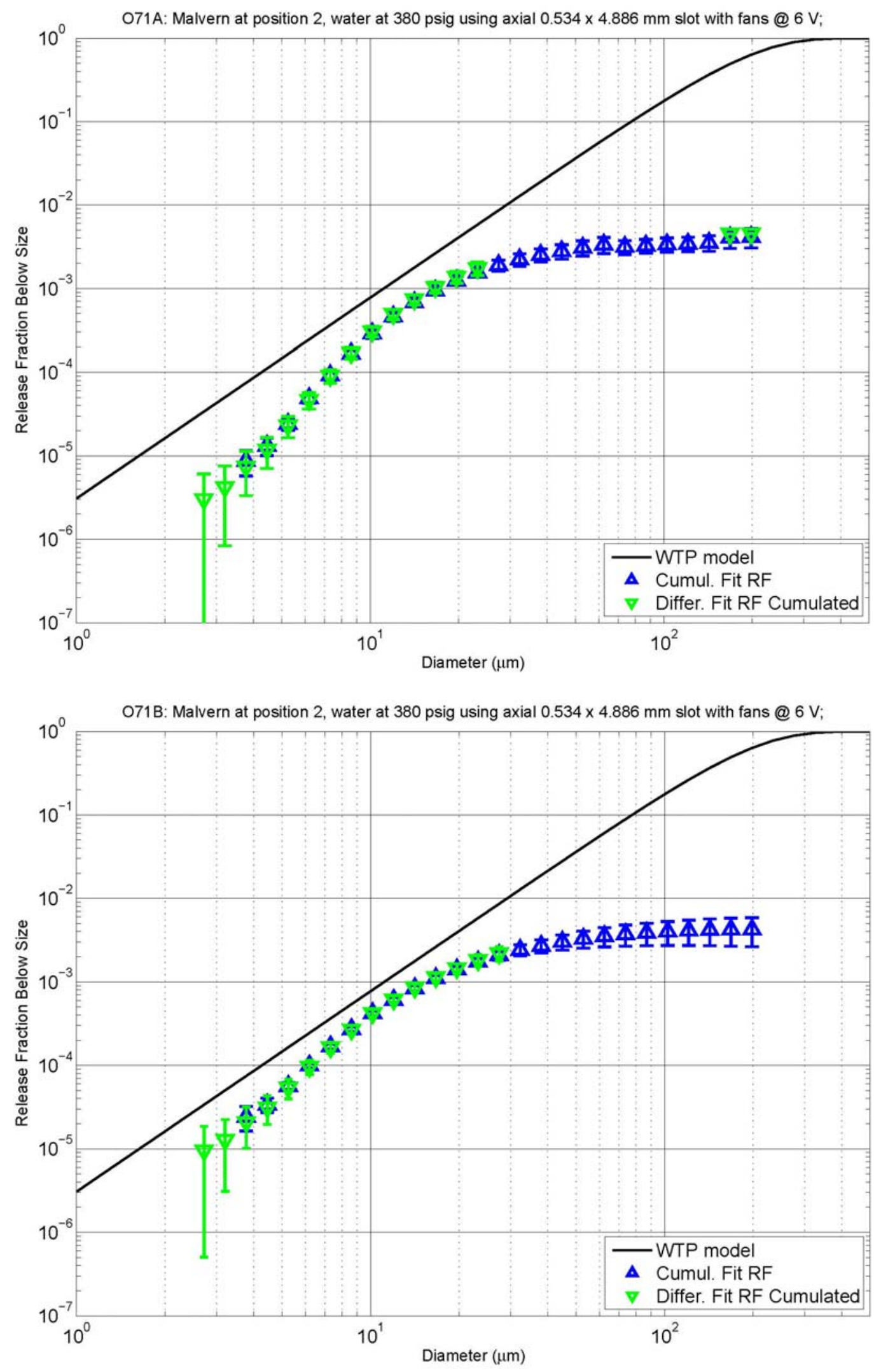

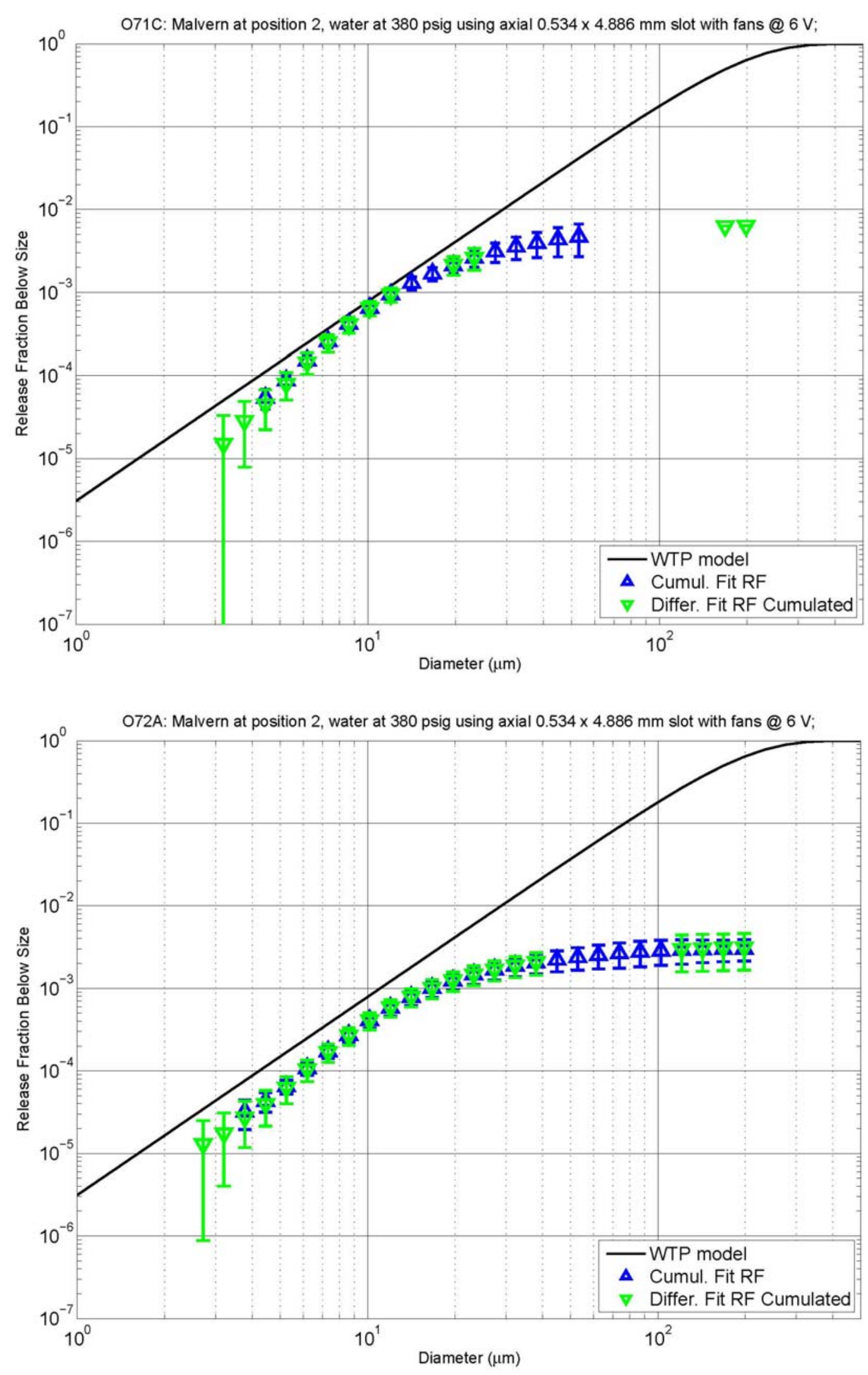

B.36 

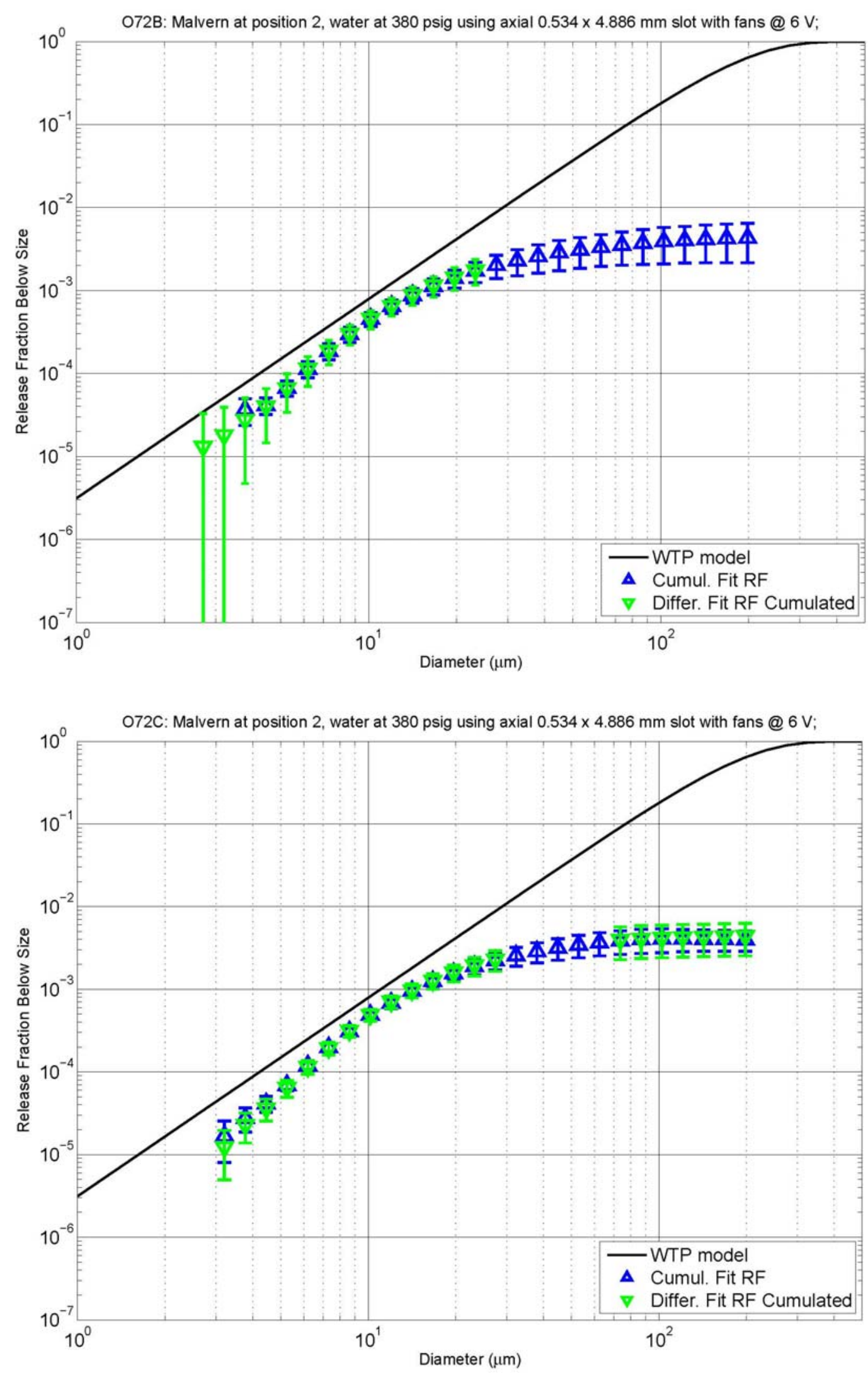

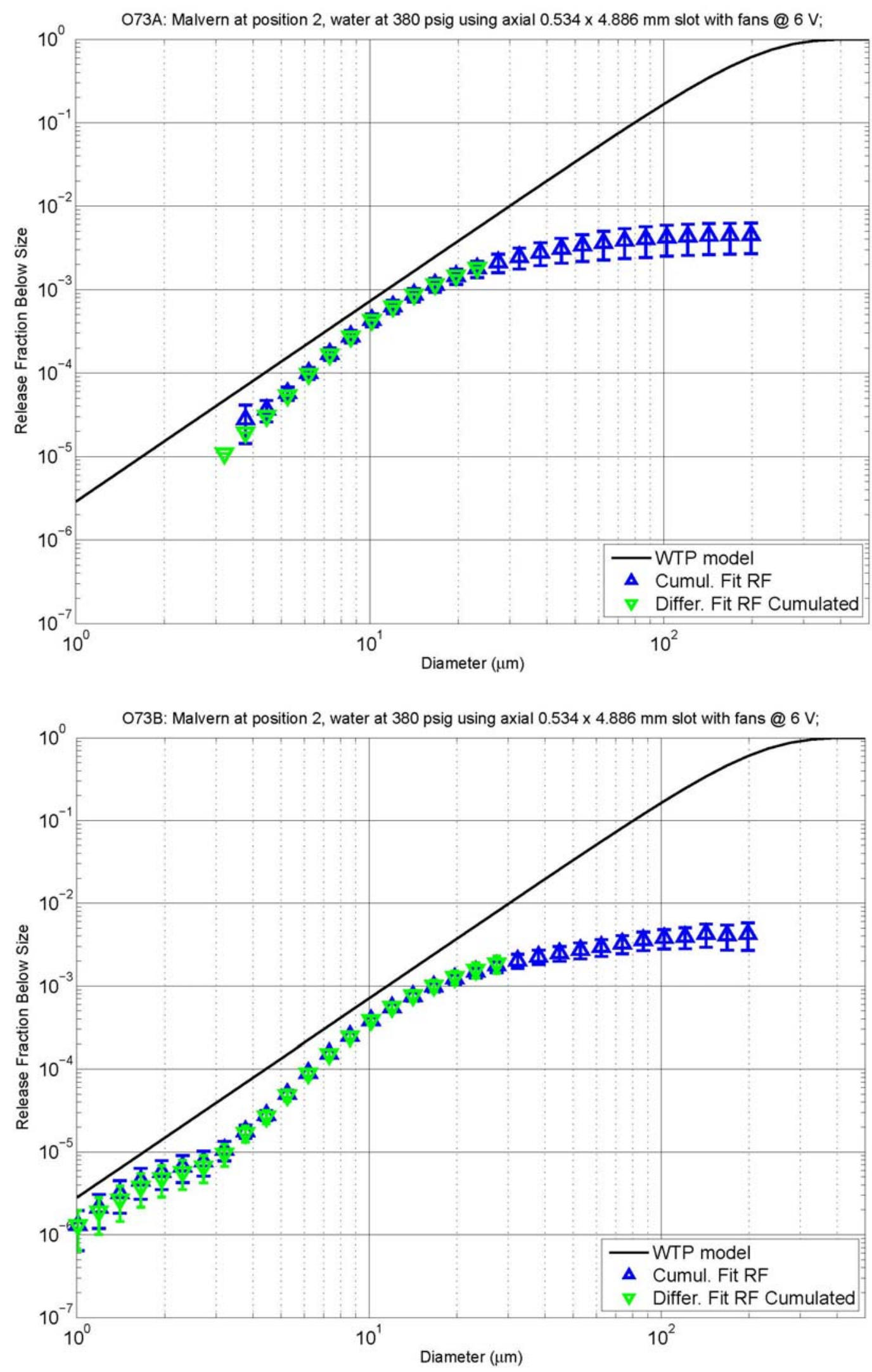

B. 38 

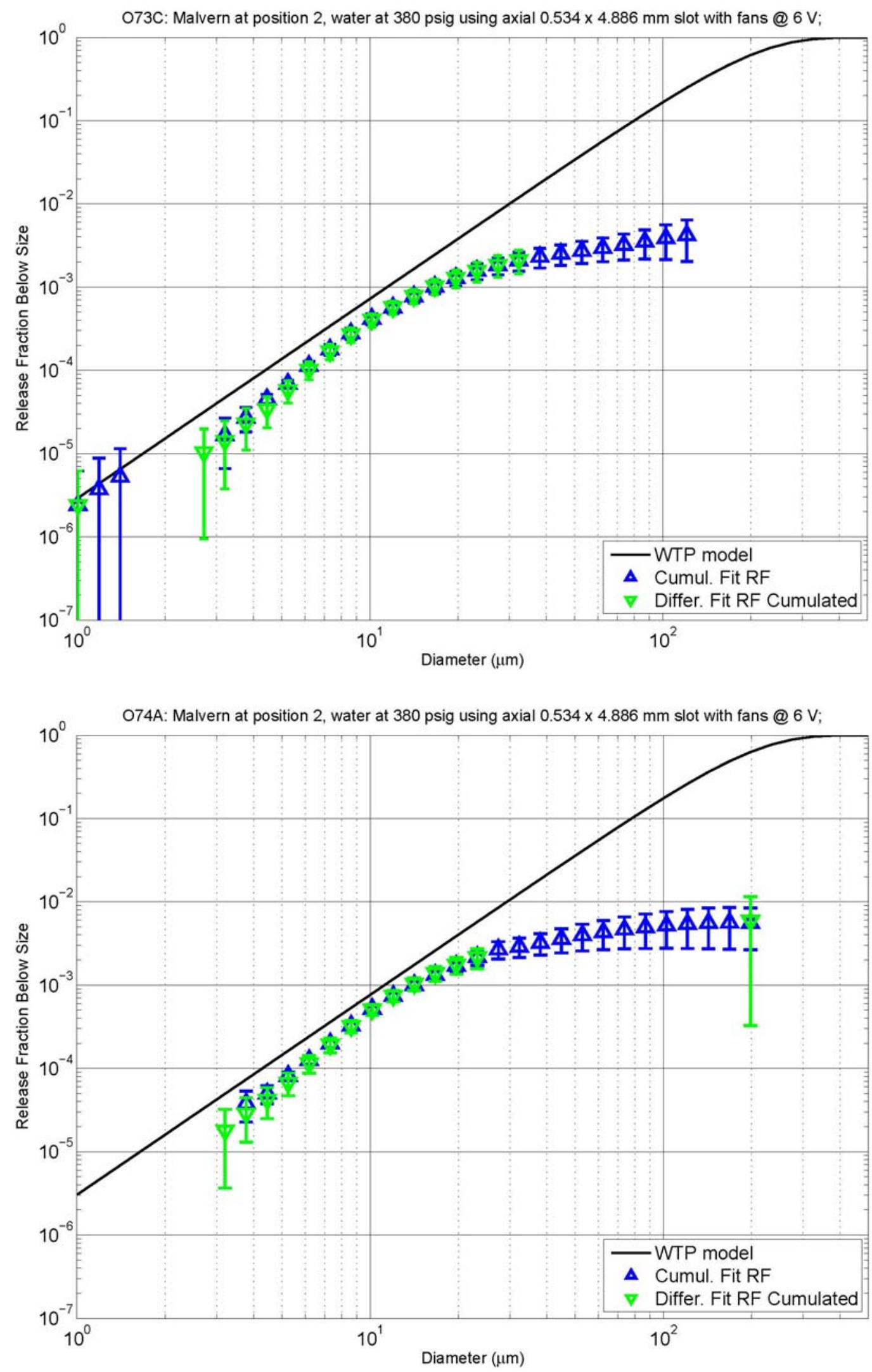

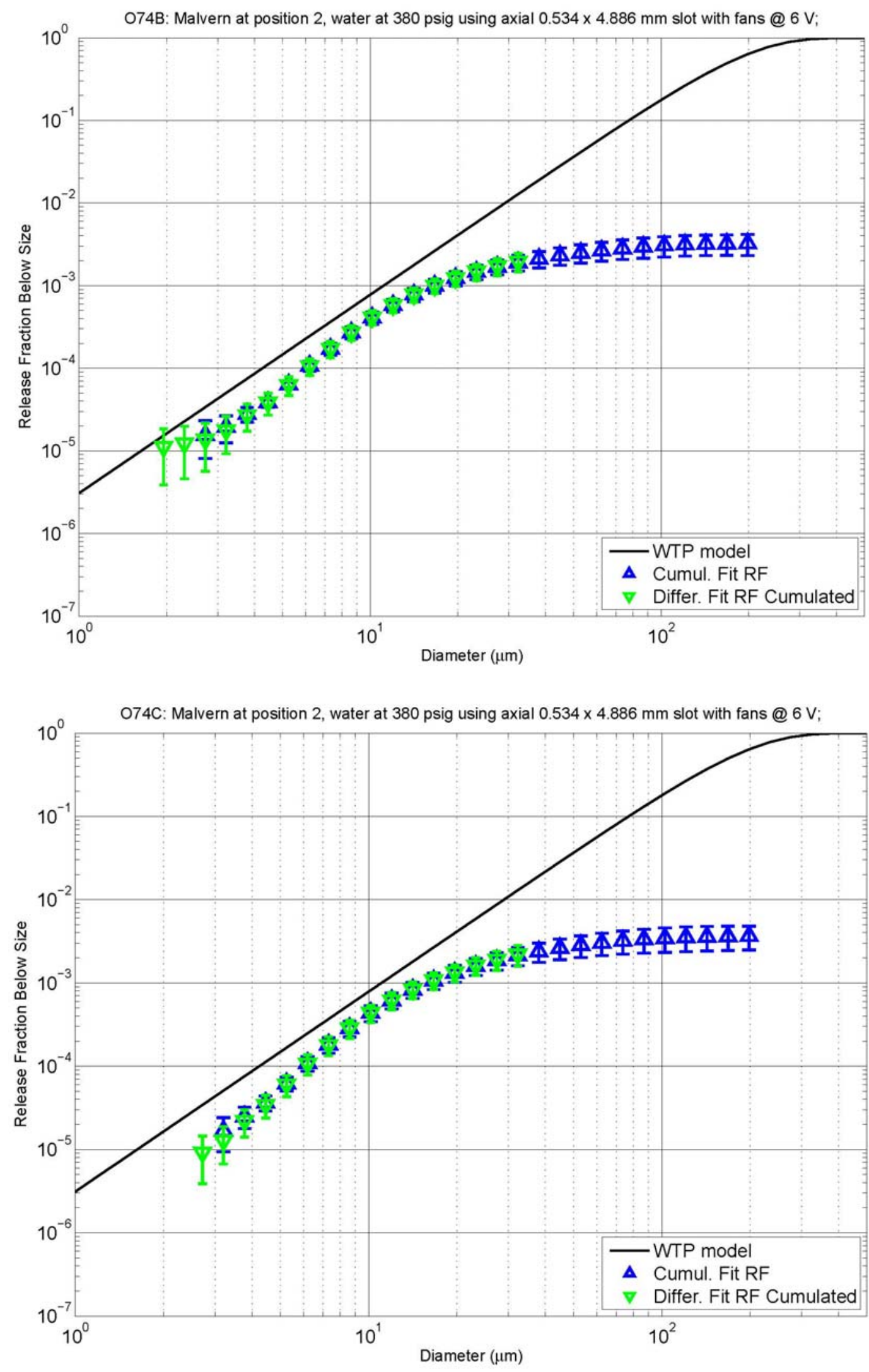

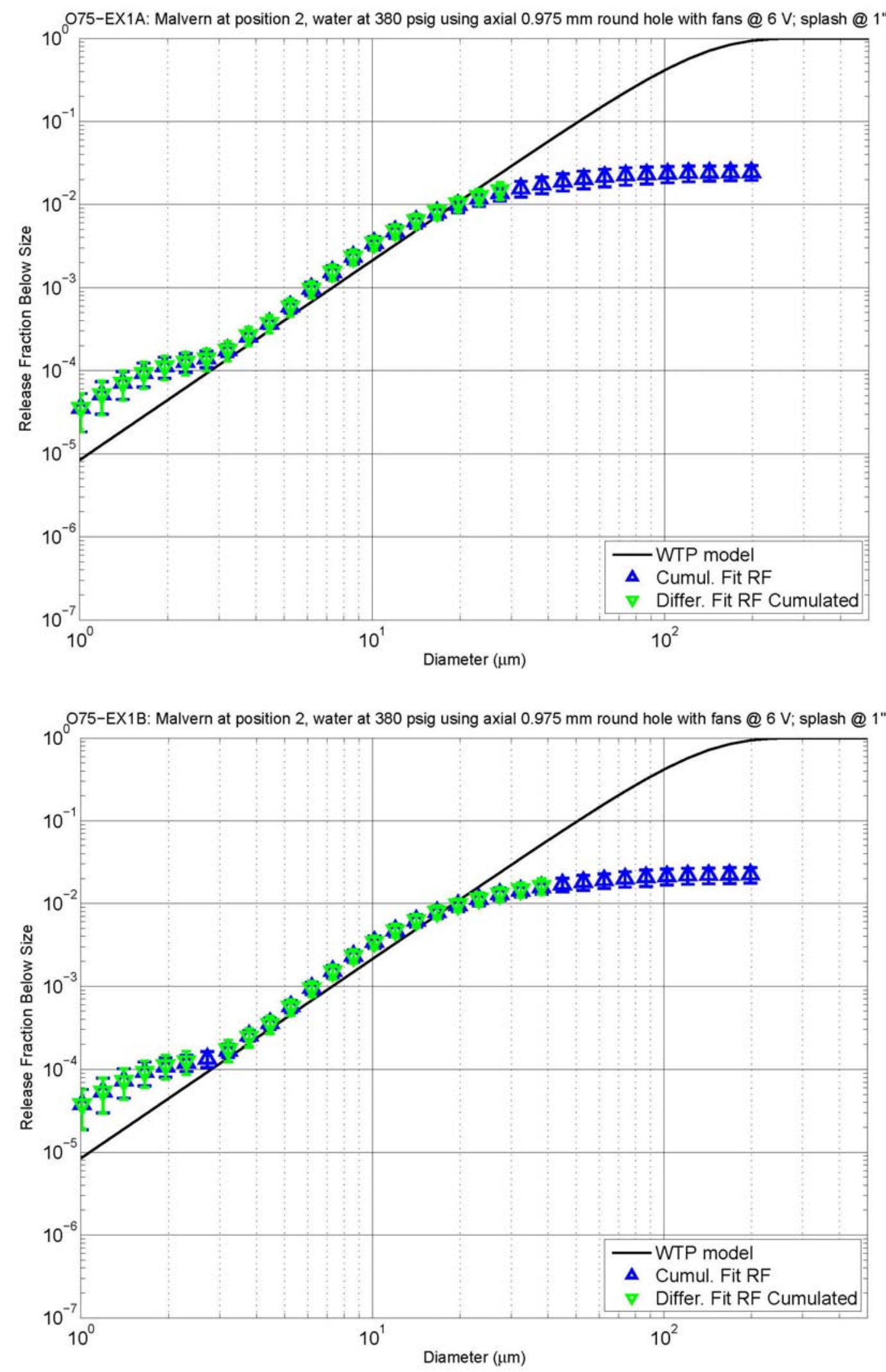

B.41 

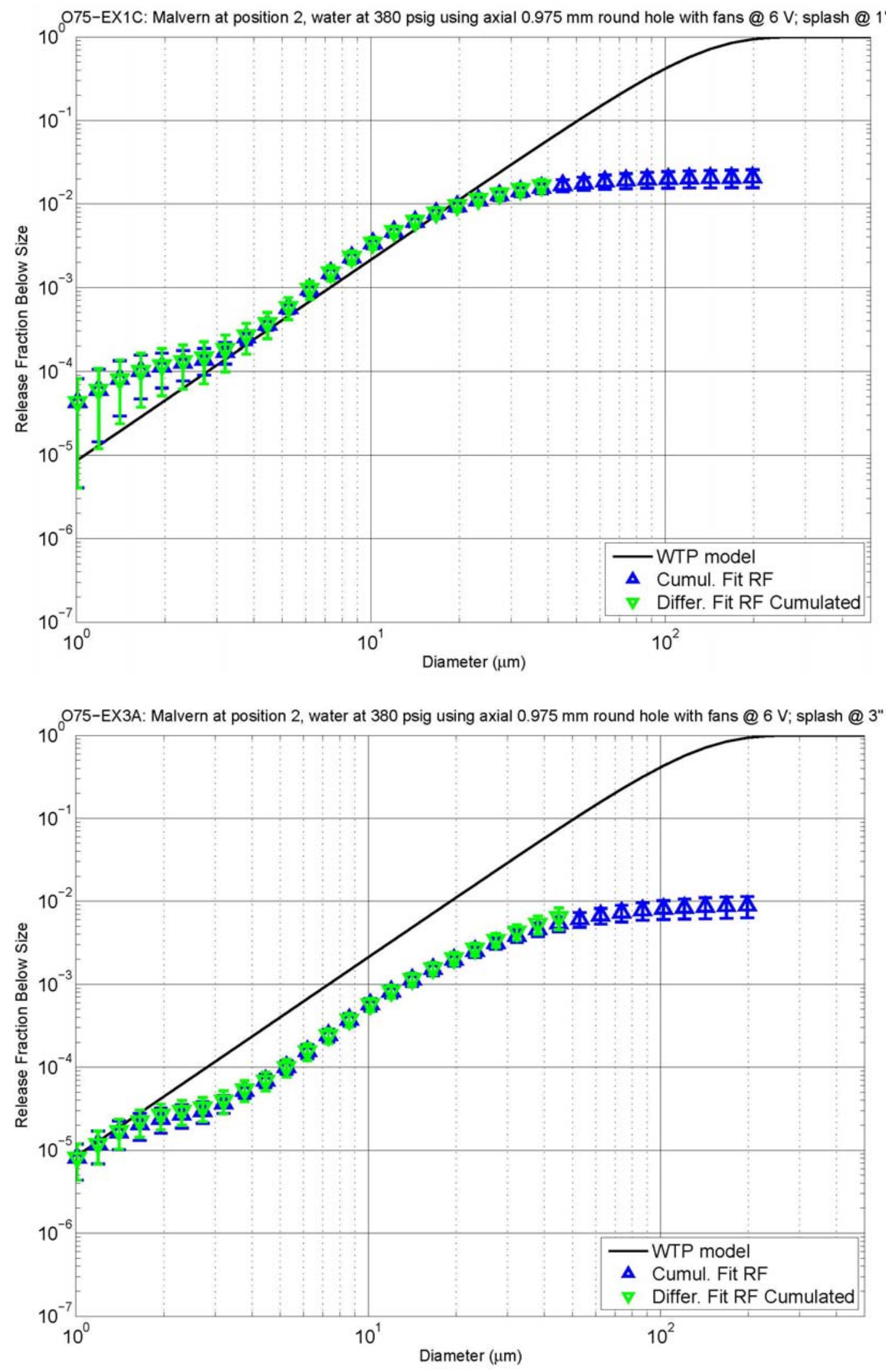

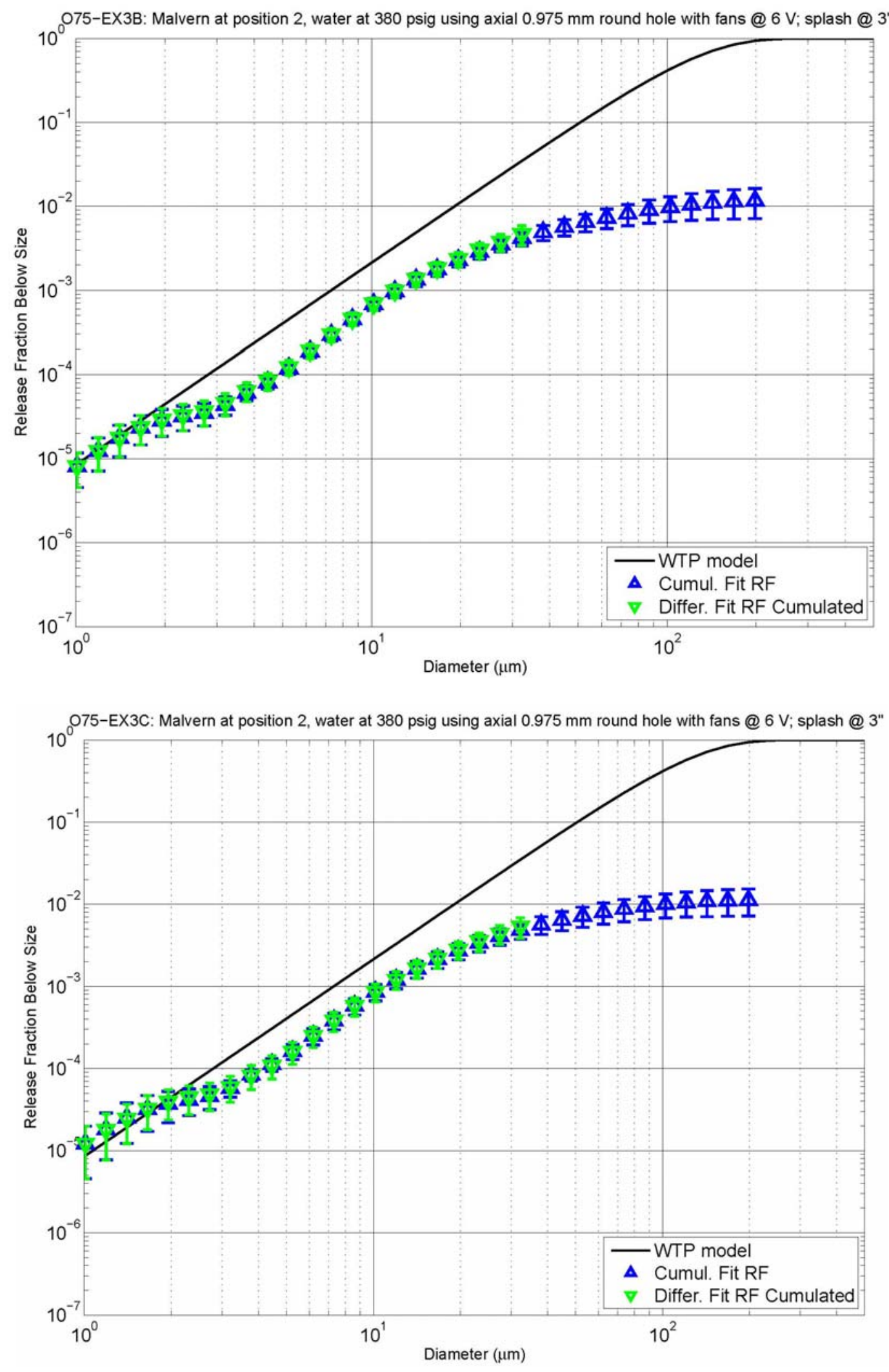

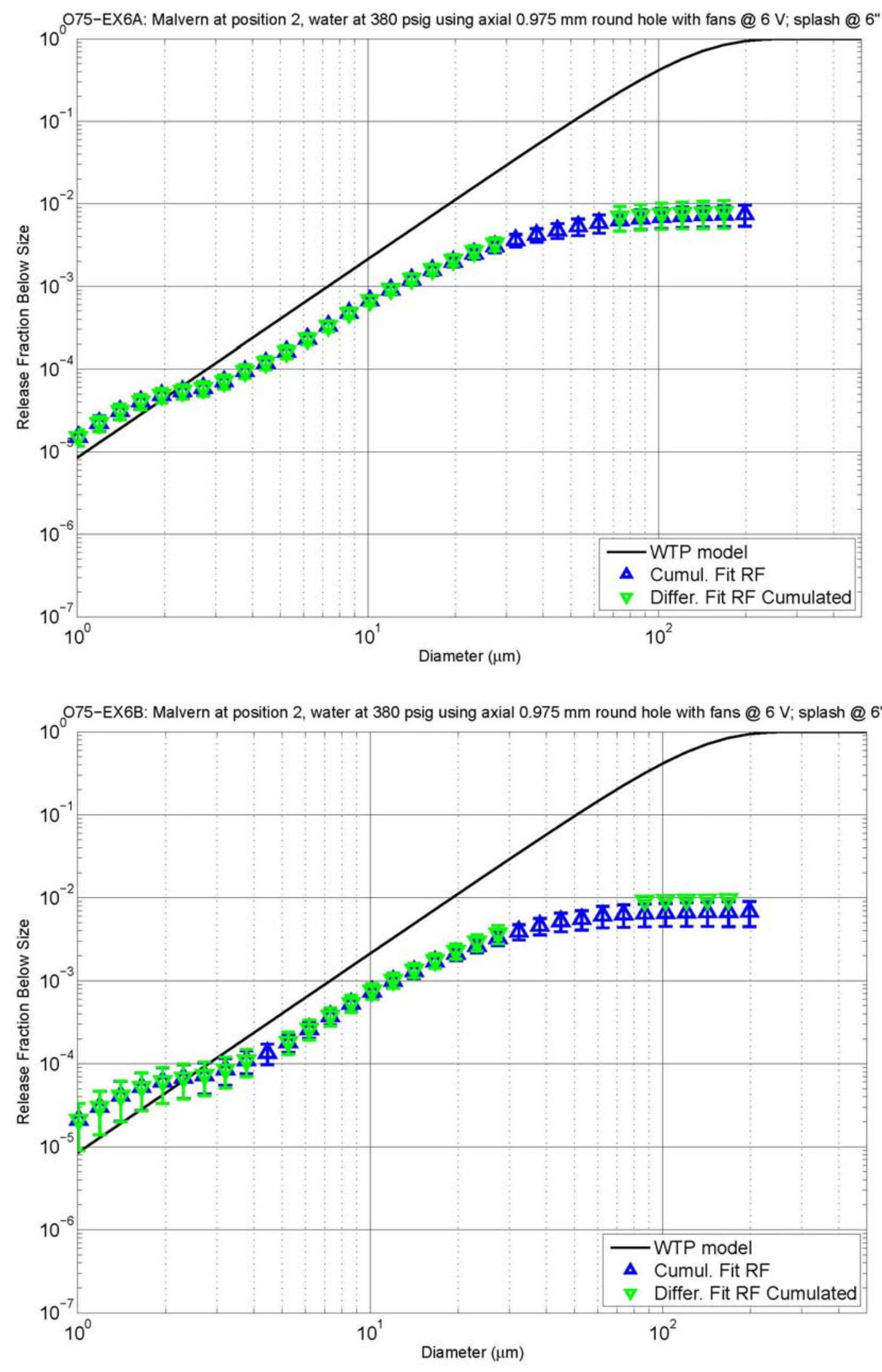

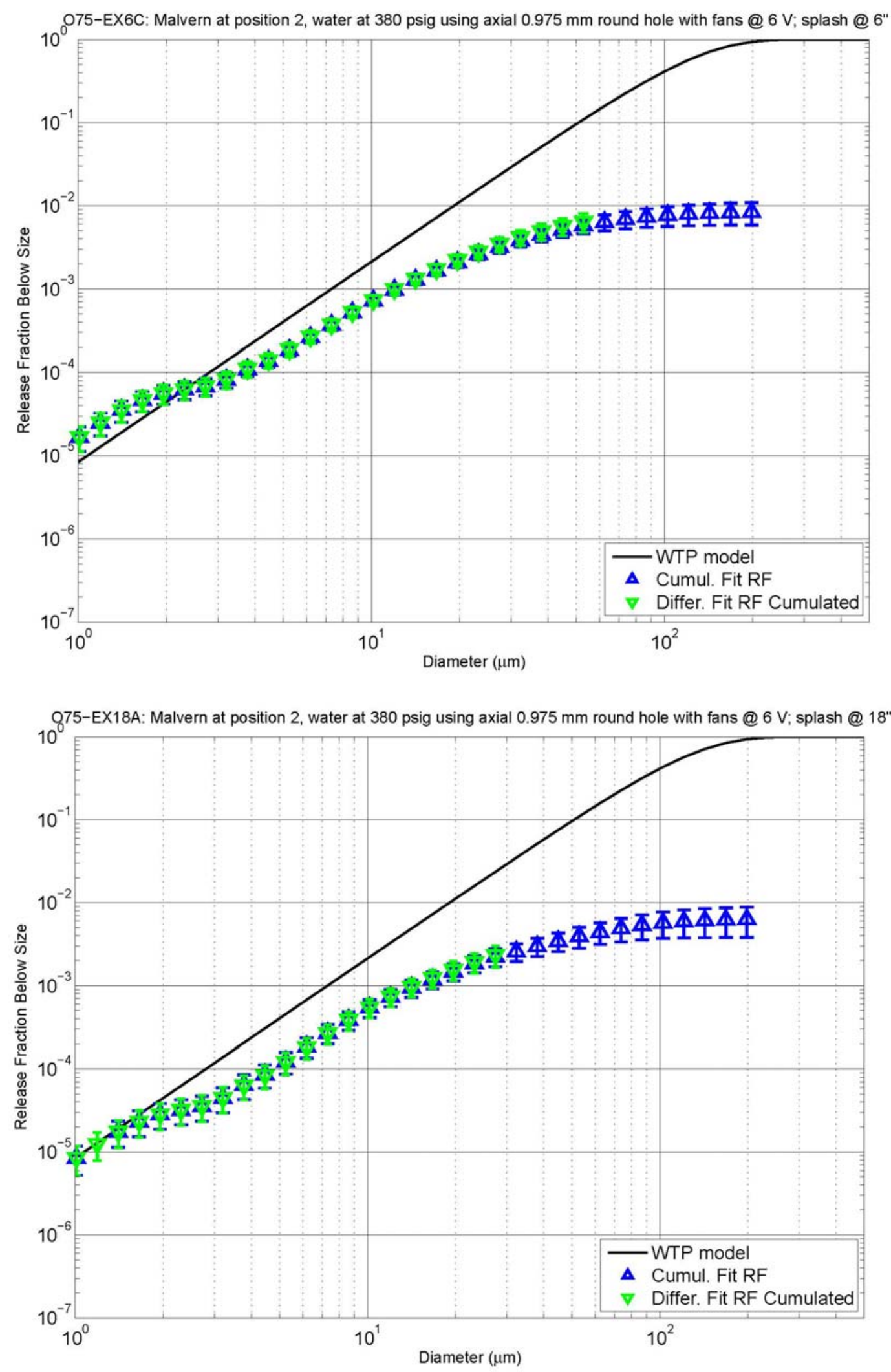

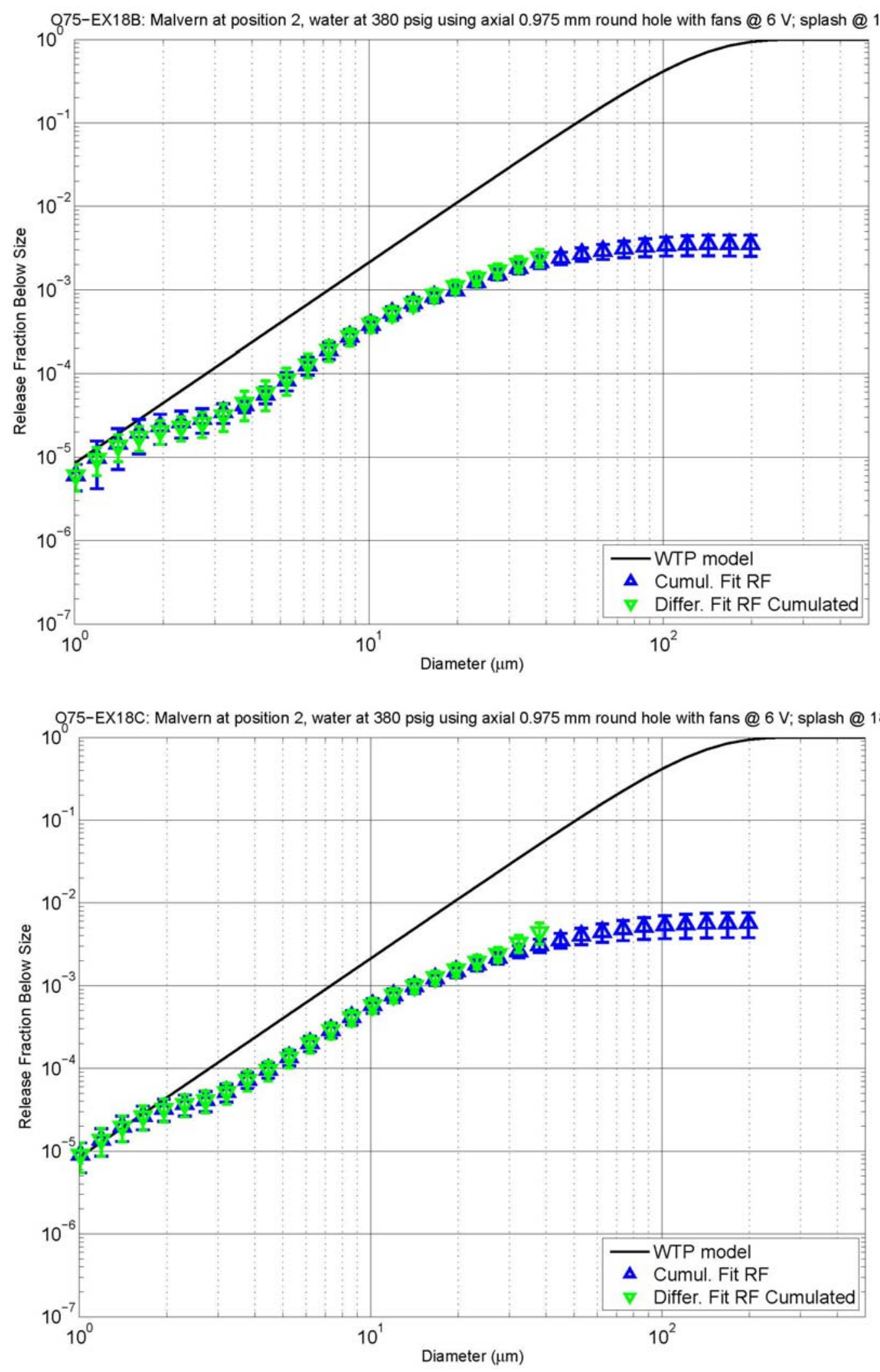

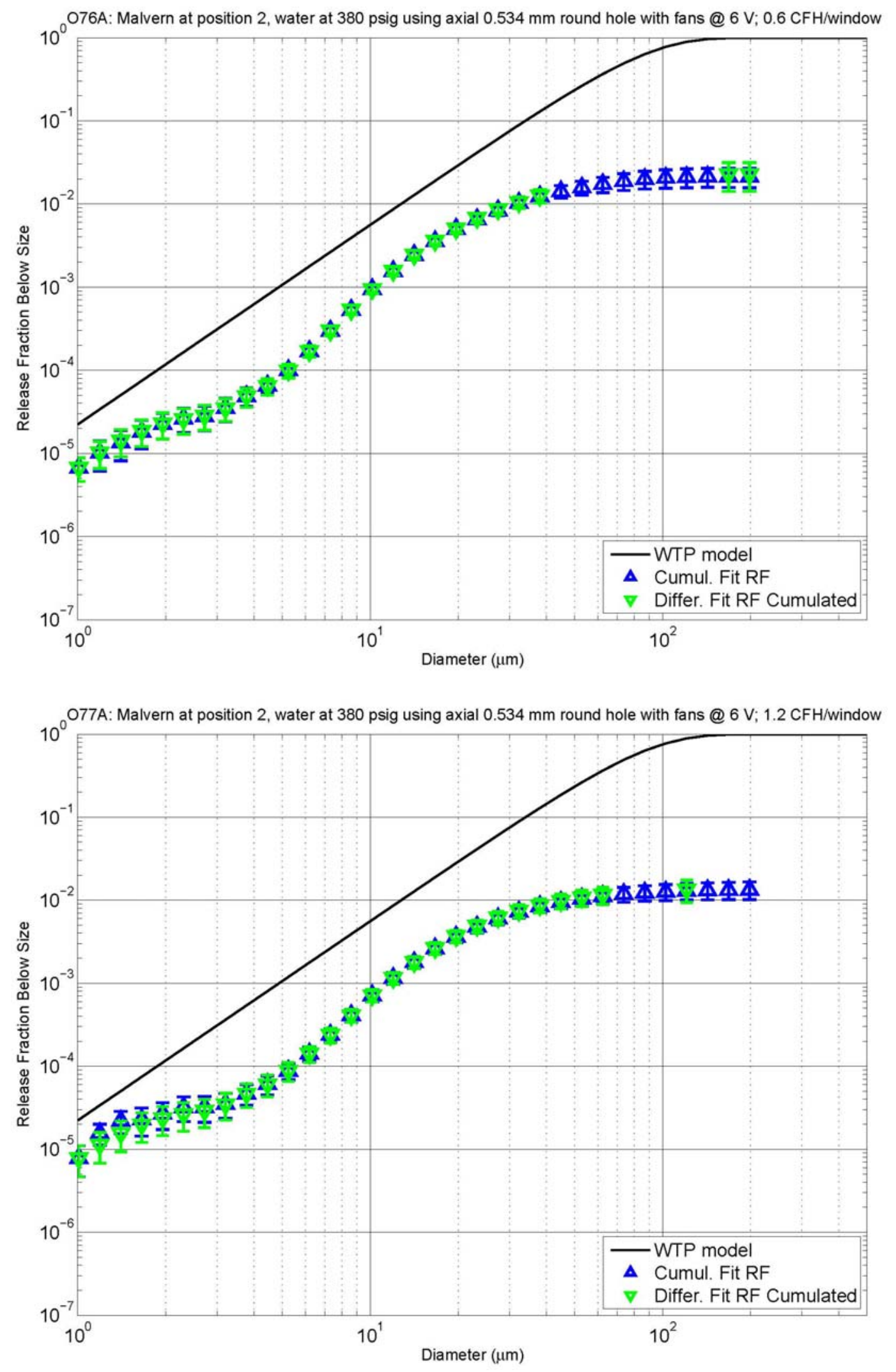

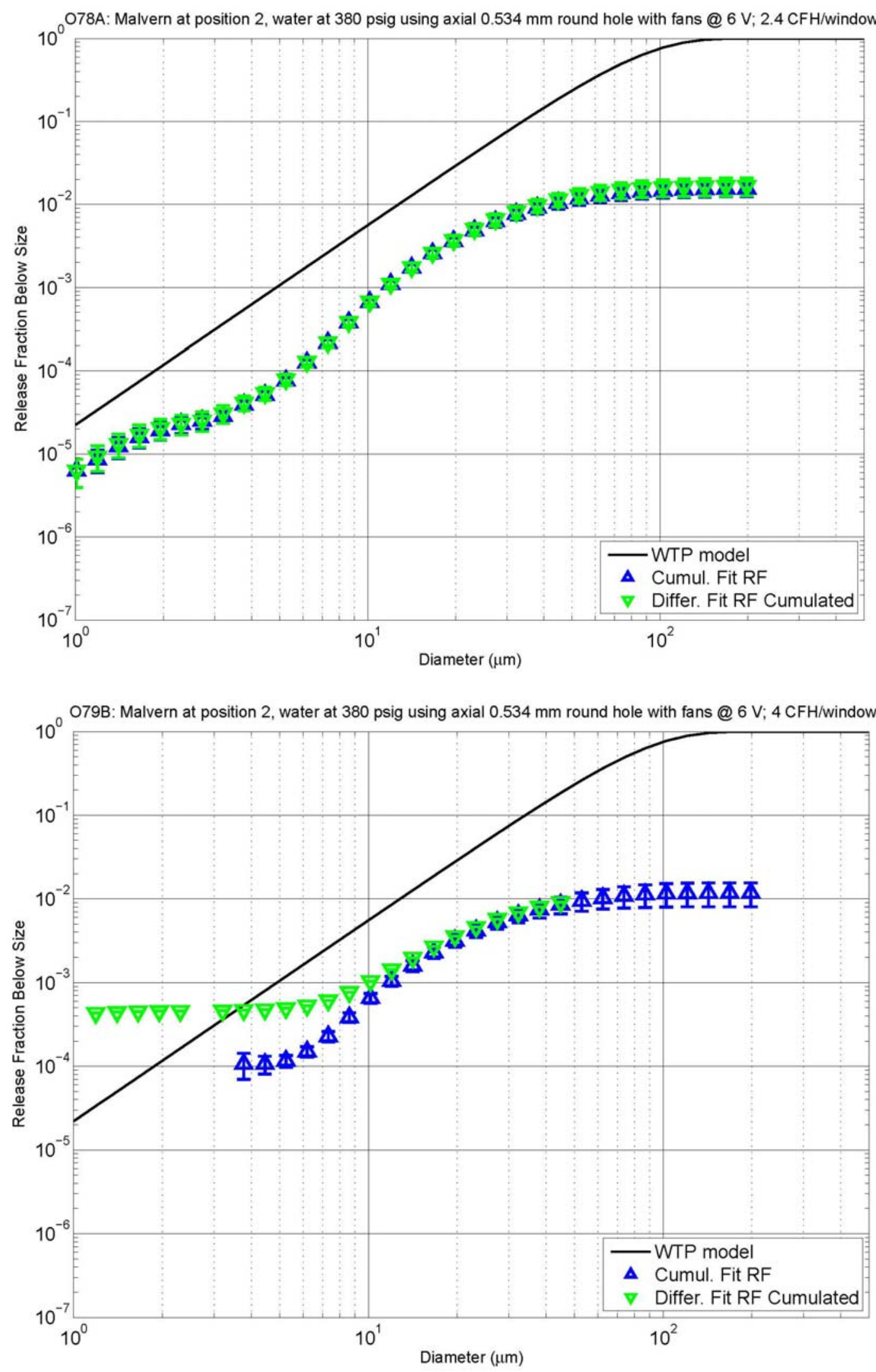

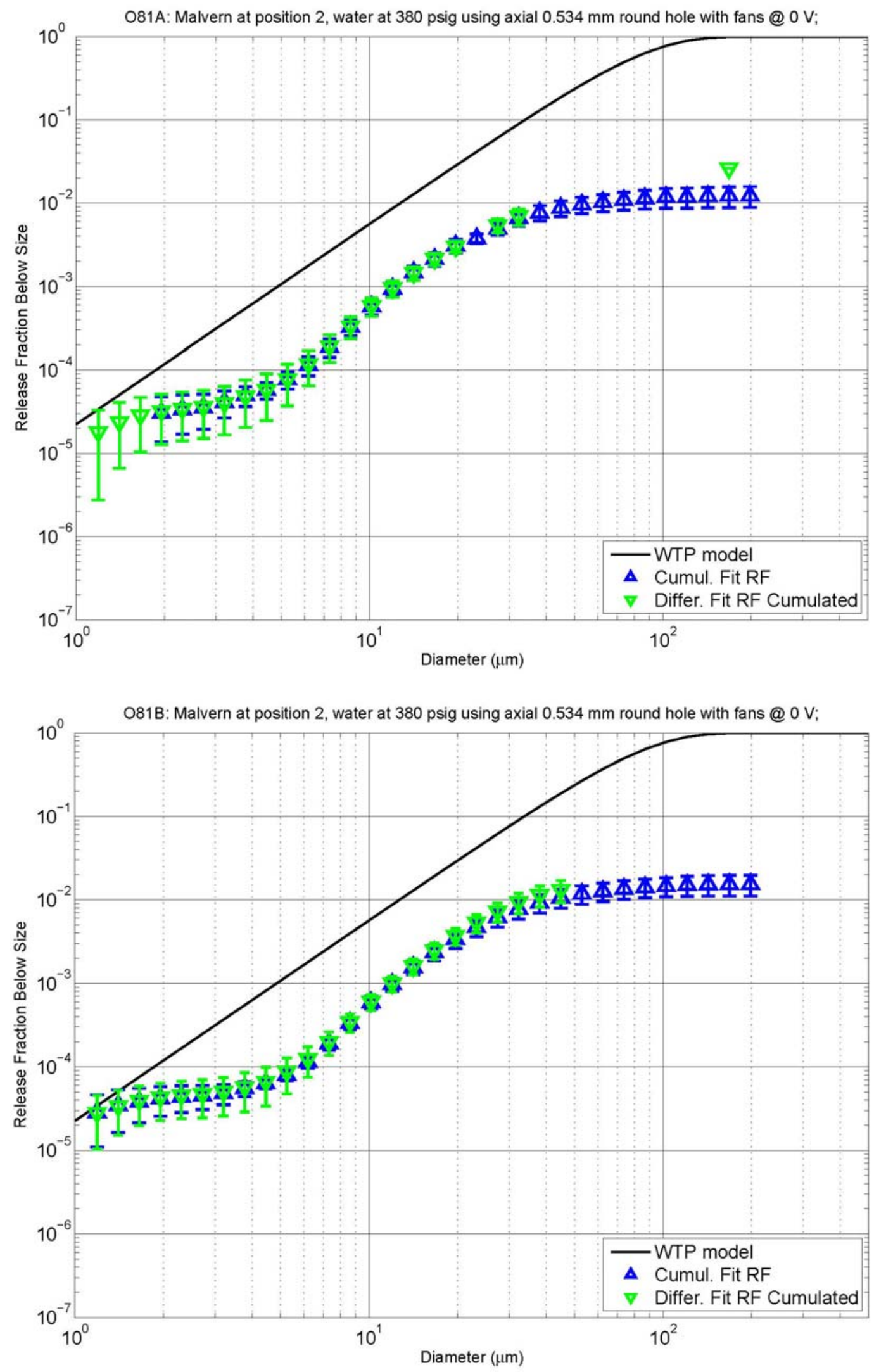

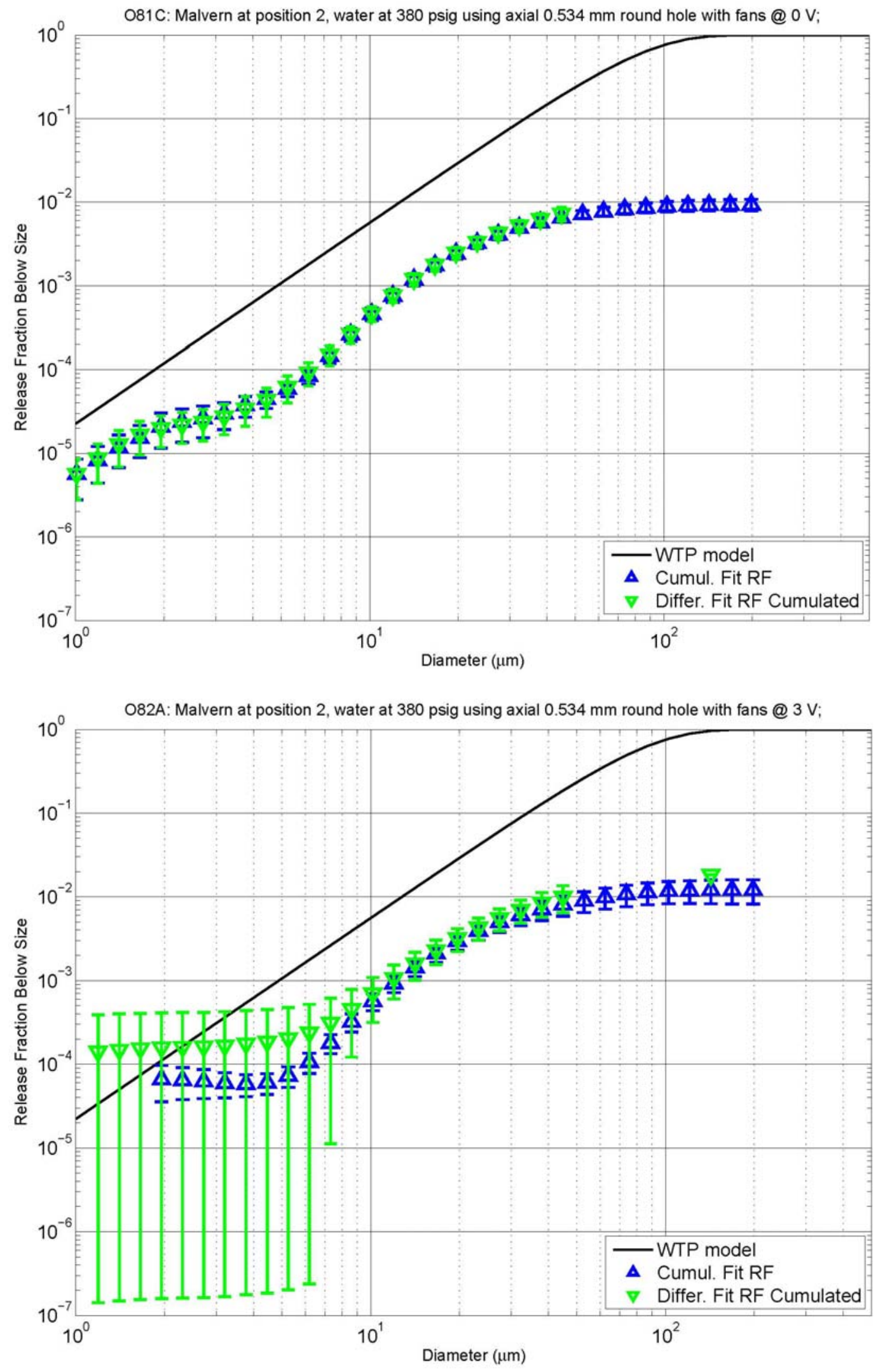

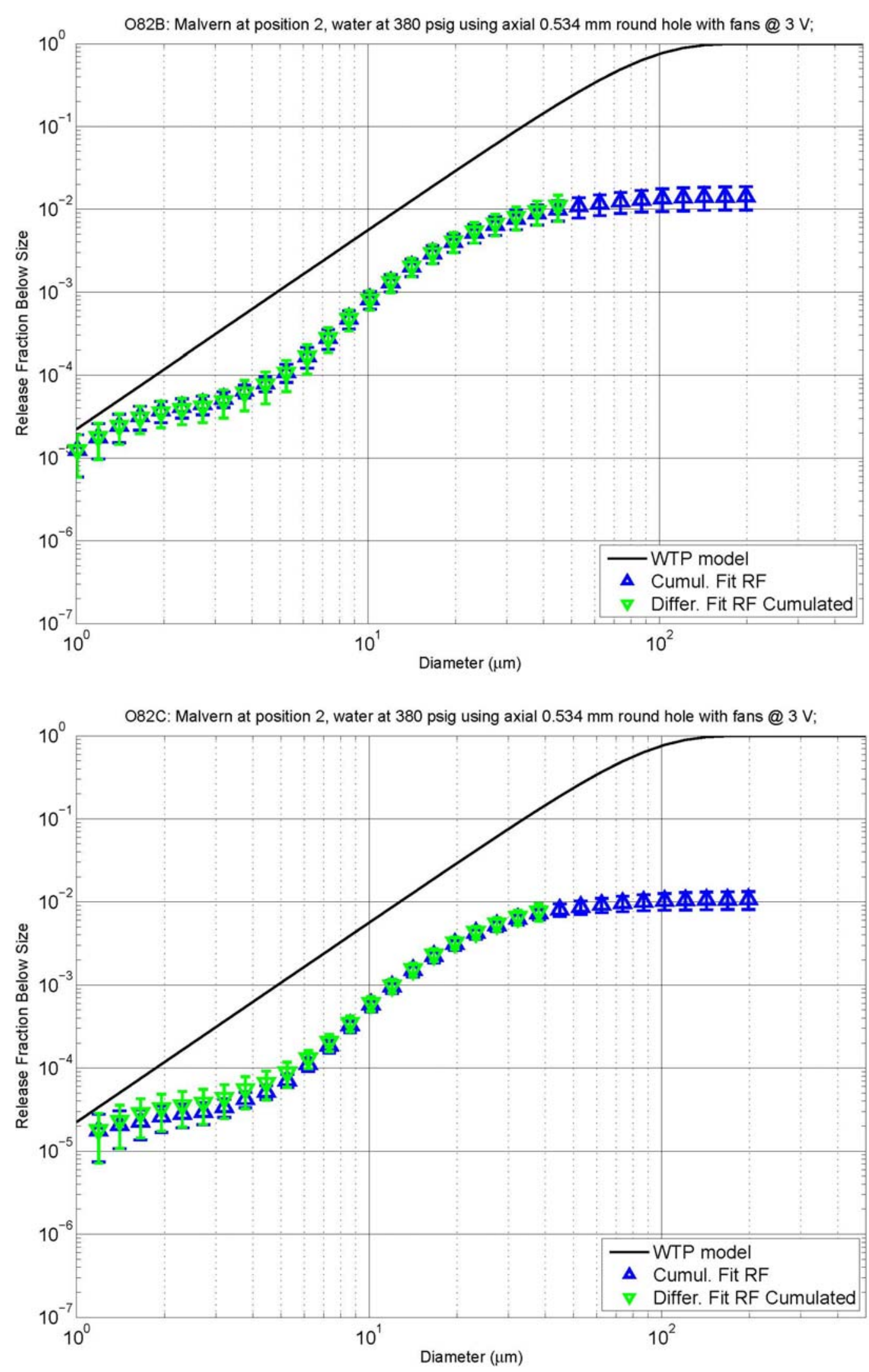

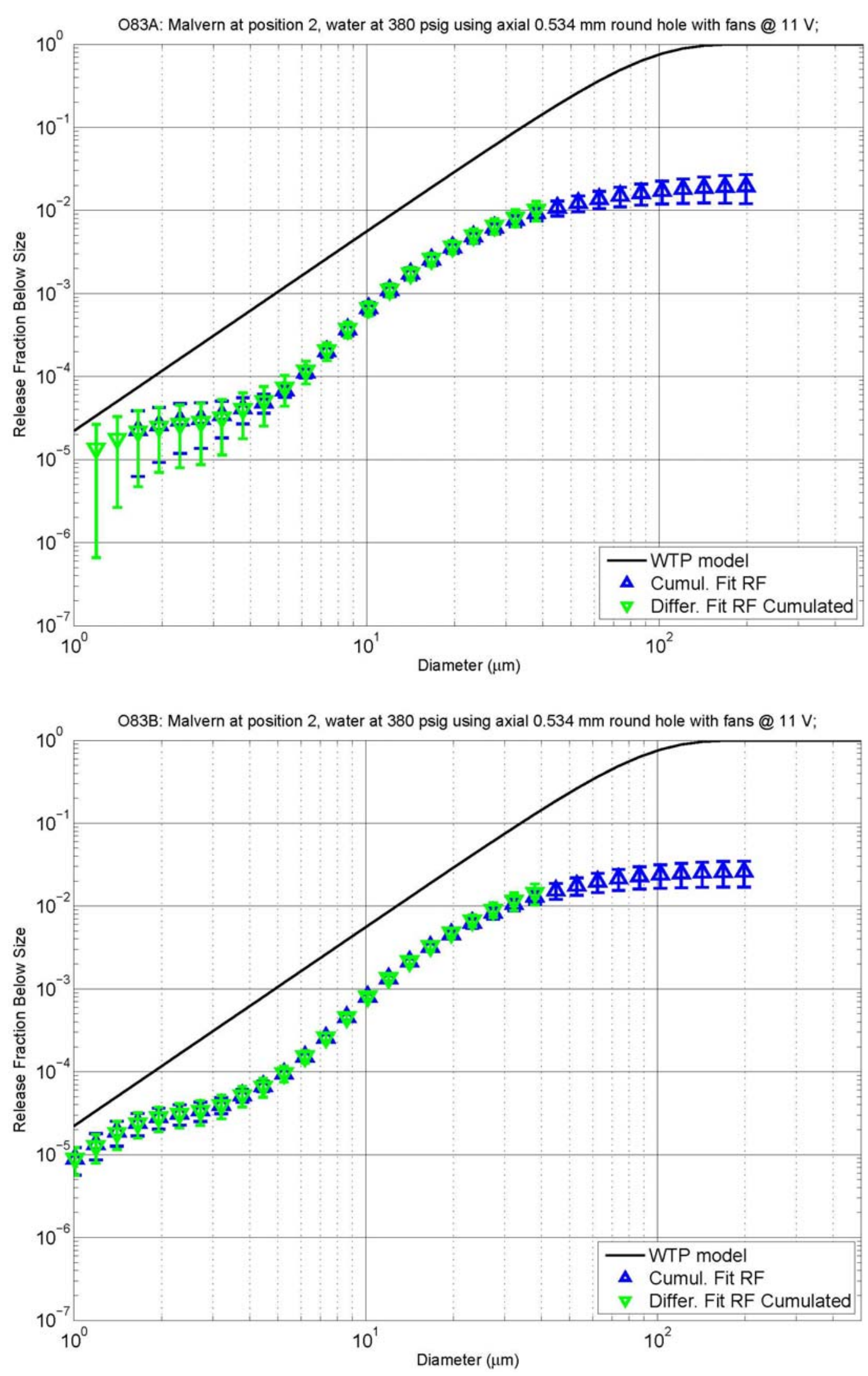

B. 52 

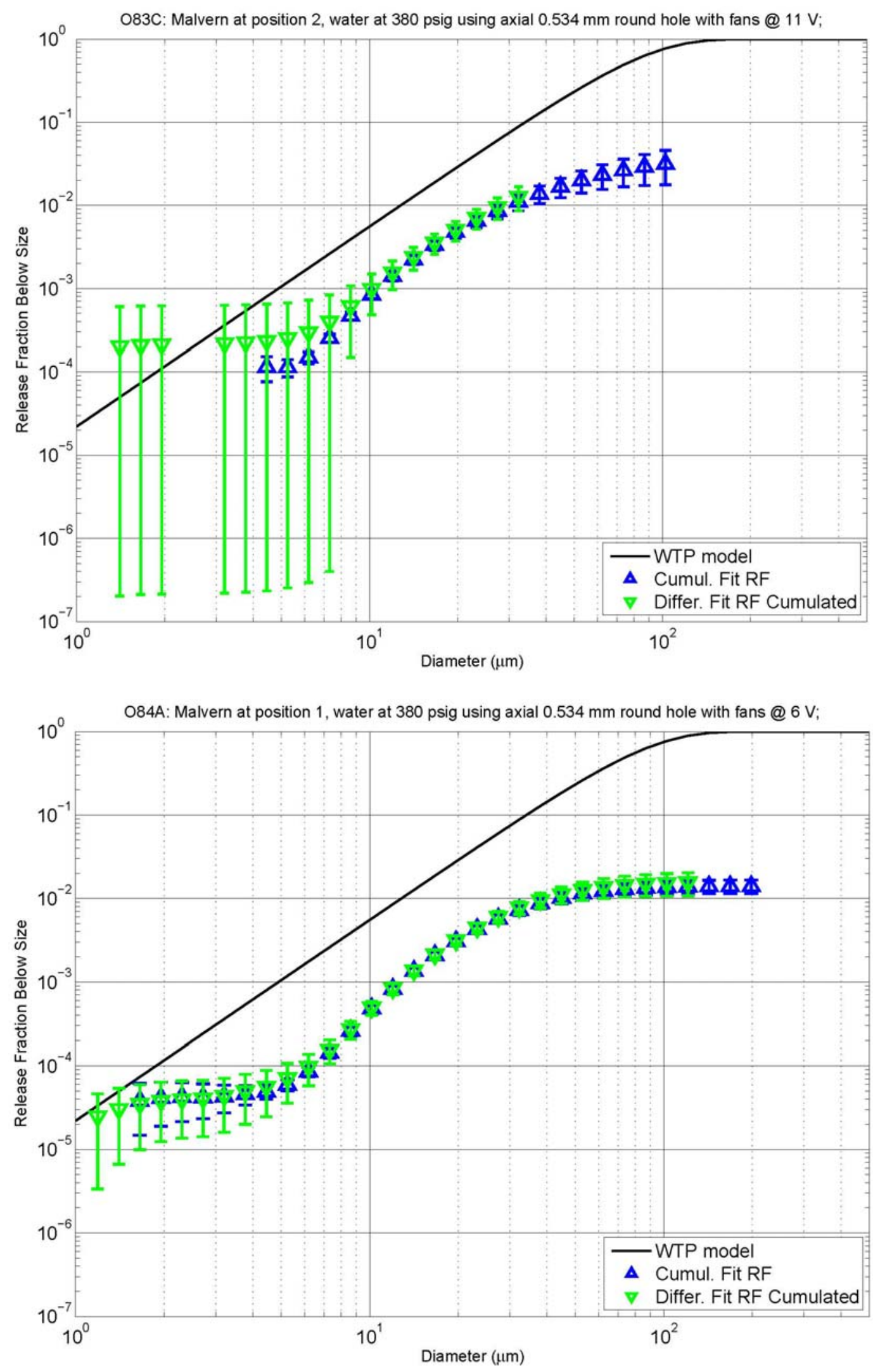

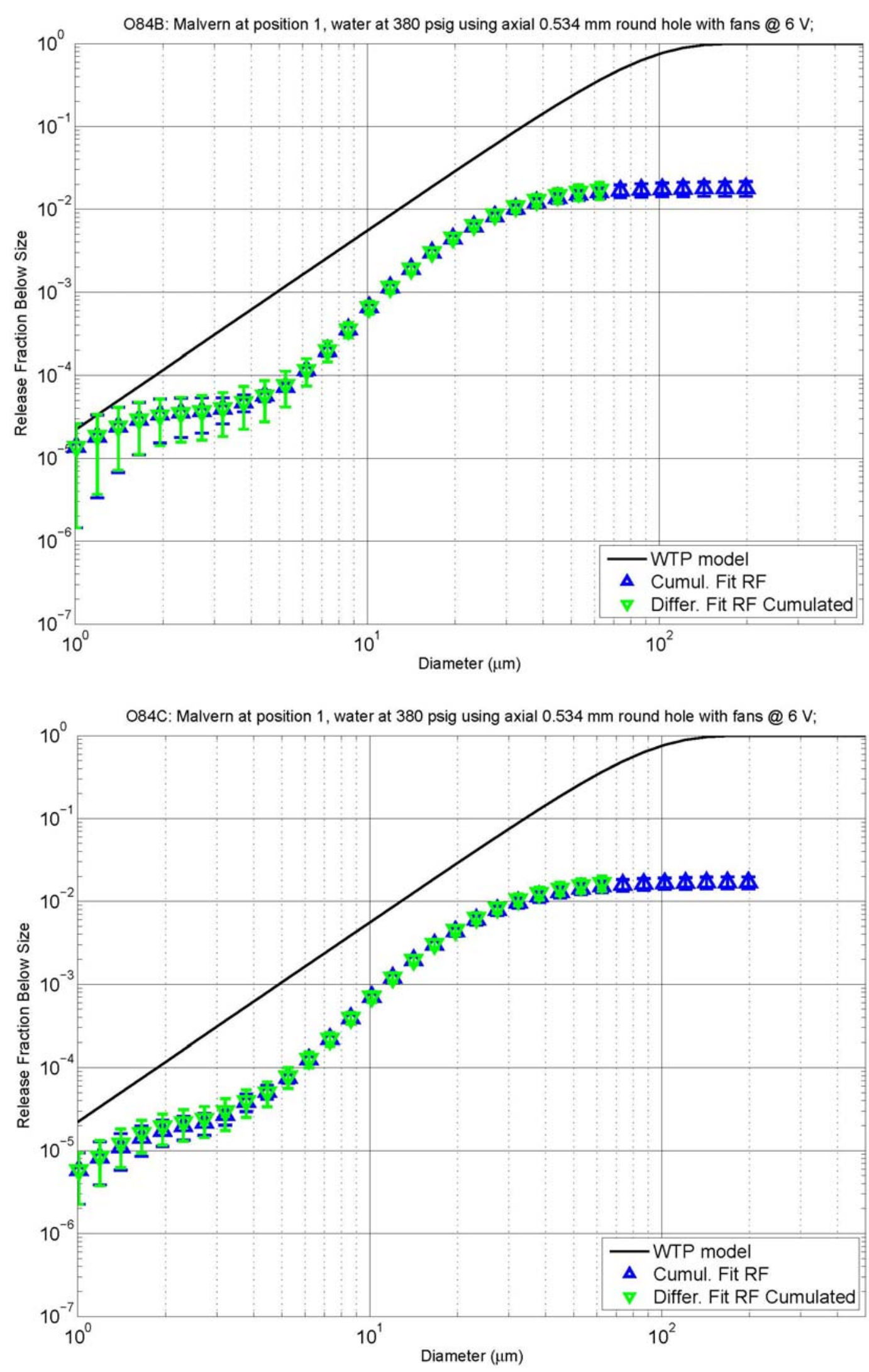

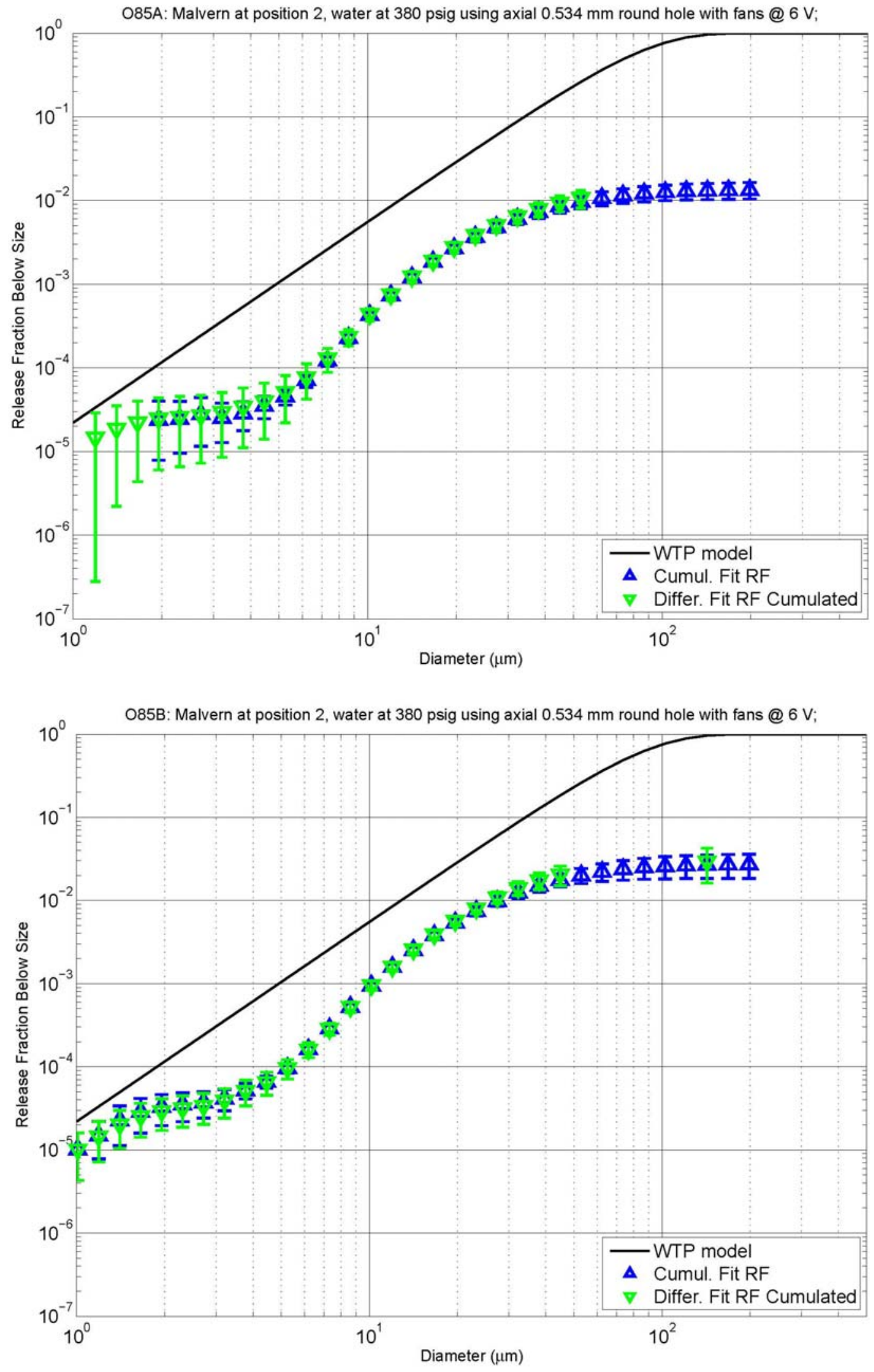

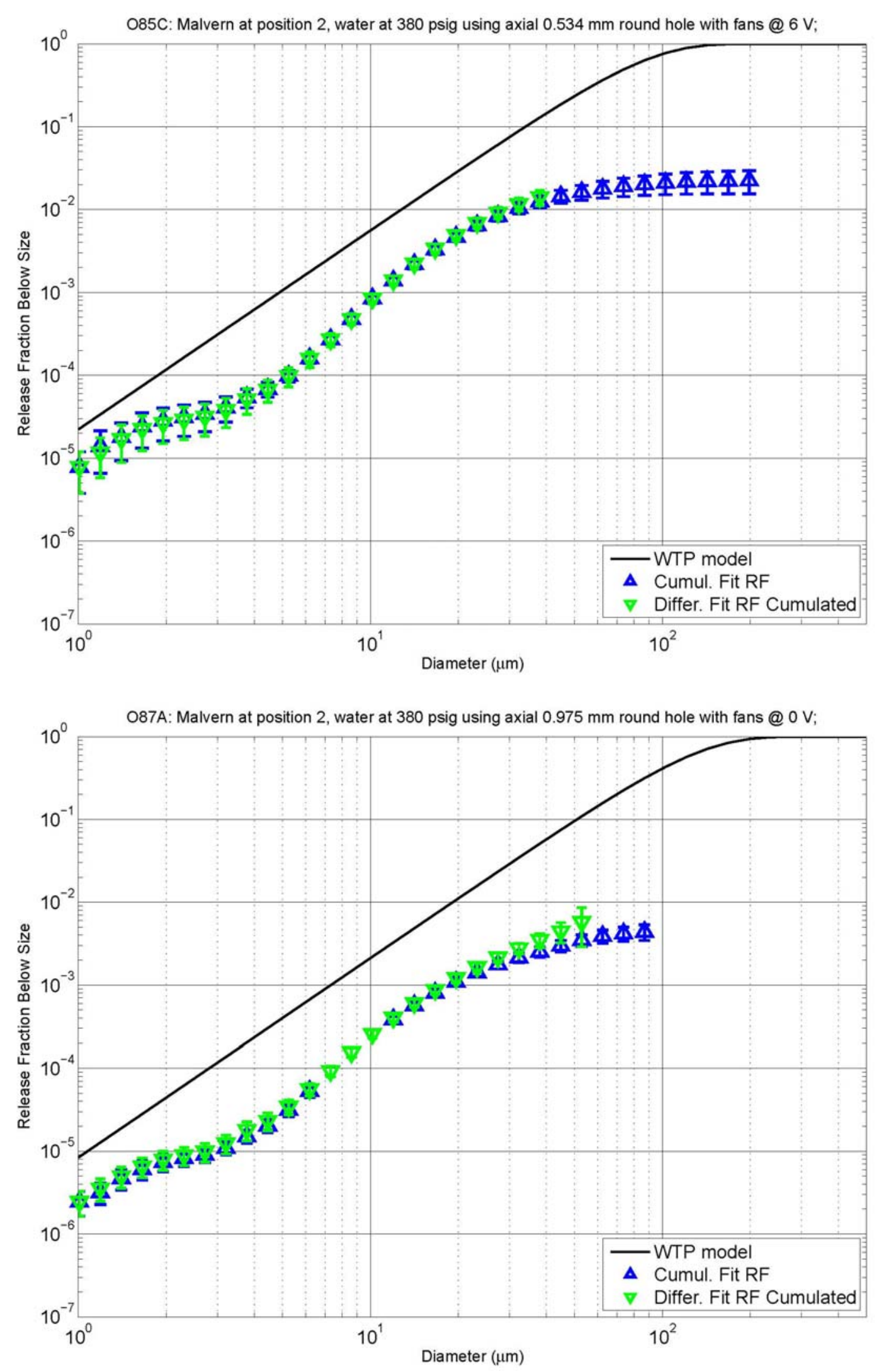

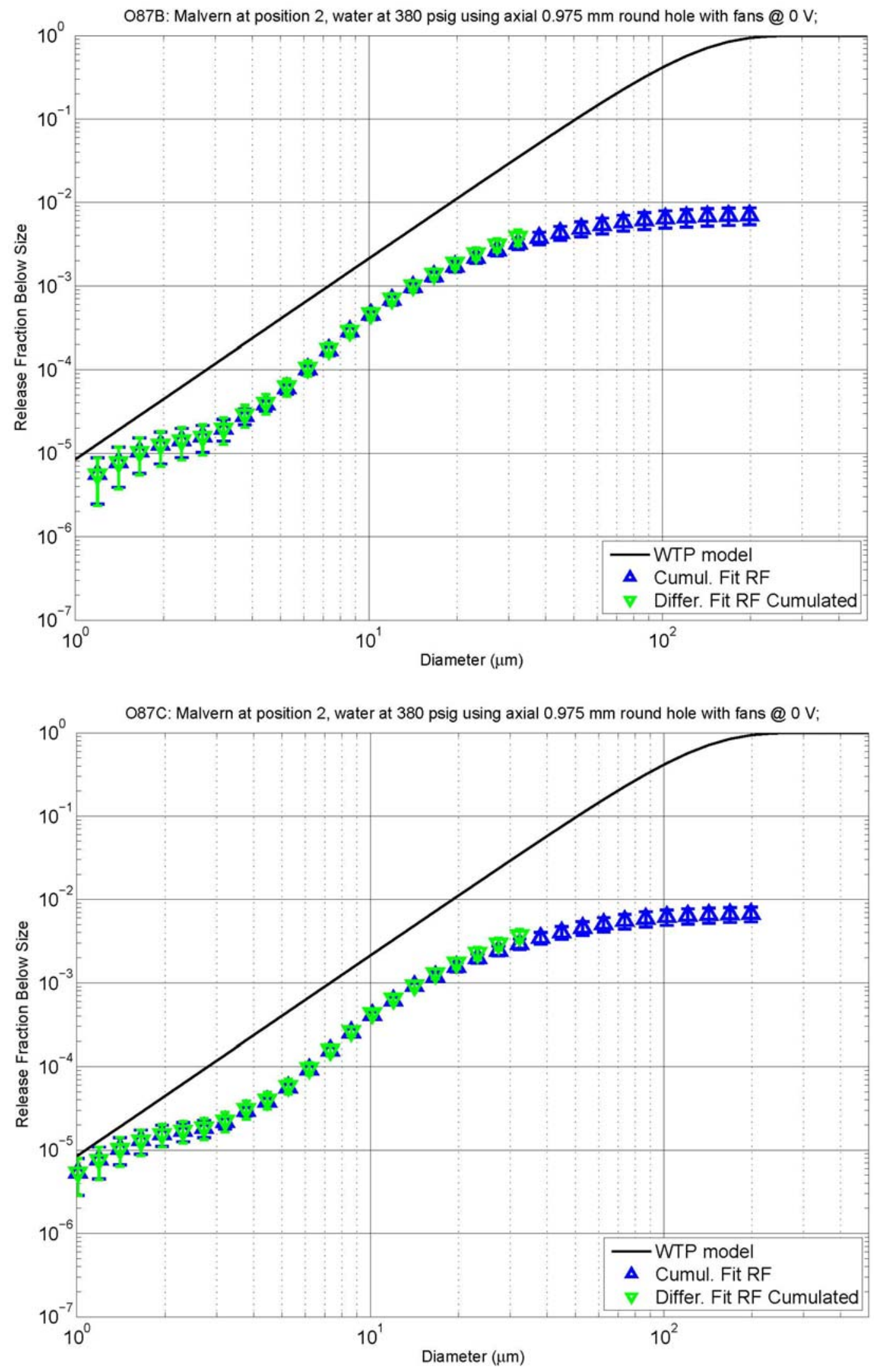

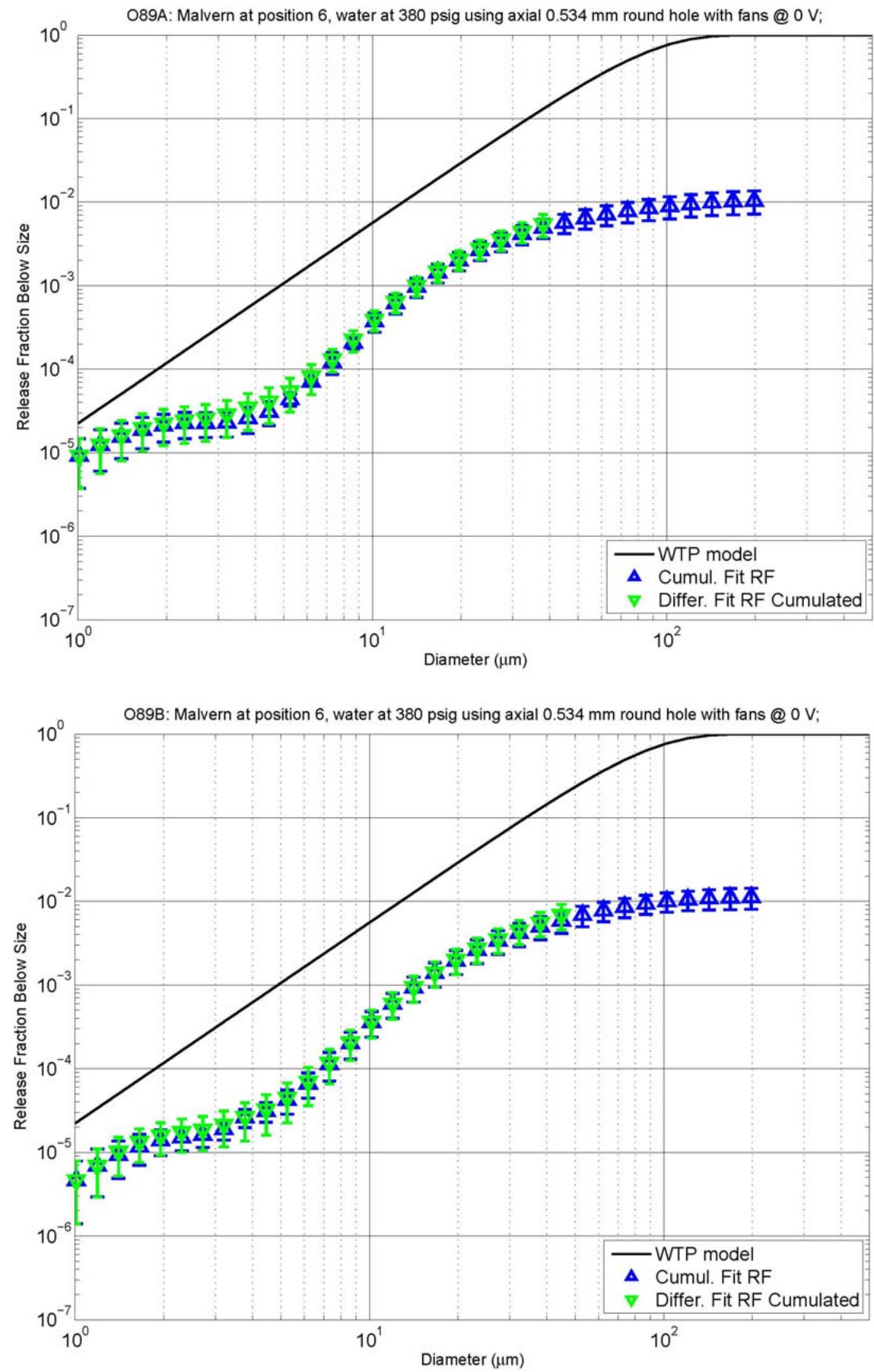

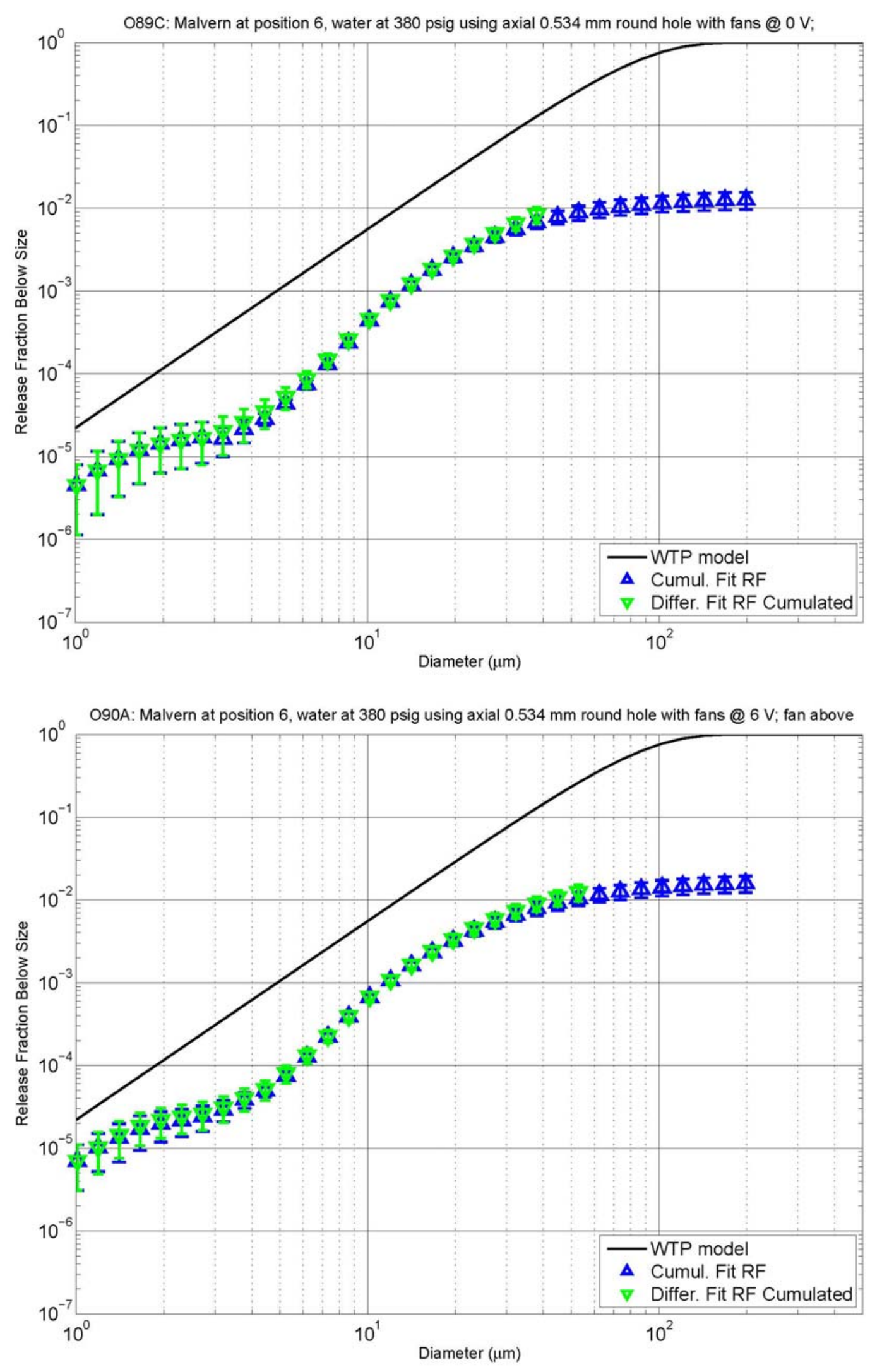

B. 59 

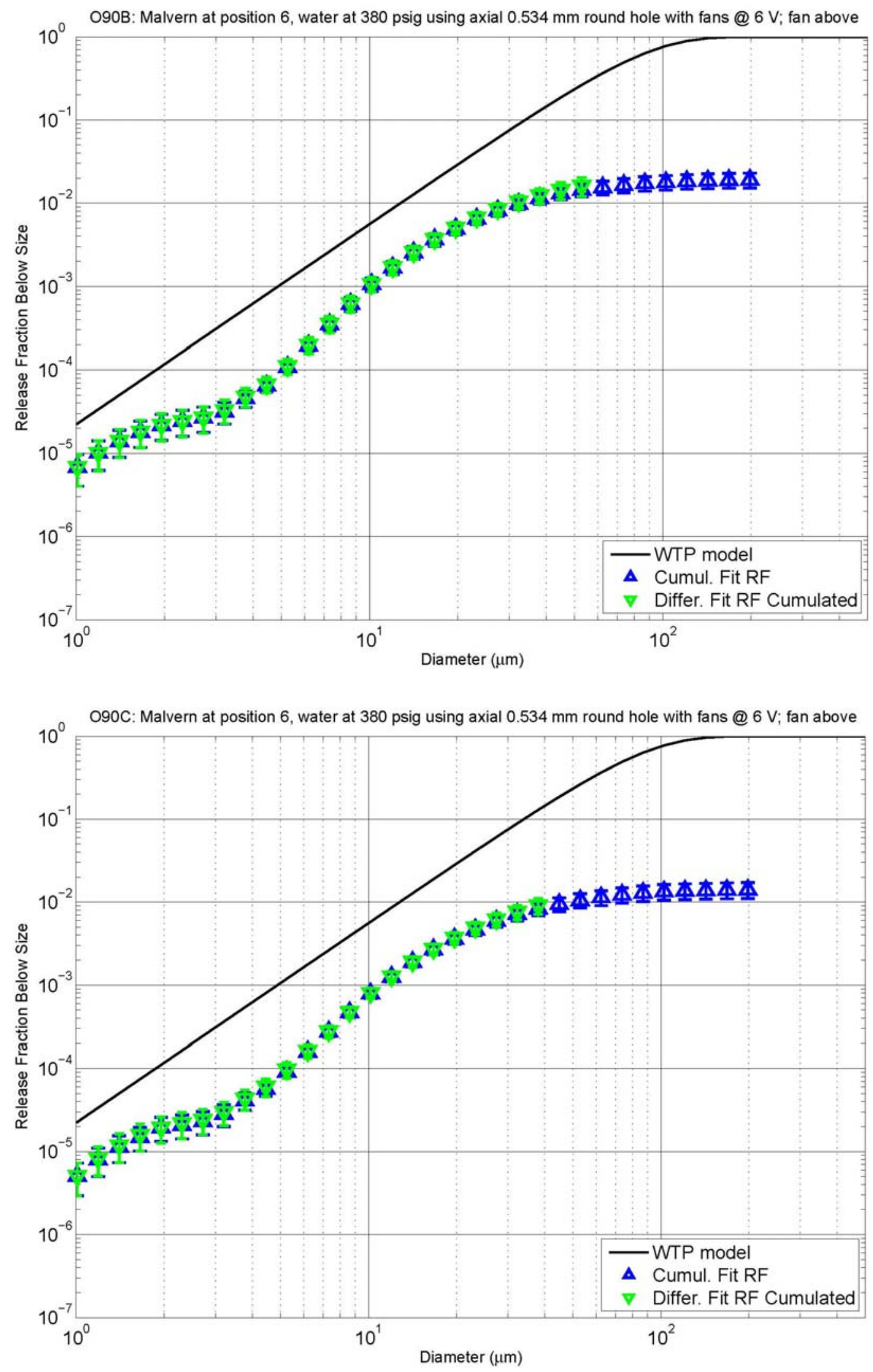
Appendix C

\section{List of Test Documents}





\section{Appendix C}

\section{List of Test Documents}

The test documents that define or describe the aerosol tests are listed below.

- Gauglitz PA. 2011. Test Plan for Spray Leak Quantification to Support WTP Spray Release Methodology, TP-WTPSP-031 R0.2. Appendix A of the test plan describes the basis for simulant development.

- Blanchard JL. 2011. Spray Release Methodology Small-scale Aerosol Release Tests Project Plan, PP-WTPSP-034 R0.7.

\section{Test Instructions}

- TI-WTPSP-037 (“Test Instruction and Procedure for Small Scale Aerosol Tests”)

- TI-WTPSP-054 (“Test Instruction and Procedure for Small Scale Aerosol Tests”)

- TI-WTPSP-086 (“Test Instruction and Procedure for Small Scale Aerosol Tests: Constant Target Pressure")

- TI-WTPSP-087 (“Test Instruction and Procedure for Small Scale Aerosol Tests: High Pressure Reduced to Target Pressure")

- TI-WTPSP-088 (“Test Instruction and Procedure for Small Scale Aerosol Tests: Low Pressure Increased to Target Pressure")

- TI-WTPSP-040 (“Simulant Blending to Support Small-Scale Spray Testing”)

- TI-WTPSP-050 (“Simulant Blending to Support Small-Scale Spray Testing”)

- TI-WTPSP-062 (“Chemical Simulant Blending to Support Small-Scale Spray Testing”)

- TI-WTPSP-076 (“Dilution of Chemical Simulant to Support Small-Scale Spray Testing”)

- TI-WTPSP-049 (“Data Collections for Small Scale Aerosol Using the Malvern Insitec-S”)

- TI-WTPSP-057 (“Data Collections for Small Scale Aerosol Using the Malvern Insitec-S”)

\section{Operating Procedures}

- OP-WTPSP-047 (“Malvern Insitec-S Operating Procedure”), CA Burns

- RPL-COLLOID-02 Rev 2 ("Measurement of Physical and Rheological Properties of Solutions, Slurries, and Sludges"), RC Daniel

- OP-WTPSP-035 (“Measurement of Static Surface Tension of Liquids, Dispersions, and Slurries”), DN Tran

\section{Laboratory Record Book}

- BNW-61117, pages 59-165, and BNW-61236, pages 1-101. 


\section{Test Data Packages: Test Stand Operation Test Instructions}

- TDP-WTPSP-640 through -682 (water tests including slot orientation, orifice size, and pressure variation)

- TDP-WTPSP-683 through -686 (water AFA tests)

- TDP-WTPSP-687 through -688 (STR8 AFA tests)

- TDP-WTPSP-689 through -690 (STR8 tests)

- TDP-WTPSP-691 through -692 (STR20 tests)

- TDP-WTPSP-693 through -694 (SAR 8 tests)

- TDP-WTPSP-695 through -696 (SAR20 tests)

- TDP-WTPSP-697 through -698 (TAR8 tests)

- TDP-WTPSP-699 $\left(\mathrm{Na}_{2} \mathrm{~S}_{2} \mathrm{O}_{3}\right.$ simulant; SALT 2.5 test)

- TDP-WTPSP-700 $\left(\mathrm{NaNO}_{3}\right.$ simulant; SALT 1.5 test $)$

- TDP-WTPSP-701 through -705, 747 (Water tests including slot length and multiple orifices)

- TDP-WTPSP-748 through -751 (FER6 (Boehmite tests)

- TDP-WTPSP-754 through -757 (FER30 tests)

- TDP-WTPSP-758 (FER6 AFA tests)

- TDP-WTPSP-760 through -763 (FER30 AFA tests)

- TDP-WTPSP-765 through -767, and 769 through 772 (FER6 AFA tests)

- TDP-WTPSP-781, 784 through -804 (supplemental water tests)

Test Data Packages: Test Support

- TDP-WTPSP-445 (“Determination of Wt\% UDS of Spray Release Simulants”)

- TDP-WTPSP-504 (“Determination of Wt\% UDS of Spray Release Simulants”)

- TDP-WTPSP-606 (“OTP Imaging of Orifice 01”)

- TDP-WTPSP-639 (“Small Scale Spray Release OTP Imaging of Orifices 37-42”)

- TDP-WTPSP-764 (“Particle Size Analysis of Small-Scale Slurry Samples”)

- TDP-WTPSP-773 (“Particle Size Analysis of Small-Scale Slurry Samples-B”)

- TDP-WTPSP-774 (“Pycnometric Density Measurement of Samples for Spray Release Project”)

- TDP-WTPSP-775 (“Surface Tension Measurement of Samples for Spray Release Project”)

- TDP-WTPSP-778 (“Surface Tension Measurement of Samples for Spray Release Project”)

- TDP-WTPSP-655 ("Rheological Measurement of Samples for Spray Release Project”)

- TDP-WTPSP-776 (“Rheological Measurement of Samples for Spray Release Project”) 
- TDP-WTPSP-779 ("Rheological Measurement of Samples for Spray Release Project”)

- TDP-WTPSP-782 (“Gas Pycnometer Measurement of NOAH Iron-Rich Slurry”)

- TDP-WTPSP-783 (“Determination of Wt\% UDS of Spray Release Simulants”)

- TDP-WTPSP-505 (“Small Scale Spray Release Aerosol Data Re-export”)

\section{Computational Packages}

- CCP-WTPSP-979 "Roadmap for Section 3 Simulants.” Originator GN Brown.

- CCP-WTPSP-1022 "Compilation and Calculation of Complex Refractive Indices for Laser Diffraction Analysis.” Originator RC Daniel.

- CCP-WTPSP-1145 Rev. 1 "Small-Scale Plugging-Tests Wall Shear Stress." Originator LA Mahoney.

- CCP-WTPSP-1154 “Component Blend for 40-gallon Slurries.” Originator GN Brown.

- CCP-WTPSP-1158 "PSDs for Spray Leak Project Simulant Project." Originator BE Wells.

- CCP-WTPSP-1159 "Image Analysis of OTP for Small Scale Spray Release Plugging Tests." Originator PP Schonewill.

- CCP-WTPSP-1160 "PSD Plots for Simulants.” Originator LA Mahoney.

- CCP-WTPSP-1163 "Volume of Small Scale Chamber.” Originator LA Mahoney.

- CCP-WTPSP-1168 “Image Analysis of OTP for Small Scale Spray Release Plugging Tests, Part II.” Originator PP Schonewill.

- CCP-WTPSP-1216, "Conversion of Small-Scale Datalogger Signals to Units.” Originator LA Mahoney.

- CCP-WTPSP-1217 “Compilation of Small-Scale TI/TDP Test Parameters.” Originator LA Mahoney.

- CCP-WTPSP-1218 “Small-Scale Offset and Pressure Determination.” Originator LA Mahoney.

- CCP-WTPSP-1219 “Small-Scale Release Determination.” Originator LA Mahoney.

- CCP-WTPSP-1220 “Plots for Small-Scale Releases.” Originator LA Mahoney.

- CCP-WTPSP-1221 "Small Scale Malvern/PPC Comparison.” Originator LA Mahoney.

- CCP-WTPSP-1222 “In-jet PSDs at Small-Scale.” Originator LA Mahoney.

- CCP-WTPSP-1223 “Small-Scale Concentration Transient.” Originator LA Mahoney.

- CCP-WTPSP-1224 “Estimate of Generation Rate.” Originator JL Blanchard.

\section{General Documents}

- GD-WTPSP-004 “Run Selection for Small-Scale Aerosol.” Originator LA Mahoney 



\section{Appendix D}

\section{Cross-References for Parametric Plots in Section 7}





\section{Appendix D}

\section{Cross-References for Parametric Plots in Section 7}

This appendix identifies the individual tests that are included in the parametric plots in Section 7 of the report. The parametric plots are those that have $\mathrm{x}$ axes based on variables other than droplet diameter; in these plots, it was not practical to identify the tests in the figures' captions. See Appendix A for more information about individual runs and Appendix B for the release fraction versus diameter plots for individual runs.

Table D.1. Runs in Figure 7.1

\begin{tabular}{|c|c|c|c|c|c|}
\hline $\begin{array}{c}\text { Target Orifice } \\
\text { Dimensions } \\
(\mathrm{mm})\end{array}$ & $\begin{array}{c}\text { Orifice Area } \\
\left(\mathrm{mm}^{2}\right)\end{array}$ & $\begin{array}{c}\text { Target } \\
\text { Pressure } \\
(\mathrm{psig})\end{array}$ & Simulant & Test ID(s) & $\begin{array}{c}\text { Discharge } \\
\text { Coefficient }\end{array}$ \\
\hline $\begin{array}{c}0.5 \\
\text { default }\end{array}$ & 0.221 & 380 & water & SO1 & 0.71 \\
\hline $\begin{array}{c}0.5 \\
\text { default }\end{array}$ & 0.224 & 380 & water & OS8-R1 & 0.70 \\
\hline $\begin{array}{c}0.5 \\
\text { dead-end }\end{array}$ & 0.221 & 380 & water & SO4-R1 & 0.69 \\
\hline $\begin{array}{c}0.5 \times 5 \\
\text { axial }\end{array}$ & 2.61 & 380 & water & OS12-R1-SG & 0.59 \\
\hline $\begin{array}{c}0.5 \times 5 \\
\text { axial }\end{array}$ & 2.61 & 380 & water & SO2-R1 & 0.57 \\
\hline $\begin{array}{c}0.5 \times 5 \\
\text { dead-end }\end{array}$ & 2.61 & 380 & water & SO5-R1 & 0.60 \\
\hline $\begin{array}{c}0.5 \times 5 \\
\text { circumferential }\end{array}$ & 2.70 & 380 & water & SO3 & 0.63 \\
\hline & & & & & \\
\hline
\end{tabular}


Table D.2. Runs in Figure 7.2

\begin{tabular}{|c|c|c|c|c|c|}
\hline $\begin{array}{c}\text { Target } \\
\text { Orifice } \\
\text { Dimensions } \\
(\mathrm{mm})\end{array}$ & $\begin{array}{c}\text { Orifice Area } \\
\left(\mathrm{mm}^{2}\right)\end{array}$ & $\begin{array}{c}\text { Target } \\
\text { Pressure } \\
(\mathrm{psig})\end{array}$ & Simulant & Test ID(s) & $\begin{array}{c}\text { Discharge } \\
\text { Coefficient }\end{array}$ \\
\hline 0.5 & 0.221 & 380 & water & SO1 & 0.71 \\
\hline 0.5 & 0.224 & 380 & water & OS8-R1 & 0.70 \\
\hline 1 & 0.747 & 380 & water & RT18 & 0.71 \\
\hline $\begin{array}{c}5 \text { holes, } \\
0.5 \text { each }\end{array}$ & $\begin{array}{c}0.870 \\
\text { total }\end{array}$ & 380 & water & MO49 & 0.75 \\
\hline
\end{tabular}

Table D.3. Runs in Figure 7.3

\begin{tabular}{|c|c|c|c|c|c|}
\hline $\begin{array}{c}\text { Target } \\
\text { Orifice } \\
\text { Dimensions } \\
(\mathrm{mm})\end{array}$ & $\begin{array}{c}\text { Orifice Area } \\
\left(\mathrm{mm}^{2}\right)\end{array}$ & $\begin{array}{c}\text { Target } \\
\text { Pressure } \\
(\mathrm{psig})\end{array}$ & Simulant & Test ID(s) & $\begin{array}{c}\text { Discharge } \\
\text { Coefficient }\end{array}$ \\
\hline 1 & 0.747 & 380 & water & OS7 & 0.74 \\
\hline 1 & 0.747 & 380 & water & RT18 & 0.71 \\
\hline 1 & 0.747 & 380 & water & RT19 & 0.77 \\
\hline 2 & 3.19 & 380 & water & OS6 & 0.62 \\
\hline $\begin{array}{c}5 \text { holes, } \\
1 \text { each }\end{array}$ & 3.94 & 380 & water & MO50F & 0.60 \\
\hline
\end{tabular}


Table D.4. Runs in Figure 7.4 and Figure 7.5

\begin{tabular}{|c|c|c|c|c|c|}
\hline $\begin{array}{c}\text { Target } \\
\text { Orifice } \\
\text { Dimensions } \\
(\mathrm{mm})\end{array}$ & $\begin{array}{c}\text { Orifice Area } \\
\left(\mathrm{mm}^{2}\right)\end{array}$ & $\begin{array}{c}\text { Target } \\
\text { Pressure } \\
(\mathrm{psig})\end{array}$ & Simulant & Test ID(s) & $\begin{array}{c}\text { Discharge } \\
\text { Coefficient }\end{array}$ \\
\hline \multicolumn{7}{|c|}{ Round Holes (default orientation) } \\
\hline 0.3 & 0.0735 & 380 & water & OS9 & $0.85^{*}$ \\
\hline 0.5 & 0.221 & 380 & water & SO1 & 0.71 \\
\hline 0.5 & 0.224 & 380 & water & OS8-R1 & 0.70 \\
\hline 1 & 0.747 & 380 & water & OS7 & 0.74 \\
\hline 1 & 0.747 & 380 & water & RT18 & 0.71 \\
\hline 1 & 0.747 & 380 & water & RT19 & 0.77 \\
\hline 2 & 3.19 & 380 & water & OS6 & 0.62 \\
\hline \multicolumn{7}{|c|}{} & 1.77 & 380 & Axial Slots & OS13 & 0.72 \\
\hline $0.3 \times 5$ & 2.61 & 380 & water & OS12-R1-SG & 0.59 \\
\hline $0.5 \times 5$ & 2.61 & 380 & water & SO2-R1 & 0.57 \\
\hline $0.5 \times 5$ & 3.52 & 380 & water & OS11 & 0.57 \\
\hline $0.7 \times 5$ & 4.94 & 380 & water & SL46B & 0.60 \\
\hline $0.5 \times 10$ & 5.01 & 380 & water & OS10-R1-SG & 0.64 \\
\hline $1 \times 5$ & 7.92 & 380 & water & SL47B & 0.61 \\
\hline $0.5 \times 15$ & 10.8 & 380 & water & SL48-R1A & 0.50 \\
\hline $0.5 \times 20$ & 10.8 & 380 & water & SL48-R1B & 0.50 \\
\hline $0.5 \times 20$ & & & & \\
\hline * This value may be too high because of difficulty in measuring the low flow rate. See \\
Section 7.8.
\end{tabular}

Table D.5. Runs in Figure 7.6

\begin{tabular}{|c|c|c|c|c|c|}
\hline $\begin{array}{c}\text { Target } \\
\text { Orifice } \\
\text { Dimensions } \\
(\mathrm{mm})\end{array}$ & $\begin{array}{c}\text { Orifice Area } \\
\left(\mathrm{mm}^{2}\right)\end{array}$ & $\begin{array}{c}\text { Target } \\
\text { Pressure } \\
(\mathrm{psig})\end{array}$ & Simulant & Test ID(s) & $\begin{array}{c}\text { Discharge } \\
\text { Coefficient }\end{array}$ \\
\hline $0.5 \times 5$ & 2.61 & 380 & water & SO2-R1 & 0.57 \\
\hline $0.5 \times 5$ & 2.61 & 380 & water & OS12-R1-SG & 0.59 \\
\hline $0.5 \times 10$ & 4.94 & 380 & water & SL46B & 0.60 \\
\hline $0.5 \times 15$ & 7.92 & 380 & water & SL47B & 0.61 \\
\hline $0.5 \times 20$ & 10.8 & 380 & water & SL48-R1A & 0.50 \\
\hline $0.5 \times 20$ & 10.8 & 380 & water & SL48-R1B & 0.50 \\
\hline
\end{tabular}


Table D.6. Runs in Figure 7.7

\begin{tabular}{|c|c|c|c|c|c|}
\hline $\begin{array}{c}\text { Target } \\
\text { Orifice } \\
\text { Dimensions } \\
(\mathrm{mm})\end{array}$ & $\begin{array}{c}\text { Orifice Area } \\
\left(\mathrm{mm}^{2}\right)\end{array}$ & $\begin{array}{c}\text { Target } \\
\text { Pressure } \\
(\mathrm{psig})\end{array}$ & Simulant & Test ID(s) & $\begin{array}{c}\text { Discharge } \\
\text { Coefficient }\end{array}$ \\
\hline $0.3 \times 5$ & 1.77 & 380 & water & OS13 & 0.72 \\
\hline $0.5 \times 5$ & 2.61 & 380 & water & OS12-R1-SG & 0.59 \\
\hline $0.5 \times 5$ & 2.61 & 380 & water & SO2-R1 & 0.57 \\
\hline $0.7 \times 5$ & 3.52 & 380 & water & OS11 & 0.57 \\
\hline $1 \times 5$ & 5.01 & 380 & water & OS10-R1-SG & 0.64 \\
\hline
\end{tabular}

Table D.7. Runs in Figure 7.8

\begin{tabular}{|c|c|c|c|c|c|}
\hline $\begin{array}{c}\text { Target } \\
\text { Orifice } \\
\text { Dimensions } \\
(\mathrm{mm})\end{array}$ & $\begin{array}{c}\text { Orifice Area } \\
\left(\mathrm{mm}^{2}\right)\end{array}$ & $\begin{array}{c}\text { Target } \\
\text { Pressure } \\
(\mathrm{psig})\end{array}$ & Simulant & Test ID(s) & $\begin{array}{c}\text { Discharge } \\
\text { Coefficient }\end{array}$ \\
\hline 1 & 0.747 & 100 & water & PV16 & 0.79 \\
\hline 1 & 0.747 & 200 & water & PV14 & 0.75 \\
\hline 1 & 0.747 & 380 & water & OS7 & 0.74 \\
\hline
\end{tabular}

Table D.8. Runs in Figure 7.9

\begin{tabular}{|c|c|c|c|c|c|}
\hline $\begin{array}{c}\text { Target } \\
\text { Orifice } \\
\text { Dimensions } \\
(\mathrm{mm})\end{array}$ & $\begin{array}{c}\text { Orifice Area } \\
\left(\mathrm{mm}^{2}\right)\end{array}$ & $\begin{array}{c}\text { Target } \\
\text { Pressure } \\
(\mathrm{psig})\end{array}$ & Simulant & Test ID(s) & $\begin{array}{c}\text { Discharge } \\
\text { Coefficient }\end{array}$ \\
\hline $0.5 \times 5$ & 2.61 & 100 & water & PV17-R1 & 0.56 \\
\hline $0.5 \times 5$ & 2.61 & 200 & water & PV15-R1 & 0.59 \\
\hline $0.5 \times 5$ & 2.61 & 380 & water & OS12-R1-SG & 0.59 \\
\hline $0.5 \times 5$ & 2.61 & 380 & water & SO2-R1 & 0.57 \\
\hline
\end{tabular}

Table D.9. Runs in Figure 7.10

\begin{tabular}{|c|c|c|c|c|c|}
\hline $\begin{array}{c}\text { Target } \\
\text { Orifice } \\
\text { Dimensions } \\
(\mathrm{mm})\end{array}$ & $\begin{array}{c}\text { Orifice Area } \\
\left(\mathrm{mm}^{2}\right)\end{array}$ & $\begin{array}{c}\text { Target } \\
\text { Pressure } \\
(\mathrm{psig})\end{array}$ & Simulant & Test ID(s) & $\begin{array}{c}\text { Discharge } \\
\text { Coefficient }\end{array}$ \\
\hline 1 & 0.747 & 200 & FER-6B & SV60B & 0.70 \\
\hline 1 & 0.747 & 380 & FER-6B & SV59B & 0.89 \\
\hline
\end{tabular}


Table D.10. Runs in Figure 7.11

\begin{tabular}{|c|c|c|c|c|c|}
\hline $\begin{array}{c}\text { Target } \\
\text { Orifice } \\
\text { Dimensions } \\
(\mathrm{mm})\end{array}$ & $\begin{array}{c}\text { Orifice Area } \\
\left(\mathrm{mm}^{2}\right)\end{array}$ & $\begin{array}{c}\text { Target } \\
\text { Pressure } \\
(\mathrm{psig})\end{array}$ & Simulant & Test ID(s) & $\begin{array}{c}\text { Discharge } \\
\text { Coefficient }\end{array}$ \\
\hline $0.5 \times 5$ & 2.61 & 200 & FER-6B & SV62A & 0.60 \\
\hline $0.5 \times 5$ & 2.61 & 380 & FER-6B & SV61C & 0.62 \\
\hline
\end{tabular}

Table D.11. Runs in Figure 7.12

\begin{tabular}{|c|c|c|c|c|c|}
\hline $\begin{array}{c}\text { Target } \\
\text { Orifice } \\
\text { Dimensions } \\
(\mathrm{mm})\end{array}$ & $\begin{array}{c}\text { Orifice Area } \\
\left(\mathrm{mm}^{2}\right)\end{array}$ & $\begin{array}{c}\text { Target } \\
\text { Pressure } \\
(\mathrm{psig})\end{array}$ & Simulant & Test ID(s) & $\begin{array}{c}\text { Discharge } \\
\text { Coefficient }\end{array}$ \\
\hline 1 & 0.747 & 200 & FER-6+AFA & SV64B & 0.73 \\
\hline 1 & 0.747 & 380 & FER-6+AFA & SV63B & 0.74 \\
\hline
\end{tabular}

Table D.12. Runs in Figure 7.13

\begin{tabular}{|c|c|c|c|c|c|}
\hline $\begin{array}{c}\text { Target } \\
\text { Orifice } \\
\text { Dimensions } \\
(\mathrm{mm})\end{array}$ & $\begin{array}{c}\text { Orifice Area } \\
\left(\mathrm{mm}^{2}\right)\end{array}$ & $\begin{array}{c}\text { Target } \\
\text { Pressure } \\
(\mathrm{psig})\end{array}$ & Simulant & Test ID(s) & $\begin{array}{c}\text { Discharge } \\
\text { Coefficient }\end{array}$ \\
\hline $0.5 \times 5$ & 2.61 & 200 & FER-6+AFA & SV66A & 0.59 \\
\hline $0.5 \times 5$ & 2.61 & 380 & FER-6+AFA & SV65A & 0.66 \\
\hline
\end{tabular}

Table D.13. Runs in Figure 7.14

\begin{tabular}{|c|c|c|c|c|c|}
\hline $\begin{array}{c}\text { Target } \\
\text { Orifice } \\
\text { Dimensions } \\
(\mathrm{mm})\end{array}$ & $\begin{array}{c}\text { Orifice Area } \\
\left(\mathrm{mm}^{2}\right)\end{array}$ & $\begin{array}{c}\text { Target } \\
\text { Pressure } \\
(\mathrm{psig})\end{array}$ & Simulant & Test ID(s) & $\begin{array}{c}\text { Discharge } \\
\text { Coefficient }\end{array}$ \\
\hline 1 & 0.747 & 200 & FER-30 & SV52C & 0.89 \\
\hline 1 & 0.747 & 380 & FER-30 & SV51A & 0.81 \\
\hline
\end{tabular}

Table D.14. Runs in Figure 7.15

\begin{tabular}{|c|c|c|c|c|c|}
\hline $\begin{array}{c}\text { Target } \\
\text { Orifice } \\
\text { Dimensions } \\
(\mathrm{mm})\end{array}$ & $\begin{array}{c}\text { Orifice Area } \\
\left(\mathrm{mm}^{2}\right)\end{array}$ & $\begin{array}{c}\text { Target } \\
\text { Pressure } \\
(\mathrm{psig})\end{array}$ & Simulant & Test ID(s) & $\begin{array}{c}\text { Discharge } \\
\text { Coefficient }\end{array}$ \\
\hline $0.5 \times 5$ & 2.61 & 200 & FER-30 & SV54A & 0.56 \\
\hline $0.5 \times 5$ & 2.61 & 380 & FER-30 & SV53B & 0.67 \\
\hline
\end{tabular}


Table D.15. Runs in Figure 7.16

\begin{tabular}{|c|c|c|c|c|c|}
\hline $\begin{array}{c}\text { Target } \\
\text { Orifice } \\
\text { Dimensions } \\
(\mathrm{mm})\end{array}$ & $\begin{array}{c}\text { Orifice Area } \\
\left(\mathrm{mm}^{2}\right)\end{array}$ & $\begin{array}{c}\text { Target } \\
\text { Pressure } \\
(\mathrm{psig})\end{array}$ & Simulant & Test ID(s) & $\begin{array}{c}\text { Discharge } \\
\text { Coefficient }\end{array}$ \\
\hline 1 & 0.747 & 200 & FER-30+AFA & SV56A & $0.41^{*}$ \\
\hline 1 & 0.747 & 380 & FER-30+AFA & SV55B & 0.56 \\
\hline
\end{tabular}

Table D.16. Runs in Figure 7.17

\begin{tabular}{|c|c|c|c|c|c|}
\hline $\begin{array}{c}\text { Target } \\
\text { Orifice } \\
\text { Dimensions } \\
(\mathrm{mm})\end{array}$ & $\begin{array}{c}\text { Orifice Area } \\
\left(\mathrm{mm}^{2}\right)\end{array}$ & $\begin{array}{c}\text { Target } \\
\text { Pressure } \\
(\mathrm{psig})\end{array}$ & Simulant & Test ID(s) & $\begin{array}{c}\text { Discharge } \\
\text { Coefficient }\end{array}$ \\
\hline $0.5 \times 5$ & 2.61 & 200 & FER-30+AFA & SV58A & 0.83 \\
\hline $0.5 \times 5$ & 2.61 & 380 & FER-30+AFA & SV57B & 0.79 \\
\hline
\end{tabular}

Table D.17. Runs in Figure 7.19 and Figure 7.20

\begin{tabular}{|c|c|c|c|c|c|}
\hline $\begin{array}{c}\text { Target } \\
\text { Orifice } \\
\text { Dimensions } \\
(\mathrm{mm})\end{array}$ & $\begin{array}{c}\text { Orifice Area } \\
\left(\mathrm{mm}^{2}\right)\end{array}$ & $\begin{array}{c}\text { Target } \\
\text { Pressure } \\
(\mathrm{psig})\end{array}$ & Simulant & Test ID(s) & $\begin{array}{c}\text { Discharge } \\
\text { Coefficient }\end{array}$ \\
\hline 1 & 0.747 & 380 & water $(\sim 1 \mathrm{mPa} \mathrm{s})$ & OS7 & 0.74 \\
\hline 1 & 0.747 & 380 & water $(\sim 1 \mathrm{mPa} \mathrm{s})$ & $\mathrm{RT} 18$ & 0.71 \\
\hline 1 & 0.747 & 380 & water $(\sim 1 \mathrm{mPa} \mathrm{s})$ & $\mathrm{RT} 19$ & 0.77 \\
\hline 1 & 0.747 & 380 & $\begin{array}{c}\mathrm{NaNO} \text { in water } \\
(1.8 \mathrm{mPa} \mathrm{s})\end{array}$ & SV45B & 0.79 \\
\hline 1 & 0.747 & 380 & $\begin{array}{c}\mathrm{Na}_{2} \mathrm{~S}_{2} \mathrm{O}_{3} \text { in water } \\
(2.6 \mathrm{mPa} \mathrm{s})\end{array}$ & SV44C & 0.76 \\
\hline
\end{tabular}




\begin{tabular}{|c|c|c|c|c|c|}
\hline \multicolumn{6}{|c|}{ Table D.18. Runs in Figure 7.31} \\
\hline $\begin{array}{l}\text { Target } \\
\text { Orifice } \\
\text { Dimensions } \\
(\mathrm{mm})\end{array}$ & $\begin{array}{l}\text { Orifice Area } \\
\left(\mathrm{mm}^{2}\right)\end{array}$ & $\begin{array}{l}\text { Target } \\
\text { Pressure } \\
\text { (psig) }\end{array}$ & $\begin{array}{c}\text { Simulant and } \\
\text { Impact Distance }\end{array}$ & Test ID(s) & $\begin{array}{l}\text { Discharge } \\
\text { Coefficient }\end{array}$ \\
\hline 1 & 0.747 & 380 & water@1” & OS75-EX1A & $*$ \\
\hline 1 & 0.747 & 380 & water@1” & OS75-EX1B & $*$ \\
\hline 1 & 0.747 & 380 & water@1” & OS75-EX1C & $*$ \\
\hline 1 & 0.747 & 380 & water@3” & OS75-EX3A & $*$ \\
\hline 1 & 0.747 & 380 & water@3" & OS75-EX3B & $*$ \\
\hline 1 & 0.747 & 380 & water@3” & OS75-EX3C & $*$ \\
\hline 1 & 0.747 & 380 & water@6" & OS75-EX6A & $*$ \\
\hline 1 & 0.747 & 380 & water@6" & OS75-EX6B & $*$ \\
\hline 1 & 0.747 & 380 & water@6" & OS75-EX6C & $*$ \\
\hline 1 & 0.747 & 380 & water@18” & OS75-EX18A & $*$ \\
\hline 1 & 0.747 & 380 & water@18” & OS75-EX18B & $*$ \\
\hline 1 & 0.747 & 380 & water@18" & OS75-EX18C & $*$ \\
\hline 1 & 0.747 & 380 & water@42" & OS7 & 0.74 \\
\hline 1 & 0.747 & 380 & water@42” & RT18 & 0.71 \\
\hline 1 & 0.747 & 380 & water@42” & RT19 & 0.77 \\
\hline \multicolumn{6}{|c|}{$\begin{array}{l}\text { * Because of flow measurement difficulties, no discharge coefficients were calculated for these } \\
\text { tests (see Section 6.6.3.). The leak flow rates were calculated based on an assumed coefficient of } \\
0.74 \text {. }\end{array}$} \\
\hline
\end{tabular}





\section{Appendix E}

Concentration Plots for Impact-Distance Tests 



\section{Appendix E}

\section{Concentration Plots for Impact-Distance Tests}

As discussed in Section 7.6, release fractions depend on the distance between the orifice and the downstream wall against which the jet splashes. This appendix provides additional information in the form of plots of droplet concentrations for one representative test for each impact distance.

Three tests were analyzed for release fraction for each of five impact distances; the release fractions are plotted in Figure 7.31 and the runs are identified in Table D.18. The plots in this appendix were chosen as being representative for each impact distance, in that they tended to produce neither the highest

nor lowest release fractions in each set of three tests. The measured concentrations and the concentrations calculated from the fitted model are plotted for six size bins. 

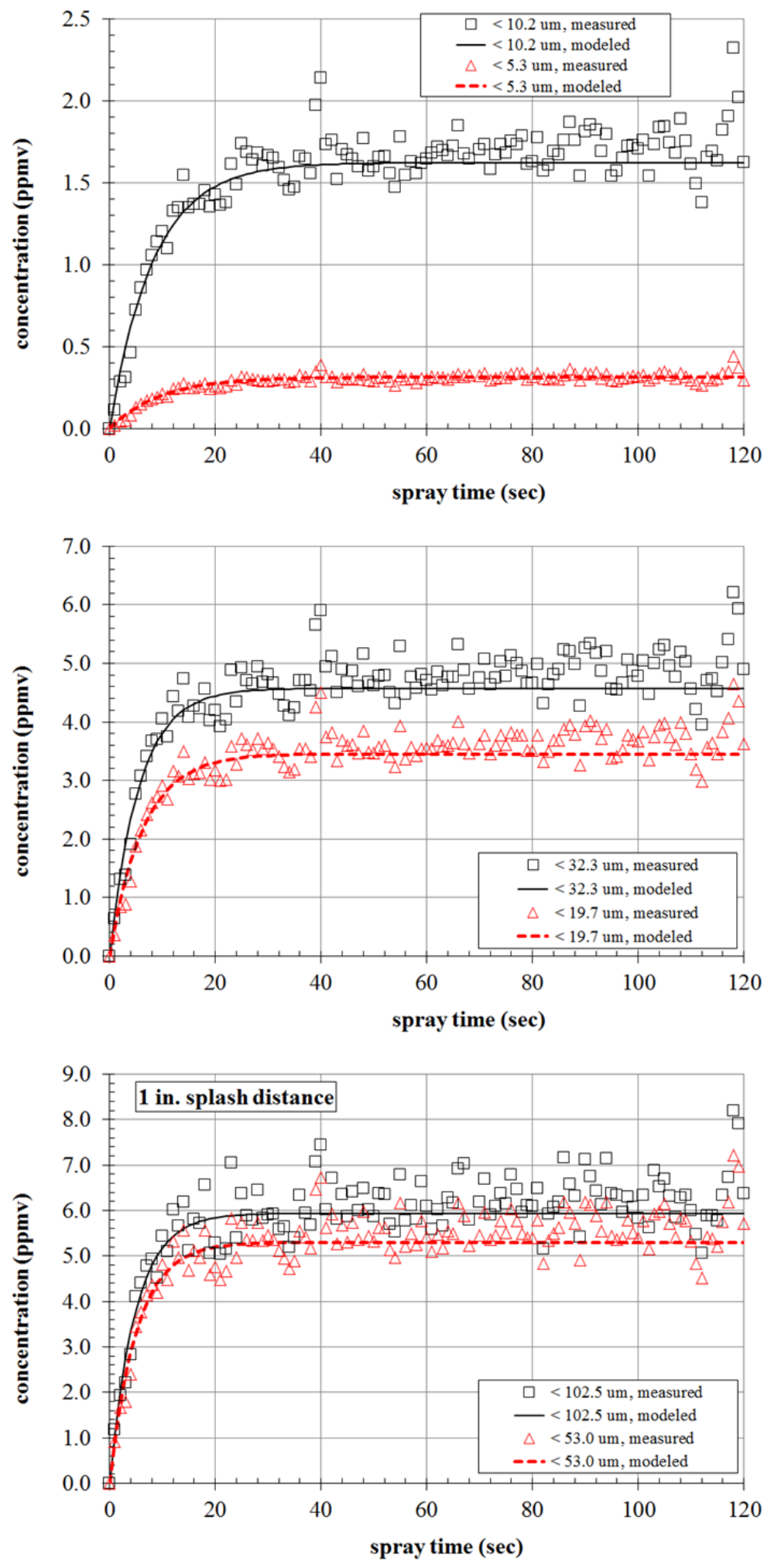

Figure E.1. Concentration versus Time for Test O75-EX1B, Conducted with Water at a Target Pressure of 380 psig Using a Target 1-mm Round Orifice and an Impact Distance of 1 Inch 

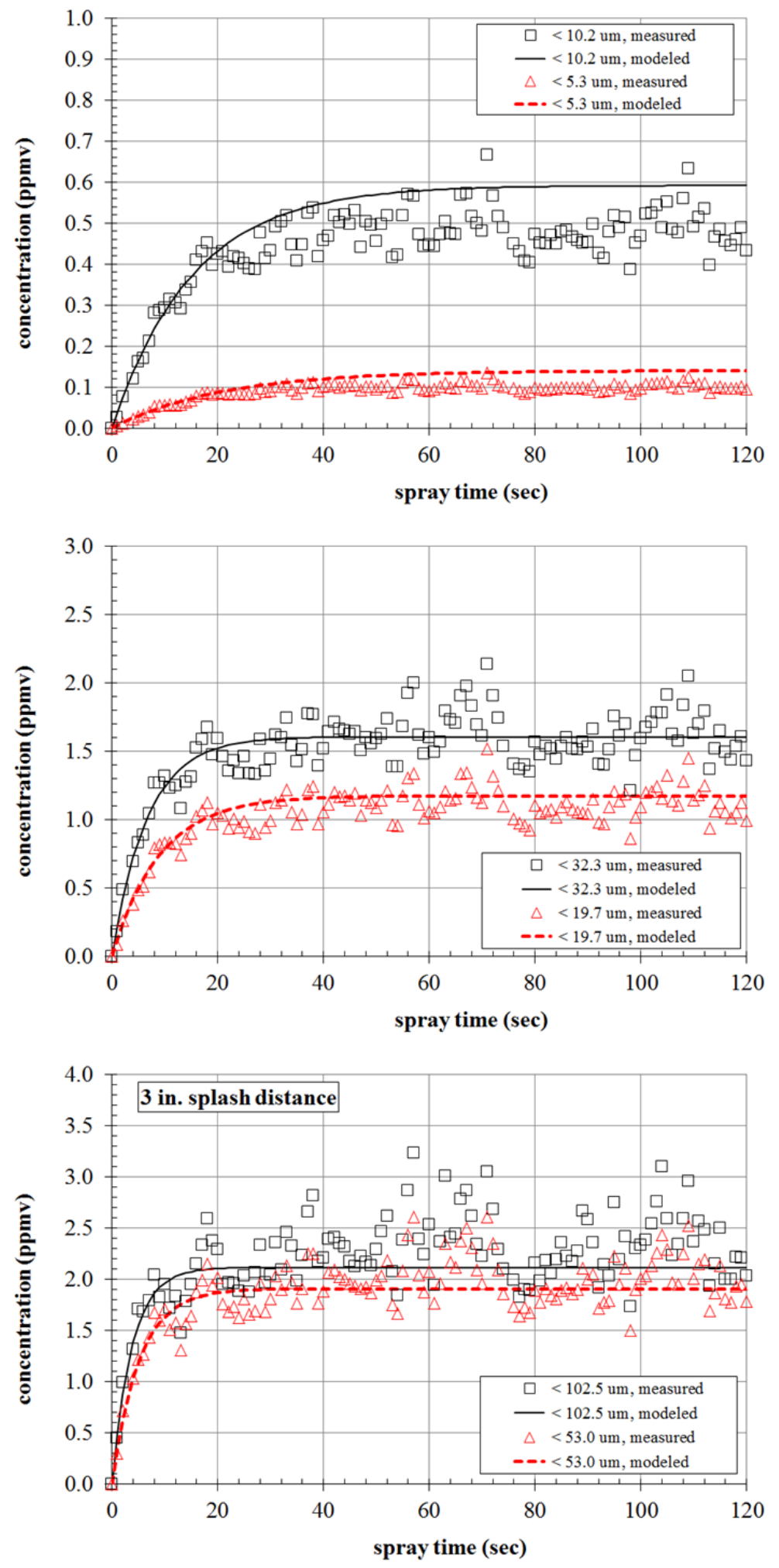

Figure E.2. Concentration versus Time for Test O75-EX3B, Conducted with Water at a Target Pressure of 380 psig Using a Target 1-mm Round Orifice and an Impact Distance of 3 Inches 

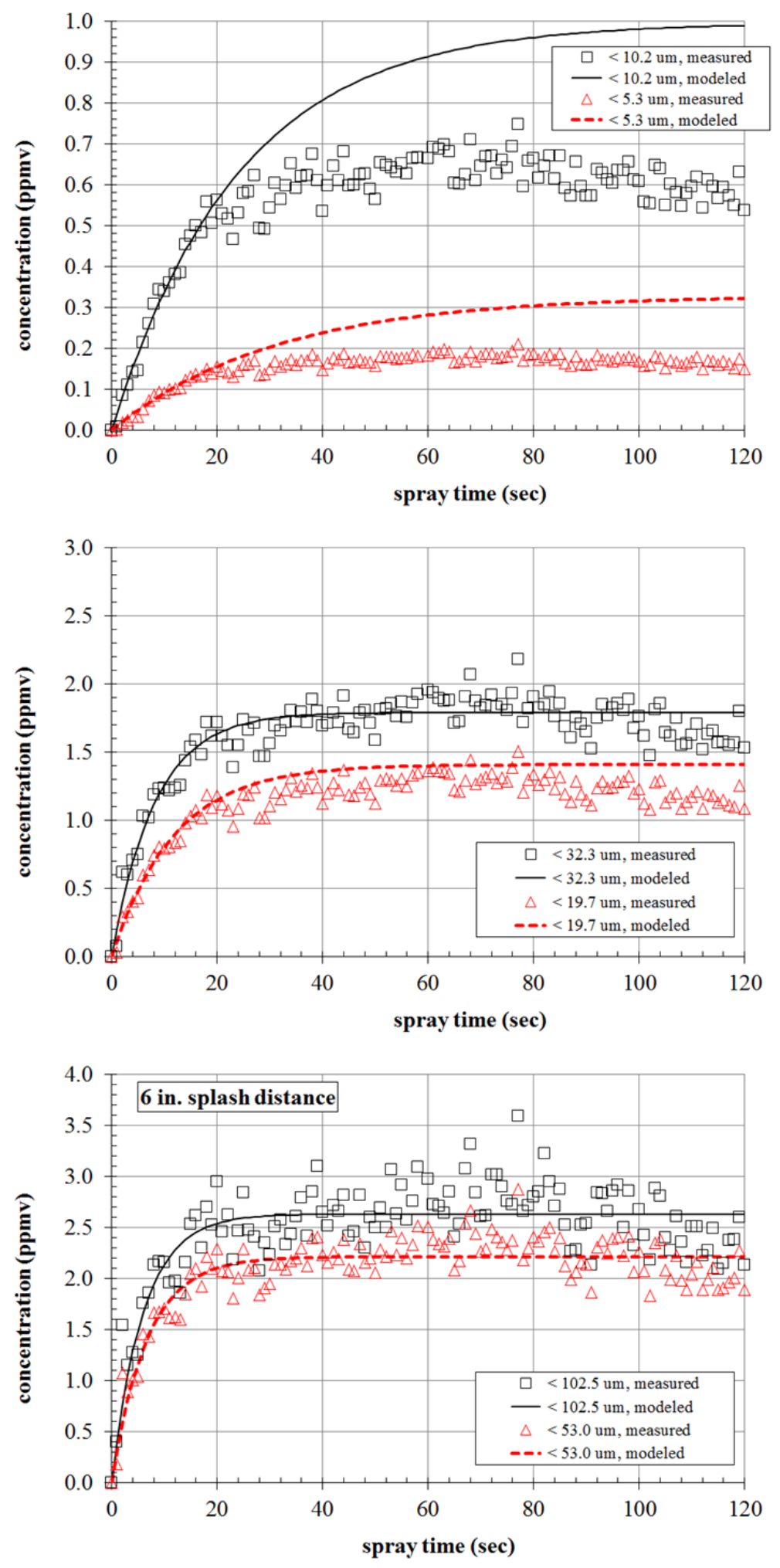

Figure E.3. Concentration versus Time for Test O75-EX6C, Conducted with Water at a Target Pressure of 380 psig Using a Target 1-mm Round Orifice and an Impact Distance of 6 Inches 

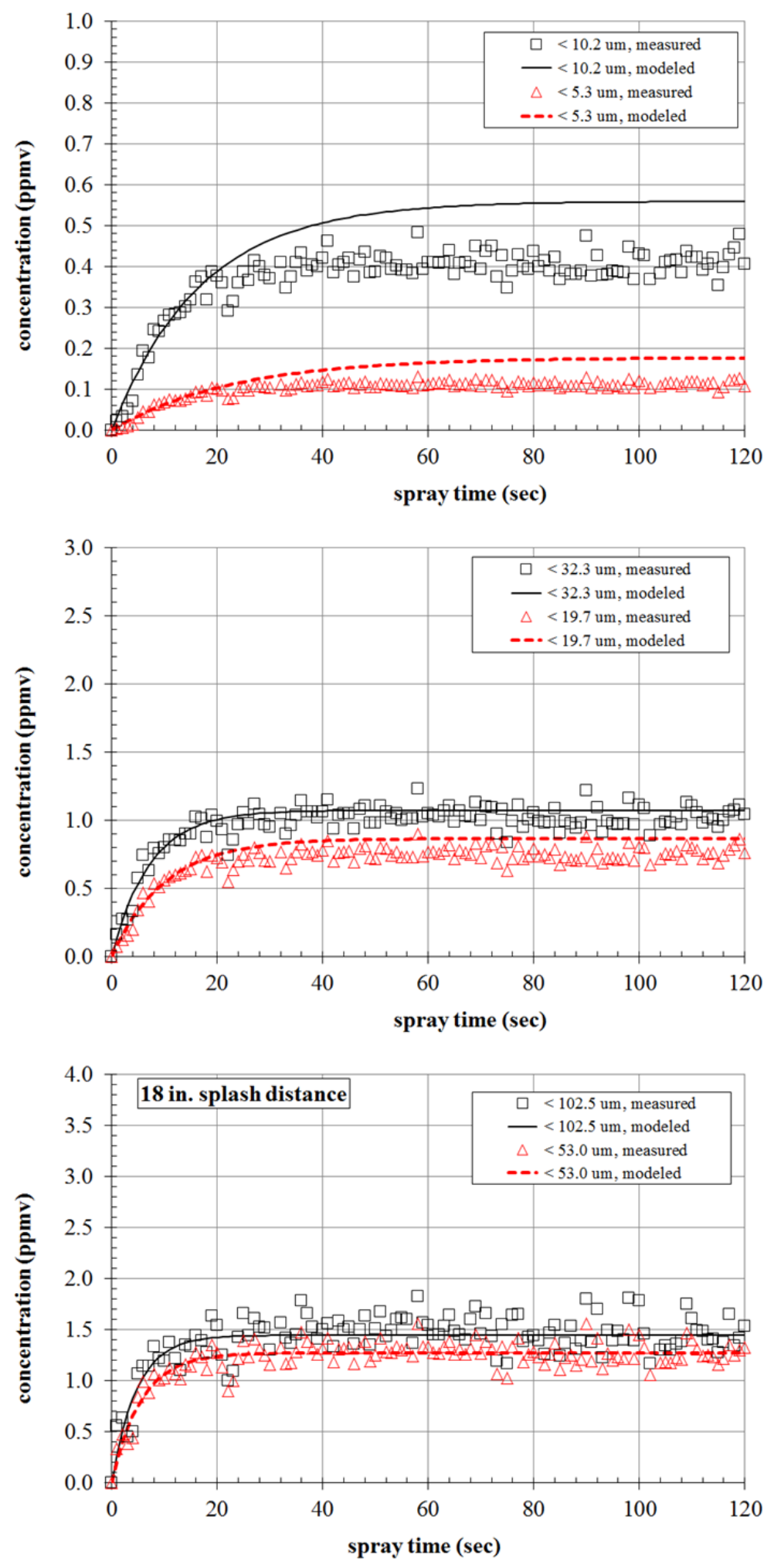

Figure E.4. Concentration versus Time for Test O75-EX18C, Conducted with Water at a Target Pressure of 380 psig Using a Target 1-mm Round Orifice and an Impact Distance of 18 Inches 

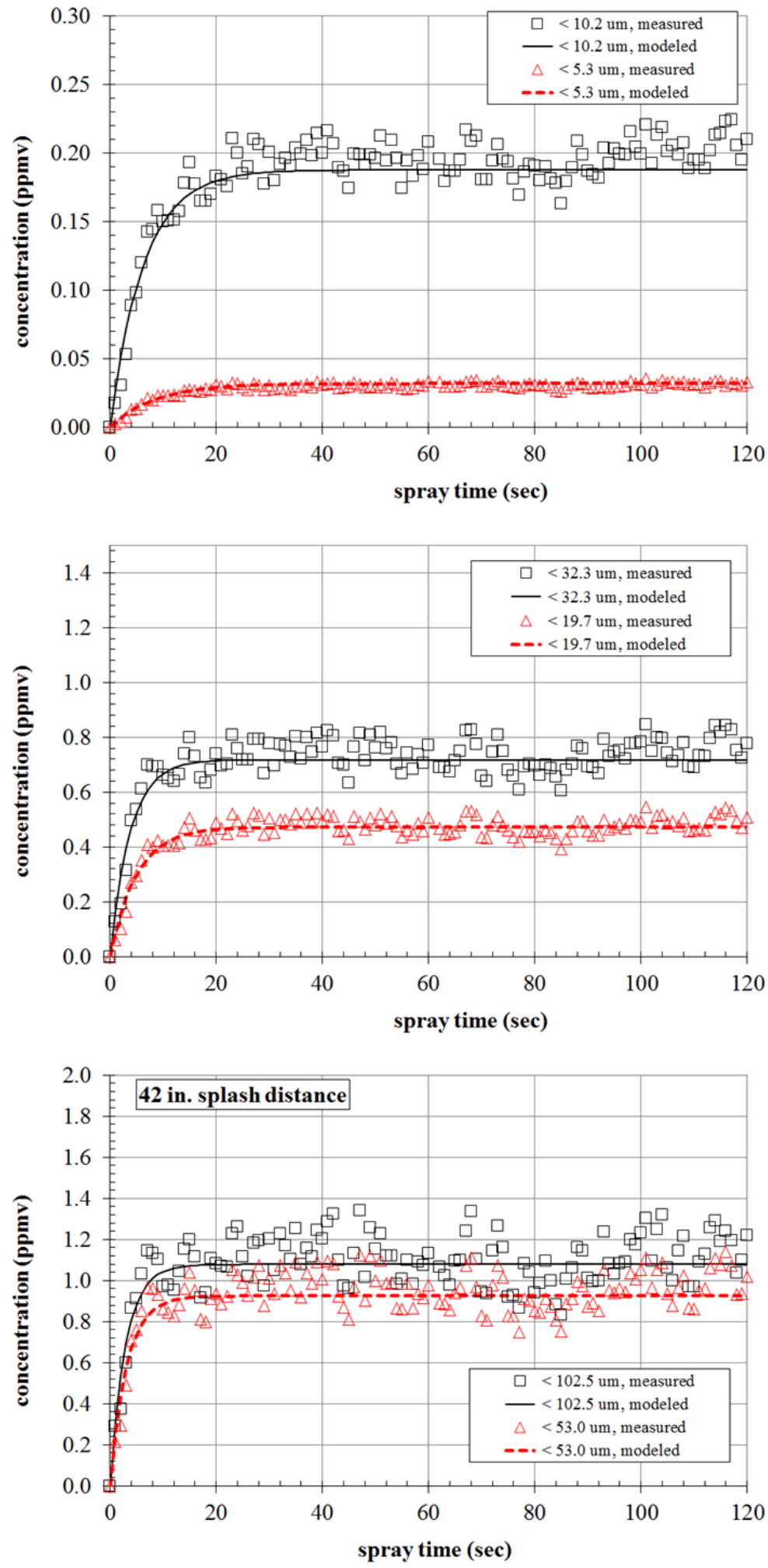

Figure E.5. Concentration versus Time for Test OS7, Conducted with Water at a Target Pressure of 380 psig Using a Target 1-mm Round Orifice and an Impact Distance of 42 Inches 


\section{Distribution}

No. of

Copies

ONSITE*

3 DOE Office of River Protection

JS Fox

CC Harrington

DL Noyes

4 Bechtel National Inc.

A Hassan

HR Hazen

S Omberg-Carro

RJ VanVleet

JL Weamer

WTP PETD Docs
No. of

Copies

12 Pacific Northwest National Laboratory

H6-60

H6-60

H6-60

$\mathrm{H} 4-02$

H4-02

$\mathrm{H} 4-02$

H4-02

$\mathrm{H} 4-02$

H4-02
J Blanchard

JR Bontha

GN Brown

CA Burns

RC Daniel

PA Gauglitz

ML Kimura

DE Kurath

LA Mahoney

PP Schonewill

C Song

DN Tran

BE Wells

Information Release (pdf)

Project File
K7-15

P7-25

$\mathrm{P} 7-25$

P7-25

P7-22

K7-15

K6-28

K3-52

$\mathrm{K} 7-15$

P7-25

K4-28

K6-24

K7-15

K3-52

*All distribution will be made electronically.

Dist. 1 




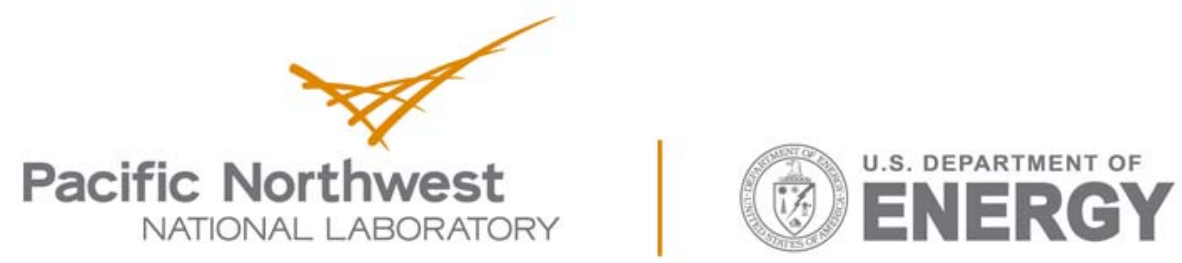

Proudly Operated by Battelle Since 1965

902 Battelle Boulevard

P.O. Box 999

Richland, WA 99352

1-888-375-PNNL (7665)

www.pnnl.gov 